


\title{
Quality Management and Six Sigma
}

\author{
edited by
}

Abdurrahman Coskun 


\section{Quality Management and Six Sigma}

http://dx.doi.org/10.5772/271

Edited by Abdurrahman Coskun

\section{(c) The Editor(s) and the Author(s) 2010}

The moral rights of the and the author(s) have been asserted.

All rights to the book as a whole are reserved by INTECH. The book as a whole (compilation) cannot be reproduced, distributed or used for commercial or non-commercial purposes without INTECH's written permission.

Enquiries concerning the use of the book should be directed to INTECH rights and permissions department (permissions@intechopen.com).

Violations are liable to prosecution under the governing Copyright Law.

\section{(cc) BY}

Individual chapters of this publication are distributed under the terms of the Creative Commons Attribution 3.0 Unported License which permits commercial use, distribution and reproduction of the individual chapters, provided the original author(s) and source publication are appropriately acknowledged. If so indicated, certain images may not be included under the Creative Commons license. In such cases users will need to obtain permission from the license holder to reproduce the material. More details and guidelines concerning content reuse and adaptation can be foundat http://www.intechopen.com/copyright-policy.html.

\section{Notice}

Statements and opinions expressed in the chapters are these of the individual contributors and not necessarily those of the editors or publisher. No responsibility is accepted for the accuracy of information contained in the published chapters. The publisher assumes no responsibility for any damage or injury to persons or property arising out of the use of any materials, instructions, methods or ideas contained in the book.

First published in Croatia, 2010 by INTECH d.o.o.

eBook (PDF) Published by IN TECH d.o.o.

Place and year of publication of eBook (PDF): Rijeka, 2019.

IntechOpen is the global imprint of IN TECH d.o.o.

Printed in Croatia

Legal deposit, Croatia: National and University Library in Zagreb

Additional hard and PDF copies can be obtained from orders@intechopen.com

Quality Management and Six Sigma

Edited by Abdurrahman Coskun

p. $\mathrm{cm}$.

ISBN 978-953-307-130-5

eBook (PDF) ISBN 978-953-51-5947-6 


\section{We are IntechOpen, \\ the world's leading publisher of Open Access books}

Built by scientists, for scientists

\section{$4,100+$}

Open access books available

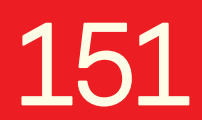

Countries delivered to
$116,000+$

International authors and editors
$120 \mathrm{M}+$

Downloads

Our authors are among the

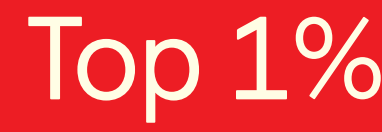

most cited scientists

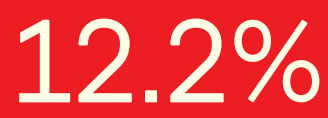

Contributors from top 500 universities

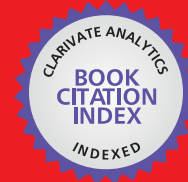

WEB OF SCIENCE ${ }^{\mathrm{TM}}$

Selection of our books indexed in the Book Citation Index in Web of Science ${ }^{\mathrm{TM}}$ Core Collection (BKCI)

Interested in publishing with us?

Contact book.department@intechopen.com

Numbers displayed above are based on latest data collected.

For more information visit www.intechopen.com

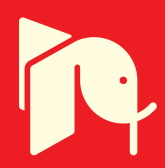





\section{Meet the editor}

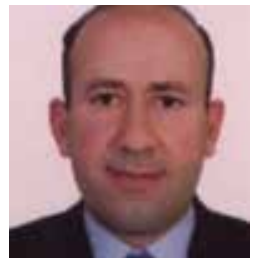

Dr. Abdurrahman Coskun has received his MD degree from Erciyes University, School of Medicine in 1994. He became a specialist in Biochemistry and Clinical Biochemistry in 1999 at the same university. He has joined the Acibadem Labmed Clinical Laboratories in 2008 and has been appointed as an associate professor of Biochemistry and Clinical Biochemistry in 2009. His research mainly focused on improvement of quality in clinical laboratories. Dr. Coskun is a member of Turkish Clinical Biochemists Society, Turkish Biochemical Society, and Clinical Biochemistry Specialists Society. 



\section{Contents}

\section{Preface XI}

Chapter 1 Six sigma and Total Quality Management 1

Yang, Ching-Chow

Chapter 2 Six Sigma and Developing Countries $\quad 31$

Ali Rizwan, PhD

Chapter 3 A Comprehensive Framework for Six Sigma Critical

Success Factors With an Experience in a Developing Country 43

Arash Shahin

Chapter 4 The importance of the strategic alignment process using Six Sigma projects 53

Bianca Soares de Oliveira Gonçalves and Marcel Andreotti Musetti

Chapter 5 Integrated model linking Maintenance Excellence, Six Sigma and QFD for process progressive improvement $\quad 67$

Maher Lazreg

Chapter 6 Sigma-TRIZ: Algorithm for Systematic Integration of Innovation within Six Sigma Process Improvement Methodologies 89 Stelian Brad

Chapter 7 Design for Six Sigma (DfSS) in Software 109 Ajit Ashok Shenvi

Chapter 8 Statistical Process Control for Software: Fill the Gap 135 Maria Teresa Baldassarre, Nicola Boffoli and Danilo Caivano

Chapter 9 MiniDMAIC: An Approach to Cause and Analysis Resolution in Software Project Development 155

Carla Ilane M. Bezerra, Adriano B. Albuquerque and Luiz Sérgio Plácido

Chapter 10 Defining Placement Machine Capability By Using Statistical Methods 183 Timo Liukkonen, Ph.D 
Chapter 11 Modelling, simulation, six sigma and their application in optimization of electrical vehicle design 207 Wei Zhan

Chapter 12 Longitudinal Robust Stability Augmentation for Micro air Vehicle - Design and Validation 225 Dr. M. Meenakshi and Prof. M. Seetharama Bhat

Chapter 13 Six Sigma as a Quality Management Tool:

Evaluation of Performance in Laboratory Medicine 247

Abdurrahman Coskun, Tamer Inal, Ibrahim Unsal and Mustafa Serteser

Chapter 14 Tesqual: A Microthesaurus for Use in Quality Management in European Higher Education 263 María Mitre 


\section{Preface}

The history of quality is the history of human efforts to make things perfect in an imperfect world.

The main purpose of the quality procedures is to reduce errors and increase customer satisfaction. Errors and mistakes are part of human nature, but so is the ability to create solutions and find better alternatives. By using modern quality management tools we can shift the balance from errors towards solutions and better alternatives.

Six Sigma methodology represents an evolution in quality management that is being widely implemented in industry and business in the new millennium. In the mid-1980s it was developed by Motorola Inc. to reduce the cost of products and eliminate defects. Using Six Sigma methodology, Motorola Inc. become a quality leader and won the Malcolm Baldrige National Quality Award in 1988.

The increasing expectation of customers and the complexity of modern products forced companies to find new solutions and better alternatives during the 20th century. Within this atmosphere, Six Sigma has provided the best solution in business and industry. Due to its flexible nature, the Six Sigma methodology was rapidly adopted by many top companies and, within only two decades, it has also been adopted by many mid-sized and even small companies. In addition to companies in Japan and Western Countries, Six Sigma methodology provides the best solutions to many problems and can be used as an accelerator in developing countries.

In the new millennium Six Sigma methodology has been considered as a strategic approach to achieve excellence in business and industry. It is the main way of doing business, rather than a simple quality system. Six Sigma is a philosophy and vision, and it is based on both reality and productivity. The ultimate goal of Six Sigma is error-free business and industry.

If you do not measure, you do not know, and if you do not know, you cannot manage. This way Six Sigma shows us how to measure and, consequently, how to manage the company. Sigma levels are a measure of error rates. A company or a medical laboratory, and even a bank, can measure their performance by sigma level. Companies that accept three or four sigma levels create 67000 and 6200 defects per million products, however, companies that accept six sigma levels create only 3.4 defects per million products.

In this book several scientists from various regions of the world share their experience and knowledge about quality management and particularly Six Sigma methodology. The chapters in the book cover the basic principles of managing quality and Six Sigma methodology in many different disciplines of industry, business and even medical laboratories. 
I hope that this book as a free resource will help to employees worldwide at all levels in different areas of business and industry, who need to improve their knowledge and experience in Six Sigma and Quality Management.

Editor

Dr Abdurrahman Coskun Acibadem University, School of Medicine,

Department of Medical Biochemistry,

Istanbul, Turkey 


\title{
Six sigma and Total Quality Management
}

\author{
Yang, Ching-Chow \\ Department of Industrial and Systems Engineering \\ Chung Yuan Christian University \\ Taiwan, R.O.C.
}

\section{The practices and implementation of Six Sigma}

In the past two decades, Six Sigma methodology has been widely adopted by industries and non-profit organizations throughout the world. In this section, we demonstrate the development of Six Sigma program, and discuss the features and the five steps of the improvements

\subsection{The introduction of Six Sigma}

Six Sigma methodology was first espoused by Motorola in the mid 1980s. (Antony \& Banuelas, 2002; Wiklund \& Wiklund, 2002). At that time, Motorola was facing Japanese competition in the electronics industry and needed to make drastic improvements in its levels of quality (Harry and Schroeder, 2000; Linderman et al., 2003). A Six Sigma initiative ,which is originally focused on manufacturing process and product quality (Harry \& Schroeder, 2000), is also designed to change the culture in an organization through breakthrough improvement in all aspects of the business (Breyfogle III et al., 2001, p.32). The Six Sigma architects at Motorola focused on making improvements in all operations within a process - thus producing results far more rapidly and effectively (Harry \& Schroeder, 2000). The successful implementation of the Six Sigma program in Motorola led to huge benefits. Motorola recorded a reduction in defects and manufacturing time, and also began to reap financial rewards. Within four years, the Six Sigma program had saved the company $\$ 2.2$ billion (Harry \& Schroeder, 2000). The crowning achievement was being recognized with the Malcolm Baldrige National Quality Award (Breyfegle III et al., 2001; Wiklund \& Wiklund, 2002).

IBM, SONY, and Allied Signal successfully followed Motorola in implementing Six Sigma. Allied Signal began its Six Sigma activities in the early 1990s, It successfully attained savings of US\$2 billion during a five-year period (Klefsjö et al., 2001). Sooner, the impressive results obtained by Allied Sigma induced General Electric (GE) to undertake a thorough implementation of the Six Sigma program in 1995 (Pande et al., 2000) as a corporate initiative to improve net profits and operating margin (Hendricks and Kelbaugh, 1998). The 1999 annual report of GE showed that the implementation produced more than US $\$ 2$ billion in benefit (Slater, 2001; Coronado \& Antony, 2002, Raisinghani et al., 2005). 
As a result, the impressive benefits of implementing Six Sigma programs in Motorola, Allied Signal, and GE led the Six Sigma methodology being widely adopted by industries throughout the world. American Express, Ford, Honda, and Samsung have all applied the methodology (Klefsjö et al., 2001; Sandholm \& Sorqvist, 2002; Yun and Chua, 2002). The Six Sigma has become the most prominent trend in quality management (Sandholm \& Sorqvist, 2002; Yang, 2004) not only for manufacturing and service industries, but also for non-profit organizations and government institutes.

The GE-6 $\sigma$ program and the Motorola Six Sigma program did have some differences. Whereas Six Sigma activities in Motorola had focused on product quality and the manufacturing process, the GE- $6 \sigma$ program extended the improvement activities to cover all key processes related to customer satisfaction.

\subsection{Some key views on Six Sigma}

Several prominent researchers have expressed views on Six Sigma.

* Hahn et al. (1999) emphasized that Six Sigma improvement is a highly disciplined and statistically based approach for removing defects from products, processes, and transactions, involving everyone in the corporation.

* Harry \& Schroeder (2000) emphasized that Six Sigma provides maximum value to companies - in the form of increased profits and maximum value to the consumer through high-quality products or service at the lowest possible cost.

* Harry \& Schroeder (2000) also concluded that Six-Sigma is a business strategy and philosophy built around the concept that companies can gain a competitive edge by reducing defects in their industrial and commercial processes.

* Pande et al. (2000) commented that Six Sigma is a comprehensive and flexible system for achieving, sustaining, and maximizing business success. It is driven by close understanding of customers' needs and disciplined use of facts, data, and statistical analysis.

* Pearson (2001) described Six Sigma as a program that combines the most effective statistical and non-statistical methods to make overall business improvements.

* Slater (2001) stated that the Six Sigma approach provides a very specific control program with control techniques that ensure continuation of improved processes.

* Lucas (2002) described Six Sigma as a statistical business system and a functional methodology for disciplined quality improvement that achieves successful outcomes.

* Treichler et al. (2002) concluded that Six Sigma is a highly disciplined process that helps organizations to focus on developing and delivering near-perfect products and services. It is also, in Treichlers' (2002) view, a change-acceleration process that focuses on pursuing success and the rapid adoption of change.

* Yang (2004) asserted that the GE-6 $\sigma$ program and the Motorola Six Sigma program did have some differences. Whereas Six Sigma activities in Motorola had focused on product quality and the manufacturing process, the GE- $6 \sigma$ program extended the improvement activities to cover all key processes related to customer satisfaction. 
In addition to the major features noted above, other features of the GE- $6 \sigma$ program include (Breyfegle III et al., 2001; Pande et al., 2000; Treichler et al. 2002).

* GE-6 $\sigma$ projects are integrated with the company's visions and strategies;

* all GE-6 $\sigma$ projects are rigorously evaluated for financial impact;

* everyone who contributes to the success of the program receives significant rewards, especially in terms of staff promotion;

* significant financial incentives (representing $40 \%$ of all bonuses received by employees) are tied to GE-6 $\sigma$ projects;

* a sound statistical approach to improvement is adopted;

* projects are completed rapidly (usually within 3-6 months); and

* bottom-line results are expected and delivered.

\subsection{Implementation of GE Six Sigma}

The main features of GE- $6 \sigma$ are discussed above, in this subsection we introduce the implementation of GE Six-Sigma:

* improvement steps;

* staff roles; and

* investment in training.

\subsubsection{Improvement steps}

There have been many improvement models for process improvement or re-engineering. Most of these have been based on the steps introduced by W. Edwards Deming, which can be characterized as 'Plan', 'Do', 'Study', and 'Act' (PDSA)(Deming, 1993). GE-6 6 has a five-phase improvement cycle that has become increasingly popular in Six Sigma organizations: 'Define', 'Measure', 'Analyze', 'Improve', and 'Control' (DMAIC). There is another cycle characterized as 'Define', 'Measure', 'Analyze', 'Design', and 'Verify' (DMADV) (Pande et al., 2000). Like other improvement models, the DMAIC (or DMADV) model is grounded in the original Deming PDCA cycle. Usually, Six Sigma organizations use DMAIC for process improvement and DMADV for process design (and redesign). Table 1.1 describes the specific tasks in each step, and the tools and techniques used in the steps.

\begin{tabular}{|c|c|c|}
\hline Step & Specific tasks & Tools and techniques employed \\
\hline $\begin{array}{l}\text { Define } \\
\end{array}$ & $\begin{array}{l}\text { - Identify improvement issues } \\
\text { - Organize project team } \\
\text { - Set-up improvement goal } \\
\text { - Estimate financial benefit }\end{array}$ & $\begin{array}{l}\text { - Customer complaint analysis } \\
\text { - Cost of poor quality (COPQ) } \\
\text { - Brainstorming } \\
\text { - Run charts, control charts } \\
\text { - Benchmarking }\end{array}$ \\
\hline Measure & $\begin{array}{l}\text { - Map process and identify inputs and } \\
\text { outputs } \\
\text { - Establish measurement system for } \\
\text { inputs and outputs } \\
\text { - Understand the existing capability of } \\
\text { process }\end{array}$ & $\begin{array}{l}\text { - Process map (SIPOC) } \\
\text { - Cause and effect matrix } \\
\text { - Gauge R\&R } \\
\text { - Control charts } \\
\text { - Process capability analysis } \\
\text { - Failure models and effects } \\
\quad \text { analysis (FMEA) }\end{array}$ \\
\hline
\end{tabular}




\begin{tabular}{|c|c|c|}
\hline Analyze & $\begin{array}{l}\text { - Identify sources of variation in } \\
\text { process } \\
\text { - Identify potential critical inputs } \\
\text { - Determine tools used in the } \\
\text { improvement step }\end{array}$ & $\begin{array}{l}\text { - Cause-and-effect diagram } \\
\text { - Pareto diagram } \\
\text { - Scatter diagram } \\
\text { - Brainstorming } \\
\text { - Analysis of variance (ANOVA) }\end{array}$ \\
\hline Improve & $\begin{array}{l}\text { - Conduct improvement actions } \\
\text { - Use experiments } \\
\text { - Optimize critical inputs }\end{array}$ & $\begin{array}{l}\text { - Design of experiment (DOE) } \\
\text { - Quality function deployment } \\
\text { (QFD) } \\
\text { - Process capability analysis } \\
\text { - Control charts }\end{array}$ \\
\hline Control & $\begin{array}{l}\text { - Maintain critical inputs in the optimal } \\
\text { area } \\
\text { - Verify long-term capability } \\
\text { - Evaluate the results of improvement } \\
\text { projects }\end{array}$ & $\begin{array}{l}\text { - Standard operation procedure } \\
\text { - Process capability analysis } \\
\text { - Fool-proofing (Poka Yoke) } \\
\text { - Run charts }\end{array}$ \\
\hline
\end{tabular}

Table 1.1 DMAIC steps and tools usage

\subsubsection{Staff roles}

Along with the systematic improvement steps described above, the design of specific roles and their effective operations are important factors of the GE- $6 \sigma$ program. Senior management is ultimately responsible for the success of the project through the provision of sufficient support, resources, and strong leadership. The implementation of GE- $6 \sigma$ is thus top-down. The chief executive officer (CEO) is usually the driving force who sets up the vision, develops the strategies, and drives the changes. Apart from the critical role of the CEO, other players also have their specific roles (Henderson and Evans, 2000):

(i) 'Champions' are usually the senior managers, who are the sponsors of the project and responsible for success of Six Sigma efforts, they are fully trained business leaders who promote and lead the deployment of Six-Sigma projects;

(ii) 'Master Black Belts (MBBs)' are the full-time teachers and consultants, they are responsible for Six-Sigma strategy, deployment, training, mentoring, and results. A master Black Belt in Motorola has leaded as a Black Belt for about ten successful projects at least five years, and needs the recommendation of high managements;

(iii) 'Black Belts (BBs)' have the key operational role in the program as full-time Six Sigma players, they are fully-trained Six-Sigma experts and lead the improvement teams. They are qualified as they successfully leaded at least two Six-Sigma projects;

(iv) 'Green Belts (GBs)' are the process owners who, led by the BBs, work on Six Sigma projects while holding down their original job functions in the company.

\subsubsection{Investment in training}

Because training is a key ingredient in achieving success through Six Sigma (Pande et al, 2000), Motorola and GE have invested heavily in employee training for their Six-Sigma programs. Motorola invested \$150 million per year in Six-Sigma courses, GE also spent \$500 million per year in the implementation of Six-Sigma program (Sandholm and Sorqvist, 2002), GE has invested more than a billion dollars in this effort (Hahn et al., 1999). GE has designed 
a complete training plan for the various roles described above-from the CEO, to the 'Champions', 'MBBs', 'BBs', and 'GBs'. In addition, the training program extends to all other employees in the organization. The training courses are comprehensive and cover team leadership skills, measurement and analytical tools, especially statistical methods, improvement tools, planning and implementation skills, and so on. For examples,

(i). Champions have one week champion training related to Six-Sigma development, leadership, and the implementation plan.

(ii). BBs spend about four to five weeks to receive the intensive, highly quantitative training, roughly corresponding to the five steps of the implementation of Six-Sigma improvement project. Thus, the length of training is approximately 16-20 weeks.

(iii) GBs receive the training of six to ten days. The courses include the statistical tools and the use of statistical software, the detailed modules of five steps, the innovative and improvement tools, and the skill of project management.

(iv) MBBs then take over the responsibility of the training for all the BBs and GBs.

\section{The critical success factors of the implementation of Six-Sigma}

In this section we want to discuss the critical success factors for the successful implementation of Six-Sigma projects. We investigate the importance degree of the critical success factors in implementing Six Sigma, and their implementation level by using the questionnaire survey.

\subsection{The consideration of critical success factors}

Table 2.1 lists the key factors, as asserted in five previous studies. The factors identified by Coronado \& Antony (2002) and Antony \& Banuelas (2002) are almost identical, with the exception that Coronado \& Antony (2002) added one extra factor ("communication"). Most of the success factors in the other three studies are included in the work of Coronado \& Antony (2002). The total twelve critical success factors in Coronado \& Antony (2002) are considered in the present study

In addition, two additional key factors, "complete evaluation system of project performance" and "promotion and incentive for employees tied to the results of Six Sigma projects", are also considered in this chapter according to Yun \& Chua (2002) and Sandholm \& Sorqvist (2002). The former introduces the factor of "accurate and fair evaluation of all successful Six Sigma projects with meaningful recognition and rewards for employees". The later suggests "focus on results" to assert that the employee promotion and incentive compensation are tied to the results of Six Sigma projects.

Finally, apart from the above, another key success factor somewhat neglected by previous studies is the application of techniques and innovations. Although Coronado \& Antony (2002) and Klefsjö et al. (2001) mention it as a required technique in the progress of Six Sigma projects, and Yun \& Chua (2002) asserts that "linkage with all innovation and infrastructure activities" is also a key factor. We therefore add another key factor: "usage of innovative techniques and IT systems". In total, a study is conducted to adopt fifteen critical success factors in the questionnaire to investigate the extent to which they are implemented and their degree of importance from the firms' perspective. 
The author conducted the empirical study for those enterprises have implemented Six Sigma program in Taiwan, The aim of this empirical study is to investigate the importance degree and the implementation level of the critical success factors. Thus, the research design is conducted according to the aim of the research. The Likert-type scale is used in the questionnaire. In the investigation of the importance degree of the critical success factors, a five-point scale from 1 (not important) to 5 (very important) is used. In the analysis of implementation level, a five-point scale from 1 (not implemented) to 5 (full implemented) is adopted

\subsection{The analysis of critical success factors}

The main focus of this study is to analyze the degree of importance of critical success factors for Six Sigma effectiveness as perceived by the respondents, and to assess the implementation level of these critical success factors by the organizations (see Table 2.2). As Henderson \& Evans (2000) notes that "top management leadership and support" should be the critical success factor, our first priority of success factors is "top management involvement and commitment". The other critical success factors are prioritized as follows: "cultural change", "communication with all employees to achieve congruence", and "training in Six Sigma", and so on. It should be noted that "employees' promotion and incentive tied to the results of Six Sigma projects" is considered as an important factor for the success of Six Sigma in GE (Hendericks \& Kelbaugh, 1998; Henderson \& Evans, 2000). However, in Taiwan, this practice is not followed in the industries investigated.

\begin{tabular}{|c|c|c|}
\hline Hahn et al., 1999 & $\begin{array}{l}\text { Key factors for Six } \\
\text { Sigma effectiveness }\end{array}$ & $\begin{array}{l}\text { - Quantified functional impact } \\
\text { - Continued top management support and } \\
\text { enthusiasm } \\
\text { - The emphasis on a quantitative and disciplined } \\
\text { approach } \\
\text { - The value placed on understanding and } \\
\text { satisfying customer needs } \\
\text { - Combining the right projects, the right people, } \\
\text { and the right tools }\end{array}$ \\
\hline Yun \& Chua, 2002 & $\begin{array}{l}\text { Success factors for } \\
\text { Six Sigma } \\
\text { effectiveness }\end{array}$ & $\begin{array}{l}\text { - Strong proactive support with required } \\
\text { resources provided by top management } \\
\text { - Acceptance and implementation of Six Sigma's } \\
\text { basic disciplines by employees } \\
\text { - Linkage with all innovative and infrastructure } \\
\text { activities } \\
\text { - Accurate and fair evaluation of all successful Six } \\
\text { Sigma projects with meaningful recognition and } \\
\text { rewards for employees }\end{array}$ \\
\hline
\end{tabular}




\begin{tabular}{|c|c|c|}
\hline $\begin{array}{l}\text { Sandholm \& } \\
\text { Sorqvist, } 2002\end{array}$ & $\begin{array}{l}\text { Requirements for } \\
\text { Six Sigma success }\end{array}$ & $\begin{array}{l}\text { - Management commitment and visible support } \\
\text { - Treatment of Six Sigma as a holistic concept } \\
\text { - Investment of adequate resources } \\
\text { - Focus on results } \\
\text { - Customer orientation } \\
\text { - Focus on training and its content } \\
\text { - Adaptation to an organization's situation and } \\
\text { needs } \\
\text { - Prioritization and selection of projects } \\
\text { - Development of uniform language \& } \\
\text { - terminology } \\
\text { - Development of strategy to introduce Six Sigma } \\
\text { - Responsiveness to external influences. }\end{array}$ \\
\hline $\begin{array}{l}\text { Coronado \& } \\
\text { Antony, } 2002\end{array}$ & $\begin{array}{l}\text { Critical success } \\
\text { factors for Six } \\
\text { Sigma projects }\end{array}$ & $\begin{array}{l}\text { - Management involvement and commitment } \\
\text { - Cultural change } \\
\text { - Communication } \\
\text { - Organization infrastructure } \\
\text { - Training } \\
\text { - Linking Six Sigma to business strategy } \\
\text { - Linking Six Sigma to customers } \\
\text { - Linking Six Sigma to human resources } \\
\text { - Linking Six Sigma to suppliers } \\
\text { - Understanding tools and techniques within Six } \\
\text { Sigma } \\
\text { - Project management skills } \\
\text { - Project prioritization and selection }\end{array}$ \\
\hline $\begin{array}{l}\text { Antony \& } \\
\text { Banuelas, } 2002\end{array}$ & $\begin{array}{l}\text { Key ingredient for } \\
\text { Six Sigma } \\
\text { effectiveness }\end{array}$ & $\begin{array}{l}\text { - Management involvement and commitment } \\
\text { - Cultural change } \\
\text { - Organization infrastructure } \\
\text { - Training } \\
\text { - Project management skills } \\
\text { - Project prioritization and selection, reviews and } \\
\text { tracking } \\
\text { - Understanding the Six Sigma methodology, } \\
\text { tools, and techniques } \\
\text { - Linking Six Sigma to business strategy } \\
\text { - Linking Six Sigma to customers } \\
\text { - Linking Six Sigma to human resources } \\
\text { - Linking Six Sigma to suppliers }\end{array}$ \\
\hline
\end{tabular}

Table 2.1 Critical success factors for Six Sigma effectiveness 


\begin{tabular}{|c|c|c|c|c|c|}
\hline \multirow[t]{2}{*}{ Critical success factor } & \multicolumn{2}{|c|}{$\begin{array}{l}\text { Importance } \\
\text { degree }\end{array}$} & \multicolumn{2}{|c|}{$\begin{array}{l}\text { Implementation } \\
\text { level }\end{array}$} & \multirow{2}{*}{$\begin{array}{l}\text { To be } \\
\text { improved } \\
\text { factor }\end{array}$} \\
\hline & mean & order & mean & order & \\
\hline $\begin{array}{l}\text { 1. Top management involvement and } \\
\text { commitment }\end{array}$ & 4.808 & 1 & 3.885 & 2 & * \\
\hline 2. Cultural change & 4.365 & 2 & 3.192 & 11 & * \\
\hline 3. Organization infrastructure & 4.019 & 10 & 3.596 & 4 & \\
\hline 4. Training in Six Sigma & 4.192 & 4 & 3.981 & 1 & \\
\hline 5. Project management skills & 3.865 & 12 & 3.577 & 5 & \\
\hline 6. Project prioritization and selection & 4.077 & 9 & 3.558 & 6 & \\
\hline $\begin{array}{l}\text { 7. Understanding methods, tools and } \\
\text { techniques within Six Sigma }\end{array}$ & 4.137 & 7 & 3.667 & 3 & \\
\hline 8. Linking Six Sigma to business strategy & 4.192 & 5 & 3.423 & 9 & * \\
\hline 9. Linking Six Sigma to customers & 4.192 & 6 & 3.269 & 10 & * \\
\hline 10. Linking Six Sigma to human resources & 3.725 & 13 & 2.882 & 14 & \\
\hline 11. Linking Six Sigma to suppliers & 3.635 & 14 & 2.692 & 15 & \\
\hline $\begin{array}{l}\text { 12. Communication with all employees to } \\
\text { achieve congruence }\end{array}$ & 4.231 & 3 & 3.519 & 7 & * \\
\hline $\begin{array}{l}\text { 13. Complete evaluation system of project } \\
\text { performance }\end{array}$ & 4.135 & 8 & 3.481 & 8 & \\
\hline $\begin{array}{l}\text { 14. Employees' promotion and incentive } \\
\text { compensation tied to the result of Six } \\
\text { Sigma projects }\end{array}$ & 3.885 & 11 & 2.981 & 12 & \\
\hline $\begin{array}{l}\text { 15. The usage of innovative techniques } \\
\text { and IT systems }\end{array}$ & 3.596 & 15 & 2.942 & 13 & \\
\hline
\end{tabular}

Table 2.2 Importance degree and implementation level of critical success factors

Most of the organizations paid significant attention to training in Six Sigma. The factor of "training in Six Sigma" is thus the first priority of implementation level, followed by such factors as "top management involvement and commitment", "understanding methods, tools and techniques within Six Sigma", "organization infrastructure", and so on (see Table 2.2). In Table 2.2, if a critical success factor has a higher importance degree with a lower implementation level, then the firm should pay more attention on its implementation. In this case, we denote five CSFs as the "to be improved" factors for the industries in Taiwan:

- Top management involvement and commitment

- Cultural change

- Communication with all employees to achieve congruence

- Linking Six Sigma to business strategy

- Linking Six Sigma to customers. 


\section{The Integrated Model of TQM and Six Sigma}

By the end of the 1970s, the competitiveness of Japanese industries had equaled or exceeded that of American industries. In large part, this was due to the successful Japanese implementation of company-wide quality control (CWQC) (Powell, 1995). By the 1980s, Japanese CWQC had been replicated in the United States, and total quality management (TQM) soon became the prevailing business strategy adopted by industries around the world. This evolution of TQM has resulted from the development, on a global scale, of a consistent philosophy concerning the relationship between business and customers. At various stages in this development, different ideologies and practices for implementing quality management have been prominent, but the consistent goal has been to pursue the quality of products and services, to reduce costs, and to raise business performance. The success of Japanese industries in the total and effective implementation of TQM meant that Japanese firms led the way in the production of good-quality products at lower cost.

\subsection{The decreasing adoption of TQM and the increasing trend of Six-Sigma}

The successful implementation of TQM does indeed result in better business performance, as firms expect (Hendricks \& Singhal, 1996; Gunasekaran, 1999; Hansson \& Eriksson, 2002). The benefits come in the areas of cost reduction, increased market share, increased profit, and enhanced business competitiveness (Youssef et al., 1996; Gunasekaran, 1999). TQM has therefore been widely adopted by industries, even in non-profit and governmental organizations (Powell, 1995; Zabaha et al., 1998).

Several critical factors are essential if TQM is to be successfully implemented. These include the support of top management, visionary leadership, effective management of human resources, employee involvement, and a corporate culture of commitment to quality and customer satisfaction (Joseph et al., 1999; Sureshchandar et al., 2001). However, in practice, these corporate factors are not easy to achieve. As a result, the literature contains reports of several cases in which the implementation of TQM has failed. Hubiak \& O'Donnell (1996), for example, have asserted that approximately two-thirds of companies in the United States have either failed or stalled in their attempts to implement TQM. Many of these TQM programs have been cancelled, or are in the process of being cancelled, as a result of the negative impact on profits (Anonymous, 1996). The failure implementation of TQM is due to several factors. Besides the difficult achievement of TQM practices, one of them is that TQM has been a rather diffuse concept, with many vague descriptions but few more graspable definitions, and the management does not have a complete picture of what TQM really means (Hellsten \& Klefsjö, 2000). Another one is that too management teams over the world do not realize that implementation of TQM means a cultural change (Hansson \& Klefsjö, 2003). In fact, TQM was one of two workplace trends that recorded a significant decline in 1996 (Anonymous, 1996). Academic discussion of TQM and its implementation has suffered a similar decline in recent years.

Is this trend really due to poor corporate business performance as a result of the implementation of TQM, with a consequent decline in the implementation of TQM, as has been asserted (Anonymous, 1996)? It is a contention that this is not an accurate reflection of the current status of TQM. Reports of instances of failed TQM implementation are only part of the explanation for the apparent declining trend in TQM. In reality, TQM has been so prominent for about twenty years that many firms and institutions have incorporated TQM 
into daily management activities. The result is that a well-established model of TQM has been so much a part of the routine business activities, that the 'decline' in discussion and implementation of the TQM is apparent, rather than real.

As interest in TQM has apparently waned, interest in the Six Sigma program has increased.

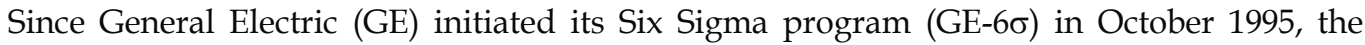
results have been far beyond the company's original hopes and expectations. Based on the remarkable business successes achieved in GE and other large corporations, an increasing number of companies have initiated the GE-6 $\sigma$ program as a business improvement and re-engineering strategy (Pearson, 2001; Lucas, 2002). As a result, the Six Sigma program has gained great popularly in recent years (Slater, 2001; Lucas, 2002). It has even been suggested that TQM will be replaced by Six Sigma as the main strategy for successful business management. However, such assertions reveal a fundamental misunderstanding of the nature of TQM and its relationship with GE-6 $\sigma$.

For example, Pande et al. (2000) have asserted that TQM is less visible in many businesses than it was in the early 1990s, pointing to several major TQM gaffes as reasons for this apparent decline. According to Pande et al. (2000), these problems include a lack of integration, leadership apathy, a fuzzy concept, an unclear quality goal, failure to break down internal barriers, inadequate improvements in performance, and so on. They conclude that Six Sigma can overcome many of the pitfalls encountered in the implementation of TQM and, hence, that Six Sigma's expansion heralds a 'rebirth' of the quality movement (Pande et al., 2000). However, Klefsjö et al. (2001) and Lucas (2002) have a different perspective. Klefsjö et al. assert that Six Sigma is a methodology within- not alternative to TQM. Lucas asserts that Six Sigma is essentially a methodology for disciplined quality improvement. Because this quality improvement is a prime ingredient of TQM, many firms have found that adding a Six Sigma program to their current business system gives them all, or almost all, of the elements of a TQM program. Lucas has thus concluded that:

Current Business System + Six Sigma = Total Quality Management

The TQM pitfalls noted by Pande et al. (2000) are not essential features of TQM. Rather, they are caused by incorrect practices adopted by firms, especially the lack of proper endeavour shown by management in the implementation of TQM.

\subsection{Total quality management}

Since TQM began in the mid 1980s, several gurus, like Deming, Juran and Ishikawa have much contribution on the development of TQM (Boaden, 1997). Besides, many researchers and experts on quality management have been eager to study the essentials of TQM. In the beginning, there was a lack of consensus on the contents and practices of TQM. Now, with TQM having been implemented for more than twenty years, academics and practitioners alike have achieved a degree of consensus on TQM.

Tobin (1990) has stated that TQM is a totally integrated program for gaining competitive advantages by continuously improving every facet of organizational culture. TQM programs are usually based on the 'quality philosophies'-- customer focus, employee participation, teamwork, and management by facts and continuous improvement (Brown, 1992). TQM is therefore an integrated management philosophy and set of practices that emphasize increased employee involvement and teamwork, continuous improvement, meeting customers' requirements, team-based problem-solving, constant measurement of results, closer relationship with suppliers, and so on (Ross, 1993). Short and Rahim (1995) 
have agreed that TQM can be viewed as a set of philosophies and methods used by an organization to guide it in continuous improvement in all aspects of its business. McAdam and McKeown (1999) have concluded that customer focus, employee involvement, empowerment, teamwork, measurement tools, training, quality systems, and top management commitment are all key factors in the successful implementation of TQM. Boaden (1997) also examine the critical elements of TQM based on some early studies. It is worthwhile to refer to the research of Sila \& Ebrahimpour (2002), they conduct a huge investigation of elements of TQM survey based on 347 researches published between 1989 and 2000 .

These views indicate that, although various researchers approach the issues of TQM from different perspectives, there is a general consensus regarding the essential principles, practices, and values of TQM (Hellsten \& Klefsjö, 2000). On the basis of these various approaches, especially the research of Sila \& Ebrahimpour (2002) and Yang (2003a), the present subsection asserts the following to be essential agreed elements of TQM:

* customer focus and satisfaction;

* training and education;

* top management commitment, support, and leadership;

* teamwork;

* employee involvement;

* quality assurance;

* quality information system and application;

* continuous improvement;

* flexibility

* benchmarking and strategy planning;

* process management;

* product and service design and quality control;

* employee management and empowerment;

* corporate quality culture;

\subsection{Comparison between TQM and GE-6 $\sigma$}

As previously noted, the passion for TQM has apparently declined, whereas GE- $6 \sigma$ has been receiving increased attention (Anonymous, 1996; Pande et al., 2000). As a result, there are several assertions related to the relationship between TQM and GE- $6 \sigma$ appeared, especially the treatise that TQM will be replaced by GE- $6 \sigma$. However, there are very few studies in the literature that directly compare TQM with GE- $6 \sigma$ completely, and in the limited studies that do exist, conclusions on the relationship between TQM and GE-6 $\sigma$ have differed significantly.

Harry (2000b) has claimed that Six Sigma represents a new, holistic, multidimensional systems approach to quality that replaces the "form, fit and function specification" of the past. However, it is not readily apparent from Harry (2000a) which aspects of this multidimensional systems approach are presumed to be absent from TQM.

Breyfegle III et al. (2001) have stated that Six Sigma is more than a simple repacking of the best from other TQM programs. Pande et al. (2000) had already taken a similar approach when they provided a review of some of the major TQM gaffes, and then compared TQM and GE-6 $\sigma$ in the light of these problems with a view to showing how successful implementation of Six Sigma can overcome these failures. However, it should be noted that 
these gaffes are principally a result of inappropriate implementation processes, rather than being caused by inherent TQM concepts and practices.

In view of a lack of consensus on the relationship between TQM and GE-6 $\sigma$, the present section wants to compare TQM and GE-6 $\sigma$ by using complete perspectives. The author reviewed several studies (Boaden, 1997; Hermel, 1997; Goh, 2002), and selected the appropriate criteria used in these researches, and then integrated into 12 dimensions. They are: (i) development; (ii) principles; (iii) features; (iv) operation; (v) focus; (vi) practices; (vii) techniques; (viii) leadership; (ix) rewards; (x) training; (xi) change; and (xii) culture (Yang, 2004). These are presented in Table 3.1, which represents a comprehensive review of the similarities and differences between the two approaches.

\subsection{Integration of TQM and GE-6 $\sigma$}

It has been suggested that the implementation of TQM results in an over-emphasis on customer satisfaction, with a relative neglect of the pursuit of profits (Anonymous, 1996). Indeed, several empirical studies have asserted that implementing TQM might not achieve any significant positive effect on profitability (Bergquist \& Ramsing, 1999; Harry, 2000b; Breyfegle III et al., 2001). Furthermore, Harry (2000a) has noted that "What's good for the customer is not always good for the company". In contrast, it is argued that GE- $6 \sigma$ achieves both customer satisfaction and excellent financial performance.

The major problem with TQM is that there is a disconnection between management systems designed to measure customer satisfaction and those designed to measure business profitability, and this has often led to unwise investments in quality (Breyfegle III et al., 2001). It should be recognized that the objective of TQM is to achieve customer satisfaction, in order to increase customer loyalty. To sustain competitiveness and long-term profitability, companies not only devote themselves to attracting new customers, but also to retaining old customers in a continuous business relationship with incremental additional purchasing. For these reasons, increasing customer loyalty should be one of the main concerns of all companies (Gorst et al., 1998). Any assessment of the effectiveness of TQM thus requires a system to measure customer loyalty.

If a management system cannot raise business performance and profitability, it will obviously be abandoned by firms. It is therefore apparent that indicators of customer loyalty and business performance should be added to TQM measurement systems. It is well known that GE-6 $\sigma$ pursues both customer satisfaction and high profits. If an integrated model of TQM and GE-6 $\sigma$ were developed, synergistic effects could be anticipated. In the integrated model proposed here, two major indicators are included-customer loyalty and high profit performance. 


\begin{tabular}{|c|c|c|c|}
\hline Dimension & TQM & GE-60 & Comments \\
\hline 1. Development & $\begin{array}{l}\text { Started in the mid 1980s, } \\
\text { influenced by Japanese } \\
\text { CWQC developed in the } \\
1970 \text { s }\end{array}$ & $\begin{array}{l}\text { First espoused by Motorola } \\
\text { in 1987. GE adopted Six } \\
\text { Sigma program in 1995, } \\
\text { resulting in many benefits. }\end{array}$ & $\begin{array}{l}\text { TQM and Six Sigma began } \\
\text { at about the same time. } \\
\text { TQM was widely and } \\
\text { quickly adopted, but } \\
\text { interest has now declined. } \\
\text { The situation with GE-6 } \sigma \\
\text { is the reverse. }\end{array}$ \\
\hline 2. Principles & $\begin{array}{l}\text { - Customer satisfaction } \\
\text { (satisfaction of } \\
\text { customers' needs) } \\
\text { - Pursues zero-defect, } \\
\text { - Responsibility for } \\
\text { quality } \\
\text { - Continuous } \\
\text { improvements }\end{array}$ & $\begin{array}{l}\text { - Pursues financial } \\
\text { performance } \\
\text { - Focuses on voice of } \\
\text { customer } \\
\text { - Pursues zero-defect } \\
\text { - Emphasis moved from } \\
\text { problem-solving to } \\
\text { problem prevention } \\
\text { - Rapid change }\end{array}$ & $\begin{array}{l}\text { TQM over-emphasizes } \\
\text { customer satisfaction, and } \\
\text { this can sometimes } \\
\text { negatively affect profits. } \\
\text { GE- } 6 \sigma \text { focuses on both } \\
\text { customer satisfaction and } \\
\text { financial performance. }\end{array}$ \\
\hline 3. Feature & $\begin{array}{l}\text { A systematic approach to } \\
\text { quality management by } \\
\text { integrating concepts, } \\
\text { methods, processes, and } \\
\text { systems. }\end{array}$ & $\begin{array}{l}\text { Uses project management } \\
\text { to perform thorough } \\
\text { change and process } \\
\text { re-engineering, which are } \\
\text { integrated with the } \\
\text { company's vision and } \\
\text { strategy. }\end{array}$ & 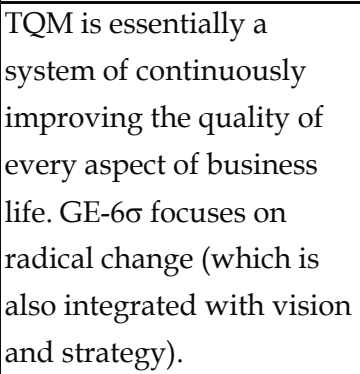 \\
\hline 4. Operation & $\begin{array}{l}\text { Continuous improvement } \\
\text { through employee } \\
\text { involvement and } \\
\text { teamwork in total quality } \\
\text { activities. }\end{array}$ & $\begin{array}{l}\text { Specially designed roles } \\
\text { and a highly disciplined } \\
\text { training program using } \\
\text { statistical methods to } \\
\text { perform reengineering of } \\
\text { key processes through } \\
\text { project management. }\end{array}$ & $\begin{array}{l}\text { TQM emphasizes that } \\
\text { every person is involved in } \\
\text { quality improvement at all } \\
\text { levels. GE- } 6 \sigma \text { uses } \\
\text { specially designed roles } \\
\text { and disciplined training to } \\
\text { progress the radical } \\
\text { changes. }\end{array}$ \\
\hline 5. Focus & $\begin{array}{l}\text { TQM focuses on all quality } \\
\text { activities, all processes, and } \\
\text { all systems. }\end{array}$ & $\begin{array}{l}\text { Key processes and systems } \\
\text { are all driven by the voice } \\
\text { of customers. }\end{array}$ & $\begin{array}{l}\text { TQM considers every } \\
\text { aspect of quality. GE-6 } \sigma \\
\text { initially emphasizes the } \\
\text { key processes related to } \\
\text { customer needs, but } \\
\text { gradually extends its } \\
\text { improvement scope. }\end{array}$ \\
\hline
\end{tabular}




\begin{tabular}{|c|c|c|c|}
\hline 6. Practices & $\begin{array}{ll}\text { - } & \text { QCC, QIT } \\
\text { - } & \text { Suggestion system } \\
\text { - } & \text { Project management } \\
\text { - } & \text { Daily control } \\
\text { - Hoshin management } \\
\text { - }\end{array}$ & $\begin{array}{l}\text { - Project management } \\
\text { - } \text { BPR } \\
\text { - } \text { DMAIC or DMADV } \\
\text { - Benchmarking } \\
\text { - Design of structural } \\
\text { roles }\end{array}$ & $\begin{array}{l}\text { TQM methods are more } \\
\text { traditional, and are } \\
\text { learnt from Japan. GE-6 } \sigma \\
\text { uses methods that can } \\
\text { produce more } \\
\text { aggressive results. }\end{array}$ \\
\hline 7. Techniques & $\begin{array}{l}\text { - Seven QC tools } \\
\text { - Control Chart } \\
\text { - } \text { DOE } \\
\text { - Taguchi methods } \\
\text { - Cp, Cpk, ppm } \\
\text { - New seven QC tools } \\
\text { - Kano's model }\end{array}$ & $\begin{array}{l}\text { - } \text { Analysis of variance } \\
\text { - Multiple linear } \\
\text { regression } \\
\text { - } \text { DOE } \\
\text { - Taguchi methods } \\
\text { - Cp, Cpk, ppm } \\
\text { - FMEA, QFD } \\
\text { - Reliability } \\
\text { - Kano's model }\end{array}$ & $\begin{array}{l}\text { The statistical tools used } \\
\text { in TQM and GE-6 } \sigma \text { are } \\
\text { very similar. However, } \\
\text { the statistical tools used } \\
\text { in TQM are quite basic, } \\
\text { whereas GE-6 } 6 \text { uses } \\
\text { more advanced SQC } \\
\text { tools. }\end{array}$ \\
\hline 8. Leadership & $\begin{array}{l}\text { - Managers } \\
\text { demonstrate best } \\
\text { behavior, and } \\
\text { influence } \\
\text { subordinates by } \\
\text { example } \\
\text { - Autonomic } \\
\text { management } \\
\text { - Decentralization and } \\
\text { delegation } \\
\text { - Motivation } \\
\text { Empowerment }\end{array}$ & $\begin{array}{l}\text { Top management } \\
\text { stresses leadership } \\
\text { - Senior managers are } \\
\text { responsible } \\
\text { - Senior managers are } \\
\text { mentors } \\
\text { - Top management } \\
\text { emphasize the } \\
\text { execution of } \\
\text { 6o-program }\end{array}$ & 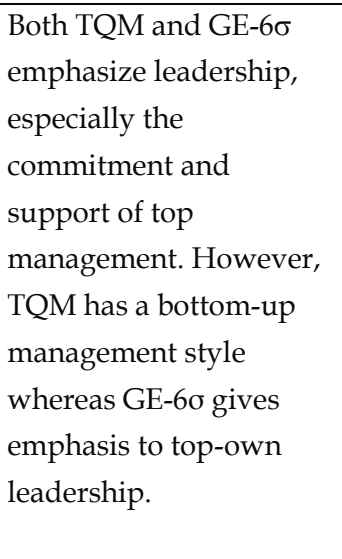 \\
\hline 9. Rewards & $\begin{array}{l}\text { - Manager's praise and } \\
\text { encouragement } \\
\text { - Promotion } \\
\text { - Bonus rewards }\end{array}$ & $\begin{array}{l}\text { - } 40 \% \text { of bonuses are } \\
\text { tied to the results of } \\
6 \sigma \text { projects } \\
\text { Promotion dependent } \\
\text { on project results } \\
\text { High status accorded } \\
\text { to MBBs and BBs }\end{array}$ & $\begin{array}{l}\text { GE-6o programs have } \\
\text { more motivations and } \\
\text { rewards than TQM. }\end{array}$ \\
\hline
\end{tabular}




\begin{tabular}{|c|c|c|c|}
\hline 10. Training & $\begin{array}{l}\text { Education and } \\
\text { training for every } \\
\text { person } \\
\text { - Focus on instilling } \\
\text { quality consciousness } \\
\text { - Leaders' instruction } \\
\text { on daily basis } \\
\text { - Improvement tools }\end{array}$ & $\begin{array}{l}\text { Vast investment in } \\
\text { training } \\
\text { MBBs are the teachers } \\
\text { and mentors } \\
\text { BBs have training, } \\
\text { combined with the } \\
\text { DMAIC process } \\
\text { - GBs have training } \\
\text { with the application } \\
\text { of improvement tools }\end{array}$ & 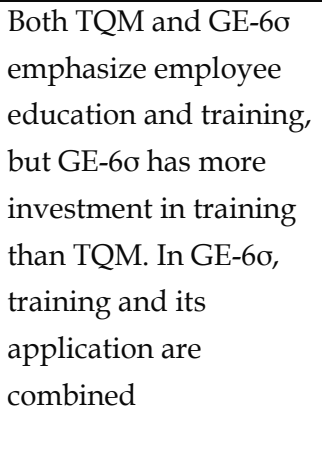 \\
\hline 11. Change & $\begin{array}{l}\text { - Gradual and slow } \\
\text { - Improvement results } \\
\text { are small, and do not } \\
\text { bring big changes }\end{array}$ & $\begin{array}{l}\text { - Vast change } \\
\text { - Re-engineering } \\
\text { - Change is fast, and its } \\
\text { scope is large. }\end{array}$ & $\begin{array}{l}\text { GE- } 6 \sigma \text { emphasizes fast } \\
\text { change and significant } \\
\text { re-engineering. Change } \\
\text { coming from TQM is } \\
\text { progressive. }\end{array}$ \\
\hline 12. Culture & $\begin{array}{l}\text { - Setting up of a } \\
\text { quality culture with } \\
\text { customer focus } \\
\text { - Employees are } \\
\text { autonomous } \\
\text { - Employees have a } \\
\text { team-awareness }\end{array}$ & $\begin{array}{l}\text { Cultivation of a } \\
\text { culture incorporating } \\
\text { the concept of } \\
\text { pursuing business } \\
\text { performance } \\
\text { - The culture change is } \\
\text { caused by the } \\
\text { re-engineering } \\
\text { - Innovation-awareness }\end{array}$ & $\begin{array}{l}\text { TQM brings about a } \\
\text { culture change with a } \\
\text { quality focus and } \\
\text { customer orientation. } \\
\text { The culture change in } \\
\text { GE-6o is fast, with an } \\
\text { emphasis on pursuing } \\
\text { customer satisfaction } \\
\text { and business } \\
\text { performance. }\end{array}$ \\
\hline
\end{tabular}

Table 3.1. Comparison between TQM and GE-6 $\sigma$

\subsubsection{Integration of management principles}

Although the management principles of TQM and GE- $6 \sigma$ are somewhat different, there is congruence among their quality principles, techniques, and culture (as was demonstrated in Table 3.1). As a result, the integration of TQM and GE-6 $\sigma$ is not as difficult as it might seem. The critical task is to combine the best aspects of TQM continuous improvement with those of GE- $6 \sigma$ re-engineering. Although the activities of a quality Control circle (QCC) and quality improvement team (QIT) cannot achieve significant effects in themselves, they can cultivate quality concepts and team awareness among employees. Therefore, QCC and QIT can be performed by the operators and junior staff members to progress continuous improvements while focusing on daily operations and processes. GE- $6 \sigma$ projects can be applied by engineers and senior staff members to the key processes and systems that are related to customer requirements and the provision of performance in products and services. For GE-6 $\sigma$ projects, some aggressive goals can be set, in conjunction with rapid project completion times. The target performances can be set according to the criteria of the critical-to-quality (CTQ) of key process - which are, in turn, determined according to the voice of customers (VOC). In TQM, the improvements are based on a customer satisfaction 
survey and an understanding of customers' requirements (Yang, 2003b). In this fashion, these two ways of understanding customers' needs and expectations can be combined. See Figure 3.1 for a depiction of the model.

\subsubsection{Integration of implementation practices}

Having discussed integration of management principles, the discussion now turns to the integration of implementation practices between the two systems.

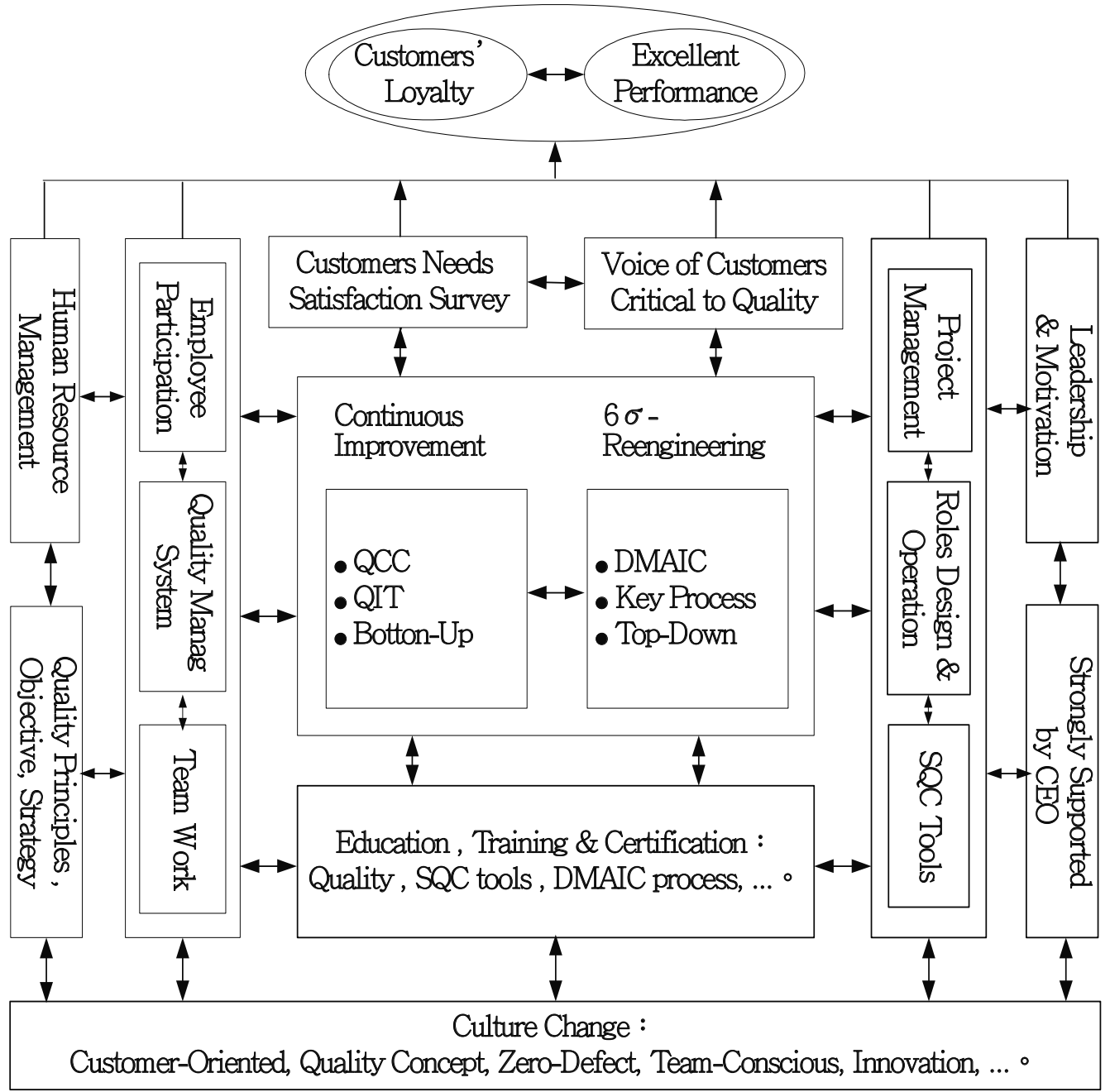

Fig. 3.1 Integrated framework of TQM and GE-6 $\sigma$

Employee participation, teamwork, quality management system, human-resources management (HRM), quality principles, objectives, and strategies are the key enablers of TQM implementation. They are also the critical factors in upgrading business performance, 
and are therefore also required for the implementation of GE- $6 \sigma$. The practices of GE- $6 \sigma$ are project management, role design and operation, statistical quality control (SQC) tools, leadership and motivation, full support from the CEO, and so on. Most of these practices are also integral to TQM implementation. The framework of the integration of these practices and related systems of TQM and GE-6 $\sigma$ is shown in Figure 3.1 (Yang, 2004).

Both TQM and GE-6 $\sigma$ emphasize employee education and training, and there is only slight difference in the details of such training. Statistical tools and improvement methods are the main ingredients of the training contents for both TQM and GE-6 $\sigma$. Apart from these statistical tools, TQM and GE- $6 \sigma$ have other shared training imperatives-including basic concepts, leadership and communication skills, and project management. Apart from these shared elements, in planning training for an integrated model of the two programs, it is necessary to cover the elements that are not shared in common. This is incorporated into the model. Moreover, a certification system for fulfilling the needs of the GE- $6 \sigma$ scale can be developed.

\subsubsection{Integration of cultural changes}

Both the implementations of TQM and GE- $6 \sigma$ will bring the culture changes of the organization (Boaden, 1997; Pande et al., 2000; Klefsjö et al., 2001). However, GE-6 $\sigma$ also emphasizes an awareness of speed and innovation, and is heavily performance oriented. These cultural features are the critical factors in pursuing excellent performance, and in raising competitiveness. In contrast, these have been somewhat neglected previously by TQM. In the integrated model presented here, these cultural features will enhance the performance effects of TQM implementation.

Summarily, in this integrated model, continuous improvement and 6б-reengineering are the key activities, located in the center of Figure 3.1, and the customers' needs and the voice of the customers are the derivers of the improvement and reengineering. The initiatives of TQM and those of GE- $6 \sigma$, located in the two sides separately, can be integrated as the enablers of the integrated system. Comprehensive education and training with certification to the employees are the powerful force in the realization of these practices. Finally, the culture changes with the features described in the base of Figure 3.1 are the fundaments of the successful implementation of this system. The overall objective of this integrated model is to reach both the customers' loyalty and excellent performance.

\subsubsection{Practical examples and conclusion}

TQM and GE- $6 \sigma$ can certainly be integrated very well, as the following two examples illustrate. INVENTEC is a hi-tech company in Taiwan that has implemented TQM for many years. Indeed, the company won the National Quality Award in Taiwan in 1995. In addition to its long-standing practice of TQM, INVENTEC also introduced the GE-6 $\sigma$ program in 2000. It then integrated this with its existing TQM system. The Ford Motor Company in Taiwan is another successful example of the integration of GE-6 $\sigma$ with TQM.

These two examples confirm that an integrated model of TQM and GE-6 $\sigma$ is feasible and practical. The successful application cased show that this integrated model will be a powerful and practical approach with great potential for all industries. This integrated model is also could be a suitable quality management system for the non-profit 
organizations. The integration of TQM and GE-6 $\sigma$ is an important trend, and should receive a favourable response from both practitioners and academics.

\section{An Integrated Model of Business Excellence System}

The integration of Six Sigma into overall business strategy is another important issue for quality researchers and practitioners. Harry \& Schroeder (2000) emphasized that Six Sigma provides maximum value to companies - in the form of increased profits and maximum value to the consumer through high-quality products or service at the lowest possible cost. It is a business strategy and philosophy built around the concept that companies can gain a competitive edge by integrating Six-Sigma program with the organization's vision and strategy. In this section, we want to discuss the integration of Six-Sigma with the strategy management, Hoshin management, and Balanced Scorecard.

4.1 The issue of the integration of Six-Sigma with other strategic management systems If the implementation of Six Sigma is to be successful, Blakeslee and Jerome (1999) suggested that "Six Sigma efforts must be integrated with existing initiatives in business strategy, and key performance measures". They also provided an implementation model by integrating Six Sigma with business strategy. Smith \& Blakeslee (2002) emphasized the potential of Six Sigma in helping companies to formulate and deploy business strategies and bring about broad transformational change. Thus, strategic Six Sigma principles and practices can help companies to formulate, integrate, and execute new and existing business strategies and missions (Smith \& Blakeslee, 2002). A growing number of companies is beginning to realize the full implications of Six Sigma as an engine to accelerate corporate strategy and organizational transformation (Smith \& Blakeslee, 2002).

It is thus apparent that the implementation of Six Sigma must be integrated with a company's business strategy. However, in this context there are several issues to be resolved. These include:

- How can the organization's vision, business strategies, and strategic goals be converted into specific Six Sigma projects?

- How can Six Sigma projects be focused on the 'voice of customer' and the organization's critical success factors?

- How can the strategic goals be communicated to lower divisions and departments in the organization, and further deploy the strategic goals to the Six Sigma projects and organize the project teams?

- How can project teams monitor and control the progression of Six Sigma projects?

In response to these issues, businesses are increasingly making use of a variety of management systems, methodologies, and tools-including ISO 9000, total quality management (TQM), Hoshin management, Six Sigma, and the balanced scorecard (BSC). In all of these practices, quality is the main focus. Quality is no longer confined to the actual product or service; rather, the concept of quality is now applied to delivery, administration, customer service, and myriad other aspects of a firm's business activities (Yang, 2009). Indeed, the concept of 'quality' now encompasses all the ways in which a company meets 
the needs and expectations of its customers, its employees, its financial stakeholders, and the community in which it operates (Tan, 2002). The effective management of such 'quality' is essential to competitiveness in the global market (Scheuermann et al., 1997; Prybutok \& Cutshall, 2004). The implementation of ISO 9000 and TQM systems can be used to improve the quality of products and services and to raise the effectiveness of process management; implementation of the Six Sigma program can raise the level of customer satisfaction, process performance, and resources management; the implementation of BSC can improve strategy planning and long-term profitability; and so on.

However, choosing and implementing these various programs is complicated by the fact that several of them have closely related concerns. For example, TQM, BSC, and Six Sigma are all involved with an organization's vision and strategy, whereas quality control circles (QCCs) and Six Sigma are both related to process improvement. These various similarities and differences can create difficulties if a firm implements several of these management systems simultaneously in an attempt to improve performance in all quality activities. In these circumstances, employees will become confused by the conflicting demands placed upon them, and this will produce a number of significant problems. For example:

* In the implementation of TQM, a firm is first required to set up quality objectives and action plans;

* In the BSC system, a firm must first develop its vision and strategies, and then deploy them in terms of performance indicators in four perspectives (financial, customer, internal process, and innovation and learning); and

* In the Six Sigma program, a firm will first consider its key performance indicators (KPIs), before linking them to a Six Sigma improvement project.

If a firm were to undertake all of these simultaneously, it would be faced with many objectives to be reached, and many strategies and action plans to be implemented. Given the finite limitations that exist in the resources of any organization, it is practically impossible for any firm to perform all of these tasks effectively. The ideal solution would be to integrate these various management systems and methods, thus enabling a firm to concentrate its focus and to navigate a unique course in the right direction.

\subsection{Development of an integrated business-excellence system}

An integrated model of business-excellence system has been developed in this section, see Figure 4.1. The critical task in developing a holistic business-excellence system is to combine the best aspects of continuous improvement in TQM with those of GE-Six Sigma reengineering. The improvement processes in TQM and Six Sigma projects can thus be integrated and implemented simultaneously (Yang, 2003b) (see Figure 4.1). Employee participation and teamwork are the prerequisite of the effective implementation of the continuous improvements. Besides, it is needed to instill the quality concepts and problem consciousness into the employees' mind. 


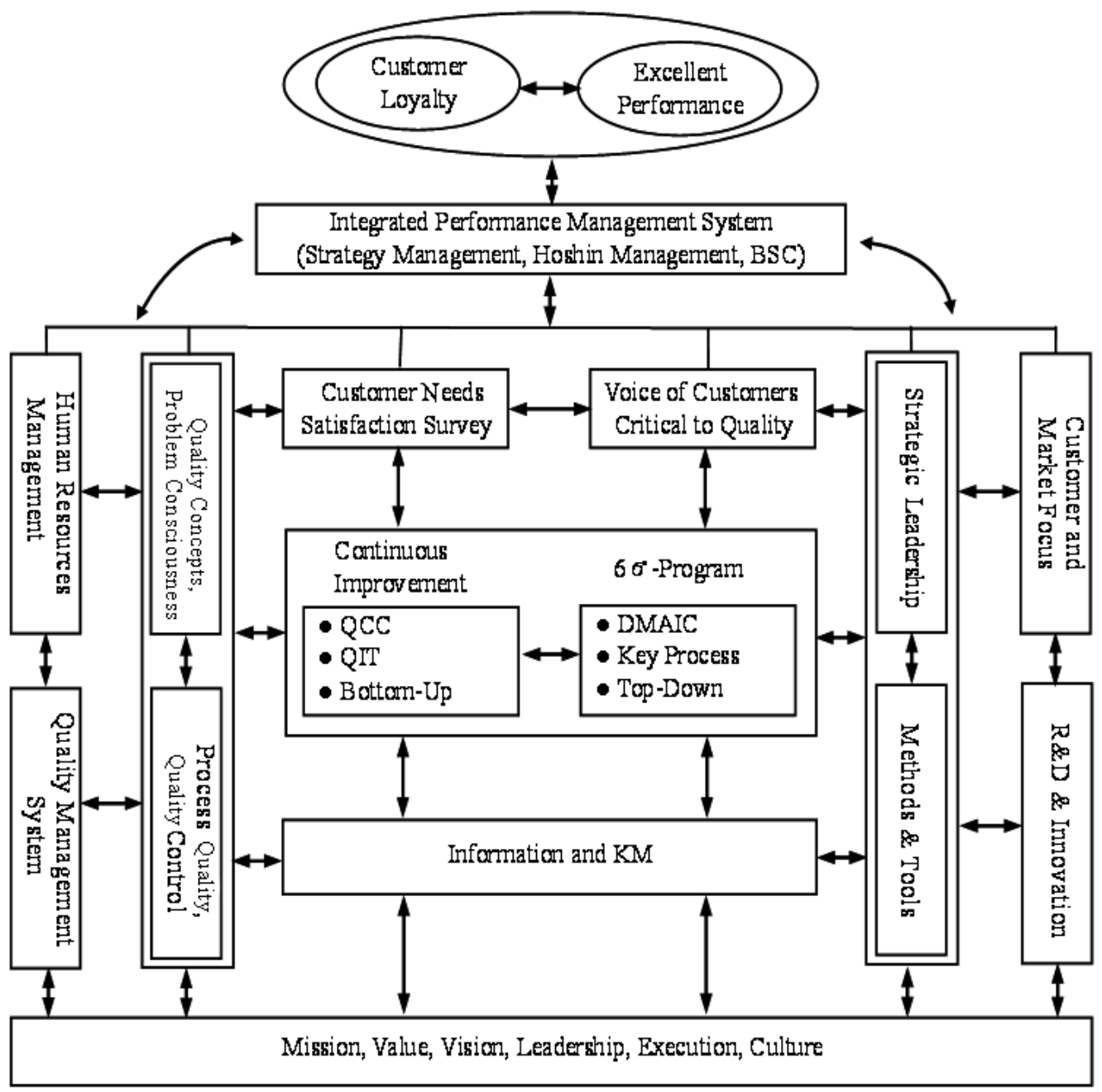

Fig. 4.1. Framework of integrated model of business excellence system

\subsubsection{Integration of relevant concepts and systems}

While implementing these programs, it is necessary to monitor process quality using various methods of statistical quality control (SQC). However, a prerequisite to any quality improvement is effective human-resource management (HRM). The key enablers of TQM implementation are therefore HRM and a comprehensive quality-management system.

The concepts, initiatives, and systems described above are also necessary for the implementation of the GE-Six Sigma program. In addition, Six Sigma also has its own unique features, including (Pande et al., 2000; Breyfegle III et al., 2001):

* the systematic operational processes of 'define, measure, analyze, improve, and control' (DMAIC) and 'define, measure, analyze, design and verify' (DMADV); 
* the staff roles design of 'champion', 'master black belt' (MBB), 'black belt' (BB), and 'green belt' (GB); and

* the utilization of advanced tools.

It is necessary to integrate all of these into the new model proposed here. In addition, strategic leadership is a key factor in the implementation of Six Sigma. In most cases, QCC or QIT are conducted 'bottom-up', but in Six Sigma they are conducted 'top-down'. In these circumstances, authoritative leadership is required. The chief executive officer (CEO) is usually the driving force who sets up the vision, develops the strategies, drives the changes, imposes the projects, and motivates the employees.

Most Six Sigma projects pursue significant financial benefits from meeting and exceeding the critical requirements of customers. If the organization is to produce and deliver attractive and value-added products and services to customers speedily, it is essential that business operations be customer-focused and market-focused. Six Sigma projects must therefore be linked to the development of 'lean production', in which research and development (R\&D) and innovation (product innovation, process innovation, and business innovation) are all key factors. $R \& D$ and innovation are also the drivers of productivity. R\&D and innovation should thus be covered in this holistic model. In passing, it is noted that these practices are not restricted to the Six Sigma program; they are also important drivers in the implementation of TQM.

TQM programs are based on 'measurement by fact', and measurement is also a key step in a Six Sigma project. Various data are collected and analyzed, including product data, customer data, business data, technique data, $R \& D$ data, service data, and so on. To use the data effectively and efficiently, an organization requires an effective information technology (IT) system. The utilization of such data represents an intangible asset, along with other intangible assets - such as skills, techniques, experience, intellectual property, know-how, knowledge, customer relationships, and so on. These intangible assets represent a valuable organizational resource, and they must be managed and applied in an effective knowledge-management (KM) system. The firm's IT system and its KM system are also powerful tools in the development of new products and services, and in ensuring the quality of the present customer service. Information technology has become an essential element in securing a competitive advantage-by facilitating the development of new products and services, assisting in adaptation to rapid market changes, incorporating new knowledge, and reducing times and costs in reaching customers (Bianchi, 2001).

\subsubsection{Fundamental principles}

The objective of integrating TQM, Six Sigma, and several other major management systems is to pursue business excellence (Yang, 2009). However, the basic decision to be made is determination of the direction of development at the outset. Mission and vision statements set the general goals and direction for the organization, and they assist shareholders, customers, and employees in understanding what the company is about and what it intends to achieve (Kaplan \& Norton, 2004). A mission statement sets out the overall reason for existence and objectives of the organization. As Welch asserted: "...an effective mission statement basically answers one question: How do we intend to win in this business?" (Welch and Welch, 2005). A vision statement is a concise statement that defines the 
medium-to-long-term goals of the organization. The vision should be market-oriented and should express how the organization wants to be perceived by the world (Kaplan \& Norton, 2004). The enunciation of the mission and the development of the vision are usually the responsibility of senior management (Welch and Welch, 2005). Actually, the vision is linked to the mission.

In the realization of the mission and vision, the values, attitudes, and activities of employees are critical. According to Kaplan \& Norton (2004), the actions of employees are guided by their values, and it is therefore important that the values proclaimed by the organization are accepted by the employees if those values are to be influential in guiding the thinking and behavior of the employees. Thus, in contrast to the creation of a mission, which is the responsibility of senior management, everyone in a company should have something to say about values (Welch and Welch, 2005). Organizations can use company-wide meetings and training sessions to encourage as much personal discussion as possible in developing organizational values (Welch and Welch, 2005).

The vision and values of the organization should thus motivate individuals and serve as a guide for allocating resources (Smith et al., 1991). Effective leadership and successful execution are the prerequisites for achieving the organization's vision. Execution has to be embedded in the reward systems and in the norms of behaviour that everyone practices. So, focusing on execution is not only an essential part of a business's culture, it is the one sure way to create meaningful culture change (Bossidy and Charan, 2002)

Mission, values, vision, leadership, execution, and organizational culture are all linked. Taken together, they represent the guiding principles for the successful implementation of an integrated business-excellence system.

\subsubsection{Implementation of strategic performance-management system}

Drucker (1999) stated that the starting point both in theory and in practice may have to be "managing for performance". The goal of an integrated business-excellence system is to go beyond mere 'customer satisfaction' to achieve customer loyalty through excellent performance (see Figure 4.1). The management systems, programs, and practices of this integrated model are the tools that can be used to achieve this goal. However, an appropriate performance-management system is needed to monitor and evaluate the performance generated by this integrated business-excellence system.

Strategic planning and Hoshin management are two popular strategic management tools (Glaister \& Falshaw, 1999; Lee \& Dale, 1998), and many organizations implement the two simultaneously. Firms commonly perform a SWOT analysis and develop a vision, objectives, and strategies according to the methodology of strategic management, before deploying the organization's objectives and strategies to the departments or units by the way of Hoshin management. During the implementation process, they commonly conduct a quality audit according to Hoshin management to produce progress reviews and an annual review. These organizations thus use an integrated model of strategic planning and Hoshin management to evaluate the performance of TQM (Kondo, 1998).

Balanced scorecard (BSC) was launched in 1992 as a framework of performance measurement that was expected to overcome some of the deficiencies of traditional performance measurement. It gives a holistic view of an organization by simultaneously looking at four important perspectives: (i) financial; (ii) customer; (iii) internal process; and (iv) innovation and learning (Kaplan \& Norton, 1992). The main benefit of the BSC is its 
ability to translate an organization's vision and strategy into tangible objectives and measures (Kanji \& $\left.S_{\hat{A}}, 2002\right)$. The process of building a scorecard clarifies the strategic objectives, and identifies the critical few drivers for strategic success. The BSC is thus more than a performance-measurement system, and is commonly adopted as a strategic management system (Kaplan \& Norton, 1992, 1996; McClintock, 2000). If a firm has adopted other performance management systems or programs before adopting BSC, it is necessary to integrate BSC with any existing systems.

Companies that wish to embark on the BSC while continuing to implement strategic planning and Hoshin management need to integrate the three systems. To do so effectively, it is necessary to understand the important features of each of these three performance management systems. They can be summarized as follow:

* All three can be used in the development of vision, objectives, and strategies, and in the evaluation of execution performance.

* Both strategic planning and the BSC involve strategic analysis, and the linkages among the objectives and strategies.

* Both strategic planning and Hoshin management impose action plans, and the allocation of resources to support the execution of these action plans.

* Both BSC and Hoshin management emphasize goal-setting, the achievement of milestones, and the measurement of progress towards the achievement of strategic objectives.

* Strategic planning focuses on the strategy of business development and competition. In this regard, environmental analysis and SWOT analysis are essential.

* BSC emphasizes long-term development, and uses a scorecard of the key performance indicators (KPIs).

* Hoshin management converts the policies and objectives of senior management to departments, and pays much attention to the daily execution of policies.

The features and relationships of strategic planning, Hoshin management, and BSC indicates that it is feasible to integrate these systems, and it is reasonable to expect that such an integrated model will be more comprehensive and powerful than each individual system acting alone. This integrated performance-management system is illustrated in Figure 4.2. 


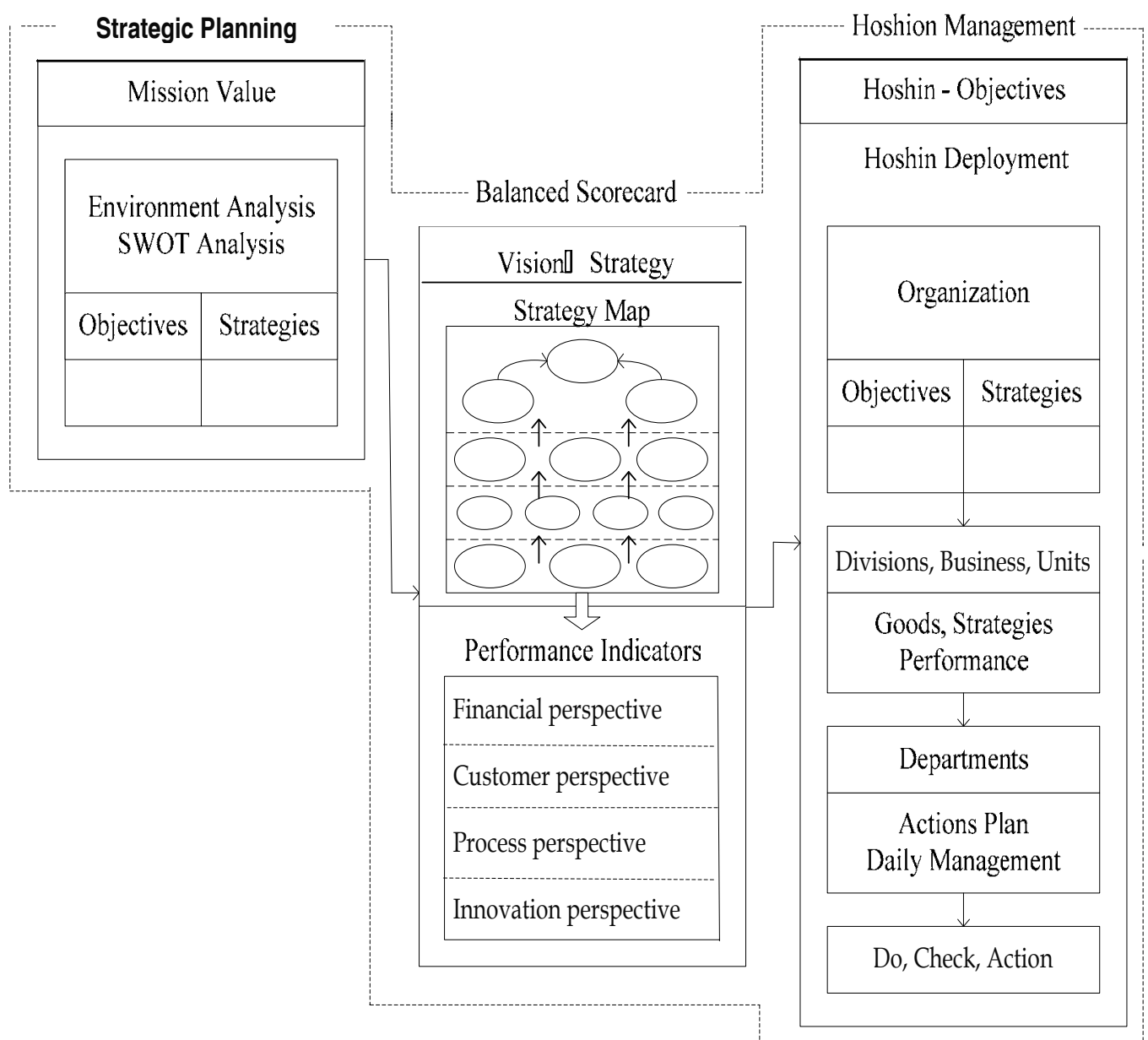

Fig. 4.2. Integrated model of strategic planning, BSC, and Hoshin management

In this integrated performance-management system, BSC remains the major construct. According to the model, strategic planning is used to perform an environmental analysis and a SWOT analysis, and to develop the vision and strategies for the organization. Having established its vision and strategies, the firm can then develop a strategy map and performance indicators according to the four perspectives of BSC. The firm can then use the methods of Hoshin management to deploy the strategies and the KPIs of the four perspectives to the departments and units within the organization. In this way, every individual receives the KPIs and a relevant action plan. The audit method of Hoshin management can then be used to manage and monitor the execution of this integrated performance-management system. 


\subsubsection{Practical examples and conclusion}

Unimicron Technology Corporation, which is located in the Taoyuan county of Taiwan. Unimicron, which was established in 1990, is the heart of the printed circuit board (PCB) industry in Taiwan. The company invests heavily in leading-edge technologies, and its products are in high demand from customers.

The senior management of Unimicron strongly emphasizes the implementation of total quality management (TQM). Management introduced TQM in 1996, at which time the company established a TQM committee, which currently has four subcommittees: a Six-sigma/QIT subcommittee, an education and training subcommittee, a QCC (Quality control circle) subcommittee, and a quality \& standardization subcommittee. The company embarked on Hoshin management in 1998, and implemented Six Sigma programs in 2001. In 2002, the company enhanced the element of strategy thinking in the Hoshin management system by introducing the management of strategic planning. With the increasing popularity of the BSC around the world, Unimicron also initiated the implementation of the BSC and a strategy map in 2003. Implementation of these systems simultaneously would have caused significant problems for both management and staff. The company therefore integrated these systems in 2005, as shown in Figure 4.1. Unimicron called this integrated model the 'Excellent Policy Management Model'.

Since Hoshin management was implemented in 1998, Unimicron has experienced strong growth in revenue. from US $\$ 0.18$ billion in 1999 to US\$7.1 billion in 2004. In the same period, profit increased from US\$120 million in 1999 to US\$710 million in 2004. The company's worldwide ranking increased to No. 2 in 2006 (from No. 35 in 1999). These significant business successes have encouraged Unimicron to implement its 'excellent policy management' model even more comprehensively and thoroughly.

The implementation principles of the 'excellent business management' model were as follows:

* PDCA cycle: integrating Deming's 'plan-do-check-act' language;

* Focus: determining the direction and priorities of the organization's development, especially the value to customer and value from customer;

* Alignment: achieving consensus (regarding vision and strategy) with the employees who are likely to make a contribution;

* Integration: integrating the 'excellent policy management system' with existing systems;

* Review E diagnosis: using monthly/quarterly diagnosis to ensure that everyone is cooperating in the execution of strategic targets; and

* Performance pursuit: ensuring desired performance through a focus on KPIs.

However, some companies have neglected the main objective of pursuing customer value - to ensure greater benefits for the organization. It means that the firms provide value to customers in order to reap the value from customers. It is therefore that the implementation of best practices can result in both value to customers and value from customers.

The management systems commonly implemented by firms-including TQM, ISO9000, human resource management, Six Sigma, Hoshin management, and BSC-all promise customer value or/and value for firms. However, the limits on resources mean that firms cannot implement all of these management systems effectively, and firms cannot therefore obtain the synergistic benefits that might be expected from the implementation of these 
systems. This has motivated scholars and practitioners to develop integrated business-excellence systems incorporating TQM, Six Sigma, and related management tools. In particular, an integrated performance-management system incorporating strategic planning, BSC, and Hoshin management is desirable as an integrated business-excellence system.

\section{References}

Anonymous, (1996), “1996”, Training, 33, pp. 67-71.

Antony, J. and Banuelas, R. (2002), "Key Ingredients for the Effective Implementation of Six Sigma Program", Measuring Business Excellence, 6(4), pp. 20-27.

Bergquist, Timothy M. and Ramsing, Kenneth D., (1999), “Measuring Performance after Meeting Award Criteria: Study Compares Perceived Success to Financial Data of Award Winners and Applicants", Quality Progress, September, 32(9), pp.66-72.

Bianchi, Alejandro Jose, (2001), "Management indicators model to evaluate performance of IT organizations", Management of Engineering and Technology, PICMET '01, Portland International Conference.

Blakeslee, J. and Jerome, A., (1999), Implementing the Six Sigma Solution: How to achieve quantum leaps in quality and competitiveness, Quality Progress, July, pp. 77-85.

Boaden, Ruth J., (1997), “What is total quality management... and does it matter?", Total Quality Management, Vol. 8, No. 4, pp. 153-171.

Bossidy, larry and Charan, Ram, (2002), Execution: The Discipline of Getting Thing Done, Grown Business, Random House, Inc., New York.

Breyfogle III, Forrest W., Cupello, James M. and Meadows, Becki, (2001), Managing Six Sigma, John Wiley \& Sons, Inc. New York.

Brown, Alan, (1992), "Industrial Experience with Total Quality Management", Total Quality Management, Vol. 3, No. 2, pp. 147-156.

Coronado, R. B. and Antony, J., (2002), Critical Success Factors for the Successful Implementation of Six Sigma Projects in Organizations, The TQM Magazine, 14(2), pp. 92-99.

Deming, W. E., (1993), The New Economics, for Industry, Government, Education, Cambridge, MA, Massachusetts Institute of Technology.

Drucker, Peter F., (1999), Management Challenges for the 21st Century, HarperCollins Publishers, Inc., New York.

Glaister, Keith W., and Falshaw, J. Richard, (1999), “Strategy Planning: Still going strong?”, Long Range Planning, 32(1), pp. 107-116.

Goh, T. N., (2002), "A strategic assessment of six sigma”, Quality and Reliability Engineering International, Vol. 18, pp. 403-410.

Gorst, Jonathan, Kanji, Gopal \& Wallage, William, (1998), “Providing Customer Satisfaction”, Total Quality Management, Vol. 9, Nos. 4 \& 5, pp. 100-103.

Gunasekaran, A., (1999), “Enablers of Total Quality Management Implementation on Manufacturing: A Case Study", Total Quality Management, Vol. 10, No. 7, pp. 987-996

Hahn, G. J., Hill ,W. J., Hoerl, R. W., and Zinkgraf, S. A. (1999), The Impact of Six Sigma Improvement - A glimpse into the future of statistics, The American Statistician, Aug., 53(3), , pp. 208-215. 
Hansson, Johas \& Eriksson, Henrik, (2002), “The Impact of TQM on financial performance", Measuring Business Excellence, vol. 6, No. 4, pp. 44-54.

Hansson, Johas \& Klefsjö, Bengt, (2003), “A core value model for implementing total Quality Management in small organizations", The TQM Magazine, Vol. 15, No. 2, pp. 71-81.

Harry, M. and Schroeder, R., (2000), Six Sigma: The Breakthrough Management Strategy Revolutionizing the World's Top Corporations, Doubleday Random House, Inc., New York.

Harry, Mikel J., (2000a), “The Quality Twilight Zone”, Quality Progress, February, 33(2), pp.68-71.

Harry, Mikel J, (2000b), “A New Definition Aims to Connect Quality Performance with Financial Performance", Quality Progress, January, 33(1), pp. 64-66.

Hellsten, Ulrike \& Klefsjö, Bengt, (2000), “TQM as a management system consisting of values, techniques and tools", The TQM Magazine, Vol. 12, No. 4, pp. 238-244.

Henderson, K. M. and Evans, J. R., (2000), "Successful implementation of Six Sigma: Benchmarking General Electric company", Benchmarking: An International Journal, Vol. 7 No. 4, pp. 260-281.

Hendricks, Kevin B. \& Singhal, Vinod R., (1996), "Quality awards and the market value of the firms: an empirical investigation", Management Science, Vol. 42, No. 3, pp. 415-436.

Hendricks, C. A. \& Kelbaugh, R. L. (1998), Implementing Six Sigma at GE", the Journal for Quality \& Participation, 21(4), July/August, pp. 48-53.

Hermel, Philippe, (1997), "The new faces of total quality in Europe and the US ", Total Quality Management, Vol. 8, No. 4, pp. 131-143

Hubiak, W. A. \& O’Donnell, S. J., (1996), “Do Americans Have Their Minds Set Against TQM?" (Abstract), National Productivity Review, 15, pp. 19-20

Joseph, L., Rajendran, N. C. and Kamalanabhan, T. J. (1999) 'An Instrument for measuring total quality management implementation in manufacturing-based business units in India', Internal Journal of Production Research, 37, 2201-2215.

Kanji, Gopal K. \& S Â, Patricia Moura E., (2002), “Kanji's Business Scorecard”, Total Quality Management, 13(1), pp. 13-27.

Kaplan, R. S. and Norton, D. P., (1992), “The balanced scorecard-measures that drive performance", Harvard Business Review, January-February, pp. 71-79.

Kaplan, R. S. \& Norton, D. P., (1996), The Balanced Scorecard: Translating Strategy into Action, Harvard Business School Press, Boston, MS.

Kaplan, R. S. \& Norton, D. P., (2004), Strategy Maps: Converting Intangible Assets into Tangible Outcomes, Harvard Business School Press, Boston, MS.

Klefsjö, Bengt, Wiklund, Hakan \& Edgeman, Rick L., (2001), "Six Sigma seen as a methodology for total Quality Management", Measuring Business Excellence, Vol. 5, No. 1, pp. 31-35.

Kondo, Yoshio, (1998), "Hoshin Kanri - a participative way of quality management in Japan", The TQM Magazine, 15(6), pp. 425-432.

Lee, R. G., \& Dale, B. G., (1998), "Policy development: an examination of the theory", The International Journal of Quality E Reliability Management, 15(5), pp. 520-534.

Linderman, K., Schroeder, R. C., Zaheer, S., and Choo, A. S. (2003), "Six Sigma: a goal-theoretic perspective", Journal of Operations management, Vol. 21 No. 2, pp. 193-203.

Lucas, James M, (2002), “The Essential Six Sigma”, Quality Progress, January, pp. 27-31. 
McAdam, Rodney \& McKeown, Michael, (1999), “Life after ISO 9000: An Analysis of the Impact of ISO 9000 and Total Quality Management on Small Business in Northern Ireland", Total Quality Management, Vol. 10, No. 2, pp. 229-241.

McClintock, C. J., (2000), "Performance Indicators in Lisburn Borough Council”, MSc. Thesis, Faculty of Business and Management, University of Ulster.

Pande, Peter S., Neuman, Robert P. and Cavanach, Roland R., (2000), The Six Sigma Way, McGraw-Hill, New York.

Pearson, Thomas A., (2001), "Measure for Six Sigma Success”, Quality Progress, February, pp. $35-40$.

Powell, Thomas C., (1995), “Total Quality Management as Competitive Advantage: A Review and Empirical Study", Strategic Management Journal, Vol. 16, pp. 15-37

Prybutok, Victor and Cutshall, Robert, (2004), "Malcolm Baldrige National Quality Award leadership model", Industrial Management $\mathcal{E}$ Data Systems, 14(7), pp. 558-566.

Raisinghani, M. S., Ette, H., Pierce, R., Cannon, G., Daripaly, P. (2005), “Six Sigma: concepts, tools, and applications", Industrial Management \& Data Systems, Vol. 105 No. 4, pp.491-505.

Ross, J., (1993), Total Quality Management: Text Cases and Readings, St. Lucie Press, Delray Beach, FL.

Sandholm, L. and Sorqvist, L. (2002), "12 requirements for Six Sigma success”, Six Sigma Forum Magazine, Vol. 2 No. 1, pp. 17-22.

Short, P. J. \& Rahim, M. A., (1995), “Total Quality Management in Hospitals”, Total Quality Management, Vol. 6, No. 3, pp. 255-263.

Sila, Ismail \& Ebrahimpour, Maling, (2002), “An investigation of the total quality management survey based on research published between 1989 and 2000", International Journal of Quality and Reliability International, Vol. 19, Nos. 6\&7, pp. 902-970.

Slater, Robert, (2001), Get Better or Get Beaten!, McGraw-Hill, New York.

Smith, Garry D., Arnold, Danny R., and Bizzell, Bobby G., (1991), Business Strategy and Policy, Houghton Mifflin Company, Boston.

Smith, D. \& Blakeslee, J. (2002), The New Strategic Six Sigma", T+D, Sept., 56(9), pp. 45-52.

Scheuermann, L., Zhu, Z., and Sheuermann, S. B., (1997), “TQM success efforts: Use more quantitative or qualitative tools?", Industrial Management $\mathcal{E}$ Data Systems, 97(7), pp. 264-270.

Sureshchandar, G. S., Rajendran, Chandrase Kharan \& Anantharaman, R. N., (2001), "A Concept Model for Total Quality Management in Service Organizations", Total Quality Management, Vol. 12, No. 3, pp. 343-363.

Tan, Kay C., (2002), "A comparative study of 16 National Quality Awards", The TQM Magazine, 14(3), pp. 165-171.

Tobin, L. M., (1990), “The New Quality Landscape: Total Quality Management ”, Journal of System Management, 41, pp. 10-14.

Treichler, David, Carmichael, Ronald, Kusmanoff, Antone, Lewis, John \& Berthiez, Gwendolyn, (2002), “Design for Six Sigma: 15 Lessons Learned”, Quality Progress, January, pp. 33-42.

Welch, Jack \& Welch, Suzy, (2005), Winning, HarperCollins Publishers, Inc., New York. 
Wiklund, Hakan \& Wiklund, Pla Sandvik, (2002), “Widening the six sigma concept: An approach to improve organizational learning", Total Quality Management, Vol. 13, No. 2, pp. 233-239.

Yang, Ching-Chow, (2003a), "The establishment of a TQM system for the health care industry", The TQM Magazine, 15(2), 2003, 93-98.

Yang, Ching-Chow, (2003b), "Improvement actions based on the customers' satisfaction survey", TQM \& Business Excellent, Vol. 14, No. 82, pp. 919-930.

Yang, Ching-Chow, (2004), "An integrated model of TQM and GE Six Sigma", International Journal of Six Sigma and Competitive Advantage, Vol. 1 No. 1, pp. 97-111.

Yang, Ching-Chow, (2009). "Development of an integrated model of a business excellence system", Total Quality Management \& Business Excellence, 20 (9-10), 931-944.

Youssef, Mohamed A., Boyd, Joseph \& Williams, Edgar, (1996), “The Impact of Total Quality Management on Firms Responsiveness: An Empirical Analysis", Total Quality Management, Vol. 7, No. 1, pp. 127-144.

Yun, J. Y. and Chua, R. C. H. (2002) "Samsung uses Six Sigma to change its image", Six Sigma Forum Magazine, Nov., Vol. 2 No. 1, pp. 13-16.

Zabaha, C. P., Rivers, A. and Munchus, G. (1998) 'Obstacles to the application of total quality management in health care organizations', Total Quality Management, 9 (1), 57-66. 


\title{
Six Sigma and Developing Countries
}

\author{
Ali Rizwan, PhD \\ University of Engineering \& Technology Taxila \\ Pakistan
}

\section{Introduction}

This chapter deals with issues of Six Sigma in the context of developing countries like Pakistan. Based on interviews and discussions with different segments of society, it provides an insight about their perceptions as well as their misconceptions from this latest quality concept and the challenges, which organizations face while trying to implement Six Sigma. Different public and private sector organizations are analyzed for this purpose, similarly, the role of developed countries are also discussed alongside to further enrich this study.

Six Sigma is one of the latest quality tools that utilize data and statistical analysis to measure and improve a company's operational performance, practices and systems. Six sigma is gradually becoming a popular process enhancement methodology that started in the manufacturing sector and has now spread to other areas as well. It helps in the identification and prevention of defects in manufacturing and service-related processes. This innovative and highly organized technique is introduced by Motorola. Nowadays, it is enjoying widespread recognition in many developed countries of the world. It helps in quality improvement by minimizing the cost of production, reducing the rate of defects, increasing yield, attracting customer, and so increases the profitability of business. Interestingly, it has yet not gained the status of a common technique in the developing countries. As we see that entrepreneurship and creativity are not common in the developing countries, so there are some hurdles in the promotion of this technique in these countries. Also, the trend of this technique in private sector differs from the public sector. As private sectors are more independent in their decision making and free in managing their financial resources. Whereas public sectors are more bound to the rules and regulations set forth for them. It is therefore difficult for the public sector organizational leaders to make drastic changes in the policies set forth by their respective governments. Also there is a feeling of mistrust between public and government in developing countries. Democracy should not be considered as a stable system of governance here like in the developed countries. Thus, people hesitate in sharing their ideas with the government leaders. In this regard, it is the joint responsibility of both government and business leaders to bridge this gap and make this transformation easier. Under these circumstances, a committed, honest and visionary leadership is required to meet the desired challenges for successfully setting up of six sigma philosophy. Government leaders and policy makers need to recognize, understand, and mark organizational challenges, especially the cultural factors, which creates hindrances to the sustainability of Six Sigma. Some reluctance can be observed on behalf of the government 
leaders and other related people in launching six sigma initiatives. The resistance in developing countries to accept Six Sigma is also related to the organizational challenges in launching this technique. Nevertheless, work has been done by some government agencies for the promotion of Six Sigma and some companies have seen tremendous success, while others have abandoned this approach or found it too difficult, because in Six Sigma, decisions are required to be based on data and statistics, not just on assumptions and anecdotal evidence. It starts from determining the need for a project, determining the cause of the problems being solved and then deciding what improvements it will make. In all these processes, data is required for decision making. This cumbersome work of data collection discourages the organizational heads to invest time and other resources in this newly developed concept of quality, which is used by Motorola and other large companies to successfully achieve positive changes in their organizations. The results of Six Sigma have the potential to benefit customers, employees, and shareholders. In order to effectively use the Six Sigma methodology, a substantial amount of time and resources must be allowed for a project.

\section{Organizational Challenges}

The organizational and structural challenges faced by developing countries in setting up six sigma encompasses but not limited to public perception, achieving operational and customer service excellence, waste reduction, and misconceptions regarding its implementation. For a sustainable and successful Six sigma programme, it is the basic need to resolve these doubtful queries against its implementation. The success of Six Sigma in the public sector of developing countries depends a lot on building a positive public perception of the projects, where contrary to developed countries whose customer base is well defined, a developing country customer base is much broader and includes people who may not directly benefit from the improvements identified by the methodology. It is the dilemma of most of the developing countries, that there is a lack of trust, commitment, sincerity and positive relations between the government and the public. Under these circumstances, public do not feel comfortable in paying taxes. Moreover, frequent shift over between dictatorships, monarchies and democracies has crumbled the infrastructure of most of the developing countries; poverty is also one of the root causes. In this scenario, it is really difficult to convince taxpayers about incorporating this new initiative in government projects because they are already dissatisfied with lavish government spending on their own perks and privileges. To initially address these concerns, governments need to effectively communicate the expected benefits and savings resulting from the improvement initiatives with the concerned stakeholders. For those governments, who plan to consider Six Sigma, picking the right project is critically important. Also, accountability and credibility of the project must be ensured at all cost. To start with, those projects can be selected initially, which appeal to a large segment of its taxpaying customer base. In the developing countries it is an estimated view that approximately $55 \%$ of small to medium sized organizations today have got no system of data collection and compilation. They carry their business transactions on the basis of centuries old non-conventional methods, while Six Sigma requires very thorough statistical data for its successful implementation. This is also true of most large public or private companies as well. 
Six Sigma can be regarded as a latest in the series of quality techniques that have been helping people to bring more quality in their lives. The Six Sigma methodology in particular has been widely used by organizations looking to streamline their processes and capitalize on opportunities. It undoubtedly has a potential to improve the business results of major organizations by ensuring that each step in the process contributes for the best possible outputs, which results in a sustainable progression from beginning to end. However, in developing countries, people are not so educated to understand multiple stages of different processes. Neither are they so customer conscious that they split each process into further divisions for its microscopic analysis.

Since the start of this technique in early 1980s the basic aim was to improve quality through statistical measurements and benchmarking. The concept entered the mainstream of public perception in the 1990s. Since then, Six Sigma has experienced wide range of success as well as failures. In the developed countries, it has become an important fixture among corporate cultures of the large multinational organizations (Darshak A. Desai \& Mulchand B. Patel., 2009). The Six Sigma process should not be regarded as a cumbersome undertaking. This methodology comprises five steps in which each step involves a series of actions to be completed before going to the next step. It includes Defining the customer, their critical issues and its core processes. Also, project boundaries and the process flow chart must be defined at the start. Measuring the performance of core business processes by collecting data to identify defects in those processes. These results are then compared with results from customer surveys to ensure their validity. Then analyze the data collected to find gaps between current performance and ideal performance. This step also includes the prioritization of processes and opportunities for improvement and reasons for observed variations. Improving the identified processes by developing creative solutions and lastly, Controlling the improvements by implementing the developed strategies with the help of an ongoing plan to monitor changes and prevent employees from going back to their old way of working.

\section{Difficulties in Implementation}

Implementing the Six Sigma methodology can become a very successful approach to process improvement. Many companies that have endeavored to implement Six Sigma have seen an improvement in their product quality, reduction in their costs and an increase in their efficiency level. However, sometimes times this success can also become a short term phenomenon if organizations fail to adequately consider all factors that can guarantee the long-term sustainability of those improvements.

Six Sigma implementation in developing countries still faces lot of difficulties. Incidentally there is really no plausible way to break Six Sigma process into pieces and then successfully implement just a segment of it because Six Sigma itself is an integrated process from beginning to end. So, it would be virtually impossible to break it down and cherry pick few aspects of this process to implement and then expect meaningful results. However, in developing countries, it is observed that the policies of government are short term and interim, rather most of them do not complete their tenure. This dis-continuity in the policies thus hampers the effectiveness of Six Sigma. On the other hand, efforts can be made to go for selective projects at the start. These selected projects should be easy to handle and must not be needing lot of resources for their completion according to Six Sigma methodology. 
Six Sigma focuses on the technical identification of different factors and then remedial measures are designed against them, interestingly; it often fails to cater for the human factor that result in the failure of nearly $60 \%$ of all Six Sigma initiatives that are taken by different organizations in developing countries. These failures indicate that companies should not focus on implementing Six Sigma in isolation. Rather, the need for human involvement in paramount in order to bring any significant change in the implementation of Six Sigma efforts. In developing countries, human factor gains more importance due to less automation and most of the time, public and private organizations depend on human capital more instead of machines due to cheap and easily available manpower. Many times, it is observed that those very aspects that make Six Sigma effective are also responsible for reducing its overall effectiveness. In this latest quality technique, cumbersome statistical analysis is required on the basis of data to identify defect areas, the correction of which can produce improved quality, decrease in costs and enhanced efficiency. Economic gains are generally set as an indicator of improvement for management that how much money a particular change can save for the company. Non-availability of high quality and precise data in most of the organizations of developing countries is a crucial factor that hampers its successful implementation.

It is observed that in developing countries factors such as; economic pressure, law and order situations and social pressures tend to bring long range variations in them. Thus, keeping in view the high costs required for Six Sigma projects, human behavior can also be incorporated into it. By doing so, management in the developing countries can try to achieve the same benefits without investing lot of resources in Six Sigma projects (Young Hoon Kwak \& Frank T. Anbari, 2006). The behavioral approach focuses on optimization of available human assets instead of making huge investments in procuring new hardware, software, and other equipment that also sometimes become necessary to implement many Six Sigma recommendations. One recent example noted that when a company applied this human capital approach to their projects, $70 \%$ of the shortlisted factors are found to be exactly the same as the findings of the Six Sigma team independently working on the same projects at the same company. This team was comprised of Six Sigma Green Belts, Yellow Belts, Black Belts and Master Black Belts.

It can also be researched that the combination of behavioral effect with six sigma technique produces better results or not. Some opinion is found to be against this effectiveness of incorporating both the Six Sigma and behavioral approaches simultaneously for better results. However, most of the people interviewed anticipate positive changes in the corporate culture by incorporating human factor in the process, and expected to gain significant benefits without putting large capital investments. Many people are also of the view that in the context of developing countries, where economic conditions are already worsened, it looks more appropriate that a reasonable effort can be made to bring a positive change in the behaviour of employees. It is not only economically viable but practically seems to be more sustainable. However, when an organization decides to make any significant change to its internal processes, especially to its people, just the initial talk of the intended change is tantamount to unsettle a workforce in its current routine. This situation can be further complicated if management fails to communicate its reasons for bringing this change and fails in demonstrating a strong follow up support for it. 


\section{Effectiveness of Six Sigma}

Nowadays, Six Sigma has become a buzzword in both the manufacturing and service industries of the world. The various methodologies used in Six Sigma are based on pure and precise data that help in reducing defects by restricting the number of possible defects to less than 3.4 defects per million. The methodologies are equally effective in both the manufacturing and service industries. In manufacturing industries, Six Sigma is mostly used for reducing the number of defects whereas in service industries, it is used mainly for increasing customer satisfaction.

Although many companies remained successful in reducing the number of defects through Six Sigma, its effectiveness is still under trial amid discussions in the business communities of the world. Some management experts are of the opinion that the analytical and statistical tools used in Six Sigma focuses on flaws at the completion of any process and do not look at the basic defects of the process. According to them, other quality management tools such as Total Quality Management (TQM) and Six Sigma are conceptually very close to each other and can be effectively used by Business organizations to improve their overall quality.

However, supporters of Six Sigma have a different viewpoint. They mostly prefer Six Sigma on the pretext that it is more than just a process improvement program and focuses on continuous quality improvements. They observe that Six Sigma concepts use the combination of statistical measurement tools with contemporary management techniques to achieve extraordinary results.

Strategic planning can be done in those areas that have far-reaching and tactical implications at the project selection stage. The basic purpose of strategic planning is to efficiently take those decisions and actions, which help in successful implementation of six sigma. Strategic planning can simply be considered as the combination of the leader's vision with the working of the organization. It may help in giving an entirely new direction to organizational growth. With the help of adequate planning, employees can overcome many hurdles in their efforts for the transformation of vision into tangible gains. However, in most of the public sector organizations in developing countries, status quo does not allow leaders to interact with their staff and subsequently transfer of vision from leaders to team members do not take place effectively. It results in rudderless thinking by the people in most of the public sector organizations. Another important concept is connecting with the customer. Customers should be involved with companies in defining their needs. The tools of Six Sigma makes this link easier between the key elements, activities, strategies and the vision, which leads to smooth sharing of ideas. The Six Sigma methodology allows effective communication of the vision to all stakeholders in a language understandable to them. Ironically, customers are not given so much importance here as in developed countries. People working in the government departments pay least attention to their visitors and those in private organizations also vary in their dealing with customers. However, change in the behaviour towards customer is witnessed in case of some leading private enterprises, who have taken a franchise from top brands of the world.

Change agents in the developing countries must be mindful of one key ingredient in their change efforts that changes in behaviour of people precede changes in processes or procedures and not vice versa. People understandably offer resistance to change because they are presently operating within a comfort zone. They must be convinced initially that why there is something wrong with the way they perform, especially if they are working within parameters set forth for them earlier by the organization itself. 
There is a common perception in the developing countries that people who are asked to implement a change first need to clarify why a specific change is required and whether their change efforts can make any difference within their areas of influence or not. If people are properly taken into confidence regarding these efforts, employees are generally more responsive and adaptive in implementing this change for a longer term. It not only results in a sustainable change but also helps in generating a feeling of involvement and ownership of the desired eventful changes.

Behavioral change that requires less capital expenditure as compared to other infra structural changes gives an ample opportunity to management to show more empathy towards their employees. In return, management can surely enjoy many of the same financial and operating benefits as other heavy investment can bring for the organization. While doing so, it seems that the overall yield of developing countries can increase and it would cast a positive effect in overall efficiency. Moreover, by utilizing the behavioral approach to implement change in the corporate culture, management can indeed enjoy many of the same benefits that Six Sigma and other quality initiatives bring for the organizations. These changes also have a better chance of long term sustainability.

\section{Some common misunderstandings}

This new quality concept is interestingly not taken in its true perspective by the people of developing countries, where literacy rate is still hovering around 30 percent. Some of the misconceptions can be interpreted as:

- Applicable in manufacturing sector

- Duplication of functions

- Extra effort

- Needs enormous training

- Requires multi disciplined teams

- Very statistical

- Needless investment

\section{Applicable in manufacturing sector}

Most of the initial work of Six Sigma is carried out in manufacturing industries. It leads people to believe that it is only limited and designed for manufacturing process. On the contrary, it has the potential to improve all process that is related to customers, products and services.

\section{Duplication of functions}

Another objective of Six Sigma is to curtail every bit of organizational waste and then reinvesting them back into the system channel. With the poor economic conditions in developing countries, there is no room to waste money through the duplication of functions. Six Sigma is about nurturing any function that adds significant value to the customer and adding additional revenue for the organization. 


\section{Extra effort}

Believers of this concept feel that in the presence of other quality tools, it is not required to go for this newly developed technique. They consider it an extra burden on the budget of organization. However, in reality, most of the organizations, who have successfully implemented Six Sigma have gained huge profits by improving their processes.

\section{Needs enormous training}

It is general mis-perception that lot of training is required for achieving the required goal.

\section{Requires multi disciplined teams}

It is believed that Six Sigma teams need to be too large, which results in the amalgamation of different ideas and thoughts, hence no one can get the idea what the other person is doing.

\section{Very statistical}

It is a common understanding that the advanced statistical tools, which are extremely valuable in identifying and solving problems, need people to possess an analytical background and understanding in the wise use of these tools. However, they make a common mistake by forgetting that understanding of all the mathematics behind these statistical techniques is not required. The wise application of statistical techniques can be achieved with the help of new and easy to use statistical softwares.

\section{Needless investment}

This assumption is again proved wrong because those organizations, who have wisely implemented Six Sigma, have obtained a very high rate of return on their investment.

\section{Six sigma and other quality programs}

In today's highly competitive environment, there is mounting pressure on organizations to enhance their quality and customer satisfaction while decreasing costs and wastages. This becomes an increasingly difficult challenge for developing countries, where there is a scarcity of resources. Thus, it is imperative for any industry or organization to identify the shortcomings and overcoming them to meet the world challenges (Sean P. Goffnett., 2004). If Six sigma is implemented wisely, it can surely help organizations to learn and excel at the challenges they encounter. Regarding Six Sigma there is a false assumption in its ideology with other company initiatives. Six Sigma cannot and should not be treated as a separate identity apart from other quality initiatives of the company, rather, it must be seen in close association with other programs and initiatives at a higher level as part of an overall business strategy. Six Sigma is not supposed to replace other initiatives, but it simultaneously offers a tactical methodology to find out the best approach for a given situation. 
The major components to consider during Six Sigma implementation are its metrics and strategy to be followed. Some people are of the opinion that Six Sigma is merely a thorough application of basic and advanced statistical tools throughout an organization. Some feel that Six Sigma consultants and training organizations have simply repackaged the old statistical components of their previous Total Quality Management (TQM) programs and renamed them. Others view Six Sigma as merely a newer version of Total Quality Management (TQM). They see it as an advanced form of TQM in which various improvement systems are integrated with the help of statistical analysis for better performance (Ywende Adeyemi, 2004). However, the ultimate goal of Six Sigma, unlike from other quality tools is not only improvement for the sake of improvement, but rather the creation of economic wealth for both customer and organization in accordance with their own perspectives. In this context, Six sigma can be better regarded as a major business initiative rather than merely a quality program. This implies that Six Sigma is not a replacement of existing and ongoing quality initiatives, but can be regarded as an additional support to further strengthen the ongoing efforts to improve the economic growth of an organization.

\section{Six Sigma and the Public Sector of developing countries}

Six Sigma methodologies can be applied in public sector organizations of developing countries at both at macro and micro levels. At macro level it can be very helpful as a catalyst for achieving economic viability. In this regard, Six Sigma methods can be used to develop a measurable, data-based and closed loop national policy. Getting a cue from developed countries, this technique can also be applied by the public sector organizations to make long term policies for its permanent incorporation. By doing this, Six Sigma can become a solid feature o all government run projects. At micro level the application of Six Sigma focuses to improve the way government is running its day to day activities. The objective of this effort is to make the under utilizing public agencies of developing countries more effective, efficient and economically viable to support national policies. It not only restores public confidence in government policies but also bring an improvement in the national economic conditions of developing countries.

On the basis of interviews with different leaders as well as middle managers of public sector organizations, it is observed that the main difficulty of implementing this procedure at the public level depends on the prevailing culture and the attitude. Unfortunately, lack of positive attitude in taking ownership of the problem is common in most of the oldfashioned and hierarchical public agencies of developing countries. Thus, in the absence of anyone taking the lead to improve departmental working, these kinds of initiatives have the tendency to die down during their infancy. So the successful implementation of Six Sigma instantly requires an adjustment to the organizational culture and a change in the mindset of its staff. In this endeavor, several strategies need to be carried out to overcome resistance against the change efforts in public agencies due to technical, political, individual and organizational factors. 


\section{Relevant training}

Relevant training can be found as another crucial factor in the successful implementation and deployment of Six Sigma initiatives in case of developing countries. It is appropriate to communicate all relevant details of Six Sigma before the start of project and then arrange training classes for the improvement of basic skills among the people, who are intended to work on these projects. The management also needs to ensure that the training contents and sessions be structured in such a way that it must be relevant to employees' everyday jobs. Because, it is observed that in today's cut throat competitive job markets, any initiative, no matter how brilliant and effective it may be, as long as it is not aligned with an individual's job performance, it usually gets a very lukewarm response. The staff can develop good understanding of Six Sigma methodology, statistical tools analytical techniques through a series of training sessions and workshops under the supervision of qualified trainers. During these training activities, it can be made compulsory for consultants and trainers to integrate these new initiatives of Six Sigma with the ongoing processes in the organizations. The high impact and convenient projects can be selected in the pilot implementation stage to avoid disappointment and frustration among people in organizations.

\section{Performance based remuneration}

In order to encourage Six sigma initiatives in the developing countries, there is a need of associating some financial benefits for those people, who come forward and take a lead in its promotion. It can be done by giving some incentives on the successful implementation of six sigma projects. In the developed countries it is estimated that more than $60 \%$ of the top performing companies practicing Six Sigma link their annual bonuses and increments to their business strategies and Six Sigma projects.

\section{Mistakes and Remedies}

Ironically, corruption, colonialism and nepotism have so much deep rooted in the day to day matters of developing countries that introduction of Six Sigma has become a great challenge for the quality seekers in this part of the world. Under these circumstances, promotion of Six Sigma culture requires an honest, trusted, committed and accountable leadership.

Government agencies are generally enjoying the monopoly of providing services without real competition from other competitors. Under this controlled market conditions in which no other party is allowed to operate, management of these organizations are least pushed about any customer expectations and quality improvement initiatives. It is evident in many organizations that the projects of Six Sigma are conceived by the few quality conscious managers but during the implementation stages, concerned process owners find no true urgency for project initiation and completion. It is thus advisable not to start and invest in these projects unless all the stakeholders are on board to make it a real success.

On the contrary many private companies who have tried to develop and implement Six Sigma consider it a brilliant technique in solving chronic, complicated and cross-functional problems. Among these organizations, some remained unsuccessful to benefit completely 
from the advantages of Six Sigma. On careful analysis, this failure is found to be due to untimely plucking of all low hanging fruits.

Slowing down of Six Sigma after few years is not an unusual phenomenon observed in the developing countries. Once the key opportunities are identified and acted upon, many companies are either found to ease down and again start following their natural course, with returns diminishing at a steady pace over time or once organizations successfully achieved the Six Sigma goal, they consider it good enough and stop the process of continuous improvement. This mindset of contentment allows quality to deteriorate. Organizations looking for a Six Sigma deployment must not be solely dependent on one executive's drive. It is thus required to create a system where the process owner asks for the creation of Six Sigma projects to improve their performance by aligning it with their business needs. Under these conditions, it is imperative for the public and the leading private organizations of developing countries to come forward and join hands with each other in their efforts to promote this latest quality concept.

Six Sigma needs constant feedback regarding monitoring and evaluation of projects under progress. Hence effective Six Sigma implementation may also be requiring a reasonable communication infrastructure to receive, organize and transfer inputs and feedbacks into effective decision making for the organization. In this regard, all the affected people be involved, otherwise a change may be wrongly implemented that can make the job of someone further difficult. Under these circumstances, cross functional teams can effectively play their role to solve inter departmental problems to its optimum level. However, most of the private sector organizations in these countries either do not pay proper attention to improve the capabilities of their staff or simply cannot afford it. Similarly, most of the public sector organizations depend on some donations and training packages from developed countries to send their people abroad for getting these trainings.

Human capital is one of the most important assets of any company. Proper planning is required to enhance the core competencies of these people. Without a trained staff, all the initiatives are having bleak chances of success because in the absence of a strong technological infrastructure in most organizations of the developing countries, a lot depends on human beings to deliver. Thus, the aim in this scenario should be to achieve the improved and sustainable success for organizations by providing all necessary and latest techniques that are required for it. Another factor observed in ineffective Six Sigma planning is poor communication. One should not expect the vision to be shared effectively if it is poorly communicated. It is therefore mandatory to make the statement as clear and simple as possible - and to the point. Six Sigma projects mainly revolve around the strategic planning of an organization. It means that the company leadership must take into account this unique combination of strategies and action plans that allows robustness with flexibility to deal with unique challenges of today's competitive market (Lora L. Loethen, 2008). In this regard, it must be taken care that the plans and objectives should be as clear to people as it is to leaders of the different public and private sector organizations.

Since, Six Sigma gained prominence as an efficient and effective quality management technique; many large organizations have used it to improve the quality of their products and services. However, researchers feel that the full potential of Six Sigma is yet to discover in developing countries. Although most of the small and medium enterprises in these countries have all the resources to implement such programs, yet they feel that it is meant only for large organizations. These companies often do not realize that Six Sigma offers the 
same benefits to both large as well as small business enterprises. Their only difference can be the magnitude of profits, which itself is proportional to the size and kind of an organization implementing Six Sigma initiatives.

\section{The Future of Six Sigma in developing countries}

Although Six Sigma appears quite similar to other quality management tools such as TQM or Kaizen Events, but in reality, it is quite different. Other quality management programs soon reach a stage after which no further quality enhancements can be achieved. Six Sigma, on the other hand operates differently, as it focuses on the improvement of processes and not the end results, in which processes are gradually improved from one level to another. This means that Six Sigma has the potential to surpass other quality management programs in the future. However, fast changing governments and sometimes even shifting from dictator ships to democracies and vice versa pose a serious threat to its sustainable growth, because under these circumstances, everyone in the power corridors prefer short term schemes for their quick results and thus may not be so much enthusiastic in applying projects on the basis of this single packaged technique. In this situation, it is imperative for the developed countries to train people in both the government and the private sector of its importance and fruitfulness. Only then, benefits of Six Sigma can be expected to trickle down slowly in comparatively less developed towns and then ultimately to rural segments of the society.

The scope of Six Sigma is also much wider than other quality management programs and thus, its application can be expanded to most of the business organizations in developing countries. Very encouraging growth in the awareness of Six Sigma among small and medium enterprises is also witnessed. At the initial stages of this concept, its growth is mostly confined to the urban areas of the developing countries. However, large numbers of people are living in rural areas, where businesses are not so well documented, therefore, its expansion may face some problems but awareness campaigns by the government agencies to realize people of its benefits can be very useful for its promotion.

Although, the challenges in implementing the six sigma method are immense, yet growing awareness in the people of developing countries is also very encouraging. Many organizations have now started incorporating the trainings of Six Sigma in their future organizational development plans. It is expected that when these people start delivering in their respective positions, results of this business management technique will become more obvious to the organizational leaders. Many technical and educated people in these countries have now realized that Six Sigma is a highly disciplined approach that helps an organization focusing on the critical processes for sustainable improvement. In this regard, lot of help is required from data, so, organizations have also started paying proper attention on the documentation and reliability of data for further analysis by Six Sigma teams.

Six Sigma can also be effectively integrated into the management system of the governments with proper planning, leadership commitment and most importantly the political will to make changes. In developing countries, most of the national leaders usually initiate any new improvement drives and policies after being triggered by certain general conditions such as budget cut; economic crisis; electorates or succumbing to taxpayers pressure for better governance; but the complexities and magnitudes of problems being faced by these countries are gigantic and it is simply out of question that governments alone will be able to 
handle them efficiently. In this situation, private entrepreneurs should come forward and must join hands with their respective governments in improving the fast deteriorating situation of big public sector organizations. Six Sigma can rightly be called a superb strategy that has the potential to deliver equally well in both private and public sector and give the developing countries a positive way to come in a race with developed countries.

\section{References}

Darshak A. Desai, Mulchand B. Patel. (2009). Impact of Six Sigma in a developing economy:

Analysis on benefits drawn by Indian industries, Journal of Industrial Engineering and Management, pp 517-538, ISSN: 2013-0953

Lora L. Loethen. (2008). Six Sigma Leadership, pp 1-25, ISBN-10:1-59942-690-0

Sean P. Goffnett. (2004). Understanding Six Sigma: Implication for industry and education. Journal of Industrial Technology, Vol. No. 20

Young Hoon Kwak, Frank T. Anbari. (2006). Benefits, obstacles and Future of Six Sigma Approach, Technovation, pp 708-715

Ywende Adeyemi. (2004). Analysis of Six Sigma at Small Vs. Large Manufacturing Companies, pp 1-88, University of Pittsburg.

http:/ / www.sixsigmaiq.com/searchresults.cfm?Searchterms=Mark\%20Aesch

http://www.ftpress.com/title/013143988X

http:/ / www.articlesbase.com/management-articles/future-of-six-sigma-differentviewpoints-57635.html

http:/ / www.computer.org/portal/web/csdl/doi/10.1109/CSO.2009.419

http://hdl.handle.net/2320/5619 


\title{
A Comprehensive Framework for Six Sigma Critical Success Factors with an Experience in a Developing Country
}

\author{
Arash Shahin \\ Department of Management, University of Isfahan \\ Isfahan, Iran
}

\section{Introduction}

Six Sigma is a business strategy and a systematic methodology, use of which leads to breakthrough in profitability through quantum gains in service quality, product performance, productivity and customer satisfaction. Today Six Sigma has been considered as a strategic approach to achieve excellence in operations and service performance through the effective utilization of statistical and non-statistical tools and techniques (Antony, 2004). Like other programs emerging under the TQM umbrella, Six Sigma requires a transformational change in an organization's culture, structure, and processes. The emergence of Six Sigma as a distinct approach to TQM occurred in 1987 at Motorola (Larson, 2003).

Six Sigma is a disciplined approach to define, measure, analyze, improve and control processes that result in variability and defect reduction. Six Sigma is a business improvement strategy that seeks to find and eliminate causes of defects or mistakes in business processes by focusing on outputs that are of critical importance to customers (Snee, 2003). It is a powerful approach to process improvement, reduced costs and increased business profitability and revenue growth. Six Sigma originated at Motorola in the early 1980s in response to a challenge to achieve ten-fold reduction in product failure levels in five years. Six Sigma has both management and technical components. The focus of management component is to select the right people for Six Sigma projects, select the right process metrics, provide resources for Six Sigma training, provide clear direction and guidance with regard to project selection, etc. The focus of technical component is on process improvement by reducing variation, creating data which explains process variation, using statistical tools and techniques for problem solving, etc. In statistical terms, Six Sigma means 3.4 defects per million opportunities (DPMO), where sigma is a term used to represent the variation around the average of a process.

Today, Six Sigma is exploited by many organisations such as GE, Honeywell, Sony, Caterpillar, J P Morgan, American Express, Common Wealth Health Corporation, Lloyds TSB, City Bank, Jaguar, Kodak, Ford and Starwood Hotel Group (Antony \& Fergusson, 2004). 
These contrast results make Six Sigma implementation a complex and central process, where the CSFs in its implementation must be recognised. Although different resources are now available on Six Sigma subjects, it seems there are only a few, in which CSFs are addressed. In the following, the efforts made in the literature are reviewed in case of CSFs for successful implementation of Six Sigma projects; then, a case study is presented in which a set of CSFs are analyzed in major car maker companies in Iran. In terms of the case study, the aim of this paper is to find out which factors have the successful companies experienced as more critical in reaching Six Sigma goals.

\section{Critical Success Factors (CSFs) in Six Sigma projects}

CSFs are those factors which are critical to the success of any organisation, in the sense that if objectives associated with the factors are not achieved, the organisation will fail catastrophically (Rockart, 1979). In the context of Six Sigma project implementation, CSFs represent the essential ingredients without which a project stands little chance of success.

In comparison with traditional approaches of quality management, Six Sigma is the most effective concept because of the interrelationship between its strategy, organisational structures, procedures, tools and methods (Pfeifer et al., 2004). In the following, some other results of the literature study on Six Sigma CSFs are presented.

Antony \& Fergusson (2004) have conducted an investigation in the software industry. They considered the following ten CSFs for the Six Sigma projects (Antony \& Fergusson, 2004):

- Leadership engagement and uncompromising commitment of top management

- Supporting organizational infrastructure

- Cultural change

- Six Sigma training

- Linking Six Sigma to business strategy

- Accountability

- Customers involvement

- Understanding the Six Sigma methodology

- Project management

- Project prioritization and selection

According to the results of their investigation, leadership engagement and uncompromising commitment of top management, cultural change, linking Six Sigma to business strategy and customers involvement have had the highest scores and therefore, needed more concentration. Henderson \& Evans (2000) also suggested upper management/involvement, organization infrastructure, training and statistical tools as the major components for a successful Six Sigma implementation (Henderson \& Evans, 2000).

Buch \& Tolentino (2006) conducted a survey, in which 216 employees of a large US company completed 15 months after the implementation of a Six Sigma quality improvement program (Buch \& Tolentino, 2006). Respondents were asked to indicate the extent to which they had the skills and resources needed for successful participation in Six Sigma (success expectancies). Their findings imply that employees as a group had low expectancies for both skills and resources, but those expectancies were significantly higher for program participants than for non-participants. The ten items they considered in their survey as Six Sigma CSFs are as follows: 
- Know how to scope project

- Knowledge of quality process

- Knowledge of tools

- Knowledge of work processes

- Knowledge of statistics

- Know how to get involved

- Adequate management support

- Access to quality tools

- Access to professionals

- Have adequate time

As it is clear, the above items are mostly related to training and knowledge of Six Sigma concepts and project management subjects.

Coronado \& Antony (2002) have addressed the following 12 CSFs of Six Sigma projects:

- Management involvement and commitment

- Cultural change

- Communication

- Organization infrastructure

- Training

- Linking Six Sigma to business strategy

- Linking Six Sigma to customer

- Linking Six Sigma to human resources

- Linking Six Sigma to suppliers

- Understanding tools and techniques within Six Sigma

- Project management skills

- Project prioritization and selection

Most of the above 12 factors are similar to the work of Antony \& Fergusson (2004). However, the 12 items seem more complete comparing to the items addressed in the former resources.

In other investigations by Pande et al. (2000) and George (2002), Success factors and benefits of Six Sigma are highlighted as:

- Customer focus for project choice

- Project feasibility of the projects in a limited timeframe

- Evaluation of resp. of profitability

- Consequent agreement on objectives and controlling of results

- Focus on the essential business processes

- Application of an approved toolset

- Consequent enabling of employees and provision of resources

Finally, Antony (2004) conducted a survey in a number of UK service organizations. He considered the following 13 items as CSFs:

- Linking Six Sigma to business strategy

- Customer focus

- Project management skills

- Executive leadership and senior management commitment

- Organizational infrastructure

- Project selection and prioritization

- Management of cultural change 
- Integration of Six Sigma with financial accountability

- Understanding the DMAIC methodology

- Training and education

- Project tracking and reviews

- Incentive program

- Company-wide commitment

Like previous studies, in which Antony was the first author or the co-author, the above items seem complete and encompass almost all CSFs addressed in the literature. Antony (2004) also found that linking Six Sigma to business strategy is the most addressed CSF. This would be aligned with Mikel Harry's definition of Six Sigma as a breakthrough improvement business strategy. Six Sigma creates a sense of urgency by emphasizing rapid completion of projects in four to six months (Snee \& Hoerl, 2003). Therefore, it was not surprising that "project management skills" was rated very high. Antony (2004) further studied the critical factors and criteria of Six Sigma project selection. He addressed the following eight important CSFs:

- Linkage to strategic business plan and organizational goals

- Sense of urgency - how important is the proposed project for improving your overall business performance (both financial improvement and service process performance improvement

- Select projects which are doable in less than six months. If the project scope is broader, the time to completion increases, the cost of the project deployment will increase. This would lead to frustration among the key players due to lack of progress, diversion of manpower away from other activities, delay in realization of financial benefits, etc.

- Project objectives must be clear, succinct, specific, achievable, realistic and measurable

- Establish project selection criteria - the following criteria may be considered during the project selection process:

- Impact on customer needs and expectations

- Financial impact on the bottom-line

- Duration of the projects considered

- Resources required for projects under consideration

- Expertise and skills required to carry out the projects

- Probability of projects success

- Risk involved in projects

- Projects have the support and approval of senior management

- Define project deliverables in terms of their impact on one or more critical characteristics in the service such as CTQ, critical-to-cost or critical-to-delivery

- Projects must be selected based on realistic and good metrics (DPMO, SQL, Capability Indices, etc.)

Finally, Shahin (2006) proposed the essential or key ingredients which are necessary for the effective implementation of Six Sigma projects. Comparing to the literature, it seems the proposed CSFs addressed by Shahin (2006) encompasses almost all those factors addressed in the literature. A comprehensive framework is developed and depicted in Figure 1, representing those CSFs. The factors are positioned in the Figure in a way that denote the business architecture and the dominated as well as the core CSFs. Shahin (2006) stressed that among the factors addressed in the Figure, leadership and top management commitment, linking Six Sigma to business strategy, supporting organizational infrastructures, and 
training and understanding Six Sigma concepts are the most important factors, any organization should consider in its Six Sigma project. It is important to note that in some resources the later mentioned factors are also referred to as the organizational activities and as the first and main pillar in the hierarchy of TQM implementation program.

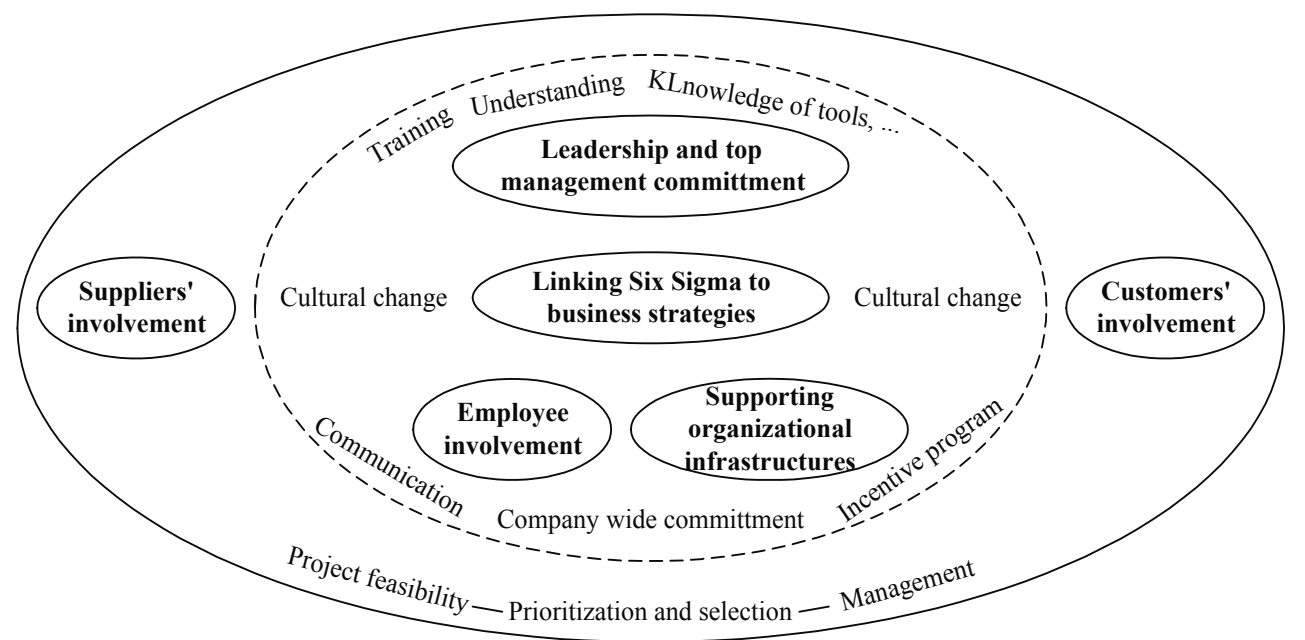

Fig. 1. Six Sigma CSFs: A comprehensive framework developed from Shahin (2006)

\section{Case Study}

The case study has been conducted in five major car maker companies in Iran. The companies include Iran Khodro, Saipa, Bahman Motors, Kerman Motors and Saipa Sazegostar. Among the companies, Iran Khodro and Saipa contribute to the majority of the shares in the market. The statistical population consists of 2600 respondents. They include Six Sigma champions, team leaders, Black Belts, Green Belts, team members and consultants from top and middle managers, supervisors and experts. The data is gathered in 2006 and after a pilot study, a sample of 260 respondents were considered and asked to fill the questionnaires, based on a 95\% confidence level, 5\% accepted error and 0.2 standard deviation.

All the data is gathered by questionnaire. Considering the availability of respondents, totally 251 out of the 260 nominated responded to the questionnaire, which indicates a high rate of response. A seven point scale is used for rating the influence of CSFs (1: no influence - 7: very high influence).

Initially 51 questions were included in the questionnaire, which were further classified under 10 major categories as Six Sigma CSFs. This study summarizes the final results of the analysis on the 10 categories. The categories are as follows:

1) Management commitment and involvement

2) Cultural changes

3) Organizational infrastructures

4) Training

5) Project manager skills

6) Selection, evaluation and prioritization of Six Sigma projects 
7) Understanding methodology and techniques of Six Sigma

8) Linking Six Sigma to business strategy

9) Linking Six Sigma to customers

10) Linking Six Sigma to employees

The reliability of the data for each company is measured by Cronbach's Alpha, ranging from 0.896 to 0.975 . Also, the value of all companies is computed as 0.954 . As it is clear, all the values can be considered as satisfactory (Nunnally, 1978).

In Table 1, the mean value of the influence of each of the CSFs is given for each of the companies. In Table 2, the CSFs are prioritized, based on their corresponding mean value of influence in Table 1.

\begin{tabular}{ccccccc}
\hline CSFs & $\begin{array}{c}\text { Iran } \\
\text { Khodro }\end{array}$ & Saipa & $\begin{array}{c}\text { Bahman } \\
\text { Motors }\end{array}$ & $\begin{array}{c}\text { Kerman } \\
\text { Motors }\end{array}$ & $\begin{array}{c}\text { Saipa } \\
\text { Sazegostar }\end{array}$ & $\begin{array}{c}\text { All } \\
\text { companies }\end{array}$ \\
\hline 1 & 5.58 & 6.04 & 5.90 & 5.86 & 5.65 & 5.81 \\
2 & 5.44 & 5.71 & 5.72 & 5.13 & 5.29 & 5.46 \\
3 & 5.43 & 5.80 & 5.78 & 5.39 & 5.32 & 5.55 \\
4 & 5.45 & 5.57 & 5.32 & 4.68 & 5.44 & 5.29 \\
5 & 5.78 & 5.88 & 5.90 & 4.90 & 5.93 & 5.68 \\
6 & 5.59 & 5.70 & 5.80 & 5.10 & 5.84 & 5.61 \\
7 & 5.54 & 5.80 & 6.34 & 6.20 & 6.04 & 5.99 \\
8 & 5.43 & 5.74 & 5.86 & 5.47 & 5.48 & 5.59 \\
9 & 5.89 & 5.79 & 6.38 & 5.80 & 5.96 & 5.97 \\
10 & 5.78 & 5.70 & 5.64 & 5.40 & 5.46 & 5.60 \\
All CSFs & 5.59 & 5.77 & 5.87 & 5.39 & 5.64 & 5.65 \\
\hline
\end{tabular}

Table 1. Mean value of the influence rates of CSFs

\begin{tabular}{ccccccc}
\hline CSFs & $\begin{array}{c}\text { Iran } \\
\text { Khodro }\end{array}$ & Saipa & $\begin{array}{c}\text { Bahman } \\
\text { Motors }\end{array}$ & $\begin{array}{c}\text { Kerman } \\
\text { Motors }\end{array}$ & $\begin{array}{c}\text { Saipa } \\
\text { Sazegostar }\end{array}$ & $\begin{array}{c}\text { All } \\
\text { companies }\end{array}$ \\
\hline 1 & 5 & 1 & 3 & 2 & 5 & 3 \\
2 & 8 & 7 & 8 & 7 & 10 & 9 \\
3 & 10 & 4 & 7 & 6 & 9 & 8 \\
4 & 7 & 10 & 10 & 10 & 8 & 10 \\
5 & 3 & 2 & 4 & 9 & 3 & 4 \\
6 & 4 & 9 & 6 & 8 & 4 & 5 \\
7 & 6 & 3 & 2 & 1 & 1 & 1 \\
8 & 9 & 6 & 5 & 4 & 6 & 7 \\
9 & 1 & 5 & 1 & 3 & 2 & 2 \\
10 & 2 & 8 & 9 & 5 & 7 & 6 \\
\hline
\end{tabular}

Table 2. Prioritization of the influence rates of CSFs

Also, in Table 3 and Table 4, the mean and standard deviation values of CSFs are presented, considering the 10 categories and the 5 companies, respectively. 


\begin{tabular}{lll}
\hline Companies & Mean & St. Dev. \\
\hline Iran Khodro & 5.5910 & 0.2808 \\
Saipa & 5.7730 & 0.1254 \\
Bahman Motors & 5.8460 & 0.3115 \\
Kerman Motors & 5.3930 & 0.4652 \\
Saipa Sazegostar & 5.6410 & 0.2808 \\
\hline
\end{tabular}

Table 3. Mean and standard deviation values of CSFs, considering the 10 categories

\begin{tabular}{lll}
\hline CSFs & Mean & St. Dev. \\
\hline 1 & 5.8060 & 0.1884 \\
2 & 5.4580 & 0.2590 \\
3 & 5.5440 & 0.2281 \\
4 & 5.2920 & 0.3534 \\
5 & 5.6780 & 0.4385 \\
6 & 5.6060 & 0.2990 \\
7 & 5.9840 & 0.3192 \\
8 & 5.5960 & 0.1919 \\
9 & 5.9640 & 0.2428 \\
\hline
\end{tabular}

Table 4. Mean and standard deviation values of CSFs, considering the five companies

One-way analysis of variance is used to find if there exists any difference between mean values of companies. According to the results, the null hypothesis, in which the means are all assumed as equal is rejected ( $\mathrm{p}$-value $=0.010$ ). Moreover, Tukey-HSD test with significance level of 0.05 is used to point out which of the companies is different with others, in case of the mean value of the influence rates. The results indicate that significant differences exist between Saipa, Bahman Motors and Kerman Motors.

Also, one-way analysis of variance is used to find if there exists any difference between mean values of CSFs. According to the results, the null hypothesis, in which the means are all assumed as equal is rejected ( $p$-value $=0.008$ ). Tukey-HSD test with significance level of 0.05 is used to point out which of the companies is different with others, considering the mean value of the influence rate. The results indicate that significant differences exist between CSFs no. 7, 9 and 4, i.e. between understanding methodology and techniques of Six Sigma, linking Six Sigma to customers and training.

Continuing the analysis, the prioritization rates in Table 2 are considered and one-way analysis of variance is used to find if there exists any difference between mean values of CSFs. According to the results, the null hypothesis, in which the means are all assumed as equal is rejected ( $p$-value $=0.000$ ). Again, Tukey-HSD test with significance level of 0.05 is used to point out which of the CSFs is different with others, considering the prioritization values. The results Indicate that significant differences exist between CSFs no. 7, 9 and 3; 1 , 7, 9 and 2; and 1, 5, 7, 9 and 4. Therefore, it seems that CSF no.4 has difference with a greater number of CSFs. The results are somehow compatible with former analysis, in which significant differences existed between CSFs no. 7, 9 and 4, considering the mean value of the influence rates. 


\section{Discussion and conclusions}

This paper reviewed literature on the CSFs of Six Sigma implementation in different sectors, worldwide and a comprehensive framework was proposed for Six Sigma critical success factors (CSFs). All those factors was extracted from literature review and seem essential for optimizing financial return from Six Sigma projects and for achieving the full potential of its application in all organizations. A case study was also conducted, in which the CSFs were prioritized in five major car maker companies who applied and experienced a number of Six Sigma projects in Iran, as a developing country.

According to the literature review, it was found that factors such as leadership and top management commitment, linking Six Sigma to business strategy, supporting organizational infrastructures, and training and understanding Six Sigma concepts are the most important factors, any organization should consider as first priorities in its Six Sigma project. However, some boundaries and limitations might exit in each of the reviewed studies, such as the number of companies, available resources, time constraints, etc. In some of the reviewed resources, it was found that due to the limited budget and time constraints, postal surveys were carried out for data collection. On the other hand, in some of the other reviewed resources, semi-structured interviews with employees in the companies enabled the author to have a deeper insight into the practice of Six Sigma business strategy. Considering the research limitations, according to Gillham (2000), the scaled questions have disadvantages because respondents often do not use the whole scale. This was also found in the case study presented in this study, in which a seven point scale was used in the questionnaire and the mean value of CSFs had a range of 5.10 to 6.38, denoting considerable, high and very high influence.

The results of the case study imply that not all companies have equal mean values of CSFs. Also, their influence rates of CSFs are not equally prioritized. Also, it has been found that almost all CSFs have same values, except for "training" that has a smaller value. Furthermore, it was highlighted that although companies such as Iran khodro and Saipa have similarities, for instance in having most of the market share, the CSFs do not have the same prioritization in both of the companies. In the analysis of the data of all companies, it was found that "understanding methodology and techniques of Six Sigma" had the highest mean value and the first priority, while, "training" had the lowest mean value and the last priority. From one point of view, this seems ambiguous; but after interviewing with top and executive managers it was found that Iranian companies are dealing with the problem of training effectiveness. In other words, there might not be any problem with scheduling or financing the training programs, rather the main problem is in implementation and taking the learnt theories into action. They were not sure whether they have used correct tools and techniques. An important point is that they do not have any defined system for measuring the effectiveness of their Six Sigma training programs.

Another important result from the analysis is the second priority, i.e. "linking Six Sigma to customers", which has a mean value of 5.97, and is very close to 5.99 that is the value of the first priority, i.e. "understanding methodology and techniques of Six Sigma". It might be due to the fact that almost all companies were found to have problems and difficulties in their after sales services in recent years and therefore, customer satisfaction is now the first strategic priority for them. However, considering the strategic plans written in the car companies, such as Iran Khodro and their policy of developing exports in the next 20 years, 
increasing quality and satisfying customers' preferences seem very important and therefore, it becomes reasonable to have "linking Six Sigma to customers" as the second priority.

It should be noted that as addressed by Shahin (2006), factors such as leadership and top management commitment, linking Six Sigma to business strategy, supporting organizational infrastructures, and training and understanding Six Sigma concepts are the most important factors, any organization should consider as first priorities in its Six Sigma project. Almost all those factors were considered in the 10 categories of CSFs in the case study and their corresponding priorities were computed as: 3, 7, 8, 10 and 1, respectively.

Due to the nature of TQM and Six Sigma, training and education will always be a primary lever for change, although the case study provided a different outcome. Perhaps it is due to the low mean value that "cultural changes" had in the case study (the ninth priority after "training", which had the 10th priority). Considering cultural changes, it seems that some companies that have succeeded in managing change have identified that the best way to tackle resistance to change is through increased and sustained communication, motivation and education. It is important as well to get as much practical feedback as possible from employees, plan the change through a detailed Six Sigma implementation milestone, delegate responsibilities when possible and empower people to make their own decisions.

In addition to the CSFs addressed, further factors and measures could be considered. For instance as some organizations define some criteria in order to measure their degree of success in their Six Sigma projects, they include financial impact on the bottom-line, reduction of defect rate or bug rate, reduction of cost of poor quality (COPQ), improvement of process capability and reduction in the number of customer complaints.

The integration of Six Sigma with quality management systems is a further step towards TQM. Future challenges for the implementation of Six Sigma will be the link of Six Sigma with the existing approaches of quality management and a smart qualification which is oriented at the existing knowledge in the organisations. In order to demonstrate the call for action for linking the approaches of Six Sigma and quality management systems (QMS), the strengths and weaknesses of each approach should be presented. Main challenges for a successful implementation of Six Sigma might be the smart integration in existing management systems. However, in the scope of Six Sigma projects, single process steps have to be systematically analyzed and improved.

\section{Acknowledgement}

The author is very grateful to Tahmooresi Shal (2006) who took the time to participate in the survey of the case study.

\section{References}

Antony, J. (2004). Six Sigma in the UK service organisations: results from a pilot survey. Managerial Auditing Journal, Vol. 19, No. 8, 1006-1013, ISSN: 0268-6902.

Antony, J. \& Fergusson, C. (2004). Six Sigma in the software industry: results from a pilot study. Managerial Auditing Journal, Vol. 19, No. 8, 1025-1032, ISSN: 0268-6902.

Buch, K.K. \& Tolentino, A. (2006). Employee expectations for Six Sigma success. Leadership \& Organization Development Journal, Vol. 27, No. 1, 28-37, ISSN: 0143-7739. 
Coronado, R.B. \& Antony, J. (2002). Critical success factors for the successful implementation of Six Sigma projects in organizations. The TQM Magazine, Vol. 14, No. 2, 92-99, ISSN: 1754-2731.

George, M. (2002). Lean Six Sigma - Combining Six Sigma Quality with Lean Speed, McGrawHill, ISBN: 0071385215, New York, NY.

Henderson, K. \& Evans, J. (2000). Successful implementation of Six Sigma: benchmarking General Electric Company. Benchmarking: An International Journal, Vol. 7, N. 4, 260268, ISSN: 1463-5771.

Larson, A. (2003). Demystifying Six Sigma, AMACOM, ISBN: 0814471846, New York, NY.

Nunnally, J. (1978). Psychometric Theory, McGraw-Hill, ISBN: 0070474656, New York, NY.

Pande, P.S., Neuman, R.P. \& Cavanagh, R.R. (2000). The Six Sigma Way - How GE, Motorola and Other Top Companies are Honing Their Performance, McGraw-Hill, ISBN: 0071358064, New York, NY.

Pfeifer, T., Reissiger, W. \& Canales, C. (2004). Integrating Six Sigma with quality management systems. The TQM Magazine, Vol. 16, No. 4, 241-249, ISSN: 1754-2731.

Rockart, J. (1979). Chief executives define their own data needs. Harvard Business Review, Vol. 57, No. 2, 238-241, ISSN: 0017-8012.

Shahin, A. (2006). Critical Success Factors: A Comprehensive Review, Proceedings of the International Conference on Problem Solving Strategies \& Techniques - PSST 2006, Tehran.

Snee, R.D. (2003). Impact of Six Sigma on quality engineering. Quality Engineering, Vol. 12, No. 3, 9-14, ISSN: 0898-2112.

Snee, R.D. and Hoerl, R.W. (2003). Leading Six Sigma, Prentice-Hall, ISBN: 0130084573, Englewood Cliffs, NJ.

Tahmooresi Shal, F. (2006). Determination of critical success factors in Six Sigma projects implementation in car making companies. M.S. Thesis, Department of Industrial Engineering, Faculty of Postgraduate Studies, Islamic Azad University, Najafabad Branch, Iran. 


\title{
The importance of the strategic alignment process using Six Sigma projects
}

\author{
Bianca Soares de Oliveira Gonçalves \\ Univerisidade Federal de Goiás \\ Brazil \\ Marcel Andreotti Musetti \\ Universidade de São Paulo \\ Brazil
}

\section{Introduction}

The administrative theories used in modern times invariably call for the need to implement improvements in companies. Whether prompted by customers or competitors, they are considered pivotal to the company's survival in an ever changing environment, which is currently the case.

An improvement alternative may result from programs that support competitiveness and organizational performance such as the Six Sigma Program. According to Santos and Martins (2005), the Six Sigma Program has been gaining ground in organizations as a quality program that promotes improving organizational performance, thus increasingly inserted into the strategic plan of organizations. According to Gerolamo (2003), for the improvement actions to be consistent with the strategy, it is necessary to unfold them and establish investment priorities in areas that advance the intended strategy. In Six Sigma, prioritization can be achieved by selecting Six Sigma projects, since this process directs the needed improvement (WERKEMA, 2004).

The literature, however, does not provide details on how the alignment between the Six Sigma program and strategy occurs, which is this chapter's main objective. Thus, this chapter proposes a systematization of the strategic alignment process for Six Sigma projects. There are several Six Sigma concepts. It may be a business strategy that seeks to identify and eliminate the causes of errors or defects in business processes, focusing on product characteristics that are pivotal to consumers (ANTONY, 2004). For Harry et al. (1998), Six Sigma is a business process that enables organizations to increase their profits by optimizing their operations, improving quality and eliminating defects. Harry and Crawford (2005) perceive Six Sigma as a tool that adds value to the product for customers. For Senapati (2004), Six Sigma is a process improvement method. According to Bisgaard, Hoerl and Snee (2002), Six Sigma is a business improvement approach by eliminating the causes of errors and defects in business processes and focusing on customer needs. Rotandaro (2002) adds that Six Sigma is a work philosophy to achieve, maximize and maintain commercial success by understanding customer needs. 


\section{Theoretical base: presentation of the models used}

For the development of the aforementioned systematization proposal, the proposals of these authors were used: Gerolamo (2003); Werkema (2004), Kaplan and Norton (1990), Yip (1995) and Santos and Martins (2004).

\subsection{Conceptual model for the improvement and change performance management process}

This approach proposes a conceptual model for the management process of improvement and change performance. Once the model is unfolded, its main steps are described, illustrated in Figure 1, which can be divided into three key-processes: review; formulate and update the strategy; explain improvement actions and change; and assess and measure the organizational performance. This model's main objective is to direct the improvement strength to the company's strategic objectives

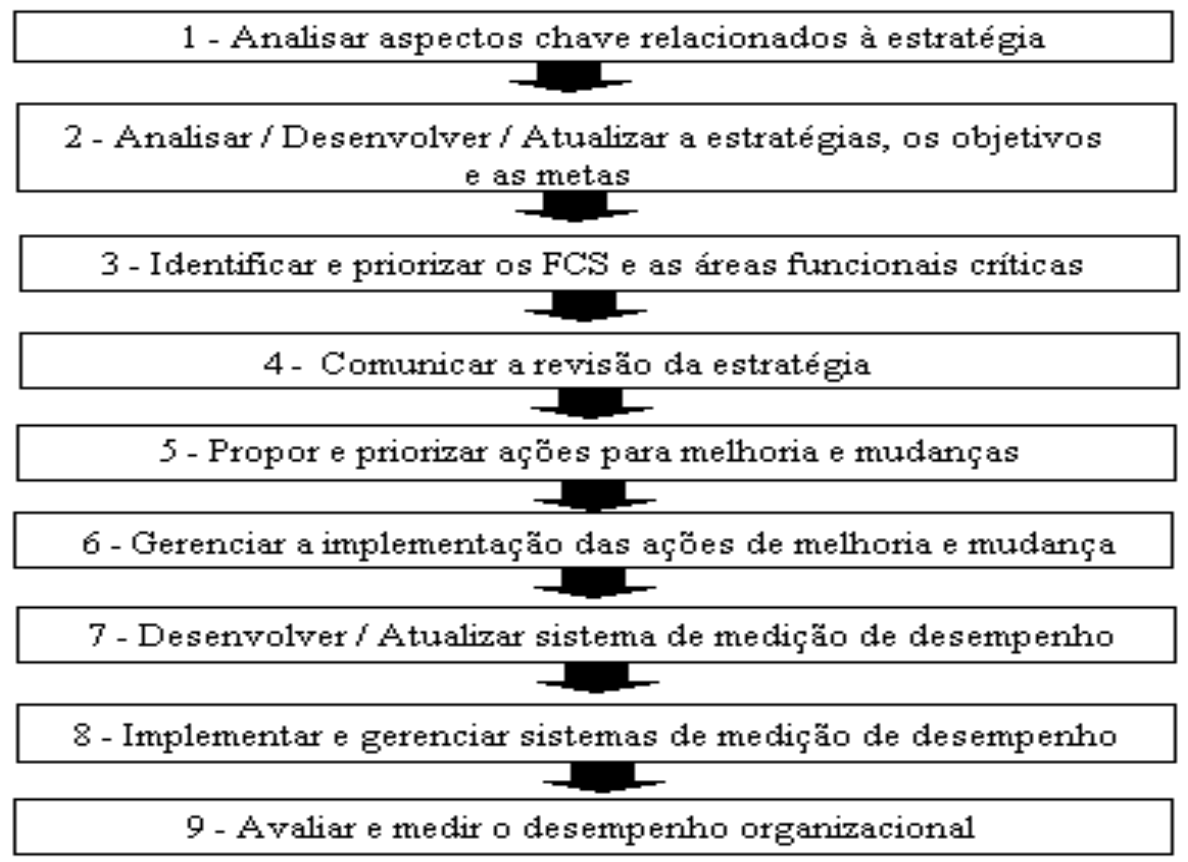

Fig. 1. Systematization proposal for the management process of improvement and change performance (GEROLAMO, 2003).

The first step is to analyze the key aspects taken into account when analyzing a strategy, so that the company in question is not taken by surprised by possible threats that may endanger its survival. They are key-aspect examples: the external environment (guidelines, laws, etc.); financial expectations of stakeholders; competitors; values and organizational principles; strengths, weaknesses, threats and opportunities; emerging strategies, etc. Next, the indicators and organizational performance data, strategic goals and the current organizational goals and outlooks are analyzed. The previous step feeds this process. From 
this strategy analysis and the key aspects related to it, the critical success factors, the business processes and critical functional areas that are important to achieving the strategy formulated are identified and prioritized.

The next step is to design a plan to disseminate, communicate and implement the strategy for the different hierarchical levels of the company. To propose and prioritize improvement actions and changes, it is necessary to map the organization's business processes, analyze process diagnoses and assess the current performance indicators. The subsequent stage is to manage the implementation of the improvement actions. To do this, the future business process should be validated and modeled; the actions implemented should be planned and detailed. Thus, a performance measurement system is necessary to support the transformation and to evaluate the performance of the improvement actions throughout the change.

The performance measurement system should be developed and/or upgraded. The organization's current performance measuring system and its relation to the critical success factors should be identified in order to evaluate to what degree the PMS is supporting the company's strategic objectives.

After this evaluation, the PMS has to be implemented and managed. Finally, the organizational performance, in which the company portrays its performance, should be assessed and measured.

\subsection{Development of the Strategy}

Fig. 2. Strategic planning model.

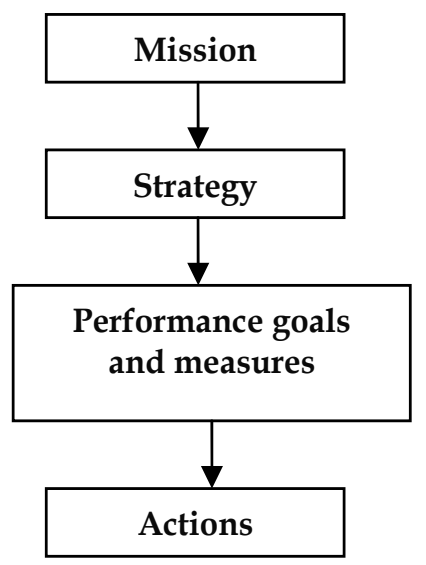

According to this model, the first step toward developing the strategy is to analyze and understand the company's mission. From this understanding, a strategy consistent with the company's mission has to be established, that is, a company that will accomplish its mission has to be established. After this step, strategic goals should be developed, in other words, separate the strategy into goals and define which indicators will measure these goals. Finally, it is necessary to develop actions to accomplish the strategy and, consequently, reach the strategic goals. 


\subsection{Balanced scorecard}

According to Niven (2002), the BSC (Balanced Scorecard) can be described as a carefully selected set of measures derived from the strategy.

These measures represent an essential tool for managers to use when reporting the results and the behavior of the performance drivers to the organizations' employees and stockholders, thus providing the necessary assistance for them to achieve the mission and strategic goals.

Kaplan and Norton (2002) define the balanced scorecard as follows:

[...] the "balanced scorecard" - is a set of indicators that gives managers a quick overview, but also comprehensive, of the entire company. The balanced scorecard includes financial indicators, which show the results of past actions, and supplements them with operational indicators for customer satisfaction with the internal processes and the organization's capacity to learn and improve - the activities that drive future financial performance. (KAPLAN; NORTON, 2002)

Niven (2002) stresses that the fundamental problem is not developing a strategy but rather its implementation, by interpreting this strategy in such a way as to facilitate the understanding of all of the organization's components, which may direct their individual actions to achieve the organizational objectives. Thus, the balanced scorecard is a strategic management method, which can be used for a long-term managing strategy, enabling critical management processes that are interconnected (as shown in Figure 3) such as:

a) interpret the strategy of the business unit into specific strategic objectives;

b) communicate the objectives and strategic measures to the company as a whole;

c) set goals;

d) align strategic initiatives (with quality) for extraordinary goals, and;

e) improve feedback and strategic learning.

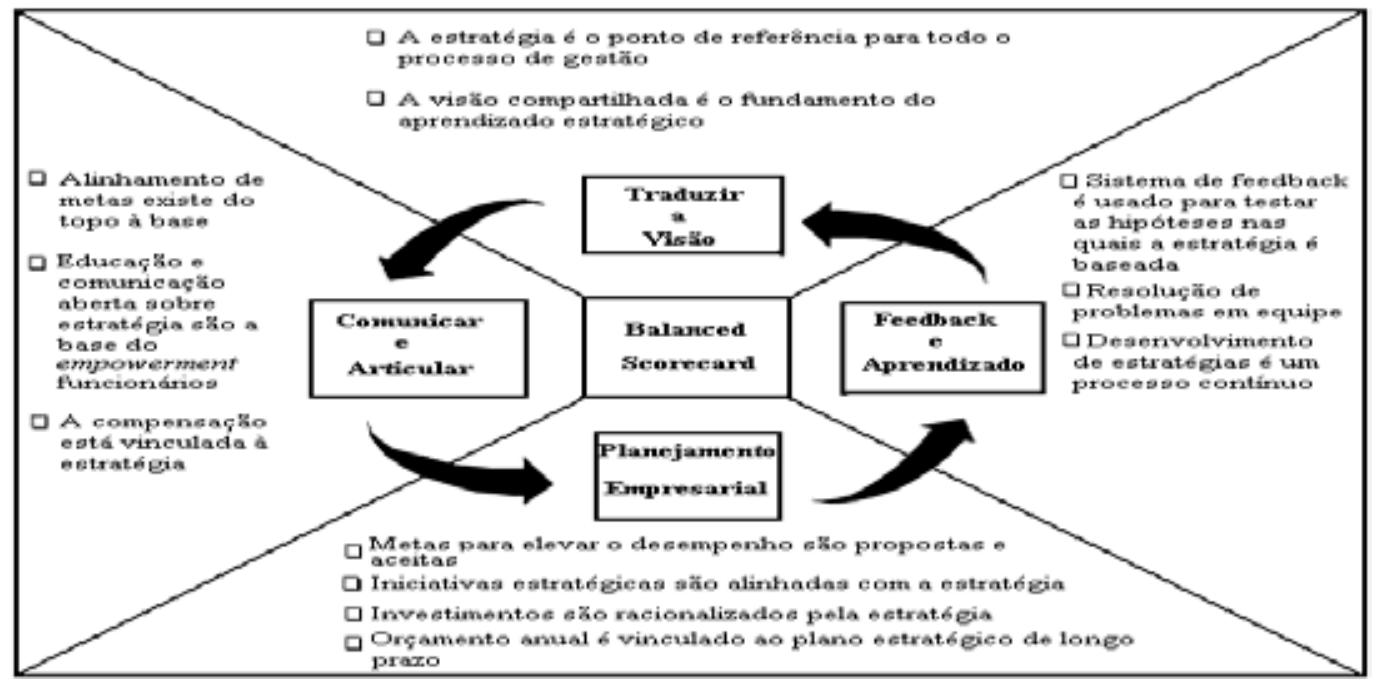

Fig. 3. BSC as a structure for strategic action. (KAPLAN et al., 2002). 


\subsection{Selection process of Six Sigma Projects}

According to Pyzdek (2003), Arthur (2000), Adams et al. (2003), Basu (2003), Pande et al. (2001), Rotandaro (2002), Eckes (2001) and Snee and Rodenbaugh (2002), the selection of Six Sigma projects is pivotal to the success of the Six Sigma program, since well selected projects will contribute to the success and consolidation of Six Sigma culture within the company. Figure 4 shows the selection process of projects according to Werkema (2004).

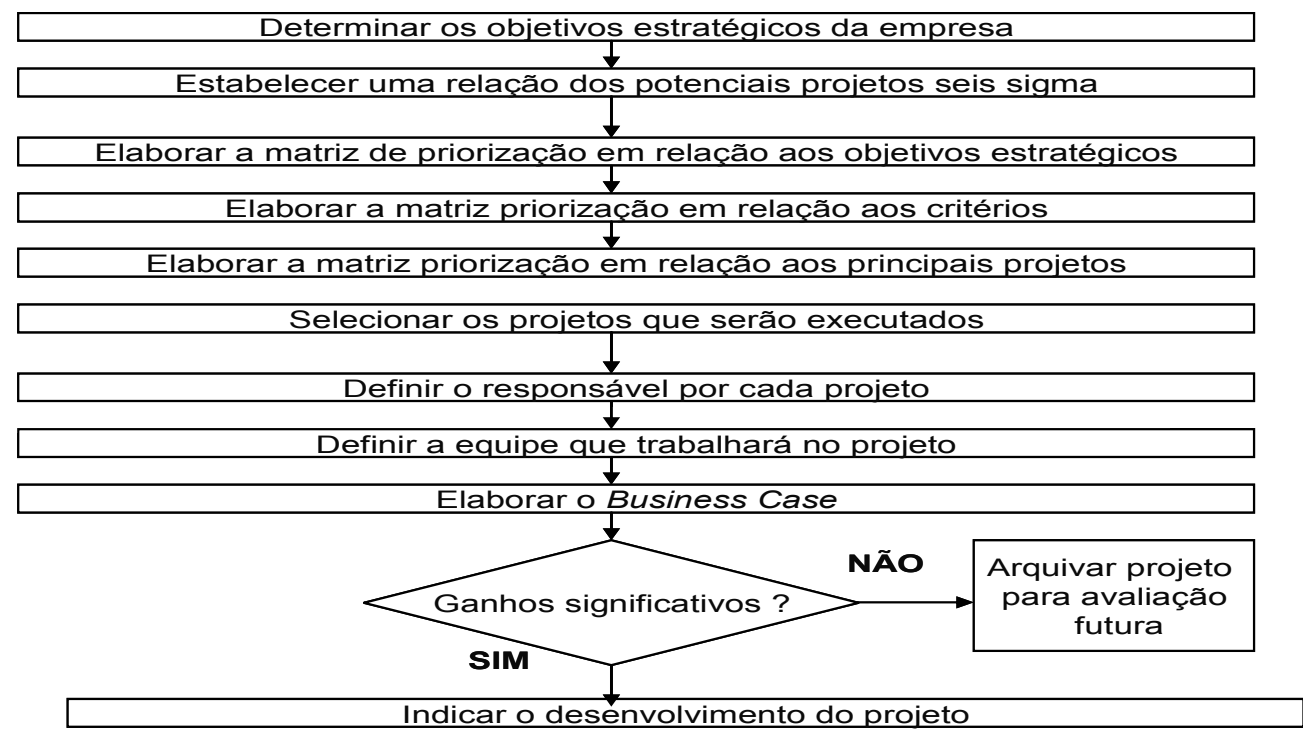

Fig. 4. Selection process of Six Sigma projects. (WERKEMA, 2004).

The first stage of the selection process of Six Sigma projects is to determine the strategic objectives decided on by top management. The projects should contribute to achieving at least one of these goals. Next, a relationship for potential Six Sigma projects should be established.

In the selection stage for potential projects, the management team holds brainstorming sessions in order to select projects according to the company's current problems.

Once the potential projects are set up, the next step is to develop and implement the priority matrix for assessing the impact of potential projects regarding the strategic objectives (PATTTERSON; BERTELS, 2003). An example of this matrix can be seen in Figure 5. For assessing the impact of potential projects on the strategic goals, one should first consider the extent to which each strategic objective is related to the project. Thus, a scale of 0 to 5 is established, where 0 means no relationship between the project and strategic goal; 1 means that the relationship is weak; 3 means that the relationship is moderate, and 5; the relationship is strong. 


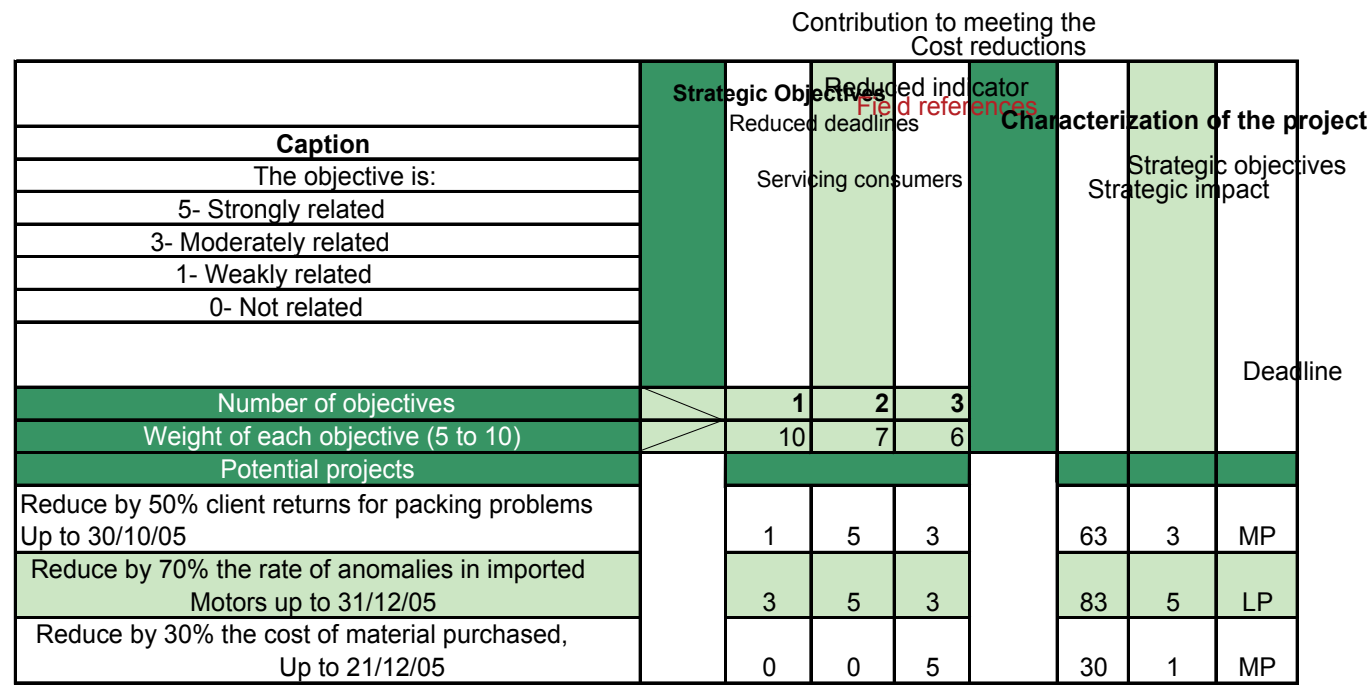

Fig. 5. Priority matrix to evaluate the relationship between the strategic objective and the projects. (WERKEMA, 2004).

For each project, multiply the resulting number of the intensity of the relationship by the degree of importance of the corresponding strategic objective and add the results of the multiplications. The result should be allocated in the "strategic impact" column on the row for the diagnosed project. Each sum must be transformed into a number on the scale of 0-13-5 and recorded in the "Contribution to achieving the strategic objectives" column. Finally, for each potential project, identify the medium-term (MT) or long-term (LT) duration.

The fourth step elaborates the priority matrix to select the projects based on the criteria to define a good Six Sigma project.

The method to establish the priority matrix is the same for the aforementioned matrix, however each column of the priority matrix to select the projects presents a criterion or filter that the company uses to define a good Six Sigma project. The degree of importance assigned to each criterion (scale of 5 to 10) is a consequence of the company's strategies. Thus, for each project listed, identify the extent to which each criterion is met, using the same scale of prioritization matrix as above. For each project, multiply the resulting number from the previous step by the degree of importance of the corresponding criterion and add the results of the multiplications, recording this result in the column.

"Total", in the row that corresponds to the project. The higher the number in the "Total", column, the higher the priority of the project as a Six Sigma project.

\subsection{Proposal of a model for strategic alignment of Six Sigma Projects}

According to Santos and Martins (2005), the Six Sigma program has gained ground in organizations as a quality program that promotes the level of organizational performance and is therefore increasingly inserted in the strategic plan of organizations, establishing a link with the infrastructure that an organization has to measure performance. This often results in the program's poor use, since any problem that may arise turns into a Six Sigma project, given that these problems could be solved with a simpler methodology. 
To properly select the critical processes in need of improvement, in order to reach high organizational performance, is one of the primary challenges of Six Sigma (SANTOS; MARTINS, 2005).

Since the alignment is a key factor in the consistency of the proposals and actions given the improvement initiatives, the Six Sigma program is a catalyst for this alignment, since it is a strategic program that promotes the improvement of the entire business from the achievement of strategic objectives.

The selection and prioritization process of Six Sigma projects is directly related to alignment, that is, selecting the projects directs the improvement strength towards the company's critical processes.

Santos and Martins (2005) propose a framework that expresses the relationship of performance indicators with the Six Sigma program as a reflection of the strategic alignment. The structure is described in nine points:

a) The organization interacts with the environment to define the strategy;

b) Construction of the performance measurement system that is aligned to the strategy;

c) The multiple categories of the performance measurement system direct the actions of the Six Sigma program by aligning the selection of Six Sigma projects;

d) The Six Sigma projects should be aligned with the strategy through its objectives;

e) The results from setting up the Six Sigma projects can promote improved efficiency and effectiveness of the company's processes;

f) The Six Sigma projects may need a revision of its goals to achieve a greater alignment;

g) The Six Sigma projects have a role as performance drivers through the link they establish with the performance measures that make up the performance measurement system;

h) Customer satisfaction is achieved to the extent that goods and services are improved, and

i) The successful implementation of Six Sigma projects enables an important strategic feedback in order to review the strategic objectives.

This structure demonstrates that selecting the projects has a strong relationship with the company's indicators and strategic direction; points three and four of this structure, previously listed. This systematization, however, does not describe in detail the selection process of Six Sigma projects, however, it details the unfolding of the strategy and the importance of its alignment with the Six Sigma projects, through the selection process of Six Sigma projects.

\subsection{Considering the approaches}

According to Gerolamo (2003), although the strategy issue is complex and depends on many areas and on a sparse literary source, it is important that organizations seek for methods to assist in their processes of analysis, formulation, development and strategy review. Then, the goals and strategic objectives are more likely to be achieved if the strategy directs the improvement strength, and the improvement strength in this article represents the Six Sigma projects.

Analyzing the proposed approaches on strategy development and strategic alignment, it is observed that the approach of Kaplan and Norton (1990) describes the unfolding of the strategy, but does not detail the alignment with the improvement strength, while Gerolamo's approach (2003) describes in detail the alignment of the strategy with the 
strength of improvement without analyzing the development of the strategy. Yip' approach (1995) is simple and without many details. However, this work portrays the importance of having a PMS to motivate improvements in critical areas, which Werkema (2004) does not make clear regarding its use in the selection of Six Sigma projects.

Thus, a systematic method that presents in detail the strategy alignment with Six Sigma projects is justified.

\section{Systematization proposal of Six Sigma strategic alignment projects}

The proposal presented here is based on the approaches presented in the theoretical framework, they are: Gerolamo (2003); Werkema (2004), Kaplan and Norton (1990), Yip (1995) and Santos and Martins (2005). The first approach mentioned presents a conceptual model on the managing process of change and improvement in performance, which for the most part lacks contextualization in the Six Sigma program. However, Werkema's approach (2004) does not detail the alignment process, but highlights its importance, thus showing a gap, which is the focus of this chapter. Kaplan and Norton (1990) make clear the strategy's development, but do not explain its alignment with the improvement strength, and as stated earlier, Yip (1995) presents an approach without many details. Thus, this proposal's major motivation is to join and/or adapt the aforementioned approaches by filling in the gaps, which is this proposal's differential, since it considers the strategy's systematic alignment (which the proposals of Werkema (2004) and Yip (1995) do not show) of the Six Sigma projects (which the approaches of Gerolamo (2003) and Kaplan and Norton (1990) do not specifically contextualize, taking into account the importance of selecting the Six Sigma projects). The proposals of Santos and Martins (2005) emphasize the importance of using performance indicators, but do not detail the selection process of Six Sigma projects. Figure 6 illustrates the systematization proposal. 

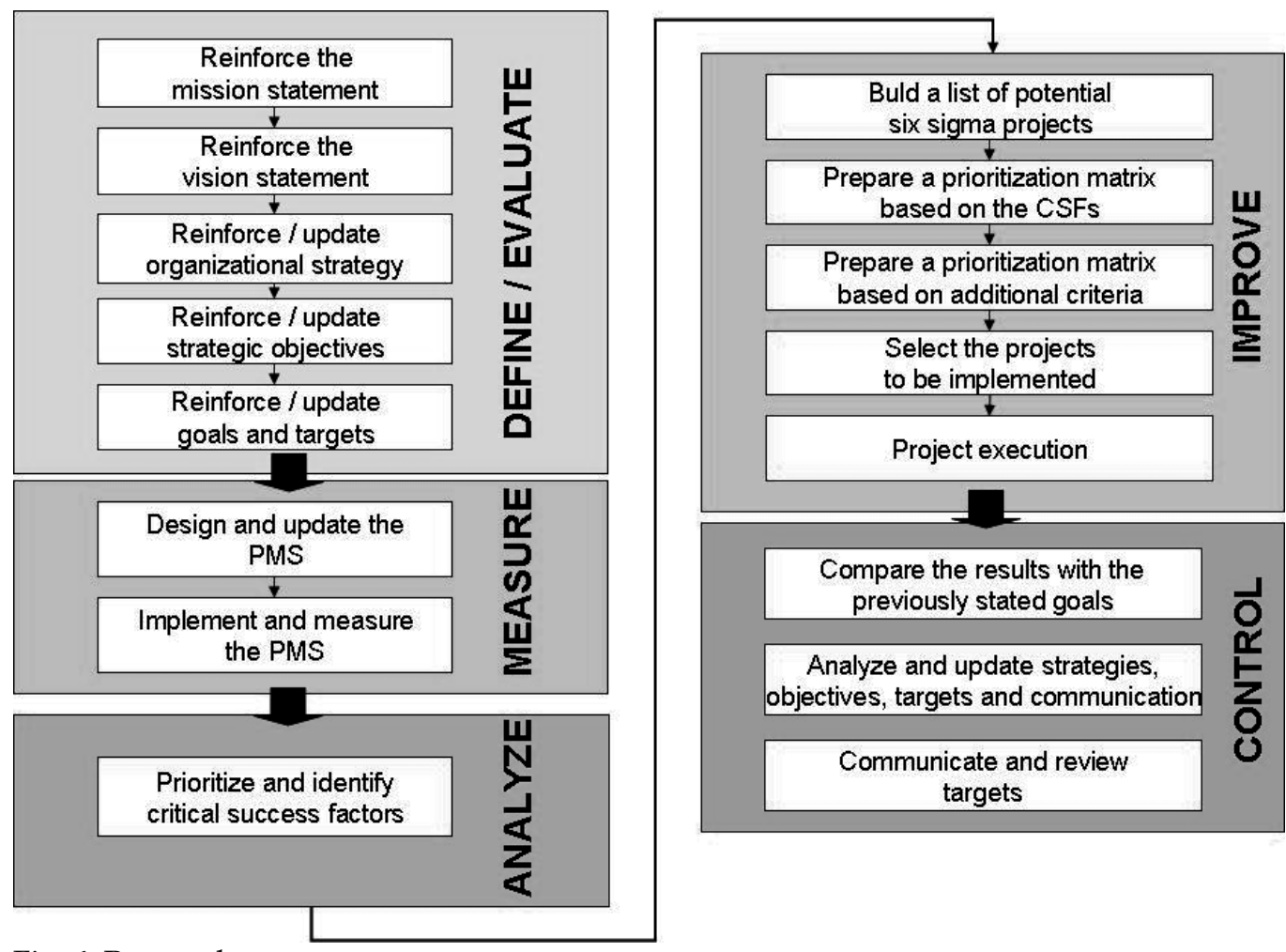

Fig. 6. Proposal.

Note that steps one, two and three are essential to implementing a quality program like Six Sigma, in other words, Six Sigma will only be successful if implemented in a company with a minimum of organization and maturity in relation to the strategy's development, therefore, these steps will focus on the rescue and updating of the concepts presented and not on its development. It is necessary to emphasize that this study will not detail the process of defining the strategy, as this process is not part of the scope of this work.

\section{1- Rescue/Upgrade the organization's Mission}

The first step in the proposed systematizing is to perform a rescue in the organization's mission.

In this process, the company's mission and updating the mission should be reviewed.

Many misunderstand the nature and the importance of the mission, while others do not even consider it. Drucker (1973) observed: “The Company's purpose and mission are so rarely considered, that this may be the main cause for many companies' frustration and failure."

According to Abrahams (1995), for a company to have a direction, not at the mercy of the erratic winds of fate, the mission should include the following concepts:

The reason for the company;

What justifies its existence; 
It is a succinct and accurate definition of the enterprise;

It is defined based on cultural factors, formed by the set of beliefs and values of the company's personnel.

The mission of an organization can be defined as its primary function, preferably related in a sentence, clearly expressing why the organization exists (CHIAVENATO, 2004).

The essential business goals are involved in the organization's mission. The mission is the reason it is an organization, in which it seeks to determine its business. And each organization has its specific mission, from which its key organizational objectives derive (CHIAVENATO, 2004).

A company is not defined by its name, status or product; it is defined by its mission. Only with a clear definition of its mission will the company exist and make possible its clear and realistic goals.

Forming the identity of a corporation begins with the definition of its mission, the reason to exist. Every company, regardless its size, needs a mission statement as a source of direction - a kind of direction - that enables its employees, its customers, and also its shareholders to know what the company stands for and where to lead it.

\section{2- Rescue/updating the Outlook and Strategy}

At this stage, the organization should review its strategy to rescue its outlook, in other words, the organization must analyze it and update it so that the company can view its current reality. A set of principles and beliefs should be obtained, which together with the mission statement, will help to achieve that outlook (CHIAVENATO, 2004). Thus, the outlook is the desired future state, related to the highest customer satisfaction.

From the rescue mission and organizational outlook, the next step is to review the rescue strategy. A well defined strategy that portrays the current organizational context is necessary in order to have an on-going six sigma program, because this type of program requires a well defined management structure. Then, at this stage the strategy should be examined, upgraded and developed (if necessary). Therefore, the key-aspects taken into account to analyze/develop a strategy should be examined, so that the company is not surprised by possible threats that endanger its survival. These are some key-aspect examples: the external environment (guidelines, laws etc.), financial expectations of stakeholders, competitors, values and organizational principles, strengths, weaknesses, threats and opportunities, emerging strategies etc.

\section{3- Rescue/update of the organization's Strategic Objectives and goals}

The strategy should be developed as strategic objectives, that is, the organizations are goaloriented entities. The strategic objectives are the organization's global and broad objectives. In some cases, the strategic objectives are broken down into operational and tactical objectives or into goals. (CHIANENATO, 2004). These goals should always be reviewed in order to achieve the organization's performance with regards to the objectives set in place, the review is conducted at this stage.

Thus, the organization must ensure that the strategic objectives:

Are related to the mission and understood and shared by the interest groups; 
Are realistic and not overly ambitious. The most specific as possible. The strategic objectives should be described so that they can be understood and used by the employees (CAMPOS, 2002).

A goal, whatever it may be, can only be conceptualized when designed according to some variables (CAMPOS, 2002). Its objective goal should be well defined, given that the more specific the definition of its purpose is, the more directed its route will be. The goal must be quantifiable, becoming objective, palpable. A goal must be attainable, possible and viable. Moreover, the goal must be important, meaningful, challenging. A goal must be attainable, possible, and feasible. Finally, the goals must be well defined, measurable, possible, important and defined within a time frame.

It is necessary to rescue the goals, determine which were achieved and which will be achieved, and those that were not may then become the objectives of a six sigma project, since the goal emerged from the strategy's unfolding.

\section{4- Develop, update and implement the performance measurement system (PMS)}

By reviewing the previous steps, it can be stated that determining the strategic direction means creating the mission and setting the strategic objectives, taking into account the organization's outlook and values. Moreover, the strategic direction is related to choosing the right destination and path for the organization. This choice requires having a high degree of understanding of the external environment and a proper assessment of the organization's capabilities and competencies (GEROLAMO, 2003).

Once the strategy is chosen, it is necessary to choose the objectives and performance indicators that show whether the organization is in the planned path and through an assessment, how much progress was made toward the strategic objectives. Thus, the next step is to develop and upgrade the performance measurement system. At this stage the performance measurement system that will measure the degree of how much the organization is or not reaching its goals should be identified. At this stage, it is necessary to develop and upgrade the PMS so that it supports the company's strategic objectives. Thus, the relationship among the indicators, definition of objective measures, and identification of the conflicting indicators and the details of the indicators should be identified.

At this stage, the PMS must be operationalized, always seeking to validate the operation and periodically evaluating the PMS.

\section{5- Prioritize and identify the Critical Success Factor (CSF)}

According to Chiavenato (2004), the critical success factors (CSF) are the determining factors in achieving the organization's goals, and are directly linked to the company's success. There are two ways to identify the CSFs: the first one is to dissect the organizational resources and market to identify the segments that are most crucial and important. The second one is to discover what distinguishes unsuccessful organizations from successful organizations and analyze the difference between them, in other words, benchmarking (CHIAVENATO, 2004).

After identifying the FCSs, they should be prioritized.

To prioritize, it should be analyzed through the PMS, in which CSF the organization is unsuccessful and then focus on their improvement strength (BROWN, 2000). 


\section{8- Establish a list of potential six sigma projects}

Once the CSFs are identified and prioritized, a list of potential six sigma projects focused on the CSFs prioritized above should be established, that is, the six sigma improvement projects should solve the CSF problems.

\section{9- Prepare a priority matrix with regards to the CSFs.}

This matrix is a tool to link the project to the company's strategic objectives.

\section{0- Develop a priority matrix regarding the criteria}

This matrix relates the projects that passed through the filter of the previous matrix with the other criteria. These criteria are important features that projects have to have in order to be selected, such as the project's implementation period, ease of data, project cost, increase of customer satisfaction, availability of the personnel involved, financial return of the projects, etc.

\section{1- Select the projects to be executed}

At this stage, the projects that passed through the filters of the former matrixes will be selected to be carried out.

\section{2- Implant the project}

At this stage, the project based on the PMSIC methodology will be developed.

\section{3- Compare the results of the projects with the desired goals}

At this stage, the results actually achieved are compared against the projects with the expected results during the planning and selection of the six sigma projects. Thus, this phase will monitor the project performance and project selection processes, that is, whether the organization's goals and objectives have been achieved through the results of the projects, this means that the projects were well selected and are actually aligned with the company's strategy.

The performance monitoring is the administrative process that ensures that what an organization is doing is consistent with what it decided to perform.

The performance indicators that comprise the performance monitoring should ensure this monitoring process.

\section{4- Analyze and update strategies, objectives, goals and communication}

At this stage the indicators and indices of organizational performance, strategy, mission, outlook, objectives and current goals of the organization should be reviewed. The objectives and goals already achieved must be replaced or upgraded in accordance with the new results obtained with the six sigma projects.

The last step is to elaborate a plan of dissemination, communication of new goals and the objectives determined in the previous step. 


\section{Conclusion}

Regarding the systematization proposal presented, one should emphasize the importance of having in the literature a systematic alignment of the strategy with Six Sigma projects, given that this alignment is essential to the success of the program. In addition, the proposal assists companies that are implementing the Six Sigma program to be successful in selecting improvement projects.

It was not within the overall objective to present a comprehensive proposal for all the improvement actions, the focus was on Six Sigma projects.

The alignment between Six Sigma projects and the strategy can be achieved through a systematized alignment process, which will maximize the success of the Six Sigma program, as presented in this chapter. For further research, the implementation of this proposal is recommended.

\section{References}

Adams, C.; Gupta, P.; Wilson, C. (2003). Six Sigma Deployment. New York: Butterworth Heinemann, 2003.

Antony, F. (2004). Some pros and cons of six sigma: an academic perspective. The TQM Magazine, v.16, n.4, p. 303-306.

Arthur, J. (2000). Six Sigma simplified: quantum improvement made easy. Denver: Lifestar.

Basu, R. (2003). Quality beyond six sigma. Oxford: Butterworth -heinemann.

Bisgaard, S.; Hoerl, R.; Snee, R. (2002). Improving business processes with Six Sigma. In: Annual Quality Congress, Milwaukee, p. 701-704.

Brown, M. (2000) Winning score: how to design and implement winning scorecards. Portland, Oregon: Productivity Press.

Campos, V. (2002). Gerenciamento pelas diretrizes. Belo Horizonte: INDG.

Chiavenato, I. (2004). Teorias da Administração. Rio de Janeiro: Campus.

Drucker, Peter. (1973). Management: Tasks, Responsabilities, Practices. New York, Harper \& Row.

Eckes, G. (2001).A revolução Seis Sigma: o método que levou a GE e outras empresas a transformar processos em lucro. Rio de Janeiro; Campus.

Gerolamo, M. (2003). Proposta de sistematização para o processo de gestão de melhorias e mudanças de desempenho. São Carlos. 165f. Dissertação (mestrado) - Escola de Engenharia de São Carlos, Universidade de São Paulo.

Harry, M.; Schroeder,R. (1998). Six Sigma: a breakthrough strategy for profitability. New York: Quality Progress.

Harry, M.; Crawford, D. (2005).Six sigma - The next generation. Machine Design Cleveland, Estados Unidos, v. 77, n.4, p. $126-130$.

Kaplan, R. S.; Norton, D. P. (1990). Organização orientada para a estratégia: como as empresas que adotaram o Balanced Scorecard prosperam. Rio de Janeiro: Campus, 1990.

Kaplan, R. S. E Norton, D. P. (2002). Organização orientada para a estratégia. Rio de Janeiro: Campus.

Niven, Paul R. (2002). Balanced scorecard step by step: maximizing performance and maintaining results. New York: John Wiley \& Sons, Inc. 
Pande P.; Neuman, R.; Cavanagh, R. (2001). A estratégia Seis Sigma: como a Motorola e outras grandes empresas estão aguçando seu desempenho.Rio de Janeiro: Qualitymark.

Pyzdek, T. (2003). The six sigma project planner a step-by-step guide to leading a six sigma project through DMAIC. New York: McGraw -Hill.

Rotandaro, R. (2002). Seis Sigma: estratégia gerencial para melhoria de processos, produtos e serviços. São Paulo: Atlas.

Santos, A.; Martins, M. (2005). Medição de desempenho e alinhamento estratégico: requisitos para o sucesso do programa Seis Sigma. In: Simpósio de administração da produção, logística e operações internacionais, 8., 2005, São Paulo. Anais...São Paulo, FGV- EAESP.

Senapati, N. (2004). Six Sigma: myths and realities. International Journal of Quality $\mathcal{E}$ Reliability Management, v. 21, n.6, p. 683-690.

Werkema, C. (2004). Criando a cultura Seis Sigma. Nova Lima: Werkema. 


\title{
Integrated model linking Maintenance Excellence, Six Sigma and QFD for process progressive improvement
}

\author{
Maher Lazreg \\ Research Center at Arass, Qassim University,Buraidah, Kingdom Saudi Arabia; \\ Institut Supérieure des Sciences Appliquées et Technique de Sousse, ISSATS, \\ Université de Sousse, Tunisie
}

\section{Introduction}

The maintenance organization is increasing importance for companies, as it directly affects other relevant processes leading to customers' satisfaction or dissatisfaction. According to this view, several companies continue to improve their maintenance organization through implementing improvement approaches such as Maintenance Excellence (ME) and Six Sigma. Simply put, the end product of such approach in general is to instil better practice within an organization in order to support its values and strategic objectives, maintain and exceed its competitive position. Despite their role in promoting quality, these frameworks have important drawbacks as improvement models, especially, given the lack of their implementation in manufacturing, their integration into the everyday organizational operations. Although Six Sigma and ME both help build quality into the design stage and they are mutually supporting each other's shortcomings, there are a number of organizations, which are failing to reap the fruits of these two approaches successfully. This could be noticed to the following four common deficiencies:

- They are often too complex to be applied as such by small companies;

- They rarely integrate the interaction between Six Sigma and ME;

- ME is treated as a separate activity of SME business operations;

- The implementation process of the excellence models is under-researched area;

This chapter is situated in a total quality strategy (Yong and Wilkinson, 1999). It discusses the practicality of deploying the QFD as a technique for 'best practice' of synergising ME with Six Sigma. However, our contribution includes two aspects: the first one concerns the extension of the QFD method, usually applied to products and services, in the improvement of the maintenance system. As a result, the performances of the maintenance function are improved in a progressive but complete way; the second one focuses on the integration of both Six Sigma and ME approaches in one model. 
In this chapter a new method of progressive improvement (Lazreg and Gien, 2007), which lies within the general scope of a methodology of re-design of the maintenance activity is proposed. In this perspective, the next section describes our Maintenance Excellence Model. Next, Six Sigma and QFD, which are used in the development of the progressive improvement model is presented. The fourth section discusses the model and provides the method detailing how the progressive improvement model is utilized for selecting an improvement action. In section five, a case study in maintenance activity is presented to illustrate the proposed model. Next, findings and limitations of the case study are considered. Finally, the paper concludes with summary and discussion of the potential contribution of this model and suggests areas for future research.

\section{Maintenance Excellence}

\subsection{Literature review}

Operational excellence is a broader program of improvement and sustenance business performance in which quality management is embedded. Operational excellence is synonymous with business excellence and it also encompasses other focused excellence programs such as Manufacturing Excellence, Production Excellence and Maintenance Excellence. According to Edgeman et al., (1999) Business Excellence is defined as:

"An overall way of working that balances stakeholder interests and increases the likelihood of sustainable competitive advantage and hence long-term organizational success through operational, customer-related, financial, and marketplace performance excellence."

Moreover Edgeman et al. (2005) reported that, the best business excellence model provides an approach for jointly optimizing the resulting simplex of business excellence criteria. The primary purpose of business excellence through their criteria is the regular, rigorous and systematic review of the organizations' approaches. Their deployment identifies the organizations' strengths, weaknesses, opportunities for improvement, and threats to its competitive position. This process is referred to as self-assessment (Conti, 1997).

The ME model sets the framework for challenging critical review of the completeness and effectiveness of any business process or project. Through the ME, the organization seeks to provide a high quality process that acknowledges $\mathrm{ME}$, which supports continuous improvement in the maintenance function and focuses on different areas such as strategy, people, information, practices and business impact aspects of ME. The criteria describe each of these areas in detail. This description includes a generic interpretation of intent in each area. The Maintenance Excellence Criteria (MEC) is considered as the guidelines for evaluating maintenance practices and performances. By using the MEC, enterprises will be able to evaluate their capabilities of maintenance management through self-assessment.

Several ME models are available to measure and support maintenance assessment in organizations. The following models for business excellence, often related with quality prizes, serve as a useful framework within which quality improvement efforts may be integrated: 
- The Australian maintenance excellence award (Sirft, 2007) seeks to provide a high quality process, which acknowledges $\mathrm{ME}$, supports continuous improvement in the maintenance function, focusing on people, practices, and the business impact of ME.

- The North American maintenance excellence award (Name, 2007) is an annual program conducted to recognize the organizations that excel in performing the maintenance process to enable operational excellence.

- $\quad$ By the late 1990's, TPM is well entrenched as a continuous improvement methodology across a wide range of industries. For illustration, look at the number of enterprises that have been awarded the TPM prize by the Japan Institute of Plant Maintenance (Shirose, 1996).

- The cornerstone value of the PRIDE maintenance award (Pride, 2007) is to implement profit-centering practices and attitudes in large and small plant maintenance operations.

- $\quad$ The Shingo prize (Shingo, 2007) is an overall systems model that incorporates all aspects of business operations and processes such as maintenance, repair and in whole.

These models have important limitations, as conceptual models but especially as measurement models (Ghobadian and Woo, 1996). When weights are attached to each criterion, they are arbitrary and do not necessarily reflect the relative importance of each model construct. Therefore, the prioritization of improvement efforts becomes somehow ambiguous. Moreover, Silberman (2001) highlights that, the top three to five ranked items that most respondents have identified, constitute the action plan. Given these deficiencies, a New Maintenance Excellence is developed, presented and discussed in the next section.

\subsection{The Maintenance Excellence Model}

The definition of the different areas of the maintenance function constituted a first solution of the management and organization of a maintenance service in the SME enterprises. The purpose of our Maintenance Excellence Model (MEM) is to determine where the maintenance organization's strengths are to leverage improvements and identify areas of opportunity to correct. It provides a view of the structure, relationships, processes and people relative to good maintenance practices. More else it strives to attain and maintain optimal equipment conditions in order to prevent unexpected breakdowns, speed losses and quality defects in process.

The MEM model consists of ten distinctive areas (figure 1), each representing a different aspect of the organization. These ten areas are subdivided into areas concerned with what results have been achieved (Results) and areas concerned with how these results have been achieved (Enablers). 


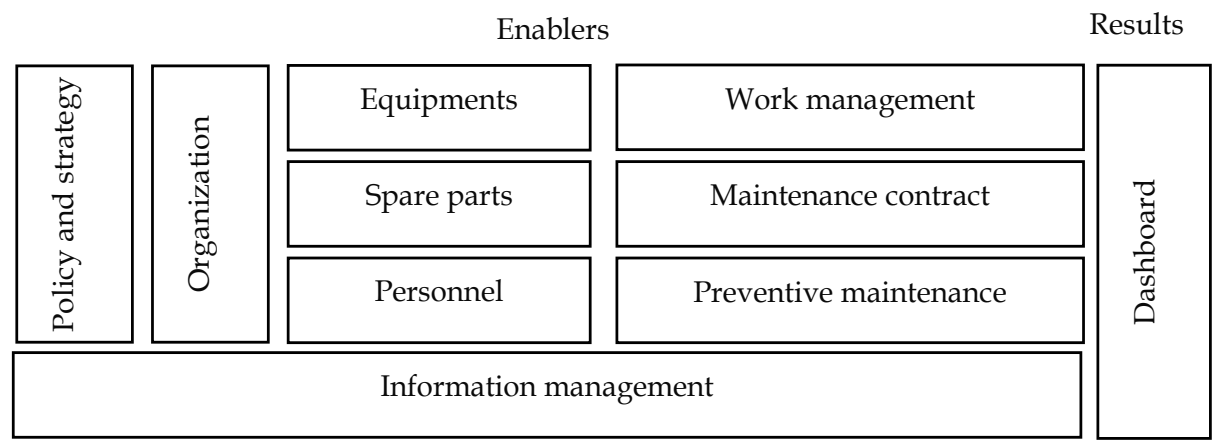

Fig. 1. The maintenance excellence model.

\subsubsection{Enabler's and Result areas}

Maintenance organizational efficiency depends upon many interdependent variables, which are:

- Policy and strategy: how this introduces an appropriate policy to the objectives? Are these objectives based on the present and future needs and on the information resulting from measures? Are they constantly developed, examined and updated under the control of the responsibility of the service? Does the organization have a real interest in employee's welfare and satisfaction? Are maintenance craftspeople involved in setting and meeting goals and objectives for the department?

- Organization: how does the organization set its mission? Is there a functional organization chart? Are the processes, the tasks and the responsibilities structured? Does the organization help to remove barriers of maintenance craftspeople encounter in their jobs, which they have no control over and, which prevent them from doing a good job? Does the management encourage the maintenance craftspeople and the production operators to work together on certain issues?

- Maintenance contract: are the works of subcontracting recorded? Are the works prepared under constraints of delay and complexity and materiel? Does the service arrange an inventory of all the subcontractors as well as their repartition by activity?

- $\quad$ Personnel: how are the performances of the staff managed? Does good job performance lead to job security in this organization? Have craftsmen received training to help them do their jobs? Do maintenance craftspeople follow safety policies and procedures?

- Information management: how can the supervisor exploit the information coming from the results of activity? How can he/she confirm the results of improvement and their transfer to the various functions of maintenance? Does the organization use a computerized system for maintenance activities? Does the organization update its computerized maintenance system? 
- Stores: how are the suppliers as well as the internal and external customers identified? How does the person in charge optimize the stocks cost? Are all inventories accounted for, for example price and lead-time? Are turn-over ratios used for storeroom control?

- Equipments: how is the equipment identified and indexed, in order to recognize its performances? How is the equipment calibrated? How does the enterprise acquire new equipment? How the inventory of equipment is prepared?

- Work management: by respecting its policy and strategies, how does the supervisor manage and improve constantly its processes and increase the service quality? How does the organization use maintenance planner to plan and prepare scheduled maintenance work such as major repairs and shutdowns? Are priorities set for maintenance job tasks?

- Preventive maintenance: does the preventive maintenance program eliminate all unplanned equipment failures? Does the organization try to prevent breakdowns and failures from recurring? How much does the organization track cost (Life Cycle Cost) to maintain equipment?

- Dashboard: how does the service reach its goals according to its forecasts? Which indicators do we have to use and represent the operational results? How do we compare our maintenance service performances with the other competitors?

\subsection{Diagnostic approach}

\subsubsection{Structure of the enablers' area}

Referring to the French Standard Agency (Afnor, 1988), which uses evolutionary levels for structuring and organizing the equipment maintenance operations. The author proposes to extend this concept to measure the different enablers. The principal base of the measurement scale, which is proposed in table 1 , is based on a constant re-evaluation of the objectives and targets to be achieved as well as a regular re-examination and re-evaluation of the methods carried out (Sonnek et al. 2001). Only an optimal management of all the parameters of the maintenance service allows achieving the goal.

\begin{tabular}{ll}
\hline Level & State \\
\hline 0 & Anecdotic or without added value. \\
] $0,0.2]$ & Weak performance. \\
] $0.2,0.4]$ & Below average performance. \\
] $0.4,0.6]$ & Average performance. \\
] $0.6,0.8]$ & Very good, effective operations. \\
] $0.8,1]$ & World Class. Best in practice. \\
\hline
\end{tabular}

Table 1. Measurement scale of the enablers' area

The evolution according to the MEM model is a measurement belonging to one of the six suggested intervals. Each number corresponds to an added value resulting from the equipment management. The value 1 translates the know-how and a control of a particular 
technology; the value 0 refers to a negligible, marginal and unimportant work. In this context, the measurement of each area state is found by carrying out a comparison between the weight of the current state and the measurement scale.

The current weight of the state of an area $A_{i}$ is obtained as follows:

$$
A_{i}=\sum_{j=1}^{n_{i}} a_{i j}
$$

The normalized subtotal $A_{i}^{\text {nor }}$ is equal to:

$$
A_{i}^{n o r}=\frac{\sum_{j=1}^{n_{i}} a_{i j}}{5 n_{i}}
$$

The total of the enablers' area $E^{\text {nor }}$ is equal to:

$$
E^{n o r}=\sum_{i=1}^{9} \frac{\sum_{j=1}^{n_{i}} a_{i j}}{5 n_{i}}
$$

Where

$$
\begin{aligned}
& a_{i j}: \text { value associated to the } \mathrm{i}^{\text {th }} \text { area and } \mathrm{j}^{\text {th }} \text { item } \\
& \mathrm{n}: \text { number of items by area } \\
& n_{i}: \text { number of items in the } \mathrm{i}^{\text {th }} \text { area }
\end{aligned}
$$

\subsubsection{Structure of the result area}

From the table 2, the model proposes four intervals and four classes of indicators: the availability of the data and the development tendency and the existence of the internal indicators and the presence of the reference indicators.

The subtotal of the result area $R t$ is obtained as follows:

$$
R t=\sum_{j=1}^{n_{i}} a_{i j}
$$

The normalized subtotal of the result area $R t^{\text {nor }}$ is equal to:

$$
R t^{n o r}=\frac{\sum_{j=1}^{n_{i}} a_{i j}}{5 n_{i}}
$$

The evaluation of the maintenance process in the result area requires quantitative and qualitative data. The results are then financial and operational. They reflect the level of the reached organization and the technology control. To carry out the diagnostic of the result area it is necessary to inventory, for each measurable area, the pertinent and measurable criterion, which determines organization performances. The interpretation of the level " 0 " 
should be ambiguous. For example, about the customers' satisfaction item, the level 0 does not involve customers' dissatisfaction. That can say only that the enterprise does not know anything of it and that it does not have any data on this subject (Cua et al. 2001).

\begin{tabular}{cccc}
\hline$[0,0.25]$ & ] $0.25,0.5]$ & ] $0.5,0.75]$ & ] $0.75,1]$ \\
\hline Disponibility of data & $\begin{array}{c}\text { Development } \\
\text { tendency }\end{array}$ & Internal indicators & Reference indicator \\
& & \\
\hline
\end{tabular}

The exact and precise data acquisition requires good and sometimes long preparation, but consequently provides quickly answers to the questions asked in the following phases.
Which tendency can deduce at the beginning from the collected data? This tendency is it positive, unchanged or negative?
Are the objectives of the enterprise achieved? The result is it better, equal or less good than the objective?
How are the enterprise services located in comparison with other competitors?

Table 2. Measurement scale of the «Results» area.

\subsubsection{Structure of the "enablers' and result" areas}

The competition of the maintenance process in its environment is identified by $G T^{\text {nor }}$ indicator, which is expressed as follows:

$$
G T^{n o r}=\sum_{i=1}^{10} \frac{\sum_{j=1}^{n_{i}} a_{i j}}{50 n_{i j}}
$$

Related to the $G T^{\text {nor }}$ indicator analysis, two significant variations are distinguished:

- Progress variation: it results from the difference between the forecasts of the period $(t+1)$ and the achievements of the period $(t)$, or the difference between the achievements of $(t)$ and the last achievements of period $(t-1)$. This variation points out the growth degree of the system and determines its future goals.

- Professional gap: it is about the difference between the system achievements for one period and those of the competitor for the same period. This variation allows the company to position itself in front of its competitors and to measure its performances as compared to others.

\section{Six Sigma}

The traditional quality initiatives, including Statistical Quality Control (SQC), Zero Defects and Total Quality Management (TQM), have been key players for many years, whilst Six Sigma is one of the more recent quality improvement initiatives to gain popularity and 
acceptance in many industries across the globe. Its popularity has grown as the companies that have adopted Six Sigma claim that it focuses on increasing the wealth of the shareholders by improving bottom-line results and achieving high quality products/services and processes. Thus, it is claimed that the implementation of Six Sigma brings more favorable results to companies in comparison with traditional quality initiatives in terms of turning quality improvement programs into profits. Success stories of big corporations that have adopted Six Sigma, such as Motorola and General Electric (GE), have been reported in various papers (Denton, 1991; Hendricks and Kelbaugh, 1998).

Six Sigma was created to improve the performance of the key processes (Bhota and Bhota, 1991). It is a disciplined method of using extremely rigorous data gathering and statistical analysis to pinpoint sources of errors and ways of eliminating them. It focuses on using quality-engineering methods within a defined problem-solving structure to identify, eliminate process defects, solve problems as well as improve, yield, productivity and operate effectiveness in order to satisfy the customer (Wiele et al., 2006).

Many of the objectives of Six Sigma are similar to Total Quality Management (e.g. customer orientation and focus, team-based activity and problem-solving methodology). Thus, several authors suggest that Six Sigma can be integrated into the existing TQM program of the company (Revere and Black, 2003; Pfeifer et al., 2004; Yang K. 2004). Similarly, Elliott (2003) presents the initiative program of the company to combine TQM and Six Sigma and improve the production process and product quality. Yang C. (2004) proposing a coupled approach linking TQM and GE-Six Sigma and using customer loyalty and business performance as a strategic goal of the model. While others suggested integrating Six Sigma with a single quality program, Kubiak (2003) proposes an integrated approach of a multiple quality system, such as ISO 9000, Baldridge, Lean and Six Sigma for improving quality and business performance.

The Six Sigma method for completed projects includes as its phases either: Define, Measure, Analyze, Improve, and Control (DMAIC) for process improvement or Define, Measure, Analyze, Design, and Verify (DMADV) for new product and service development. Knowing that the goal of this chapter is oriented towards the progressive improvement of the maintenance process, the DMAIC approach will be considered in the rest of our development.

DMAIC is a data-driven, fact-based approach emphasizing discernment and implementation of the Voice of Costumer (VOC). It is briefly described as follows:

- $\quad$ Define the problem and customer requirements.

- Measure defect rates and document the process in its current incarnation.

- Analyze process data and determine the capability of the process.

- Improve the process and remove defect causes.

- Control process performance and ensure that defects do not recur.

The use of the DMAIC method properly can be fruitful to any manufacturing system:

- DMAIC shows how to align the organization through customer-focused measures of performance. 
- $\quad$ DMAIC projects are specifically designed to involve all stakeholders.

- A successful organization is one which first puts its customers on its list of priority. If the customer is fully satisfied, then, any organization the world over wins and thus "never goes bust".

- Successful DMAIC projects recognize that people and processes are connected in an interdependent system. They achieve significant breakthroughs by striving for measurable stretch goals which span the end-to-end system.

- DMAIC project teams focus their energy on collecting and analyzing data, to slice through opinions and arguments and win collaborative understanding.

\section{Quality function deployment}

In planning a new maintenance process, engineers have always examined the process and performance history of the current system. They look at field test data, comparing their organization to that of their competitor's field. They examine any customer satisfaction information that might happen to be available (Tapke et al., 1998). Unfortunately, much of this information is often incomplete. It is frequently examined as individual data, without comparison to other data that may support or contradict it. By contrast, Quality Function Deployment (QFD) uses a matrix format to capture a number of issues that are vital to the planning process. It has been first developed in Japan in 1966 by Yoji Akao (1990). It is a method for structured product planning and development that enables a development team to specify clearly the customer desires and needs (Revelle et al. 1997).

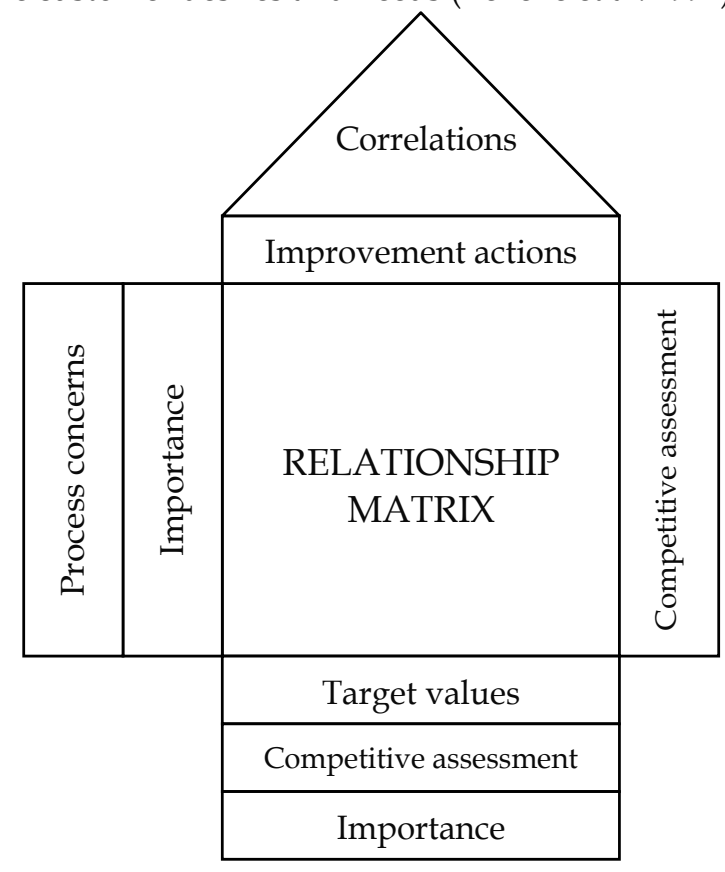

Fig. 3. House of quality for manufacturing process 
The deployment of the quality functions contributes to the improvement of the process and facilitates the planning of the system design in agreement with the positioning of the company in its competing environment. The crucial importance of QFD is considered in the process of communication that it generates as well as in the decision-making. The QFD process involves constructing one or more matrices. The first one is called the House of Quality (HoQ). This consists of several sections or sub-matrices joined together in various ways, each of which containing information related to the others. There are nearly as many forms of the HoQ as there have been applications and it is this adaptability to the needs of a particular project or user group, which is one of its strengths.

\subsection{Process concerns}

The initial steps in forming the House of Quality include determining, clarifying, and specifying the customers' needs. These steps lay the foundation for a clearly defined venture and will prepares the enterprise to implement the maintenance excellence

\subsection{Improvement actions}

The next step of the QFD process is identifying what the enterprise wants (Maintenance Excellence) and what must be achieved to satisfy these wants (Maintenance Excellence Criteria). In addition, regulatory standards and requirements dictated by management must be identified. Once all requirements are identified it is important to answer what must be done to the process to fulfill the necessary requirements.

\subsection{Competitive assessment}

The next step in the QFD process is forming a planning matrix. The main purpose of the planning matrix is to compare how well the team met the customer requirements compared to its competitors. The planning matrix shows the weighted importance of each requirement that the team and its competitors are attempting to fulfill.

\subsection{Relationship matrix}

The main function of the interrelationship matrix is to establish a connection between the maintenance activity requirements and the performance measures designed to improve the process. The first step in constructing this matrix involves obtaining the opinions of the consumers as far as what they need and require from a specific process. These views are drawn from the planning matrix and placed on the left side of the interrelationship matrix. After setting up the basic matrix, it is necessary to assign relationships between the customer requirements and the performance measures. These relationships are portrayed by symbols indicating a strong relationship, a medium relationship, or a weak relationship. The symbols in turn are assigned respective indexes such as 9-3-1, 4-2-1, or 5-3-1. When no relationship is evident between a pair, a zero value is always assigned. The interrelationship matrix should follow the Pareto Principle keeping in mind that designing to the critical $20 \%$ will satisfy $80 \%$ of the customer desires.

The QFD matrix is used to translate the priority for improvement in the specific actions. The following relation obtains the calculation of the characteristics importance:

$$
w_{j}=\sum_{i=1}^{I} v_{i j} \cdot u_{i}
$$


where:

$$
\begin{aligned}
& \mathrm{w}_{\mathrm{j}} \text { : characteristics' weight. } \\
& \mathrm{V}_{\mathrm{ij}} \text { : correlation's coefficient between the "improving ways" and the "weaknesses". } \\
& \mathrm{u}_{\mathrm{i}} \text { : importance's weight; } \mathrm{u}_{\mathrm{i}} \in\{1,3,5,7,9\} .
\end{aligned}
$$

The result is then standardized to post a percentage:

$$
w_{j}^{n}=100 \frac{w_{j}}{\sum_{j=1}^{J} w_{j}}
$$

\subsection{Correlations}

Performance measures in existing designs often conflict with each other. The technical correlation matrix, which is more often referred to as the "Roof", is used to aid in developing relationships between maintenance activity requirements and process requirements and identifies where these units must work together otherwise they will be in a design conflict. The four symbols (Strong Positive, Positive, Negative and Strong Negative) are used to represent what type of impact each requirement has on the other. They are then entered into the cells where a correlation has been identified. The objective is to highlight any requirements that might be in conflict with each other.

Any cell identified with a high correlation is a strong signal to the team, and especially to the engineers, that significant communication and coordination are a must if any changes are going to be made. If there is a negative or strongly negative impact between requirements, the design must be compromised unless the negative impact can be designed out. Some conflicts can't be resolved because they are an issue of physics. Others can be design-related, which leaves it up to the team to decide how to resolve them. Negative impacts can also represent constraints, which may be bi-directional. As a result, improving one of them may actually cause a negative impact to the other. Sometimes an identified change impairs so many others that it is just simply better to leave it alone. According to Step-By-Step QFD by John Terninko (1997), asking the following question when working with this part of the House of Quality helps to clarify the relationships among requirements: "If technical requirement $X$ is improved, will it help or hinder technical requirement $Z$ ?"

\section{The progressive improvement model}

With proper interaction among ME, DMAIC and QFD (Lazreg and Gien, 2009), the manufacturing system-wide involvement and its capability of improvement and innovation can be reached. The goal is to have disciplined control of the process such as the potential defects are avoided when they do occur: the cause is immediately addressed and eradicated. Our approach is not only to correct the existing process, but also to extend it and redesign the manufacturing system.

In the process of progressive improvement, as shown in (Figure 2), the focus is trained on the identification of the Maintenance Excellence Criteria, technical improvements, elementary actions, implementation of targeted solutions and monitoring plan. In this perspective, DMAIC is applied as follows: 


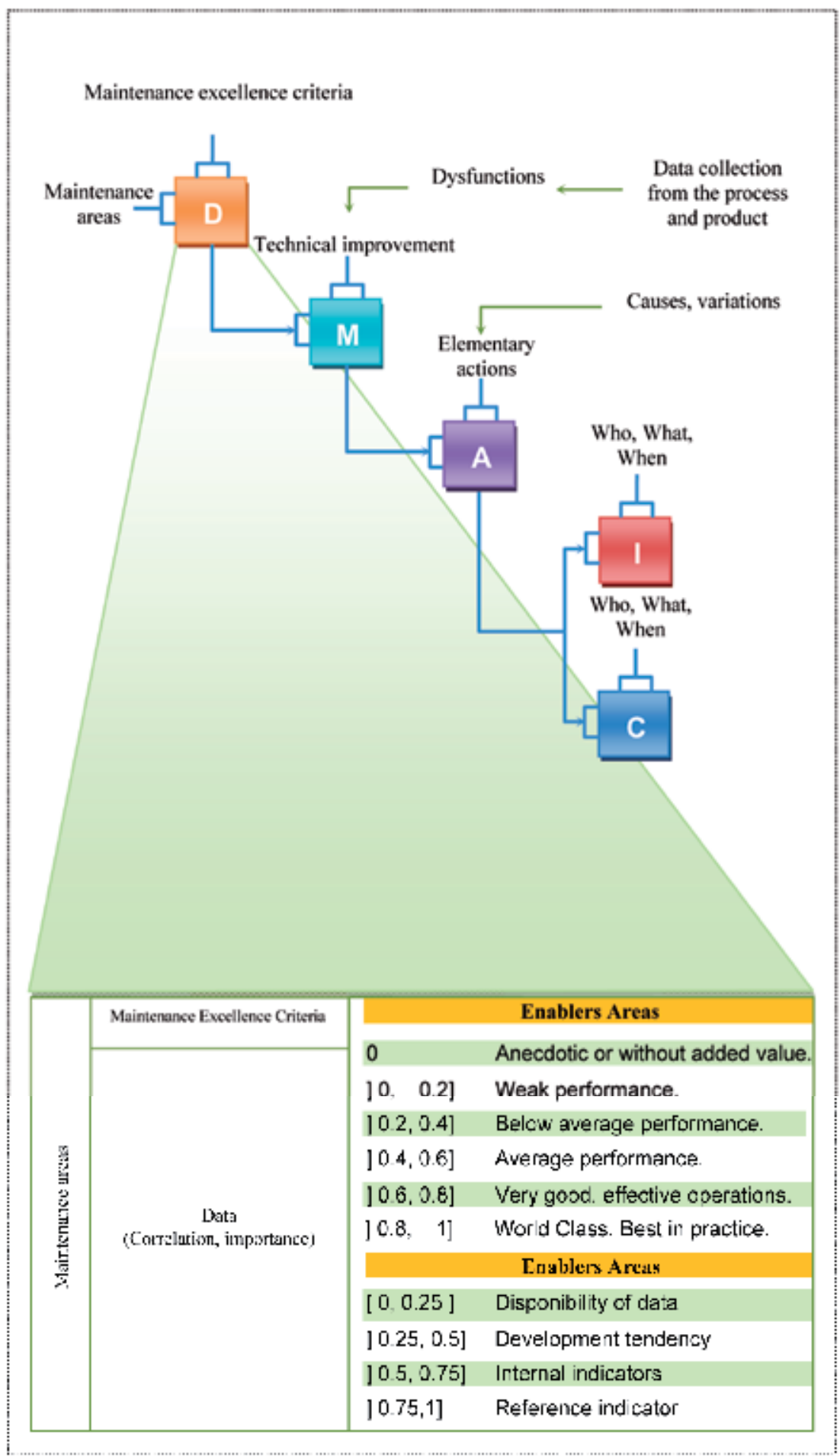

Fig. 4. Integrated model for progressive improvement in maintenance 


\subsection{Define}

The first step in the DMAIC improvement cycle is the 'Define' phase, which helps the user to answer four critical questions (Pande et al. 2000) such as:

- What is the actual problem to focus on?

- What is the goal for the project?

- Who is the customer to this process and what are the effects of the problem for the customer?

- What is the investigated process?

The ' $\mathrm{D}$ ' matrix is the initial stage of starting the improvement project. It includes the needs and concerns of a group of enterprises. They are expressed by several criteria, which describe the enterprise goals, rather than generic expressions of the future of the organization. In this stage, the needs of internal functioning are identified by all that is necessary and indispensable to reach the required performances. The identification of the MEC began with focused group of small and medium enterprises. The interviews and discussions involve their needs and expectations with priority ratings.

\subsection{Measure}

This phase is applied when recording the existing maintenance process and determining the processes relevant for maintenance. As a phase to examine the current state of the process, it precisely pinpoints the area causing problems; hence, using it as a basis of problem-solving. All possible and potential dysfunctions should be identified in this step. Workers-direct executives in manufacture and workers in maintenance, with their practical experience, may contribute to identify dysfunctions, as they are directly faced with concrete problems in their field of work in daily activities.

This second matrix ' $\mathrm{M}$ ', which captures the MEC is described as 'the Voice of the Customer' in matrix rows and aligns these to the technical improvement in matrix columns. The "relationship matrix" section of the ' $\mathrm{M}^{\prime}$ matrix measures the strength and relationships between the MEC and the technical improvement that can impede the maintenance system. These technical improvements include both quantitative (defects, failure, cost, time, etc.) and qualitative items (resistance to change, engagement of the leader, etc.). In fact, measurements of several factors, data collection and the identification of the dysfunctions which are coming from the measurement of the process, converted into quality characteristics and added to the initial technical improvement which had been already established during the definition of the expressed needs.

Moreover, the measurement in the process includes not only gathering information from the process, but also analysis of the existing information about the technical system, starting from its delivery, implementation and putting into operation, to moment of establishing a reliable way of measuring parameters and performances of the process.

\subsection{Analyze}

The purpose of analyzing the process of maintenance is to determine what is not good in the process, what are the causes of its inefficiency, as well as to propose the elementary actions. In fact, there are two key sources of input to be able to determine the true cause of a 
problem: data analysis and process analysis. The combination of these two techniques produces the real power of our integrated model.

However, using the outputs of the ' $\mathrm{M}^{\prime}$ matrix, which link MEC and technical improvement, the subsequent matrix ' $\mathrm{A}$ ' deploys the elementary actions and determines the priority of each one.

The determination of the elementary actions needs a step for analyzing why, when and where the defect occurs. The objective of this step is to describe the defects statistically and to minimize various aspects of the causes in the process. When the selection process is made to detect major causes of the dysfunctions, the scientific verification process of the causes as well as gap analysis in which the discrepancy of the target value and the actual goal achieved are then conducted. Major elements to be performed in the analysis step are as follows:

- Development should be statistically and precisely defined in terms of the mean, standard deviation or regularity;

- The gap between the goal and actual state in reality should be clearly defined based on minimizing variance and moving average;

- Comprehensive list of the potential causes of the problems should be produced;

- Statistical analysis should be made to reduce the listed items for potential causes, into a few key factors;

- Basis on such analysis, objective prediction of the financial performance and reexamination should be made;

- Elementary actions should be made for the final step of improve.

\subsection{Improve}

It is a step to improve a few key factors confirmed in the previous analysis process and pursue a method to improve real problems to be ultimately resolved. It is also a phase to explore the solution such as how to change, fix or modify the process. If the result is unsatisfactory, additional improvement plans should be carried out.

The connection of this phase to the 'I' matrix drives the improvement process in the selection of the potential action, cost-effective solution and then workable and executable action.

Here, it is recommended that the organization makes a conscious effort to focus on a smalldefined set of improvement priorities that align with the organization's broad business goals and objectives, and that should, therefore, be actually deliverable.

Once the technical plan is established, attention is then directed towards the planning of the actions, cost's re-examination, the definition of the plan timetable and the deployed resources. All these items are undertaken in the implementation matrix in order to ensure the execution of the project reorganization, which includes the assignment of the tasks. Furthermore, the development of an implementation plan is an important part of any goalsetting or problem-solving. Process, activity and task are the sub-categories used to describe in detail the content of the implemented plan. The economic report is a sub-category of the implement plan outcome referring to its quantitative economic evaluation. It can be considered to introduce the economic view in the framework of enterprise architectures. 
Implementation plan is the mean by which the future is planned. It converts a goal or a solution into a step-by-step statement of 'who is to do what and when'. One benefit of this analysis would be revealing where additional resources might be needed and to point out where they can be available.

One of the most frequent reasons cited for failure of all types of change programs is the lack of communication and understanding between (a) the person who will be impacted by the changes and (b) the group involved in creating the new process and associated changes. By introducing our intermediate process, the risks of failure is reduced because there is a greater and continuing focus on the needs of the customers of the process being reengineered.

\subsection{Control}

The purpose of this phase is to ensure that the voice of the maintenance function captured in earlier stages has been correctly translated into the organization. Moreover, the control phase ensures the confirmation of introduced improvements. It involves participation of all employees of the company, starting from top-managers, through teams of improvement, to the workers-operators and maintainers, who are in charge of activities according to the excellence-concept.

In this monitoring matrix (C), it is possible to deploy techniques, control methods, and monitor procedures in the realization process. Because it includes the necessary actions in each phase of the process to make sure that all the improvement actions will be under control. As far as operation is concerned, it provides the piloting means and the control methods used to control characteristics, which are likely to cause non-quality. Once established and updated, this matrix constitutes the base of the strategy of the control process and it provides the basis for the development of an effective document monitoring.

\subsection{Graphical user interface}

The Quality Function Deployment System (QFDS) is a Graphical User Interface (GUI) designed to manipulate QFD matrices in decision making environment. This GUI is developed using Visual Basic Language. The QFDSinstall.exe executable program can be installed to any PC with windows operating system platform. It is designed by respecting the different characteristics of the QFD process, which includes process concerns (WHATs), improvement actions (HOWs), correlations and relationship matrices, importance and competitive assessment and graphic representation.

The user interface consists of a graphical interface with pull-down menus, panels and dialog boxes, as well as a textual command line interface. The user interface is made up of four main components: a console, control panels, dialog boxes, and graphics windows.

The menu bar organizes the GUI menu hierarchy using a set of pull-down menus. A pulldown menu contains items that perform commonly executed actions. Figure 5 shows the QFDS menu bar. Menu items are arranged to correspond to the typical sequence of actions that the user perform in QFDS.

The graphical interface menu (Figure 5) shows five QFD matrices, which are created for this project. The active QFD-matrix is identified by its red color (QFD2). In this case, the user can manipulate the different characteristics of this matrix. 


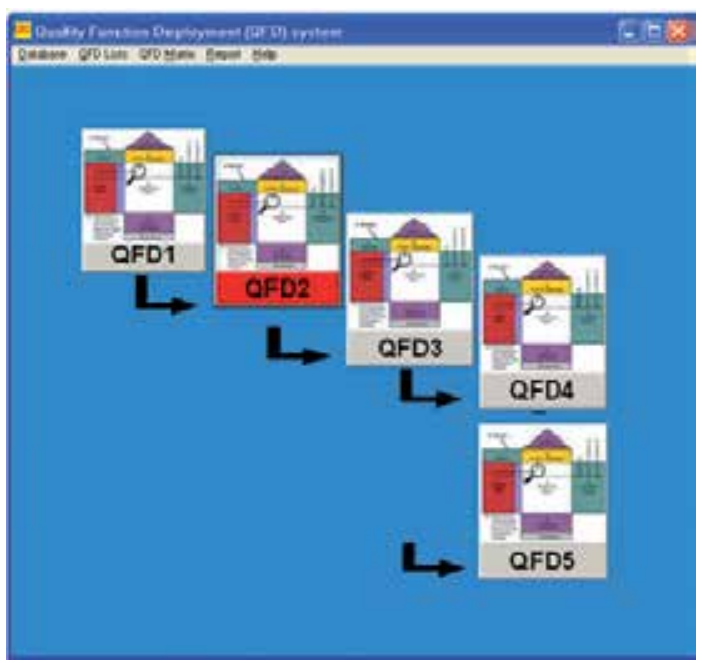

Fig. 5. DMAIC matrices

As shown in the Figure 6, the window shows how the user can edit the relation values in the crossed cells. Each value represents the correlation between 'Whats' and 'Hows'.

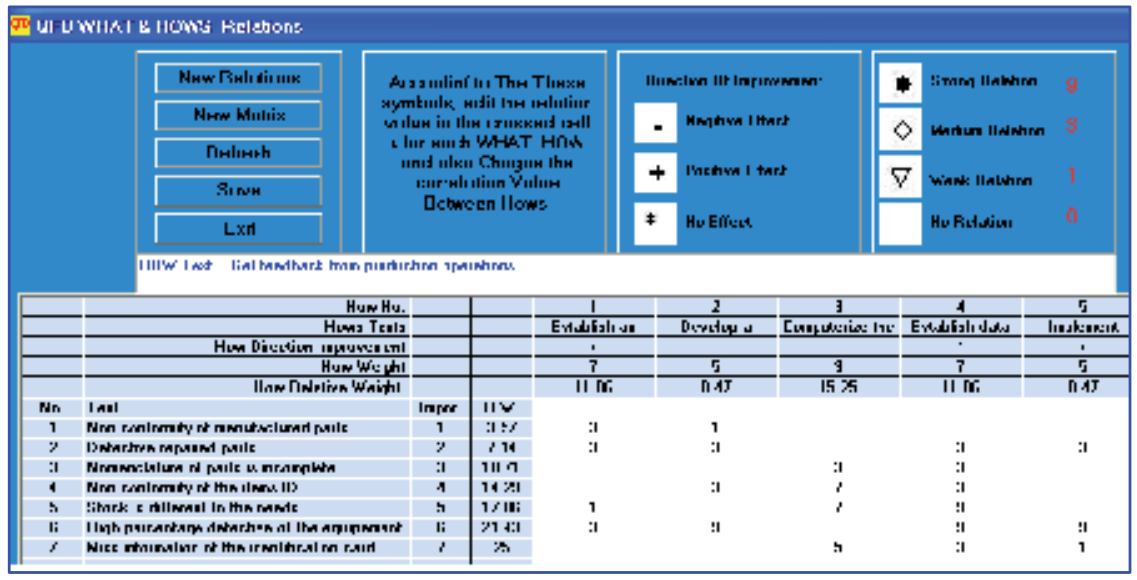

Fig. 6. Relationship matrix

\section{Case study}

\subsection{Presentation}

The "Sotim" is a medium-sized enterprise of the production of mechanical parts. The workshop is composed of a thermal treatment unit, a manufacturing unit and a laboratory of metrology. The production operation includes: forming shop, tool room and a fully equipped product test-room. There are two assembly cells: semi-automated and manuallyoperated cell. An integrated computer system is used to monitor production planning and scheduling. Currently the "Sotim" employs around 43 people.

Current maintenance in this company is based on traditional practices and is reactive, i.e., breakdown. It is a practice that is inherently wasteful and ineffective with disadvantages 
such as: unscheduled downtime of machinery, possibility of secondary damage, no warning of failure with possible safety risks, production loss or delay, and the need for standby machinery where necessary.

\subsection{Findings and limitations}

- According to the results of the (D) matrix, the evaluation of the "Equipments" function, reaches $22 \%$. Although this value represents the operation on the basis of simple procedure with functioning equipment, it does not hide in any case the technician ability and the existence of several procedures.

- The "spare parts" $\left(\mathrm{A}_{4}=0.7\right)$ function, as shown in Figure 7, is higher than the competitors $\left(\mathrm{y}_{\text {sotim }}\left(\mathrm{A}_{4}\right)>\mathrm{y}_{\mathrm{i}}\left(\mathrm{A}_{4}\right)>\mathrm{y}_{\mathrm{k}}\left(\mathrm{A}_{4}\right)\right)$.

- $\quad$ The "Result" area shows certain positive tendencies and satisfactory performances.

- As well as its benefits defined so far, the QFD methodology has some limitations for practical implementations. Another point is the application process itself. The process is lengthy requiring a great deal of time, resource and effort to perform. The size of the operational and especially, technical matrices vary according to the importance of the functional activity of the enterprise.

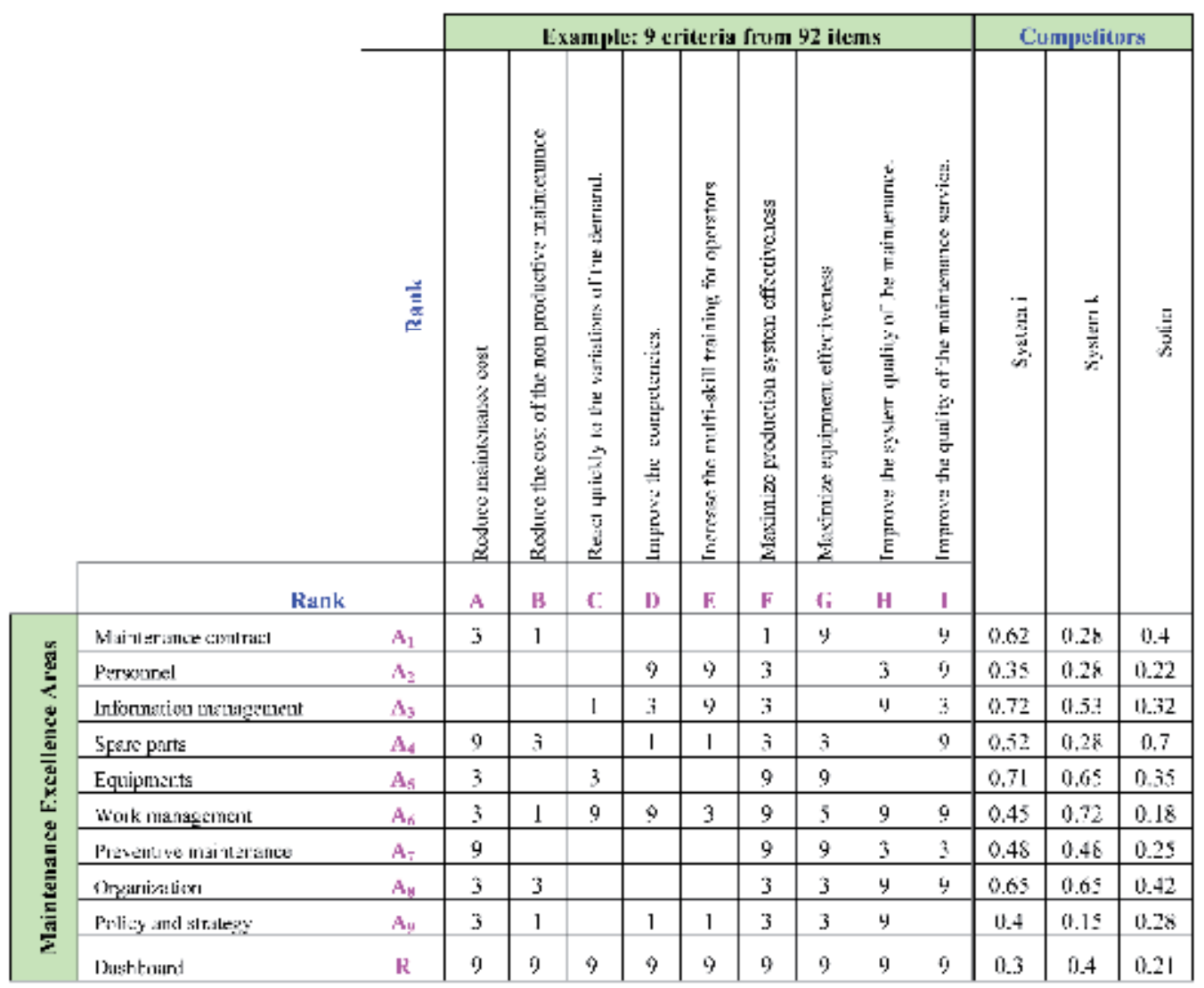

Fig. 7. Define matrix 


\begin{tabular}{|c|c|c|c|c|c|c|c|c|c|}
\hline & 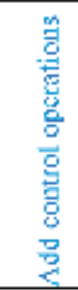 & 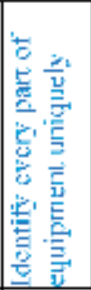 & 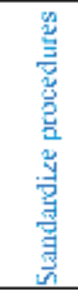 & 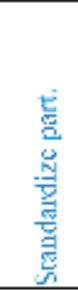 & 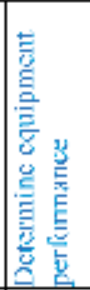 & 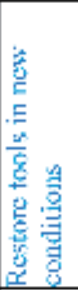 & 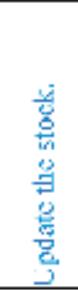 & 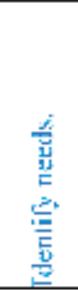 & 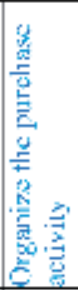 \\
\hline Storeroom not sccurcd & 1 & & & & & & & 1 & \\
\hline $\begin{array}{l}\text { Lnsuitable spare parts area } \\
\text { layout }\end{array}$ & & 1 & & & & & 1 & & \\
\hline $\begin{array}{l}\text { Difference between inwentory } \\
\text { and exisling }\end{array}$ & 1 & 1 & 1 & & & & 9 & & \\
\hline $\begin{array}{l}\text { Inventory is not still available } \\
\text { wher meded }\end{array}$ & 1 & & 1 & & & & 1 & & 1 \\
\hline $\begin{array}{l}\text { Miss information in index } \\
\text { curdsi }\end{array}$ & 1 & 1 & 1 & & 1 & & & & \\
\hline Incomplete nomenclarure & 1 & 9 & & 9 & & & & & \\
\hline Incomplete catalog & 1 & 3 & & & 3 & & & & 1 \\
\hline Parts in stock since few years & 1 & 1 & & & 9 & & & & 1 \\
\hline Nun functional equipment. & 1 & & 1 & & 3 & 9 & & 3 & 3 \\
\hline Relatire weight & 8.19 & 13.6 & 5.94 & 7.22 & 13.3 & 13 & 10.3 & 5.62 & 17.2 \\
\hline Rank & 6 & 2 & 8 & 7 & 3 & 4 & 5 & 9 & 1 \\
\hline
\end{tabular}

Fig. 8. Measure matrix (Qualitative data)

\begin{tabular}{|c|c|c|c|c|c|c|c|c|c|}
\hline & 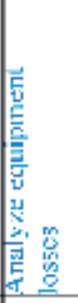 & 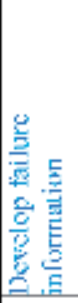 & 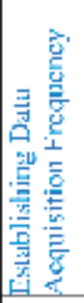 & 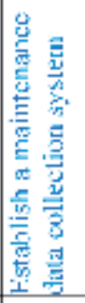 & 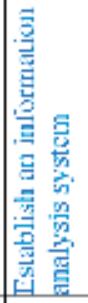 & 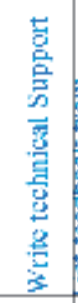 & 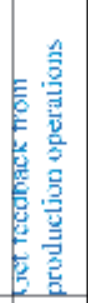 & 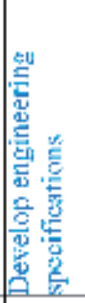 & 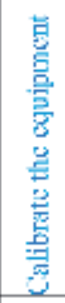 \\
\hline Add control operations & 9 & 3 & 3 & 3 & 3 & 1 & 1 & & 1 \\
\hline $\begin{array}{l}\text { Tdentify every part of } \\
\text { cquipment uniqucly }\end{array}$ & 1 & 1 & 1 & 1 & 1 & y & 1 & 9) & \\
\hline Standardize procedures. & 1 & 1 & & 1 & 1 & 9 & 1 & 9 & \\
\hline Standardize part. & 9 & 9 & 1 & 1 & 1 & 1 & 1 & 9 & \\
\hline $\begin{array}{l}\text { Determine apujpment } \\
\text { perlormance }\end{array}$ & 9 & 9 & 1 & 1 & 3 & 1 & 9 & 1 & 1 \\
\hline Update the stock. & 9 & 3 & & 3 & 3 & & 9 & 1 & 1 \\
\hline $\begin{array}{l}\text { Restore tools in new } \\
\text { conditions }\end{array}$ & 3 & & & & & 1 & & & \\
\hline Identify neses. & $y$ & & 3 & $y$ & 1 & & 9 & 1 & \\
\hline $\begin{array}{l}\text { Organize the purchase } \\
\text { activity }\end{array}$ & & & & 1 & & & 9 & 3 & \\
\hline Relative weighı & 20 & 9 & 4.8 & 11 & 6.6 & 2.1 & 31 & 4.8 & 11 \\
\hline Kank & 2 & 5 & 7 & 4 & 6 & 9 & 1 & 7 & 3 \\
\hline
\end{tabular}

Fig. 9. Improve matrix (Qualitative data) 


\section{Conclusions and future development}

This work focuses on developing a method of progressive improvement of the small and medium manufacturing systems. The main objectives of this chapter consist in providing a methodology and a practical support to help these systems to satisfy their needs for progress by appropriate improvement actions. The goal is the Maintenance Excellence in the enterprises, which is characterized by the satisfaction of all the external and internal users. The customer is obviously considered but the enterprise staff and workers are also included in the need definition process.

In this perspective, the "MEM-DMAIC-QFD" model is developed for determining the improvement priorities of the small and medium enterprises. This model uses QFD to apply a contingency-oriented approach to improvement priorities. It allows the maintenance activity to coordinate change in processes.

By integrating processes, methods and a technique such as Maintenance Excellence, DMAIC, Quality Function Deployment, this study provides a practical approach and useful model for manufacturing systems looking to drive balanced execution.

Moreover, the "MEM-DMAIC-QFD" model integrates the elements of management culture and quality techniques that are critical to drive performance improvement and business excellence.

This new tool solves the paradox that manufacturing systems find themselves in our present-time society able to simultaneously achieve short-term financial gains through fast business improvement projects. Moreover, it integrates the elements of management culture and quality technique that are critical to driving performance improvement and business excellence.

The subjective assignment of the relationships and weights in the matrices is another important limitation of the QFD methodology. The vagueness and the imprecision in the subjective inputs reduce the reliability of the decisions quite considerably. Therefore systems that take into account these factors should be imposed to the conventional QFD calculations. Quantitative methods such as Fuzzy sets and Grey method can be combined together with the model to improve the reliability of the decisions. In this perspective, the characteristic of the alternative with respect to the criteria can be represented in terms of a linguistic term set, and the weight of the criteria can be described by triangular fuzzy numbers, respectively.

According to the Grey and Fuzzy set theories, a closeness coefficient can be defined to determine the ranking order of all alternatives by calculating the grade of grey relation to the fuzzy positive-ideal solution and fuzzy negative-ideal solution simultaneously.

\section{Acknowledgments}

This research is supported by the Research Deanship of the Qassim University (Grant 2009). We thank the Research Deanship for her cooperation. We are especially grateful to Pr. Denis Gien (Laboratoire LIMOS, Université Blaise Pascal, Institut Français de Mécanique Avancé. Aubière, France) for his valuable comments. 


\section{References}

Afnor, (1988), French Standard Agency, E 60 182, Recueil des normes française.

Akao, Y., (1990) 'Quality function deployment: integrating customer requirements into product design'. Cambridge, UK, Productivity Press. 369 p.

Bhota, K.R. and Bhota, A.K., (1991), 'World-class quality: using design of experiments to make it happen', 2nd edition, New York: America Management Association.

Conti, T. (1997) 'Organisational Self-Assessment', London: Chapman and Hall.

Cua, K. O, McKone, K. E., Schroeder, R. G., (2001), “Relationships between implementation of TQM, JIT, and TPM and manufacturing performance", Journal of Operations Management, 19 (6) pp. 675-694.

Denton, D. K. (1991), 'Lessons on Competitiveness: Motorola's Approach', Production and Inventory Management Journal, Vol.32, No.3, pp.22-25.

Edgeman, R.L., Dahlgaard, S.M.P., Dahlgaard, J.J., and Scherer, F., (1999) 'Leadership, Business Excellence Models and Core Value Deployment', Quality Progress, Vol. 32, No. 10, Pp. 49-54.

Edgeman, R.L., Bigio, D.I., Ferleman, T.E. (2005) ‘Six sigma and business excellence: strategic and tactical examination of IT service level management at the office of the chief technology officer of Washington, DC'; Quality $\mathcal{E}$ Reliability Engineering International, Volume 21, No.3, pp. 257-273.

Elliott, M., (2003) 'Opening up to efficiency', Industrial Engineer: IE, Vol.35, No.7, pp.28-33.

Ghobadian, A., Gallear, D. N., (1996) "Total Quality Management in SME", Omega, 24(1), pp. 83-106.

Hendricks, C. A., and Kelbaugh, R. L. (1998), 'Implementing six Sigma at GE', The Journal for Quality and Participation, Vol.21, No.4, pp.48-53. Hwang C.L., Yoon K.,(1981), Multiple Attribute Decision Making, Springer-Verlag, Berlin.

Kubiak, T., (2003) 'An integrated approach system', Quality Progress, Vol.36, No.7, pp.41-45.

Lazreg, M., and Gien, D., (2007) 'A hybrid decision model to evaluate various strategies of manufacturing improvement'; International Conference on Engineering Design ICED'07. Paris, France, 28-31 August, pp. 587-598.

Lazreg, M., and Gien, D., (2009) 'Integrating Six Sigma and maintenance excellence with QFD', Int. J. Productivity and Quality Management, Vol. 4, No. 5-6, pp.676 - 690.

Name, (2007) available at: http:/ / www.nameaward.com/ (Accessed October 20, 2007).

Pande, S; Neuman, R.P., Cavangh, R.R. (2000) 'The six sigma way- how GE, Motorolla and other top companies are homing their performance'. New York, NY: McGraw-Hill.

Pfeifer, T., Reissiger, W., and Canales, C., (2004) 'Integrating six sigma with quality management systems', The TQM Magazine, Vol.16, No.4, pp.241-249.

Pride, (2007); available at: http://www.pride-in-maintenance.com/ (Accessed October 20, 2007)

Revelle, B.J., Moran, J.W., Cox, A.C., (1997) 'The QFD Handbook', John Wiley \& Sons, Inc. p.403.

Revere, L., and Black, K., (2003) 'Integrating six sigma with total quality management: A case example for measuring medication errors', Journal of Healthcare Management, Vol.48, No.6, pp.377-391.

Shingo, (2007) 'Prize for excellence in manufacturing' available at: www.shingoprize.org/ (Accessed October 20, 200). 
Shirose, K., Ed., (1996), “TPM-Total Productive Maintenance: New Implementation Program in Fabrication and Assembly Industries", Tokyo, Japan, Japan Institute of Plant Maintenance.

Silberman M. (2001), The consultant's Toolkit. High-Impact Questionnaires, Activities, and How-to Guides for Diagnosing and Solving Client Problems. McGraw-Hill. 0-07139498-2. pp 369.

Sirft, (2007) available at: http:/ / www.sirfrt.com.au/ (Accessed October 20, 2007).

Sonnek A., Scharitzer D., Korunka C., (2001), "Monitoring quality of organizational changes in public service organizations: the development of a survey instrument", Proceedings of the 4 èmes congrès international pluridisciplinaire: Qualité et Sûreté de Fonctionnement. Annecy, France, 22-23 march, pp 391-397.

Tapke J., Muller A., Greg J., Sieck J. (1998) Steps in House of Quality: Understanding the House of Quality, I E 361. Internal Report.

Terninko, J.; Step-by-Step QFD Customer Driven Product Design; Second Edition, St. Lucie Press, 1997.

Wiele V. D, T., Iwaarden, V. J., Dale, B.G. and Williams, R., (2006), 'A comparison of five modern improvement approaches', Int. J. Productivity and Quality Management, Vol. 1, No. 4, pp.363-378.

Yang, C.-C., (2004), 'An integrated model of TQM and GE-Six Sigma', International Journal of Six Sigma and Competitive Advantage, Vol.1, No.1, pp.97-111.

Yang, K., (2004), 'Multivariate statistical methods and six sigma', International Journal of Six Sigma and Competitive Advantage, Vol.1, No.1, pp.76-96.

Yong J., A. Wilkinson (1999). 'The state of total quality management: a review', The International Journal of Human Resource Management, Vol. 10, º 1, pp. 137-161. 


\title{
Sigma-TRIZ: Algorithm for Systematic Integration of Innovation within Six Sigma Process Improvement Methodologies
}

\author{
Stelian Brad \\ Technical University of Cluj-Napoca \\ Romania
}

\section{Introduction}

Continuous process improvement is a constant preoccupation of companies operating in strong competitive markets (Thawani, 2002; Cronemyr, 2007). The goal of process improvement projects is about increasing both efficiency and effectiveness of the business system (Brad, 2008). A widely used methodology for process improvement is Six Sigma DMAIC (Cascini et al., 2008; Hamza, 2008). Some researches reveal a strong relationship between the Six Sigma DMAIC's effectiveness and the qualification of the team involved in its application (Jean-Ming \& Jia-Chi, 2004; Treichler et al., 2002). Therefore, top experts are usually hired by potent companies to supervise Six Sigma DMAIC implementation and to generate solutions for process improvement.

Despite the strengths of the Six Sigma DMAIC methodology, the solution generation process is a challenging issue (Smith \& Pahdke, 2005). Hence, for formulating reliable results, adequate tools are required to support this activity. Keeping the same register, when significant "noise" factors act upon business processes, creative problem solving and innovation become key approaches for achieving high levels of process maturity and capability (Khavarpour et al., 2008). A powerful tool for inventive problem solving that might be considered in this respect is TRIZ method (Altshuller, 2000).

Integration of TRIZ method within Six Sigma DMAIC methodology has been analyzed by several researchers, recent results being reported in this respect. However, there are no proposals in the current published works on how effectively to integrate TRIZ within Six Sigma DMAIC. For example, Qi et al. (2008) only highlights the positive effect of using TRIZ in connection with Six Sigma DMAIC for stimulating creativity and reducing the effort towards the formulation of mature solutions to the problem under consideration. In the same spirit, the paperwork (Zhao, 2005a) stresses the necessity to use TRIZ together with Six Sigma DMAIC for accelerating the innovation process but it lacks in proposing a detailed solution of integration. In (Zhao et al., 2005b), the use of quality planning tools like QFD in connection with TRIZ for key process identification and innovation within Six Sigma DMAIC framework is put into evidence. However, this research work does not reveal a way 
to inter-correlate TRIZ and Six Sigma DMAIC. The systematic integration of TRIZ method within the Six Sigma DMAIC methodology was first time proposed by the author of this chapter (Brad, 2008).

The algorithm is called Sigma-TRIZ. It approaches the process improvement problem from a comprehensive perspective, by creating a systematic framework of identification and prioritization of the conflicting zones within the analyzed process. Sigma-TRIZ algorithm starts from the premise that any improvement should increase both efficiency and effectiveness of the analyzed process, without affecting the balance within processes that are correlated with the one analyzed. From this position, Sigma-TRIZ algorithm allows formulation of balanced and robust improvement solutions with respect to the "noise" factors (also called "attractors") acting upon the process. In principle, Sigma-TRIZ connects the innovation vectors generated by the TRIZ framework with the improvement objectives. It does this by considering a complex set of barriers and challenges from the "universe" describing the analyzed process. It starts by prioritizing the intervention areas considering the criticality of the conflicts within the process (Brad, 2008).

In this chapter, an enhanced version of Sigma-TRIZ algorithm is introduced. Enhancements are related to the prioritization of solutions and identification of the correlations between them, as well as to the formulation of the algorithm for being easy-to-implement in a software tool. A case study showing the step-by-step application of the algorithm within Six Sigma DMAIC procedure is also illustrated. The "Conslusions" part of this chapter highlights the practical implications of Sigma-TRIZ for increasing the competitiveness of companies operating in a knowledge-based economic environment.

\section{The Sigma-TRIZ algorithm}

\subsection{Background philosophy}

From practical experience it is known that most of the business-related problems are not simple; and for solving them, consideration of several interrelated and convergent process improvement projects in relation to a given intended improvement objective is required. Under such conditions, integration of innovative problem solving tools like TRIZ should increase the effectiveness of results within the "Improve" phase of the Six Sigma DMAIC methodology.

Denoting with $\mathrm{P}=\left\{\mathrm{p}_{1}, \mathrm{p}_{2}, \mathrm{p}_{3}, \ldots, \mathrm{p}_{\mathrm{n}}\right\}$ the set of interrelated and convergent process improvement projects linked to the intended improvement objective $\mathrm{O}$, where $\mathrm{n}$ is the number of improvement projects in the set $\mathrm{P}$, the objective $\mathrm{O}$ is achieved if and only if $\mathrm{P}$ leads to a required level of process effectiveness $\mathrm{E}$ and efficiency e in a time horizon $\mathrm{T}$; time horizon imposed by the dynamics of the competitive business environment (see Fig. 1). In order to achieve this goal, trade-offs and trial-and-errors approaches (e.g. brainstorming) are not efficient means (Silverstein et al., 2005).

Moreover, to keep a sustainable evolution of performance within the considered process, E and e should be balanced along time. Denoting with $t$ the time variable, with $\mathrm{E}_{0}$ the level of process effectiveness at the initial moment $t_{0}$, with $E_{1}$ the expected level of process 
effectiveness at the moment $t_{1}$, with $e_{0}$ the level of process efficiency at the initial moment $t_{0}$, with $e_{1}$ the expected level of process efficiency at the moment $t_{1}$, and with $T$ the difference $t_{1}-t_{0}$, the generic correlation between $E$ and e is described by relationship (1), where the function $\mathrm{f}$ depends on the adopted innovation strategy (e.g. upsizing, downsizing).
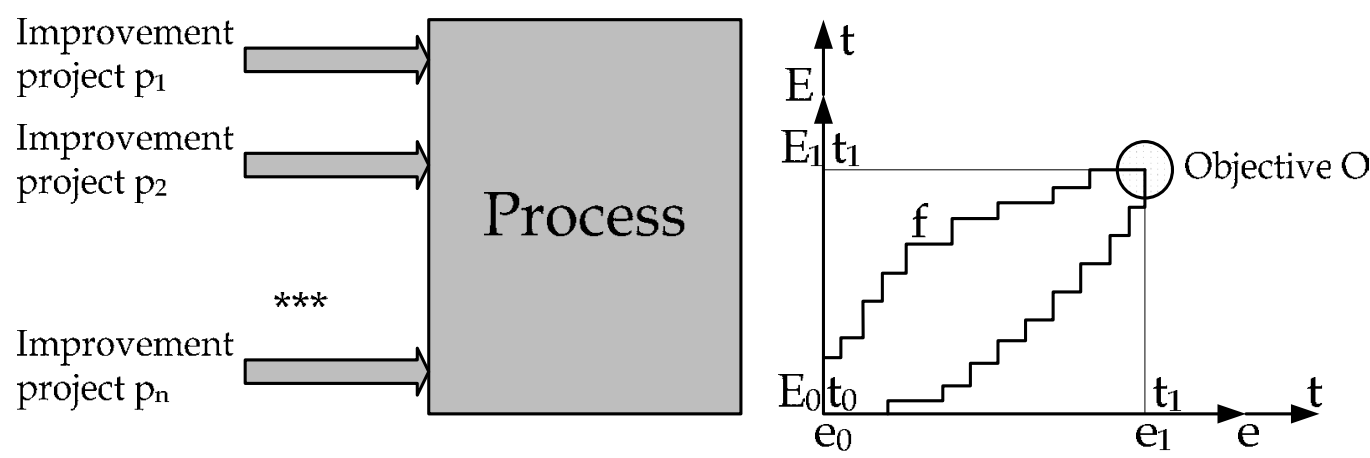

Fig. 1. Competitive approach in process improvement

$$
E(t) \mid \begin{aligned}
& E_{1} \\
& E_{0}
\end{aligned}=f\left(t\left|t_{1}, e(t)\right| \begin{array}{l}
e_{1} \\
e_{0}
\end{array}\right) .
$$

In order to follow a competitive process improvement path, the focus within all improvement projects $\mathrm{p}_{1}, \mathrm{p}_{2}, \ldots, \mathrm{p}_{\mathrm{n}}$ should constantly be on two key paradigms: (a) the ideality paradigm (Altshuller, 2000); (b) the convergence paradigm (Silverstein et al., 2005). The ideal final result (IFR) is the ratio between the sum of all useful functions and effects and the sum of all harmful functions and effects (including the related costs) (Altshuller, 2000). The convergence paradigm focuses on reducing the difficulty of problem resolution (Silverstein et al., 2005). In this respect, the convergence paradigm operates with the ratio between the total number of possible variants and the total number of possible steps that lead to mature solutions (which solve the problem without compromises).

Denoting with I the ideality, with $\Sigma \mathrm{F}_{\mathrm{U}}$ the sum of useful functions and effects, with $\Sigma \mathrm{F}_{\mathrm{H}}$ the sum of harmful functions and effects, and with $\Sigma \mathrm{C}$ the sum of costs because of poorperformances (losses), the mathematical formulation of the law of ideality is (Altshuller, 2000):

$$
\mathrm{I}=\frac{\sum \mathrm{F}_{\mathrm{U}}}{\sum\left(\mathrm{F}_{\mathrm{H}}+\mathrm{C}\right)} .
$$

According to relationship (2), the goal is having as low as possible harmful functions, effects and costs, and as much as possible useful functions and effects. Thus, in theory, when ideality is achieved, the result is: $\mathrm{I} \rightarrow \infty$. In real systems this cannot happen, but the practical target is to move as close as possible towards the ideal result - this target is known in the literature as "local ideality" (Altshuller, 2000).

Symbolizing with $\mathrm{D}$ the difficulty in problem resolution, with TE the number of trial and 
error iterations of variants, and with ST the number of steps leading to acceptable solutions, the mathematical formulation of the law of convergence is visualized in relationship (3). Obviously, the goal is having $\mathrm{D} \rightarrow 1$.

$$
\mathrm{D}=\frac{\mathrm{TE}}{\mathrm{ST}}
$$

TRIZ is a powerful tool towards deployment into practice of the laws described in (2) and (3). Therefore, by systematic integration of TRIZ within Six Sigma DMAIC it is expected to formulate highly mature process improvement projects during the "Improve" phase of DMAIC. An effective way for systematically integrating TRIZ within Six Sigma DMAIC is proposed by Sigma-TRIZ algorithm, which is further described into detail.

\subsection{Step-by-step Sigma-TRIZ algorithm}

Sigma-TRIZ algorithm consists of twelve steps, schematically presented in Fig. 2. The detailed description of these steps covers the next paragraphs of this section.

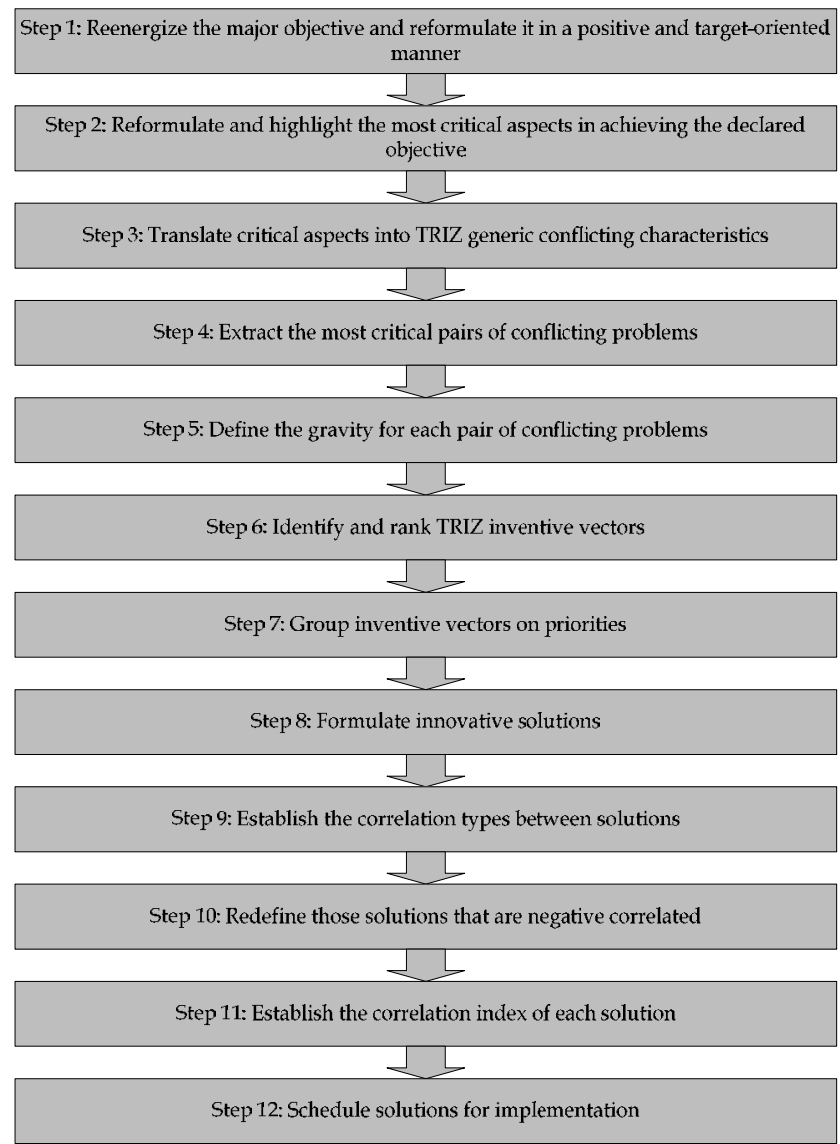

Fig. 2. The main steps of Sigma-TRIZ 
Step 1: Reenergize the major objective and reformulate it in a positive and target-oriented manner: The improvement objective $\mathrm{O}$ is very often expressed by the target group in a negative and/or vague and/or too large manner. Thus, a clear statement of the improvement objective is firstly required. The result is a re-phrased objective $\mathrm{O}_{\mathrm{p}}$. For example, considering a software development company, a possible improvement objective O would be: reduction of the number of "bugs" for the work delivered to the customer. The reformulated objective $\mathrm{O}_{p}$ would be: no "bug" in the software application when it is delivered to the customer. This reformulation includes the intended target: "zero bugs".

Step 2: Reformulate and highlight the most critical aspects in achieving the declared objective: The set $\mathrm{B}$ of significant barriers in achieving the objective $\mathrm{O}_{\mathrm{p}}$ is identified. The set $B$ is represented as:

$$
B=\left\{b_{1}, b_{2}, \ldots, b_{k}\right\},
$$

where: $b_{j}, j=1, \ldots, k$, are the process-related barriers ( $k$ is the number of barriers).

Step 3: Problem translation into TRIZ generic conflicting characteristics: For each barrier $b_{j}$, $\mathrm{j}=1, \ldots, \mathrm{k}$, a set of TRIZ-generic parameters that require improvements (maximized or minimized) should be determined. For details about TRIZ-generic parameters reader is advised to consult the reference (Altshuller, 2000). Thus, each barrier $b_{j}, j=1, \ldots, k$, has a corresponding set of generic improvement requests $G R\left(b_{j}\right)_{i}, i=1, \ldots, h\left(b_{j}\right), j=1, \ldots, k$, where $h\left(b_{j}\right)$ is the number of generic improvement requests associated to the barrier $b_{j}, j=1, \ldots, k$. For each generic parameter $G R\left(b_{j}\right)_{i}, i=1, \ldots, h\left(b_{j}\right), j=1, \ldots, k$, a set of generic conflicting parameters should be further determined. They are extracted from the same table of TRIZ parameters (see (Altshuller, 2000)). At the end, a number of $\mathrm{k}$ sets of generic conflicting parameters are determined. These sets are denoted with: $\mathrm{GC}\left(\mathrm{GR}\left(\mathrm{b}_{\mathrm{j}}\right)_{\mathrm{i}}\right)_{\mathrm{f}}, \mathrm{f}=1, \ldots, \mathrm{g}\left(\mathrm{GR}\left(\mathrm{b}_{\mathrm{j}}\right)_{\mathrm{i}}\right)_{1}$, $\mathrm{i}=1, \ldots, \mathrm{h}\left(\mathrm{b}_{\mathrm{j}}\right), \mathrm{j}=1, \ldots, \mathrm{k}$, where $\mathrm{g}\left(\mathrm{GR}\left(\mathrm{b}_{\mathrm{j}}\right)_{\mathrm{i}}\right)$ is the number of generic conflicting parameters associated to the generic improvement request $G R\left(b_{j}\right) i_{i} i=1, \ldots, h\left(b_{j}\right), j=1, \ldots, k$.

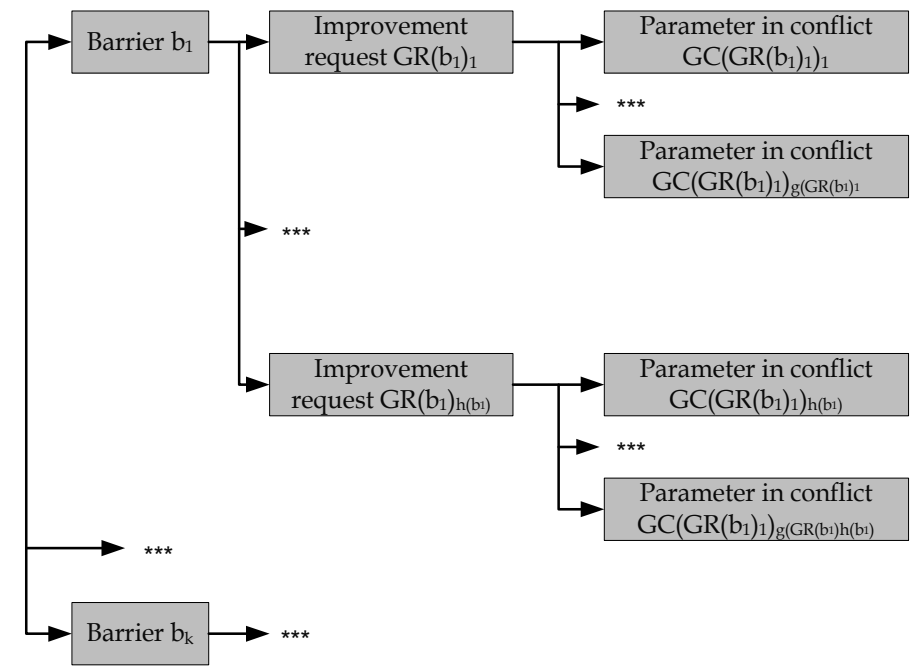

Fig. 3. Step 3 of Sigma-TRIZ 
For example, assuming that in a given process one of the barriers identified is: $b_{x}=$ "Lack of proper infrastructure (there is no stated system for assuring a good coordination between departments)", the TRIZ-generic parameters (see Appendix) requiring improvement in relation with this barrier are: $\mathrm{GR}_{\mathrm{x}, 1}=$ "Energy spent by moving object" (meaning: reduction of human effort in transferring information; optimization trend: minimization); $\mathrm{GR}_{\mathrm{x}, 2}=$ "Loss of information" (meaning: avoid loss of information because of lack of communication; optimization trend: minimization); $\mathrm{GR}_{\mathrm{x}, 3}=$ "Convenience of use" (meaning: reduction of time required to transfer information; optimization trend: minimization).

In the attempt to improve the system with respect to the requests $\mathrm{GR}_{x, 1}, \mathrm{GR}_{\mathrm{x}, 2}$ and $\mathrm{GR}_{\mathrm{x}, 3}$, some other performances of the system might be affected. Thus, in relation with $\mathrm{GR}_{\mathrm{x}, 1}$ the following TRIZ-conflicting parameters are determined: $\mathrm{GC}\left(\mathrm{GR}_{\mathrm{x}, 1}\right)_{1}=$ "Amount of substance" (meaning: money and effort spent to set up a software information system). In relation with $\mathrm{GR}_{\mathrm{x}, 2}$, the following TRIZ-conflicting parameters are determined: $\mathrm{GC}\left(\mathrm{GR}_{\mathrm{x}, 2)_{1}=}\right.$ "Tension/Pressure"(meaning: increased pressure on people for respecting rules and procedures); GC(GR, $\left(\mathrm{GR}_{\mathrm{x}, 2}\right)_{2}=$ "Harmful side effects" (meaning: possibility of system

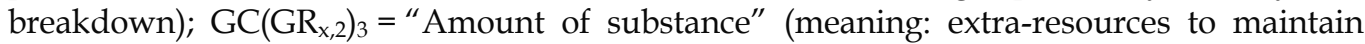
and enhance the information system". In relation with $\mathrm{GR}_{\mathrm{x}, 3}$, the following TRIZ-conflicting parameters are determined: $\mathrm{GC}\left(\mathrm{GR}_{\mathrm{x}, 3}\right)_{1}=$ "Energy spent by moving objects" (meaning: effort required by all people in the company learning how to use the information system).

Step 4: Extract the most critical pairs of conflicting problems: From the pairs of conflicting problems formulated at step 3, the most critical ones are extracted for further transformations. In some cases it might be possible to keep all pairs of conflicting problems. Thus, in the most general case, the result is a set of pairs of conflicting problems like this:

- $\quad \mathrm{PR}_{1,1}=\left\{\mathrm{GR}\left(\mathrm{b}_{1}\right)_{1}\right.$ versus $\left.\mathrm{GC}\left(\mathrm{GR}\left(\mathrm{b}_{1}\right)_{1}\right)_{1}\right\} ;$

- $\quad \mathrm{PR}_{1,2}=\left\{\mathrm{GR}\left(\mathrm{b}_{1}\right)_{1}\right.$ versus $\left.\mathrm{GC}\left(\mathrm{GR}\left(\mathrm{b}_{1}\right)_{1}\right)_{2}\right\}$;

- $\quad$...;

- $\quad \mathrm{PR}_{1, \mathrm{~g}(\mathrm{GR}(\mathrm{b}) \mathrm{i})}=\left\{\mathrm{GR}\left(\mathrm{b}_{1}\right)_{1}\right.$ versus $\left.\mathrm{GC}\left(\mathrm{GR}\left(\mathrm{b}_{1}\right)_{1}\right)_{\mathrm{g}(\mathrm{GR}(\mathrm{b} j \mathrm{j}) \mathrm{i})}\right\}$

- $\quad$..;

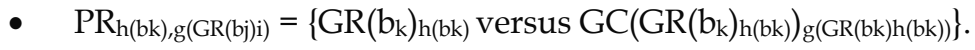

In order to simplify the mathematical representation of the pairs of conflicting problems, from this point ahead the set is denoted $P R=\left\{P_{1}, P R_{2}, \ldots, P R_{m}\right\}$, where $m$ is the number of pairs of conflicting problems.

Step 5: Define the gravity for each pair of conflicting problems: Using a scale from 1 (enough critical) to 5 (extremely critical), a factor of gravity $\mathrm{fg}_{\mathrm{t}}, \mathrm{t}=1, \ldots, \mathrm{m}$ is associated to each pair $\mathrm{PR}_{\mathrm{t}}, \mathrm{t}=1, \ldots, \mathrm{m}$.

Step 6: Identify and rank TRIZ inventive vectors: TRIZ method operates with a set of 40 inventive generic vectors (see (Altshuller, 2000)). For each pair of conflicting problems (which at this point are only generically formulated) a well-defined subset of inventive vectors from the complete set of 40 vectors (counted from 1 to 40) exists; this subset comprises between 0 and 4 inventive vectors (also called inventive principles). If a certain 
subset comprises 0 vectors, the analyzed case is critical and only radical changes on the system would improve the situation. Thus, for each pair $\mathrm{PR}_{\mathrm{t}} \mathrm{t}=1, \ldots, \mathrm{m}$, a set of inventive principles $V_{t}=\left\{V_{1, t}, V_{2, t}, V_{3, t}, V_{4, t}\right\}, t=1, \ldots, m$, is associated. Each set $V_{t}, t=1, \ldots, m$ is revealed by the so-called "TRIZ matrix of contradictions" (see (Altshuller, 2000)). According to the TRIZ matrix of contradictions some sets $V_{t}, t=1, \ldots, m$, might be null or might have less then 4 members (i.e. only 1, 2 or 3 members).

Once the sets $V_{t}, t=1, \ldots, m$, are defined, a rank is given to each inventive vector. The rank is actually the sum of the gravity factors belonging to the pairs for which a certain inventive vector occurs in the sets $V_{t}, t=1, \ldots, m$. Thus, if for example, a certain inventive vector $V_{e}$ is present for the pairs $\mathrm{PR}_{\mathrm{x}}, \mathrm{PR}_{\mathrm{y}}$ and $\mathrm{PR}_{\mathrm{z}}$, and if the factors of gravity for these pairs are $\mathrm{fg}_{\mathrm{x}}, \mathrm{fg}_{\mathrm{y}}$ and $f g_{z}$, the rank of the vector $V_{e}$ is $r_{e}=f g_{x}+f g_{y}+f g_{z}$.

It is important to note that the TRIZ matrix of contradictions, as it is defined by its author (G. Altshuller), proposes a certain inventive vector not only once, but several times, depending on the combination of generic conflicting problems. At the end of this process, a set of $z$ unique, ranked inventive vectors is generated. This set is denoted with $U=\left\{U_{1}\left(r_{1}\right)\right.$, $\left.\mathrm{U}_{2}\left(\mathrm{r}_{2}\right), . ., \mathrm{U}_{\mathrm{z}}\left(\mathrm{r}_{\mathrm{z}}\right)\right\}, \mathrm{z}<40$, where each inventive vector $\mathrm{U}_{\mathrm{l}}, \mathrm{l}=1, \ldots, \mathrm{z}$, has a rank $\mathrm{r}_{\mathrm{l}}, 1=1, \ldots, \mathrm{z}$.

For a better visualization, a certain inventive vector from the set $U$ could be denoted as: $\mathrm{X}(\mathrm{Y} / \mathrm{Z})$, where $\mathrm{X}$ is the position of the inventive vector in the table of TRIZ inventive vectors, $Y$ is the number of times the inventive vector is called in the set $V_{t}, t=1, \ldots, m$, and $\mathrm{Z}$ is the rank of the respective inventive vector (the sum of the factors of gravity of the pairs of conflicting problems that have associated the respective inventive vector).

Step 7: Group inventive vectors on priorities: A qualitative analysis is done for each inventive vector $X(Y / Z)$. According to the value of $Z$ and then of $Y$, the inventive vectors of the set $U$ are structured on priority groups. This structuring is not a "mechanical" process. The expert must analyze the potential impact of the vectors based on the values $\mathrm{Z}$ and $\mathrm{Y}$. Thus, vectors having a close value of their gravities $(Z)$ and with close values of their occurrences $(Y)$ could be grouped together. Each group has a certain priority. The group having the vectors with the highest gravities $(\mathrm{Z})$ and number of occurrences $(\mathrm{Y})$ is of first priority, and so on. Actually, each inventive vector comprises some generic directions of intervention where innovative solutions should be searched and defined. It is important to mention that, in the table of 40 TRIZ inventive vectors, each inventive vector has associated several sub-vectors (see (Altshuller, 2000)). For example, if the inventive vector is "segmentation", the related directions of intervention are: "divide the system into independent parts", "increase the level of segmentation", "make the system sectional".

Thus, at the end of this process, for each priority group a number of generic directions of interventions will be revealed. The number of priority groups is not a fixed one; it comes up after the qualitative analysis done by the experts. For a better visualization of the results, the affinity groups are denoted with $\mathrm{a}(\mathrm{s}), \mathrm{s}=1, \ldots, \mathrm{w}$, where $\mathrm{s}$ is the priority associated to the respective group and $\mathrm{w}$ is the number of groups generated at the end of the process. A direction of intervention of a certain group is symbolized $\mathrm{DI}_{\mathrm{a}(\mathrm{s}), \mathrm{q}}$, where $\mathrm{q}=1, \ldots, \mathrm{y}(\mathrm{a}(\mathrm{s})$ ), with $y(a(s))$ the number of directions of intervention in the group $a(s), s=1, \ldots, w$. 
Step 8: Formulate innovative solutions: For each direction of intervention $\mathrm{DI}_{\mathrm{a}(\mathrm{s}), \mathrm{q}}, \mathrm{q}=1, \ldots$, $\mathrm{y}(\mathrm{a}(\mathrm{s}))$, with $\mathrm{y}(\mathrm{a}(\mathrm{s}))$ the number of directions of intervention in the group $\mathrm{a}(\mathrm{s}), \mathrm{s}=1, \ldots, \mathrm{w}$, and in the spirit of the direction of intervention, one or several innovative solutions might be proposed. A solution is innovative when it solves the conflict without compromises. The process of solution generation is a creative one; this task requires "openness" in "translating" the generic direction of intervention into effective, practical solutions. The process should start with the directions of intervention from the first priority group and continue up to the last priority group. At the end of this step a set of solutions is generated. This set is denoted with $S=\left\{S_{1}\left(z_{1}\right), S_{2}\left(z_{2}\right), \ldots, S_{d}\left(z_{d}\right)\right\}$, where $d$ is the number of solutions, $z_{i}$, $\mathrm{i}=1, \ldots, \mathrm{d}$, is the factor of gravity associated to the inventive vector to which the direction of intervention $\mathrm{DI}_{\mathrm{i}}, \mathrm{i}=1, \ldots, \mathrm{d}$, belongs; $\mathrm{DI}_{\mathrm{i}}, \mathrm{i}=1, \ldots, \mathrm{d}$, being the direction of intervention to which the solution $S_{i}, i=1, \ldots, d$, is associated.

Step 9: Establish the correlation types between solutions: It is important having all solutions positive correlated for complying with the laws of ideality and convergence (see relationships (2) and (3)). Hence, each solution is analyzed with respect to all the other solutions in order to establish the type of correlations between them. To perform this task, a correlation matrix is worked out. It consists of a number of columns and rows equal with the number of solutions. The main diagonal of the matrix is not taken into account. Each correlation is analyzed following each column in turn, from top to bottom.

Step 10: Redefine solutions that are negative correlated: If there are two negative correlated solutions, the one having a lower value of the factor of gravity $\mathrm{z}$ will be primarily eliminated and a new solution will be proposed in place, such as the positive correlation to be established. It might be possible that some solutions to have no correlation with the other solutions. This is not at all a drawback in solution definition.

Step 11: Establish the correlation index of each solution: Using the same matrix of correlation from steps 9 and 10, the correlation level related to each pair of solutions is determined. In this respect the following scale is used: 0 - no correlation; 1 - weak/possible correlation; 3 medium correlation; 9 - strong correlation; 27 - extremely strong correlation (almost indispensable each other). Denoting with $a_{i j}, i, j=1, \ldots, d, i \neq j$, the correlation level between solution $S_{i}$ and solution $S_{j}$, the correlation index $C_{i}, i=1, \ldots, d$, of the solution $S_{i}, i=1, \ldots, d$, is calculated with the following formula:

$$
C_{i}=z_{i} \cdot \sum_{j=1 j ; \neq i}^{d} a_{j i} ; i=\overline{1, d}
$$

Step 12: Schedule solutions for implementation: Considering the correlations between solutions as qualitative indicators of prioritization and considering the correlation indexes as quantitative indicators of prioritization, experts should schedule the implementation of solutions. Actually, each solution is a kind of mini-project that requires planning and implementation. Results from a mini-project could influence the results in other miniprojects or require running other mini-projects, according to the correlations between miniprojects. For each mini-project, several issues have to be clearly defined, like: time, costs, responsibilities, tools, etc. 


\section{Case study}

The integration of Sigma-TRIZ algorithm within the Six Sigma DMAIC methodology is further illustrated via a case study from the IT sector. It is actually about an IT company which provides outsourcing services in software development. In order to have the overall picture of the improvement project, the case study introduces all phases of the Six Sigma DMAIC process, with highlights on the "Improve" phase, where Sigma-TRIZ algorithm is effectively implemented.

\section{1 "Define" (D) phase within Six Sigma DMAIC methodology}

The project: Reorganization of the whole process of outsourcing service provision in software development.

Intended objectives: (O1) Reduction of "bugs" for deliverables sent to the client (bug = nonconformity in software jargon): this objective automatically leads to increase in customer satisfaction, reduction of failure costs and on-time delivery of results; (O2) Reduction of the non-productive time in software development: this objective automatically leads to increase of labor productivity.

Performance metrics: (M1) Deviation from the scheduled deadline; (M2) Level of poor-quality costs with respect to the income of the project; (M3) Return on net assets; (M4) Customer satisfaction (on a scale from 0 to 5 ).

Actors in the process: (A1) The project manager; (A2) The project manager of the client; (A3) The software programmers (members of the development team); (A4) The testers (members of the quality assurance team); (A5) The contact person with the customer; (A6) The technical director; (A7) The quality management director; (A8) The executive director; and (A9) The executive director of the customer.

Key requirements and expectations:

- $\quad$ The project manager: (R1) Short feedback time from the customer (getting answer to the questions asked); (R2) Enough time to perform a detailed project planning;

- The programmer: (R3) Requirements document to be clear and detailed; (R4) Enough time for development; (R5) Less cases of change requests in the project;

- The tester: (R6) Enough time to perform testing; (R7) Adequate and detailed documentation about test scenarios and test plans;

- The project manager of the client: (R8) Good communication with the development team of the supplier; (R9) Detailed documentation of the delivered solution; (R10) High quality of services - no critical "bugs";

- The technical director: (R11) On-time delivery of the project; (R12) High quality (from all perspectives: functionality, reliability, etc.); (R13) Low fluctuations of the team members during project development;

- $\quad$ The executive director: (R14) Project delivered on-time; (R15) Adequate quality to avoid penalties stipulated in the contract; (R16) Low costs with "bug" fixing;

- $\quad$ The quality management director: (R17) Adequate project documentation (records, etc.); (R18) High level of customer satisfaction; 
- The executive director of the customer: (R19) On-time project delivery; (R20) Project delivered within the scheduled budget; (R21) Quality of solution at the level specified in the requirements document.

\section{2 "Measure" (M) phase within Six Sigma DMAIC methodology}

"Suppliers" in the process: Project manager + development team + testing team + company (infrastructure, procedures, documentation, training, etc.) + customer (documentation, access to certain resources, etc.) + contact person with the client.

Constrains: (C1) The project duration is, in most of the cases, imposed by market (e.g. the final customer); (C2) The project budget is relatively rigid; (C3) The previous experience of the team in the project field is sometime insufficient.

The process (main phases):

- Main flow: MF1. Requirements analysis $\rightarrow$ MF2. Capability definition $\rightarrow$ MF3. Effort estimation $\rightarrow$ MF4. Contract negotiation $\rightarrow$ MF5. Technical analysis $\rightarrow$ MF6. Design $\rightarrow$ MF7. Code implementation $\rightarrow$ MF8. Module testing $\rightarrow$ MF9. Integration testing and validation $\rightarrow$ MF10. Deployment $\rightarrow$ MF11. Delivery.

- $\quad$ Supporting flow: SF1. Project planning $\rightarrow$ SF2. Monitoring and control.

Details about process phases: This information is extracted from quality management system's documentation (records, procedures, instructions, etc.) and/or from one-to-one interviews with actors involved in each phase of the process.

- $\quad$ Requirements analysis: MF1.1. Product vision analysis $\rightarrow$ MF1.2. Actor definition $\rightarrow$ MF1.3. Requirements formulation $\rightarrow$ MF1.4. Business use-case formulation $\rightarrow$ MF1.5. Requirements prioritization $\rightarrow$ MF1.6. Formulation of possible solutions;

- Capability analysis: MF2.1. Technical characteristics analysis $\rightarrow$ MF2.2. Preliminary effort estimation $\rightarrow$ MF2.3. Technical risk identification $\rightarrow$ MF2.4. Technical risk estimation $\rightarrow$ MF2.5. Technical risk assessment $\rightarrow$ MF2.6. Preliminary data formulation for project planning and contract negotiation $\rightarrow$ MF2.7. Establish quality objectives $\rightarrow$ MF2.8. Define and communicate iterations;

- $\quad$ Effort estimation: MF3.1. Detailed data analysis $\rightarrow$ MF3.2. Detailed effort estimation;

- Contract negotiation: MF4.1. Define key issues in the framework agreement $\rightarrow$ MF4.2. Analysis of contractual requirements $\rightarrow$ MF4.3. Negotiation $\rightarrow$ MF4.4. Contract signing $\rightarrow$ MF4.5. Order management;

- Technical analysis: MF5.1. Set up the specification document $\rightarrow$ MF5.2. Use-case formulation;

- $\quad$ Design: MF6.1. Top level architecture design $\rightarrow$ MF6.2. Interface design $\rightarrow$ MF6.3. Unit design $\rightarrow$ MF6.4. Data structure design $\rightarrow$ MF6.5. Description of system workflow $\rightarrow$ MF6.6. Supporting unit design $\rightarrow$ MF6.7. Test scenarios design;

- Code implementation: MF7.1. Coding and code documentation $\rightarrow$ MF7.2. Unit testing;

- Module testing: MF8.1. Testing of modules;

- Integration testing and validation: MF9.1. Module integration $\rightarrow$ MF9.2. Testing $\rightarrow$ MF9.3. Validation; 
- Deployment: MF10.1. Functionality documentation $\rightarrow$ MF10.2. Elaboration of the deployed structure $\rightarrow$ MF10.3. Structure documentation;

- Delivery: MF11.1. Internal check of solution $\rightarrow$ MF11.2. Delivery to the customer $\rightarrow$ MF11.3. Assessment of results;

- Project planning: SF1.1. Refining and description of iterations $\rightarrow$ SF1.2. Plan and schedule iterations $\rightarrow$ SF1.3. Define deadlines $\rightarrow$ SF1.4. Resource allocation $\rightarrow$ SF1.5. Detailed planning for various project phases;

- Monitoring and control: SF2.1. Cost monitoring and control $\rightarrow$ SF2.2. Time monitoring and control $\rightarrow$ SF2.3. Quality monitoring and control.

Expected results: (U1) Projects to be delivered on-time, each time; (U2) No major "bug" at delivery; (U3) No major "bug" at internal testing (before delivery); (U4) Actual effort not exceeding the scheduled effort.

Beneficiaries of results: (B1) The software outsourcing company; (B2) The customer; (B3) The development team (e.g. less stress, professional satisfaction; success bonus, etc.).

Necessary inputs to ensure an adequate progress of the process: The most important inputs are the followings: (I1) The estimated effort not below the real effort; (I2) Clear and detailed requirements and specifications; (I3) Adequate communication infrastructure for distance cooperative work; (I4) Adequate data and document management infrastructure; (I5) Very high skills and expertise of the project manager in the programming technologies; (I6) High skills of the team members in the programming technologies; (I7) Existence of predefined templates for recording deliverables in all phases of the project; (I8) Existence of clear methodologies for project monitoring and control, etc.

\section{3 "Analyze" (A) phase within Six Sigma DMAIC methodology}

Current nonconformities: (N1) Errors in the code delivered to the customer; (N2) Difficulties in monitoring the "true" labor productivity; (N3) Difficulties to have a direct and controlled intervention on labor productivity (because of job specificity).

Root causes for existence of current nonconformities:

- A software product is characterized by flexibility, "invisibility" and very high complexity per unit of effort, being from these perspectives extremely difficult (or even impossible) to estimate the real effort from the planning phase;

- The object-oriented programming technologies ensure a high flexibility in design and coding, with side effects on covering all possible user scenarios in the testing phase;

- Not enough time allocated for testing because of delays in coding, rigidity in deadlines, low budget allocated by the customer for an extensive testing, etc.;

- $\quad$ Testing scenarios are not complete (and sometimes not applied 100\%);

- Lack of effectiveness in the case of testing scenarios;

- Insufficient programming skills;

- Programmers do not work all the time with maximum responsibility;

- It is almost impossible to impose a constant labor productivity (human brain does not work linear); 
- Incomplete and ambiguous specification document;

- Too many change requests come up from the customer in the late phases of the development, etc.

Once the root causes are identified, specific actions must be taken to overpass problems or at least to minimize their effect; and this thing is a very challenging one.

\section{4 "Improve" (I) phase within Six Sigma DMAIC methodology}

At this point, integration of Sigma-TRIZ algorithm within the Six Sigma DMAIC methodology has to be done. The goal is to minimize the effort in searching for and setting up mature solutions (if it is possible, solutions that are "free of conflict"), as well as to minimize the capability of identifying these solutions.

Reenergizing the major objective and reformulate it in a positive way: No bug at delivery and capacity to deliver on-time.

Highlighting the most critical issues in achieving the intended objective: The following barriers have high significance: (a) Insufficient planning of software product/application quality in the initial phases of the development process; (b) customer's pressure to reduce both the budget and the delivery date.

Problem translation into generic characteristics that need improvement: For the above mentioned barriers, equivalences within the TRIZ parameters are searched. For this case study, the following generic TRIZ characteristics requiring improvements have been identified: $\left(a_{1}\right)$ engagement of employees (maximized); $\left(b_{1}\right)$ pressure upon employees (minimized); $\left(c_{1}\right)$ solidity of the software development process to various external disturbances (maximized); $\left(d_{1}\right)$ effort required to the top management for involving dynamic systems (employees, customers) (minimized); ( $\left.\mathrm{e}_{1}\right)$ effort spent per unit of time by employees without affecting productivity (minimized); $\left(\mathrm{f}_{1}\right)$ waste of energy/resources (minimized); $\left(\mathrm{g}_{1}\right)$ software system reliability when it becomes operational (maximized); $\left(h_{1}\right)$ labor productivity (maximized); $\left(\mathrm{i}_{1}\right)$ clarity of the process flow (maximized).

Identification of conflicting generic characteristics: In the attempt of improving the generic characteristics presented in the previous paragraph, some other generic characteristics might be affected. They are: $\left(a_{2}\right)$ quantity of money spent (minimized); $\left(b_{2}\right)$ project duration (minimized); $\left(\mathrm{c}_{2}\right)$ effort spent by dynamic elements (effort required to the customer for providing clear and complete information on-time) (minimized).

Formulation of the most critical pairs of conflicting characteristics: From the analysis of the generic characteristics that need to be improved and the generic characteristics that might be affected because of the expected improvement in relation with the intended objective, the following pairs of conflicting issues are identified: A) $a_{1}-a_{2}$; B) $b_{1}-a_{2}$; C) $b_{1}-b_{2}$; D) $b_{1}-c_{2}$; E) $c_{1}-a_{2} ;$ F) $\left.\left.\left.\left.\left.\left.\left.\left.c_{1}-b_{2} ; G\right) c_{1}-c_{2} ; H\right) d_{1}-a_{2} ; I\right) e_{1}-a_{2} ; J\right) e_{1}-b_{2} ; K\right) e_{1}-c_{2} ; L\right) f_{1}-b_{2} ; M\right) g_{1}-b_{2} ; N\right)$ $\left.\left.\left.\left.\mathrm{g}_{1}-\mathrm{c}_{2} ; \mathrm{O}\right) \mathrm{h}_{1}-\mathrm{a}_{2} ; \mathrm{P}\right) \mathrm{h}_{1}-\mathrm{c}_{2} ; \mathrm{Q}\right) \mathrm{i}_{1}-\mathrm{b}_{2} ; \mathrm{R}\right) \mathrm{i}_{1}-\mathrm{c}_{2}$. Thus, 18 conflicting problems have been formulated within the analyzed process. All these conflicts must be proper solved; otherwise, significant improvements in process performances cannot be expected. 
Establishing a gravity factor to each pair of problems: The gravity factor is denoted with $\mathrm{f}_{\mathrm{g}}$. A scale from 1 (enough critical) to 5 (extremely critical) is associated to $f_{g}$. For the pairs of problems in this case study, the following results are obtained: A) $a_{1}-a_{2}\left(f_{g}=5\right)$; B) $b_{1}-a_{2}$ $\left.\left.\left.\left.\left.\left(f_{g}=5\right) ; C\right) b_{1}-b_{2}\left(f_{g}=4\right) ; D\right) b_{1}-c_{2}\left(f_{g}=3\right) ; E\right) c_{1}-a_{2}\left(f_{g}=2\right) ; F\right) c_{1}-b_{2}\left(f_{g}=5\right) ; G\right) c_{1}-c_{2}$ $\left.\left.\left.\left.\left.\left(f_{g}=3\right) ; H\right) d_{1}-a_{2}\left(f_{g}=1\right) ; I\right) e_{1}-a_{2}\left(f_{g}=5\right) ; J\right) e_{1}-b_{2}\left(f_{g}=5\right) ; K\right) e_{1}-c_{2}\left(f_{g}=3\right) ; L\right) f_{1}-b_{2}\left(f_{g}=3\right) ;$ M) $\left.\left.\left.\left.\left.g_{1}-b_{2}\left(f_{g}=5\right) ; N\right) g_{1}-c_{2}\left(f_{g}=3\right) ; O\right) h_{1}-a_{2}\left(f_{g}=5\right) ; P\right) h_{1}-c_{2}\left(f_{g}=3\right) ; Q\right) i_{1}-b_{2}\left(f_{g}=2\right) ; R\right)$ $\mathrm{i}_{1}-\mathrm{c}_{2}\left(\mathrm{f}_{\mathrm{g}}=1\right)$.

Identification and ranking of TRIZ inventive vectors: The TRIZ inventive vectors for the 18 pairs of problems in this case study are further presented. Numbers associated to each pair represent positions of the inventive vectors in the TRIZ table of 40 inventive vectors (see Altshuller (2000)). A) $a_{1}-a_{2}: 14,29,18,36:$; B) $b_{1}-a_{2}: 10,14,36$; C) $b_{1}-b_{2}: 6,35,36$; D) $b_{1}-$ $c_{2}: 14,24,10,37$; E) $c_{1}-a_{2}: 29,10,27$; F) $\left.\left.c_{1}-b_{2}: 8,13,26,14 ; G\right) c_{1}-c_{2}: 19,35,10 ; H\right) d_{1}-a_{2}: 34$, $23,16,18$; I) $\mathrm{e}_{1}-\mathrm{a}_{2}: 4,34,19 ;$ J) $\left.\mathrm{e}_{1}-\mathrm{b}_{2}: 15,35,2 ; \mathrm{K}\right) \mathrm{e}_{1}-\mathrm{c}_{2}: 16,6,19,37$; L) f $\mathrm{f}_{1}-\mathrm{b}_{2}: 10,13,28,38$; M) $g_{1}-b_{2}: 21,35,11,28$; N) $g_{1}-c_{2}: 21,11,27,19 ;$ O) $\left.h_{1}-a_{2}: 35,38 ; P\right) h_{1}-c_{2}: 1 ;$ Q) $i_{1}-b_{2}: 35$, $37,10,2 ; R) i_{1}-c_{2}: 32,1,19$. Just for exemplification, if we take the pair $a_{1}-a_{2}$, the numbers $14,29,18$ and 36 are the positions in the TRIZ table of 40 inventive vectors of the following vectors: 14 - replace a linear "approach" with a nonlinear "approach"; 29 - replace "rigid" components of the system with "fluid" components; 18 - use the "resonance frequency"; and 36 - use effects generated during a transition phase.

According to the Sigma-TRIZ algorithm, denoting with $X$ the position of the vector in the TRIZ table of 40 inventive vectors, with $Y$ the number of occurrences of the vector in the set of 18 pairs of problems and with $Z$ the sum of the gravity factors of the pairs of problems having associated the respective vector, the vector is symbolized as: $\mathrm{X}(\mathrm{Y} / \mathrm{Z})$. Thus, for this case study, the following situation occurs:

- Vectors of rank 1: $\{35(6 / 24), 10(6 / 18), 14(4 / 18)\}$;

- Vectors of rank 2: $\{19(5 / 15), 36(3 / 14)\}$;

- Vectors of rank 3: \{37 (3/8), 38 (2/8), 28 (2/8), 21 (2/8), 13 (2/8), 11 (2/8), 29 (2/7), $6(2 / 7), 2(2 / 7)\}$;

- $\quad$ Vectors of rank 4: $\{34(2 / 6), 18$ (2/6), 27 (2/5), 26 (1/5), 15 (1/5), $4(1 / 5), 8(1 / 5)\}$;

- Vectors of rank 5: $\{1(2 / 4), 16(2 / 4), 24(1 / 3)\}$.

The inventive vectors of rank 1 should be considered as priority 1 , the inventive vectors of rank 2 should be considered as priority 2 and so on. As the above data reveal, vectors with close values of the sum of their gravity factors and with close number of occurrences are included in the same rank.

Define generic directions of intervention: The generic directions of intervention (DI) describe possible generic facets of the inventive vectors. The reader can find them in the TRIZ table of 40 inventive vectors (Altshuller, 2000). For this case study, results are presented below.

Priority 1:

- $\quad$ DI1. Change the degree of flexibility (vector 35);

- DI2. Change the state "concentration" (vector 35); 
- DI3. Perform in advance, completely or partial, the required actions upon the system (vector 10);

- DI4. Replace linear approaches with nonlinear ones (vector 14);

Priority 2:

- DI5. Replace a continuous action with a periodical one or with an impulse; and if the action is periodical, change its frequency (vector 19);

- DI6. Use various effects of "phase transition" (vector 36);

Priority 3:

- DI7. "Thermal expansion" (see motivation) (vector 37);

- DI8. "Strong" interactions (see transition towards optimal approaches for effort and time reduction) (38);

- $\quad$ DI9. Replace rigid parts with soft parts (vector 28);

- DI10. Perform harmful operations at high speed (vector 21);

- DI11. Instead of doing something according to specification, implement a completely opposite action (vector 13);

- DI12. Compensate a low reliability with some actions done in advance (vector 11);

- DI13. "Fluid" construction of the system (vector 29);

- $\quad$ DI14. Make the system able to perform multiple functions (vector 6);

- DI15. Remove from the system the part or property which disturbs (vector 2);

Priority 4:

- DI16. "Modify" some elements of the system during process operation once those elements have completed their tasks (vector 34);

- DI17. Use the "resonance frequency" to activate the system (vector 18);

- DI18. Replace an expensive system with several cheap systems (vector 27);

- DI19. Use simple copies instead of a single complex system (vector 26);

- DI20. Some parts of the system or of its environment must be automatically adjusted for an optimal performance (vector 15);

- DI21. Replace a symmetrical "unit" or "element" with one or several asymmetrical "units" or "elements" (vector 4);

- DI22. For a better balance, compensate the system's "weight" with another system (vector 8);

Priority 5:

- DI23. Increase the level of segmentation (vector 1);

- DI24. If it is difficult to get $100 \%$ of the intended effect, try however to achieve as much as possible from it (vector 16);

- DI25. Temporarily use an intermediary and easy replaceable system for performing some actions (vector 24).

Numbers in the brackets represent the position of the inventive vectors in the TRIZ table of 40 inventive vectors. According to the above data, 25 generic directions of intervention are proposed in this case study. With respect to these directions of intervention, adequate solutions have to be formulated. 
Formulation of innovative solutions: This process, even if it is guided by the generic directions of intervention, is a highly creative one. Innovative solutions are actually the improvement projects which the company should implement in order to achieve the intended objective. Thus, in the next paragraphs, the term "innovative solution" is replaced with the term "improvement project". In this case study, under the guidance of the directions of intervention, the following improvement projects have been proposed:

- $\quad$ Project P1: Define your development process to be easy customizable to the specificity of the customer processes $\{$ DI1 $\}$;

- $\quad$ Project P2: Flexible organized teams, according to project requirements $\{$ DI2 $\},\{D I 13\}$;

- Project P3: Apply simultaneous engineering (some processes are run quasi-parallel: analysis-design; coding-testing) $\{\mathrm{DI} 3\}$;

- $\quad$ Project P4: Prepare and use optimized templates for each process - new people can be very fast integrated in the company $\{\mathrm{DI} 3\}$;

- $\quad$ Project P5: Rotate the team leadership $\{$ DI4\};

- Project P6: Apply quality circles for knowledge shearing within teams and between teams $\{$ DI4\};

- $\quad$ Project P7: Apply planning and innovation tools to help the customer in formulating its needs (provide solutions, not just execute orders) $\{$ DI4\};

- $\quad$ Project P8: Consider rapid application development approaches to early verification of some concepts $\{\mathrm{DI} 4\}$;

- Project P9: Use feature teams (your best people, for very short time) for rapid reaction in the starting phase of critical projects $\{$ DI4\};

- $\quad$ Project P10: Cross testing $\{$ DI5\};

- Project P11: Periodical review (e.g. weekly) of code samples by the best people in the company $\{\mathrm{DI} 5\}$;

- $\quad$ Project P12: Internal audits at irregular time intervals $\{$ DI5\};

- Project P13: Define performance requirements for each phase of the software development process $\{\mathrm{DI} 6\}$;

- Project P14: Apply the concept of "internal client-internal supplier" $\{$ DI6 $\}$;

- Project P15: Individual recognition (bonuses) \{DI7\};

- Project P16: Collective recognition (success bonus) \{DI7\};

- Project P17: Use the best people in the company in various phases of a project for advising the team $\{$ DI8\};

- Project P18: Periodically, "inject" professional challenges to the team members $\{$ DI8\};

- Project P19: Electronic management of all documents related to a certain project \{DI9\};

- $\quad$ Project P20: Use creativity techniques (e.g. mind-map) and innovative problem solving techniques (e.g. TRIZ, ASIT) in the design phase of a project $\{$ DI9\};

- Project P21: Use spiral development model to approach highly innovative projects $\{D I 4\},\{D I 10\}$;

- Project P22: Urgent change of a member if he/she does not handle the project $\{$ DI10\};

- Project P23: When problems occur, find solutions to improve the process not to blame the team $\{$ DI11\};

- Project P24: Think to contingency plans from the early phases of a project \{DI12\};

- $\quad$ Project P25: Negotiate projects considering pessimistic scenarios \{DI12\};

- Project P26: Consider periodical „back-up" actions \{DI12\}; 
- Project P27: Start development with "C" in the PDCA cycle $\{$ DI12\};

- Project P28: Multi-qualified staff and multiple roles in the project (e.g. the project manager has also some tasks of coding and testing) \{DI13\};

- Project P29: Fast and facile communication between the top management and the team members (breakdown the communication barriers) \{DI14\};

- $\quad$ Project P30: Flexible teams, of variable size, in various phases of the project $\{$ DI16\};

- Project P31: Use external consultants for certain phases of a critical project \{DI16\}, \{DI25\};

- Project P32: Daily communication, in multiple modes, with the customer (e-mail, messenger, phone, etc.) $\{$ DI17\};

- $\quad$ Project P33: Apply $360^{\circ}$ review $\{$ DI17\}, $\{$ DI21\};

- $\quad$ Project P34: Before delivery, perform multiple and various module tests $\{$ DI18\}, $\{$ DI19\};

- Project P35: Flexible organization (dynamic-oriented teams) \{DI20\};

- $\quad$ Project P36: More time allocated to P and C within PDCA cycle $\{$ DI21\};

- Project P37: Focus on solutions not on service (thus, the process of analysis, design and technical innovation should be highly mature) $\{$ DI4 $\},\{$ DI22\};

- $\quad$ Project P38: Monitor team profitability (autonomous profit units) \{DI23\};

- $\quad$ Project P39: From time-to-time, for very short periods, apply tele-work \{DI23\};

- Project P40: Rotate team members in projects to avoid monotony $\{$ DI24\};

- Project P41: Better adaptation to project diversity by increasing flexibility in customer selection $\{$ DI24\};

- $\quad$ Project P42: Subcontract auxiliary functions $\{$ DI25\}.

To each project, one or more directions of intervention are associated (see the symbols in the brackets \{\} ). None of the 42 projects are in conflict each other, thus none of them should be removed. According to step 11 of the Sigma-TRIZ algorithm, a correlation index can be associated to each project (see the relationship (5)). This information is very useful to establish priorities in starting the implementation of the projects in the list. However, this process should not be applied in a "mechanical" way. First of all, projects should be analyzed; and selected from the list those which can start immediately (e.g. because they are simple rules; because do not involve so much resources and time, etc.). There should be kept for prioritization only those projects which effectively involve more resources and time.

Actually, in this case study, from the set of 42 projects, a subset of 27 projects can be distributed to various units of the company to be implemented immediately, as long as they primarily describe good-practice rules and simple working routines. In this category are included the following projects: P2, P3, P5, P6, P9, P10, P11, P12, P14, P15, P16, P17, P18, P22, P23, P24, P25, P26, P27, P28, P29, P30, P31, P32, P34, P36, P42. The remaining subset, constituted from 15 projects: P1, P4, P7, P8, P13, P19, P20, P21, P33, P35, P37, P38, P39, P40, $\mathrm{P} 41$, should be further analyzed for prioritization.

Project prioritization: For the subset of 15 projects above mentioned, a matrix of correlation is set up. The results are shown in Table 1. In the matrix, the correlations between projects and their correlation indexes are put into evidence. According to the results in Table 1, project $\mathrm{P} 4$ is of first priority, followed by projects $\mathrm{P} 1, \mathrm{P} 7, \mathrm{P} 8$ and so on. This priority is not necessarily the order in which implementation will effectively happen in practice. 


\begin{tabular}{|l|c|c|c|c|c|c|c|c|c|c|c|c|c|c|c|}
\hline & P1 & P4 & P7 & P8 & P13 & P19 & P20 & P21 & P33 & P35 & P37 & P38 & P39 & P40 & P41 \\
\hline P1 & & 27 & 27 & 27 & 9 & 27 & 27 & 27 & 9 & 27 & 27 & 27 & 9 & & 9 \\
\hline P4 & 9 & & & & 1 & 27 & & & & & & 3 & & 9 & 27 \\
\hline P7 & 9 & 9 & & 9 & & & 27 & 9 & & 3 & & & & & \\
\hline P8 & 9 & & 9 & & & & 1 & 27 & & & & & & & \\
\hline P13 & 9 & 9 & & & & & & & & & & 3 & & & \\
\hline P19 & 9 & 27 & & & & & & & & & & & & & \\
\hline P20 & 9 & & 27 & 9 & & & & 1 & & & & & & & \\
\hline P21 & 9 & 9 & 27 & 27 & & & 27 & & & 1 & & & & 1 & \\
\hline P33 & & 9 & & & & & & & & 27 & & 3 & & 3 & \\
\hline P35 & 9 & 27 & & 9 & & 9 & 1 & & 1 & & 9 & 9 & & 9 & 27 \\
\hline P37 & 9 & 27 & & & & 9 & & & & 9 & & 3 & & & \\
\hline P38 & 9 & 9 & & & 3 & 9 & & & 3 & & & & & 9 & \\
\hline P39 & 3 & 27 & & & & 27 & & & & & & & & & \\
\hline P40 & & 27 & & & & 9 & 1 & & & 27 & & 9 & & & \\
\hline P41 & 27 & & & & & 27 & 27 & & & 27 & 3 & & & & \\
\hline $\mathrm{Z}_{\mathrm{i}}$ & 24 & 18 & 18 & 18 & 14 & 8 & 8 & 18 & 6 & 5 & 18 & 4 & 4 & 4 & 4 \\
\hline La $\mathrm{a}_{\mathrm{i}}$ & 120 & 207 & 90 & 81 & 13 & 144 & 111 & 64 & 13 & 121 & 39 & 57 & 9 & 31 & 63 \\
\hline $\mathrm{C}_{\mathrm{i}}$ & 2880 & 3726 & 1620 & 1458 & 182 & 1152 & 888 & 1152 & 78 & 605 & 702 & 228 & 36 & 124 & 252 \\
\hline Priority & 2 & 1 & 3 & 4 & 12 & 5 & 7 & 6 & 14 & 9 & 8 & 11 & 15 & 13 & 10 \\
\hline
\end{tabular}

Table 1. Prioritization of the subset of 15 projects

Results in Table 1 highlight the importance which a well-documented, highly mature quality management system plays in the equation of competitiveness of a software outsourcing company (P4). They also show how important is to define a customizable software development process (P1), as well as to provide solutions, not just being a simple executive (P7) and to consider evolutionary approaches in software development (P8, P21). An important role is also played by running the whole process in a virtual environment (P19), etc.

Please remember that Table 1 does not include the rest of 27 projects in the analysis. The fact these projects are simpler in terms of time and resources required for their implementation does not necessarily mean they are less important than the 15 projects analyzed in Table 1 . Only an exhaustive analysis could give an answer to this issue. However, for the scope of improvement, such discussions are not at all relevant as long as all projects have to be implemented in order to set up a mature business process.

Implementation plan: Implementation of projects requires several actions, like: definition of implementation means, resources, scheduling, etc. This task strongly depends on the context in which the company operates; therefore, this part of the exercise is not included here for presentation. 


\section{5 "Control” (C) phase within Six Sigma DMAIC methodology}

This phase includes two important steps: a) development of the monitoring plan; and b) institutionalization of improvements (e.g. by means of procedures, rules, instructions, records, etc.). These kinds of issues overpass the scope of this paper, thus they are not further treated here.

\section{Conclusion}

Conflicts occurring between various project actions represent the true barriers in setting up mature business processes. However, identification of the "real" conflicts is not a simple task. To this, formulation of effective solutions to various problems requires innovations in many cases. Starting from these premises, this chapter explores the integration of innovative problem solving tools within Six Sigma DMAIC methodology to increase the effectiveness of process improvement projects. The result is a novel algorithm for systematic approach of the "Improve" phase within Six Sigma DMAIC methodology. It is called Sigma-TRIZ algorithm. The success in formulating effective solutions of process improvement with Sigma-TRIZ is direct proportional with the capacity of solving without compromises conflicts within the analyzed process. This effort is guided by the paradigm of ideality and the paradigm of convergence.

Some other concluding remarks derive from the case study presented in this chapter. First, improvements within business processes cannot be effectively done without systematic approaches, where innovation plays a key role. Second, generation of visible results in the effort of process improvement necessitates identification and implementation of convergent, positive correlated improvement projects. Third, understanding the impact of each project in the equation of process improvement increases the level of effectiveness, especially for those situations where resources are limited. Fourth, the number of improvement projects is proportional with the number of conflicts occurring in the process. Fifth, initiatives of process improvement are not so simple, requiring simultaneous implementation of more improvement projects. Without a clear commitment and support from the top management, such initiatives could fail. Sixth, to have mature business processes, a clear focus should be on extended business models, where customers are key parts of the business process.

The research in this paper is also subjected to some limitations which open new opportunities for further works. In this respect, consideration of a single tool for inventive problem solving (specifically, the TRIZ method) would be seen a restrictive condition. In fact, a space for exploring similar methods within the Six Sigma DMAIC methodology is open. A kind of drawback in the Sigma-TRIZ algorithm comes up from the fact that TRIZ method, by itself, raises up some difficulties in being properly use by usual people; but "without pain, no gain".

In addition, results presented in the case study could be of real support for people operating in the field of software outsourcing industry. In the same register, the case study details a significant part of a Six Sigma DMAIC methodology, being from this perspective a useful guide for practitioners in the field of quality management, as well as an instructive material for students. 


\section{Abbreviations}

DMAIC $=$ Define - Measure - Analyse - Improve - Control.

TRIZ $=$ Theory of Inventive Problem Solving.

QFD $=$ Quality Function Deployment.

\section{References}

Altshuller, G. (2000). The Innovation Algorithm: TRIZ, Technical Innovation Center, ISBN 09640740-4-4, Worcester

Brad, S. (2008). Integration of innovation tools within Six Sigma process improvement methodologies, Proceedings of the International Conference Quality-InnovationEuropean Integration-Special Issue Calitatea AS, Vol. 93, No. 1, pp. 66-72, ISSN 15822559, Romania, September 2008, Publisher Calitatea AS, Sibiu

Cascini, G.; Rissone, P. \& Rotini, F. (2008). Business re-engineering through integration of methods and tools for process innovation, Proceedings of the Institution of Mechanical Engineers Part B-Journal of Engineering Manufacture, Vol. 222, No. 12, pp. 1715-1728, ISSN 0954-4054, Italy, December 2008, Publisher Professional Engineering Publishing Ltd, Florence

Cronemyr, P. (2007). DMAIC versus DMADV. Differences, similarities and synergies. International Journal of Six Sigma and Competitive Advantage, Vol. 3, No. 3, pp. 193209, ISSN 1479-2494

Hamza, A. (2008). Design process improvement through the DMAIC six sigma approach. International Journal of Six Sigma and Competitive Advantage, Vol. 4, No. 1, pp. 35-47, ISSN 1479-2494

Jean-Ming, C. \& Jia-Chi, T. (2004). An optimal design for process quality improvement: modeling and application. Production Planning and Control, Vol. 14, No. 7, pp. 603612, ISSN 0953-7287

Khavarpour, M.; Asadian, N.; Hoseinpour, S. \& Malihi, H. (2008). A new approach to cost reduction with TRIZ method, Proceedings of the 38th International Conference on Computers and Industrial Engineering, Vol. 1-3, pp. 1551-1557, ISBN 978-7-121-074370, China, November 2008, Publisher Publishing House Electronics Industry, Beijing

Qi, M.; Dai, Q.Q.; Lin, Q.Y. \& Shang, W.F. (2008). The design of enterprise innovation model that integrated TRIZ into six sigma, Proceedings of the International Workshop on Computer Science and Engineering, pp. 418-421, ISBN 978-1-84626-172-5, Russia, May 2008, Publisher World Acad Press, Moscow

Silverstein, D.; DeCarlo, N. \& Slocum, M. (2005). In-sourcing Innovation: How to Transform Business as Usual into Business as Exceptional, Breakthrough Performances Press, ISBN 0-9769010-0-5, Longmont

Smith, L. \& Pahdke, M. (2005). Some thoughts about problem solving in a DMAIC framework. International Journal of Six Sigma and Competitive Advantage, Vol. 1/2, pp. 151-166, ISSN 1479-2494

Thawani, S. (2002). Six sigma: strategy for organizational excellence. Total Quality Management \& Business Excellence, Vol. 15, No. 5-6, pp. 655-664, ISSN 1478-3371

Treichler, D.; Caramichael, R.; Kusamanoff, A.; Lewis, J. \& Berthiez, G. (2002). Design for six sigma: 15 lessons learned. Quality Progress, Vol. 35, No. 1, pp. 33-42, ISSN 0033-524X 
Zhao, X.J. (2005a). Integrated TRIZ and six sigma theories for service/process innovation, Proceedings of the International Conference on Services Systems and Services Management, Vol. 1-2, pp. 529-532, ISBN 0-7803-8971-9, China, June 2005, Publisher IEEE, Chongqing

Zhao, X.J.; Feng, C.X. \& Zhou, X. (2005b). Integrating TRIZ and QFD into six sigma processes for satisfying customers, Proceedings of the 2005 International Conference on Management Science E Engineering (12th), Vol. 1-3, pp. 732-736, ISBN 7-5603-2189-5, Korea, July 2005, Publisher Harbin Institute Technology Publishers, Incheon

\section{Appendix: TRIZ-generic parameters}

\begin{tabular}{|c|l|c|l|c|l|}
\hline No. & Characteristic & No. & Characteristic & No. & Characteristic \\
\hline \hline 1 & $\begin{array}{l}\text { Weight of moving } \\
\text { object }\end{array}$ & 14 & Strength & 27 & Reliability \\
\hline 2 & $\begin{array}{l}\text { Weight of nonmoving } \\
\text { object }\end{array}$ & 15 & $\begin{array}{l}\text { Durability of moving } \\
\text { object }\end{array}$ & 28 & $\begin{array}{l}\text { Accuracy of } \\
\text { measurement }\end{array}$ \\
\hline 3 & $\begin{array}{l}\text { Length of moving } \\
\text { object }\end{array}$ & 16 & $\begin{array}{l}\text { Durability of } \\
\text { nonmoving object }\end{array}$ & 29 & $\begin{array}{l}\text { Accuracy of } \\
\text { manufacturing }\end{array}$ \\
\hline 4 & $\begin{array}{l}\text { Length of nonmoving } \\
\text { object }\end{array}$ & 17 & Temperature & 30 & $\begin{array}{l}\text { Harmful factors acting } \\
\text { on object }\end{array}$ \\
\hline 5 & Area of moving object & 18 & Brightness & 31 & Harmful side effects \\
\hline 6 & $\begin{array}{l}\text { Area of nonmoving } \\
\text { object }\end{array}$ & 19 & $\begin{array}{l}\text { Energy spent by moving } \\
\text { object }\end{array}$ & 32 & Manufacturability \\
\hline 7 & $\begin{array}{l}\text { lolume of moving } \\
\text { object }\end{array}$ & 20 & $\begin{array}{l}\text { Energy spent by } \\
\text { nonmoving object }\end{array}$ & 33 & Convenience of use \\
\hline 8 & $\begin{array}{l}\text { Volume of nonmoving } \\
\text { object }\end{array}$ & 21 & Power & 34 & Repairability \\
\hline 9 & Speed & 22 & Waste of energy & 35 & Adaptability \\
\hline 10 & Force & 23 & Waste of substance & 36 & Complexity of device \\
\hline 11 & Tension/Pressure & 24 & Loss of information & 37 & Complexity of control \\
\hline 12 & Shape & 25 & Waste of time & 38 & $\begin{array}{l}\text { Level of system } \\
\text { automation }\end{array}$ \\
\hline 13 & Stability of object & 26 & Amount of substance & 39 & Capacity or productivity \\
\hline
\end{tabular}




\title{
Design for Six Sigma (DfSS) in Software
}

\author{
Ajit Ashok Shenvi \\ Philips Innovation Campus \\ India
}

\section{Introduction}

It is difficult to imagine a product or service these days that does not have software at its core. The flexibility and differentiation made possible by software makes it the most essential element in any product or service offering. The base product or features of most of the manufactures/service providers is essentially the same. On one hand, the differentiation is in the unique delighters, intuitive user interface, reliability, responsiveness etc i.e. the nonfunctional aspects and software is at the heart of such differentiation. On the other hand being such a crucial aspect of a product or a service, failures or quality issues and correspondingly, user dissatisfaction often get associated with software.

Compared to other fields such as civil, electrical, mechanical etc, software industry is still in its infancy. Although there are some architecture patterns, design rules, coding guidelines, software development is not yet a fully mature engineering discipline. The fundamentals principles of PDCA (Plan-DO-Check-Act) do apply, however intangibility associated with the output and absence of samples makes the in-process verification at every stage a very and challenging and person dependent affair.

Historically the development of software has been governed by "software engineering principles" applied though application of SEI-CMM R model. This is a collection of best practices across the industry that has been compiled and structured into a framework and has strong emphasis on a process based philosophy. The essential idea is that when the input to the process as well as process steps are controlled, the output of the process is expected to be predictable and of good quality. On the other hand, the core principle of DfSS is to minimize variation. As it is often said - "Variation is an enemy of Quality". However, software is mainly digital in nature (it works or it does not, yes/no) and is expected to be $100 \%$ predictable with "no inherent variation" by itself -i.e. the same software would have exactly the same behaviour under same environmental conditions/inputs. In addition, there is nothing like "samples" with respect to software development process. It is the same piece of code that evolves right from development phase to maturity phase. With all this, the very concept of "statistics" and correspondingly the various fundamental DfSS metrics like the Z-score, etc start to become fuzzy in case of software. Moreover "software does not wear out with time, it only becomes obsolete. 
This leads to lot of questions....

- Can the time tested principles of DfSS be really applied in software development?

- If yes then how does it fit into the overall framework that is CMMI based?

- What kind of tools and statistics would really help?

- Are software requirements always digital or they can be converted into Continuous parameters?

- What does it mean to say a product / service process is six sigma?

- And so on ...

This chapter is an attempt to answer these questions by sharing experiences of applying the DfSS methodology in real-life software development of an embedded consumer product. Although the chapter exemplifies the case study of a product, the same concepts could be easily applied to "service" also. This chapter is divided into 3 parts --

1. Part-1 is briefly introducing the fabric of the DfSS methodology - the DIDOVM phases of DfSS, the deliverables of these phases, spectrum of tools, the training required, the Green belt mechanism etc

2. Part-2 is a Case study of the application of the various DfSS concepts such as Voice of customer (VOC), Critical to Quality parameters (CTQs), Failure modes and Effects Analysis (FMEA) in the software development life cycle of an embedded product - the DVD-Hard disk combi recorder. Here it gives few examples of starting from Voice of customer, translating them into CTQs, quantifying the various non-functional elements such as Usability, Reliability and mapping to the Voice of customer, the way it was designed in the software, the results seen

3. Part-3 of the chapter revolves around some challenges of DfSS in software such as mapping into CMMI, elements to be careful about software FMEA and use of statistics in context of software.

Most of the contents of this chapter is taken from the author's published paper at the $1^{\text {st }}$ India Software Engineering conference (Ajit Shenvi, 2008), "[Design for Six Sigma: Software Product Quality] (c) 2008 Association for Computing Machinery, Inc. Reprinted by permission. http://doi.acm.org/10.1145/1342211.1342231.

\section{DfSS Methodology}

\subsection{The phases}

Fig. 1. The DfSS phases: DIDOVM

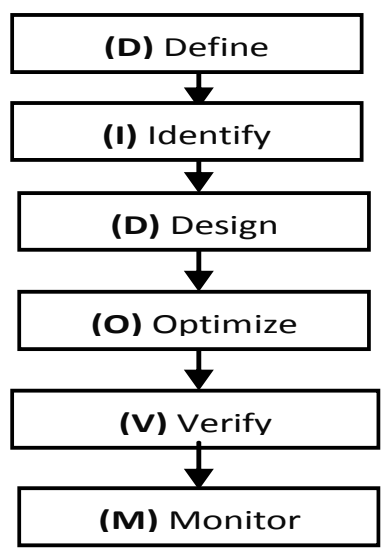


DfSS is a scientific methodology and as with any methodology, there are various phases and deliverables associtaed with these phases. Number of DfSS flavours are prevalent in the industry and DIDOVM is one of them as depicted in the Figure 1.

Define: In this phase, the problem area or opportunity is defined. The main deliverable of this phase is the "project charter defined with management sign-off". This is a crucial step because lot of focussed effort and management support would be spent in the area scoped in the charter.

Identify: As with all flavours of Six sigma project, the DFSS projects start with identifying the Voice of Customer (VOC); This phase concentrates on translating the VOC i.e. the customer needs into "Critical to Quality" parameters. This VOC in customer language is translated into "Critical to Quality" parameters (CTQs) with clear targets and defined specification limits. Also the mechanism to measure these CTQs need to be articulated very clearly.

Design: This is the phase where the design takes place with CTQs as the basis. The "best designs" are chosen that will help meet the CTQs. The top level CTQs (Y) are broken down into lower level input factors (Xs) and "transfer functions" are developed. At this stage based on the transfer functions, it is possible to predict the capability of CTQ (Y) in terms of Zscore, given the variations of Xs. Failure Mode $\mathcal{E}$ Effects Analysis (FMEA) is also done in this phase to make the design robust and insensitive to noise factors.

Optimize: There could be same Xs impacting multiple CTQs in contradictory ways. Hence trade-off decisions, as well optimizing the design to meet the CTQs takes place in this phase. The tracking of actions from FMEAs for risk reduction is also done.

Verify: The optimized CTQs are now verified on the pilot products/systems. Here-in, when the products are beginning to be manufactured in large quantities, it is crucial to ensure that the CTQs are still within the specified limits on the produced items.

Monitor: Finally the performance of the CTQs is monitored in the field to ensure the real customer satisfaction.

In summary, the entire development, and testing effort of the product is centred on the "Voice of the customer" through the mechanism of "CTQs".

\subsection{The roles}

A typical DfSS fabric is anchored on "leadership commitment". As described earlier, DfSS is not only about a methodology but also a philosophy change; hence certain roles as described below are pivotal for the successful execution of DfSS projects

Champion/Sponsor: This person from senior management, champions the overall cause, provides budget, and removes bottlenecks if any. Champion has belief in the cause and stands-by the teams in the initial days when there is lot of dis-belief from the project teams and resistance to change in the system.

Master Black Belt (MBB): The MBB identifies, trains, coaches, and guides the Black belts towards the overall goal of the organization.

Black Belt (BB): This is a real "change agent" who is trained in DfSS methodology and gets the break-through improvement done. Since the BB is the real change agent, it naturally follows that this person should be sufficiently senior and influential in the team. The best candidate then would be the project architect or Function owner etc. The BB ensures that the VOC, CTQs and other techniques get deployed in the project, escalate issues if necessary, 
keep the senior management and champion/sponsor updated on the progress. Training the Green belts is also responsibility of the BB.

Green Belt (GB): These are the functional members who deploy the DfSS tools and techniques in their respective functions. The essential difference between the BB and GB is the scope of deployment. A BB project has a very wide scope whereas GB project is on a smaller scope such as a functional area. The financial savings could also be a factor that distinguishes a BB project from a GB project. For e.g. a GB project could typically save $250 \mathrm{~K}$ Euros whereas a BB project would in order of 1 Million Euros.

\subsection{The Training}

The BB and GBs have to be trained on the DfSS concepts and tools. The training is not just classroom training, but a workshop type where the selected participants identify problem/opportunity areas to work on before they start on the training. These trainee BBs/GBs are then expected to deploy the applicable tools and techniques in their respective projects once they go back to their work. The results, issues faced, improvisations done, progress made are then presented by the BBs/GBs for review before they come for the next session. To maintain the seriousness of the trainings and the philosophy, this is an important pre-requisite condition for continuation of the BB/GB training. Around 4-6 weeks gap is required to be planned between the sessions for people to get adequate time to deploy the techniques, track progress and monitor results. The MBB has to work closely with the BB and the BB has to closely with the GBs during this time to coach, mentor, course-correct and steer the GBs towards the goal. The Figure 2 below depicts the GB training structure (Philips-SigMax DfSS Training material, 2005).

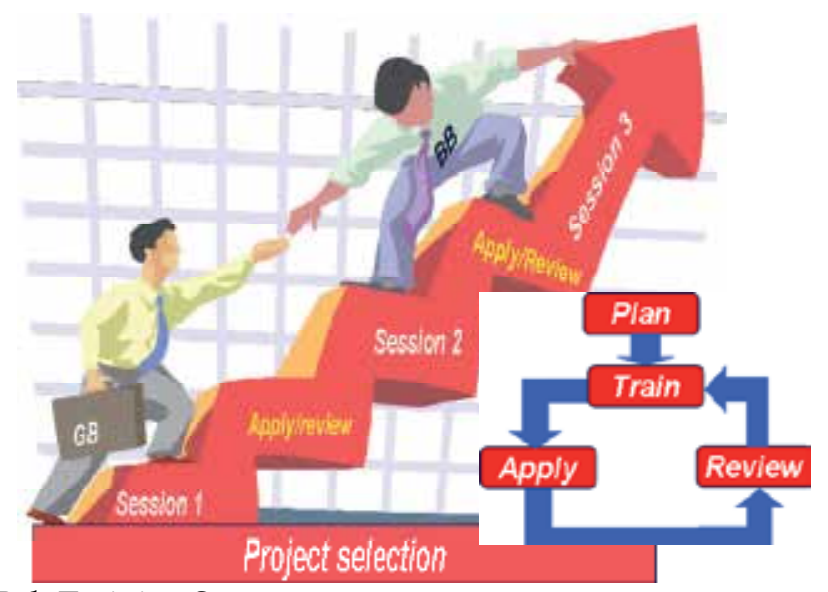

Fig. 2. The Green Belt Training Structure

For a GB training the typical training could be planned for 6.5 days and spread over duration of 3-4 months with the following sessions:

- 0.5 day brief on the need for change and DfSS overview

- 2 days for Define and Identify phase

- 2 days for Design phase

- 2 days for Optimize, Verify and Monitor phase. 
All this investment in time, effort and cost makes the project selection very crucial. Every project cannot be a GB project. It has to be one where enough problems/opportunities exist to be able to classify it as a candidate for break-through improvement. Also the improvement has to be critical to business and sensed so by the sponsor. Hence it should be mandated that GBs prepare a project charter signed off by the sponsor before they could start on the GB training. The charter should have a clear problem/ opportunity statement, scope, targets, top level dates, resource requirement and operating principles of the GB project team. As a thumb rule, an improvement of "atleast 50\% improvement" on chosen areas be demonstrated to be able classify it as a GB project. The successful completion of the $\mathrm{BB} / \mathrm{GB}$ project with demonstrated results as mentioned in the charter would qualify for $\mathrm{BB} / \mathrm{GB}$ certification.

\subsection{Change Management}

For successful deployment of any initiative it is important to identify the customers and the stakeholders and get them involved. The purpose of identifying and mapping stakeholders is important from "Change Management" perspective. Any break through initiative is bound to introduce number of changes and these changes are bound to meet with lots of resistance. So to manage this, the stakeholders especially the project team has to be sold on this idea as they are the ones finally implementing the changes. The mapping could be done into three categories:-

Blockers: who are against the idea and will try to resist the change either with valid or personal reasons

Floaters: who are on the fence and do not have particular opinions either ways

Movers: who are the supporters and are enthusiastic about the change

The Structure shown in Figure 3 can be used to plan and track the Stakeholder involvement from Change Management perspective.

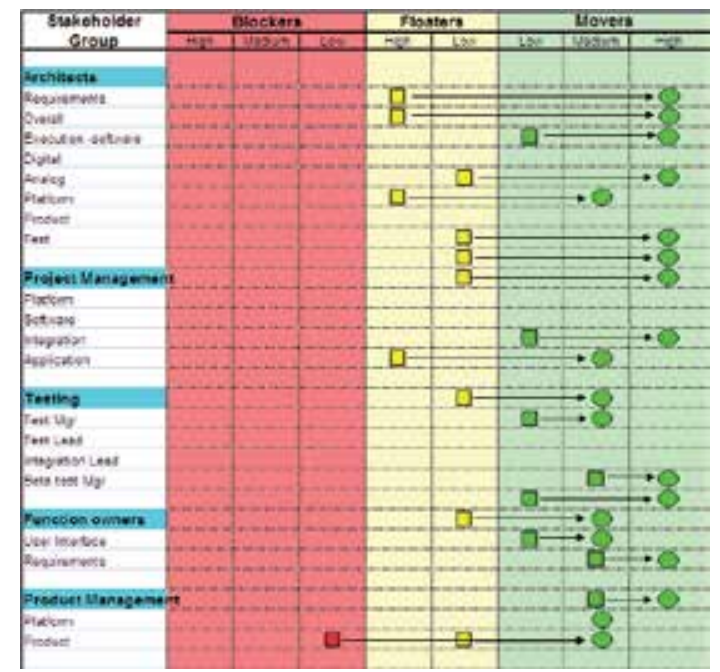

Fig. 3. The Change Management Structure

Movers can be used to convince Blockers about the need for change and get them on your side. Current state and the desired state for each of the stakeholders and actions to facilitate 
this movement need to be identified as depicted in Figure 3 above. Such actions need to be identified for each and every stakeholder including senior and middle management members and tracked on a periodic basis. The goal in doing this exercise is to ensure that adequate support and push is available from all sides to bring about break-through changes in the Way of Working.

\section{Case Study}

Philips Innovation Campus (PIC), Bangalore is a division of Philips Electronics India Limited, owned by Royal Philips Electronics N.V., The Netherlands. There are various groups in PIC, that develop embedded software including user interface for consumer electronics (CE) devices such as Televisions, DVD players \& recorders, Juke boxes, Set top boxes etc. These CE products like any other go through the typical product life cycle of inception, growth, maturity and decline. This transition is very rapid, due to which the industry is extremely competitive. The margins on the product are very small and it is only through volume sales that the CE companies are able to make any profit. Moreover the base product and features of almost all the manufacturers is essentially the same. What differentiates them then is some unique delighters, intuitive user interface, responsiveness i.e. often the non-functional requirements. Software is at the heart of such differentiation. On the flip side since software is such an important element of the embedded product, it is also cause of failures, user dissatisfaction (perceived as well as real).

One such product range that had just entered from inception phase to growth phase is the DVD-Hard disk recorder. This product with all its combinations of use cases makes it a very complex product. Correspondingly it has a potential of having field issues and user complaints leading to Non-Quality Costs that would ultimately eat into the profit margins of the current business. Loss of brand image arising out of this would also affect the future business as well. Hence it was decided to use DfSS techniques as a focussed approach in the development to ensure good software quality product.

\subsection{The Product}

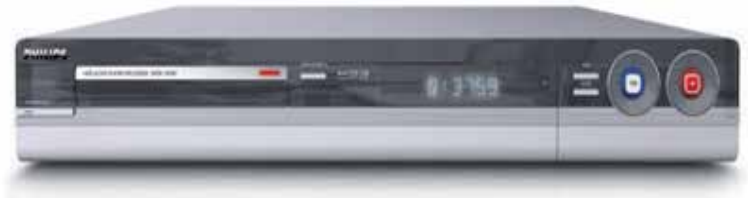

Fig. 4. The Product: DVD-Hard disk recorder

This is a product that records and plays DVD, VCD and many other formats. It has an inbuilt hard disk that can store pictures, video, audio etc. Due to the presence of the hard disk, it is possible to a pause the live-TV and resumes it later from the point it was paused. The product is packed with many (more than 50) features. All these features and their associated use-cases with some of them in parallel make this a very complicated product. Also because of the complexity, the intuitiveness of user-interface assumes enormous importance to address the usability of the product. For convenience sake, let us call this product XYZ. 


\subsection{Customer Identification}

The DFSS methodology is strongly anchored on listening to the "Voice of customer (VOC)" and ensuring that this voice is satisfied throughout the development life cycle. For this DVD product, the external customers are very clear and they are the end users of this consumer product and the retailers/dealers who stock them. So when VOC is being referred to in this context, it is this group that we refer to.

At the same time, being a development community it is also imperative to understand that there are other set of internal customers as well, whose voice also needs to be heard. They are the sales group who face the end users on a day-to-day basis, product management who decide what features get into which products and factory where the products actually get produced. For example - factory "VOC" could be to make it simple to produce the sets and a related CTQ could be number of times the hard disk needs to be formatted on the production line.

\subsection{Stakeholder Analysis}

Stakeholders also needed to be identified as they are directly linked to the success/failure of our DfSS project with the project team being the most important one. Therefore, as indicated in section 2.4, it is advisable not only to identify the stakeholders but also to map them into various categories and have actions to facilitate their movement from blockers to enthusiastic supporters. These are some of the "change management" techniques that could be used. The customers and stakeholders identified for this project are represented below in the Figure 5.
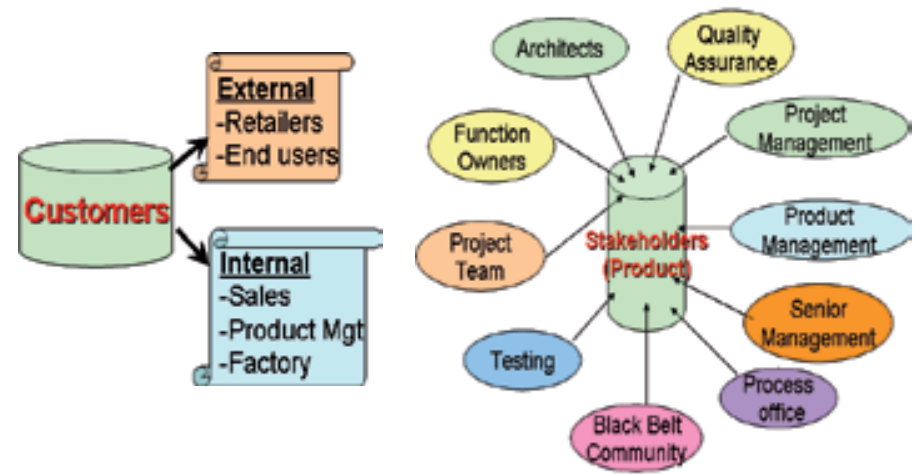

Fig. 5. Customers and Stakeholders

\subsection{Define and Identify phase}

As mentioned in section 3.1, this product range due to its complexity and large software base has a potential of high Non Quality costs due to field issues and usability calls. The DfSS Black belt project therefore had a charter of preventing this. In other words, both limiting the Non-Quality costs due to quality issues as well as usability enhancement was the target of this project.

Having defined the charter the next step was to identify the Voice of the Customer (VOC) for this product. The various techniques to get this VOC are focus group interviews with consumers/dealers, surveys, benchmarking etc. As a development community, this activity 
had already been done by the market intelligence and product management community. The VOC information was available in the form of consumer requirements specifications (CRS), and Product Value Proposition House. These were validated and assumptions challenged using some DfSS techniques such as Risk Benefit matrix, Kano analysis and mechanism of identifying CTQs. These are the tools that can be used in Requirements management phase of the software development to enhance requirements analysis and prioritization.

\subsubsection{Risk Benefit Matrix}

Products are often packed with lots of features making it complicated to use. Typically $80 \%$ of users do not use more than $30 \%$ of the features.

Risk-Benefit is a simple matrix that can challenge each and every requirement or feature and its need. The matrix has 2 axes: one axis represents the "customer impact" attribute and the other axis is the "business/development risk" attribute. Each of these attributes has 3 levels: high, medium and low. The Figure 6 below shows such a matrix template.

\begin{tabular}{|c|c|c|c|}
\hline \\
\hline \multicolumn{4}{|l|}{ Customer } \\
\hline Impact & Low & Medium & High \\
\hline Low & $\begin{array}{l}\text { Feature A } \\
\text { Feature B }\end{array}$ & $\begin{array}{l}\text { Feature C } \\
\text { Feature D }\end{array}$ & $\begin{array}{l}\text { Feature } \mathrm{E} \\
\text { Feature } \mathrm{F}\end{array}$ \\
\hline Medium & $\begin{array}{l}\text { Feature } \mathrm{H} \\
\text { Feature B }\end{array}$ & $\begin{array}{l}\text { Feature I } \\
\text { Feature J }\end{array}$ & $\begin{array}{l}\text { Feature K } \\
\text { Feature L }\end{array}$ \\
\hline High & $\begin{array}{l}\text { Feature M } \\
\text { Feature N }\end{array}$ & $\begin{array}{l}\text { Feature } \mathrm{O} \\
\text { Feature } \mathrm{P}\end{array}$ & $\begin{array}{l}\text { Feature Q } \\
\text { Feature R }\end{array}$ \\
\hline
\end{tabular}

Fig. 6. The Risk-Benefit Matrix

All the features identified for the product in the Consumer Requirements Specifications are then filled in the appropriate cell of this matrix. For maximum benefit, this should be a joint exercise between the development community and the product management. All those features in the low customer impact and high/medium business risk could simply be removed.

For the XYZ product, a similar exercise was done and the product management was challenged on the position of each feature in the above matrix. Some of the features in "High risk-Low impact" zone got dropped in the process making the product simpler than what it was already conceived, without even getting even a single step into development.

Previously also similar exercises took place but they were adhoc and sometimes too late in the development cycle after lot of effort were already spent in designing and coding the high risk features. The risk benefit gave a very structured mechanism to prioritize the features. Another added benefit was that, it helped improve the communication between the product management and the development community by giving an appropriate platform to debate and discuss. Development community could now think from the problem domain perspective and product management from the solution domain.

Having done the filtering of features, Kano analysis can then be done to prioritize the requirements further. 


\subsubsection{Kano Analysis}

Kano Analysis is one of the techniques that classifies the features/requirements into 3 categories namely-

Must Haves: These are the basic needs that the customers expect in a product/service and therefore take it for granted. Its absence would cause extreme dissatisfaction, however more of it does not guarantee increased satisfaction.

Satisfiers: These are the specifications that increase customer satisfaction as more and more is added. For example-higher speed has better satisfaction.

Delighters: These are the real value add attributes that act as differentiators. The customer is not expecting them but their presence gives a "WOW" feeling.

Part of Kano analysis done for this XYZ product can be seen in Figure 7. This prioritization done through Kano analysis, then helps to allocate effort and bandwidth when identifying CTQs and focusing development.

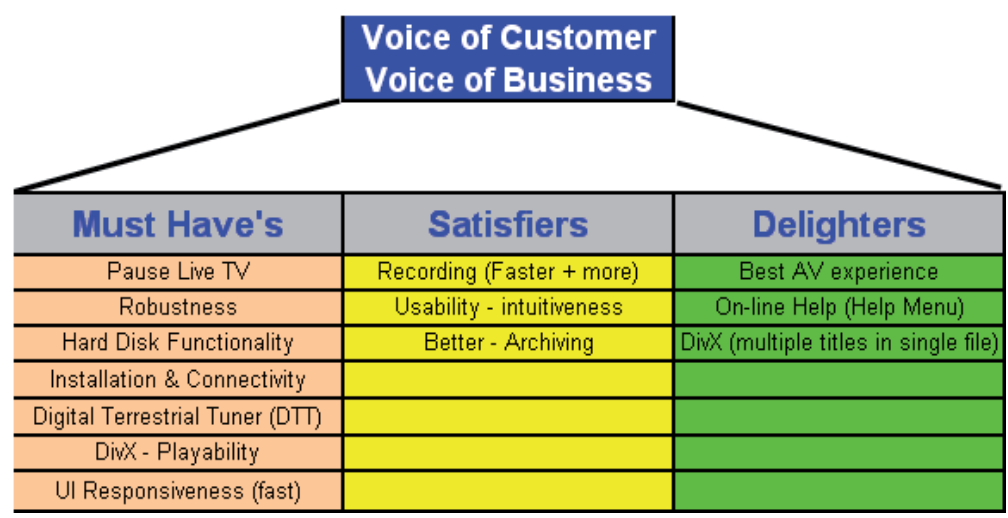

Fig. 7. The Kano Analysis for the XYZ Product

\subsubsection{The CTQs (Critical To Quality)}

CTQs are the Critical to Quality parameters as called in the DfSS jargon. Basically CTQs are those parameters that are directly linked to Voice of customer. CTQs are of 3 types:

Continuous: These are the quantitative ones that can be measured using gauges and instruments.

Discrete: These are the ones that can be classified into Pass/Fail, Yes/No category.

Critical factors: These are CTQs that are either present or absent. For example - Wi-Fi compliance is a critical factor. Either all sets are compliant or not.

The real crux of the DfSS BB/GB project lies in identifying the right CTQs that are mapped to the VOC which are the needs of the customer. Effort available is limited and if spent on unwanted CTQs is actually wasted. So once the VOC was identified through CRS, Value proposition, Risk benefit and Kano, the challenge then was to identify the right software CTQs for this product XYZ.

The complete landscape that could lead us to the right CTQs was analyzed. The CRS and value proposition was an obvious starting point. The VOC expressed as field complaints and feedback of previous products, both from external customers (consumers) and internal 
customers (sales, factory) turned out be another valuable input in determining these CTQs. An often after-thought element "non-functional requirements" such as responsiveness etc. was another dimension to look at. Thinking about VOC made us also look at competitor products for determining CTQs via benchmarking. Last but not the least each of us in the development community was also a consumer and wearing an end-user hat changed our perspective when we were trying to identify the CTQs.

All these inputs as shown in Figure 8 were used in iterations along with product management to churn out the CTQs for this product XYZ.

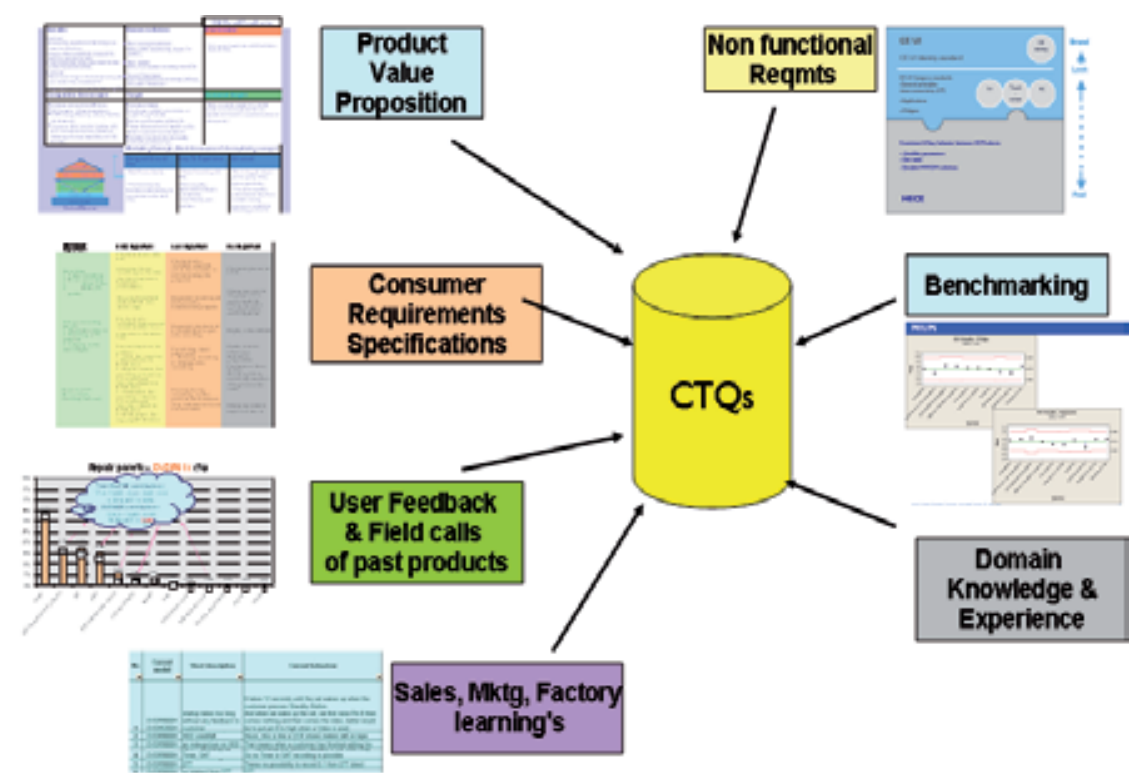

Fig. 8. Inputs for CTQ Identification

For each of the continuous and discrete CTQs, the measurement method, target and specification limits must be clearly identified. For the critical factor CTQs, since quantitative measurements or classification is not available, the verification criteria, method and risk should be elaborated instead.

This Identify stage turned out to be one of the most difficult phase when it comes to software development. Everything is digital in software - it works or does not, so all the CTQs we identified from the VOC started becoming "Critical factors". Identifying test cases as verification criteria was what we did previously also in the software development lifecycle.

So we started challenging them by further breaking down to lower levels and identifying some numbers and measurements with it. The 2 examples below on DivX and USB elaborate this approach. 


\subsubsection{Feature DivX}

DivX was one of the new features for the product and an important VOC. But as a CTQ, its value in guiding software development was not high. So we started asking what in DivX is important to the user, in a brainstorming exercise with product management. After some deliberation we came up with 3 main things:

a) DivX playability - a measure of how well our product can play all flavours of DivX content available in the market.

b) DivX playback time - How fast can our device respond and start playing once the user presses "Play" and other related operations.

c) DivX certification - this is Voice of business and not really Voice of consumer. To put a DivX logo on the product we need to get the product certified from the standardizing body. Each round of certification costs a lot of money. Moreover time-slots have to be booked in advance with the standardizing body. So an unsuccessful round is not only an immediate financial loss but also an opportunity lost due to loss of time.

The next step was to set targets for each of these CTQs so that the architecture/design and implementation can be guided by the same.

For Playback-time the case was simple. There was already research papers available on what are the typical human irritation thresholds when they interact with devices. A compilation of these for different use-cases was already available, so we decided to use the same. So DivX playback time became our continuous CTQ and we could easily give a target number with upper limit and measurement method to it.

DivX certification on the other hand was a Critical factor but we still wanted to treat it as a measurable CTQ. So we set a target to achieve DivX certification on the first try itself as that would save us lot of costs of re-certification trials.

DivX playability was an interesting case. An end user would typically want everything that is called as DivX content to play on his device. This is a free content available on the internet and it is humanly impossible to test all. To add to the problems, users can also create text files and associate with a DivX content as "external subtitles". Defining a measurement mechanism for this CTQ was becoming very tricky and setting target even trickier. So we again had a brainstorming with product management and development team, searched the internet for all patterns of DivX content available, and created a repository of some 500 audio-video files. This repository had the complete spectrum of all possible combinations of DivX content from best case to worst case and would address at least $90 \%$ of use cases. The success criterion then was to play as many of these 500 files and the target defined was at least $90 \%$ of them should play successfully. So DivX playability then became our discrete CTQ with a measurement method of verifying the \% of files the product XYZ was able to play and the target was $90 \%$ with a lower limit of $80 \%$.

All the exceptional use cases identified in the meeting were then used for conducting the Failure Mode and Analysis (FMEA) to ensure robustness and graceful exits in case of feature abuse.

\subsubsection{Feature USB}

USB (Universal Standard Bus) was another very important feature from VOC as users use USB as a medium to copy/transfer content. USB 2.0 is a standard which we wanted to comply with. 
So here again it was very easy to consider this as a critical factor and go ahead with the development. But just as in DivX case, we wanted to dwell deeper to understand what could be the CTQs. From DivX experience, few straightforward ones we could come up with were USB certification, USB notification time, content feedback time etc. The real challenge was to define how an end user would consider USB feature as successful and one of the ways is if the user is able to copy/playback content from the USB device on our product XYZ. In other words the CTQ parameter we identified is "Interoperability". This is easier said than done - just like DivX, there are at least thousands of USB manufactures and a variety of USB devices ranging from simple memory sticks to ipods, juke boxes to digital cameras. It is again humanly possible to verify the compatibility with each and every type. To add to the complications there are some device manufactures who sell USB those are not compatible with the USB 2.0 standard. Furthermore the market is flooded with devices that are USB 1.0, USB 2.0, High speed etc and one doesn't expect a user to check what version his USB is before plugging into our device. So to define this CTQ was really a challenge. So we decided to go back to basics. What is the single most important use case that any user would use the USB port of a DVD recorder extensively? In other words what is the real voice of consumer? The answer was obvious; to connect digital cameras to be able to view and store JPEG images. That limited the sample space of USB devices primarily to digital cameras. It reduced the complexity of the problem drastically but still did not solve it completely as types and makes of digital cameras itself easily runs into thousands. As a next step we scanned the market space, where this product $X Y Z$ was supposed to be launched to see the most popular digital cameras currently available and those that are in the pipeline to be launched in the timeframe of our product launch. We zeroed down on some 5-6 different brands with 6-7 different models in each brand. This list was augmented with some popular make memory sticks and juke boxes. The CTQ definition then was percentage of devices that could successfully interoperate with our product and target was at least $90 \%$. The Figure 9 below describes the process pictorially.

\section{USB Cameras}

\section{USB storage other USB devices}
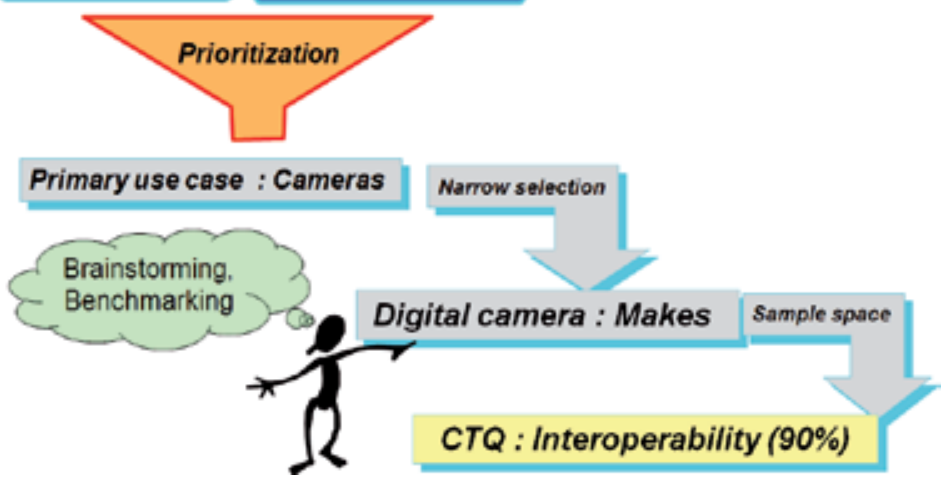

Fig. 9. USB Feature - Interoperability CTQ

As with DivX, all the exceptional conditions identified during these discussions were taken for doing the FMEA. 
Similar approach was followed for all other features (VOC). At the end of the exercise we had list of all the CTQs mapped to VOC.

Continuous CTQs: mostly performance/responsiveness related e.g. startup time, content feedback time, USB notification time etc

Discrete CTQs: mostly on the "ilities" such as playability, interoperability, reliability, usability etc. Reliability and Usability being generic are further elaborated later in the chapter in the next section.

Critical factors: mostly compliance related such DivX certification, USB certification, FNAC 4 stars etc

For both Continuous and discrete CTQs clear targets and specification limits were identified as success factors. For critical factors only verification criteria and method were elaborated.

\subsection{Design and Optimize phase}

Once the CTQs are identified the next step is to guide the development cycle around these CTQs. Design phase has two primary goals - one is to select best design and second is to decompose the top level CTQ (Y) into its lower level factors (Xs) called as CTQ flow-down. These maps to architecture, design, implementation and integration phase of a typical software development life-cycle.

Tools like Pugh matrix can be used to select the best design form the alternative choices using CTQs as selection drivers. Appropriate weightage based on priority decided from Kano is given to the CTQs and all design choices are rated on their capabilities to meet the CTQs. Best design is then selected appropriately that has the highest score and minimum negatives.

Another aspect of design phase is to break down the CTQs (Y) into lower level inputs (Xs) and a make a transfer function. The transfer function basically helps to identify the strength of correlation between the inputs (Xs) and output $(\mathrm{Y})$ so that we know where to spend the effort. Various statistical techniques as shown in Figure 10 below are available to make this transfer function such as Regression analysis if past data is available, Design of experiments (DOE) if past data is not available and of course domain knowledge of experts.

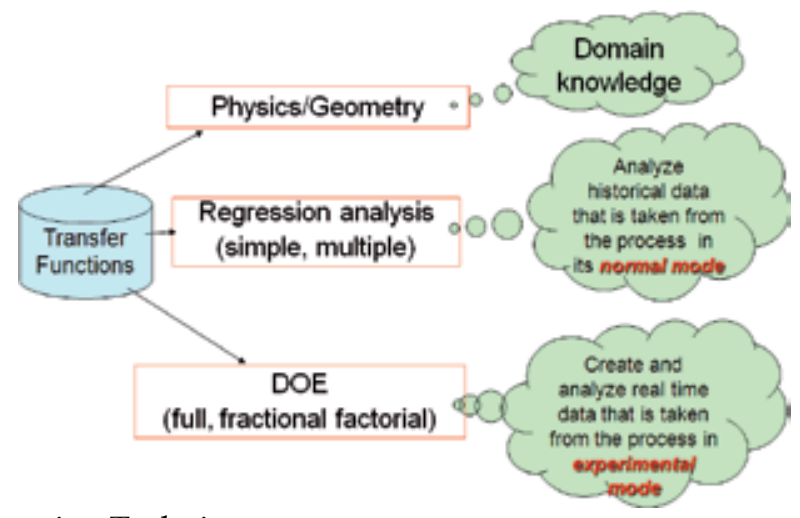

Fig. 10. Transfer Function Techniques

For many cases in software, the actual transfer function may not be necessary as the number of inputs and their combinations would be very high. What is more important to know is which are the input parameters (Xs) that can be controlled to meet the CTQs, which of the 
inputs are constants/fixed and which of them are noise parameters. An example of such a block for DivX is illustrated in the Figure 11 below.

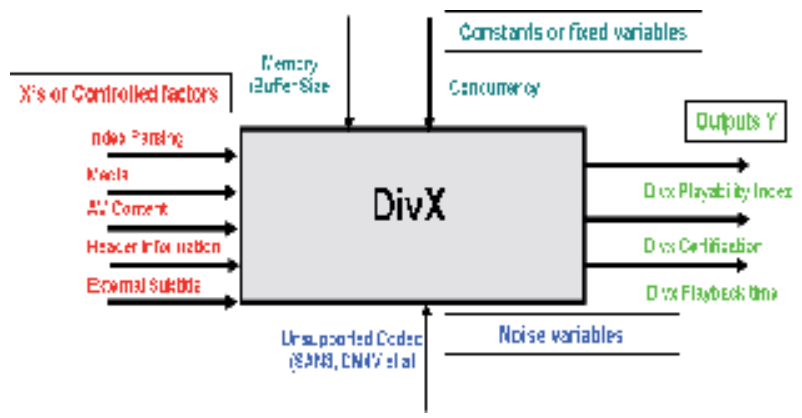

Fig. 11. DivX Feature : Transfer function

For performance CTQs, the actual transfer functions really make sense as they are linear in nature. One can easily decide from the values itself those $X_{s}$ that need to be changed and by how much. For e.g.

Start-up time $(Y)=$ drive initialization $(X 1)+$ software initialization $(X 2)+$ diagnostic check time $(\mathrm{X} 3)$

For other CTQs, main effects plot and interaction plots are sufficient enough to know the inputs to tweak. These plots can be made in any statistical tools such as Minitab (www.minitab.com) either from Regression analysis or conducting few Design Of Experiments (DOEs).

Main effects plot give an indication of the impact each of the Xs have on Y. For example- the Figure 12 shows the variation in USB copy speed CTQ (Y) for the variation in each of the Xs (buffer, device speed etc).

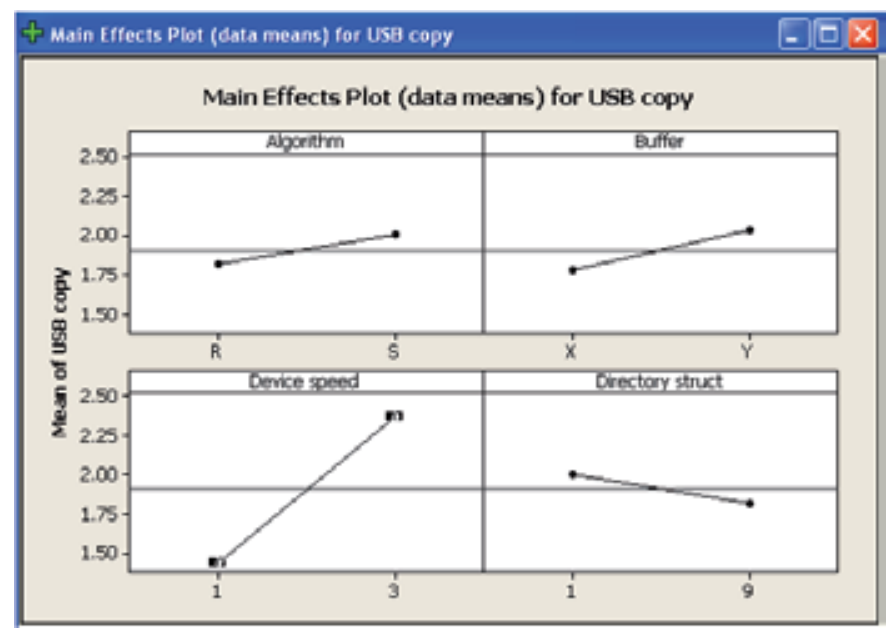

Fig. 12. USB copy: Main Effects Plot

The Interaction plot on the other hand will show the impact of the interactions of the Xs on the CTQ Y as shown in Figure 13. 


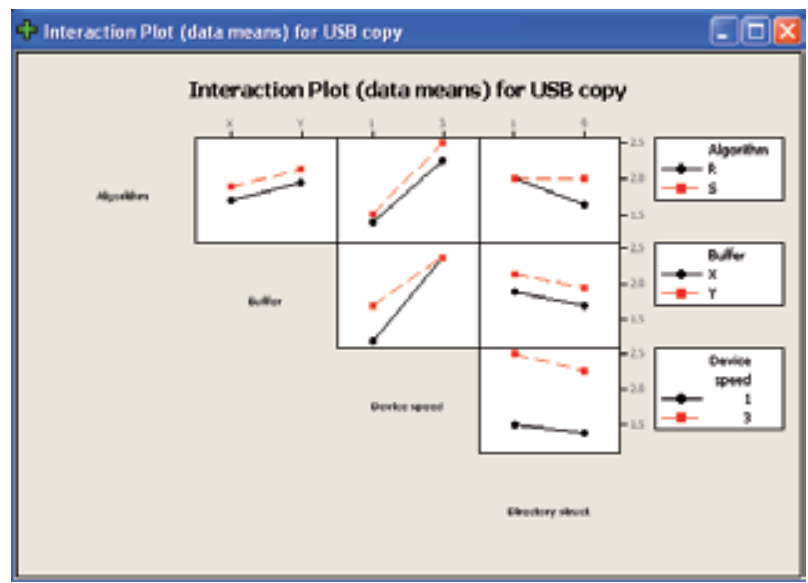

Fig. 13. USB copy: Interaction Plot

Knowledge on both the main effects and interactions helps in optimizing the design and trade-off decisions. Many a time in software, most of modules are interrelated, and a single $X$ might impact multiple CTQs in opposite ways i.e. for meeting CTQ Y1, an increase in X may be necessary and for CTQ Y2 a decrease would be required. In such a case interaction plots can help to make trade-off decisions by masking input $X$ with another interacting input X2.

Another important aspect of the Design and Optimize phase is the FMEA and mistake proofing i.e. to make designs resilient to failures or mask the users from making mistakes itself. A Standard FMEA template was tailored by mapping the definitions and scale of the "Severity", "Occurrence" and "Detection" parameters to software context. For example we already had severity definitions defined for classifying software bugs in our process framework. We used the same for FMEA severity attribute. Occurrence attribute was simplified to mean 1 in 3 chances as a high value for example and so on and so forth. Guidelines for detection were also accordingly simplified. More details on pitfalls and learning's of applying FMEA in software are discussed in detail in section 4.2.

The Risk priority number (RPN) from this FMEA after implementing the actions was tracked on a periodic basis. For software, the demarcation between the Design and Optimize is very thin as the same code base is used iteratively.

\subsubsection{Software Reliability}

Software by itself does not have a "Constant Failure rate"; hence defining MTBF (Mean Time Between Failure) for software alone starts becoming fuzzy. The typical bath-tub curve for software looks something like shown in Figure 14 (Jiantao Pan, 1999).

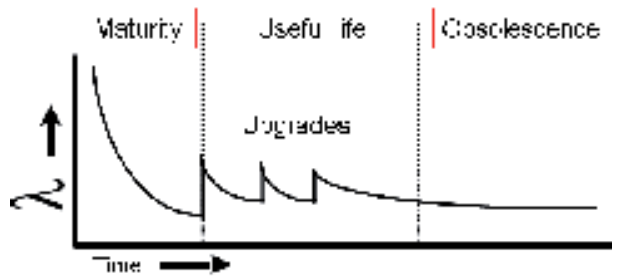

Fig. 14. Typical Bath-Tub curve for software (where $\lambda$ is the failure rate). 
One way to determine software reliability would be in terms of its robustness. We tried to define Robustness as a CTQ for the product XYZ. This was again turning out to be "critical factor". So we defined the CTQ (Y) in terms of "Number of Hangs/crashes" in normal usecase scenarios as well as stressed situations and target was set at 0 .

The lower level factors ( $\left.X^{\prime} \mathrm{s}\right)$ affecting the CTQ robustness was then identified as:

- Null pointers

- Memory leaks

- CPU loading

- Exceptions/Error handling

- Coding errors

Robustness $=f$ (Null pointers, Mem leaks, CPU load, Exceptions, Coding errors)

The exact transfer function could have been found out by doing a number of "Design of experiments". This would have consumed a lot of effort and would have turned out to be an academic exercise. The purpose of finding transfer function is really to find out which of the Xs are really correlating heavily with $\mathrm{Y}$ so that optimizing them would yield maximum benefits. In case of robustness however each of these Xs are equally important and all of them need to be optimized. So we decided to take actions on each of these input parameters in different ways.

Some of these actions are as follows:-

- A small tool was developed to find null pointers if any in the code stack. Most of these were then eliminated.

- Stringent limits set for memory allocation of subsystems. This was tracked at every release to ensure that all subsystems are within budget and that there is no overlap of memory space. (Subsystems come from different project teams and external suppliers).

- From programming experience, it has been found that CPU load $>65 \%$ makes the embedded system unstable and unpredictable. Hence different combinations of concurrent scenario's (stressed conditions) were chosen and CPU load tracked using a tool (proprietary) for every release as shown Figure 15. Any increase in the load led to code optimisation
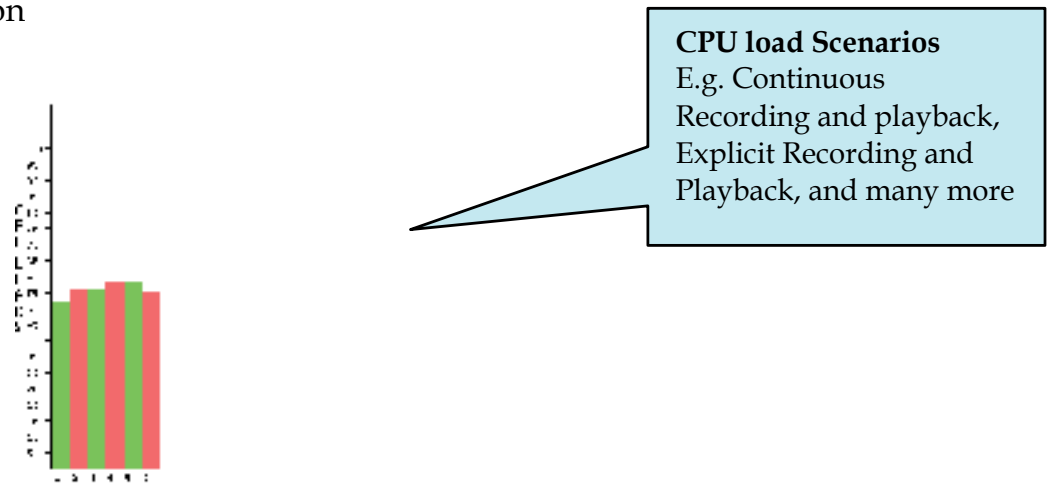

Fig. 15. CPU load tracking: Various scenarios

- $\quad$ FMEA was done to identify failure modes leading to exceptional conditions for new features. Graceful exits and error recovery mechanisms were implemented. For example- exit with an error message rather than be in a continuous loop when nonstandard USB device is connected to the recorder. 
- Static analyzer tools such QAC was run and the target set was $85 \%$ code coverage. Errors and warnings were closed. For each code module, the QAC coverage was measured and improved before "build generation".

- An operational profile of typical user scenarios was created and the software run on the product with different profiles continuously for 4-days at elevated temperatures (Duration test). The results were verified every alternate week.

- $\quad$ Finally the overall CTQ of robustness - hangs and crashes were measured on weekly builds to verify the results in normal as well as stressed conditions. Refer Figure 16 below

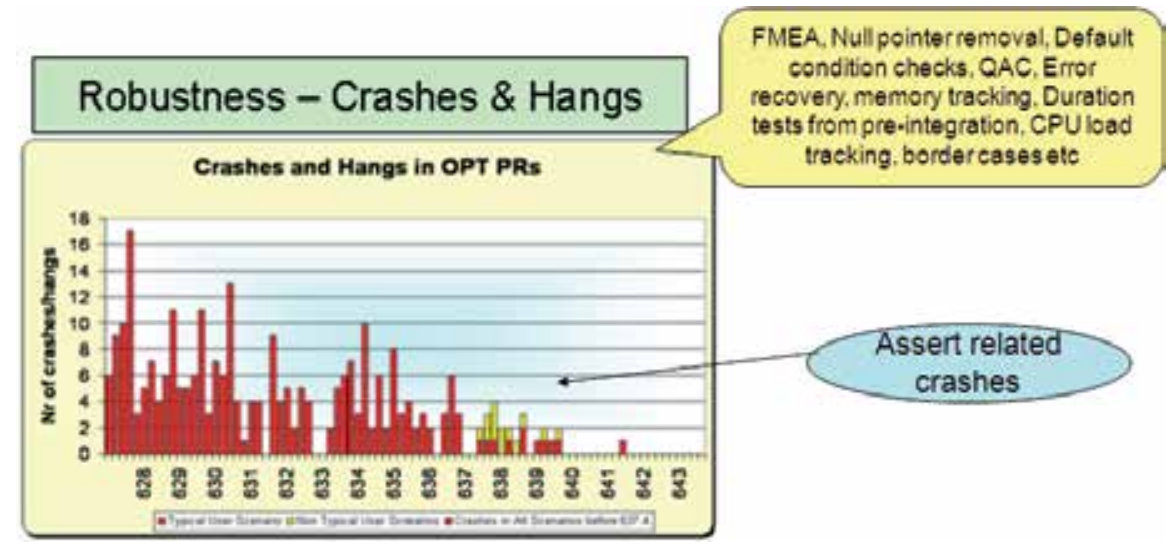

Fig. 16. Robustness CTQ Tracking

The stability of the set was well appreciated by sales and Field test personnel stating that it was indeed much better than previous sets. This was an early leading indicator, and the first feedback results coming from user tests, dealer meetings, field tests and market reviews were definitely indicating the improved robustness before the commercial release of the product.

\subsubsection{Usability}

Usability is very subjective parameter to measure and very easily starts becoming a critical factor. Living with the "Sense and Simplicity" theme of Philips, it was important that we treated it as a continuous CTQ and spend enough time to really quantify it.

A small questionnaire was prepared based on few critical features and weightage was assigned to them. A consumer experience test was conducted with a prototype version of product. Users with different age groups, nationality, gender, educational background were selected to run the user tests. These tests were conducted in home-like environment set-up as shown in Figure 17, so that the actual user behaviour could be observed. 


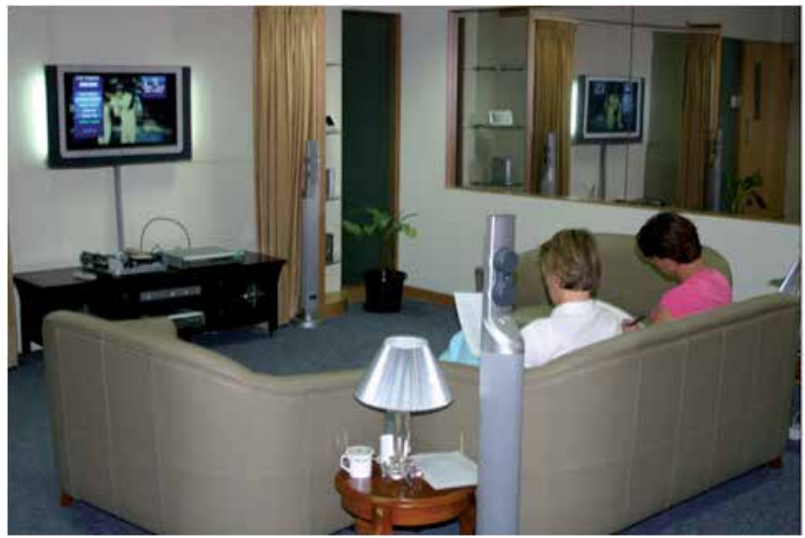

Fig. 17. Consumer Experience Test Set-up

The ordinal data of user satisfaction was then converted into a measurable CTQ based on the weightage and the user score. This CTQ we called as "Usability Index". The Xs impacting this case were the factors such as Age, Gender etc. The interaction plot shown in the Figure 18 below helped to figure out and correct a lot of issues at a design stage itself.

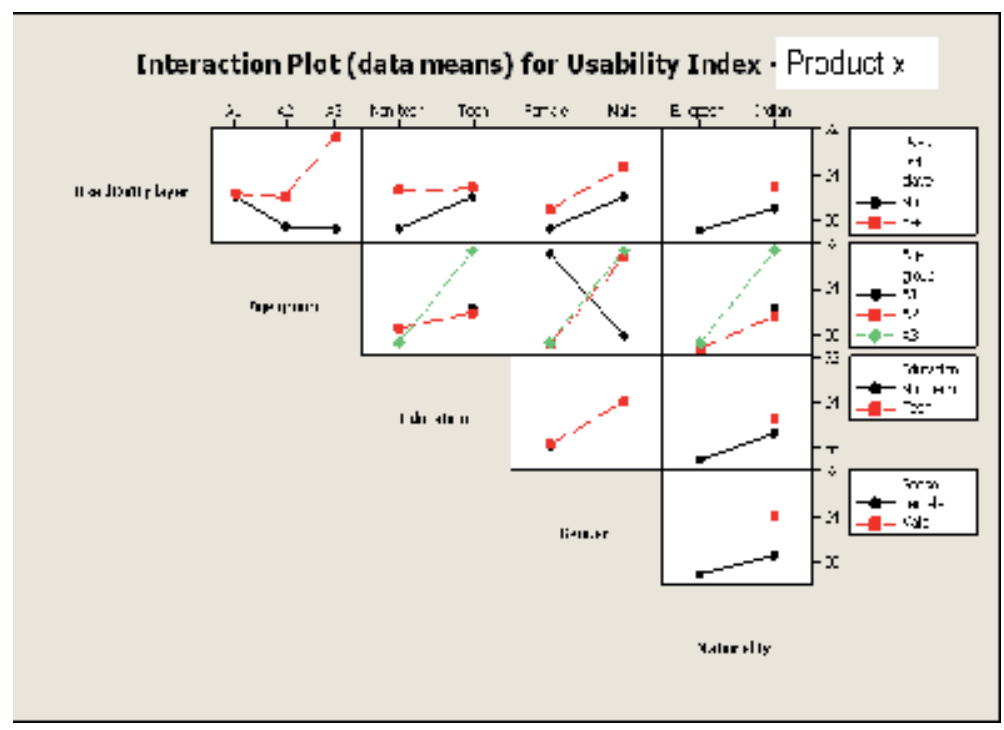

Fig. 18. Interaction Plot for Usability

For example - if the product is targeted towards European housewives of age group 25 - 40 who had no technical background and who had not used a DVD player before, we could already know what the usability issues could crop up in the field. Such feedbacks in different combinations were used to improve these issues at the design stage itself based on the target consumer group for this product XYZ. 


\subsection{Verify}

This phase of DFSS maps to the testing phase of software development life cycle. Once the system is integrated, it is essential to verify that the CTQs that were achieved in the development environment during the design \& optimize phase are still met on "production builds".

Here is where statistical tests and Z-scores could be used to verify that the CTQs have indeed been met on production sets. For all the performance (responsiveness) CTQs, we used statistical tests and Z-scores to verify the process capability. We configured 5 different sets with 2-3 operators measuring each of the performance CTQs for every release build. That makes it 10-15 samples for each CTQ per build. To avoid measurement errors simple set of clear instructions were made and explained to the testers doing the measurements. Similar stop watches from the same manufacturer were used to avoid any device related measurement errors creeping into the system. A few trials were done and observed before doing the actual measurements. In DfSS terms, this is referred to as "Gage Repeatability and Reproducibility" analysis.

When we talk about six-sigma, we are not only interested in mean but also the variation (standard deviation). Z-score is a measure that is a reflection of this variation.

$\mathrm{Z}=\mathrm{Abs}(\mathrm{SL}-\mu) / \sigma$; where SL is the specification limit, $\mu$ is the mean and $\sigma$ is the standard deviation.

By definition, anything outside specification limits is considered defect. From that perspective Z-score is also an indication of DPMO (defects per million opportunities). A 6 sigma process (i.e. $Z=6$ ) has a DPMO of just 3.4

Figure 19 shows the process capability (Z-score) for one such CTQ - "Content feedback time"

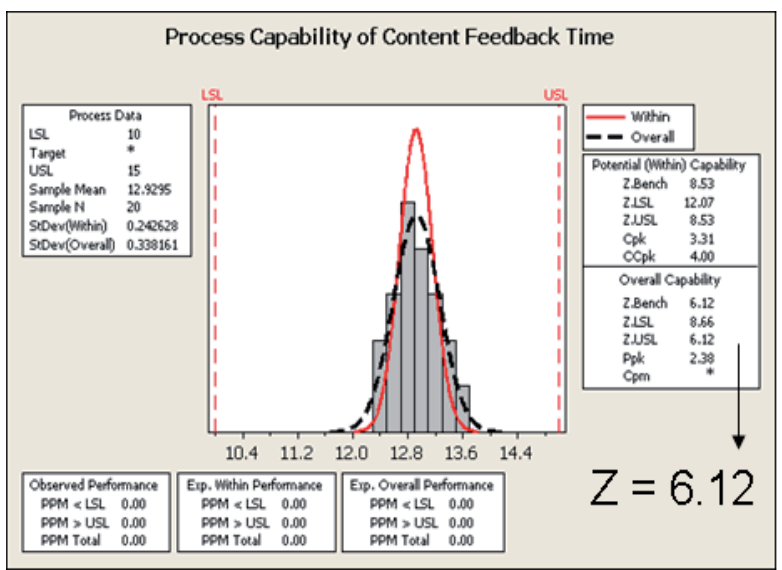

Fig. 19. Capability: Content Feedback Time

We also tried to see the change in Z-scores from initial condition to that after improvement. The 2 figures - Figure 20 and 21 show the previous and the current Z-scores for another CTQ - "USB notification time". 


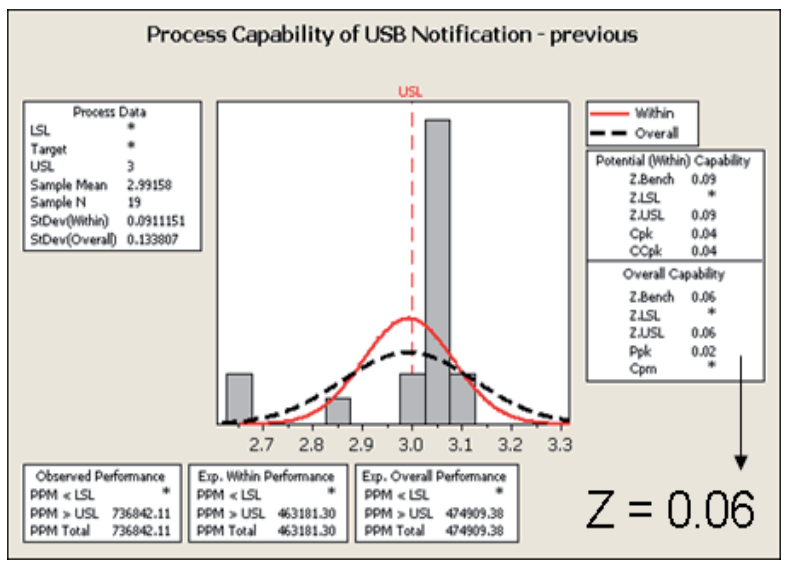

Fig. 20. USB Notification Time: Before

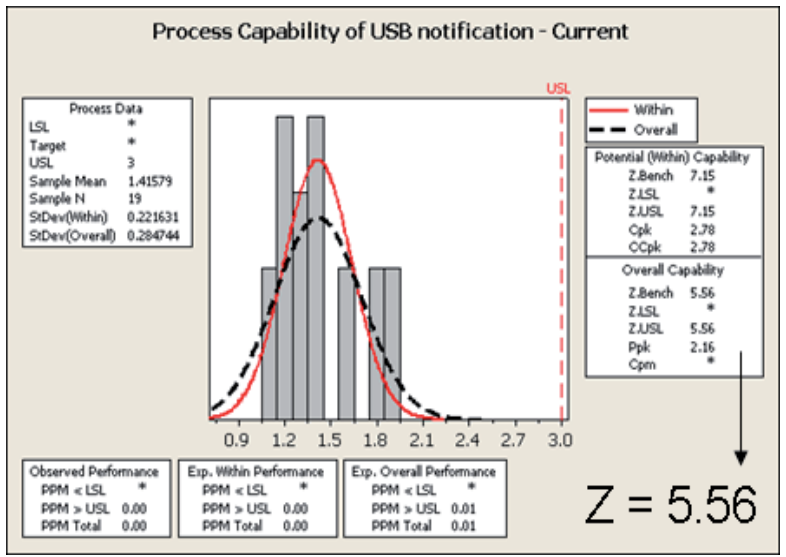

Fig. 21. USB Notification: After

One catch here is that it is quite likely that in software when we measure different samples we would get almost the same readings as software by itself does not have inherent variation. So we would land up with very high Z-scores and things would look very rosy. Hence when we are verifying the CTQs it should be done on an integrated system along with hardware (i.e. on a product) and not for only software. That would give a realistic picture as a good software code should also be able to mask the small variations arising out of hardware.

In addition to Z-scores, a set of statistical tests can be used to ascertain that there is indeed an improvement that is statistically significant and not just due to random variation. There are number of tests that we used such as

1-sample T test to compare mean of a sample against a target,

2 -sample $\mathrm{T}$ test to compare the means of 2 samples

F-test to compare the variation of 2 samples etc

In all these tests, the null hypothesis we used was "status quo" i.e. no change.

At the end of verify phase we had met most of the CTQs that we started with. For example:

DivX playability $>90 \%$, USB interoperability $-87 \%$. 


\subsection{Monitor}

This is the phase where the "proof of the pudding" is really available. The customers and stakeholder satisfaction is monitored in this phase. If our CTQs are right and if we meet them then customers should be satisfied, correspondingly the field calls and customer complaints should reduce leading to lower non-quality costs and improved usability scores. Some proof points indicating the success of the journey:-

1) All the product certifications such as DivX certification etc. went off successfully on the first trial itself saving lost of recertification costs

2) Referring to section 3.2, the first set of customers were the Sales personnel and the dealers.

Some Comments from sales personnel - "Compared to previous sets, the stability of XYZ is better".

Some reactions from dealer meetings - "Today we have many customers visiting us to show our new products. Just wanted to let you know that we received great feedback on the new XYZ. Some couldn't even believe it! Sense and Simplicity brought to life....... Congratulations on a job well done!"

All these lead us to believe firmly that market response also would be very positive

3) After the release, the market response was closely monitored in terms of field complaints as well as user feedbacks in various Audio-Video forums such as web pages

a. In most of the popular forums, the user views were extremely positive. The product XYZ always scored 8 or above (on a 10-point scale) on a comparative benchmark in the popular web forums

b. The software related field calls were less than $2.5 \%$ translating to potential savings of 2 Million Euros

\subsection{Conclusion}

The case study described above serves as a good evidence to ascertain that the DfSS approach and tools can be used effectively also in a software development environment. The learning's are summarized in the following two sections as "Gains" at one end of spectrum and "Points to ponder" at the other end.

\subsubsection{Gains}

Software engineering (addressing the pain areas)

- Better Requirements Management in terms of specifications, prioritization, and traceability. Focus on non-functional aspects of usability, interoperability, performance, robustness

- Importance of Execution architecture (State-transitions, CPU loading, Memory)

- Increase in Design effort, upfront design discussions automatically leads to reduction of rework in the end

- Early involvement of test team - CTQ measurement mechanism

- CTQs as leading indicators of product quality

\section{Cross-functional approach}

- Reduction in communication barrier - way of working with marketing, product management e.g. challenging specifications, Kano, risk-benefit analysis

- Common language of CTQs with other disciplines for synergy 
End-user perspective

- Development community sensitive to VOC - forces to think from problem domain rather than jumping into solutions.

- Measurement focus (variation rather than average), best case-worst case spectrum

System understanding (Product perspective)

- Transfer functions (CTQ flow-downs) triggers to understand the system better

- Understanding of noise and its effect on the system (usage environment)

- Trigger on "what could fail" (FMEA, mistake-proofing) improves robustness

Soft Aspects

- Mindset of "first time right" instead of "build-test-fix"

\subsubsection{Points to Ponder}

CTQ / domain dependency

- Everything is linked to CTQs so there is a chance of completely missing important ones

- Does not compensate for domain competency (Effectiveness of CTQ flow down, FMEA etc is determined by domain competency)

- Product management along with development community needs to be able to specify CTQs in a quantifiable way and as part of Consumer requirements specifications itself.

\section{Software Engineering}

- CTQs do not represent the complete requirements, hence the handling of other requirements, traceability, reviews, test coverage, regression need to be done also

- Configuration Management has to be addressed in the traditional way

- Additional effort needs to be budgeted in the initial phases (confidence of Project managers to plan more effort upfront that will compensate for effort saved in the end)

Use of Statistics in software

- $\quad$ Section 4.3 describes this topic in detail.

\section{Challenges for DfSS in software}

\subsection{Software process framework}

Software development organizations have traditionally followed the SEI-CMMIR framework. Many of them have well established process framework and Quality management system built on CMM/CMMI model. So trying to deploy another methodology is a challenge in itself and cause confusion to the stakeholders. The obvious question in the minds of people is - we already have CMM and yet another model? Will it replace CMMI? Will it cause more overheads, more documentation? etc. It is important to answer these doubts upfront and rest assure the stakeholders that a happy marriage is indeed possible between DfSS and CMM/CMMI.

After studying both the models and also number of research papers (Jeannine \& Forrester, 2004; Jeannine \& Halowel, 2005), it is quite evident that both of them actually complement each other very well instead of working against one another. The CMM/CMMI addresses 
the "What" (process) part with DfSS complementing it with the "How" part (methods and tools). So it is not one model versus another but rather a "methodology", that helps accelerate the CMM/CMMI journey by helping deploy processes better.

The Figure 22 below captures the essence of this thought process.

\section{Fig. 22. DfSS-CMMI Mapping}

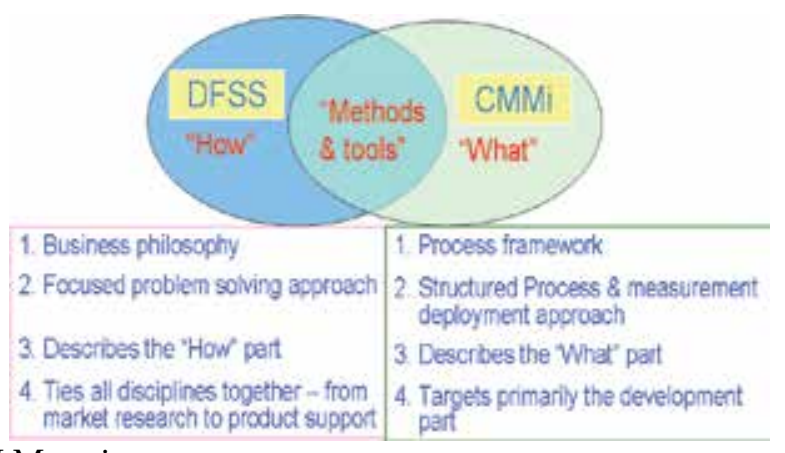

The other aspect is to ensure that the various phases and deliverables of DfSS are coupled with the internal milestones and processes as well as the overall goal of the organization. This is important part of Change management as described in section 2.4. The Figure 23 shows a broad level mapping of DfSS phases to the typical software development life cycle.

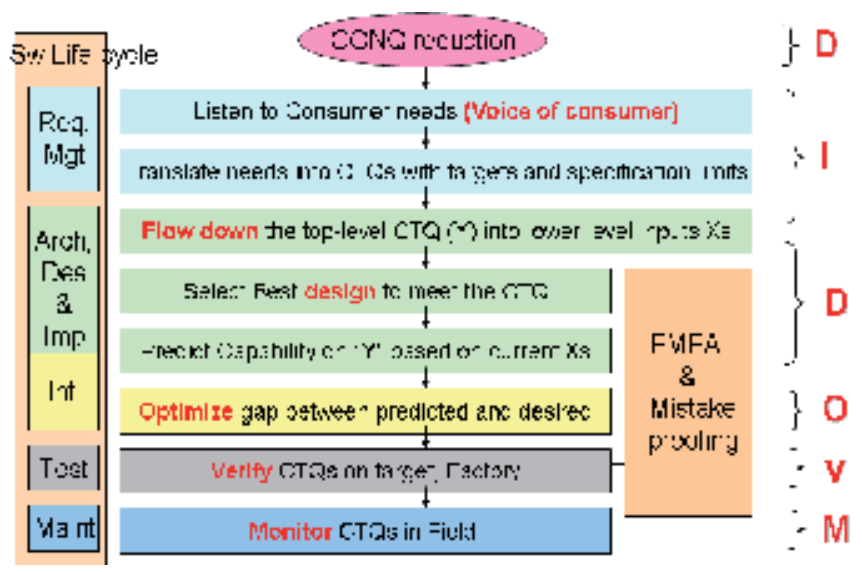

Fig. 23. DfSS-Software Life cycle Mapping 


\subsection{Software FMEA}

Failure mode and effects analysis (FMEA) is one of the well-known analysis methods having an established position in the traditional reliability analysis. The purpose of FMEA is to identify "UPFRONT" possible failure modes of the system components, evaluate their influences on system behaviour and propose proper countermeasures to suppress these effects. A failure mode and effects analysis (FMEA) can be described as a systematic way of identifying failure modes of a system, item or function, and evaluating the effects of the failure modes on the higher level. A bottom-up technique such as FMEA is an effective way to identify component failures or system mal-functions, and to "design rightly" the system under consideration (Pentti \& Atte, 2002).

The standard guidelines provided by the FMEA cannot be directly used and would have to be tailored for applying it to software. Typically the best definition for "Severity" would be the one that the software teams use for their problem report classifications. Similarly for "Occurrence" and "Detection" it is better that the teams use their own tailored guideline based on a simplistic criteria of "Very high" to "Very Low".

By nature, software failure modes generally are unknown - "software modules do not fail in the literal sense as hardware failure, they only display incorrect behaviour" - and depend on dynamic behaviour of the application. The aim of the FMEA is to then uncover those situations.

The following are certain alerts/pitfalls/learning's to be aware of when doing software FMEA:-

1) Use case explosion - Software due to its very nature has many permutations /combinations of inputs and outputs which could be prone to failures. Hence FMEA would soon run into thousands of use-case combinations of failure-modes. Hence it is advisable to focus on failure modes associated with CTQs, Critical components/modules/functionalities etc

2) Capturing "Requirements not meeting" as failure modes e.g. set not recording as a failure mode for a DVD recorder etc. Recording is a basic requirement itself of a recorder so listing it as failure mode at a global level would not help. Instead the failure mode should delve deeper into the features

3) Not having the appropriate subject matter experts in the analyses. Failure modes largely dependent on competence, hence knowledge of domain (not software engineering but rather the usage of product in actual environment) is crucial

4) Attempting to perform FMEA on $100 \%$ of the design or code instead of sampling the design/code most likely to cause a serious failure

5) Excluding hardware from the analysis or isolating the software from the rest of the system as many of the failures result from the combination and not software alone

6) Typically for software, the severity "SEV" would remain unchanged and it is mainly the occurrence and detection that can be improved. For e.g. a hang/crash in a normal user operation is a severity " $\mathrm{A}$ " failure mode translating to a value of 8 for SEV. By taking various actions, its occurrence can be reduced/ eliminated or detectability can be improved. However even after taking actions, the severity would remain unchanged

7) The occurrence "OCC" value can be tricky sometimes for software. In a product development environment, normally a test will be done on few devices say 5 to 10 and issues do not surface out. When long duration tests are conducted in the factory on a 
larger sample say 100 devices then the product starts failing. So OCC value could be different based on the sample taken and has to be accordingly adapted when validating the results

8) From software development life-cycle perspective, the DET value can take on different values for the same detection levels. For e.g. a control mechanism may have a high chance of detecting a failure mode making the DET value 4 as per the guideline. However based on whether that detection can happen in design itself or testing may vary the value. The team might give a higher vale for DET for something that can be detected only in testing as against that which can be detected in design.

\subsection{Use of Statistics in software}

Often this is one of most important challenge when it comes to using concepts like DfSS for software. Many software requirements fall into the Yes/No, Pass/Fail category so limit setting is fuzzy. Most of them would become critical factors (CFs) and not CTQs in the "continuous data" sense

- $\quad$ Predicting DPMO (defects per million opportunities) may be misleading (out of limits). This is because the specifications limits in cases like responsiveness are soft targets. Just because it takes 0.5 seconds more than Upper Specification Limit to start-up does not necessarily classify it as a defective product. In Six sigma terms anything beyond Upper spec limit and less than Lower spec limit becomes a defect

- Random failures due to only software are rare due to which concept like Mean-TimeBetween-Failures (MTBF) for software alone is questionable, however it makes sense at overall product level

- No concept of samples - the same piece of code is corrected and used, so advanced statistical concepts have to be applied with discretion

However this does not mean that statistical concepts cannot be applied at all.

- The starting point is to challenge each specification to ensure if some numbers can be associated with it. Even abstract elements such as "Usability" can be measured as seen in section 3.5.2

- For many of the software CTQs, the Upper limits and lower limits may not be hard targets, nevertheless it is a good to use them as such and relax it during the course of the development

- The change in Z-scores over the releases would be more meaningful rather than absolute Z-scores

- All Statistical concepts can be applied for the "Continuous CTQs"

- Many of the Design of experiments in software would happen with discrete Xs due to nature of software. So often the purpose of doing these is not with the intent of generating a transfer function but more with a need to understand which "Xs" impact the $Y$ the most - the cause and effect. So the Main effects plot and Interaction plots have high utility in such scenarios

- The hypothesis tests such as t-Tests, F-Tests, ANOVA are useful in the Verify and Monitor phase to determine if indeed there have been statistical significant changes over the life cycle or from one product generation to next etc. 
- Statistical Capability analysis to understand the variation on many of the CTQs in simulated environments as well as actual hardware can be a good starting point to design in robustness in the software system.

\section{References}

Ajit Ashok Shenvi (2008). Design for Six Sigma : Software Product Quality, Proceedings of the 1st India Software Engineering Conference, pp. 97-106, ISBN:978-1-59593-917-3, Hyderabad, India, February 19 - 22, 2008. ISEC '08. ACM, New York, NY, DOI= http:// doi.acm.org/10.1145/1342211.1342231

Haapanen Pentti \& Helminen Atte, Stuk-yto-tr 190/August 2002. Failure modes and effects analysis of software based-automation systems

Jeannine M. Siviy and Eileen C. Forrester. (2004). Accelerating CMMi adoption using Six Sigma,Carnegie Mellon Software Engineering Institute

Jeannine M. Siviy (SEI), Dave Halowell (Six Sigma advantage). 2005. Bridging the gap between CMMi \& Six Sigma Training. Carnegie Mellon Sw Engineering Institute

Jiantao Pan. 1999. Software Reliability. Carnegie Mellon http://www.ece.cmu.edu/ koopman/des_s99/sw_reliability/

Minitab tool - Statistical tool. http://www.minitab.com

Philips DFSS training material for Philips. 2005. SigMax Solutions LLC, USA 


\title{
Statistical Process Control for Software: Fill the Gap
}

\author{
Maria Teresa Baldassarre, Nicola Boffoli and Danilo Caivano \\ University of Bari \\ Italy
}

\section{Introduction}

The characteristic of software processes, unlike manufacturing ones, is that they have a very high human-centered component and are primarily based on cognitive activities. As so, each time a software process is executed, inputs and outputs may vary, as well as the process performances. This phenomena is better identified in literature with the terminology of "Process Diversity" (IEEE, 2000). Given the characteristics of a software process, its intrinsic diversity implies the difficulty to predict, monitor and improve it, unlike what happens in other contexts. In spite of the previous observations, Software Process Improvement (SPI) is a very important activity that cannot be neglected. To face these problems, the software engineering community stresses the use of measurement based approaches such as QIP/GQM (Basili et al., 1994) and time series analysis: the first approach is usually used to determine what improvement is needed; the time series analysis is adopted to monitor process performances. As so, it supports decision making in terms of when the process should be improved, and provides a manner to verify the effectiveness of the improvement itself.

A technique for time series analysis, well-established in literature, which has given insightful results in the manufacturing contexts, although not yet in software process ones is known as Statistical Process Control (SPC) (Shewhart, 1980; Shewhart, 1986). The technique was originally developed by Shewhart in the 1920s and then used in many other contexts. The basic idea it relies on consists in the use of so called "control charts" together with their indicators, called run tests, to: establish operational limits for acceptable process variation; monitor and evaluate process performances evolution in time. In general, process performance variations are mainly due to two types of causes classified as follows:

- Common cause variations: the result of normal interactions of people, machines, environment, techniques used and so on.

- Assignable cause variations: arise from events that are not part of the process and make it unstable.

In this sense, the statistically based approach, SPC, helps determine if a process is stable or not by discriminating between common cause variation and assignable cause variation. We can classify a process as "stable" or "under control" if only common causes occur. More precisely, in SPC data points representing measures of process performances are collected. 
These values are then compared to the values of central tendency, upper and lower limit of admissible performance variations.

While SPC is a well established technique in manufacturing contexts, there are only few works in literature (Card, 1994; Florac et al., 2000; Weller, 2000(a); Weller, 2000(b); Florence, 2001; Sargut \& Demirors, 2006; Weller, \& Card. 2008; Raczynski \& Curtis, 2008) that present successful outcomes of SPC adoption to software. In each case, not only are there few cases of successful applications but they don't clearly illustrate the meaning of control charts and related indicators in the context of software process application.

Given the above considerations, the aim of this work is to generalize and put together the experiences collected by the authors in previous studies on the use of Statistical Process Control in the software context (Baldassarre et al, 2004; Baldassarre et al, 2005; Caivano 2005; Boffoli, 2006; Baldassarre et al, 2008; Baldassarre et al, 2009) and present the resulting stepwise approach that: starting from stability tests, known in literature, selects the most suitable ones for software processes (tests set), reinterprets them from a software process perspective (tests interpretation) and suggest a recalculation strategy for tuning the SPC control limits.

The paper is organized as follows: section 2 briefly presents SPC concepts and its peculiarities; section 3 discusses the main differences and lacks of SPC for software and presents the approach proposed by the authors; finally, in section 4 conclusions are drawn.

\section{Statistical Process Control: Pills}

Statistical Process Control (SPC) (Shewhart, 1980; Shewhart, 1986) is a technique for time series analysis. It was developed by Shewhart in the 1920s and then used in many contexts. It uses several "control charts" together with their indicators to establish operational limits for acceptable process variation. By using few data points, it is able to dynamically determine an upper and lower control limit of acceptable process performance variability. Such peculiarity makes SPC a suitable instrument to detect process performance variations. Process performance variations are mainly due to: common cause variations (the result of normal interactions of people, machines, environment, techniques used and so on); assignable cause variations (arise from events that are not part of the process and make it unstable). A process can be described by measurable characteristics that vary in time due to common or assignable cause variations. If the variation in process performances is only due to common causes, the process is said to be stable and its behavior is predictable within a certain error range; otherwise an assignable cause (external to the process) is assumed to be present and the process is considered unstable. A control chart usually adopts an indicator of the process performances central tendency (CL), an upper control limit (UCL = $\mathrm{CL}+3$ sigma) and a lower control limit $(\mathrm{LCL}=\mathrm{CL}-3$ sigma). Process performances are tracked overtime on a control chart, and if one or more of the values fall outside these limits, or exhibit a "non random" behavior, an assignable cause is assumed to be present. 


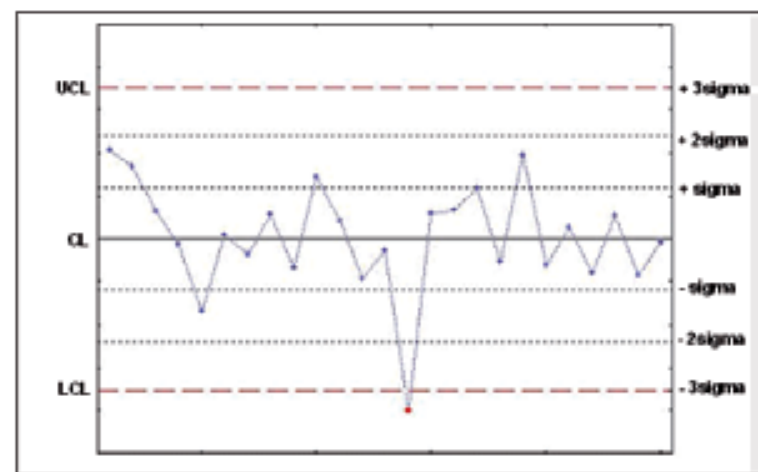

Fig. 1. Example of SPC charts (X charts)

"Sigma" is calculated by using a set of factors tabulated by statisticians (for more details refer to (Wheeler \& Chambers, 1992)) and it is based on statistical reasoning, simulations carried out and upon the heuristic experience that: "it works". A good theoretical model for a control chart is the normal distribution shown in figure 2 where: the percentage values reported express the percentage of observations that fall in the corresponding area; $\mu$ is the theoretical mean; $\sigma$ is the theoretical standard deviation. In the $[\mu-3 \sigma, \mu+3 \sigma]$ interval, fall $99.73 \%$ (i.e. $2.14+13.59+34.13+34.13+13.59+2.14$ ) of the total observations. Thus only the $0,27 \%$ of the observations is admissible to fall outside the $[\mu-3 \sigma, \mu+3 \sigma]$ interval.

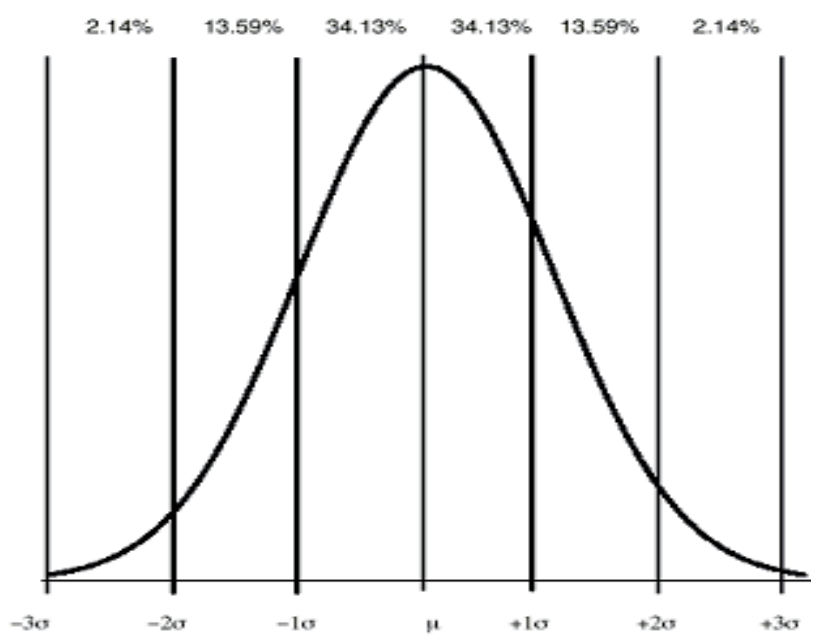

Fig. 2. Normal distribution, the bell curve

If we consider sigma in place of $\sigma$, the meaning and rational behind a control chart results clear. For completeness it is necessary to say that the normal distribution is only a good theoretical model but, simulations carried out have shown that independently from the data distribution, the following rules of thumb work:

- Rule1: from $60 \%$ to $75 \%$ of the observations fall in the [CL-sigma, CL+1sigma]

- Rule2: from $90 \%$ to $98 \%$ of the observations fall in the [CL-2sigma, CL+2sigma]

- Rule3: from $99 \%$ to $100 \%$ of the observations fall in the [CL-3sigma, CL+3sigma] 
The control limits carried out using SPC are based on a process observation and they are expression of it. They are not the result of expert judgment and, furthermore, they can be clearly obtained.

In general, control charts are used as follows: samples are taken from the process, statistics (for example, average and range) are calculated and plotted on charts, and the results are interpreted with respect to process limits or, as they are known in SPC terminology, control limits. Control limits are the limits within which the process operates under normal conditions. They tell us how far we can expect sample values to stray from the average given the inherent variability of the process or, to use the SPC terms, the magnitude of common-cause variation. Data points beyond the control limits or other unusual patterns indicate a special-cause variation.

\section{SPC for Software}

Software processes and manufacturing ones present deep differences that the use of SPC in software cannot exempt from considering. Moreover, according to the discussions in (Jalote, 2002(a); Eickelmann \& Anant, 2003) we can consider three main differences between manufacturing and software processes that have to be kept in mind in order to assure a more appropriate use of SPC in software context in terms of control charts, run test indicators, anomalies interpretation and control limits calculation.

Measurement of Software Processes. In manufacturing, the observed and actual number of defects is not significantly different. In software development, these two numbers routinely vary significantly. Possible causes for extreme variation in software measurement include the following:

- People are the software production process.

- Software measurement might introduce more variation than the process itself.

- Size metrics do not count discrete and identical units.

Such extreme variations in software processes need different indicators for the anomalies detection and more specific interpretations.

Product Control and Product Rework. The primary focus of using SPC control charts in manufacturing is to bring the process back in control by removing assignable causes and minimize as much as possible the future production losses. In the manufacturing process when an anomaly occurs the products usually do not conform to the expected standards and therefore, must be discarded. On the other hand, in the software process the product can be "reworked". For example, when using control charts for an inspection process, if a point falls outside the control limits, besides the process improvement actions like improving the checklist, inevitably, product improvement actions like re-reviews, scheduling extra testing also occurs. With software processes, besides improving the process, an important objective of using control charts is to also control the product. In (Gardiner \& Montgomery, 1987), which is perhaps the first paper on the use of SPC in software, Gardiner and Montgomery suggest "rework" as one of the three actions that management should carry out if a point falls outside the control limits. The use described in (Ebenau, 1994) clearly shows this aspect of product control. The survey of high maturity organizations also indicates that project managers also use control charts for project-level 
control (Jalote, 2002(b)). Due to this product-control, project managers are more likely to want test indicators and interpretations that highlight potential warning signals, rather than risk to miss such signals, even if it means more false alarms.

Shutdown and Startup is "Cheaper". The cost parameters that affect the selection of control limits are likely to be quite different in software processes. For example, if a manufacturing process has to be stopped (perhaps because a point falls outside the control limits), the cost of doing so can be quite high. In software, on the other hand, the cost of stopping a process is minimal as elaborate "shutdown" and "startup" activities are not needed. Similarly, the cost of evaluating a point that falls outside the control limits is likely to be very different in software processes as compared to manufacturing ones. For these reasons the control limits could be recalculated more often than in manufacturing processes.

Due to these differences, it is reasonable to assume that, to get the best results, control charts, the use of the indicators and their interpretation, as well as the tuning of process limits, will need to be adapted to take into account the characteristics of software processes.

Finally, in spite of the rather simple concepts underlying statistical process control, it is rarely straightforward to implement (Card, 1994). The main lacks for software processes are listed below:

Focus on individual or small events. The indicators generally used in SPC highlight assignable causes related to the individual events. However the high variability of a software process and its predominant human factor make such indicators ineffective because they usually discover occasional variations due to passing phenomena that should be managed as false positives (false alarms).

Therefore the SPC indicators, in software processes, should detect the assignable variations and then also interpret them if occasional variations (as false positives) or occurred changes in the process (in the manufacturing processes the passing phenomena are very rare). For such reasons the control charts should be constructed with a view toward detecting process trends rather than identifying individual nonconforming events (Figure 3).

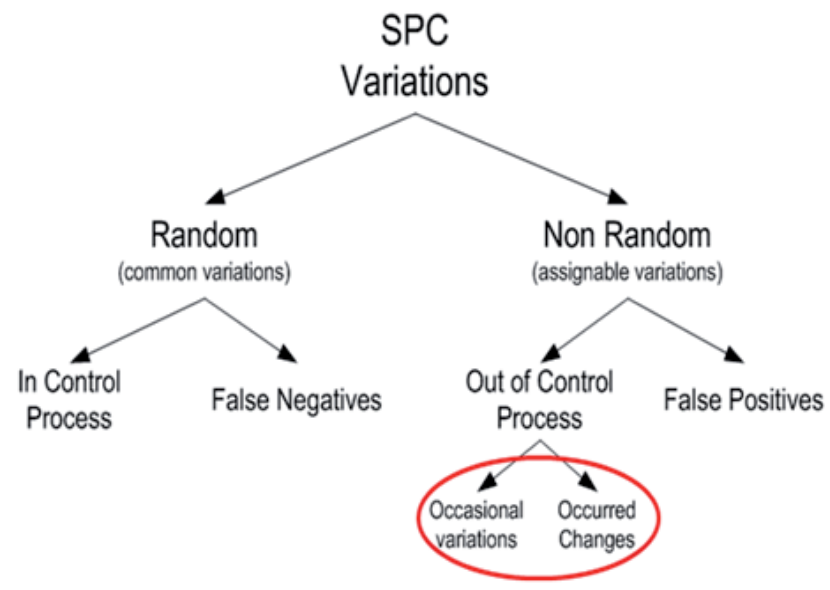

Fig. 3. SPC variations tree 
Failure to investigate and act. Statistical process control only signals that a problem may exist. If you don't follow through with a detailed investigation, like an audit, and follow-up corrective action, there is no benefit in using it. In these sense a larger set of anomalies indicators and a more precise anomalies interpretation is necessary.

Incorrect computation of control limits. Several formulas exist for computing control limits and analyzing distributions in different situations. But although they are straightforward, without proper background, it is easy to make mistakes. Such mistakes might concern:

- the correct calculation of control limits

- the appropriate timing for the recalculation of control limits ("tuning" activities)

In order to mitigate such differences and face these issues, in the past the authors have proposed and experimented an SPC framework for software processes (Baldassarre et al., 2007). Such framework, based on the software process peculiarities, proposes the most appropriate control charts, a set of indicators (run-test set) and related interpretations (runtest interpretation) in order to effectively monitor process variability. When such indicators are used, SPC is able to discover software process variations and discriminate between them. For these reasons such indicators:

- are able to detect process trends rather than identify individual nonconforming events (i.e. occasional variations that in software processes would be considered like the false alarms)

- enable to discover assignable variations and address some quality information about "what happens" in the process. Thereby such framework supports the manager during the causes-investigation activities.

Furthermore, our framework faces problems related to incorrect computation of control limits and proposes "when" and "how" to recalculate the SPC control limits (the "tuning" activities) that supports manager in:

- Choosing the control charts and measurement object to use in SPC analysis

- Selecting the appropriate data-points, building the Reference Set and calculating the control limits needed for monitoring process variations

- Monitoring the process variations and detecting run-tests failures

- Evaluating the assignable events occurred and then undertaking the appropriate actions (for example recalculating the control limits)

Figure 4 summarizes the steps for applying the framework: first, process characterization is carried out, i.e. a process characteristic to monitor is observed over time, and related data points are collected; the appropriate control chart is selected and upper and lower control limits are calculated (Step 1); secondly anomaly detection occurs, i.e. each new data point observed is plotted on the chart, keeping control limits and central line the same; the set of run tests (RT1...RT8) is executed and anomalies are detected each time a test fails (Step 2); at this point, causes investigation is carried out, i.e. the cause of the anomaly pointed out is investigated in order to provide an interpretation (Step 3). Finally, according to the process changes occurred and identified in the previous step, appropriate tuning actions are applied to tune the sensibility of the monitoring activity and adapt it to the new process performances (Step 4). 


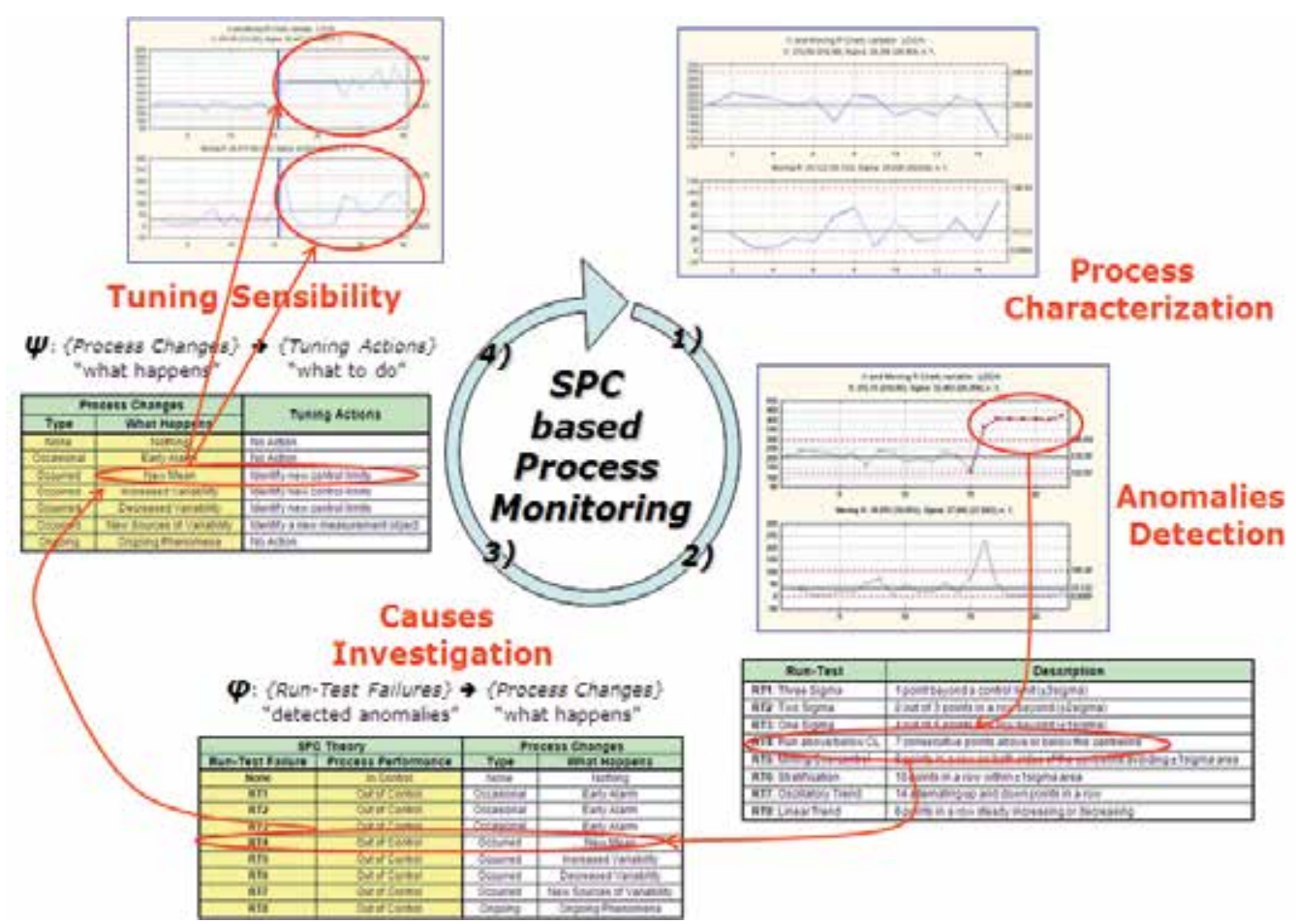

Fig. 4. SPC based Process Monitoring guidelines

\subsection{Process Characterization}

A reference set must be determined in order to characterize a process, i.e. a set of observations that represent the process performances and do not suffer from exceptional causes. In short, the reference set provides a reference point to compare the future performances with. After determining the reference set, each following observation must be traced on the control chart obtained and then the set of tests included in the test set must be carried out in order to identify if eventual exceptional causes come up. More precisely, the following two steps are executed:

- Identify the measurement object

- Identify the reference set

Identify the measurement object. The process to evaluate is identified along with the measurement characteristics that describe the performances of interest. The most appropriate control charts for the phenomena being observed are selected. There are charts for variables data (measurement data such as length, width, thickness, and moisture content) and charts for attributes data ("counts" data such as number of defective units in a sample). 


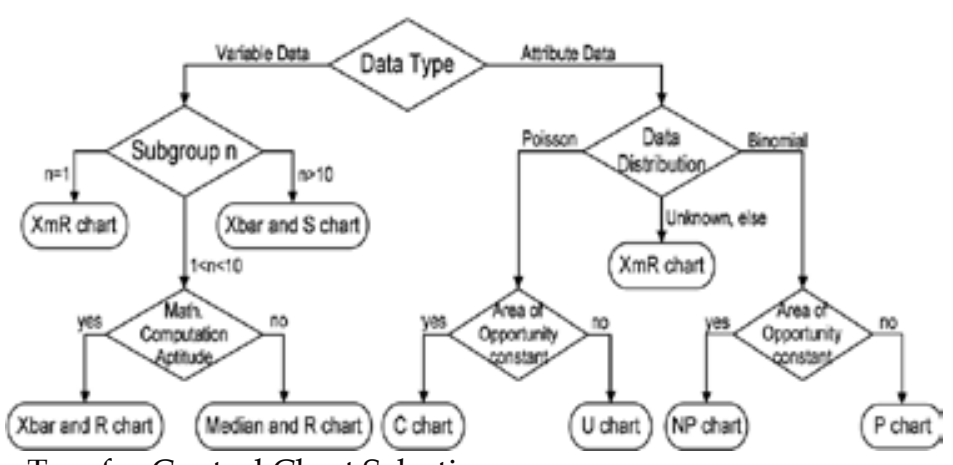

Fig. 5. Decision Tree for Control Chart Selection

In software processes, where data points are not so frequent, generally, each data point is individually plotted and evaluated. Hence, charts that work on single observation points (like the XmR or the U charts) are more suitable for software (Gadiner \& Montgomery, 1987; Weller, 2000(a); Zultner, 1999) and are the most commonly used charts, as reported in the survey (Radice, 2000). On the other hand, in manufacturing, the Xbar-R charts, which employ a sampling based technique, is most commonly used. Consequently, modeling and analysis for selecting control limits optimal performance has also focused on Xbar-R charts.

Identify the Reference Set. Identifying the "reference set" is a mandatory activity for correctly monitoring and evaluating the evolution of process performances in time. It consists in a set of observations of the measurement characteristics of interest. The set expresses the "normal" process behaviour, i.e. the process performances supposing that the variations are determined only by common causes. As so, first, process performances in time must be measured and, CL and control limits must be calculated. The observations collected are then traced on the control charts and the tests included in the test set are carried out. If no anomalies are detected, the process can be considered stable during the observation period. The observations collected along with the CL and control limits values become the reference set. If one of the tests points out anomalies, then the process is not stable. As so, it must be further investigated. The exceptional causes, if present, need to be eliminated from the process and, the CL and control limits must be recalculated. This is repeated until a period of observed data points indicate a stable process, i.e. until a new reference set can be determined.

In an $X$ chart: each point represents a single value of the measurable process characteristic under observation; CLX is calculated as the average of the all available values; UCLX and LCLX are set at 3sigmaX around the CLX; sigmaX is the estimated standard deviation of the observed sample of values calculated by using a set of factors tabulated by statisticians (for more details refer to (Wheeler \& Chambers, 1992; Park, 2007)). In a mR chart: each point represents a moving range (i.e. the absolute difference between a successive pair of observations); $C L m R$, is the average of the moving ranges; $\mathrm{UCLmR}=\mathrm{CLmR}+3$ sigmamR and $\mathrm{LCLmR}=0$; sigmamR is the estimated standard deviation of the moving ranges sample.

For example, given a set of 15 observations $X=\{213.875,243.600,237.176,230.700,209.826$, $226.375,167.765,242.333,233.250,183.400,201.882,182.133,235.000,216.800,134.545\}$, the following values are determined: 


$$
\begin{aligned}
& \overline{m R}=\frac{1}{m-1} \times \sum_{i=1 \ldots m-1}\left|x_{i-1}-x_{i}\right|=33.11 \\
& 3 \text { sigmax }=2,660 * \overline{m R}=88.07 \\
& \mathrm{CLx}=\bar{X}=210.58 \\
& \mathrm{UCLx}=\bar{X}+2,660 * \overline{m R}= \\
& 298.64 \\
& \mathrm{LCLx}=\bar{X}-2,660 * \overline{m R}=122.52 \\
& \mathrm{CLmR}=\overline{m R}=33,11 \\
& \mathrm{UCLmR}=3,268 * \overline{m R}=108,2 \\
& \mathrm{LCL}{ }_{m R}=0
\end{aligned}
$$

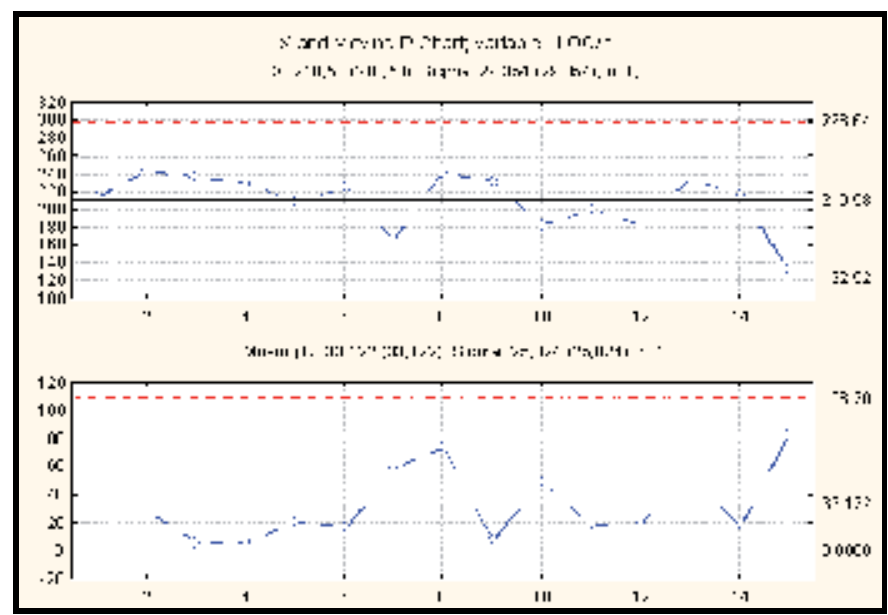

Fig. 6. Example of Individual and moving ranges charts (XmR charts)

\subsection{Anomalies Detection}

In software processes, one should look for systematic patterns of points instead of single point exceptions, because such patterns emphasize that the process performance has shifted or is shifting. This surely leads to more insightful remarks and observations. There is a set of tests for such patterns referred to as "run rules" or "run tests" (see (AT\&T, 1956; Nelson, 1984; Nelson, Grant \& Leavenworth, 1980; Shirland, 1993)) that aren't well known (or used) in the software engineering community.

\begin{tabular}{|l|l|}
\hline \multicolumn{1}{|c|}{ Run-Test } & \multicolumn{1}{c|}{ Description } \\
\hline RT1: Three Sigma & 1 point beyond a control limit $( \pm 3$ sigma $)$ \\
\hline RT2: Two Sigma & 2 out of 3 points in a row beyond $( \pm 2$ sigma) \\
\hline RT3: One Sigma & 4 out of 5 points in a row beyond $( \pm 1$ sigma $)$ \\
\hline $\begin{array}{l}\text { RT4: } \text { Run above/below } \\
\text { CL }\end{array}$ & 7 consecutive points above or below the centreline \\
\hline $\begin{array}{l}\text { RT5: } \\
\text { Mixing/Overcontrol }\end{array}$ & $\begin{array}{l}8 \text { points in a row on both sides of the centreline avoiding } \\
\pm \text { sigma area }\end{array}$ \\
\hline RT6: Stratification & 15 points in a row within \pm 1 sigma area \\
\hline RT7: Oscillatory Trend & 14 alternating up and down points in a row \\
\hline RT8: Linear Trend & 6 points in a row steadily increasing or decreasing \\
\hline
\end{tabular}

Table 1. Run-Test Set Details 
As sigma, the run rules are based on "statistical" reasoning. For example, the probability of any observation in an $X$ control chart falling above the $C L$ is at a glance equal to 0.51 . Thus, the probability that two consecutive observations will fall above the CL is equal to 0.5 times $0.5=$ 0.25 . Accordingly, the probability that 9 consecutive observations (or a run of 9 points) will fall on the same side of the $C L$ is equal to $0.5^{\wedge} 9=0.00195$. Note that this is approximately the probability with which an observation can be expected to fall outside the 3-times sigma limits. Therefore, one could look for 9 consecutive observations on the same side of the CL as another indication of an out-of-control condition. Duncan (Duncan, 1986) provides details concerning the "statistical" interpretation of the other tests presented in this paragraph.

In order to simplify the test execution, the chart area is conventionally divided in three zones: Zone A is defined as the area between 2 and 3 times sigma above and below the center line; Zone B is defined as the area between 1 and 2 times sigma, and Zone $C$ is defined as the area between the center line and 1 times sigma. For the execution of the zone based tests, the distribution of the values in the charts need to be assumed as symmetrical around the mean. This is not the case for $\mathrm{mR}$ charts and thus, in general, all the zone based tests are not applicable to R chart (see Figure 7 for applicability). Although this is a shared opinion, someone (Wheeler \& Chambers, 1992) states that these tests help process monitoring. Furthermore, according to (Jalote, 2000(a)), managers are more likely to want warning signals to be pointed out, rather than missing them, even if it means risking for false alarms.

The presented framework points out which SPC tests may be applied to which control charts. It presents, interprets and organizes tests in order to manage software processes. Although in the software engineering community only "a point falling outside control limits" test is usually used for testing process stability, we are of the opinion that the SPC based software process monitoring should be based on the following tests that we have rearranged in three conceptual classes according to the type of information they provide (Figure 6). When one or more of these tests is positive, it is reasonable to believe that the process may no longer be under control, i.e. an assignable cause is assumed to be present. For completeness and clearness it is the case to point out that the first 4 tests among those that follow are also referred to as "detection rules" and are the most (and often the only ones) used tests (Wheeler \& Chambers, 1992; Florac et al., 1997) within the software engineering community.

${ }^{1}$ provided (1) that the process is in control (i.e., that the centre line value is equal to the population mean), (2) that consecutive sample means are independent, and (3) that the distribution of means follows the normal distribution. 

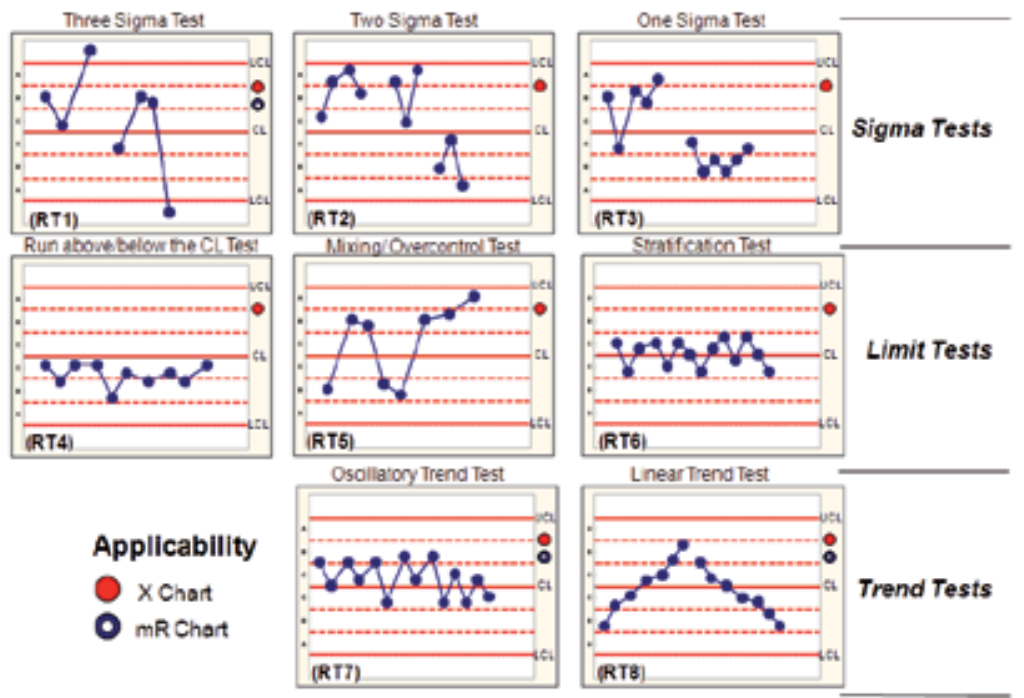

Fig. 7. Run-tests set

\subsubsection{Sigma Tests}

These tests point out the possible presence of an assignable cause. The three sigma test can be applied to both, $\mathrm{X}$ and $\mathrm{R}$ charts. The One and Two sigma tests are Zone Tests and thus they should not be applied to $R$ the chart due to its lack of symmetry around the mean.

1. Three Sigma Test (Extreme Points Test): The existence of a single point beyond a control limit signals the presence of an out-of -control condition, i.e. the presence of an assignable cause.

2. Two Sigma Test: This test watches for two out of three points in a row in Zone A or beyond. The existence of two of any three successive points that fall on the same side of, and more than two sigma units away from, the central line, signals the presence of an out-of -control condition. This test provides an "early warning" of a process shift.

3. One Sigma Test: This test watches for four out of five subgroups in a row in Zone B or beyond. The existence of four of any five successive points that fall on the same side of, and more than one sigma unit away from, the central line, signals the presence of an out-of-control condition. Like the previous test, this test may be considered to be an "early warning indicator" of a potential shift in process performance.

The three sigma test is the most (and often the "only" one) used test in software engineering literature.

\subsubsection{Limit Tests}

All the tests included in this class use chart Zones and thus they are applicable to the $X$ charts only.

1. Run above or below the Centerline Test: This test watches for 7,8 or 9 consecutive observations above or below the centerline. The presence of such a run indicates 
that the evidence is strong and that the process mean or variability has shifted from the centerline.

2. Mixing/Overcontrol Test: Also called the Avoidance of Zone C Test. This test watches for eight subgroups in a row on both sides of the centerline avoiding Zone $\mathrm{C}$. The rule is: Eight successive points on either side of the centerline avoiding Zone C, signals an out-of-control condition.

3. Stratification Test: Also known as the Reduced Variability Test. This test watches for fifteen subgroups in a row in Zone C, above and below the centerline. When 15 successive points on the $X$ chart fall in Zone $C$, to either side of the centerline, an out-of control condition is signaled.

\subsubsection{Trend Tests}

This class of tests point out a trend resulting in a process performance shift. Neither the chart centerline nor the zones come into play for these tests and thus they may be applied to both $\mathrm{X}$ and $\mathrm{R}$ charts.

1. Oscillatory Trend Test: it watches for fourteen alternating up or down observations in a row. When 14 successive points oscillate up and down, a systematic trend in the process is signaled.

2. Linear Trend Test: it watches for six observations in a row steadily increasing or decreasing. It fails when there is a systematic increasing or decreasing trend in the process.

\subsection{Causes Investigation}

SPC is only able to detect whether the process performance is "out of control" and if an anomaly exists. It doesn't support the manager during the causes investigation and the selection of the appropriate corrective actions. This solution extends the SPC-theory by providing a specific interpretation (Table 2) of the anomaly for each run test failure (section 3.2) from the software process point of view, and suggesting possible causes that make the process "Out of Control" (Baldassarre, 2004). More precisely, the authors have arranged and interpreted the selected SPC indicators (Table 1) in logical classes: sigma (RT1, RT2, RT3), limit (RT4, RT5, RT6) and trend (RT7, RT8), for details refer to (Baldassarre, 2004).

\subsubsection{Sigma Tests}

They provide an "early" alarm indicator that must stimulate searching for possible assignable causes and, if the case, identify and eliminate them. One and Two sigma tests point out a potential anomalous "trend" that "may" undertake assignable causes. In general, due to the high variance in software processes especially when we manage individual rather than sample data, the faults highlighted by these tests could be numerous but less meaningful than in manufacturing contexts. For example, in a manufacturing process a party of poor quality raw material may be a potential assignable cause that must be investigated and removed. In a software process, a possible assignable cause may be an excessive computer crash due to a malfunctioning peripheral but also to a headache of the developer. Different considerations could be made if the point on the chart represents a group of observations, such as the productivity of a development team. In this case the 
peaks accountable to a single developer's behavior are smoothened. Therefore, the point on the charts may express a general behavior determined by an assignable cause.

Similar considerations can be made on the use of Three sigma test, based on a single observation that falls outside limits, rather than One or Two sigma tests, that refer to a sequence of observations and thus to a "potential behavioral trend".

\subsubsection{Limit Tests}

This class of tests point out an occurred shift in process performances. They highlight the need to recalculate the control limits when the actual ones are inadequate, because they are too tiny or larger than required. In software process monitoring and improvement we represent a measurable characteristic that expresses human related activity outcomes (time spent, productivity, defect found during inspection etc.) on a control chart. Thus while a single point falling outside control limits can be interpreted as the result of a random cause, a "sequence" of points means that something has changed within the process.

The Run above or below the Centerline Test watches for 8 points on one side of the central line. If this pattern is detected, then there is strong evidence that the software process performance has changed in better or worse. The longer the sequence is, the stronger the evidence is.

A failure of the Mixing/Overcontrol Test could mean more than one process being plotted on a single chart (mixing) or perhaps over control (hyper-adjustment) of the process. In software process this test failure highlights that the process is becoming less predictable than in the past. Typically this occurs immediately after an induced improvement, and continues until the improvement is fully acquired by the developers or organization.

A failure of the Stratification Test can arise from a change (decrease) in process variability that has not been properly accounted for in the $X$ chart control limits. From the software process point of view this is a typical behavior of process when a maturity effect is identified. Introduction of a new technology in a software process is usually followed by, an unstable period until developers become more confidant and performance variability decreases. Substantially, although in SPC theory this test highlights the presence of an assignable cause, in software process the interpretation of this test may be positive: the process is becoming more stable and predictable than in the past.

\subsubsection{Trend Tests}

While the previous tests class points out the presence of an occurred shift, this one highlights an ongoing or just occurred phenomena that represents an ongoing shift that needs to be investigated. Typically, a failure in this test class can be the result of both spontaneous or induced process improvement initiatives. The tests will be briefly commented.

When the Oscillatory Trend Test is positive, two systematically alternating causes are producing different results. For example, we may monitor the productivity of two alternating developer teams, or monitor the quality for two different (alternating) shifts. As a consequence the measurable characteristic observed must be investigated in a more straightforward way in order to isolate the two causes. Probably, when this test fails we are observing the wrong characteristic or the right one measured in a wrong way.

The Linear Trend Test fails when there is a systematic increasing or decreasing trend in the process. This behavior is common and frequent in software processes. It is the result of an 
induced process improvement, such as the introduction of a new technology, or a spontaneous one, such as the maturation effect. This test, give insightful remarks when it fails on $\mathrm{R}$ chart and it is interpreted jointly between $\mathrm{X}$ and $\mathrm{R}$ charts. For example:

- If $R$ chart shows a decreasing trend as in Figure 8(d), a possible interpretation is that the process is going asymptotically towards a new stability point: better as in Figure 8 (b) or worse than actual Figure 8(a). If this is the case, this test failure should be followed by a limit test failure (typically test 4 ) on $X$ chart. Another situation is represented in Figure 8(c) i.e. a process is going towards a more stable situation around the central line, after a strong period of destabilization.

- If $R$ chart shows an increasing trend, as in Figure 9(d), then the process is becoming unstable, its performance are changing in a turbulent manner and it is far from reaching a new point of stability (see as in Figure $9(a, b, c)$. Typically this test failure occurs together with test 5 failure on $X$ chart.
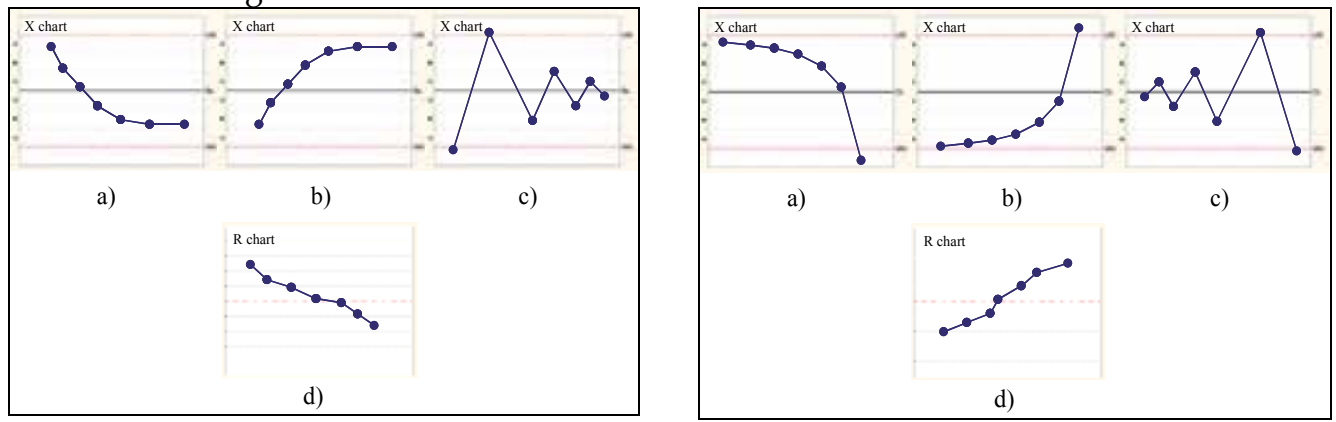

Fig. 8. Decreasing linear trend test interpretation Fig. 9. Increasing linear trend test interpretation

As so, according to the interpretations given, we are able to define the following function: $\varphi:\{$ Run-Test Failures $\rightarrow \rightarrow$ \{Process Changes $\}$

"detected anomalies" "what happens"

\begin{tabular}{|c|c|c|c|}
\hline \multicolumn{2}{|c|}{ SPC Theory } & \multicolumn{2}{c|}{ Process Changes } \\
Failure & Process Performance & Type & What Happens \\
\hline None & In Control & None & Nothing \\
\hline RT1 & Out of Control & Occasional & Early Alarm \\
\hline RT2 & Out of Control & Occasional & Early Alarm \\
\hline RT3 & Out of Control & Occasional & Early Alarm \\
\hline RT4 & Out of Control & Occurred & New Mean \\
\hline RT5 & Out of Control & Occurred & Increased Variability \\
\hline RT6 & Out of Control & Occurred & $\begin{array}{c}\text { Decreased } \\
\text { Variability }\end{array}$ \\
\hline RT7 & Out of Control & Occurred & $\begin{array}{c}\text { New Sources of } \\
\text { Variability }\end{array}$ \\
\hline RT8 & Out of Control & Ongoing & $\begin{array}{c}\text { Ongoing } \\
\text { Phenomena }\end{array}$ \\
\hline
\end{tabular}

Table 2. Run-Test Interpretation Details. 
For each run-test failure, $\varphi$ is able to relate the "detected anomalies" to "what happens" within the process and suggest their cause.

\subsection{Tuning Sensibility}

SPC control limits need to be recalibrated according to relevant process performance changes. The sensibility of the monitoring activity has to be tuned continuously. The risk of not tuning sensibility is to miss anomalies as the result of using larger limits than necessary or having several false alarms.

- The monitoring activity based on SPC is carried out with control limits as baselines within which the process can vary randomly. Process is monitored according to specific characteristics (known as measurement objects) selected by the manager.

- Even when control limits are well estimated they can become obsolete due to process performance changes.

- Control limits are too tight, too wide, or the central line is no longer representative of the average process performances.

- Measurement object is no longer representative, the measures used may no longer express process variability.

In both cases it is necessary to:

1. identify when a relevant process performance change occurs;

2. tune the control model (i.e. recalibrate control limits) according to performance changes.

Point (1) follows from the experience acquired during empirical validation of the SPC approach in a previous study (Baldassarre et al., 2004). Following to this experience we have generalized a set of relations between "what happens" in the process and what the best actions to undertake are (Table 3).

\begin{tabular}{|c|c|l|}
\hline \multicolumn{2}{|c|}{ Process Changes } & \multicolumn{1}{c|}{ Tuning Actions } \\
\hline Type & What Happens & \multicolumn{1}{|c|}{ No Action } \\
\hline None & Nothing & No Action \\
\hline Occurred & Early Alarm & Identify new control limits (new reference set) \\
\hline Occurred & Increased Variability & Identify new control limits (new reference set) \\
\hline Occurred & Decreased Variability & Identify new control limits (new reference set) \\
\hline Occurred & New Sources of Variability & Identify a new measurement object \\
\hline Ongoing & Ongoing Phenomena & No Action \\
\hline
\end{tabular}

Table 3. Relationship between Process Changes and the necessary SPC Tuning Actions.

According to such relations and to "Process Changes" described through the "run-test interpretation" we have defined the following function:

$$
\begin{gathered}
\Psi:\{\text { Process Changes }\} \\
\text { "what happens" }
\end{gathered}
$$


$\Psi$ is defined so that it assigns the appropriate tuning actions needed to update the SPC settings preserving the sensibility of monitoring.

Thus $\psi$ can be defined as follows:

- if the process change is "Occasional", the process performance:

- should be the same as in the past if assignable causes have been detected and removed or, if this is not the case, further observations are needed to exhibit the new process performance;

- is probably changing due to the fact that assignable causes were made part of the process. In this case further observations have to be collected.

In both cases the control limits and the measurement objects remain the same.

- if the process change is "Occurred":

$\circ$ if process mean or variability are changed then the control limits should always be recalculated in order to determine a new reference set that expresses the new process performance. The candidate points to be included in the reference set are those responsible for the test failure.

o if there is a new source of variability then the different sources must be identified, separated and tracked on different charts.

- if the process change is "Ongoing" additional observations are needed to determine reliable limits for the process because the actual observations express a change in actions and thus, they are not suitable for a reference set. In this case "no action" is advisable.

Point (2) derives from composing functions $\varphi$ and $\psi$, in $\rho=\psi о \varphi$ :

$$
\begin{aligned}
& \rho:\{\text { Run-Test Failures }\} \rightarrow \\
& \text { "detected anomalies" }
\end{aligned}
$$

$\rho$ for each statistical "signal" suggests the suitable action to undertake to preserve monitoring sensibility (Table 4).

Section 2, therefore, outlines a quick and effective solution that takes into account the issue of process monitoring, allows to identify anomalies, suggests the most appropriate tuning actions and preserves the monitoring model in use.

\begin{tabular}{|c|l|}
\hline Run-Test Failure & \multicolumn{1}{|c|}{ Tuning Actions } \\
\hline None & No Action \\
\hline RT1 & No Action \\
\hline RT2 & No Action \\
\hline RT3 & No Action \\
\hline RT4 & Identify a new control limits \\
\hline RT5 & Identify a new control limits \\
\hline RT6 & Identify a new control limits \\
\hline RT7 & Identify a new measurement object \\
\hline RT8 & No Action \\
\hline
\end{tabular}

Table 4. Relationship between the Signals and the SPC Tuning Actions 
Let us now apply these concepts to the explanatory figures 10 and 11 . We can see that RT1, RT2, and RT3 are classified as "occasional" process changes. They detect an early alarm, and according to $\psi$ do not require any tuning action. On the other hand, RT4 and RT5 are classified as "occurred" process changes because the process mean has changed (RT4) and the process variability, considering the limits in use, has also increased (RT5) as can clearly be seen in figure 10. Indeed, the observed data points, from 16 on, no longer fall within the fixed limits. Consequently, in accordance to $\psi$ and to the guidelines in table 4, new control limits must be calculated. Figure 11 shows the result of the tuning action, i.e. the new control limits calculated from data points 16-30.

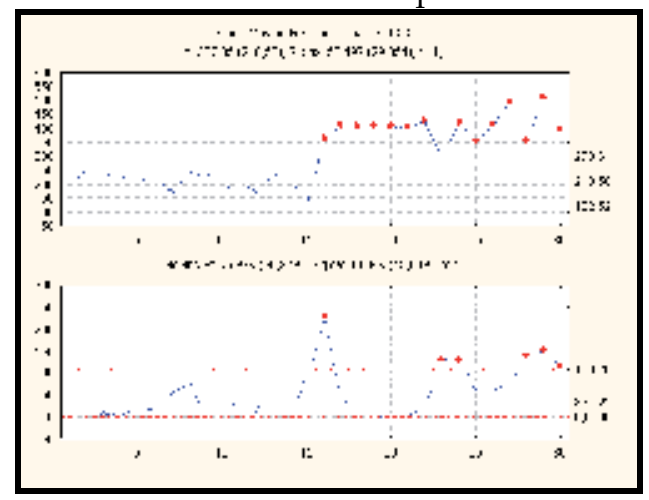

Fig. 10. RT4 and RT5 suggesting a shift in process performances

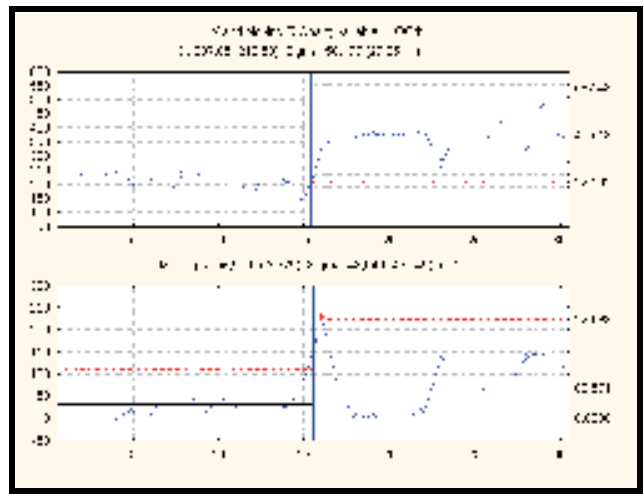

Fig. 11. new control limits calculated from data points $16-30$

\section{Discussion and final remarks}

The presented framework, starting from the analysis of the Statistical Process Control as commonly used in the manufacturing contexts, and based on the issues that characterize software production, presents a set of evolutions and improvements that allow to:

- take into account the trends of observations rather than exclusively considering, single data points, even if anomalous. Indeed, in software and in human intensive processes, the behavioural trends are more significant than the single observations. Furthermore, in software, a single event such as an observation that falls outside the limits is not as critical as an observation in the manufacturing context. Indeed, in the latter case, an observation out of the limits is most likely an indicator that leads to discarding part of the production and stopping the production chain to avoid further relevant economical losses. Fortunately, in software it is possible to "rework" rather than discard the work already produced. The framework presented in this paper on one hand implies Run Tests that focus on a longsequence of events (Limit and Trend tests) and, on the other, reinterprets the Run Tests based on a short-sequence (Sigma Test) reorganizing them in meaning and effect.

- make up for the lacks of SPC in the investigation phase of the anomalies and in identifying appropriate interventions to make the monitored process stable again. In this sense, it foresees a function $\varphi$ that, based on the anomalies detected by the Run-Tests, determines what happens in the process, i.e. identifies the changes 
occurred or taking place. As so, focused and specific actions can be identified and carried out in order to regain a stable process.

- $\quad$ adapt the sensibility of monitoring actions with respect to the actual performances of the monitored process. This characteristic is particularly important in pursuing the effectiveness of monitoring. The current literature does not present useful guidelines for determining when the control limits should be recalculated, in that they are no longer representative of the process performances. Consequently an incorrect use of SPC occurs, based on inadequate control limits which lead to ineffective monitoring and control actions: too wide limits do not allow to promptly raise significant variations, while too narrow ones determine numerous false alarms. The proposed framework foresees the $\psi$ function that associates Tuning Actions, expression of "what to do", to Process Changes, the expression of "what happens". This assures a dynamic and continuous calibration of monitoring based on the actual observed process performances.

The framework represents an alternative to other software process monitoring techniques, which can generally be considered as based on expert judgment, use measures collected in time, and subject to subjective evaluations. In this sense, it is interesting to point out that the framework:

- makes it possible to characterize process performances, even without having any previous knowledge, by determining a reference set through a deterministic procedure. Note that lack of previous knowledge usually occurs for innovative processes, or for processes that are used in different contexts with different maturity levels, or refer to various application domains (technical rather than business). Moreover, in our framework, control limits are not an expert-based estimation, but an actual expression of the process itself.

- provides a conceptual manner for defining process anomalies and, at the same time, an operational means for identifying them. Without such instruments (conceptual and operational) the interpretation of a trend rather than a single observation would completely rely on the project manager, who may not necessarily have the previous knowledge needed and thus, may neglect important events or focus on irrelevant ones resulting in ineffective monitoring.

- represents an objective rather than subjective tool, a clear reference point, follows rom explicit reasoning and based on a solid theoretic model (SPC).

Nevertheless, software process monitoring still represents an open issue. As discussed in (Baldassarre et al., 2007), there are many aspects related to software process measurement such as the difficulty of collecting metrics, their reliability and the selection of monitored process characteristics (Sargut \& Demirors, 2006); the violation of assumptions underlying SPC (Raczynski \& Curtis, 2008); predominance of human factors in software processes that can impact on the SPC-theory and monitoring effectiveness [17]. All these aspects leave much space for subjective management decisions that can influence the success/failure of monitoring activities. Given these limitations, this framework is not intended as the solution to monitoring problems, nor as a silver bullet for applying SPC to software processes.

Rather, it should be considered as a perspective on how SPC can contribute to practically solve some monitoring issues according to the authors' experience from the trench in real industrial software projects. It can be seen as a contribution for guiding practitioners 
towards a more disciplined use of SPC starting from understanding how it can really address software process monitoring. In this way operational, practical issues and pitfalls of SPC can be faced more systematically.

\section{References}

AT\&T. (1956). "Statistical quality control handbook", Indianapolis, AT\&T Technologies, 1956

Baldassarre, M.T.; Boffoli, N.; Caivano, D. \& Visaggio, G. (2005). Improving Dynamic Calibration through Statistical Process Control. In: 21st International Conference on Software Maintenance, pp. 273-282. IEEE Press, Budapest Hungary (2005)

Baldassarre, M.T.; Boffoli, N.; Bruno, G. \& Caivano, D. (2009). International Conference on Software Process, ICSP 2009 Vancouver, Canada, May 16-17, 2009 Proceedings. Lecture Notes in Computer Science 5543 Springer 2009, ISBN 978-3-642-01679-0

Baldassarre, M.T.; Boffoli, N. \& Caivano, D. (2008). Statistical Process Control for Software: a Systematic Approach. In Proceedings of the Second International Symposium on Empirical Software Engineering and Measurement, ESEM 2008, October 9-10, 2008, Kaiserslautern, Germany. ACM 2008, ISBN 978-1-59593-971-5

Baldassarre, M.T.; Boffoli, N.; Caivano, D. \& Visaggio, G. (2004). Managing Software Process Improvement (SPI) through Statistical Process Control (SPC). In: 5th International Conference on Product Focused Software Process Improvement, pp. 30-46. LNCS Springer, Kansai Science City Japan (2004)

Baldassarre M.T.; Caivano D.; Kitchenham B. \& Visaggio G. (2007). Systematic Review of Statistical Process Control: an Experience Report. In: 11th International Conference on Evaluation and Assessment on Software Engineering, pp.119-129. BCS, Keele UK (2007)

Basili, V. R.; Caldiera, G. \& Rombach, H.D. (1994). “Goal Question Metric Paradigm”, Encyclopedia of Software Engineering, Vol. 1, John Wiley \& Sons, 1994, pp. 528-532.

Boffoli, N. (2006). Non-Intrusive Monitoring of Software Quality. In: 10th European conference on Software Maintenance and Reengineering, pp. 319-322. IEEE Press, Bari Italy (2006)

Caivano, D. (2005). Continuous Software Process Improvement through Statistical Process Control. In: 9th European Conference on Software Maintenance and Reengineering, pp. 288-293. IEEE Press, Manchester UK (2005)

Card, D. (1994). Statistical Process Control for Software. IEEE Software, May 1994 pp. 95-97. IEEE Press (1994)

Duncan, A. J. (1986). Quality Control and Industrial Statistics, R.D.IRWIN 5th edition, 1986

Ebenau, R.G. (1994). "Predictive Quality Control with Software Inspections", Crosstalk, June 1994

Eickelmann, N. \& Anant, A. (2003). Statistical Process Control: What You Don't Measure Can Hurt You! IEEE Software, Mar. / Apr. 2003, pp. 49-51. IEEE Press (2003)

Florac, W. A.; Carleton, A.D. \& Bernard, J.R. (2000). "Statistical Process Control: Analyzing a Space Shuttle Onboard Software Process", IEEE Software, pp. 97-106, July/Aug. 2000. 
Florac, W. A.; Park, R. E. and Carleton, A. D. (1997). "Practical Software Measurement: Measuring for Process Management and Improvement", Carnegie Mellon University, 1997.

Florence, A. (2001). “CMM Level 4 Quantitative Analysis and Defect Prevention”, Crosstalk, Feb. 2001.

Gardiner, J. S. \& Montgomery, D.C. (1987). "Using Statistical Control Charts for Software Quality Control," Quality and Reliability Eng. Int'l, vol. 3, pp. 40-43, 1987.

Grant, E. L. \& Leavenworth, R.S. (1980). "Statistical quality control", 5th Edition, New York, McGraw-Hill, 1980

IEEE Software (2000). "Process Diversity", July - August 2000.

Jalote, P. (2002a). Optimum Control Limits for Employing Statistical Process Control in Software Process, IEEE Transaction on Software Engineering, vol. 28, no.12, pp. 1126-1134. IEEE Press 2002 (a)

Jalote, P. (2002b). "Use of Metrics in High Maturity Organizations" Proc. Software Eng. Process Group Conf. (SEPG'00), Mar. 2002(b)

Nelson, L. (1984). “The Shewhart control chart - tests for special causes", Journal of Quality Technology, 15, 237-239, 1984.

Nelson, L. (1984). "Interpreting Shewart X-bar contol charts", Journal of Quality Technology, 17, 114-116, 1985.

Park, Y., Choi, H., Baik, J.: A Framework for the Use of Six Sigma Tools in PSP/TSP. In: 5th International Conference on Software Engineering Research, Management \& Applications, pp. 807-814. Springer, Busan Korea (2007)

Raczynski B. \& Curtis, B. (2008). Software Data Violate SPC's Underlying Assumptions. IEEE Software, May/June 2008 pp. 49-51. IEEE Press (2008)

Radice, R. (2000). "Statistical Process Control in Level 4 and 5 Organizations Worldwide," Proc. 12th Ann. Software Technology Conf., 2000, also available at www.stt.com.

Sargut, K. U \& Demirors O. (2006). Utilization of statistical process control in emergent software organizations: pitfalls and suggestions. Software Quality Journal 14, pp. 135-157. (2006)

Shewhart, W. A. (1980). "The Economic Control of Quality of Manufactured Product”, D. Van Nostrand Company, New York, 1931, reprinted by ASQC Quality Press, Milwaukee, Wisconsin, 1980.

Shewhart, W. A. (1986). "Statistical Method from the Viewpoint of Quality Control”, Dover Publications, Mineola, New York, 1939, republished 1986.

Shirland, L. E. (1993). "Statistical quality control with microcomputer applications", New York, Wiley, 1993

Weller, E. F. (2000a). "Practical Applications of Statistical Process Control”, IEEE Software, pp. 48-54, May/June 2000 (a).

Weller, E. F. (2000b). “Applying Quantitative Methods to Software Maintenance”, ASQ Software Quality Professional, vol. 3, no. 1, Dec 2000 (b).

Weller, E. \& Card. D. (2008). Applying SPC to Software Development: Where and Why. IEEE Software, May/June 2008 pp. 48-51. IEEE Press (2008)

Wheeler, D. J. \& Chambers, D.S. (1992). “Understanding Statistical Process Control”, 2nd ed., SPC Press, 1992

Zultner, R. E. (1999). "What Do Our Metrics Mean?" Cutter IT J., vol. 12, no. 4, pp. 11-19, Apr. 1999. 


\title{
MiniDMAIC: An Approach to Cause and Analysis Resolution in Software Project Development
}

\author{
Carla Ilane M. Bezerra, Adriano B. Albuquerque and Luiz Sérgio Plácido \\ Master Program in Applied Informatics, University of Fortaleza \\ Fortaleza, Brazil
}

\section{Introduction}

To achieve practices in CMMI a great amount of organizations are adopting Six Sigma as strategy. This methodology does not support practices of high levels of maturity but also of low levels (Siviy et al., 2005).

The Six Sigma and CMMI have compatible goals and the Six Sigma is, in most of the cases, extremely compatible with others quality initiatives that can be already implemented on the organization. The Six Sigma can be executed in macro and micro levels of the organization and can be successful either with elementary graphical tools or with advanced statistical tools (Dennis, 1994).

One of the fundamental aspects of the quality improvement is the analysis and resolution of problems. For this, a formal method of solving problems can be used, that may bring a lot of benefits, such as (Banas Qualidade, 2007):

- Prevent the problem solvers pass straight to the conclusion;

- Ensure the root-cause analysis;

- Demystify the process for solving problems;

- Establish analytical tools to use and determine when to use them.

In this context, the use of Six Sigma methodology's tools such as DMAIC, has been outstanding. Unlike other approaches to solve the problems, that focus only on eliminating the problem itself, the DMAIC methodology (Rath and Strong 2005) used by the Six Sigma comprises from the selection of issues that deserve a deeper treatment to the control of results obtained in the course of time.

The DMAIC method presents step by step how the problems should be addressed, grouping the aim quality tools, while establishing a standardized routine to solve problems with a proved efficient implementation in software organizations.

Although appropriate for the organizational level, the formal methods to solve problems can be not viable at projects level. A major challenge faced by companies that want the CMMI level 5 is exactly the implementation of the process area "Causal and Analysis Resolution - CAR" in the context of software projects, since they generally have very limited 
resources. Thus, immediate actions are taken only to resolve problems and, in most of the cases, the same problems happen again.

Some works suggest approaches for analysis of causes focusing at the organizational level. However, it is often necessary to perform analysis of causes within the projects, quick and effective, attacking the root causes of the problem. In organizations that aim to achieve high levels on maturity mode, such as CMMI, this practice is required within the project to maintain adherence to the model.

Furthermore, none of the approaches investigated involving analysis and resolution of causes, is based on DMAIC. The proposed approach in this paper aims to make effective the root cause analysis in the context of projects providing a structured set of steps based on the DMAIC method, to be run in a simple way.

Despite all the benefits of using Six Sigma methodology in conjunction with the CMMI, the implementation of the process area "Causal Analysis and Resolution" in software projects often becomes impractical for the following reasons:

- DMAIC projects have duration between 3 to 6 months. However, projects require rapid resolution of their problems and cannot wait too long;

- Due to the great necessity of using statistical tools, the DMAIC can become excessively expensive, the savings may be less than the cost to achieve improvements, and the projects often have limited resources;

- The qualification level of the DMAIC team is quite strict, however, in the context of software development projects, other attributes such as business domain and project management can bring greater results than the fact of having a team with great knowledge in statistics.

Given this background, this work aims at developing an approach based on the DMAIC (Six Sigma), called MiniDMAIC, to address the process area "Causal an Analysis and Resolution" from CMMI, in software development projects, looking for reducing the disadvantages described above related to the use of DMAIC. It also aims to present the application of the methodology in software development projects in an organization using a workflow tool, which was implemented the practices of MiniDMAIC.

This work is organized into five sections, besides this introduction. In section 2, we present the theoretical basis related to Six Sigma and, more specifically, the DMAIC methodology. In Section 3, we discuss the CMMI process area "Causal Analysis and Resolution" pertaining to the maturity level 5 . In section 4, we present the proposed approach, called MiniDMAIC. In sections 5 and 6, we present a mapping MiniDMAIC with the area of CAR and the DMAIC process, respectively. Aspects concerning the use of MiniDMAIC on real projects, and the obtained results are presented in section 7 . In Section 8, contains papers relating to the preparation of the approach. Finally, in section 9, we present the final considerations and limitations of the proposed methodology.

\section{The Six Sigma and the DMAIC Methodology}

The Six Sigma é is a methodology that focuses on reducing or eliminating the incidence of errors, defects and failures in a process. The Six Sigma methodology also aims to reduce the process variability and can be applied in most of the sectors of the economic activity (Smith, 2000). 
Achieving the Six Sigma means reducing defects, errors and failures ${ }^{1}$ to zero and to achieve near the perfection in processes' performance. The methodology combines a rigorous statistical approach to an arsenal of tools that are employed in order to characterize the sources of variability to demonstrate how this knowledge can control and optimize the process results (Watson, 2001).

The Six Sigma methodology aims to define the obvious and not obvious cause that affect the process in order to eliminate or improve them and controlling them (Rotondaro 2002).

The Six Sigma presents some techniques to address problems and improvements, such as DMAIC (Define, Measure, Analyze, Improve and Control), DCOV (Define, Characterize, Optimize, Verify) and DFSS (Design For Six Sigma). In this work, the DMAIC methodology will be used.

The DMAIC methodology was created by General Electric and, according to Tayntor (2003), is the most used in companies that implement the Six Sigma, and also more suitable for software development.

The DMAIC methodology consists of five phases: define, measure, analyze, improve and control. In the phase "define" is necessary to identify the problem and then to define the existent opportunities to resolve it according to the customer requirements. In phase "measure", the current situation should be verified through quantitative measurements of the performance, so that subsequent decisions are based on facts. In phase "analyze", the achieved performance and their causes should be identified and the existent opportunities should be analyzed. After doing this analysis, it is possible to perceive points to improve the performance and to implement improvements in phase "improve." In phase "control" the improvement should be ensured, through the control of the deployed process performance. Pande (2001) highlights that one cannot use the DMAIC for any improvement. A Six Sigma improvement project, according to the author, must have three qualifications:

- There is a gap between current performance and required/expected performance;

- The cause of the problem is not understood clearly;

- The solution is not predetermined, nor is the optimal apparent solution.

Besides, the viability criteria should be observed, such as: the necessary resources, available skills, the complexity, the probability of success and support and engagement of the team.

\section{The CMMI and the Causal Analysis and Resolution}

The Capability Maturity Model Integration (CMMI) (Chrissis, 2006) is a maturity model for the development of products developed by the Software Engineering Institute (SEI), which is increasingly being adopted by software organizations, since this model aims to guide organizations in implementing continuous improvements in their development process.

\subsection{The Maturity Level 5}

The focus of the maturity level 5 is the continuous improvement of processes. While level 4 focuses on the special causes of variation in the organization' process, level 5 tries to find common causes and address them, resulting in many improvements, which are

1 On methodology Six Sigma, the defects, errors and failures are any deviation of a characteristic that generate custome dissatisfaction (Blauth, 2003). 
implemented in a disciplined manner. Measurements are used to select the improvements and estimate the costs and benefits to meet the proposed improvements. The same measurements can be used to justify efforts for further improvements (Kulpa, 2003).

The CMMI level 5 consists of two process areas: Organizational Innovation and Deployment - OID and Causal Analysis and Resolution - CAR. The latter is the focus of this work.

The goal of the Causal Analysis and Resolution - CAR is to identify causes of defects and other problems and take actions to prevent their occurrence in the future.

Table 2 shows the relationship of specific goals (SG) with their respective specific practices (SP) for this process area.

\begin{tabular}{|l|l|l|}
\hline SG 1 & \multicolumn{2}{|l|}{ Determine Causes of Defects } \\
\hline \multirow{2}{*}{ SP 1.1 } & Select Defect Data for Analysis \\
\cline { 2 - 3 } & SP 1.2 & Analyze Causes \\
\hline \multirow{3}{*}{ Address Causes of Defects } \\
\cline { 2 - 3 } & SP 2.1 & Implement the Action Proposals \\
\cline { 2 - 3 } & SP 2.2 & Evaluate the Effect of Changes \\
\cline { 2 - 3 } & SP 2.3 & Record Data \\
\hline
\end{tabular}

Table 1. Causal Analysis and Resolution in CMMI (Chrissis, 2006)

\section{MiniDMAIC}

The MiniDMAIC is a strategy that aims to simplify the DMAIC method in order to address the causes and resolution of problems in software development projects in a more practical and faster manner, with less risk and cost, preventing future recurrences, implementing improvements on the development process and thus, continually increasing the customer satisfaction (Gonçalves et al., 2008 and Bezerra et al., 2009).

This approach was originally defined in Gonçalves (2008a) and was applied in pilot projects in a software organization that was deploying the levels 4 and 5 of the CMMI model. During the implementation of the approach in the pilot projects some improvements to the approach were identified and so it was refined.

Based on the implemented improvements, the MiniDMAIC was executed in other software development projects and a second work has been published with case studies of some projects that implemented the refined approach (Bezerra et al., 2009). After this last work, improvements were added to the approach and were validated in a CMMI level 5 official assessment in the organization that was executed the MiniDMAIC. We can see that the approach presented in this work underwent for several validations and was refined and implemented in several software development projects, demonstrating effectiveness in the analysis and resolution of causes in the context of these projects.

The great difference between MiniDMAIC and DMAIC is that the DMAIC, from the analysis and resolution of the causes of the defined prolem defined, has the main objective the improvement of one of the organization's standard processes, implementing the improvements in a controlled manner in the organization. The MiniDMAIC addresses the causes only in the project level and aims to prevent and treat the defined problems through the analysis and resolution of the problems root-causes. It can assist only in the organizational processes improvement (Bezerra et al., 2009). 
Moreover, the DMAIC requires a statistical proof of the problems causes and achieved improvements, that is not required in MiniDMAIC, which identifies and prioritizes the causes using simpler tools such as : Ishikawa diagram and Pareto Charts, and analyzes the obtained improvements observing the progress of the project's indicators (Bezerra et al., 2009).

The main characteristics of MiniDMAIC are:

- Short duration;

- Need for basic knowledge of statistics;

- $\quad$ Linked to risks;

- $\quad$ Low cost when compared to DMAIC;

- $\quad$ Suitable for software development projects.

The problems that need to be addressed more careful by applying the MiniDMAIC approach can be defined at the organizational level (ex.: control limits, number of defects, etc.). However, it is important to clear that, to the project team, the difference between problems that require only simple and immediate actions, and those that require the treatment defined in MiniDMAIC. Simple actions are appropriate for treatment of simple improvement items which can be typically performed by a person with little effort and when the cause/solution is known or likely.

The execution of the MiniDMAIC in a software development project must also consider the size of the project and the frequency of the indicators collection in an organization. For organizations that collect monthly the indicators, the execution of the approach should consider that the project must have at least one month in duration. If the project has short iterations, the treatment of the problem by MiniDMAIC approach will be useful to prevent the problem does not occur in later iterations. For month-long projects the action's execution can end up at the end of the project. Although the action does not address the problem in time to present the effects of the improvements in the project, the execution of this action may have benefits that will help other organization's projects.

Examples of project's problems that deserve treatment by MiniDMAIC approach are:

- Out of control project, where the results of the indicators of statistically controlled processes do not satisfy the specification limits defined by the project or organizational baseline boundaries (e.g., productivity, delivery deviation, defect density, etc.);

- $\quad$ Recorrent problems in the project;

- High number of defects found in systemic tests;

- High number of defects found by the customer.

When the cause and defect analysis is performed, the selection of defects for analysis must take into account the following factors:

- $\quad$ Types of most common defects;

- $\quad$ Frequency of occurrence;

- $\quad$ Similarity between defects.

In this approach, defects are considered as failures, taking into account the defect, error and failure definitions presented in the IEEE 610.12-1990. We chose to use these concepts in a similar way, because the MiniDMAIC approach bases the phase "Measure" on the orthogonal defect classification (Chillarege et al., 1992), which uses the same definition.

As support to the approach, tools like: spreadsheets, project management tools, among others, may be used. 
The items below describe the phases of MiniDMAIC, which uses the same phases of the DMAIC method, and a final phase that was included to provide the improvement opportunities, identified during the execution of the approach, to the organizational assets. The Figure 1 shows the sequence of steps of the approach.

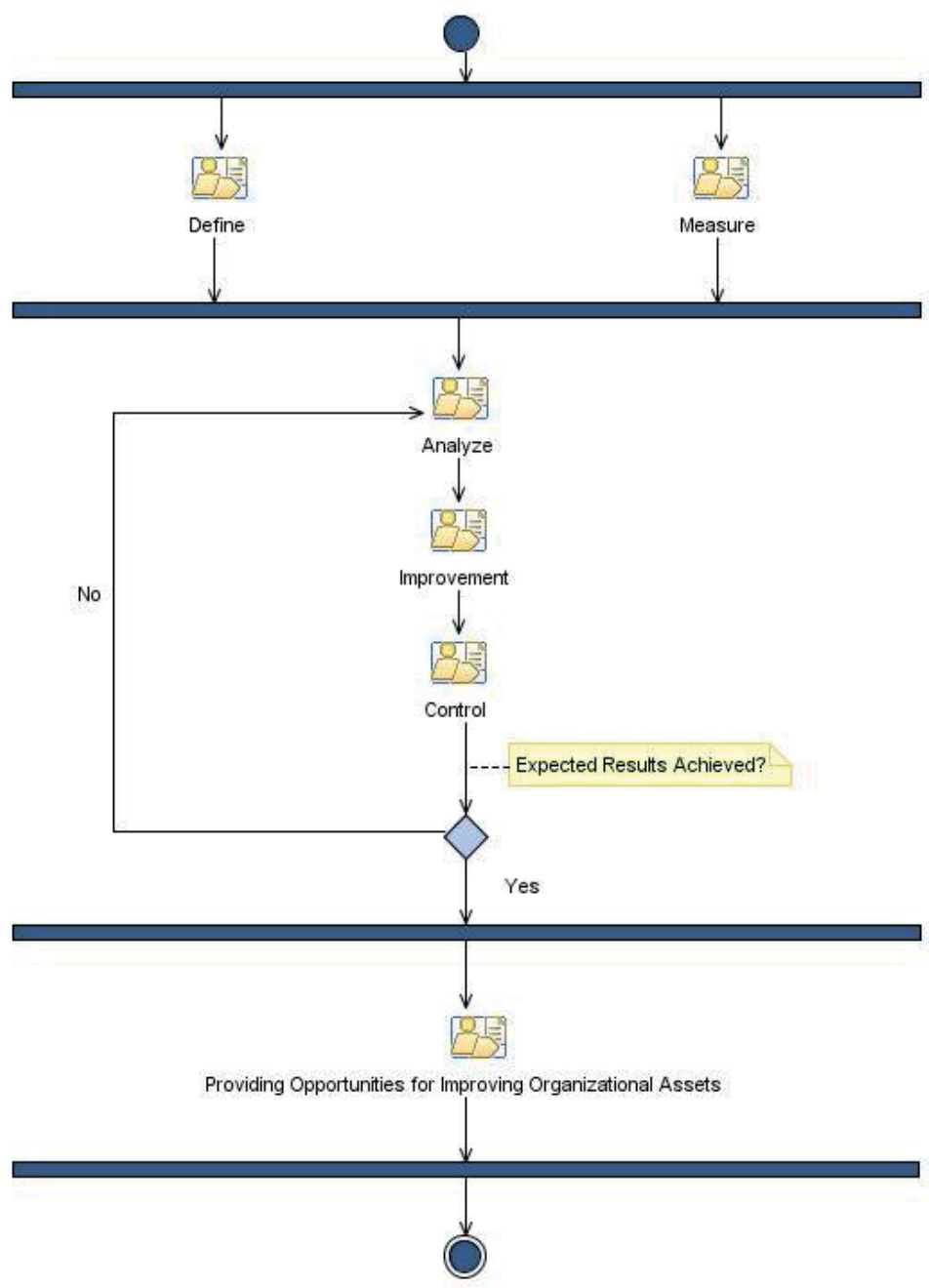

Fig. 1. Phases of MiniDMAIC

\subsection{Phase: Define}

The phase "Define" is a phase of action planning and encompasses the definition of the problem, sources, impacted processes and subprocesses and expected results. Besides, the formation of the team (Table 2). 


\begin{tabular}{|c|c|c|}
\hline \multirow{6}{*}{ 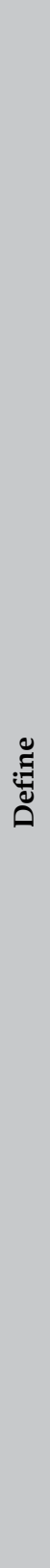 } & $\begin{array}{l}\text { Step } 1 \text { - Define the } \\
\text { Problem }\end{array}$ & $\begin{array}{l}\text { The problem trat will be adressed must be defined to be clear its } \\
\text { importance and defined its objectives. A search should be made on the } \\
\text { historical organizational base to look for similar problems that were } \\
\text { treated in other projects using a MiniDMAIC action to help in defining } \\
\text { and solving the problem's root-causes. It is important to describe the } \\
\text { impact or consequences of the problem in the project. This description } \\
\text { should be focused only on symptoms rather than in causes or solutions. }\end{array}$ \\
\hline & $\begin{array}{l}\text { Step } 2 \text { - Determine } \\
\text { the Source of the } \\
\text { Problem }\end{array}$ & $\begin{array}{l}\text { This step should show what was the source who revealed the occurrence } \\
\text { of the problem. Examples of sources of problems in software } \\
\text { development projects are: } \\
\text { - Project's indicators; } \\
\text { - Report of systemic tests; } \\
\text { - Results of integration tests; } \\
\text { - Client's test report; } \\
\text { - Problems identified in technical review that affect the requirements or } \\
\text { - the correct operation of the software; } \\
\text { - Customer Complaints. }\end{array}$ \\
\hline & $\begin{array}{l}\text { Step } 3 \text { - Identify the } \\
\text { Affected Processes }\end{array}$ & $\begin{array}{l}\text { Identify which processes and subprocesses were affected by the defined } \\
\text { problem. If the problem is the result of an out of control indicator, the } \\
\text { baseline associated to the process should be identified associated with } \\
\text { baseline. The process baselines selected by the project should consider the } \\
\text { client's performance objectives. }\end{array}$ \\
\hline & $\begin{array}{l}\text { Passo } 4 \text { - Identify } \\
\text { the Risks Related to } \\
\text { do not Address the } \\
\text { Problem }\end{array}$ & $\begin{array}{l}\text { The risks related to do not address the problem can be identified by the } \\
\text { project manager in order to treat and monitor them according to process } \\
\text { defined to the process area Risk Management - RSKM of CMMI. }\end{array}$ \\
\hline & $\begin{array}{l}\text { Passo } 5 \text { - Define the } \\
\text { Expected Results }\end{array}$ & $\begin{array}{l}\text { In this step, the expected results to be achieved with the implementation } \\
\text { of MiniDMAIC approach are defined aiming to address the problem. The } \\
\text { expected results must be defined in a quantitative manner, and indicators } \\
\text { associated with the defined problem can be used. }\end{array}$ \\
\hline & $\begin{array}{l}\text { Passo } 6 \text { - Forming } \\
\text { the team and } \\
\text { Estimating the Time } \\
\text { of Execution }\end{array}$ & $\begin{array}{l}\text { In this step the team that will participate in each phase of MiniDMAIC is } \\
\text { formed and the time for implementing each one is estimated. In a } \\
\text { MiniDMAIC action is not necessary to have Black Belts as leader. As they } \\
\text { are simple and directly related to the project, the only need is a basic } \\
\text { knowledge in Six Sigma and training in MiniDMAIC approach. The most } \\
\text { important is the understanding of knowledge related to the project and } \\
\text { management techniques and it is important that the Project Manager } \\
\text { leads the MiniDMAIC. The MiniDMAIC team size may vary according to } \\
\text { the needs of the problem. In situations that we may have just the project } \\
\text { manager and a team member others collaborators can participate only in } \\
\text { certain steps, for example, the support of a Green Belt leader (especially } \\
\text { during the phases Measure and Analyze). }\end{array}$ \\
\hline
\end{tabular}

Table 2. Steps of the Phase "Define"

\subsection{Phase: Measure}

The phase "Measure" is the collection and analysis of measurements (existing or to be defined) related to the problem aiming to know the current situation of the project and the related processes, as shown in Table 3. This phase can be executed in parallel to the phase "Define", supporting the definition of the problem. If the results of the measurements are 
analyzed at the project level, the analysis must be verified in the report that comprises the collected data and the measurements' analysis. If the defined measurement is within the MiniDMAIC action, this should be collected and analyzed in the phase "Measure".

\begin{tabular}{|c|c|c|}
\hline \multirow{2}{*}{ 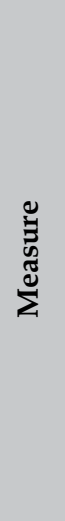 } & $\begin{array}{l}\text { Step } 1 \text { - Plan the } \\
\text { Measurements }\end{array}$ & $\begin{array}{l}\text { In this step we should examine whether there is a need for a new } \\
\text { measurement that provides more evidences for the problem at hand. In } \\
\text { most situations, the measurements are already being conducted in } \\
\text { accordance with the defined process that addresses the process area } \\
\text { Measurement and Analysis - MA. A new measurement can also be } \\
\text { planned to provide more evidences to consolidate and enlarge the } \\
\text { understanding of the problem and its consequences. }\end{array}$ \\
\hline & $\begin{array}{l}\text { Step } 2 \text { - Measure the } \\
\text { Current Situation }\end{array}$ & $\begin{array}{l}\text { The measurements selected in the previous step must be executed } \\
\text { according to the plan. It is necessary to collect information and measure } \\
\text { the current situation of the project. Later, these same measures will be } \\
\text { used to measure the obtained improvement. In case of collection of } \\
\text { defects, it is recommended to use the template - Analysis of Causes } \\
\text { provided by Bezerra (2009b), in order to prioritize the defects that } \\
\text { deserve a more detailed analysis of the causes. }\end{array}$ \\
\hline
\end{tabular}

Table 3. Steps of the Phase "Measure"

\subsection{Phase: Analyze}

The phase "Analyze" encompasses the identification and prioritization of the problem's root causes using techniques to ensure that the root causes to be addressed are actually related to the problem and to the definition of possible actions to solve the problem, as we can see on Table 4.

\begin{tabular}{|c|c|c|}
\hline \multirow{3}{*}{ 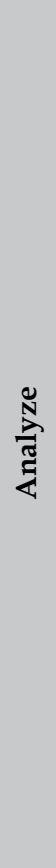 } & $\begin{array}{l}\text { Step } 1 \text { - Determine the } \\
\text { Problem's Causes }\end{array}$ & $\begin{array}{l}\text { This is one of the most important steps of MiniDMAIC, since its } \\
\text { purpose is to find out the problem's root cause. If this step is not } \\
\text { done correctly, the result of MiniDMAIC may be compromised } \\
\text { because all of the following activities will be based on the outcome of } \\
\text { this step. So, it is important that the people who has knowledge } \\
\text { related to the problem and can contribute with information about } \\
\text { their causes. Examples of techniques to determine problem's causes } \\
\text { are: brainstorming, five whys, cause and effect diagram (Ishikawa, } \\
\text { 1985), among others. To execute this step the Template "Analysis of } \\
\text { causes" provided by Bezerra (2009b) can be used. If defects are } \\
\text { analyzed, the classification of defects to determine where the defects } \\
\text { are more concentrated should be used as input for this phase. }\end{array}$ \\
\hline & $\begin{array}{l}\text { Step } 2 \text { - Priorityze the } \\
\text { Problem's Causes }\end{array}$ & $\begin{array}{l}\text { The prioritization of the problem's causes must be carried out in } \\
\text { accordance with the process defined to the area Decision Analysis and } \\
\text { Resolution - DAR. Another way to prioritize the causes is using the } \\
\text { Pareto chart (Juran, 1991), where } 20 \% \text { of the causes can contribute to } \\
80 \% \text { of defects. If the Pareto chart is adopted, the causes can be } \\
\text { grouped according to the level of criticism of the defects, the origin of } \\
\text { the defects and the type of them. To execute this step, the Template - } \\
\text { Analysis of causes provided by Bezerra (2009b) can be used. }\end{array}$ \\
\hline & $\begin{array}{c}\text { Step } 3 \text { - Define } \\
\text { Candidate Actions }\end{array}$ & $\begin{array}{l}\text { In this step, the possible actions to address the problem should be } \\
\text { identified with the project team using the brainstorming technique. } \\
\text { Every action should be linked to the related causes. }\end{array}$ \\
\hline
\end{tabular}

Table 4. Steps of the phase "Analyze" 


\subsection{Phase: Improve}

The phase "Improve" comprises the definition and the analysis of feasibility of the proposed the working up and implementing of the action plan and the monitoring the obtained results (Table 5).

\begin{tabular}{|c|c|c|}
\hline \multirow{3}{*}{ 宫 } & $\begin{array}{c}\text { Step } 1 \text { - Prioritize the } \\
\text { Actions }\end{array}$ & $\begin{array}{l}\text { The candidates actions can be prioritized according to the process } \\
\text { defined to the process area Decision Analysis and Resolution - DAR. A } \\
\text { analysis of feasibility can also be carried out for the implementation of } \\
\text { each action. Any priorityzed cause may have one or more actions, as } \\
\text { well as an action can be addressing one or more causes prioritized in } \\
\text { phase "Analyze". Besides, they should be traceable. The analysis of } \\
\text { feasibility should verify aspects such as: complexity, time and cost to } \\
\text { implement the action within the project. }\end{array}$ \\
\hline & $\begin{array}{c}\text { Step } 2 \text { - Prepare } \\
\text { Execute the Act } \\
\text { Plan }\end{array}$ & $\begin{array}{l}\text { An action plan for the implementation of the priority and approved } \\
\text { actions should be worked up by the project manager to address and } \\
\text { follow up the actions. This plan should contain the following } \\
\text { information: } \\
\text { - Tasks to be performed; } \\
\text { - Responsible for executing the task; } \\
\text { - Effort required to perform the task; } \\
\text { In the execution of the action plan, the tasks can be distributed to the } \\
\text { project team. }\end{array}$ \\
\hline & $\begin{array}{c}\text { Step } 3 \text { - Monitor the } \\
\text { Actions }\end{array}$ & $\begin{array}{l}\text { In this step, the tasks should be monitored in order to know the progress } \\
\text { of MiniDMAIC. These results should be followed up by the project } \\
\text { manager according to the process area Project Monitoring and Control - } \\
\text { PMC. }\end{array}$ \\
\hline
\end{tabular}

Table 5. Steps of the phase "Improve"

\subsection{Phase: Control}

The phase "Control" comprises the measurement, evaluation of obtained results and dissemination of results and lessons learned (Table 6).

\begin{tabular}{|c|c|l|}
\hline $\begin{array}{c}\text { Step 1-Measure the } \\
\text { Results }\end{array}$ & $\begin{array}{l}\text { After the implementation of the actions in the project, the project } \\
\text { manager and its team should measure the results obtained in the period } \\
\text { using the same indicators selected in phase "Measure" in order to verify } \\
\text { if the quantitative result was achieved. }\end{array}$ \\
\hline \multirow{2}{*}{$\begin{array}{l}\text { Step 2-Evaluate the } \\
\text { Results }\end{array}$} & $\begin{array}{l}\text { When the obtained results are evaluated, an analysis should ne carried } \\
\text { out by the project manager and its team to verify if the expected results } \\
\text { established in the phase "Control" have been achieved and whether there } \\
\text { was an improvement when compared to what was collected in the phase } \\
\text { "Measure" before of the problem's treatment . This comparison will be } \\
\text { useful as a basis to confirm if there was an improvement on the project } \\
\text { and to verify if the problem was actually addressed. }\end{array}$ \\
\hline
\end{tabular}




\begin{tabular}{|c|l|}
\hline Step 3 - Publicize the & $\begin{array}{l}\text { After the execution of MiniDMAIC, the results should be shared by the } \\
\text { project throughout the organization, recording them in an } \\
\text { organizational repository, accessible to all projects. Sharing this } \\
\text { information can be useful to address similar problems in other projects, } \\
\text { Lessons Learned } \\
\text { as well to improve the process at the organizational level. The way to } \\
\text { publicize should follow the process defined to the process area } \\
\text { Organizational Process Focus - OPF, which defines how the lessons } \\
\text { learned must be shared by the organization. If possible improvements to } \\
\text { organizational processes were identified, they should be sent to the } \\
\text { Engineering Process Group - EPG to be analyzed and properly } \\
\text { addressed. }\end{array}$ \\
\hline
\end{tabular}

Table 6. Steps to phase "Control"

\subsection{Providing Improvement Opportunities for the Organizational Assets}

The organizational historical base should include much information from the execution of MiniDMAICs projects. Considering data from more than one project, the engineering process group can analyze more data aiming to identify trends of problems in order to define improvements to be implemented in the processes and their assets at the organizational level. If the problem has already a known cause, or causes have just been identified within the projects, a single action organization must be defined.

Besides the MiniDMAIC, according to Albuquerque (2008), the following data sources may also help to identify recurrent problems in the organizational process assets: (i) evaluation of process suitability, (ii) evaluation process adherence; (iii) evaluation of the work products to the standards established in the organization, (iv) post-mortem analysis, (v) indicators for monitoring the processes, (vi) lessons learned (vii) request for exemption the execution of activities, (viii) guidelines, (ix) rationales to addapt the process and ( $\mathrm{x}$ ) requests to change the process.

It is important to highlight that some of these sources can be useful, also, in the context of the defects and problems.

Some information should be registered in the organizational historical base as: type of problem, problem's causes, actions taken to treat the causes and obtained improvements. These information are important to organize the problems identified in the projects using the approach MiniDMAIC in order to enable the identification of problems at the organizational level.

\section{Dmaic x minidmaic}

The MiniDMAIC is based on the steps of the DMAIC method defined by Tayntor (2003). Some steps have been suppressed due to the complexity of the used statistical techniques, for example, the step "Calculating the Current Sigma Level". And the steps related to customer requirements and changes in the standard processes were also removed, as illustrated in Table 7. The main goal of MiniDMAIC is to analyze and solve the causes of software development projects and does not focus on changes in the organization's standard process, which is the main goal of DMAIC. 


\begin{tabular}{|c|c|c|c|}
\hline Phase & DMAIC (Steps) & MiniDMAIC (Steps) & $\begin{array}{l}\text { Rationales to Suppress the } \\
\text { Steps }\end{array}$ \\
\hline \multirow{7}{*}{ פّ๊ } & Define the Problem & - Define the Problem & - \\
\hline & Forming the team & $\begin{array}{l}\text { - Forming the team and } \\
\text { Estimating the Time of } \\
\text { Execution }\end{array}$ & - \\
\hline & Establish a Project Charter & $\begin{array}{l}\text { - Determine the Source of the } \\
\text { Problem } \\
\text { - Identify the Risks Related to } \\
\text { do not Address the Problem } \\
\text { - Identify the Affected } \\
\text { Processes } \\
\text { - Define the Expected Results }\end{array}$ & - \\
\hline & Prepare the Project Plan & - & $\begin{array}{l}\text { - There is no need to have a } \\
\text { lot of plans to analyze the } \\
\text { causes in projects }\end{array}$ \\
\hline & Identify the Customers & - & $\begin{array}{l}\text { - The customer must be } \\
\text { identified in the software } \\
\text { project plan. }\end{array}$ \\
\hline & $\begin{array}{l}\text { Identify the Resulting } \\
\text { Artifacts }\end{array}$ & $\begin{array}{l}\text { - Throughout the } \\
\text { implementation of } \\
\text { MiniDMAIC }\end{array}$ & - \\
\hline & $\begin{array}{l}\text { Identify e Prioritize the } \\
\text { Customer Requirements }\end{array}$ & - & $\begin{array}{l}\text { - Customer requirements } \\
\text { are not identified directly. } \\
\text { They can be related to the } \\
\text { step "Identify Affected } \\
\text { Processes". }\end{array}$ \\
\hline \multirow{5}{*}{ 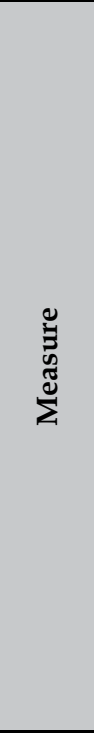 } & Define the Measurements & - Plan the Measurements & - \\
\hline & Conduct Measurements & $\begin{array}{l}\text { - Measure the Current } \\
\text { Situation }\end{array}$ & - \\
\hline & $\begin{array}{l}\text { Calculate the Current Sigma } \\
\text { Level }\end{array}$ & - & $\begin{array}{l}\text { - A high knowledge in } \\
\text { statistical techniques is } \\
\text { necessary, which may be } \\
\text { impractical in the context } \\
\text { of projects. }\end{array}$ \\
\hline & $\begin{array}{l}\text { Determine the Process } \\
\text { Capability }\end{array}$ & - & $\begin{array}{l}\text { - A high knowledge in } \\
\text { statistical techniques is } \\
\text { necessary, which may be } \\
\text { impractical in the context } \\
\text { of projects. }\end{array}$ \\
\hline & $\begin{array}{l}\text { Carry out the Process Leaders } \\
\text { Benchmark }\end{array}$ & - & $\begin{array}{l}\text { - This Benchmark should } \\
\text { be carried out at the } \\
\text { organizational level, since } \\
\text { there are no changes in the } \\
\text { process executed at the } \\
\text { project level. }\end{array}$ \\
\hline$\frac{\stackrel{N}{\frac{N}{\pi}}}{\mathfrak{Z}}$ & $\begin{array}{l}\text { Determine the Causes of } \\
\text { Variation }\end{array}$ & $\begin{array}{l}\text { - Determine the Problem's } \\
\text { Causes - Priorityze the } \\
\text { Problem's Causes }\end{array}$ & - \\
\hline
\end{tabular}




\begin{tabular}{|c|c|c|c|}
\hline & $\begin{array}{l}\text { Carry out the Process } \\
\text { Improvement Ideas } \\
\text { Brainstorming }\end{array}$ & - Define Candidate Actions & - \\
\hline & $\begin{array}{l}\text { Determine the Improvements } \\
\text { that have Major Impact on } \\
\text { Customer Requirements }\end{array}$ & - Define Candidate Actions & - \\
\hline & $\begin{array}{l}\text { Prepare the Proposed process } \\
\text { Map }\end{array}$ & - & $\begin{array}{l}\text { - There is no need to } \\
\text { provide changes in the } \\
\text { process executed at the } \\
\text { project level at the project } \\
\text { level. }\end{array}$ \\
\hline & $\begin{array}{l}\text { Evaluate the Risks Associated } \\
\text { with the Reviewd Process }\end{array}$ & - & $\begin{array}{l}\text { - There is no need to } \\
\text { provide changes in the } \\
\text { process executed at the } \\
\text { project level at the project } \\
\text { level, because the risks can } \\
\text { be addresses at } \\
\text { organizational level. }\end{array}$ \\
\hline \multirow{3}{*}{ 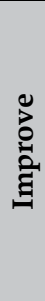 } & $\begin{array}{l}\text { Obtain the Approval of the } \\
\text { Proposed Changes }\end{array}$ & - Prioritize the Actions & - \\
\hline & $\begin{array}{l}\text { Finalize the Implementation } \\
\text { Plan }\end{array}$ & $\begin{array}{l}\text { - Prepare and Execute the } \\
\text { Action Plan }\end{array}$ & - \\
\hline & $\begin{array}{l}\text { Implement the Approved } \\
\text { Changes }\end{array}$ & $\begin{array}{l}\text { - Prepare and Execute the } \\
\text { Action Plan } \\
\text { - Monitor the Actions }\end{array}$ & - \\
\hline \multirow{5}{*}{${ }_{0}^{0}$} & Establish the Key Metrics & $\begin{array}{l}\text { - Measure the Results } \\
\text { - Evaluate the Results }\end{array}$ & - \\
\hline & Develop the control Strategy & - & $\begin{array}{l}\text { - There is no need to } \\
\text { provide changes in the } \\
\text { process executed at the } \\
\text { project level at the project } \\
\text { level. }\end{array}$ \\
\hline & $\begin{array}{l}\text { Celebrate and Communicate } \\
\text { the Success }\end{array}$ & $\begin{array}{l}\text { - Publicize the Main Results } \\
\text { and Lessons Learned }\end{array}$ & - \\
\hline & Implement the Control Plan & - & $\begin{array}{l}\text { - There is no need to } \\
\text { provide changes in the } \\
\text { process executed at the } \\
\text { project level at the project } \\
\text { level. }\end{array}$ \\
\hline & $\begin{array}{l}\text { Measure and Communicate } \\
\text { the Improvements }\end{array}$ & $\begin{array}{l}\text { - Measure the Results } \\
\text { - Evaluate the Results } \\
\text { - Publicize the Main Results } \\
\text { and Lessons Learned }\end{array}$ & - \\
\hline
\end{tabular}

Table 7. Comparison of DMAIC Steps Defined by Tayntor (2003) and MiniDMAIC Approach Steps. 


\section{Minidmaic $\times$ CAR}

For a better understanding of the relationship between MiniDMAIC and the Causal Analysis and Resolution (CAR) process area, a mapping was prepared to represent the relationship between the MiniDMAIC steps and the specific practices of CAR as we can see in Table 8. It is important to emphasize that such relationship does imply that the approach is covering the entire practice, since the process area is not related only to projects, but also has subpractices to the organizational level.

\begin{tabular}{|c|c|c|c|}
\hline Phase & MiniDMAIC (Steps) & CAR (Specific Practices) & Observations \\
\hline \multirow{6}{*}{$\stackrel{\Xi}{\Xi}$} & Step 1 - Define the Problem & - & $\begin{array}{l}\text { Related to Quantitative } \\
\text { Project Management - } \\
\text { QPM PA }\end{array}$ \\
\hline & $\begin{array}{l}\text { Step } 2 \text { - Determine the Source of } \\
\text { the Problem }\end{array}$ & - & $\begin{array}{l}\text { Related to Quantitative } \\
\text { Project Management - } \\
\text { QPM PA }\end{array}$ \\
\hline & $\begin{array}{l}\text { Step } 3 \text { - Identify the Affected } \\
\text { Processes }\end{array}$ & - & $\begin{array}{l}\text { Related to Quantitative } \\
\text { Project Management - } \\
\text { QPM PA }\end{array}$ \\
\hline & $\begin{array}{l}\text { Step } 4 \text { - Identify the Risks Related } \\
\text { to do not Address the Problem }\end{array}$ & - & $\begin{array}{l}\text { Related to Risk } \\
\text { Management - RSKM } \\
\text { PA }\end{array}$ \\
\hline & $\begin{array}{l}\text { Step } 5 \text { - Define the Expected } \\
\text { Results }\end{array}$ & - & $\begin{array}{l}\text { Related to Quantitative } \\
\text { Project Management - } \\
\text { QPM PA }\end{array}$ \\
\hline & $\begin{array}{l}\text { Step } 6 \text { - Forming the team and } \\
\text { Estimating the Time of Execution }\end{array}$ & - & $\begin{array}{l}\text { Relaletd to Project } \\
\text { Monitoring and } \\
\text { Control - PMC PA and } \\
\text { GP 2.7 - Identify and } \\
\text { Involve Relevant } \\
\text { Stakeholders }\end{array}$ \\
\hline \multirow{2}{*}{ 递 } & Step 1 - Plan the Measurements & $\begin{array}{l}\text { SP } 1.1 \text { - Select Defect Data for } \\
\text { Analysis }\end{array}$ & - \\
\hline & $\begin{array}{l}\text { Step } 2 \text { - Measure the Current } \\
\text { Situation }\end{array}$ & $\begin{array}{l}\text { SP } 1.1 \text { - Select Defect Data for } \\
\text { Analysis }\end{array}$ & - \\
\hline \multirow{3}{*}{$\frac{\stackrel{N}{\frac{N}{\pi}}}{\mathfrak{Z}}$} & $\begin{array}{l}\text { Step } 1 \text { - Determine the Problem's } \\
\text { Causes }\end{array}$ & SP 1.2 - Analyze Causes & - \\
\hline & $\begin{array}{l}\text { Step } 2 \text { - Prioritize the Problem's } \\
\text { Causes }\end{array}$ & SP 1.2 - Analyze Causes & - \\
\hline & Step 3 - Define Candidate Actions & SP 1.2 - Analyze Causes & - \\
\hline \multirow{2}{*}{ 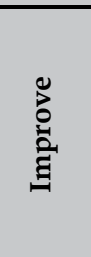 } & Step 1 - Prioritize the Actions & $\begin{array}{l}\text { SP } 2.1 \text { - Implement the Action } \\
\text { Proposals }\end{array}$ & $\begin{array}{l}\text { Related to GP } 2.10 \text { - } \\
\text { Review Status with } \\
\text { Higher Level } \\
\text { Management }\end{array}$ \\
\hline & $\begin{array}{l}\text { Step } 2 \text { - Prepare and Execute the } \\
\text { Action Plan }\end{array}$ & $\begin{array}{l}\text { SP } 2.1 \text { - Implement the Action } \\
\text { Proposals }\end{array}$ & - \\
\hline
\end{tabular}




\begin{tabular}{|c|l|l|l|}
\hline \multirow{2}{*}{ Step 3 - Monitor the Actions } & & $\begin{array}{l}\text { Related to Project } \\
\text { Monitoring and } \\
\text { Control - PMC PA }\end{array}$ \\
\hline \multirow{3}{*}{} & Step 1 - Measure the Results & $\begin{array}{l}\text { SP 2.2 - Evaluate the Effect of } \\
\text { Changes }\end{array}$ & - \\
\cline { 2 - 4 } & Step 2 - Evaluate the Results & $\begin{array}{l}\text { SP 2.2 - Evaluate the Effect of } \\
\text { Changes }\end{array}$ & - \\
\cline { 2 - 4 } & $\begin{array}{l}\text { Step 3 - Publicize the Main } \\
\text { Results and Lessons Learned }\end{array}$ & SP 2.3 - Record Data & - \\
\hline
\end{tabular}

Table 8. Relationship between the MiniDMAIC Steps and Specific Practices of CAR

As can be observed, to be attend the process area Causal Analysis and Resolution - CAR, several steps defined in DMAIC were not necessary. The analysis of the DMAIC phases was the basis for defining the proposed approach.

\section{Minidmaic Execution}

The MiniDMAIC was and is still being executed in software development projects of Atlantic Institute, a software organization assessed at CMMI level 5 in August 2009 that achieved the highest level of maturity of this model. One of the factors that helped to be adherent to CMMI level 5 in relation to the process area Causal Analysis and Resolution, was the implementation of MiniDMAIC in the context of software projects. Four projects were assessed and all of them executed the MiniDMAIC approach for the analysis of causes and no weaknesses were found in any process area from levels 4 and 5 of CMMI during the official assessment.

During the execution of MiniDMAICs in the Atlantic's software development projects, the approach was being refined and better adequate to an analysis of causes more effectively and efficiently in the context of projects. Nevertheless, as the intent of the organization was to continuously improve their processes, the approach is being constantly improved for use in projects.

All the MiniDMAIC steps were implemented in the Jira, a commercial tool for workflow management that can be easily customized. The tool is already used in the organization to issue tracking, and other actions, and made possible to implement actions to causal analysis in projects in a simplest manner. Figure 2 shows the initial screen to create a MiniDMAIC action in the Jira tool. 


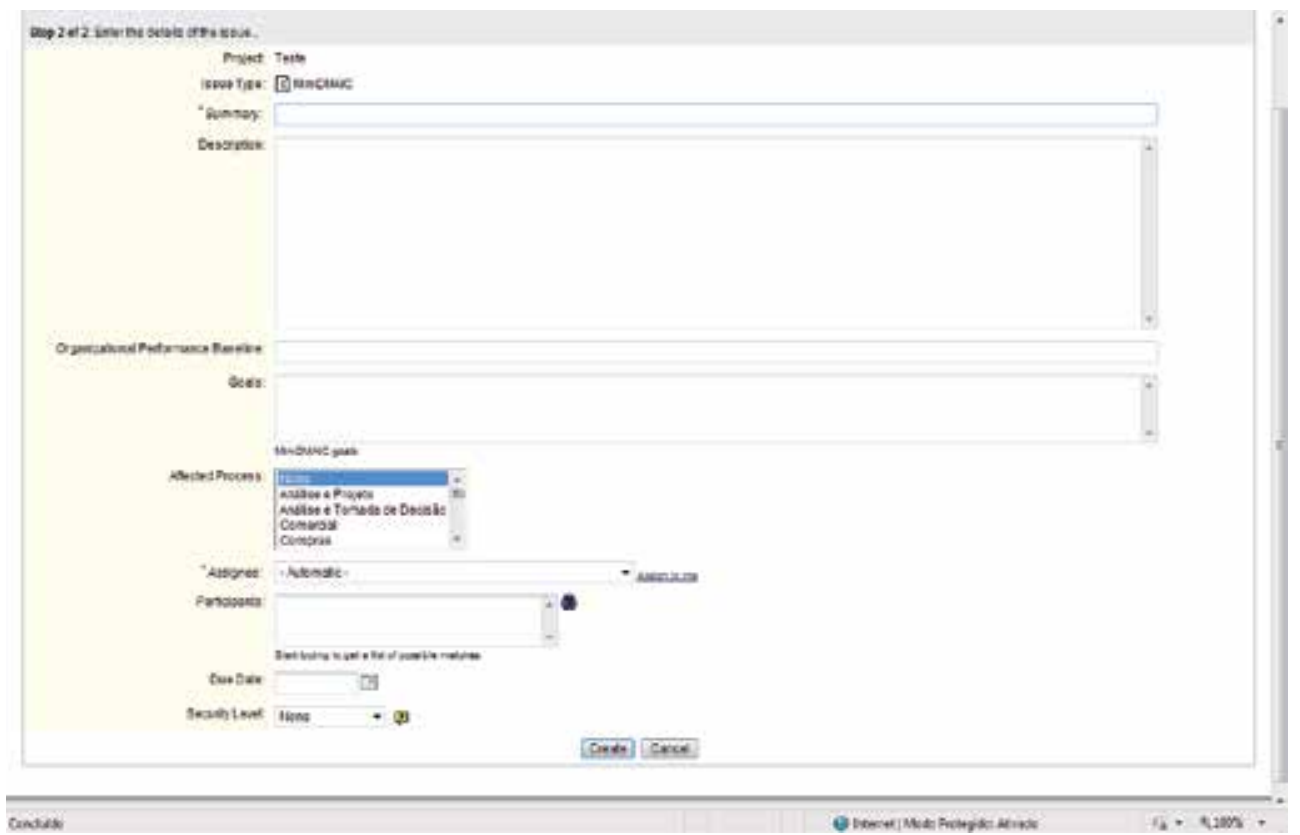

Fig. 2. Initial Screen to Create a MiniDMAIC Action in Jira

\subsection{Characterization of Organization to MiniDMAIC}

Following the practices of the process area Causal Analysis and Resolution of CMMI, some criteria and conditions were defined by the organization to initialize a MiniDMAIC action on projects. The MiniDMAICs could be initialized for analyzing the causes of defects/problems or deviation in the indicators. In the management meetings, the project coordinator should analyze together with the manager the need to carry out a MiniDMAIC to the presented situation. The collaborator responsible for planning and monitoring a MiniDMAIC action should be the project coordinator.

The organization defined the following typical sources of defects/problems:

- Indicators of the project;

- Report of systemic tests;

- Results of integration tests;

- $\quad$ Report from the client tests;

- Problems found in the technical review that affect requirements or the proper execution of the application;

- Customer Complaints.

Moreover, the situations listed below may required the analysis of cause and defect using the MiniDMAIC:

- High value on the systemic tests indicators. For example, indicator above the project goal or out of the specified limits;

- $\quad$ Out of control project, where the results of the indicators with statistically controlled processes do not meet the limits defined by the project or the organizational baseline limits (e.g., productivity, deviation on delivery, defect density, etc.); 
- High number of defects classified as critical and blocker in the systemic tests (according to the coordinator analysis);

- High number of defects found by the client (according to the coordinator analysis).

- Defects found in the first project's set of tests;

- $\quad$ Need to analyze the most common types of defects;

- Errors that occur so frequently in the various set of test.

When the analysis of cause and defect is performed, the selection of defects for analysis should consider the following factors:

- Types of the most common defects;

- $\quad$ Frequency of occurrence;

- $\quad$ Similarity between defects.

The organization has a well-defined testing process and to classify the defects should be considered: (i) criticality, (ii) the types of defects and (iii) the sources of defects in relation to the software development life cycle phases.

The level of criticality of the defects was based on the IEEE 1044 (1994) and has the following classification:

- Blocker: failure that causes the block of the main tested functionality or application, preventing the running of the tests. The cases that prevent the execution of other requirements are also considered;

- Critical: failure where the test case steps might be performed, however, they had a disastrous outcome. The cases where a secondary functionality could not be performed successfully are considered;

- Major: failure that has an incorrect results, but do not bring a high impact to the customer;

- $\quad$ Minor: failure in not essential requirements points;

- Trivial: Problems considered cosmetics / accessories that do not affect the functionality of the system.

The organization's types of defects were based on Orthogonal Defect Classification (Chillarege et al., 1992) that comprises the following types of defects:

- Interface;

- $\quad$ Function (functionality);

- Assembling / packaging / integration;

- Attribution;

- Documentation;

- Verification (field validation);

- $\quad$ Algorithm (internal logic);

- $\quad$ Time / serialization / performance.

The defects' sources also were based on Orthogonal Defect Classification (Chillarege et al., 1992), comprising the following sources:

- Requirements;

- A \& D - Architecture;

- A \& D - Design;

- Implementation;

- $\quad$ Testing. 


\subsection{Pilot Project Characterization}

The organization's software development project selected as a pilot project was considered large, had short iterations and used the Scrum methodology (Schwaber, 2004). This project corresponded to the development of various sub-projects of experimental applications to mobile devices (cell phones). The general characterization of the sub-projects within the context of the project can be seen in Table 9.

\begin{tabular}{|l|l|}
\hline Type & Embedded Software \\
\hline Restrictions & $\begin{array}{l}\text { Limited fixed price + Deadline + Flexible } \\
\text { Scope }\end{array}$ \\
\hline Duration & 2 or 3 months. Sprints lasting 4 weeks \\
\hline Estimate & Story Points + Use Case Points \\
\hline Team Size & Small (up to 6 employees) \\
\hline Product Line & Mobile \\
\hline Stability Requirements & Small (Very volatile requirements) \\
\hline Customer Engagement & Average \\
\hline Design Complexity & Large \\
\hline
\end{tabular}

Table 9. Characterization of the Pilot Project's Sub-projects

In the next sections will show the execution of each phase of MiniDMAIC approach in the selected pilot project.

\subsection{Performing the Phases "Define" and "Measure" of MiniDMAIC}

All of the organization's software development projects collect and analyze, monthly, the project's indicators in the Project Performance Report. One of the indicators of the organization that has statistically managed processes and subprocesses is the indicator "Defect density".

In the project that MiniDMAIC was executed to this experience report, a great number of defects in systemic tests were identified and it was verified that the values of defect density in systemic tests indicator were above of the organizational baseline limits, as shown in the control chart (Figure 3). 


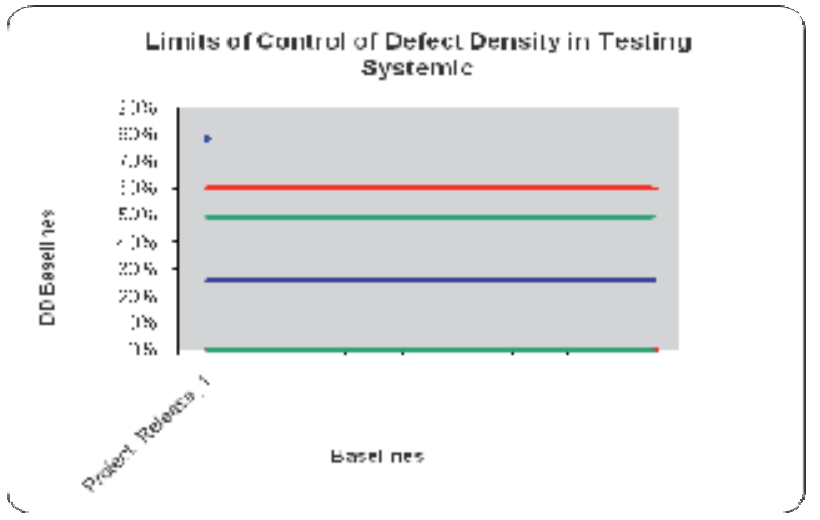

Fig. 3. Project's Control Chart for the Defect Density in Systemic Tests Baseline

Thus, we identified the need to open a MiniDMAIC action for the project in order to analyze the root cause of the project's defects.

The organization has a historical projects base located in a knowledge management tool, accessible to all employees of the organization. This historical base contains: general information from the projects, projects' indicators, lessons learned, risks and MiniDMAICs opened by the projects.

Initially, the organization's historical basis was analyzed to find MiniDMAICs related to the density of defects that have been executed in other projects. There were two MiniDMAICs related to this problem that were considered as a basis for a better execution and analysis of project' causes.

Analyzing the organization's performance baseline of the defect density in systemic tests was defined as the goal of the project, remain within the specified limits of the project (upper and lower target), reducing the density of defects in $81 \%$ to achieve the goal of defect density in systemic tests that had been established.

There was no need to identify a new measurement to measure the problem, since the problem was already characterized in the defect density in systemic tests indicator, which was already considered in the projects of the organization and that is statistically controlled. In a spreadsheet, all defects related to the release's scope were collected and these defects were classified by criticality, source and type of defect, as shown in Figure 4. This classification helps to know the source of the defects according to its classification and to know which are the most recurrent. In the project's context, the largest number of defects was classified as major critical, the source in the implementation and the types of defects were: functionality and algorithm. 


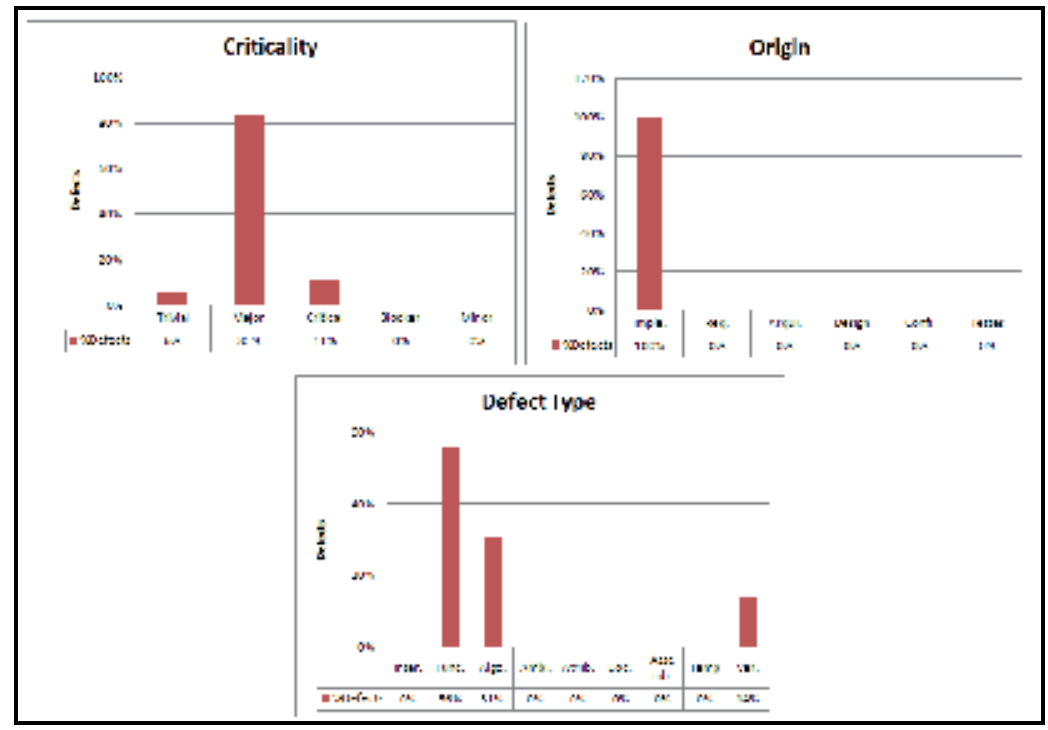

Fig. 4. Classification of the Defects Found in the Project's Systemic Tests

At this phase it was established the following:

- Goal: reduce the defect density in systemic tests in $81 \%$, remaining within the specified limits of the project;

- $\quad$ Affected process (es): Implementation;

- $\quad$ Risks: No risks were identified related to the problem;

- Organizational Performance Baseline: defect density in systemic tests;

- $\quad$ Responsible for the phase: project coordinator, technical leader and Quality Assurance;

- Duration: 1 day.

During the execution of these two phases in parallel, there was only difficulty for classifying the defects, which required a great effort from the team to analyze them.

\subsection{Performing the Phase "Analyze" of MiniDMAIC}

At this stage, experts were allocated aiming to analyze the defects. In the case of the MiniDMAIC action on the pilot project, were allocated the following specialists: project coordinator, technical leader, Quality Assurance, developers, requirements analyst and test analyst.

Based on the defect classification of the phase "Measure" and grouping of the recurrent defects, a brainstorming meeting was held with the project team in order to find the root cause of defects. The brainstorming was organized in two meetings to identify and prioritize the causes of the problem. At the first meeting, the team had as input the defects collected in the phase "Measure" and their classification, and ideas of possible causes were collected without worrying whether those causes were actually the problem's root causes.

After identifying the causes, each defect were analyzed to know what the causes it was related. So, the most recurrent causes when they were consolidated by defects. Based on that consolidation, a second meeting was held with the project team and shown the consolidated causes to prioritize problem's root causes. The following causes were identified and prioritized by the team, with the help of Pareto charts: 
- $\quad$ Cause 1: architectural components developed in parallel with use cases;

- $\quad$ Cause 2: baseline generated without testing in an environment similar to production;

- Cause 3: lack of understanding of requirements by developers;

- Cause 4: Sprint's scope badly estimated (estimation and sequence of the use cases development);

- $\quad$ Cause 5: architecture is not suitable for the concurrent development of the team.

Analyzing the identified and prioritized causes related to the found problems in the iteration was observed that:

- The planning was badly estimated. Many use cases were planned for a short time (fixed time of 4 weeks). Aiming to achieve the scope defined for the iteration, some activities essential to the quality of the final product were not performed in accordance to the planned estimation. Among them, the integration test and the testing on mobile device can be cited;

- The team did not have a full knowledge of the project requirements. It was the first sprint of the project and meetings or workshop were not held with the developers for sharing and discussing the requirements. The artifacts to define the requirements were defined, but they were not followed;

- The initial architecture was not mature, resulting in various problems and additional efforts for the development.

Then, a brainstorming was performed at a meeting to identify possible actions for addressing the causes. The following actions were identified:

- $\quad$ Action 1: perform integration tests before systemic tests;

- Action 2: held a requirement workshop for improving the understanding of the use cases by the project team;

- Action 3: carry out use case tests in an environment similar to the production environment;

- Action 4: define and communicate the concept of "done" to complete the implementation of the use case;

- $\quad$ Action 5: improve the planning to the next iterations, with the participation of the team (the planning should include the development and integration of architectural components before the development of the use cases);

- Action 6: perform the refactoring of architectural components.

In Table 10 we can observe the relationship between the identified causes and the prioritized actions for their treatment.

\begin{tabular}{|l|l|}
\hline Causes & \multicolumn{1}{|c|}{ Action } \\
\hline Cause 1 & Action 1, Action 3, Action 4 \\
\hline Cause 2 & Action 1, Action 3, Action 4 \\
\hline Cause 3 & Action 2 \\
\hline Cause 4 & Action 5 \\
\hline Cause 5 & Action 6 \\
\hline
\end{tabular}

Table 10. Relationship Between the Causes and Actions Identified to Address the Defects' Causes 
The phase "Analyze" of MiniDMAIC on the project was very detailed and all defects found to improve the effectiveness of the action were analyzed. In addition, we focus in the defects' root causes in order to do address wrong causes. The phase lasted two days. Nevertheless, the project team has difficult to understand what really was the defects' root cause, requiring the support of the Quality Assurance to guide the team and to focus on the causes of the problem.

\subsection{Performing the Phase "Improve" of MiniDMAIC}

All actions identified in the brainstorming were considered important to be implemented and were easy to implement. An action plan to implement the actions was defined on Jira and each action was inserted in MiniDMAIC action in the Jira MiniDMAIC as a sub-task of MiniDMAIC. For each action were assigned responsible to execute the action and defined a deadline to the action within the project. At this phase, all experts assigned on the phase "Analyze" played a role. Below are described the execution of the actions:

- Action 1: The team performed the integration tests in the sprints 2 and 3 before the systemic test. It was found that the development team identified virtually the same amount of problems that the systemic test team, proving the effectiveness of action.;

- $\quad$ Action 2: A requirements workshop was held in sprints 2 and 3 with the participation of requirements, IHC, testing and development teams. During the implementation of the action the understanding of the requirements was transferred by the requirements team for the rest of the team. The practice contributed a lot for leveling the understanding of the requirements and necessary changes in the requirements that had not previously been thought were highlighted;

- Action 3: In the first execution of this action there was an impediment. Because the use case tests had not been executed in an environment similar to the production environment, we found a bug that prevented the test. Moreover, some test team's members did not have mobile phones to execute the tests, which limited the execution of the action. The error that prevented the test was corrected and the use case tests began to be executed in sprints 2 and 3;

- $\quad$ Action 4: In the planning meeting of project's sprint 2, the concept of "done" has been defined together with the team and shared to all, through minutes and posters attached in the project's room. This practice was used during sprints 2 and 3 . The concepts of "done" that were defined:

- Requirements: use cases completed and reviewed with adjustments.

- Analysis and Design: class diagram completed and reviewed with adjustments.

- Coding: code generated and reviewed with adjustments and unit tests coded and documents with $75 \%$ of coverage.

- $\quad$ Action 5: Improve the planning of the next iterations with the participation of the team (the planning should include the development and integration of architectural components before the development of use cases). The planning improvements started in sprint 2 of the project. For this sprint was held a planning meeting with the project team, that was recorded in the minutes. In the planning, the development and integration of architectural components were planned to begin before the development of use cases. Furthermore, both the use cases refactoring activities as the activities for 
understanding the implemented requirements in accordance with Action 3 were planned to be held initially. During the sprint 3, the same action was performed again;

- Action 6: this action was planned in the execution of Action 5 and the architectural component refactoring was performed by the project team, improving the application's maintainability.

The team had difficulty in deploying the action 3 due to the unavailability of an environment identical to the production environment for the whole team. The other actions were implemented more easily by the project team. On average, the implementation of the actions lasted two weeks.

\subsection{Performing Phase "Control" of MiniDMAIC}

After the implementation of the actions for addressing the causes of defects, the results were measured to analyze the achieved degree of effectiveness. In the project's second sprint the result was measured and we identified $38 \%$ of improvement in the systemic tests defect density indicator and that the result satisfied the project's limits. Nevertheless, the established of $81 \%$ was not achieved. So we decided to execute the phase "Improvement", implementing the same actions in the sprint 3, and measuring the results again to verify if the actions actually eliminated the root causes of defects.

In the sprint 3 was measured again the defect density in systemic tests indicator and was found a greater improvement, coming very close to the target defined to the project. Despite the goal was not achieved in sprint 3 , the expected results were considered satisfactory and we could observe in two later sprints of the projects that the causes of defects were actually addressed. The improvement in the third sprint was $51 \%$. The Figure 5 shows a control chart illustrating the improvement achieved by the project over the sprints.

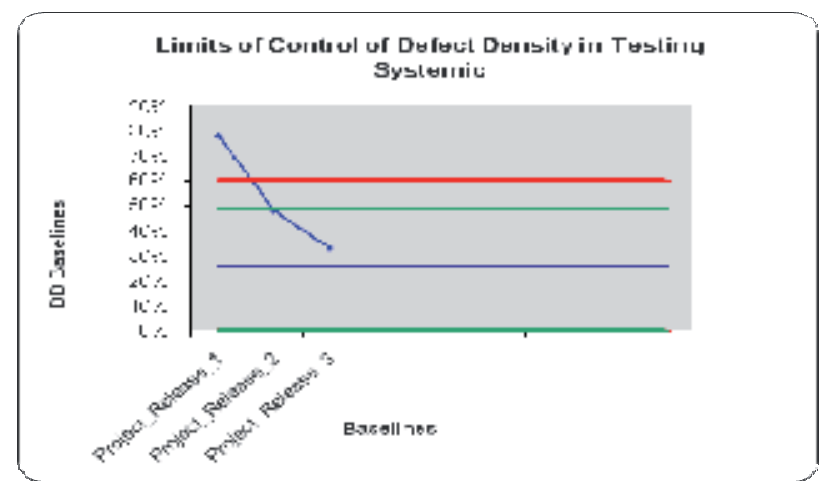

Fig. 5. Project's Control Chart for Defect Density in Systemic Tests Baseline with Final Results after the Execution of the MiniDMAIC Action

After the evidence of the implemented improvements, a meeting was held with the team to collect lessons learned and to close the action with the collected results. As the main lesson learned from the execution of cause analysis on the project, it was observed the importance, in the first sprint, to establish a minimum scope that would allow the architecture development and the knowledge of the team about application's business domain that was being developed. 
After closing the action, the project coordinator sent the entire MiniDMAIC action execution's input for the organization's historical basis, through an action in Jira.

Due to the project has being returned to the phase "Improve" to perform the actions in project's sprint 3, the MiniDMAIC on the project had a longer duration, approximately 6 weeks. The strategy of re-performing the phase "Improve" on the next sprint of the project was chosen by the team to check if the actions were really effective and to eliminate the problem's root causes. If the project had obtained, actually, an improvement at the first moment, the duration of the MiniDMAIC action would be, on average, from two to three weeks.

\subsection{Providing Improvement Opportunities for the Organizational Assets}

All organization's MiniDMAIC actions are reviewed and consolidated by the process group and measurement and analysis group of the organization. The Jira tool generates a document, in Word format, for every execution of MiniDMAIC action that is sent to the historical basis by the project and published in a knowledge management tool, becoming able to be searched by all organization's projects.

To facilitate the monitoring of all MiniDMAIC actions by the process group, some information considered most important are consolidated into a spreadsheet. Table 11 presents the consolidated information including the MiniDMAIC executed on the project illustrated in this work. 


\begin{tabular}{|c|c|c|c|}
\hline $\begin{array}{l}\text { Type of } \\
\text { Problem }\end{array}$ & Problem's Causes & $\begin{array}{l}\text { Actions Executed for } \\
\text { Addressing the Cause }\end{array}$ & $\begin{array}{c}\text { Achieved } \\
\text { Improvement }\end{array}$ \\
\hline $\begin{array}{c}\text { High Defect } \\
\text { Density in } \\
\text { Systemic Tests }\end{array}$ & $\begin{array}{l}\text { - Cause 1: architectural } \\
\text { components developed in } \\
\text { parallel with use cases. } \\
\text { - Cause 2: baseline } \\
\text { generated without testing } \\
\text { in an environment similar } \\
\text { to production } \\
\text { environment. } \\
\text { - Cause 3: lack of } \\
\text { understanding of } \\
\text { requirements by } \\
\text { developers. } \\
\text { - Cause } 4 \text { : Sprint's scope } \\
\text { badly estimated } \\
\text { (estimation and sequence } \\
\text { of use cases } \\
\text { development). } \\
\text { - Cause } 5 \text { : architecture is } \\
\text { not suitable for the } \\
\text { concurrent development } \\
\text { of the team. }\end{array}$ & $\begin{array}{l}\text { - Action 1: perform } \\
\text { integration tests before } \\
\text { systemic tests. } \\
\text { - Action 2: held a requirement } \\
\text { workshop for improving the } \\
\text { understanding of the use } \\
\text { cases by the project team. } \\
\text { - Action 3: carry out use case } \\
\text { tests in an environment } \\
\text { similar to the production } \\
\text { environment. } \\
\text { - Action } 4 \text { : define and } \\
\text { communicate the concept of } \\
\text { "done" to complete the } \\
\text { implementation of the use } \\
\text { case. } \\
\text { - Action } 5 \text { : improve the } \\
\text { planning to the next } \\
\text { iterations, with the } \\
\text { participation of the team (the } \\
\text { planning should include the } \\
\text { development and integration } \\
\text { of architectural components } \\
\text { before the development of the } \\
\text { use cases). } \\
\text { - Action 6: perform the } \\
\text { refactoring of architectural } \\
\text { components. }\end{array}$ & $\begin{array}{l}\text { Defect density } \\
\text { reduction in } 51 \%\end{array}$ \\
\hline
\end{tabular}

Table 11. Consolidated Information from MiniDMAICs

\subsection{Benefits of the MiniDMAIC Approach}

Some of the main benefits identified during the execution of MiniDMAIC actions in software development projects were:

- The execution of MiniDMAIC in the organization, reduced considerably, on the projects context, the defect density in systemic tests, as reported in Bezerra (2009b) and increased the productivity as described in Bezerra (2009a);

- The classification of defects used on the approach and adapted by the organization was essential for helping the projects to understanding the defects and to identify of root causes;

- The analysis of many MiniDMAIC is fundamental to identify improvement opportunities for the processes at the organizational level. Thus, we observed that, according to the organization's maturity level, new data sources can aggregate greatly 
to the processes improvements. These new sources can be added to the list of data that can be analyzed, defined in Albuquerque (2008);

- The approach implemented in the Jira tool facilitated the use and increased the speed of MiniDMAIC execution, because this tool already contains all the required fields to perform each phase;

- Intensifying the use of the action in the projects an improvement was implemented, the execution of MiniDMAIC in the first set of tests of the projects to analyze the causes of defects. If the project has none actions to be executed to address the defects, the MiniDMAIC could be completed in phase "Analyze";

- The template for analyzing the causes of defects in systemic tests, available from the approach, was of great importance in facilitating the process of analysis and prioritization of the problem's root causes addressed in the projects;

- Integration of MiniDMAIC approach to the processes that deal with identifying and implementing process improvements at the organizational level.

\section{Related Works}

According to Kalinowski (2009), the first approach to analysis of causes found was described by Endres (1975), in IBM. This approach deals with individual analysis of software defects so that they can be categorized and their causes identified, allowing taking actions to prevent its occurrence in future projects, or at least ensuring its detection in these projects. The analysis of defects in this approach occurs occasionally, as well as corrective actions.

The technique RCA (Root Cause Analysis) (Ammerman, 1998), which is one of the techniques used to analyze the root cause of a problem, aims at formulating recommendations to eliminate or reduce the incidence of the most recurrent errors and hose with higher cost in organization's software development projects. According to Robitaille (2004), the RCA has the purpose of investigating the factors that are not so visible that has contributed to the identification of nonconformities or potential problems.

Triz (Altshuller, 1999) is another methodology developed for analysing causes. It is a systematic human-oriented approach and based on knowledge. His theory defines the problems where the solution raises new problems.

Card (2005) presents an approach for causal analysis of defects that is summarized in six steps: (i) select a sample of the defects, (ii) classify the selected defects, (iii) identify systematic errors, (iv) identify the main causes (V) develop action items, and (vi) record the results of the causal analysis meeting.

Kalinovski (2009) also describes an approach called DBPI (Defect Based Process Improvement), and is based on a rich systematic review for elaboration of the approach to organizational analysis of causes.

Gonçalves (2008b) proposes a causal analysis approach, developed based on the PDCA method, that applies the multicriteria decision support methodology, aiming to assist the analysis of causes form complex problems in the context of software organizations.

ISO / IEC 12207 (2008) describes a framework for problem-solving process to analyze and solve problems (including nonconformances) of any nature or source, that are discovered during the execution of the development, operation, maintenance or other processes. 
Most of the research cited in this work proposes approaches for analysis of causes focusing on the organizational level. However, it is often necessary to perform analysis of causes within the projects that must be quick and effective. In organizations seeking high levels of maturity models of process improvement like CMMI, this practice has to be executed within the project to maintain the adherence to the model. Furthermore, from the investigated approaches involving analysis and resolution of causes, none is based on DMAIC method. The approach presented in this work has the main difference from other approaches the focus of causal analysis in the context of projects, providing a structured set of steps based on the DMAIC method, that are simple to execute.

\section{Conclusion}

The treatment of problems and defects found in software projects is still deficient in most organizations. The analysis, commonly, do not focus sufficiently on the problem and its possible sources, leading to wrong decisions, which will ultimately not solve the problem. It is also difficult to implement a causal analysis and resolution process (CAR) in projects, as prescribed by the CMMI level 5, due to limited resources which they have to work.

The approach presented in the work aims to minimize these difficulties by proposing a consistent approach to analysis and resolution of causes based on the DMAIC method, that is already consolidated in the market. This proposed approach is also adherent to the process area Causal Analysis and Resolution - CAR of CMMI. Moreover, the approach was implemented in a workflow tool, and has been executed in several software development projects in an organization assessed in level 5 of CMMI.

As the main limitation of the approach we have that the MiniDMAIC was defined in the context of organizations that are at least level 4 of CMMI maturity model, since the MiniDMAIC actions will have even better results, because several parameters to measure the projects' results will be already defined, and the use of statistical analysis tools will already be a common practice in the organization. However, it can be executed in less mature organizations, adapting the approach to the organization's reality, but some steps may not get the expected results.

\section{References}

Albuquerque, A. B. (2008). Evaluation and improvement of Organizational Processes Assets in Software Development Environment. D.Sc. Thesis, COPPE/UFRJ, Rio de Janeiro, RJ, Brazil.

Altshuller, G. (1999). Innovation Algorithm: TRIZ, systematic innovation and technical creativity. Technical Innovation Ctr.

Ammerman, M. (1998). The Root Cause Analysis Handbook: A Simplified Approach to Identifying, Correcting, and Reporting Workplace Errors. Productivity Press.

Banas Qualidade. (2007). "Continuous improvement - Soluctions to Problems", Quality News. São Paulo. Accessible in

http://www.estatbrasil.com.br/PgQtN20030003.htm. Acessed in: 2007, Feb 22. 
Bezerra, C. I. M.; Coelho, C.; Gonçalves, F. M.; Giovano, C.; Albuquerque, A. B. (2009a). MiniDMAIC: An Approach to Causal Analysis and Resolution in Software Development Projects. VIII Brazilian Simposium on Software Quality, Ouro Preto. Proceedings of the VIII Brazilian Simposium on Software Quality.

Bezerra, C. I. M. (2009b). MiniDMAIC: An Approach to Causal Analysis and Resolution in Software Development Projects. Master Dissertation, University of Fortaleza (UNIFOR), Fortaleza, Ceará, Brazil.

Blauth, Regis. (2003). Six Sigma: a strategy for improving results, FAE Business Journal, $\mathrm{n}^{\circ} 5$. Card, D. N. (2005). Defect Analysis: Basic Techniques for Management and Learning, Advances in Computers 65.

Chillarege, R. et al. (1992). Orthogonal Defect Classification: a Concept for in-Process Measurements. IEEE Transactions on SE, v.18, n. 11, pp 943-956.

Chrissis, Mary B.; Konrad, Mike; Shrum, Sandy. (2006). CMMI: Guidelines for Process Integration and Product Improvement, 2nd edition, Boston, Addison Wesley.

Dennis, M. (1994). The Chaos Study, The Standish Group International.

Endres, A. (1975). An Analysis of Errors and Their Causes in Systems Programs, IEEE Transactions on Software Engineering, SE-1, 2, June 1975, pp. 140-149.

Gonçalves, F., Bezerra, C., Belchior, A., Coelho, C., Pires, C. (2008a). Implementing Causal Analysis and Resolution in Software Development Projects: The MiniDMAIC Approach, 19th Australian Conference on Software Engineering, pp. 112-119.

Gonçalves, F. (2008b) An Approach to Causal Analysis and Resolution of Problems Using Multicriteria. Master Dissertation, University of Fortaleza (UNIFOR), Fortaleza, Ceará, Brazil.

IEEE standard classification for software anomalies (1944). IEEE Std 1044-1993. 2 Jun 1994.

ISO/IEC 12207:1995/Amd 2:2008, (2008). Information Technology - Software Life Cycle Process, Amendment 2. Genebra: ISO.

Ishikawa, K. (1985). What is Total Quality Control? The Japanese Way. Prentice Hall.

Juran, J. M. (1991). Qualtiy Control, Handbook. J. M. Juran, Frank M. Gryna - São Paulo Makron, McGraw-Hill.

Kalinowski, M. (2009) "DBPI: Approach to Prevent Defects in Software to Support the Improvement in Processes and Organizational Learning". Qualifying Exam, COPPE/UFRJ, Rio de Janeiro, RJ, Brazil.

Kulpa, Margaret K.; Johnson, Kent A. (2003). Interpreting the CMMI: a process improvent approach. Florida, Auerbach.

Pande, S. (2001). Six Sigma Strategy: how the GE, the Motorola and others big comnpanies are sharpening their performance. Rio de Janeiro, Qualitymark.

Rath and Strong. (2005). Six Sigma/DMAIC Road Map, 2nd edition.

Robitaille, D. (2004). Root Cause Analysis: Basic Tools and Techniques. Chico, CA: Paton Press.

Rotondaro, G. R; Ramos, A. W.; Ribeiro, C. O.; Miyake, D. I.; Nakano, D.; Laurindo, F. J. B; Ho, L. L.; Carvalho, M. M.; Braz, A. A.; Balestrassi, P. P. (2002). Six Sigma: Management Strategy for Improving Processes, Products and Services, São Paulo, Atlas.

Smith, B.; Adams, E. (2000). LeanSigma: advanced quality, Proc. 54th Annual Quality Congress of the American Society for Quality, Indianapolis, Indiana. 
Siviy, J. M.; Penn, L. M.; Happer, E. (2005). Relationship Between CMMI and Six Sigma. Techical Note, CMU / SEI -2005-TN-005.

Tayntor, Christine B. (2003). Six Sigma Software Development, Flórida, Auerbach.

Watson, G. H. (2001). Cycles of learning: observations of Jack Welch, ASQ Publication. 


\title{
Defining Placement Machine Capability by Using Statistical Methods
}

\author{
Timo Liukkonen, Ph.D. (Eng.) \\ Nokia Corporation
}

Finland

\section{Introduction}

Modern placement machine's capability to place certain electrical components can be defined as a question of required accuracy. In six sigma methodology the discussion about accuracy is divided into accuracy and precision. Accuracy can be defined as the closeness of agreement between an observed value and the accepted reference value and it is usually referred as an offset value, see Fig.1. Precision is often used to describe the expected variation of repeated measurements over the range of measurement, see Fig.2, and can also be further broken into two components: repeatability and reproducibility (Breyfogle, 2003).

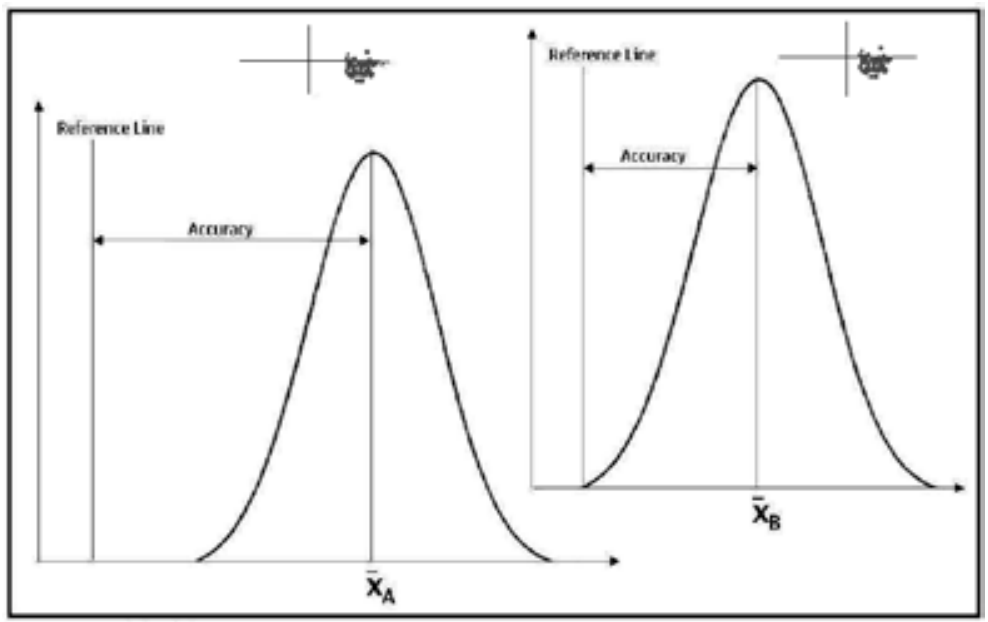

Fig. 1. Definition of accuracy: Process $X_{A}$ has lower accuracy than process $X_{B}$ i.e. process $\mathrm{X}_{\mathrm{A}}$ has bigger offset from reference line. Both have approximately the same precision.

In common everyday language the word accuracy is often used to mean both accuracy and precision at the same time: machine is accurate when both its offset from reference and its variation are small. A rifle e.g. can be said to be "accurate" when all ten bullet holes are found between scores 9.75 and 10.00, but mathematically the shooting process, including also the shooter and conditions, is both accurate and precise. 


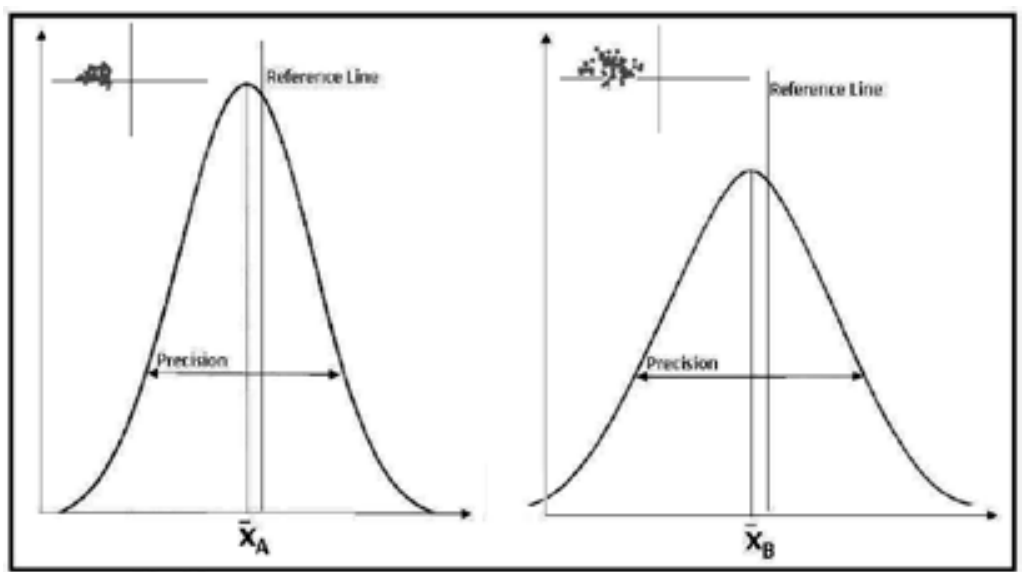

Fig. 2. Definition of precision: Process $X_{A}$ has better precision (less variation) than process $\mathrm{X}_{\mathrm{B}}$. Both processes have approximately the same accuracy (same offset from reference line).

\section{Placement machine accuracy and former studies}

Rotary turret SMD (Surface Mounted Device) placement machine (Fig.3) has moving XYtable to transfer Printed Wiring Board (PWB) to correct position below the placement head. $\mathrm{XY}$-table moves also in vertical direction to adjust placement height to various component thicknesses. Component feeders are arranged behind the machine in a table, which transfers the correct feeder below the placement head. Placement heads with various sizes of vacuum nozzles are arranged in the turret, which revolves and moves pickup nozzles from part pickup point to placement point in a continuos movement providing vision inspection and rotational correction on the way.

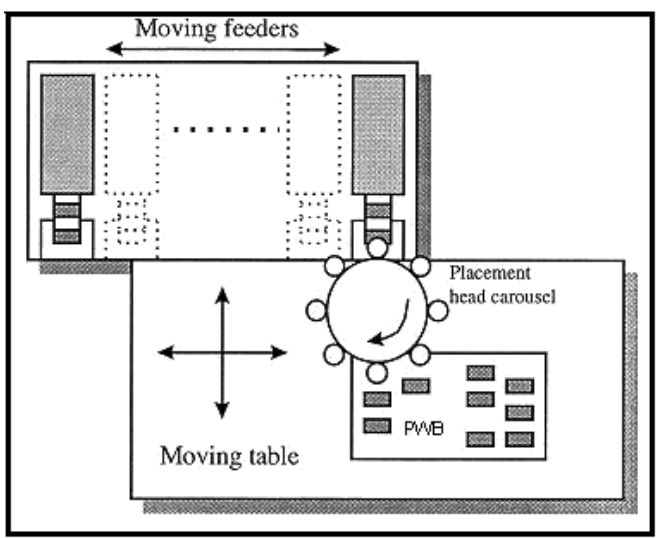

Fig. 3. Principle of a rotary turret placement machine (Johnsson, 1999).

Placement defects such as misaligned or missing parts on PWB are expensive when reworked after reflow soldering. Naturally good quality of the preceding solder paste printing process is crucial for successful component placement (Liukkonen \& Tuominen, 2004). One cause for placement defect is poor placement accuracy of the placement machine 
(Kalen, 2002; Kamen, 1998). Controlling of placement accuracy has a significant role in placement quality and becomes even more important when placement machines gain more operation hours (Liukkonen \& Tuominen, 2003).

CeTaq $\mathrm{GmbH}$ provides placement capability analysis services for electronics manufacturing field. In order to reduce the extra variation coming from e.g. inaccurate materials CeTaq $\mathrm{GmbH}$ uses special glass components and glass boards, as well as dedicated camera based measuring device for the results (Sivigny, 2007; Sauer et al., 1998). In this six sigma study the purpose is to use commercial standard components and very simple FR4 type glas epoxy PWB. Problem with special materials is the extra cost and extra time needed to prepare and perform the test under the special circumstances. By using standard materials we can keep the cost down and also speed up the time needed for the testing when e.g. the same board thickness and size can be used as normally in the production line. This will make it easier for the line engineers to start the test when needed because it takes only 15-30 minutes. Kamen has studied the factors affecting SMD placement accuracy, but has put especially focus on effects coming from variations in solder paste printing, vertical placement force and different component types, whereas in this study they all are considered and kept more or less as constant (Kamen, 1998). Wischoffer discusses about correct component alignment and possible offsets after placement and points out four factors that affect the most: part mass, part height, lead area contacting solder paste and solder paste viscosity (Wischoffer, 2003). Baker studies also the factors affecting placement accuracy and highlights that limits used in placement machine parameters should be defined separately by each company and are based on economics on machine cost, process cost, overall production cost, repair cost and the cost having a defective or potentially defective product reach the customer (Baker, 1996). In this study the technical limits are set by the technical acceptance for the new technology requirements coming from the company.

CeTaq GmbH defines the purpose of capability measurements in three different customer groups as shown in Table 1 (CeTaq, 2010). For this project the main purpose well aligned with CeTaq's grouping can be found in Technical acceptance and machine qualification.

\begin{tabular}{|c|c|c|}
\hline $\begin{array}{l}\text { Equipment } \\
\text { Manufacturer }\end{array}$ & $\begin{array}{c}\text { Retailer Distributer } \\
\text {-After Sales Service } \\
\text {-Electronic Manufacturer } \\
\text {-OEM }\end{array}$ & $\begin{array}{c}\text { Customer- } \\
\text { Designer - Auditors }\end{array}$ \\
\hline $\begin{array}{c}\text {-Design } \\
\text {-Validation } \\
\text {-DOE } \\
\text {-Machine qualification } \\
\text { before shipping } \\
\ldots\end{array}$ & $\begin{array}{c}\text {-Technical Acceptance } \\
\text { and machine } \\
\text { Qualification } \\
\text {-Line Configuration } \\
\text {-Maintenance optimization } \\
\text {-Statistical Process } \\
\text { Control } \\
\text {-Task force / Six sigma } \\
\text {-Customer report on } \\
\text { demand } \\
\text {-Identify root-causes } \\
\text { for Quality issues }\end{array}$ & $\begin{array}{c}\text {-Audits } \\
\text {-Quality management } \\
\text { systems } \\
\text {-Design for } \\
\text { manufacturability } \\
\ldots\end{array}$ \\
\hline
\end{tabular}

Table 1. Capability measurements defined in three customer groups (CeTaq, 2010). 


\section{The DEFINE phase in a Six Sigma project}

This study was completed like a six sigma project including the identifiable DMAIC-process phases: Define, Measure, Analyse, Improve and Control (Breyfogle, 2003). However, because this project is quite short some phases like analyze and improve were combined partly together already in the beginning of planning the experiments. Design Of Experiments (DOE), a statistical tool used to screen the factors to determine which are important for explaining process variation (Montgomery, 2008), has been mostly presented in the Analysis chapters and the interactions found there are presented in Improve phase.

\subsection{Selection of the project and the voice of the customer}

Project selection is the most important part of a Define phase in a six sigma project. In this project the purpose was to find out what is minimum placement machine's Sigma Quality Level (later also referred as Placement Sigma Level, PSL) that still produces good placement quality when spacing between the components on the PWB will be decreased by $33 \%$. Customer's plan to decrease component spacing by 33\% may be too demanding for, at least, those machines which have a lower placement sigma level in placement accuracy, but are still assumed to be used in production for several years. This leads to the second important part of the Define phase, to the business case behind the selected project (Breyfogle, 2003): a lot of bad Quality may be produced if the most capable machines can not be selected. At the same time new investments in machinery can be postponed in the future which will bring additional economical value. Therefore ranking of the available machines is essential.

The smallest component to be assembled is 0402 size capacitor and resistor, where the nominal length of the component is $1 \mathrm{~mm}$ and width $0.5 \mathrm{~mm}$. The height of a resistor is $0.3 \mathrm{~mm}$ and that of the capacitor is $0.5 \mathrm{~mm}$. Because the required placement nozzle is wider than the 0402 component, , it may be necessary to place all resistors first before any of the taller capacitors to prevent the protruding nozzle hitting the components already been placed, i.e. place components according to their height. When component-to-component spacing is larger the problem arising from protruding nozzle does not matter. The kind of "forced" placement sequence will deteriorate free placement optimization and will then have negative effect on line output and also on placement quality as has been shown in previous publications (Liukkonen \& Tuominen, 2003).

\subsection{Problem Statement}

It is essential to determine the project scope in relation to business case and also to available project resources. Primary target of this study is to rank the placement machines according to their capability to place high-density 0402s i.e. what is the minimum requirement in terms of sigma quality level? Secondary target is to verify the need for forced placement sequence: should all resistors be placed before any taller capacitors? 


\section{Process Exploration: the MEASURE phase}

\subsection{Response Variables and Metrics}

In six sigma projects the monitored process outputs are divided into variable type data and attribute type data. Variable data is quantitative data (continuous data) where measurements are used for analysis, e.g. shaft diameter in millimeters. Attribute data is qualitative data that can be counted for recording and analysis. Examples include characteristics such as "missing" or "present", "good" or "bad", "accepted" or "rejected". Attribute data can also include characteristics that are inherently measurable but where results are finally recorded in a simple yes/no or go/no-go fashion (AIAG, 1995). According to six sigma the process output (response) is a function of process inputs (e.g. materials or process setup parameters) i.e. $\mathrm{Y}=\mathrm{f}(\mathrm{X})$. In this study the following responses are monitored.

Attribute data type responses:

Placement errors

Referred later in Figures as Y1 e.g. missing, misaligned, skewed

- Specification used for category "Misaligned" in placement errors before reflow soldering: +/- $180 \mu \mathrm{m}$ for 0402 components

Variable data type responses:

Placement position against nominal in $X$ and $Y$ axes i.e. $\Delta X, \Delta Y$

$X$ Mean (referred later in Figures as $Y_{21}$ )

$X$ StDev (standard deviation, referred later in Figures as $Y_{22}$ )

$Y$ Mean (referred later in Figures as $Y_{23}$ )

Y StDev (standard deviation, referred later in Figures as $Y_{24}$ )

Specification for Means: $+/-100 \mu \mathrm{m}$ (at 3 sigmas, machine manufacturer's specification)

Specification for StDevs: $+/-33 \mu \mathrm{m}$ (tolerance area /6, i.e. $200 \mu \mathrm{m} / 6$ )

\subsection{Measurement System Analysis}

Measurement system description The optical-based AOI (automated optical inspection) system used in this study utilizes solid shape modeling to measure and characterize components and solder joints with lifelike 3D visualization. System has 20-25 $\mu \mathrm{m} /$ pixel resolution at all times with a single high-resolution digital camera and high-speed precision $\mathrm{XY}$-robot. The very same AOI machine was used throughout the study and the machine was calibrated by the manufacturer before the study. Post-placement inspection tools are common sight in a modern SMT (Surface Mount Technology) production line today, and these in-line tools are very often also utilized in various placement accuracy tests and evaluations (Kamen, 1998).

\section{Measurement system Gage}

For repeatability test (precision) of the AOI five populated PWB panels were measured with pre-reflow AOI, each three times, totally including 13680 observations. Gage test was based on two randomly selected components. Calculated Gage error result $1.09 \%$ was excellent (see Fig.4) and AOI seemed to be fully capable as a measurement system for the analysis in this study. 


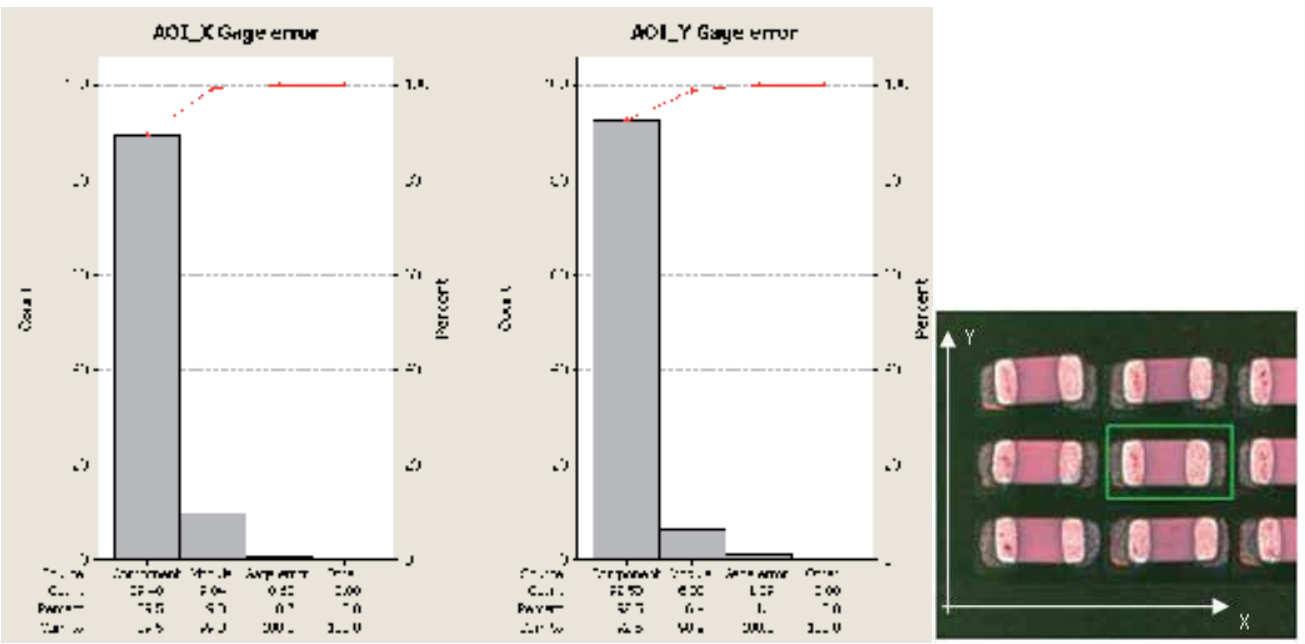

Fig. 4. On the Left: AOI Gage error result showing that $0.68 \%$ of inaccuracy comes from the AOI itself on $\mathrm{X}$ axis and $1.09 \%$ on $\mathrm{Y}$ axis. On the Right: Test boards' coordinate system and AOI screenshot of 0402 components in 0 placement angle.

For additional reliability a second gage test round was made. Measurements were taken from all the components separately using two randomly selected PWB panels and entered into a Boxplot chart. Boxplot is a tool that can visually show differences between characteristics of a data set. Box plots display the lower and upper quartiles (the 25th and the 75th percentiles), and the median (the 50th percentile) appears as a horizontal line within the box (Breyfogle, 2003). The analysis produced Fig. 5 where AOI deviation defined as XRange (i.e. measured max $\Delta X$ value - $\min \Delta X$ value separately calculated for each circuit reference) in $X$ axis is large when placement angle 0 is used. Fig. 5 shows that $X$ range is 80 $\mu \mathrm{m}$ with capacitors and $30 \mu \mathrm{m}$ with resistors. See right part of Fig. 4 for clarification of placement angles and PWB coordinate system. AOI deviation defined as Y-range in $\mathrm{Y}$ axis is large when angle 270 is used. Fig. 5 shows that $Y$ range is $60 \mu \mathrm{m}$ with capacitors and $30 \mu \mathrm{m}$ with resistors. Because this observed repeatability error was randomly distributed all over the board area and therefore could not be avoided by deleting certain references it was decided not to use $\mathrm{Y}$ axis data with 270 placement angle and $\mathrm{X}$ axis data with 0 angle in further analysis of this study. Fig. 5 also shows that $X$ axis data with 270 angle and $Y$ axis data with 0 angle is fully reliable and usable for this study. The gage problem originates from AOI's inability to detect component location accurately in its lengthwise direction with selected algorithm, especially with capacitors. AOI manufacturer was informed about the observed algorithm problem. 


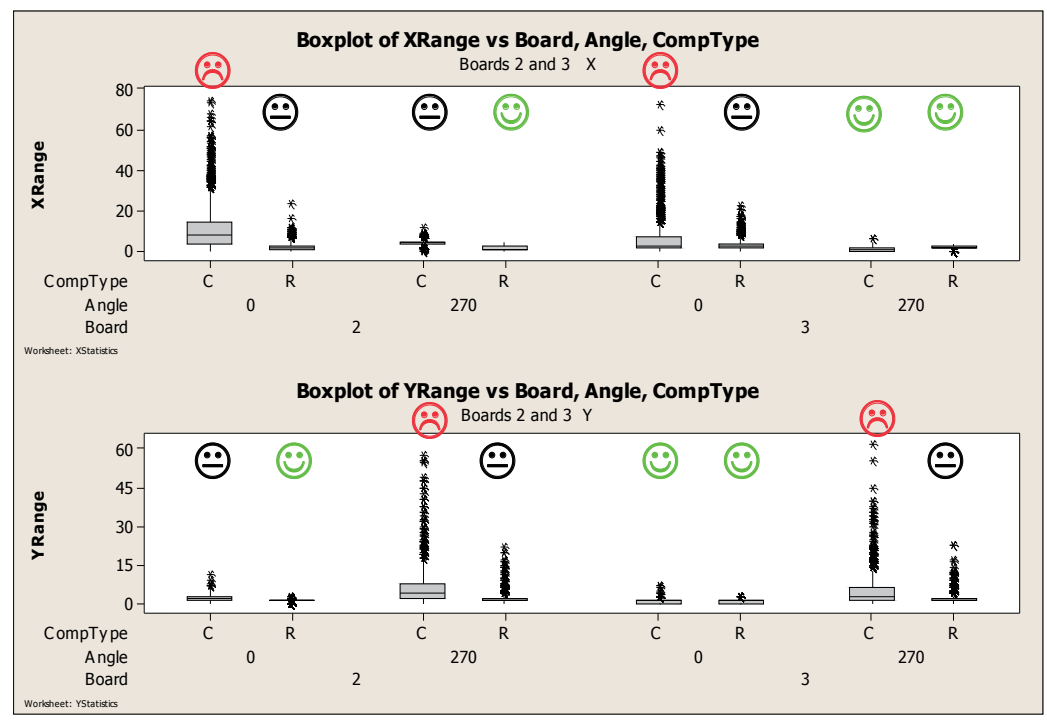

Fig. 5. Boxplot of range for $\Delta \mathrm{X}$ (XRange) and $\Delta \mathrm{Y}$ (YRange) in relation to board, placement angle and component type, including categorization of repeatability results into "Good = Happy-Face", "OK = Neutral-Face" and "Not Used = Sad-Face" symbols showing the goodness levels. Range values shown in $\mu \mathrm{m}$, angles in degrees. $\mathrm{C}=$ Capacitor, $\mathrm{R}=$ Resistor.

\subsection{Process Map}

It is advantageous to represent system structure and relationships using flowcharts. This provides a complete pictorial sequence of what happens from start to finish of a procedure in order to e.g. identify opportunities for improvement and identify key process input variables. An alternative to flowchart is higher level process map that shows only a few major process steps as activity symbols (Breyfogle, 2003). The process map of a turret type placement machine is shown in Fig.6. The two main areas where input parameters in this study are affecting the process are "X/Y table moves to placement position" and "head comes down to placement height". The process map is created by the six sigma project team.

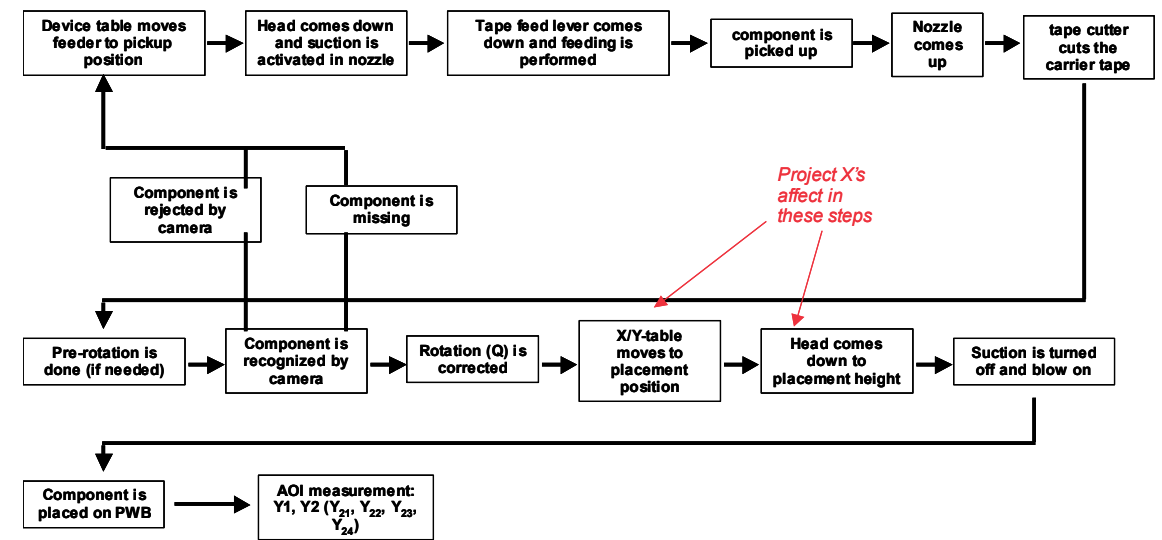

Fig. 6. Component pickup and placement process mapping. 


\subsection{Measuring basic machine capability with PAM-Board}

In this study the purpose was to find out what is minimum placement machine's Sigma Quality Level that still produces good placement quality when spacing between the components is decreased by $33 \%$.

Machines' Placement Sigma Level (PSL) were defined by placing 960 pcs 0402 size resistors and capacitors on sticky taped PWB called PAM-board using the original i.e. current component-to-component spacing (PAM, Placement Accuracy Measurement, see Liukkonen \& Tuominen, 2003). Use of double sided sticky tape eliminates e.g. the possible variation caused by poor solder paste printing, and use of original spacing instead of coming tighter one ensures that the machine's measured original process capability is very reliable and fully comparable between the machines. The machine in question was fully calibrated according to manufacturer's specification prior to this PAM-board testing. Placement results were measured using the optical based AOI machine. Customized Microsoft ${ }^{\circledR}$ Office Excel macro for calculating and presenting PSL result is shown in Fig. 7.

Placement machine has several placement nozzles arranged in a rotating turret head. To be able to test capability for the new spacing with machines which have different Placement Sigma Levels (i.e. measured through PAM-board testing) the offsets of each nozzle were manipulated manually to alter the total variation of the machine. Because the offsets of the nozzles were manipulated symmetrically this did not change the total accuracy (possible offset) of the machine, only total variation (precision). This step produced the simulation possibility for machines having Placement Sigma Levels 1, 2, 3 and 4, to be further studied.

0402 resistors are thinner (thickness $0.3 \mathrm{~mm}$ ) than 0402 capacitors (thickness $0.5 \mathrm{~mm}$ ). Vacuum pickup nozzle for 0402 is wider than the component which produces an expectation that the nozzle currently placing a resistor may hit an adjacent capacitor that has already been placed on the PWB earlier and thus cause a placement defect e.g. missing capacitor. This issue becomes even more critical when we remember that most often components are not picked up summetrically from the center because of free movement of some degree in the pocket of the component feeder. Generally the best placement sequence optimization is achieved when resistors and capacitors are placed mixed based on their location thus producing shortest process cycle time (Liukkonen \& Tuominen, 2003). The use of smaller component spacing on PWB may require new placement sequencing so that all resistors are placed before any capacitors, which may deteriorate placement cycle time. The possible need to place resistors before capacitors was the second purpose of the study.

In PAM-Board testing the fixed tolerance area $\pm 100 \mu \mathrm{m}$ is symmetrical i.e. reference value 0 is in the middle, thus the result is calculated using the basic formula for Sigma Quality Level (Breyfogle, 2003) shown in Equation 1, where USL=100 $\mu \mathrm{m}$ (Upper Specification Limit).

$$
\begin{gathered}
\text { Sigma Total }=\frac{\mathrm{USL}-|\mu|}{\mathrm{s}} \text {, where } \mu=\text { mean, } \mathrm{s}=\text { standard deviation, } \\
\mathrm{USL}=\text { Upper Specification Limit }
\end{gathered}
$$




\begin{tabular}{|c|c|c|c|c|c|c|c|c|}
\hline \multicolumn{2}{|l|}{ BAMtesic niformitions: } & \multicolumn{7}{|c|}{ 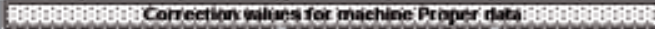 } \\
\hline \multicolumn{2}{|l|}{ Serial neumber: } & Head & X-eorr: & Y.eorr: & Devilation X & Deviation $\mathrm{Y}:$ & Sigma $x$ & Sigma Y \\
\hline \multicolumn{2}{|l|}{ PAM datafiles: } & Alinead & -1 & 2 & 2,2 & 4,0 & 6 & 832: \\
\hline Phacement started by hewd & A & B-head & -1 & -4 & 2,5 & 35 & 25 & $23:$ \\
\hline thekname of equipment: & & C-head & -1 & 0 & 2,3 & 28 & 40 & 3,5 \\
\hline Ine: & & D-head & 0 & 0 & 2,3 & 3,5 & 44 & (35: \\
\hline Dates & 06.03 .2003 & E.head & -1 & 0 & 2,3 & 3,5 & 28 & 32 \\
\hline \multirow[b]{2}{*}{ Import PMen dota } & \multirow{2}{*}{ 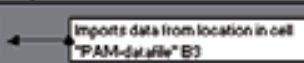 } & F-hewd & 1 & 0 & 2,4 & 3.3 & 39 & $239:$ \\
\hline & & G-head & -1 & 1 & 1,9 & 3,0 & 50 & $130:$ \\
\hline \multirow{2}{*}{$X$ and $Y$ eorrection } & \multirow{2}{*}{ 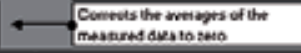 } & Hhead & 1 & 0 & 2,1 & 3,4 & 42 & 32: \\
\hline & & Hhead & 0 & 0 & 2,8 & 2,9 & 27 & 3,3 \\
\hline$x$ Correction & 0 & I-hesd & 0 & 1 & 1.5 & 3.1 & 83 & 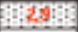 \\
\hline Y Correctione & 9 & K-head & 0 & 1 & 2,3 & 2,6 & 4 & 3,6 \\
\hline \multirow{11}{*}{ Comments: } & & Lhead & 1 & 0 & 1,8 & 3,3 & 48 & 83 \\
\hline & & Mhead & 1 & 0 & 1,7 & 3,3 & 80 & 32 \\
\hline & & W-head & -1 & 1 & 2,3 & 3.1 & 40 & $23:$ \\
\hline & & O-head & 1 & -1 & 18 & 38 & 49 & 13:3:1: \\
\hline & & Plinead & -1 & 1 & 1,9 & 2,8 & 80 & 3,3 \\
\hline & & Qhead & 1 & -1 & 2,4 & 3,2 & 28 & $32:$ \\
\hline & $=$ & R-head & 0 & -2 & 2,3 & 3.1 & 4 & 25: \\
\hline & & S-head & 0 & .2 & 2,4 & 2,2 & 4 & 35 \\
\hline & & Thead & 0 & 0 & 1,5 & 27 & 62 & 3,6 \\
\hline & & \begin{tabular}{|l} 
Min: \\
\end{tabular} & $-1,32$ & 2,18 & \multicolumn{2}{|c|}{ Doviation total: } & \multicolumn{2}{|c|}{ Sigma total: } \\
\hline & & Max: & 1,37 & 1,71 & 2,28 & 3,30 & 4,4 & 3,0 \\
\hline
\end{tabular}

Fig. 7. Example of customized Microsoft ${ }^{\circledR}$ Office Excel macro for calculating and presenting PSL result. This placement accuracy measurement (PAM) procedure is generated using 0402 placements (with current component spacing) on sticky tape and on dedicated PAMboard (see Liukkonen \& Tuominen, 2003).

\subsection{Creating HD-Board in order to define capability for the new component-to- component spacing}

Placement capability for the new spacing was measured with the machines having produced different PSL results. This step can also be regarded as representing basic process capability for the new technology requirement. Fig. 8 and 9 show process capability distributions from placements using especially designed test PWB called HD-board ("High-Density" placement to highlight new tighter component-to-component spacing). HD-board has 5050 pcs 0402 components placed on wet solder paste and with new tighter component spacing. HD-Board is presented in Fig. 11. All machines of different placement sigma levels are placing the same kind of board using the same process. Subtitle "Placement Sigma Level $=1$ " in Fig. 8 and 9 means that PSL result of this particular machine has shown "Sigma total:" 1.0 in original PAM-Board testing, subtitle "Placement Sigma Level $=2$ " means "Sigma total:" 2.0 etc. respectively. Sigma Quality Level from HD-Board is presented with "Z.Bench" value in the Fig. 8 and 9, and specification limits (Z.USL, Z.LSL) for it are calculated automatically by Minitab® software from the data. Fig. 8 and 9 show roughly that process changes remarkably somewhere between PSL levels 2 and 3. Generally, instead of sigma level, process capability can also be defined using a Capability Index $C_{p k}$, value of which is one third of Sigma Quality Level value (Breyfogle, 2003). Analyse phase in the next chapters shows distributions from HD-Board analysed deeply against fixed specification limits. 


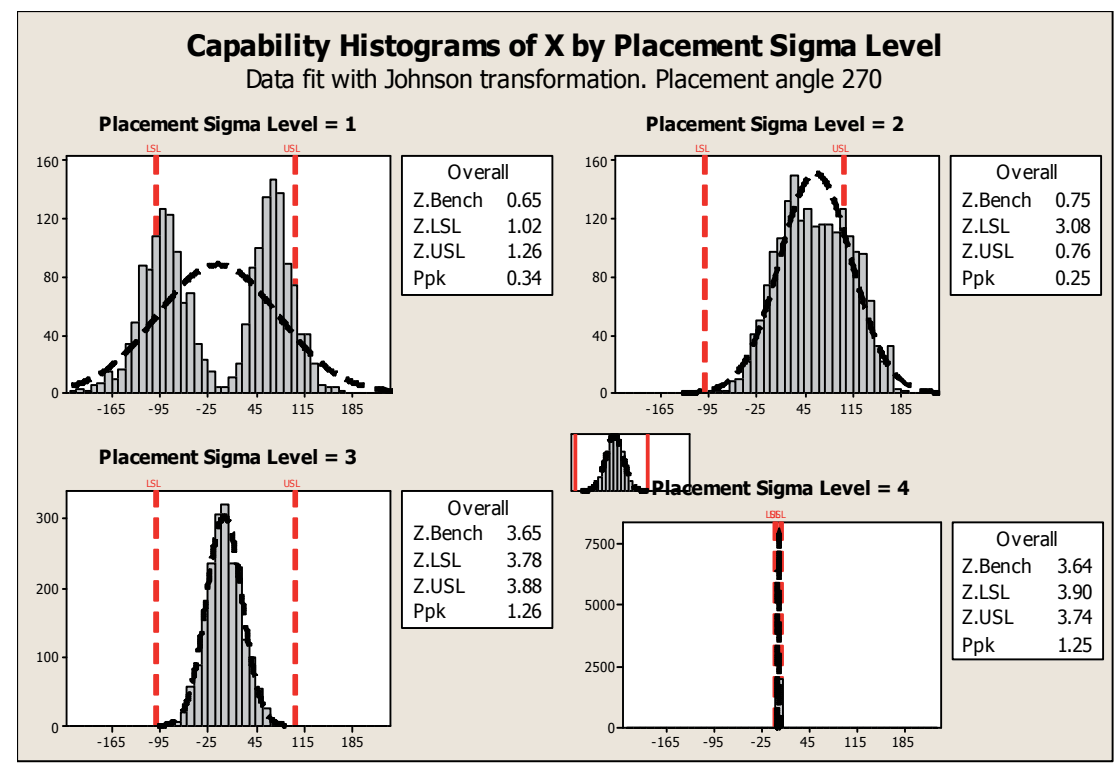

Fig. 8. Capability histograms of 0402 placements on $\mathrm{X}$ direction by different PSL values. $\Delta \mathrm{X}$ values are presented in micrometers.

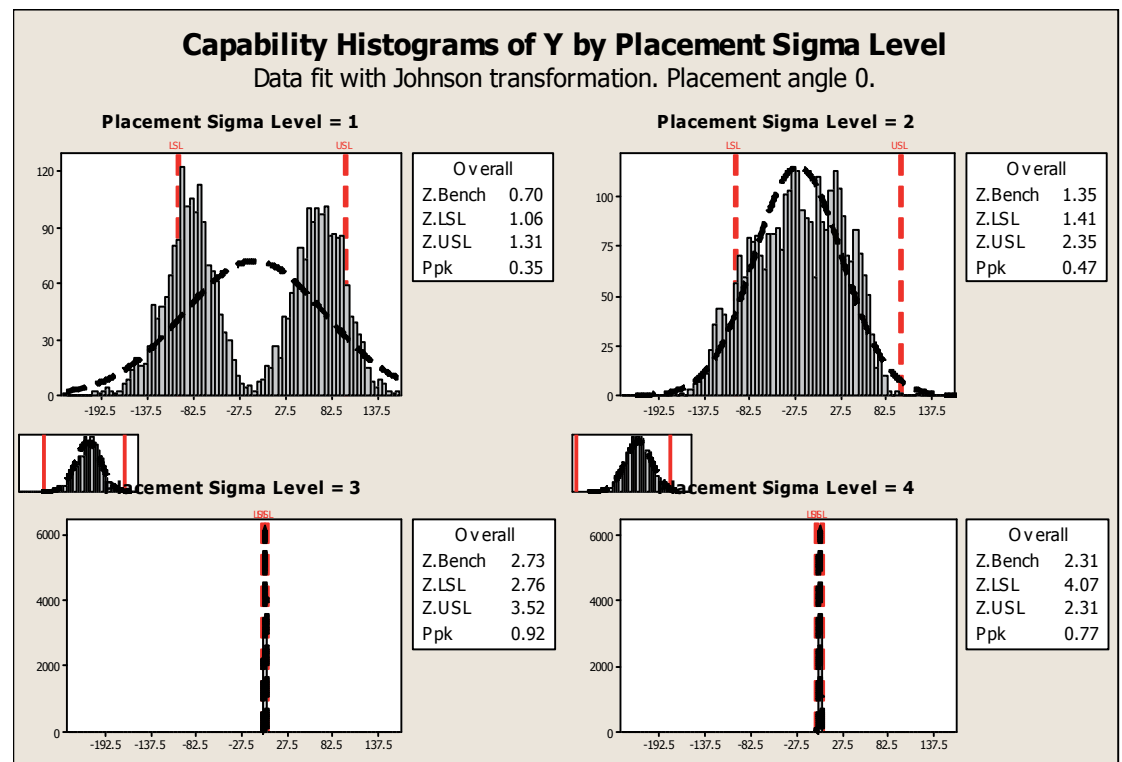

Fig. 9. Capability histograms of 0402 placements on $\mathrm{Y}$ direction by different PSL values. $\Delta \mathrm{Y}$ values are presented in micrometers.

Placement sigma levels 1, 2 and 3 are created manually by manipulating the parameters (the means of head groups in north-east, south-east, south-west and north-west directions) of the very same original machine and thus affecting the total deviation (precision) of the placement heads. Means (accuracy, offset) should however be approximately the same in every case, which should be seen in further analysis of distributions. 


\subsection{XY Matrix}

Prioritization matrices are used to help to decide upon the order of importance of a list of items (Breyfogle, 2003). XY matrix is one of them and will take into account not only how often things might happen but also the severity of the effect it will create. Fig. 10 shows XY matrix on placement process key input variables. Prioritization matrices are often completed by the selected project team.

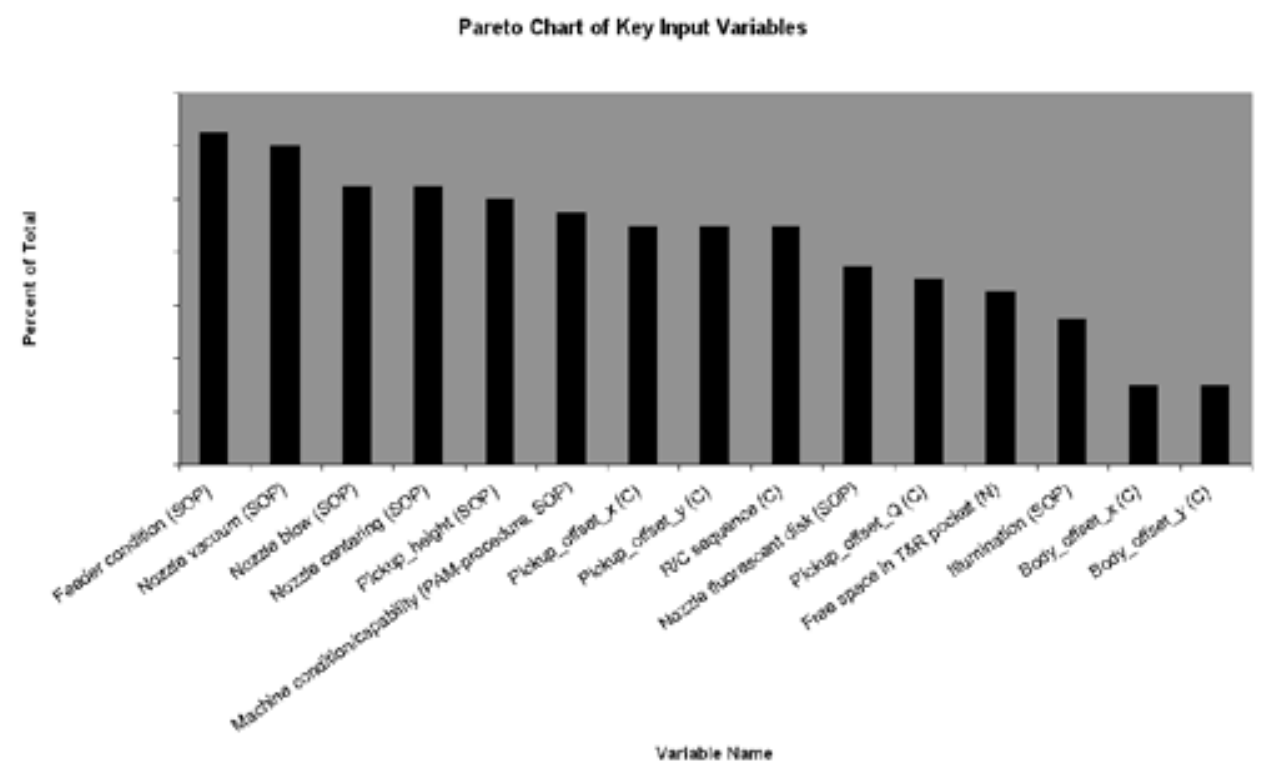

Fig. 10. XY matrix on placement process key input variables showing the relative importance and effect of each input variable $X$ on response variable $Y$ (pickup and placement error). SOP $=$ Standard Operating Procedure, $\mathrm{C}=$ Controllable, $\mathrm{N}=$ Noise.

\subsection{X's from Measure Phase}

From measure phase three $X^{\prime}$ 's were identified and prioritized for the project scope by the six sigma project team.

1) $R / C$ sequence

2) Feeder condition

Placement sequence of resistors (R) and capacitors (C)

$=>$ this $X$ is to be further studied

3) Machine condition/capability

Elimination of $\mathrm{X}$ by using maintained/calibrated machine (i.e. machine is in good condition), but what machine placement sigma level from PAM-board is required?

$=>$ this $X$ is to be further studied 


\section{The ANALYSE phase}

A DOE was performed with a dedicated HD-board test PWB. Picture of HD board is seen in Fig.11. The HD boards were first solder paste printed with a modern high-accuracy stencil printing machine. Then 0402 resistors and capacitors were placed on the boards by machines having placement sigma levels of 1, 2, 3 and 4 respectively. Totally four HDboards were produced, one for each placement sigma level. Components were placed only on modules 1 and 3 of the HD-board panel (see Fig.11). Resistors and capacitors were placed on modules 1 and 3 using different placement sequence, which is described in Fig.11. AOI inspection was performed immediately after placement and totally 20200 components were placed.

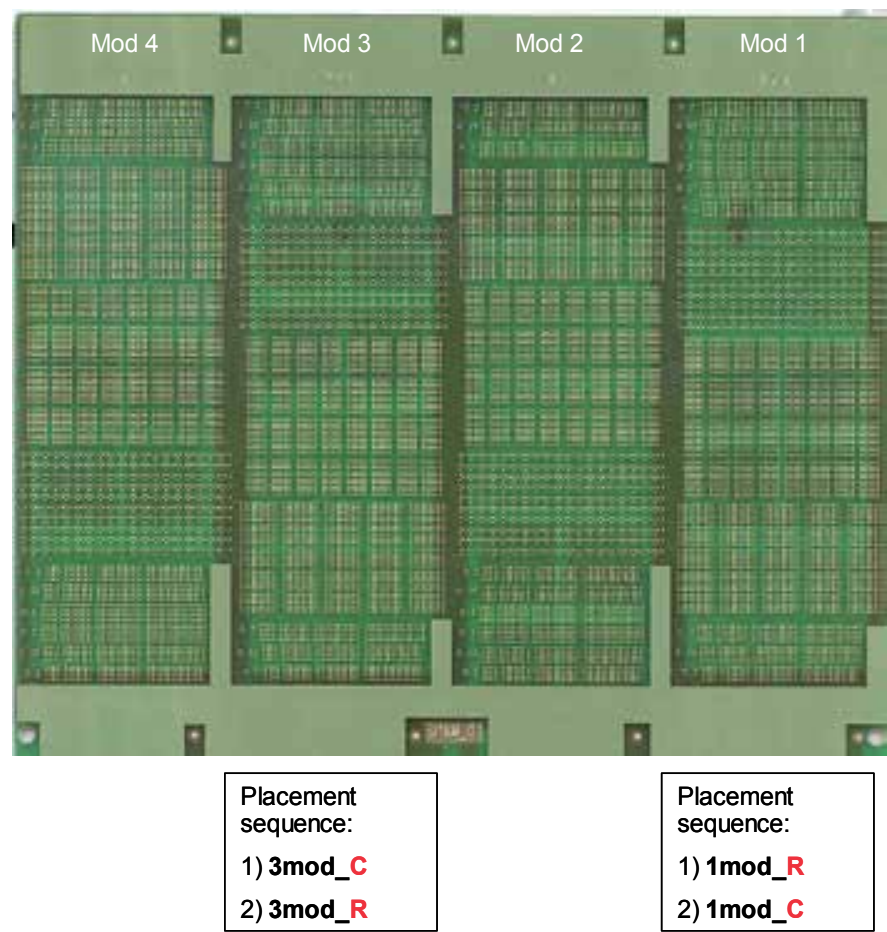

Fig. 11. HD-Board test PWB panel having four identical modules. Modules are numbered from right to left. On Module1 (1mod) all resistors were placed before any capacitors and on Module3 (3mod) all capacitors were placed before any resistors. Modules 2 and 4 were not used at all.

\subsection{Graphical Analysis}

Totally four HD-boards were produced, one for each placement sigma level. Basic process capability distributions from these boards were already shown in Fig.8 and 9 using specification limits calculated automatically from the data. In this chapter graphical analysis are made from the same data using Minitab® statistical software. 


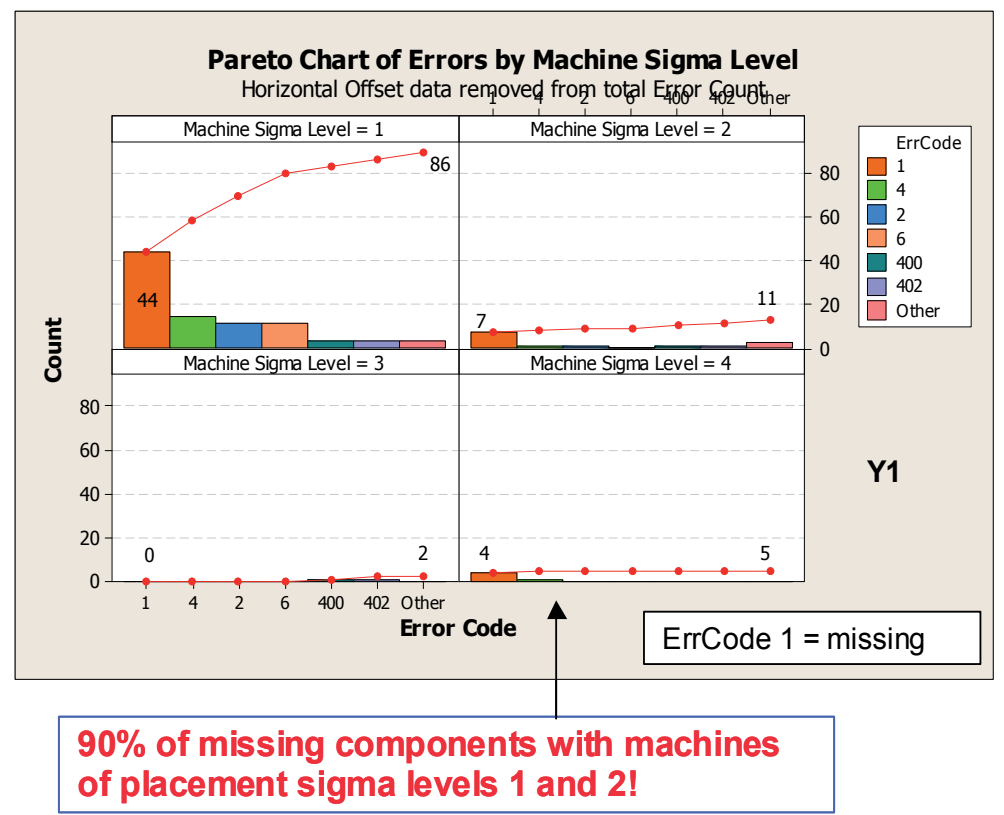

Fig. 12. Pareto chart of placement error counts (Y1) by machine sigma level (i.e. PSL).

The Pareto chart of error counts analysis in Fig. 12 shows that $90 \%$ of missing components come from machines having PSL 1 and 2. It can also be seen that PSL 4 board shows 5 errors and PSL 3 only 2 errors, both being however at a very low level.

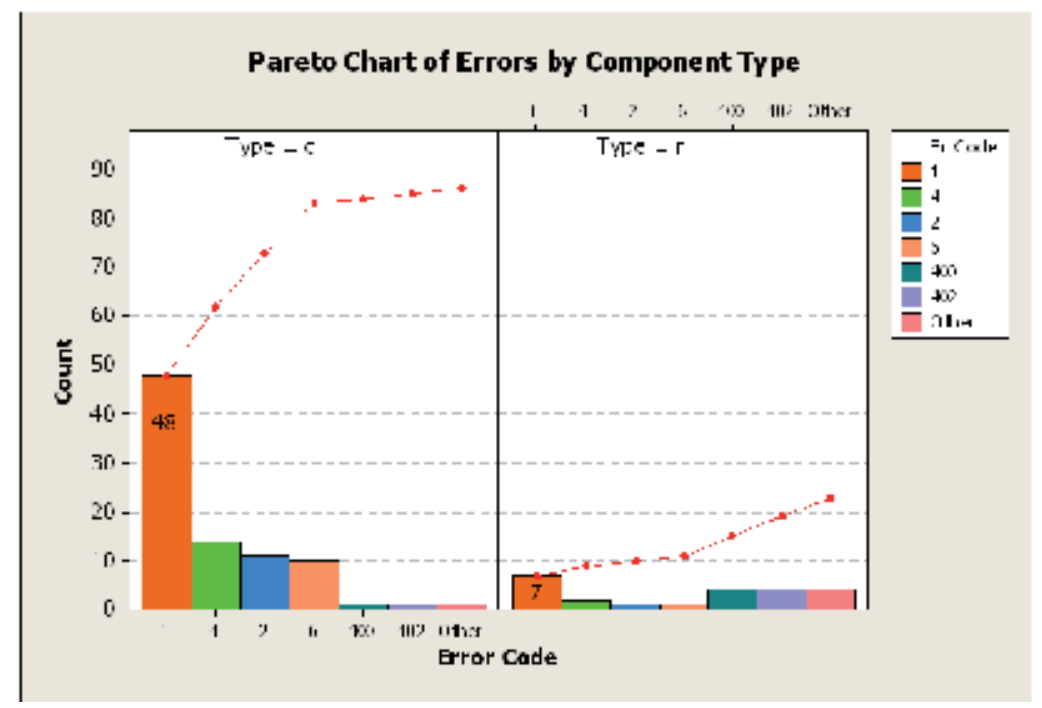

Fig. 13. Pareto chart of placement error counts (Y1) by type (i.e. resistors and capacitors).

Fig. 13 shows Pareto chart of error counts analysis separately for resistors and capacitors. We can see that missing components are clearly found with capacitors, where missing chip count is 48 against that of only seven with resistors. 


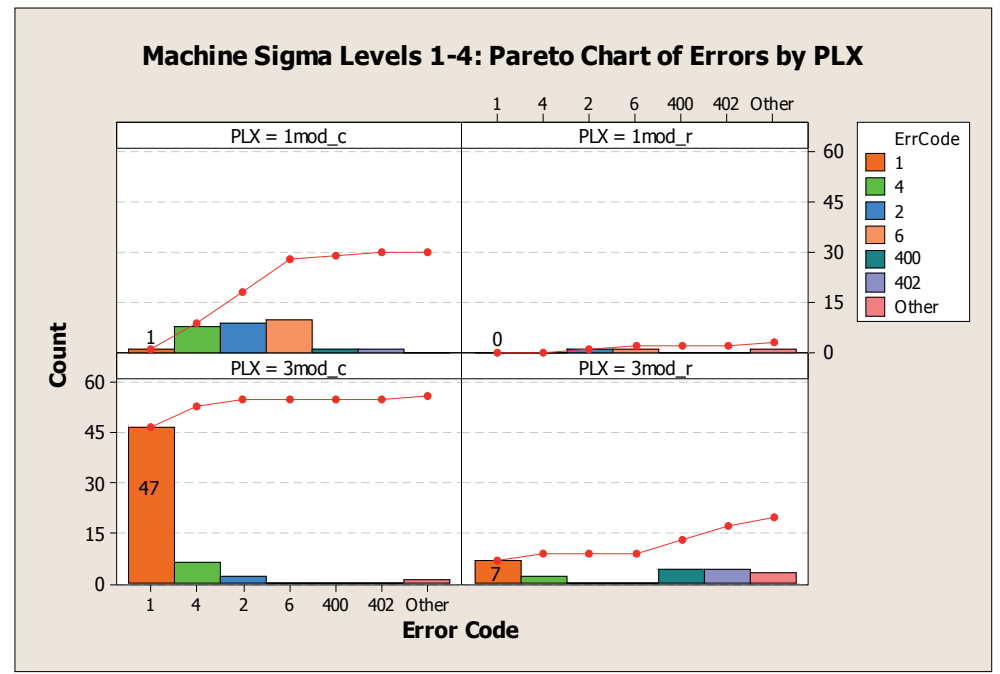

Fig. 14. Pareto chart of placement error counts (Y1) by placement sequence (1mod_c = capacitors on module $1,1 \mathrm{mod} \_r=$ resistors on module $1,3 \bmod \_c=$ capacitors on module 3 and 3 mod_r $=$ resistors on module 3).

Further studies show that placement errors are found clearly on module 3 capacitors, which all were placed before any resistors on that module. On module 3 capacitor error count for missing (ErrCode=1) is 47 and resistor error count is 7 . On module 1 all resistors were placed before any capacitors and the error levels are then much lower. On module 1 total error count for missing (ErrCode=1) is 1 . These conclusions can be made from Pareto chart of error counts analysis by placement sequence in Fig. 14.

All three Paretos in Fig. 12, 13 and 14 show together that placement errors are found with machines of PSL 1 and 2, and in those machines especially with capacitors on module 3. On module 3 all capacitors are placed before any resistors.

Boxplot analysis (see chapter 4.2 for description on boxplot tool.) in Fig. 15 and 16 show that means from placement sigma levels 3 and 4 are approximately on the same level and around zero in $X$ axis, and that mean is slightly on higher level with sigma level 4 in $Y$ axis, which was already seen in basic capability distributions in Fig. 8 and 9. Generally, however, means are good. Standard deviations are good with placement sigma levels 3 and 4, especially in Xaxis. Machines of placement sigma levels 1 and 2 show significantly bigger standard deviation. Also mean is off the center with PSL 2 in X-axis. 


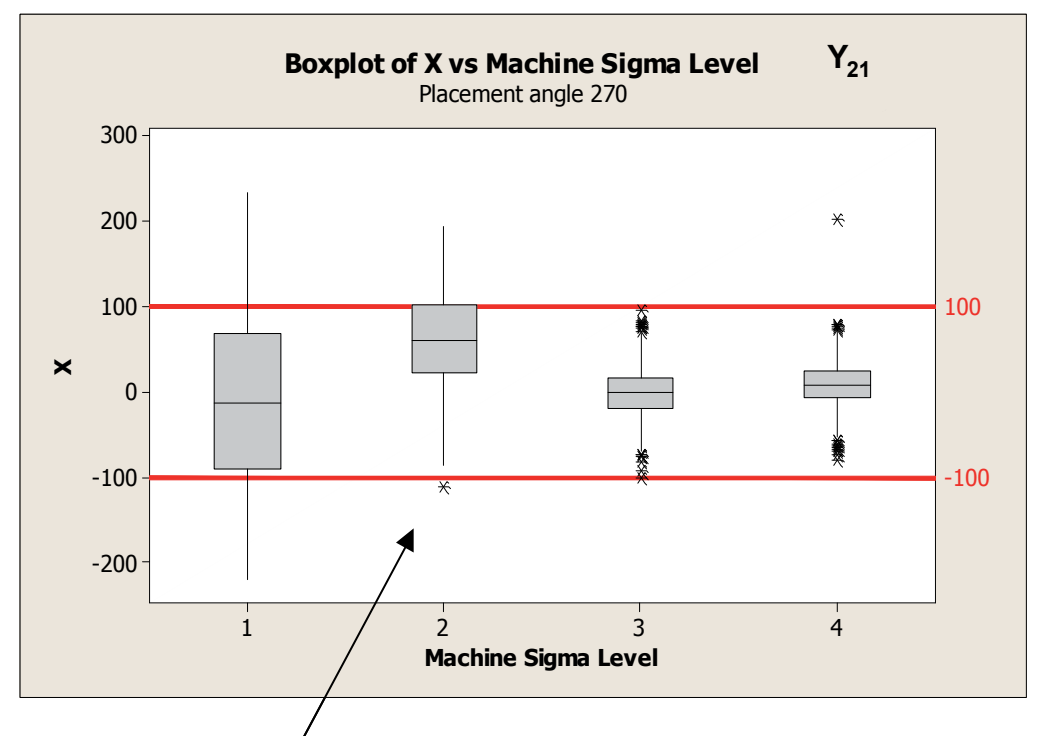

Mean is off the center with machine of placement sigma level 2 in X-axis!

Fig. 15. Boxplot analysis of $\Delta \mathrm{X}$ results by PSL. $\Delta \mathrm{X}$ values presented in micrometers.

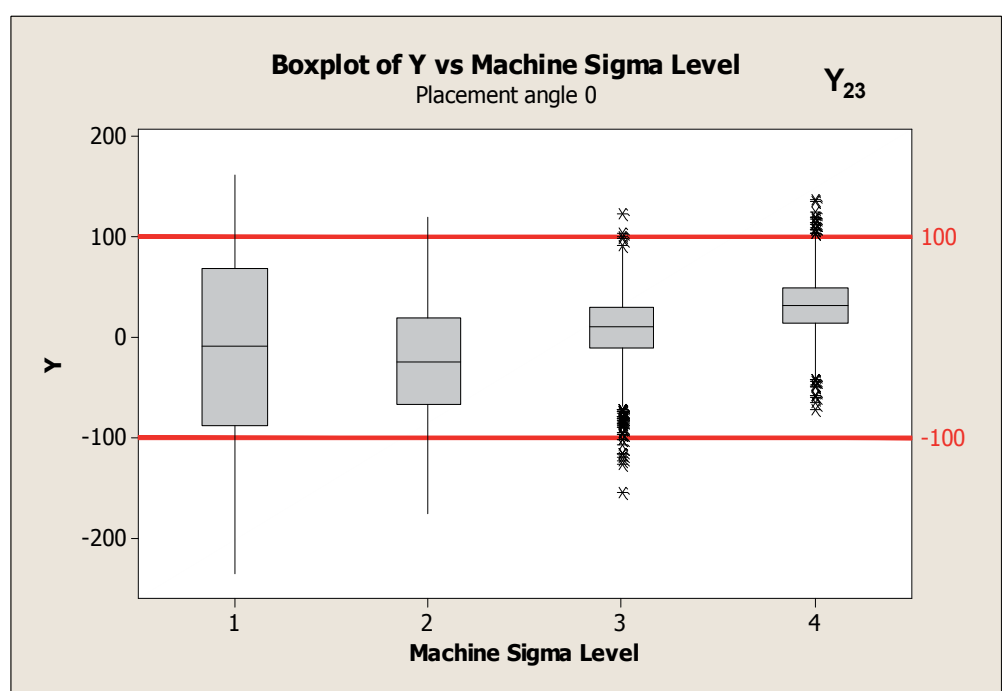

Fig. 16. Boxplot analysis of $\Delta \mathrm{Y}$ results by PSL. $\Delta \mathrm{Y}$ values presented in micrometers. 


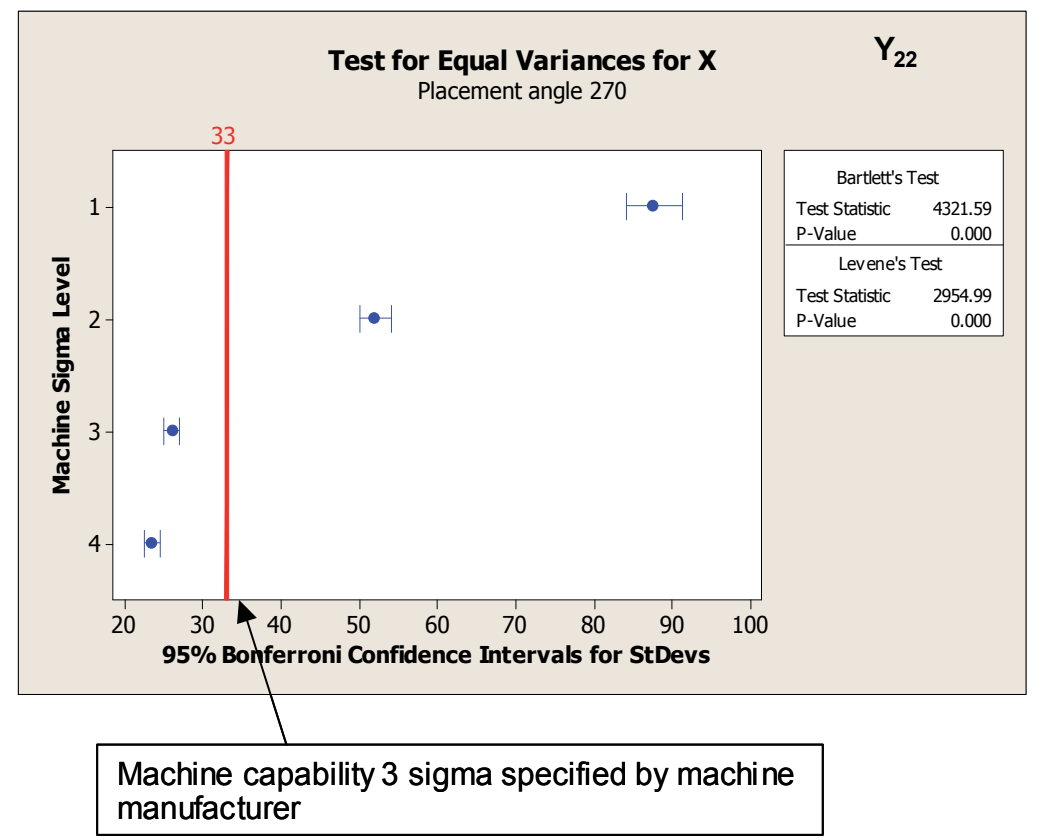

Fig. 17. Test for equal variances of $\Delta \mathrm{X}$ results by different PSL levels. $\Delta \mathrm{X}$ values presented in micrometers.

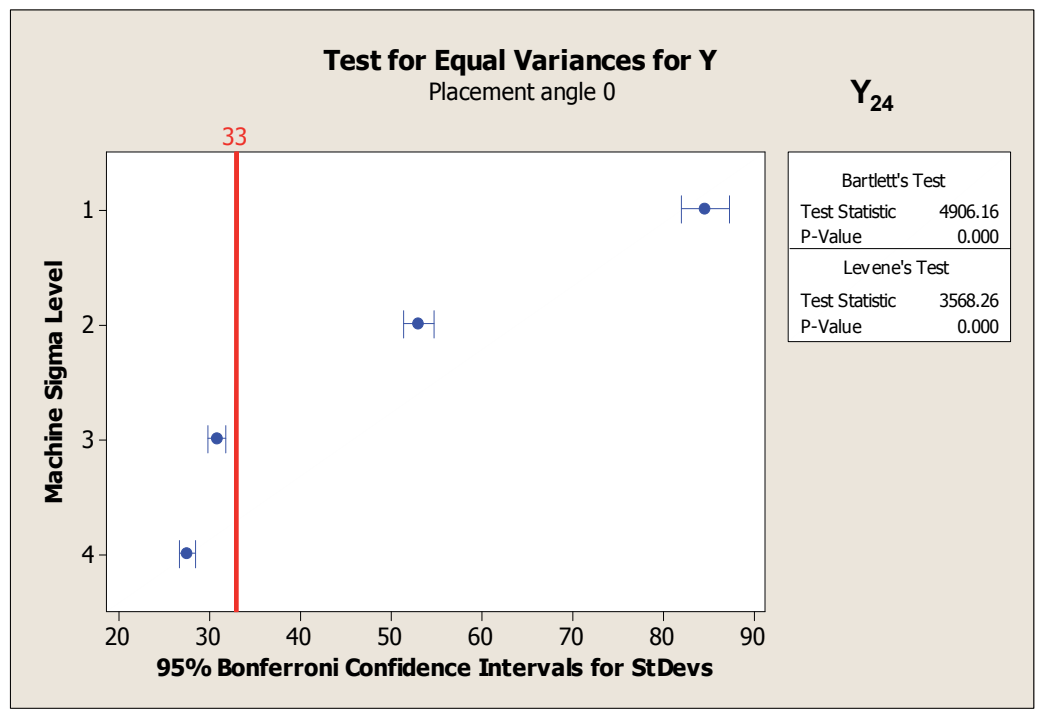

Fig. 18. Test for equal variances of $\Delta \mathrm{Y}$ results by different PSL levels. $\Delta \mathrm{Y}$ values presented in micrometers.

Two analysis of variances in Fig. 17 and 18 show that machines with placement sigma levels 3 and 4 are clearly inside minimum machine capability 3 sigma (Standard deviation $33 \mu \mathrm{m}$ ) specified by machine manufacturer. Standard deviation required to achieve six sigma 
process would be $17 \mu \mathrm{m}$. Analysis show also that machines with placement sigma levels 1 and 2 are clearly outside the 3 -sigma limit on both axes.

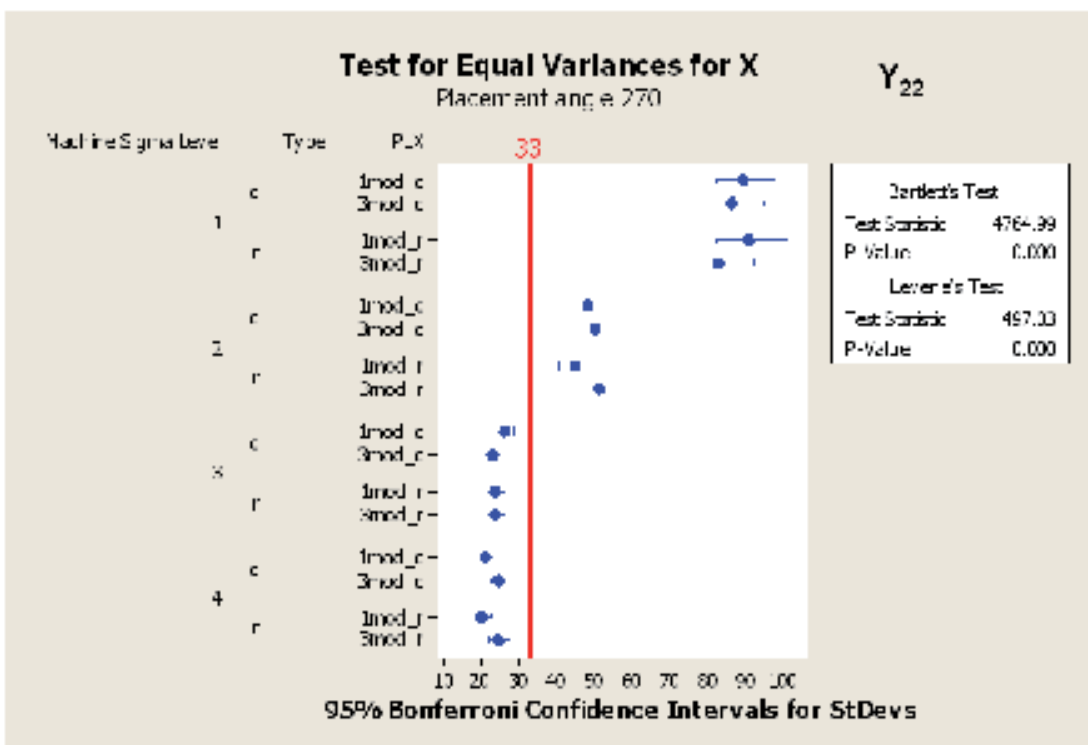

Fig. 19. Test for equal variances of $\Delta \mathrm{X}$ by PSL, component type (R/C) and placement sequence for $\mathrm{R} / \mathrm{C}$. $\Delta \mathrm{X}$ values presented in micrometers.

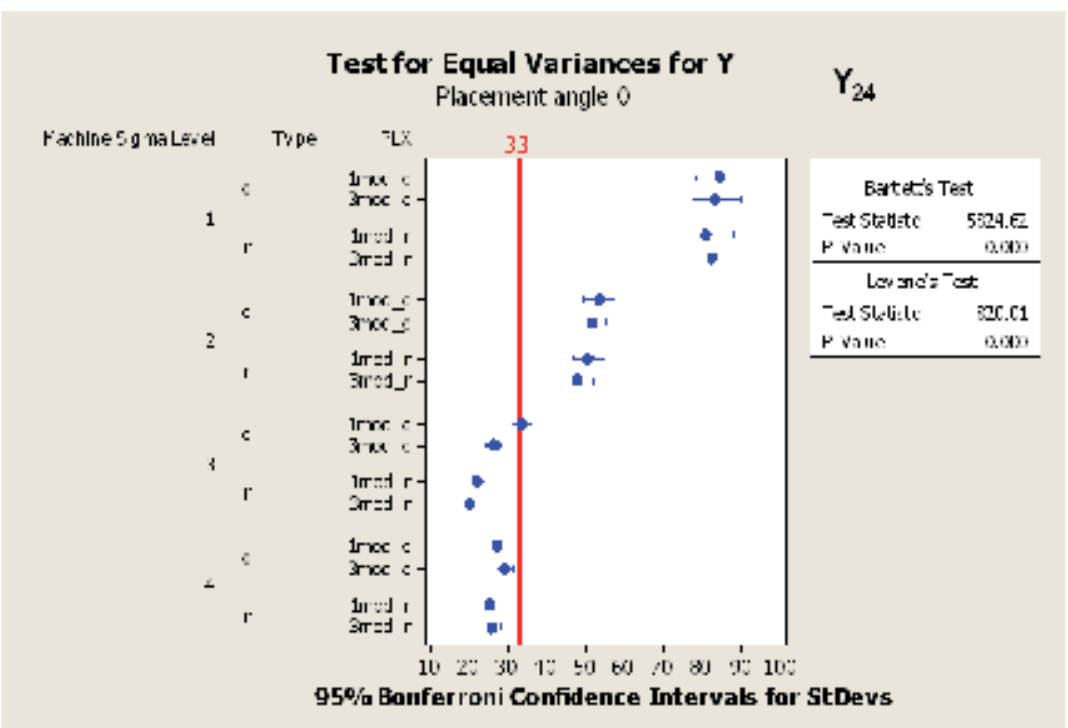

Fig. 20. Test for equal variances of $\Delta \mathrm{Y}$ by PSL, component type (R/C) and placement sequence for $\mathrm{R} / \mathrm{C} . \Delta \mathrm{Y}$ values presented in micrometers.

Analysis of variances in Fig. 19 and 20 show that no difference is found between module 1 and module 3 results when analyzed separately for resistors and capacitors (i.e. component 
type) and machine sigma levels. This means that no difference is found with placement sequence for resistors vs. capacitors based on variance test inside each PSL.

\title{
5.2 Test of Hypotheses
}

Test of hypotheses showed in this chapter are meant to make sure that our sample sizes have been large enough to give reliable results during the graphical analysis made.

\subsubsection{Power and Sample Size}

\section{2-Sample $t$ Test in Minitab® statistical software}

Testing mean $1=$ mean 2 (versus not $=$ )

Calculating power for mean $1=$ mean $2+$ difference

Alpha $=0.05$, assumed standard deviation $=33$

\author{
Sample \\ Size Power Difference \\ $\begin{array}{lll}5050 & 0.9 & 2.12898\end{array}$
}

The sample size is for each group. With sample size 5050 and "target" standard deviation 33 $\mu \mathrm{m}$ ( 3 sigma process, specified by machine manufacturer) we are sensitive enough to reliably detect $2.12 \mu \mathrm{m}$ shift in distribution mean (95\% Confidence Interval). This shows that our analysis made are very reliable.

\section{Test for Two Proportions in Minitab® statistical software}

Testing proportion 1 = proportion 2 (versus not $=$ )

Calculating power for proportion $2=0.5$

Alpha $=0.05$

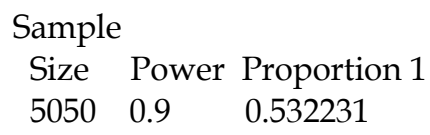

The sample size is for each group. With sample size 5050 and error rate $50 \%$ (proportion 2 default in Minitab® statistical software is 0.5 ) we are sensitive enough to reliably detect $3.2 \%$ error rate change ( $95 \%$ Confidence Interval). This shows that our analysis made are very reliable.

\subsubsection{Test and Confidence Intervals for Two Proportions}

P-charts (proportion of defects) were created in Minitab ${ }^{\circledR}$ to analyze statistically that the sample sizes used have been statistically large enough and therefore the confidence intervals are acceptable (Breyfogle, 2003; Montgomery, 2008).

Fig. 21 shows error counts per PSL level in P-chart from Minitab® including confidence intervals. Fig. 21 is supporting the following statistical analysis A, B and C. It should be 
noted that "HorOff" (horizontal offset) placement errors were removed from the following analysis data because AOI showed poor repeatability (precision) with that inspection direction (see chapter 4.2).

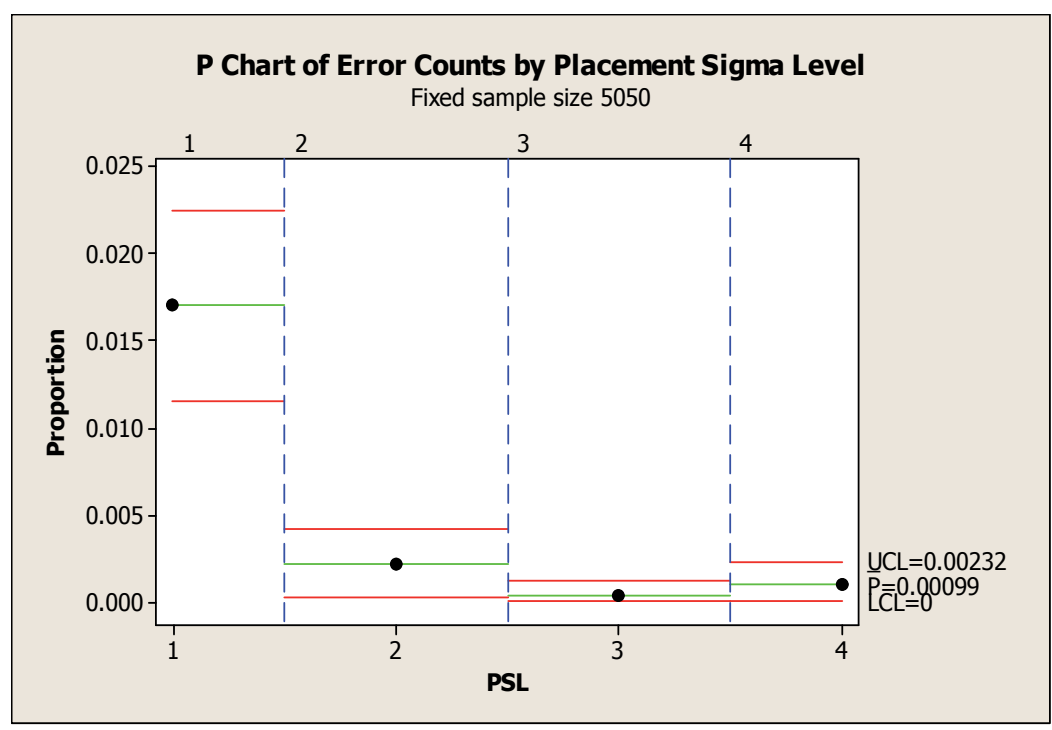

Fig. 21. Error counts per PSL level in P-chart from Minitab® including confidence intervals.

A) Test and CI for Two Proportions in Minitab® statistical software (Error Count between Machine Sigma Level 1 and 2, HorOff removed)

$$
\begin{array}{llll}
\text { Sample } & \mathrm{X} & \mathrm{N} & \text { Sample p } \\
1 & 86 & 5050 & 0.017030 \\
2 & 11 & 5050 & 0.002178
\end{array}
$$

Difference $=p(1)-p(2)$

Estimate for difference: 0.0148515

95\% CI for difference: $(0.0110585,0.0186445)$

Test for difference $=0$ (vs not $=0): Z=7.67$ P-Value $=0.000$

$=>$ since $\mathrm{P}$-value $<0.05$ there is statistically sicnificant difference between proportions of PSL level 1 and 2

B) Test and CI for Two Proportions in Minitab® statistical software (Error Count between Machine Sigma Level 2 and 3, HorOff removed)

$$
\begin{array}{lcll}
\text { Sample } & X & \mathrm{~N} & \text { Sample } \mathrm{p} \\
1 & 11 & 5050 & 0.002178 \\
2 & 2 & 5050 & 0.000396
\end{array}
$$

Difference $=\mathrm{p}(1)-\mathrm{p}(2)$

Estimate for difference: -0.00178218

95\% CI for difference: $(-0.00318020,-0.000384155)$

Test for difference $=0($ vs not $=0): Z=-2.50$ P-Value $=0.012$

$=>$ There is statistically sicnificant difference between proportions of PSL level 3 and 2 
C) Test and CI for Two Proportions in Minitab® statistical software (Error Count between Machine Sigma Level 3 and 4, HorOff removed)

$\begin{array}{llll}\text { Sample } & X & N & \text { Sample p } \\ 1 & 2 & 5050 & 0.000396 \\ 2 & 5 & 5050 & 0.000990\end{array}$

Difference $=p(1)-p(2)$

Estimate for difference: -0.000594059

95\% CI for difference: $(-0.00162049,0.000432366)$

Test for difference $=0($ vs not $=0): Z=-1.13$ P-Value $=0.257$

=> There isn't statistically sicnificant difference between error counts of PSL level 3 and 4, which can also be seen from Fig. 21 where confidence intervals overlap between PSL3 and 4.

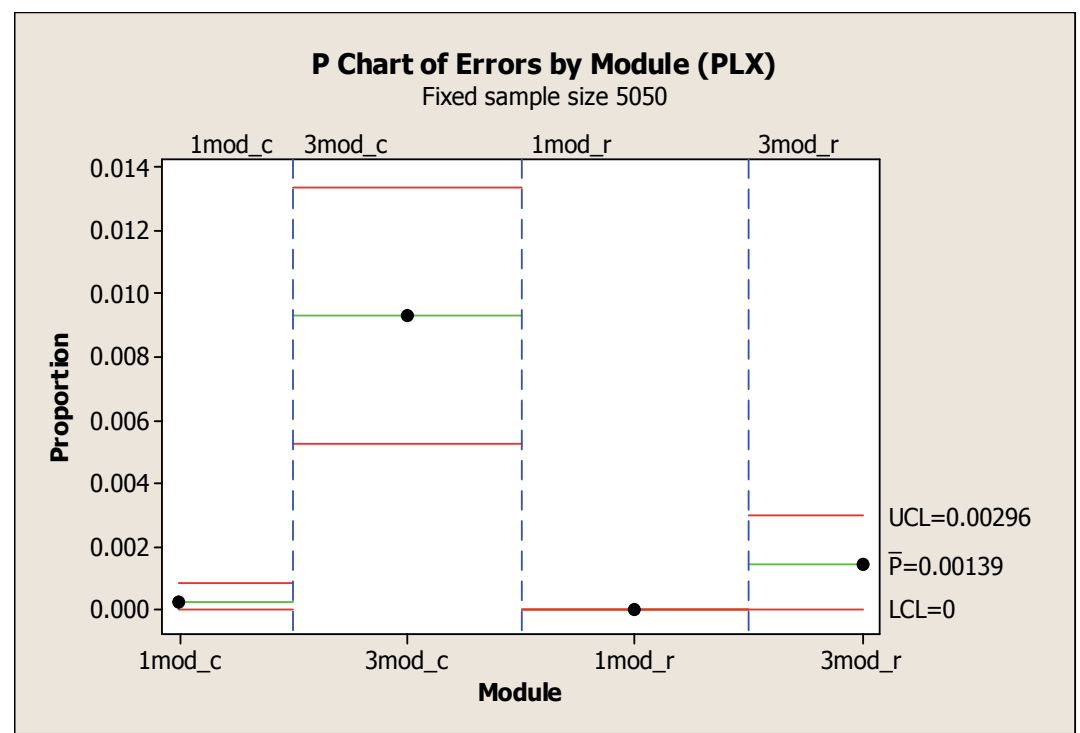

Fig. 22. Error counts per PWB module in P-chart from Minitab® including confidence intervals.

Fig. 22 shows Error counts per PWB module in P-chart from Minitab® including confidence intervals. PWB module represents different placement sequences for resistors and capacitors. Fig. 22 is supporting the following statistical analysis D and E.

D) Test and CI for Two Proportions in Minitab® statistical software (Error count for "Missing Chip" between 1mod_c and 3mod_c)

$$
\begin{array}{llll}
\text { Sample } & \mathrm{X} & \mathrm{N} & \text { Sample } \mathrm{p} \\
1 & 1 & 5621 & 0.000178 \\
2 & 47 & 5621 & 0.008362
\end{array}
$$

Difference $=p(1)-p(2)$

Estimate for difference: -0.00818360

95\% CI for difference: $(-0.0105895,-0.00577774)$ 
Test for difference $=0$ (vs not $=0): Z=-6.67$ P-Value $=0.000$

=> There is statistically sicnificant difference between proportions $1 \mathrm{mod} \_c$ and 3mod_c

E) Test and CI for Two Proportions in Minitab® statistical software (Error count for "Missing Chip" between 1mod_r and 3mod_r)

$\begin{array}{llll}\text { Sample } & X & N & \text { Sample p } \\ 1 & 0 & 4476 & 0.000000 \\ 2 & 7 & 476 & 0.014706\end{array}$

Difference $=p(1)-p(2)$

Estimate for difference: -0.0147059

95\% CI for difference: $(-0.0255196,-0.00389221)$

Test for difference $=0$ (vs not $=0): Z=-2.67$ P-Value $=0.008$

=> There is statistically sicnificant difference between proportions of $1 \mathrm{mod} \_r$ and $3 \mathrm{mod} \_r$

\subsection{X's from Analyze Phase}

What placement sigma level is required to place high-density 0402 s with good quality? Analyses showed that the problem is not the mean, e.g. even with placementy sigma level 1 the mean is in the center of the specification limits $( \pm 100 \mathrm{um})$ but also a lot of data is outside the limits. The problem is concentrated generally on too large deviation. Because lower placement sigma levels $(1,2,3)$ are "created" manually by manipulating the machine parameters of the very same machine and thus affecting the deviation of the placement heads, means are approximately the same and good in every case. If PSL procedure (PAMboard testing) shows that the means are not in the center (offset) they can be moved easily inside the specification limits by changing the parameter values and ensuring then the result by repeating PSL measurement. The $\mathrm{X}^{\prime}$ 's from analyze phase can now be defined as follows:

1) Define required placement sigma level in order to keep standard deviation and error counts within desired range

2) Investigate the effect of forced placement sequence to error counts and standard deviations between machines of different placement sigma levels

\section{The IMPROVE phase}

\subsection{DOE Plan}

Because this six sigma project is quite short some phases like analyze and improve were combined partly together already in the beginning of planning the experiments. DOE has been mostly presented already in the previous analysis and only the interactions found there are presented in this improve phase. 


\subsection{DOE Results}

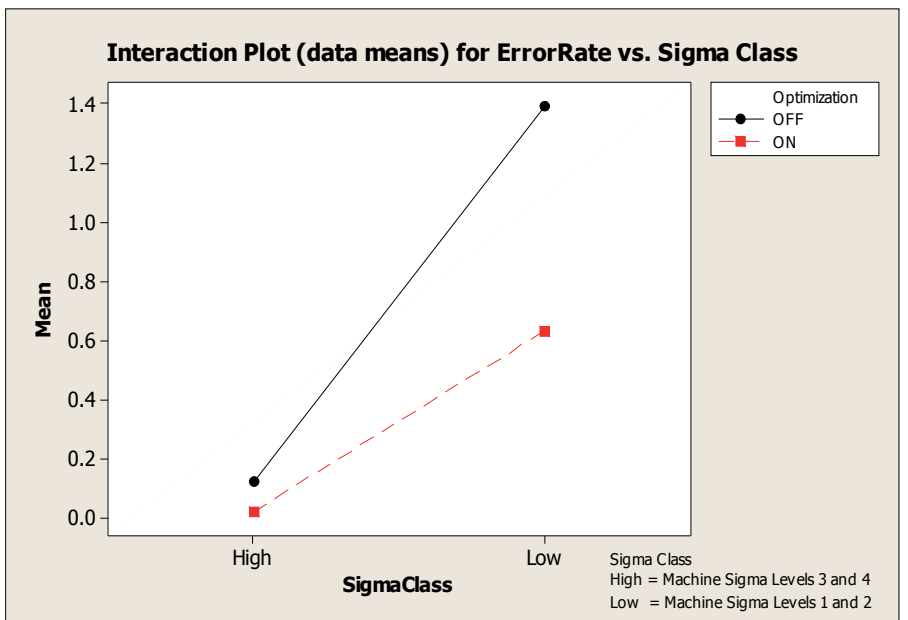

Fig. 23. Interaction plot of error rate versus Sigma class. Optimization ON means that all resistors have been placed before any capacitors. Sigma class HIGH includes PSL levels 3 and 4, LOW includes PSL 1 and 2.

Interaction plot of Minitab® in Fig. 23 shows that optimization of resistors' and capacitors' placement sequence is not needed when placement sigma level of the machine is at least 3 sigmas (i.e. belonging to high sigma class). However we can clearly see that with low sigma class machines placement sequence has a strong effect on placement Quality.

Improvement actions are based on analysis of error counts and variance analysis. Standard deviation can be measured using PSL procedure (PAM-board) and means/offsets can be corrected if those are found. The analysis made show that PSL result is critical when defining high-density capability of an individual placement machine.

\section{The CONTROL phase}

\subsection{Control Plan}

Placement machines having placement sigma level 3 or higher can be used for high-density placement. However this six sigma study strongly recommends ensuring the capability using PAM-board testing for individual machines before starting high-density production for the first time due to e.g. machine irregularities. Forced placement sequence of resistors and capacitors is not needed for machine sigma levels 3 or higher. Machines having placement sigma level lower than 3 may not be used for high-density placement, not even with forced placement sequence, which, however, gives better placement results with these machines; we can say clearly better but not good enough.

When machines are ranked according to PSL result the best ones can then be selected for high-density production. The project recommends that PSL level is measured on regular basis e.g. once per month to maintain the placement accuracy required by the new PWB technology. 


\section{Conclusions}

Turret type placement machines having different placement sigma levels were investigated and "ranked" according to their capability to place high-density 0402s. This was managed using standard commercially available 0402 type components and simple FR4 type PWB material. Standard widely used in-line type AOI machine was used successfully for measurements. Project outcome was that placement machines having sigma level 3 or better can be used. Possible need for forced placement sequence was also investigated. Project found out that we don't have to place resistors before capacitors (with placement sigma level $\geq 3$ ), which would have decreased quantitative placement capacity in the future. As an extra result the company can also delay globally some preliminary planned machine investments that were based on new technology requirements.

Future studies should concentrate on developing placement machine accuracy measurements for leaded and especially solder bumped integrated circuits (IC) type components, where the solderable bumbs to be used in component alignment by the placement machine are located beneath the component body and therefore are invisible after placement. Some basic and pioneering development in this area has already been published by some members of the project team (Hurtig \& Liukkonen, 2007).

\section{Acknowledgement}

The author would like to thank the superior six sigma project team and especially Master Black Belt Mr. Pekka Kytösaho for the dedicated assistance.

\section{References}

AIAG, Automotive Industry Action Group (1995), Statistical Process Control (SPC), Reference Manual, Carwin Continuous Ltd., Essex, England

Baker, S. (1996), Factors affecting SMD placement accuracy, EPEP Electronic Packaging and Production, Vol. 36, No.1, January 1996, pp. 30-36.

Breyfogle, F. (2003), Implementing Six Sigma, John Wiley \& Sons Inc., ISBN 0-471-26572-1, New York, U.S.A.

CeTaq (2010), Using Machine and Process Capability, available (April 2010) under Theory/Practice - Basic Statistics at http://www.cetaq.com

Hurtig, J. and Liukkonen, T., Analysis of Fine-pitch BGA Placement Accuracy, Proceedings of EMPC 2007 the $16^{\text {th }}$ European Microelectronics and Packaging Conference E Exhibition, June 17-20 2007, Oulu Finland, pp. 542-545.

Johnsson, M. (1999), Operational and tactical level optimization in printed circuit board assembly, TUCS Dissertations, No.16 May 1999, Turku center for computer science, ISBN 95212-0435-4, Turku, Finland

Kalen, D. (2002), Placing 0201 components accurately, Surface Mount Technology, Vol. 16, No. 7, July 2002, pp. 38-40

Kamen, E. (1998), Analysis of factors affecting component placement accuracy in SMT electronics assembly, Proceedings of IEEE/CPMT International Electronics Manufacturing Technology Symposium, October 19-21 1998, Austin U.S.A., pp. 50-57 
Liukkonen, T. and Tuominen, A. (2003), Improvement of Placement Accuracy by Placement Optimization, Proceedings of IMAPS 2003, November 18-20 2003, Boston U.S.A., pp. 429-434.

Liukkonen, T. and Tuominen A. (2004), Statistical monitoring of solder paste printing, Journal of Japan Institute of Electronics Packaging (JIEP), Vol. 7, No. 3, May 2004, pp. 255-260.

Montgomery, D. C. (2008), Design and Analysis of Experiments, John Wiley \& Sons Inc., ISBN 0-470-128666, New York, U.S.A.

Sauer, W., Wohlrabe, H., Zerna, T. (1998), Process capability coefficient and placing accuracy as benchmarking values of SMT placement systems, Proceedings of SMI 98, August 23-27 1998, San Jose U.S.A., pp.489-501

Sivigny, M. (2007), Increasing profitability through process optimization: better than outsourcing, Proceedings of 2007 IPC Printed Circuits Expo, APEX \& the Designers Summit, February 20-22 2007, Los Angeles U.S.A.

Wischoffer, S. (2003), Regulating Table Motion Effects on Component Placement, EPEP Electronic Packaging \& Production, Vol. 43, No. 1, January 2003, pp. 22-25 


\title{
Modelling, simulation, six sigma and their application in optimization of electrical vehicle design
}

\author{
Wei Zhan \\ Department of Engineering Technology and Industrial Distribution \\ Texas AEM University \\ College Station, TX 77843-3367 \\ USA
}

\section{Introduction}

Six Sigma is a structured, disciplined, data-driven methodology and process where the focus is placed on improving business performances using tools with an emphasis on statistical analysis (Breyfogle, 2003; Harry \& Schroeder, 2000; Pande \& Holpp, 2002; Pyzdek, 2003). It has evolved and grown over the years, and today is being used by companies such as GE, Honeywell, Motorola, DOW, DuPont, American Express, Ford, GM, TRW Automotive, and many others to improve the business performance. Several companies in manufacturing and pharmaceutical industries even mandate the practicing of these tools in their everyday business operations. According to (Wortman, 2001), Motorola credited the Six Sigma initiative for saving $\$ 940$ million over three years and AlliedSignal reported a $\$ 1.5$ billion savings in 1997.

In recent years, there has been increasing interest in both research and application of the Six Sigma methodology (Nonthaleerak \& Hendry, 2006; Snee, 2004). Details on the history of Six Sigma and success stories of its implementation can be found in literature such as (Jones, 2007; Nonthaleerak \& Hendry, 2006; Snee, 2004). Nonthaleerak and Hendry (Nonthaleerak and Hendry 2006) have provided an extensive review of the literature in this area.

Before a Six Sigma project can be started in any organization, a decision maker usually asks the following two questions: "How much is the project cost?" and "How long will it take?". The answers to these questions can determine the fate of the project. Unfortunately, due to its data-driven nature and wide use of statistics, a typical Six Sigma project requires large amounts of data to be collected. The data collection can be both costly and time consuming. Many projects that could potentially improve the quality of products never got started because of the high cost and long time associated with data collection. The use of modeling and simulation can help solving this dilemma. Zhan (Zhan, 2008) used a first principle model for brushed DC permanent magnetic motors and Six Sigma tools to improve a motor speed control design based on MATLAB (Pratap, 2006; The MathWorks, 2008) simulation results. Under the assumption that all the motor parameters such as inertia, inductance, 
resistance, friction, and torque gain are random variables with known probability distributions, one thousand sets of motor parameters were randomly generated. These "randomly generated" motors were then simulated to collect data for statistical analysis including Design of Experiments (DOE) (Mathews, \& Mathews, 2004; Montgomery, 2008; Taguchi, 1987; Taguchi, 1993) and Response Surface Method (Myers, \& Montgomery, 1995). It was proven to be an effective way of improving the motor speed control algorithm based on the results of Monte Carlo analysis (Casella, 2004; Liu, 2001) A similar modeling and simulation based approach was used in (Zhan, 2009) to solve the Monte Carlo analysis for the inverse problem of motor PWM control. In this paper, the same approach is used to solve a design optimization problem for electrical vehicles.

The rest of the paper is organized as follows: In Section 2, an optimization problem for electrical vehicles is introduced; The application of Design of Experiments (DOE) to identify the main factors is discussed in Section 3; The Response Surface Method (RSM) is used to find a solution to the optimization problem in Section 4; Section 5 includes the conclusion and brief discussion for future research work in this area. The MATLAB code that was used to derive the results in this paper is included in the appendix so that interested readers can easily reproduce these results.

\section{Design Optimization for Electrical Vehicles}

The design of electrical vehicles involves many challenges due to the complexity of the system (Ehsani et al., 2005; Gillespie, 1992; Husain, 2003). A vehicle dynamics based model was derived in (Zhan et al., 2009) to develop component level requirements based on basic performance requirements such as the maximum driving range, maximum cruise speed, maximum acceleration, etc. In theory, any variation in a particular parameter can cause the performance of the electrical vehicle to be different. However, the influences of the parameters are different. Small change in some parameters can cause large change in the vehicle performance, while relatively large change in other parameters may not have much impact on the vehicle performance.

In order to calculate the maximum driving range, the aerodynamic drag $D_{A}$ (Gillespie, 1992) needs to be calculated first

$$
\mathrm{D}_{\mathrm{A}}=\frac{1}{2} \rho \mathrm{V}^{2} \mathrm{C}_{\mathrm{D}} \mathrm{A}
$$

where $V$ is the vehicle speed $(\mathrm{ft} / \mathrm{sec}), \mathrm{A}$ is the frontal area of the vehicle $\left(\mathrm{ft}^{2}\right), C_{D}$ is the aerodynamic drag coefficient, and $\rho$ is the air density $\left(\mathrm{lb}-\mathrm{sec}^{2} / \mathrm{ft}^{4}\right)$.

$$
\rho=0.00236\left(\frac{P_{r}}{29.92}\right)\left(\frac{519}{460+T_{r}}\right)
$$

where $P_{r}$ is the atmospheric pressure in inches of mercury and $T_{r}$ is the air temperature in degrees Fahrenheit.

The maximum driving range is determined by

$$
d_{\text {max }}=63.29 \frac{\eta W_{b}}{D_{A}+R_{x}+W \sin (\theta)} D_{s e}
$$

where $W$ is the gravity force, $\theta$ is the angle of the inclined surface, $W_{b}$ is the weight of the battery, $\eta$ is the efficiency of the battery/motor subsystem, $D_{s e}$ is the specific energy density of the battery $(\mathrm{MJ} / \mathrm{kg})$, and $R_{x}$ is the rolling resistance. Details of the derivation and definitions can be found in (Zhan et al., 2009).

The rolling resistance can be modeled as the vehicle static weight $W$ multiplied by the coefficient of rolling resistance $f_{r}$ : 


$$
R_{x}=f_{r} W
$$

Under the assumption that the vehicle is traveling at a constant speed, the maximum driving range can be plotted as a function of the vehicle speed for a given set of parameters, as shown in Fig. 1. It can be seen that the driving range is reduced if the vehicle speed is increased. When design parameters are chosen to take different values, this curve will move up or down accordingly. Clearly, one would like to select the parameters such that any given speed, the driving range is longer. The following metric is proposed to measure the driving range performance

$$
P=\int_{0}^{V \max } d_{\max }(V) d V
$$

In other words, the area underneath the curve in Fig. 1 is an indication of the vehicle driving range performance. Vmax in equation (5) is the maximum cruise speed. In Fig. 1, it is assumed that Vmax is equal to $85 \mathrm{mph}$.

Naturally, one can ask: How should we choose the design parameters to maximize the performance index $P$ ? For each given set of parameters, $P$ can be calculated. But there are eleven parameters and each parameter can take thousands of different values. The combinations can be astronomical. To make the numerical search realistic, one needs to narrow down the combinations to a level that can be handled by a typical desktop computer. Initial simulation revealed that the performance index $P$ is more sensitive to certain design parameters than others. The Design of Experiments is a Six Sigma tool that can be used to identify the parameters that have major impact on the results. The design engineer can then focus on these important parameters by assuming all other parameters are constant. This will not provide an optimal design, but should yield a suboptimal solution. The main advantage is the significantly reduced computation time and memory required for the parameter selection.

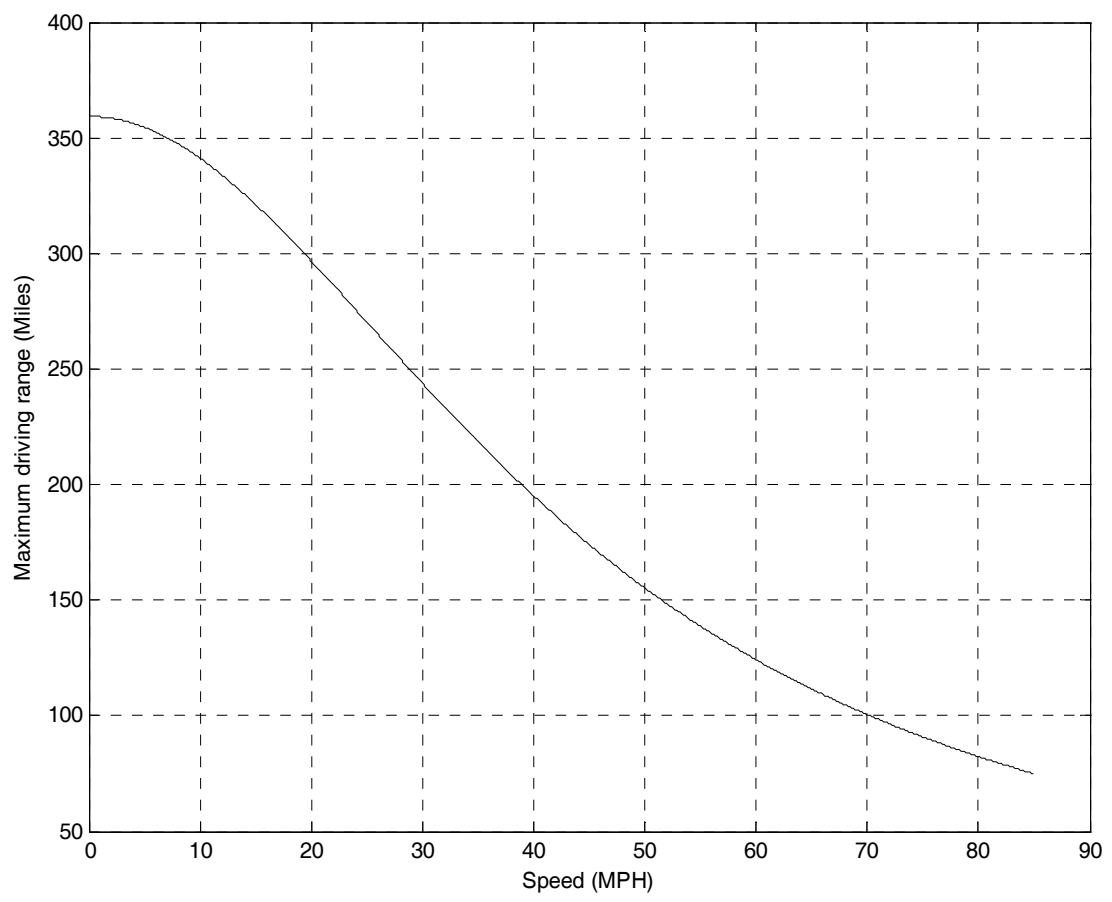

Fig. 1. Driving range as a function of vehicle speed 


\section{Design of Experiments}

A two-level, $\mathrm{N}$-factor full factorial DOE matrix requires $2^{\mathrm{N}}$ runs. To calculate the performance index $P$ using equation (5), the following eleven parameters are needed

- Vmax: the maximum cruise speed

- $W$ : the total vehicle weight

- $W_{b}$ : the weight of the battery

- $D_{s e}$ : the specific energy density of the battery

- $\eta$ : the efficiency of the battery/motor

- $f_{r}$ : the coefficient of rolling resistance

- A: the frontal area of the vehicle

- $C_{D}$ : the aerodynamic drag coefficient

- $\theta$ : the angle of the inclined surface

- $P_{r}$ : the atmospheric pressure in inches of mercury

- $T_{r}$ : the air temperature in degrees Fahrenheit.

Among the eleven parameters, some are environmental factors, e.g., the atmospheric pressure, the air temperature, and the angle of the inclined surface. Typically, an optimal or suboptimal design is selected under one set of nominal environmental conditions. In this paper, we use the nominal values of 29.92 inches of $\mathrm{Hg}$ for atmospheric pressure, $59 \mathrm{oF}$ for air temperature, and a flat surface $(\theta=0)$.

There are other parameters that take specific values due to other requirements. For example, one can assume that the body of the vehicle has been designed, thus the frontal area of the vehicle has a fixed value (e.g. $\mathrm{A}=34 \mathrm{ft}^{2}$ ); the maximum cruise speed has been determined to be $85 \mathrm{mph}$. Since the total vehicle weight $W$ includes the battery weight $W_{b}$, there is a coupling between $W$ and $W_{b}$. To avoid the coupling between these two factors, a new factor $W_{0}$, defined as the weight of the vehicle without the battery, is used

$$
W_{0}=W-W_{b}
$$

As a result, there are six remaining parameters that need to be analyzed. The DOE matrix was created using Minitab (Meyer, \& Krueger, 2005), as illustrated in Table 1. The -1 and 1 represent the two extreme levels for each factor. These values are defined in Table 2.

Notice that for six factors, there are $2^{6}=64$ runs in the DOE matrix. The simulation runs were carried out in MATLAB using mathscript files attached in the appendix (SpdDisOptimization.m and EVSimdoeSixFactors.m). The DOE test matrix was set up in EVSimdoeSixFactors.m, which calls SpdDisOptimization.m to calculate the performance index $P$ in equation (5). The resulting value $P$ from simulation was recorded in the last column of the Table 1 with a common multiplier of $10^{4}$, labeled as "Area* $10^{\wedge} 4^{\text {". }}$

Based on the results in Table 1, the Pareto Chart of the standardized effects was plotted, as illustrated in Fig. 2. It can be seen that the top three factors are: $D_{s e}, W_{b}$, and the interaction between them. Therefore, the conclusion is that the design optimization effort should be focused on $D_{s e}, W_{b}$, and their interaction. 


\begin{tabular}{|c|c|c|c|c|c|c|c|c|c|c|c|c|c|c|c|}
\hline in & 0 & $\sqrt{b}$ & $\mathrm{Cd}$ & $\mathrm{fr}$ & $\mathrm{ta}$ & se & $\mathrm{rea}^{*} 10^{\wedge} 4$ & Run & W0 & $\mathrm{Wb}$ & $\mathrm{Cd}$ & $\mathrm{fr}$ & eta & Dse & Area*10^4 \\
\hline 1 & -1 & -1 & -1 & -1 & 1 & -1 & 3766396 & 33 & -1 & -1 & -1 & 1 & -1 & 1 & \begin{tabular}{|l}
1.5065585 \\
\end{tabular} \\
\hline$\overline{2}$ & & -1 & -1 & -1 & 1 & -1 & 879 & $32+2+2$ & $T$ & & -1 & & -1 & $\overline{1}$ & 4179517 \\
\hline$\overline{3}$ & -1 & $\overline{1}$ & -1 & -1 & 1 & -1 & 257004 & $35-5$ & -1 & & -1 & & -1 & $\overline{1}$ & .7028017 \\
\hline$\overline{4}$ & 1 & 1 & -1 & -1 & 1 & -1 & 8790451 & $36-2-2$ & 1 & & -1 & & -1 & 1 & .5161803 \\
\hline 5 & -1 & -1 & 1 & -1 & -1 & -1 & $\overline{3384682}$ & 37 & -1 & -1 & 1 & - & -1 & 1 & .3538727 \\
\hline 6 & 1 & -1 & 1 & -1 & -1 & -1 & 306 & 38 & 1 & -1 & 1 & -1 & -1 & 1 & 1.277224 \\
\hline 7 & -1 & 1 & 1 & -1 & -1 & -1 & .8361176 & $\overline{39}$ & -1 & & 1 & -1 & -1 & 1 & 3.3444704 \\
\hline 8 & 1 & 1 & 1 & -1 & -1 & -1 & 0.7956222 & 40 & 1 & 1 & 1 & -1 & -1 & 1 & 3.1824888 \\
\hline 9 & -1 & -1 & -1 & 1 & -1 & -1 & 0.3437897 & $\overline{41}$ & -1 & -1 & -1 & 1 & -1 & 1 & 1.3751589 \\
\hline 10 & 1 & -1 & -1 & 1 & -1 & -1 & 0.3232284 & 42 & 1 & -1 & -1 & T. & -1 & 1 & \begin{tabular}{|l|}
1.2929137 \\
\end{tabular} \\
\hline 11 & -1 & 1 & -1 & 1 & -1 & -1 & 0.8430283 & $\overline{43}$ & -1 & $\overline{1}$ & -1 & 1 & -1 & 1 & 3.3721131 \\
\hline 12 & 1 & 1 & -1 & 1 & -1 & -1 & 0.7997976 & 44 & 1 & 1 & -1 & 1 & -1 & 1 & \begin{tabular}{|l|}
3.1991903 \\
\end{tabular} \\
\hline 13 & -1 & -1 & 1 & 1 & -1 & -1 & 0.31 & 45 & -1 & -1 & 1 & 1 & -1 & 1 & \begin{tabular}{|l|l|}
1.2401632 \\
\end{tabular} \\
\hline 14 & 1 & -1 & 1 & 1 & -1 & -1 & 0.29 & 46 & 1 & -1 & $\overline{1}$ & . & -1 & 1 & 1.1688458 \\
\hline 15 & -1 & 1 & 1 & 1 & -1 & -1 & 0.7 & 47 & -1 & 1 & 1 & 1 & -1 & 1 & \begin{tabular}{|l}
3.0572697 \\
\end{tabular} \\
\hline 16 & 1 & 1 & 1 & 1 & -1 & -1 & 0.72 & 48 & 1 & 1 & 1 & 1 & -1 & 1 & 2.9067492 \\
\hline 17 & -1 & -1 & -1 & -1 & 1 & -1 & & 49 & -1 & -1 & -1 & -1 & $\bar{T}+2>$ & 1 & \begin{tabular}{|l|}
1.6239527 \\
\end{tabular} \\
\hline 18 & 1 & -1 & -1 & -1 & 1 & -1 & & 50 & 1 & -1 & -1 & -1 & 1 & 1 & 1.5284414 \\
\hline 19 & -1 & 1 & -1 & -1 & 1 & -1 & 0.99 & 51 & -1 & 1 & -1 & -1 & 1 & 1 & 3.9913317 \\
\hline 20 & 1 & 1 & -1 & -1 & 1 & -1 & 21 & 52 & 1 & 1 & -1 & -1 & 1 & 1 & 3.7901683 \\
\hline 21 & -1 & -1 & 1 & -1 & 1 & -1 & $\overline{23}$ & 53 & -1 & -1 & 1 & -1 & 1 & 1 & \begin{tabular}{|l}
1.4593693 \\
\end{tabular} \\
\hline 22 & 1 & -1 & 1 & -1 & 1 & -1 & 7 & 54 & 1 & -1 & 1 & -1 & 1 & 1 & \begin{tabular}{|l|}
1.376748 \\
\end{tabular} \\
\hline 23 & -1 & 1 & 1 & -1 & 1 & -1 & 96 & 55 & -1 & 1 & 1 & -1 & 1 & 1 & 3.6050785 \\
\hline 24 & 1 & 1 & 1 & -1 & 1 & -1 & & 56 & 1 & 1 & 1 & -1 & 1 & 1 & \begin{tabular}{|c|}
3.430475 \\
\end{tabular} \\
\hline 25 & -1 & -1 & -1 & 1 & 1 & -1 & & 57 & -1 & -1 & -1 & 1 & 1 & 1 & \begin{tabular}{|l|}
1.4823142 \\
\end{tabular} \\
\hline 26 & 1 & -1 & -1 & 1 & 1 & -1 & & 58 & 1 & -1 & -1 & & 1 & 1 & 1.3936602 \\
\hline 27 & -1 & 1 & -1 & 1 & 1 & -1 & & 59 & -1 & $\overline{1}$ & -1 & & T & 1 & 3.6348752 \\
\hline 28 & 1 & 1 & -1 & 1 & 1 & -1 & & 60 & 7 & 1 & -1 & T & $T$ & 1 & 3.4484778 \\
\hline 29 & -1 & -1 & 1 & 1 & 1 & -1 & & 61 & -1 & -1 & 1 & T & 1 & 1 & \begin{tabular}{|l}
1.3367993 \\
\end{tabular} \\
\hline$\overline{30}$ & 1 & -1 & 1 & 1 & 1 & -1 & & 62 & 1 & -1 & 1 & 1 & 1 & 1 & 1.2599247 \\
\hline$\overline{31}$ & -1 & 1 & $\overline{1}$ & 1 & 1 & -1 & $\overline{746}$ & 63 & -1 & $\overline{1}$ & 1 & 1 & 1 & 1 & 3.2954985 \\
\hline 32 & -1 & 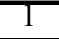 & 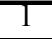 & & & 1 & 0.1030125 & 64 & & $x^{2}+2>$ & & 1 & 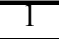 & & 3.1332492 \\
\hline
\end{tabular}

Table 1. DOE test matrix

\begin{tabular}{|c|c|c|c|c|c|c|}
\hline & $\boldsymbol{W}_{\mathbf{0}}$ (lbs) & $\boldsymbol{W}_{\boldsymbol{b}}(\mathbf{l b s})$ & $\boldsymbol{C}_{\boldsymbol{D}}$ & $f_{r}$ & $\boldsymbol{\eta}$ & $\boldsymbol{D}_{\text {se }} \mathbf{( \mathbf { M J } / \mathbf { k g } )}$ \\
\hline $\mathbf{- 1}$ & 3800 & 500 & 0.4 & 0.014 & $77 \%$ & 0.2 \\
\hline $\mathbf{1}$ & 4000 & 1400 & 0.55 & 0.016 & $83 \%$ & 0.8 \\
\hline
\end{tabular}

Table 2. Definitions of extreme values for each factor 


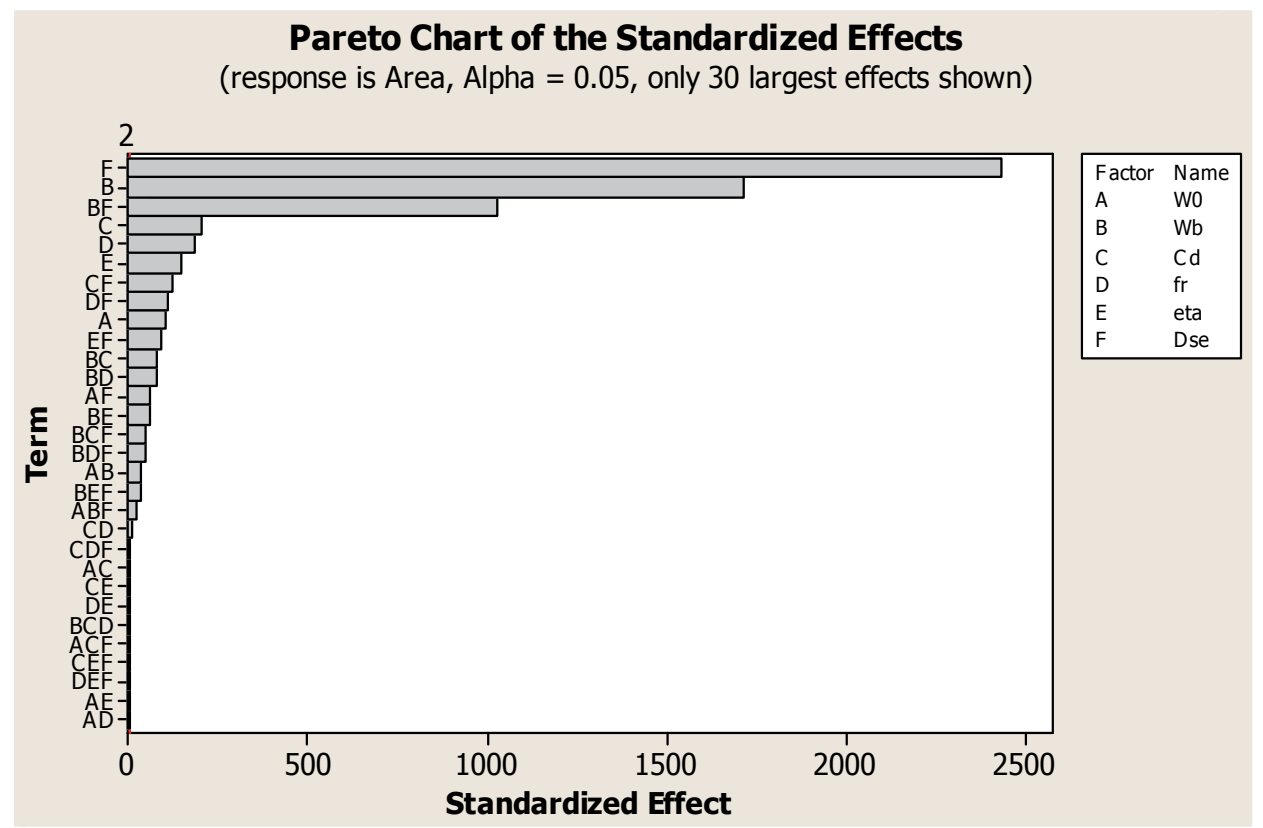

Fig. 2. Identification of main factors

The conclusion from the Pareto Chart can be verified with the Main Effect Plot and the Interaction Plot in Figs. 3 and 4.

In Fig. 3, the effects of these factors with steeper slopes are more significant on the results than others. Fig. 3 also indicates the direction of impact, for example, lower $W_{0}$, higher $W_{b}$, lower $C_{D}$, lower fr, higher $\eta$ (eta), and higher Dse will lead to larger value for index $P$. In Fig. 4, larger differences between slopes of the two lines inside each box imply more significant interactions between the horizontal and vertical factors related to the box. It can be seen that the most significant interaction is the one between $W_{b}$ and $D_{s e}$.

The simulation result can also be used to create the Contour Plot of the performance index $P$ as a function of the two main factors $D_{s e}$ and $W_{b}$, as illustrated in Fig. 5. The -1 and 1 levels for the two factors are defined in Table 2. The points in between the two extreme values are obtained using linear interpolation. For simplicity, the factor of $10^{4}$ is not included in the index $P$, labeled as "Area". 


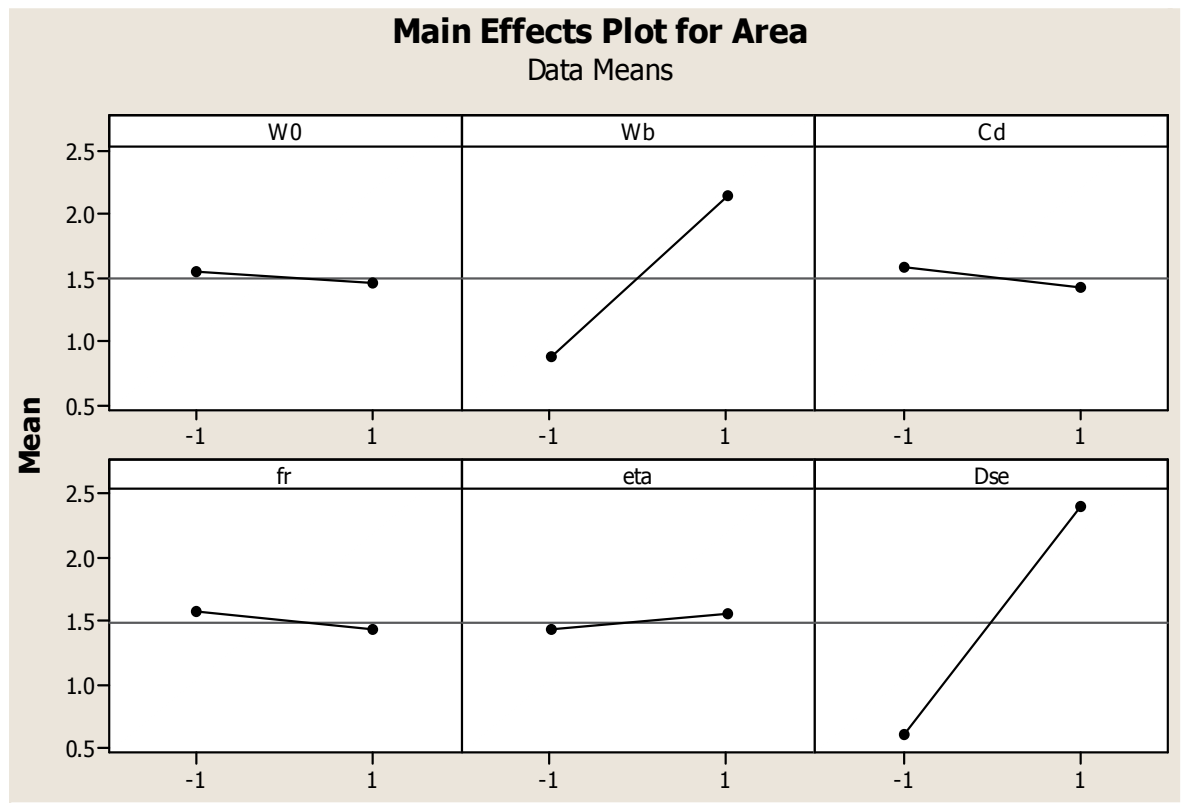

Fig. 3. Impact of the six factors

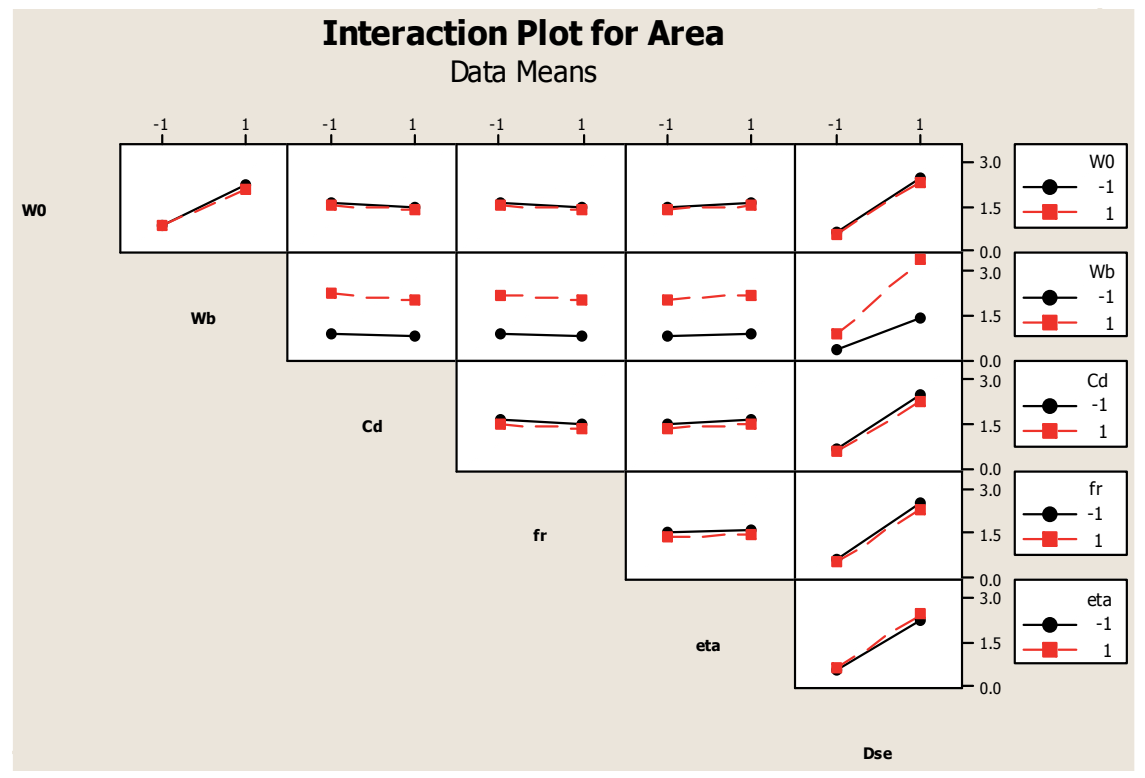

Fig. 4. Impact of the interactions between factors 


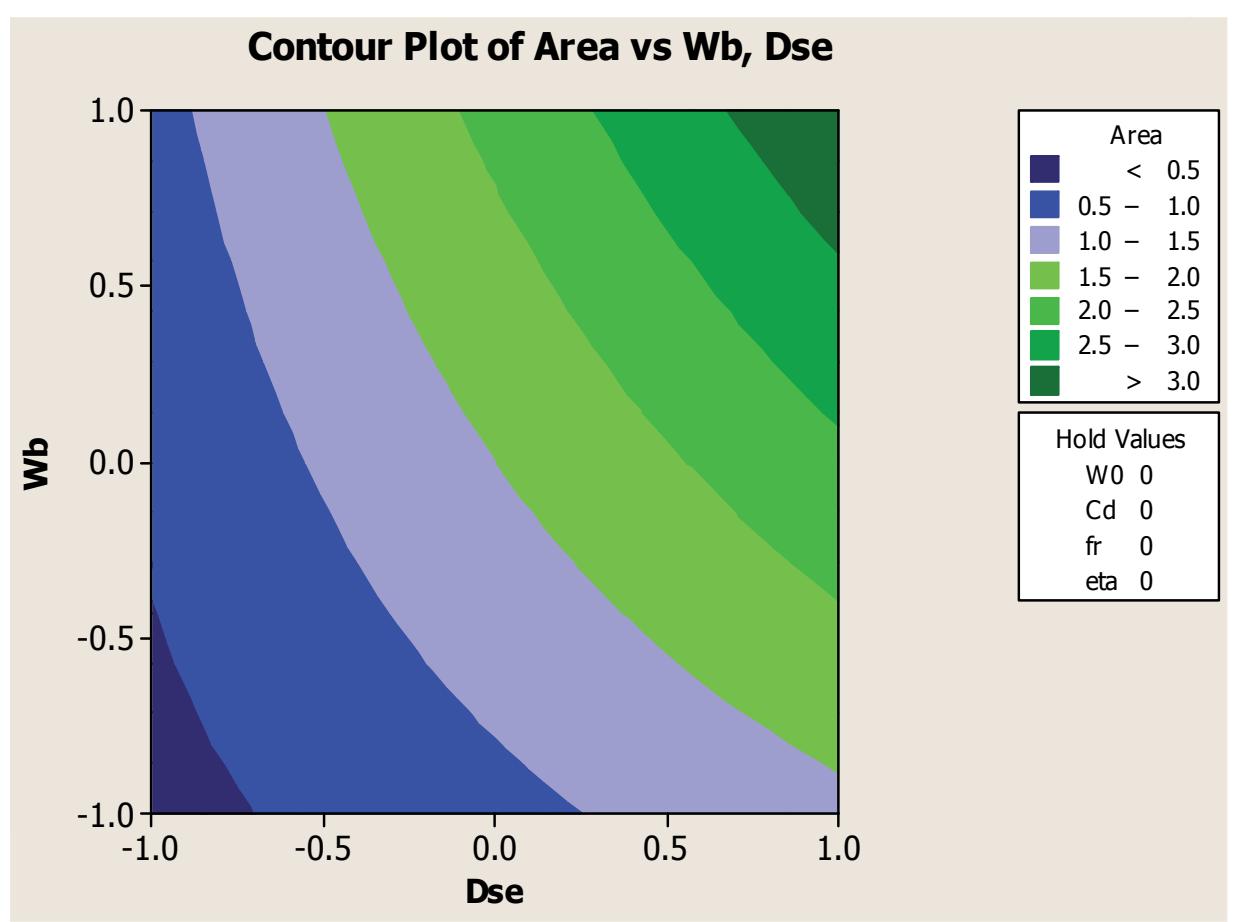

Fig. 5. The index $P$ as a function of $D_{s e}$ and $W b$.

To illustrate the different impacts of the factors, a mathscript file ThreeCasePlotting.m was written (see Appendix) to plot three different cases:

Case 1: Worst case $D_{s e}$ and $W_{b}$ and best case for other factors.

Case 2: Best case $D_{s e}$ and $W_{b}$ and worst case for other factors.

Case 3: Best case $D_{s e}$ and $W_{b}$ and nominal values for other factors.

The graphs for these three cases are illustrated in Fig. 6. It can be seen that there is a big difference between Case 1 and the other two cases. The difference between Cases 2 and 3 is relatively small. In other words, if $D_{s e}$ and $W_{b}$ are not selected properly, then the result will not be good, even if all other parameters are selected properly. On the other hand, if $D_{s e}$ and $W_{b}$ are selected properly, then the selection of other parameters will not make much difference. Noticing that $D_{s e}$ and $W_{b}$ are the specific energy density and the weight of the battery, the DOE analysis tells us that the battery technology is the key to the success of electrical vehicles. 


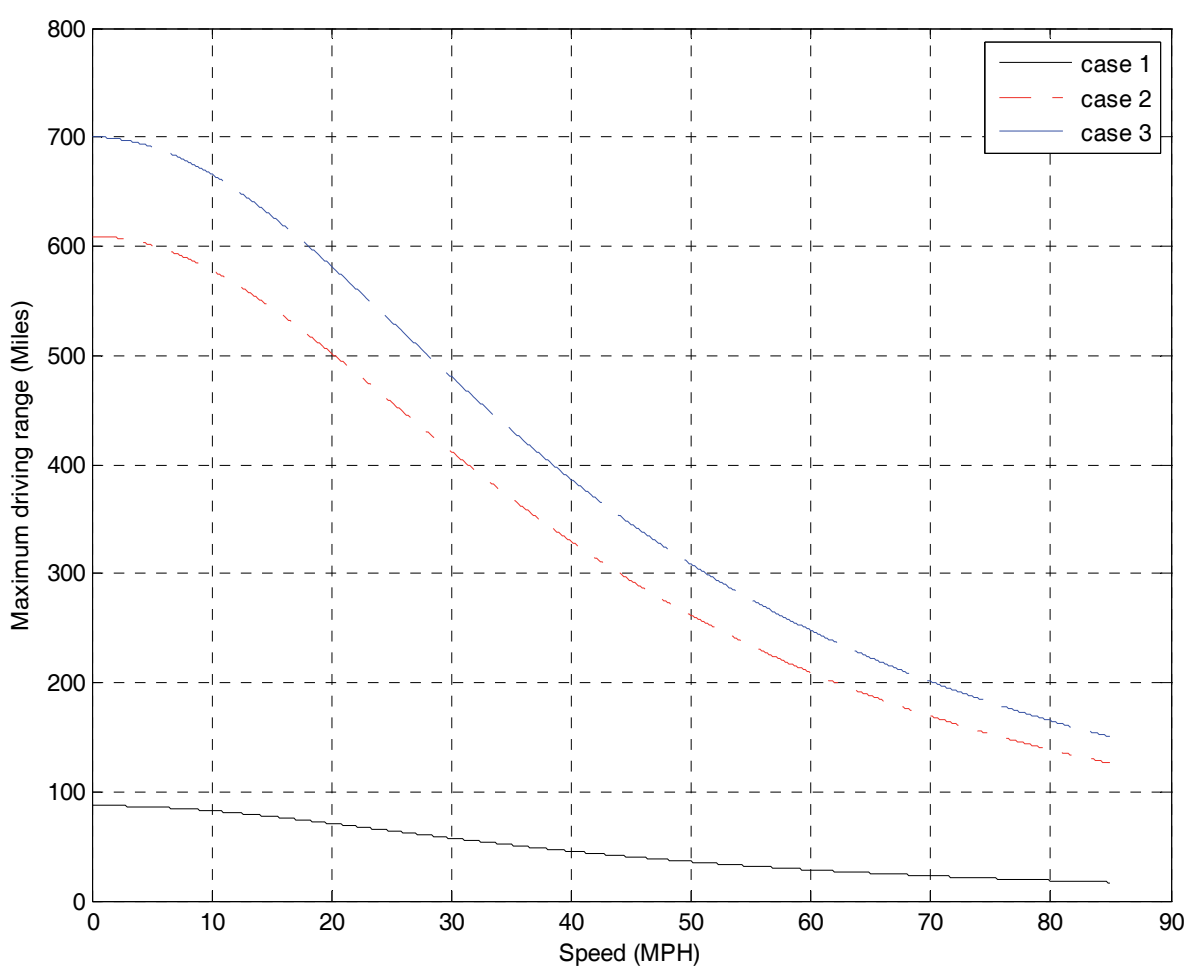

Fig. 6. Three cases for performance index.

\section{Response Surface Method and Optimization}

In Section 3, the specific energy density and weight of battery are identified as the two main design parameters that have major impact on the performance index $P$. In this section, these two parameters will be studied to optimize the performance and the associated cost.

It has been analyzed in Section 3 that larger values for battery weight and the specific energy density can improve the driving range performance. However, the batteries with higher specific energy density are more expensive. The cost associated with the specific energy density value is usually nonlinear. If the specific energy density is doubled, the price of the battery is more likely to be quadrupled. For the same type of battery, the cost associated with weight is usually linear. Doubling the weight of battery means twice as many battery units, thus twice the cost. Based on the above analysis, the following cost function is defined for performance/cost optimization

$$
J=K_{1}\left(\frac{D_{\text {se }}}{D_{\text {se } 0}}\right)^{2}+K_{2} \frac{W_{b}}{W_{b 0}}+K_{3} \frac{P_{0}}{P}
$$

where $K_{1}, K_{2}$, and $K_{3}$ are weights for each term, $D_{s e 0}, W_{b 0}$, and $P_{0}$ are the nominal values for each term that are used to normalize each term. The normalization for each term is necessary, since without normalizing, one of the terms will dominate the cost function and make other two terms irrelevant. The average values in Table 1 can be used as the nominal values.

With the $15 \%, 35 \%$, and $50 \%$ weights on the three terms, the cost index becomes

$$
\mathrm{J}=0.15\left(\frac{\mathrm{D}_{\mathrm{se}}}{0.5}\right)^{2}+0.35 \frac{\mathrm{W}_{\mathrm{b}}}{950}+0.5 \frac{15000}{\mathrm{P}}
$$


The objective of optimization is to minimize the cost function J. Clearly, larger performance value $P$, lower specific energy density, and lower battery weight will result in smaller $J$. Minimizing $J$ requires a trade-off between cost and performance: higher performance $P$ will drive up the cost.

Since the performance index $P$ can be calculated as a function of specific energy density and weight of battery, one can calculate the cost function $J$ as a function of the specific energy density and the weight of the battery.

Since the focus is on the specific energy density and weight of battery, in addition to the nominal values for the atmospheric pressure, the air temperature, the angle of the inclined surface, and the frontal area of the vehicle, we further assume that

- $W_{0}=4000$;

- $C_{D}=0.45$

- $f_{r}=0.015$

- $\eta=0.8$.

The Response Surface is plotted in Fig. 7 by letting the battery weight vary from 500 lbs to $1400 \mathrm{lbs}$ at an increment of $10 \mathrm{lbs}$ and the specific energy vary from $0.2 \mathrm{MJ} / \mathrm{kg}$ to $0.8 \mathrm{MJ} / \mathrm{kg}$ at an increment of $0.01 \mathrm{MJ} / \mathrm{kg}$. The mathscript code for creating the Response Surface is attached in the Appendix (TotalOptimization.m). The contour of the cost function, i.e., the values for $D_{s e}$ and $W_{b}$ with constant levels of cost function values, is plotted on the $\left(D_{s e}, W_{b}\right)$ plane. From Fig. 7, it can be seen that the optimal value for cost function is achieved inside the oval shaped curve. The optimal parameter values can be calculated in MATLAB as: $W_{b}=$ $970 \mathrm{lb}, D_{s e}=0.58 \mathrm{MJ} / \mathrm{kg}$.

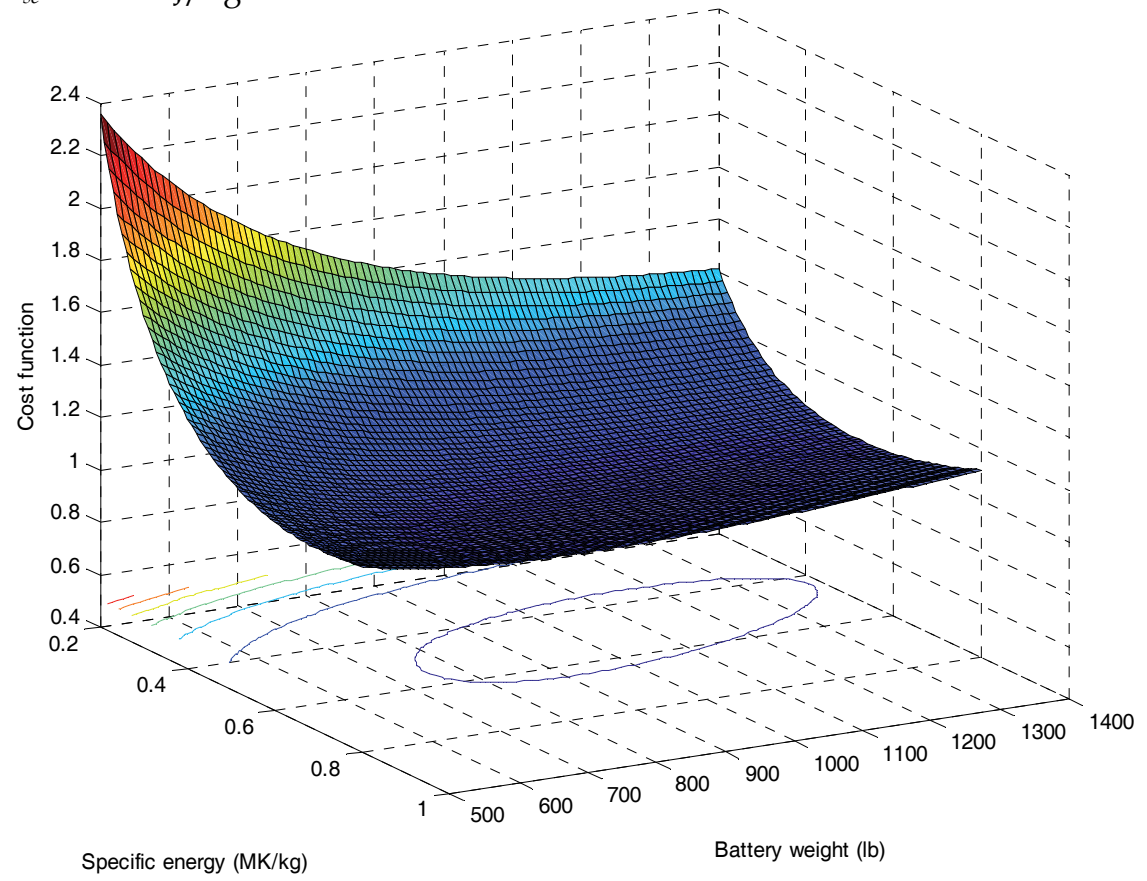

Fig. 7. Cost function as a function of battery weight and specific energy density

The optimization of cost function using RSM was made possible after the DOE analysis that narrowed down the design parameters to two. 


\section{Conclusion and Discussion}

This paper discusses a design optimization problem for electrical vehicles using Six Sigma tools such as DOE and RSM. The analysis was carried out in the MATLAB simulation environment. The DOE technique was used to narrow down the number of design parameters to be analyzed. Some parameters were assumed to be constant during the DOE analysis. The selection of these constant parameters and their values may influence the conclusions one can draw from the DOE analysis, but the approach used in this paper would work in a similar way with different choices. For example, the friction coefficient can be assumed to be constant and the frontal area can be selected as a factor in DOE matrix, which makes more sense if the vehicle body is still being designed. The Response Surface Method was applied to find the optimal design parameter values for the battery weight and the battery specific energy density. Both cost and performance are taken into consideration in the optimization process. The weights in the cost function are determined by the actual cost for the batteries and the importance of the performance.

Only the maximum driving range was considered as the performance of the vehicle, but the method works in a similar way if other performance metrics are used. Future research work includes considering other vehicle level performance requirements such as maximum cruise speed, 0-60 mph acceleration time, and maximum gradeability (Ehsani et al., 2005; Gillespie, 1992; Husain, 2003; Zhan et al., 2009). In analyzing some of these dynamic requirements, detailed models for the motor, battery, and transmission need to be included in the model. The approach used in this paper can be applied to many other engineering design and optimization problems. It is a quick and cost effective way of using Six Sigma method in engineering applications.

\section{Appendix: MATLAB Code}

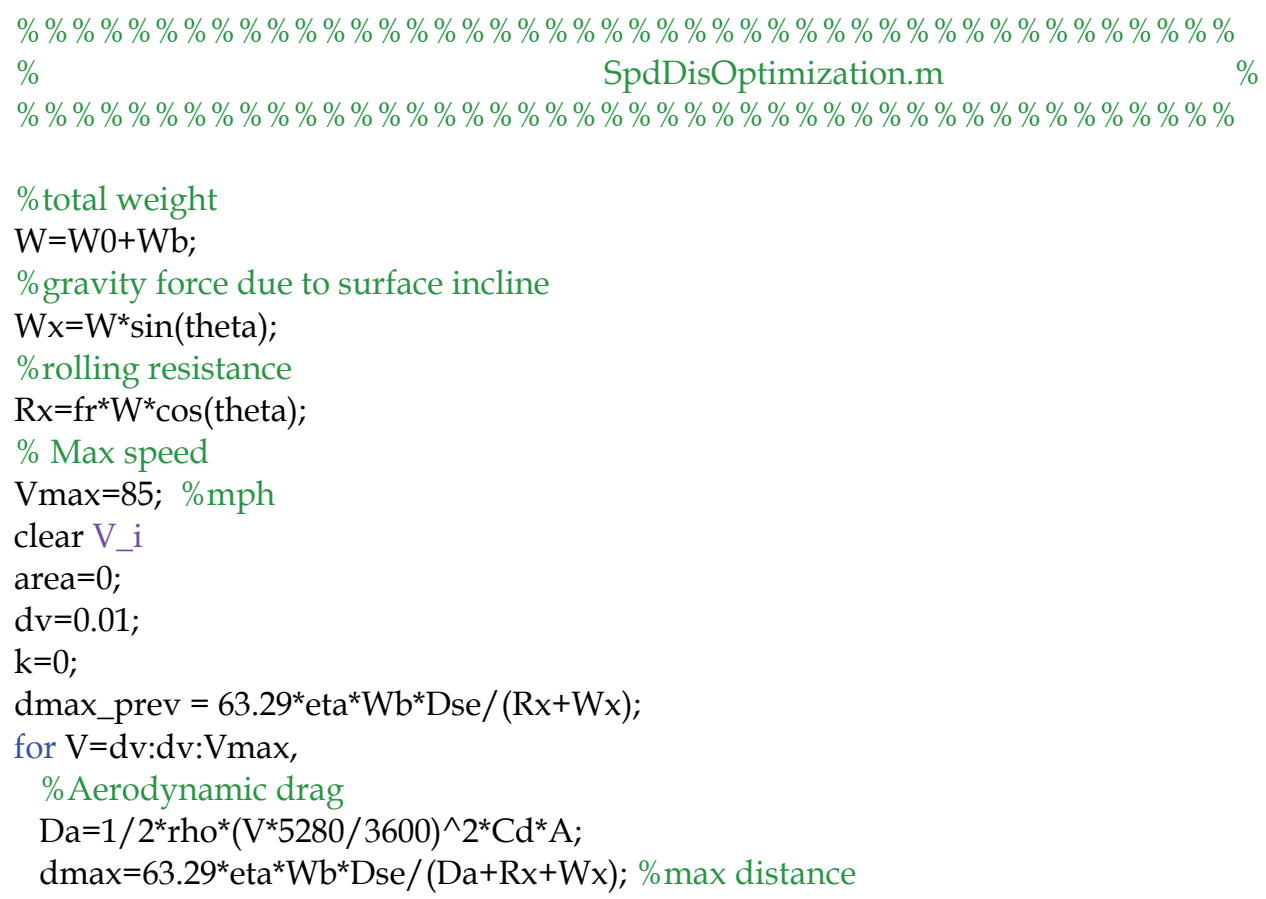




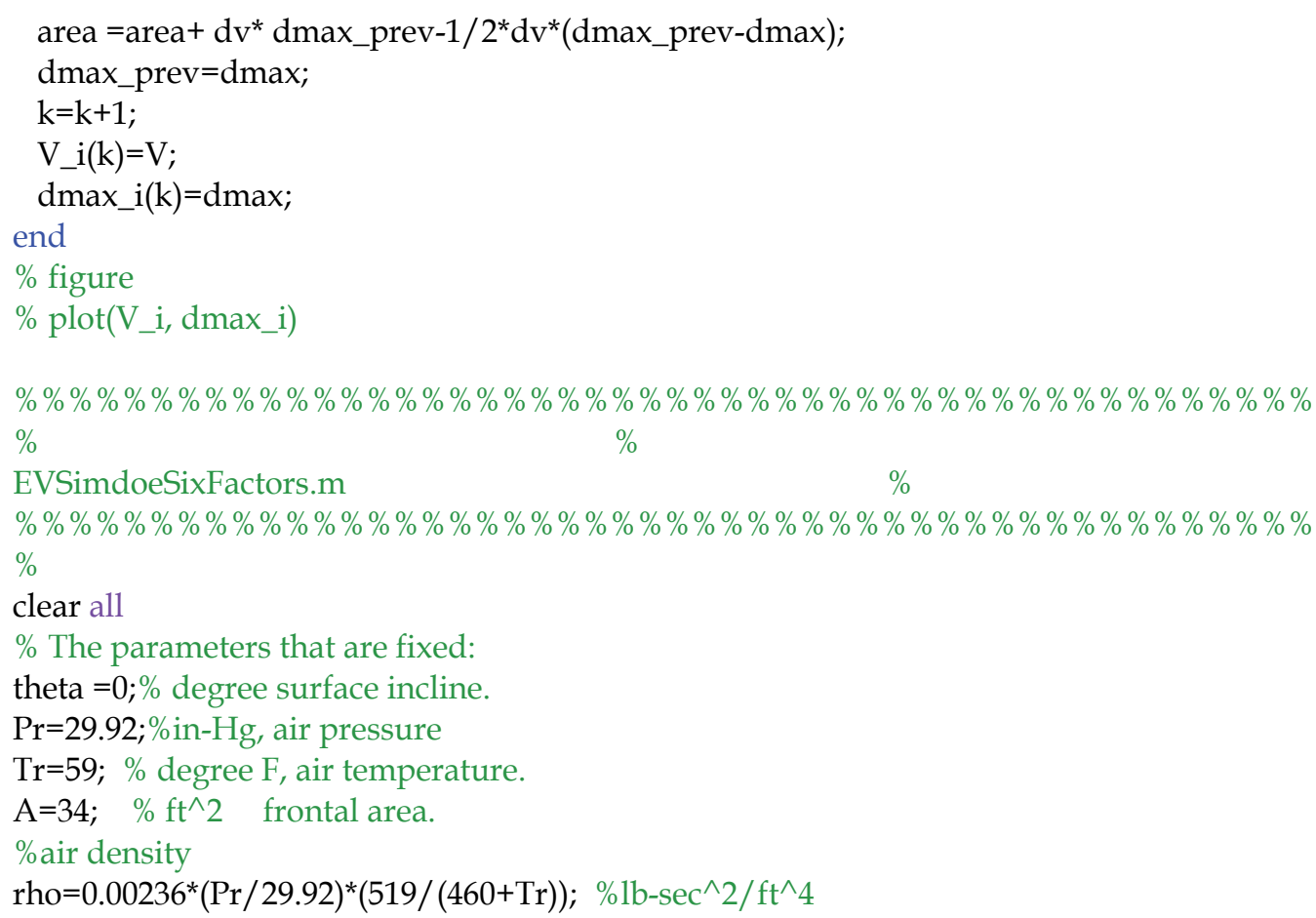


$\begin{array}{lllllll}11 & -1 & 1 & -1 & 1 & -1 & -1\end{array}$

$\begin{array}{lllllll}12 & 1 & 1 & -1 & 1 & -1 & -1\end{array}$

$\begin{array}{lllllll}13 & -1 & -1 & 1 & 1 & -1 & -1\end{array}$

$\begin{array}{lllllll}14 & 1 & -1 & 1 & 1 & -1 & -1\end{array}$

$\begin{array}{lllllll}15 & -1 & 1 & 1 & 1 & -1 & -1\end{array}$

$\begin{array}{lllllll}16 & 1 & 1 & 1 & 1 & -1 & -1\end{array}$

$\begin{array}{lllllll}17 & -1 & -1 & -1 & -1 & 1 & -1\end{array}$

$\begin{array}{lllllll}18 & 1 & -1 & -1 & -1 & 1 & -1\end{array}$

$\begin{array}{lllllll}19 & -1 & 1 & -1 & -1 & 1 & -1\end{array}$

$\begin{array}{lllllll}20 & 1 & 1 & -1 & -1 & 1 & -1\end{array}$

$\begin{array}{lllllll}21 & -1 & -1 & 1 & -1 & 1 & -1\end{array}$

$\begin{array}{lllllll}22 & 1 & -1 & 1 & -1 & 1 & -1\end{array}$

$\begin{array}{lllllll}23 & -1 & 1 & 1 & -1 & 1 & -1\end{array}$

$\begin{array}{lllllll}24 & 1 & 1 & 1 & -1 & 1 & -1\end{array}$

$\begin{array}{lllllll}25 & -1 & -1 & -1 & 1 & 1 & -1\end{array}$

$\begin{array}{lllllll}26 & 1 & -1 & -1 & 1 & 1 & -1\end{array}$

$\begin{array}{lllllll}27 & -1 & 1 & -1 & 1 & 1 & -1\end{array}$

$\begin{array}{lllllll}28 & 1 & 1 & -1 & 1 & 1 & -1\end{array}$

$\begin{array}{lllllll}29 & -1 & -1 & 1 & 1 & 1 & -1\end{array}$

$\begin{array}{lllllll}30 & 1 & -1 & 1 & 1 & 1 & -1\end{array}$

$\begin{array}{lllllll}31 & -1 & 1 & 1 & 1 & 1 & -1\end{array}$

$\begin{array}{lllllll}32 & 1 & 1 & 1 & 1 & 1 & -1\end{array}$

$\begin{array}{lllllll}33 & -1 & -1 & -1 & -1 & -1 & 1\end{array}$

$\begin{array}{lllllll}34 & 1 & -1 & -1 & -1 & -1 & 1\end{array}$

$\begin{array}{lllllll}35 & -1 & 1 & -1 & -1 & -1 & 1\end{array}$

$\begin{array}{lllllll}36 & 1 & 1 & -1 & -1 & -1 & 1\end{array}$

$\begin{array}{llllllll}37 & -1 & -1 & 1 & -1 & -1 & 1\end{array}$

$\begin{array}{lllllll}38 & 1 & -1 & 1 & -1 & -1 & 1\end{array}$

$\begin{array}{lllllll}39 & -1 & 1 & 1 & -1 & -1 & 1\end{array}$

$\begin{array}{lllllll}40 & 1 & 1 & 1 & -1 & -1 & 1\end{array}$

$\begin{array}{lllllll}41 & -1 & -1 & -1 & 1 & -1 & 1\end{array}$

$\begin{array}{lllllll}42 & 1 & -1 & -1 & 1 & -1 & 1\end{array}$

$\begin{array}{lllllll}43 & -1 & 1 & -1 & 1 & -1 & 1\end{array}$

$\begin{array}{lllllll}44 & 1 & 1 & -1 & 1 & -1 & 1\end{array}$

$\begin{array}{lllllll}45 & -1 & -1 & 1 & 1 & -1 & 1\end{array}$

$\begin{array}{lllllll}46 & 1 & -1 & 1 & 1 & -1 & 1\end{array}$

$\begin{array}{lllllll}47 & -1 & 1 & 1 & 1 & -1 & 1\end{array}$

$\begin{array}{lllllll}48 & 1 & 1 & 1 & 1 & -1 & 1\end{array}$

$\begin{array}{lllllll}49 & -1 & -1 & -1 & -1 & 1 & 1\end{array}$

$\begin{array}{lllllll}50 & 1 & -1 & -1 & -1 & 1 & 1\end{array}$

$\begin{array}{lllllll}51 & -1 & 1 & -1 & -1 & 1 & 1\end{array}$

$\begin{array}{lllllll}52 & 1 & 1 & -1 & -1 & 1 & 1\end{array}$

$\begin{array}{lllllll}53 & -1 & -1 & 1 & -1 & 1 & 1\end{array}$

$\begin{array}{lllllll}54 & 1 & -1 & 1 & -1 & 1 & 1\end{array}$

$\begin{array}{lllllll}55 & -1 & 1 & 1 & -1 & 1 & 1\end{array}$

$\begin{array}{lllllll}56 & 1 & 1 & 1 & -1 & 1 & 1\end{array}$ 
$\begin{array}{lllllll}57 & -1 & -1 & -1 & 1 & 1 & 1\end{array}$

$\begin{array}{lllllll}58 & 1 & -1 & -1 & 1 & 1 & 1\end{array}$

$\begin{array}{lllllll}59 & -1 & 1 & -1 & 1 & 1 & 1\end{array}$

$\begin{array}{lllllll}60 & 1 & 1 & -1 & 1 & 1 & 1\end{array}$

$\begin{array}{lllllll}61 & -1 & -1 & 1 & 1 & 1 & 1\end{array}$

$\begin{array}{lllllll}62 & 1 & -1 & 1 & 1 & 1 & 1\end{array}$

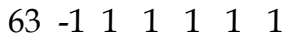

$\left.\begin{array}{lllllll}64 & 1 & 1 & 1 & 1 & 1 & 1\end{array}\right]$;

for $i=1: 64$,

$\operatorname{RunOrder}(\mathrm{i})=\operatorname{doematrix}(\mathrm{i}, 1)$;

if $\operatorname{doematrix}(\mathrm{i}, 2)==1$

W0_i(i)=W0max;

else

W0_i(i)=W0min;

end

if $\operatorname{doematrix}(i, 3)==1$

Wb_i $(i)=W b m a x$;

else

$\mathrm{Wb} i \mathrm{i}(\mathrm{i})=\mathrm{Wbmin}$;

end

if $\operatorname{doematrix}(\mathrm{i}, 4)==1$

Cd_i(i)=Cdmax;

else

Cd_i $(i)=C d m i n ;$

end

if $\operatorname{doematrix}(i, 5)==1$

fr_i(i)=frmax;

else

$$
\text { fr_i } i(i)=\text { frmin; }
$$

end

if $\operatorname{doematrix}(i, 6)==1$

eta_i(i)=etamax;

else

eta_i(i)=etamin;

end

if $\operatorname{doematrix}(\mathrm{i}, 7)==1$

Dse_i(i)=Dsemax;

else

Dse_i(i)=Dsemin;

end

W0=W0_i(i);

$\mathrm{Wb}=\mathrm{Wb} \_\mathrm{i}(\mathrm{i})$;

$\mathrm{Cd}=\mathrm{Cd} \_\mathrm{i}(\mathrm{i})$;

$\mathrm{fr}=\mathrm{fr} \_\mathrm{i}(\mathrm{i})$;

eta=eta_i(i);

Dse=Dse_i $(\mathrm{i})$; 


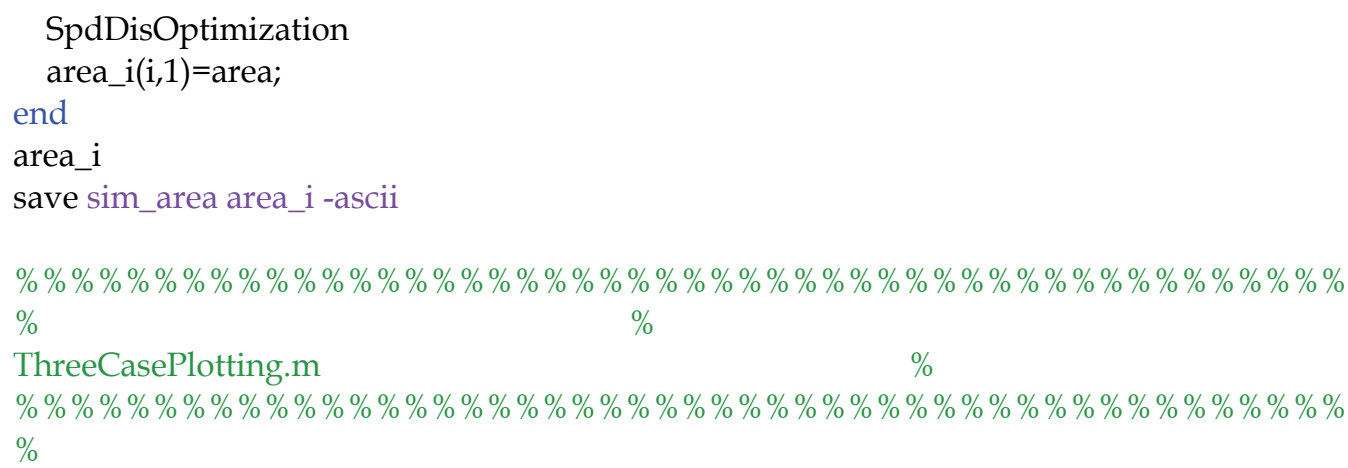


Wb_i $(i)=W b m i n$;

else

$W b \_i(i)=W b m a x ;$

end

if $\mathrm{i}==1$,

Cd_i $(i)=C d m i n$;

elseif $\mathrm{i}==2$,

Cd_i(i) $=$ Cdmax;

else

Cd_i $(i)=(C d m a x+C d m i n) / 2$;

end

if $\mathrm{i}==1$,

fr_i $i(i)=$ frmin;

elseif $i==2$,

fr_i(i)=frmax;

else

fr_i(i) $=($ frmin + frmax $) / 2$;

end

if $i==1$,

eta_i(i)=etamax;

elseif $i==2$,

eta_i(i)=etamin;

else

eta_i $i(i)=($ etamin + etamax $) / 2$;

end

if $\mathrm{i}==1$,

Dse_i $(\mathrm{i})=$ Dsemin;

else

Dse_i $(i)=$ Dsemax;

end

W0=W0_i(i);

$\mathrm{Wb}=\mathrm{Wb} \_\mathrm{i}(\mathrm{i})$;

$\mathrm{Cd}=\mathrm{Cd} \_\mathrm{i}(\mathrm{i})$;

$\mathrm{fr}=\mathrm{fr} \_\mathrm{i}(\mathrm{i})$;

eta=eta_i(i);

Dse=Dse_i $(\mathrm{i})$;

SpdDisOptimization

area_i $(\mathrm{i}, 1)=$ area;

if $i==1$,

color_i ${ }^{\prime}-\mathrm{k}^{\prime}$;

elseif $\mathrm{i}==2$,

color_i='-.r';

else

color_i='--b';

end

area 


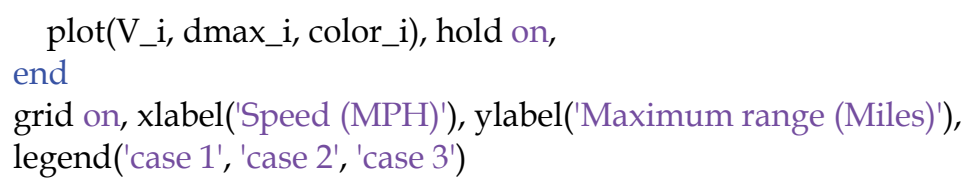




\section{References}

Breyfogle, F. W. (2003). Implementing Six Sigma: Smarter Solutions Using Statistical Methods, John Wiley \& Sons, Inc., Hoboken, NJ.

Casella, G. (2004). Monte Carlo Statistical Methods, Springer.

Ehsani, M.; Gao, Y., Gay, S.E., \& Emadi, A. (2005). Modern Electric, Hybrid Electric, and Fuel Cell Vehicles, CRC Press LLC, London.

Gillespie, T.D. (1992). Fundamentals of Vehicle Dynamics, Society of Automotive Engineers, Inc., Warrendale, PA.

Harry, M. \& Schroeder, R. (2000). Six Sigma: The Breakthrough Management Strategy Revolutionizing the World's Top Corporations, Doubleday, New York.

Husain, I. (2003). Electric and hybrid vehicles, CRC Press.

Jones, E. (2007). Integrating of A Project Management Database For Six Sigma Quality Course, Proceedings of 2007 ASEE Annual Conference, Hawaii, June, 2007.

Liu, J. S. (2001). Monte Carlo Strategies in Scientific Computing, Springer, New York.

Mathews, P. \& Mathews, P. G. (2004). Design of Experiments With MINITAB, ASQ Quality Press.

Montgomery, D. C. (2008). Design and Analysis of Experiments, 7th ed., John Wiley \& Sons, Inc.

Meyer, R. \& Krueger, D. (2005). A Minitab guide to statistics, 3rd ed., Prentice Hall.

Myers, R.H. \& Montgomery, D.C. (1995). Response Surface Methodology, John Wiley \& Sons, Inc.

Nonthaleerak P. \& Hendry, L.C. (2006). Six Sigma: literature review and key future research areas, International Journal of Six Sigma and Competitive Advantage, Vol. 2, No. 2, pp. $105-161$.

Pande P. \& Holpp, J. (2002). What is Six Sigma. McGraw Hill, New York.

Pratap, R. . (2006). Getting Started with MATLAB 7: A Quick Introduction for Scientists and Engineers, Oxford University Press.

Pyzdek, T. (2003). The Six Sigma Handbook: The Complete Guide for Greenbelts, Blackbelts, and Managers at All Levels, McGraw-Hill, New York.

Snee, R. D. (2004). Six-Sigma: the evolution of 100 years of business improvement methodology, International Journal of Six Sigma and Competitive Advantage, Vol. 1, No. 1, pp. $4-20$.

Taguchi, G. (1987). System of Experimental Design, Unipub/Kraus/American Supplier Institute, Dearborn, MI.

Taguchi, G. (1993). Taguchi on Robust Technology Development, ASME Press, New York. The MathWorks, Inc. (2008). MATLAB® 7 Getting Started Guide.

Wortman, B.; Richdson, W. R. Gee, G., Williams, M., Pearson, T., Bensley, F., Patel, J., DeSimone, J., \& Carlson, D. R. (2001). The Certified Six Sigma Black Belt Primer, West Terre Haute, IN: Quality Council of Indiana.

Zhan, W., (2008). A Six Sigma Approach for Robust Design of Motor Speed Control, Int. Journal of Six Sigma for Competitive Advantage, Vol. 4, No. 2, pp. 95-113.

Zhan, W. (2009). Monte Carlo Analysis for The Inverse Problem for Motor PWM Control, in : IAENG Transactions on Engineering Technologies, Volume II, pp. 186-197.

Zhan, W.; McDermott, M., Zoghi, B. \& Hasan, M. (2009). Requirement Development for Electrical Vehicles Using Simulation Tools, Proceedings of The International Conference on Modeling, Simulation and Control 2009, pp. 932-937, San Francisco, Oct., 2009. 


\title{
Longitudinal Robust Stability Augmentation for Micro air Vehicle - Design and Validation
}

\author{
Dr. M. Meenakshi ${ }^{1}$ and Prof. M. Seetharama Bhat ${ }^{2}$ \\ ${ }_{1}^{1}$ Professor, Dept. of Instrumentation Technology, Dr. AIT Bangalore, India \\ Email: meenakshi_mbhat@yahoo.com \\ 2Professor, Dept. Of Aerospace Engineering, Indian Institute of Science Banaglore, India \\ Email:msbdcl@aero.iisc.ernet.in
}

\begin{abstract}
This chapter presents a robust fixed order $\mathrm{H}_{2}$ controller designed using Strengthened discrete optimal projection equations (SDOPEs), which approximate the first order necessary optimality condition. Also, the problem of robust performance analysis for a particular robust controller design application is addressed. The novelty of this work is the application of the robust $\mathrm{H}_{2}$ controller to a Micro Aerial Vehicle MAV, named Sarika2 developed in house. The controller is designed in discrete domain for the longitudinal dynamics of Sarika2 in the presence of low frequency atmospheric turbulence (gust) and high frequency sensor noise. The design specification includes simultaneous stabilization, disturbance rejection and noise attenuation over the entire flight envelope of the vehicle. Six degrees of freedom nonlinear equations are linearized, and validated using nonlinear simulation model and is used for the controller design. The resulting controller performance is comprehensively analyzed by means of linear and nonlinear simulation. In addition, robust performance analyses based on LMI techniques are also carried out to strengthen the results. For this, parametric uncertainties due to modeling errors or due to operating point changes have been considered.
\end{abstract}

\section{Introduction}

Ever since mankind's first powered flight was made, research efforts have continuously pushed the envelope to create flying machines that are faster and/or larger than ever before. Now however; there is an effort to design aircraft at the other end of largely unexplored spectrum, where the desire for low cost portable, low-altitude aerial surveillance has driven the development and testing of aircraft that are as small as possible - in other words, on the scale and in the operational range of small birds. Vehicles in this class of small-scale aircraft are known as Micro Air Vehicles or MAVs.

Equipped with small video cameras and transmitters, MAVs have great potential for surveillance and monitoring tasks in areas either too remote or dangerous to send human scouts. Operational MAVs will enable a number of important missions which include 
chemical/radiation spill monitoring, forest-fire reconnaissance, visual monitoring of volcanic activity, surveys of natural disaster areas, and even inexpensive traffic and accident monitoring [1, 2] etc. Additional on-board sensors can further augment MAV mission profiles to include, for example airborne chemical analysis.

In military, one of the primary roles for MAVs will be as small-unit battlefield surveillance agents, where they act as an extended set of eyes in the sky. This use of MAV technology is intended to reduce the risk to military personnel. MAVs can penetrate potential opposite camps and other targets prior to any action against on those targets, which are virtually undetectable from the ground. This significantly raises the chance for overall mission success.

Researchers at the Aerospace Engineering Department at the Indian Institute of Science (I.I.Sc) Bangalore, India have established a long track record in designing, building and testflying (remotely human-piloted) practical MAVs [3-4]. Fig. 1 shows one among few of the recently developed MAVs as well as small UAVs at I.I.Sc. While much progress has been made in the design of ever-smaller MAVs by researchers at I.I.Sc, India and others in the past five years, there is a significant scope for research on autonomous MAV so as to improve their utility to wide array of missions.

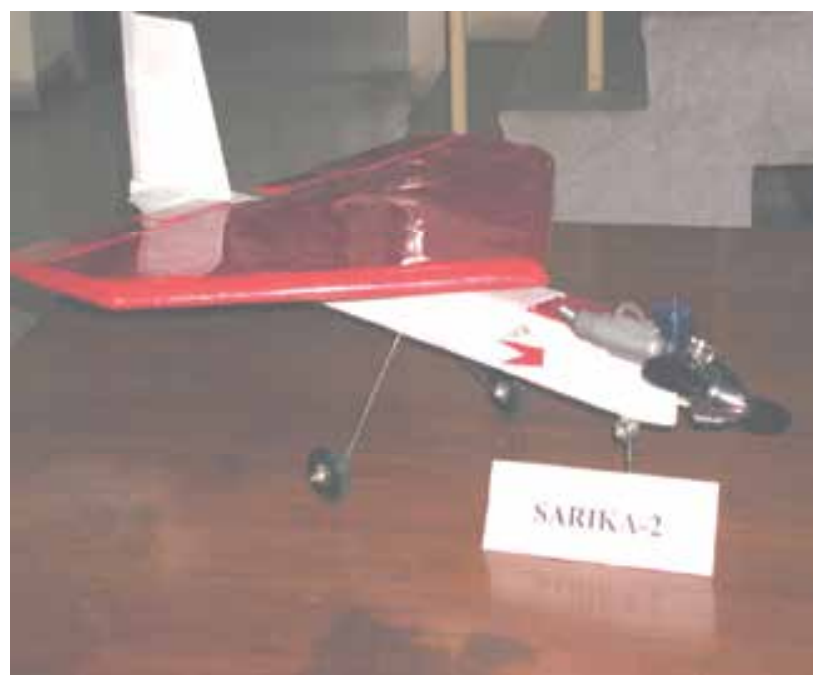

Fig. 1 Micro Air Vehicle: Sarika-2

The first challenging step in achieving such MAV autonomy is the design and development of a robust flight stabilization system because, the uncertainties in the mathematical model associated with the low Reynolds number flight are not fully understood and is high. MAVs have very low moments of inertial property; hence they are highly vulnerable to rapid angular accelerations. Another potential source of instability for MAV is the relative magnitudes of wind gusts, which are much higher at the MAV scale than for larger aircraft [1]. An average wind gust can immediately effect a dramatic change in the flight path of these vehicles. In addition, the pilot may find it difficult to control the aircraft based on visual cues, if its dynamic modes are of high frequency and are lightly damped. Therefore, the problem of controlling an uncertain system such as MAV has been the subject of extensive research in the area of systems and control. 
Generally, a well motivated control goal is to achieve a certain level of performance while controlling an uncertain system. i.e., when designing control system, it is often desirable to obtain guarantees of stability and performance against uncertainty on the physical parameters of the system. Examples of the physical parameters include stiffness, inertia, or viscosity coefficients and aero-dynamical coefficients in flight control. Hence, performance analysis of systems is obviously a very important problem in flight control theory. This problem is also referred to as the robust performance problem. A measure of performance which arises in several situations is given by the $\mathrm{H}_{2}$ norm of a system. For example, in optimal control design, the quadratic performance index of a system can be expressed as the system's $\mathrm{H}_{2}$ norm equivalently [5]. Next, in the design of white noise attenuation, the variance of the output of the system's error caused by white noise can also be represented in the form of $\mathrm{H}_{2}$ norm [6],[7]. In both cases, the purpose of the system design is to select a stabilizing compensator that make the $\mathrm{H}_{2}$ norm of the system as small as possible or less than a given value $\gamma>0$, i.e.,

$$
|| F(s)||_{2}<\gamma
$$

Lower bounds on the achievable $\gamma$ is depends on many constraints like finite bandwidth and non minimum phase zeros of the plant [8]. The design of the compensator is simpler when there are no uncertainties in the system. However, the design process becomes complex when there is uncertainties in the system and hence system becomes a set of family. Generally, in such a case we design a controller for the nominal system first and then check the robust stability and robust performance specifications for the whole system family.

Thus, robust flight controller plays an important role to simplify the task of operating the MAV while enhancing the utility of MAVs for a wide range of missions. Reduced fixed order, robust $\mathrm{H}_{2}$ control is an attractive option among the several robust multivariable methods for controller design, as $\mathrm{H}_{2}$ norm is the more realistic measure of the performance [9]. This allows the direct incorporation of the multivariable robustness measures in to the optimization criterion. Reduced fixed order controller can be synthesized in one step in contrast to the other multivariable robust controller design methods involving two step designs, and hence, guarantees the robustness and stability [10].

Therefore, to deal with the above mentioned challenges in MAV flight control, this chapter proposes the design of digital longitudinal stability augmentation system to improve the handling qualities of Sarika-2 and to achieve satisfactory closed loop disturbance rejection, sensor noise attenuation and robustness specifications [11]. Since Sarika-2 use non inertial quality sensors, and the velocity sensor is not available, a single controller is designed at the central operating point of the vehicle to achieve the desired specifications over the entire flight envelope. Controller is designed using linearized model $[12,13]$ and is validated using nonlinear simulation model of Sarika2, which is developed using simulation software [14]. Next, $\mathrm{H}_{2}$ performance and robustness analysis using LMI techniques is carried out to demonstrate the robustness of the designed system. $\mathrm{H}_{2}$ performance robustness analysis considered here is based on the quadratic Lyapunov function with affine dependence on the uncertain parameters. The resulting tests are less conservative than quadratic stability when the parameters are constant or slowly varying.

The organization of this chapter is as follows. Section 2 briefly explains longitudinal dynamics of Sarika 2 and its verification using nonlinear simulation model. Next section 3 
presents briefly about the controller design methodology. Section 4 briefly explains the $\mathrm{H}_{2}$ performance robustness analysis using LMI techniques. Section 5 describes the simulation results using linear and nonlinear simulation models. Also robust performance analysis results are highlighted in section 5. Finally conclusions are drawn in section 6.

\section{Longitudinal Dynamics of Sarika 2}

Sarika2 (Fig.1) is a remotely piloted small flying vehicle with a wing span of about $0.6 \mathrm{~m}$ and $0.8 \mathrm{~m}$ in length. The vehicle is weighting about $1.75 \mathrm{k}$.g at its takeoff. The control surfaces are outboard elevators, inboard ailerons and rudder. The power plant is a 4cc propeller engine with methanol plus castor oil as fuel. Sarika2 can carry a payload comprising video camera, sensors, and transmission systems. Sarika2 has a swept-back delta wing without a horizontal tail. It has a planform area of $0.195 \mathrm{sqm}$, and a constant area square section fuselage of width $0.06 \mathrm{~m}$.

The nonlinear six degrees of freedom equations of the vehicle is given by the following force balance and moment balance equations:

\section{Force Equations}

\section{Moment Equations}

$$
\begin{aligned}
& \dot{U}_{1}=R V_{1}-Q W_{1}-g_{0} \sin \theta+\frac{F_{x}}{m} \\
& \dot{V}_{1}=-R U_{1}+P W_{1}+g_{0} \sin \phi \cos \theta+\frac{F_{y}}{m} \\
& \dot{W}_{1}=Q U_{1}-P V_{1}+g_{0} \cos \phi \cos \theta+\frac{F_{z}}{m}
\end{aligned}
$$

$$
\begin{aligned}
& \dot{P}=\left(c_{1} R+c_{2} P\right) Q+c_{3} L+c_{4} N \\
& \dot{Q}=c_{5} P R-c_{6}\left(P^{2}-R^{2}\right)+c_{7} M \\
& \dot{R}=\left(c_{8} P-c_{2} R\right) Q+c_{4} L+c_{9} N
\end{aligned}
$$

where, $\quad c_{1}=\frac{\left(J_{y}-J_{z}\right) J_{z}-J_{x z}^{2}}{J_{x} J_{z}-J_{x z}^{2}} ; \quad c_{2}=\frac{\left(J_{x}-J_{y}+J_{z}\right) J_{x z}}{J_{x} J_{z}-J_{x z}^{2}} ; \quad c_{3}=\frac{J_{z}}{J_{x} J_{z}-J_{x z}^{2}} ; \quad c_{4}=\frac{J_{x z}}{J_{x} J_{z}-J_{x z}^{2}}$ ，

$c_{5}=\frac{J_{z}-J_{x}}{J_{y}}, c_{6}=\frac{J_{x z}}{J_{y}} \quad c_{7}=\frac{1}{J_{y}} ; c_{8}=\frac{J_{x}\left(J_{x}-J_{y}\right)+J_{x z}^{2}}{J_{x} J_{z}-J_{x z}^{2}} ; \quad c_{9}=\frac{J_{x}}{J_{x} J_{z}-J_{x z}^{2}}$

The following two equations (eq. $2 \mathrm{c}$ and $2 \mathrm{~d}$ ) gives the kinematic and navigations equations of the aircraft, which is needed to develop the complete nonlinear simulation model of the aircraft. 


\section{Kinematic equations}

\section{Navigation Equations}

$$
\begin{aligned}
& \dot{\phi}=P+\tan \theta(Q \sin \phi+R \cos \phi) \\
& \dot{\theta}=Q \cos \phi-R \sin \phi \\
& \dot{\psi}=\frac{Q \sin \phi+R \cos \phi}{\cos \theta}
\end{aligned}
$$

$$
\begin{aligned}
\dot{p}_{n}= & U_{1} \cos \theta \cos \psi+V_{1}(-\cos \phi \sin \psi+\sin \phi \sin \theta \cos \psi) \\
& +W_{1}(\sin \phi \sin \psi+\cos \phi \sin \theta \cos \psi) \\
\dot{p}_{e}= & U_{1} \cos \theta \sin \psi+V_{1}(\cos \phi \cos \psi+\sin \phi \sin \theta \sin \psi) \\
& +W_{1}(-\sin \phi \cos \psi+\cos \phi \sin \theta \sin \psi) \\
\dot{h}= & U_{1} \sin \theta-V_{1} \sin \phi \cos \theta-W_{1} \cos \phi \cos \theta
\end{aligned}
$$

For the purpose of controller design, the above set of nonlinear equations is decoupled using small perturbation theory and developed linearized equations, which represents the longitudinal and lateral dynamics of the vehicle. Linearized longitudinal state space equations (Eq. 3) are developed for a straight and level flight, trimmed at six operating points in the speed range of $16-26 \mathrm{~m} / \mathrm{s}$. The state variables are $\mathrm{x}=\left[\begin{array}{llll}\Delta \mathrm{u} & \alpha & \mathrm{q} & \theta\end{array}\right]^{\mathrm{T}}$ where $\Delta \mathrm{u}$ is the forward speed (m/s), $\alpha$ is the angle of attack (radians), $\mathrm{q}$ (radians/s) is the pitch rate and $\theta$ (radians) is the pitch angle.

$$
\begin{gathered}
\Delta \dot{u}=\left(X_{u}+X_{T u}\right) \Delta u+X_{\alpha}\left(\alpha+\frac{w_{g}}{U_{1}}\right)+\frac{Z_{u}}{U_{1}} q-g\left(\cos \theta_{1}\right) \theta+X_{\delta e} \delta_{e} \\
\dot{\alpha}=\frac{Z_{u}}{U_{1}} \Delta u+\frac{Z_{\alpha}}{U_{1}}\left(\alpha+\frac{w_{g}}{U_{1}}\right)+\left(\frac{Z_{q}}{U_{1}}+1\right) q+\frac{Z_{\delta e}}{U_{1}} \delta_{e} \\
\dot{q}=\left(M_{u}+M_{T u}\right) \Delta u+\left(M_{\alpha}+M_{T \alpha}\right)\left(\alpha+\frac{w_{g}}{U_{1}}\right)+M_{q} q+M_{\delta e} \delta_{e} \\
\dot{\theta}=q
\end{gathered}
$$

where, $\frac{w_{g}}{U_{1}}=\alpha_{g}$ is the angle of attack due to vertical wind gust $\mathrm{w}_{\mathrm{g}}$. The elevator is actuated by electro-mechanical servo systems. The dynamics of the servo actuator measured experimentally, is given by,

$$
\dot{\delta}_{e}=-9.5 \delta_{e}+6.37 u
$$

The measured variables are normal acceleration and pitch rate of the vehicle. The normal acceleration at the centre of gravity c.g. of the vehicle is given by,

$$
a_{z}=U_{1}(\dot{\alpha}-q)
$$

The coefficients of the equations ( $3 a-3 d)$, known as aerodynamic stability derivatives are computed using analytical approach $[12,13]$ and are refined using wind tunnel generated 
data [3]. The computed values are again validated using nonlinear simulation model, named FAST [14]. Table 1 shows that the trim values calculated by analytical means match well with those obtained by means of nonlinear simulation. Table 2 gives the steady state coefficients for each trimmed flight condition calculated using the analytical relations. For comparison, Table 2 also lists the corresponding values obtained from nonlinear simulation [14].

\begin{tabular}{|c|l|l|l|l|}
\hline \multirow{2}{*}{$\begin{array}{c}\text { Speed } \\
\text { m/s }\end{array}$} & \multicolumn{2}{|c|}{$\begin{array}{c}\text { Trim Elevator } \delta_{\mathrm{e}} \text { in } \\
\text { Degrees }\end{array}$} & \multicolumn{2}{c|}{ Trim Alpha $\alpha$ in Degrees } \\
\cline { 2 - 5 } & $\begin{array}{l}\text { Analytical } \\
\text { Approach }\end{array}$ & $\begin{array}{l}\text { Nonlinear } \\
\text { Model }\end{array}$ & $\begin{array}{l}\text { Analytical } \\
\text { Approach }\end{array}$ & $\begin{array}{l}\text { Nonlinear } \\
\text { Model }\end{array}$ \\
\hline 16 & -16.02 & -15.91 & 16.93 & 17.96 \\
\hline 18 & -15.21 & -15.17 & 13.24 & 13.26 \\
\hline 20 & -14.68 & -14.42 & 10.59 & 10.54 \\
\hline 22 & -13.55 & -13.36 & 8.64 & 8.67 \\
\hline 24 & -12.69 & -12.57 & 7.15 & 7.29 \\
\hline 26 & -12.02 & -11.96 & 5.99 & 6.23 \\
\hline
\end{tabular}

Table 1. Trim settings of alpha and elevator

\begin{tabular}{|c|c|c|c|c|}
\hline \multirow{2}{*}{$\begin{array}{c}\text { Speed } \\
\mathrm{m} / \mathrm{s}\end{array}$} & \multicolumn{2}{|c|}{$\mathrm{C}_{\mathrm{L} 1}$} & \multicolumn{2}{|c|}{$C_{D 1}$} \\
\hline & $\begin{array}{l}\text { Analytical } \\
\text { Approach }\end{array}$ & $\begin{array}{l}\text { Nonlinear } \\
\text { Model }\end{array}$ & $\begin{array}{l}\text { Analytical } \\
\text { Approach }\end{array}$ & $\begin{array}{l}\text { Nonlinear } \\
\text { Model }\end{array}$ \\
\hline 16 & 0.56 & 0.5 & 0.14 & 0.104 \\
\hline 18 & 0.43 & 0.4 & 0.10 & 0.075 \\
\hline 20 & 0.36 & 0.33 & 0.08 & 0.06 \\
\hline 22 & 0.29 & 0.27 & 0.07 & 0.058 \\
\hline 24 & 0.23 & 0.21 & 0.06 & 0.055 \\
\hline 26 & 0.20 & 0.19 & 0.05 & 0.053 \\
\hline
\end{tabular}

Table 2. Trim values and Steady state Coefficients

The continuous state space model is discretized at $50 \mathrm{~Hz}$ (to synchronize with the command PWM input received at the vehicle from radio/pilot command from ground station).The final linearized model used for the controller synthesis includes one sampling period delay to account for computational time requirements. Hence, the final model of the plant consists of six states (four for MAV airframe, one for actuator and one for delay), one control input, wind disturbance input and two sensor outputs from rate gyro and accelerometers.

\section{Fixed order $\mathrm{H}_{2}$ Controller Design}

Fixed reduced order $\mathrm{H}_{2}$ controller is designed to meet the following closed loop specifications. The main requirement of stability augmentation system (SAS) is towards improvement of handling qualities summarized as in S1. In addition, the disturbance rejection and robustness specifications related to the controller design are also summarized in S2, S3 and S4: 
S1: Level - 1-flying qualities of stable airframe dynamics:

Short period damping ratio: $0.35 \leq \xi_{\mathrm{sp}} \leq 1.3$

Phugoid damping ratio: $\xi_{\mathrm{p}} \geq 0.5$

S2: Disturbance rejection Specification:

Minimize the sensitivity function below $0 \mathrm{~dB}$ for $\omega<9 \mathrm{rad} / \mathrm{s}$

S3: Sensor noise attenuation Specification:

Obtain $-40 \mathrm{~dB} /$ decade roll off above $\omega=20 \mathrm{rad} / \mathrm{s}$

S4: Robustness Specification:

The controller should be robust to structured and unstructured uncertainty in plant models at all flight conditions. Apart from the above specifications, the closed loop system should also be robust to maximum expected time delays, which may arise due to computational complexity. In addition, the control surface deflection should not exceed its full-scale deflection of \pm 16 degrees.

To meet the above closed loop requirements, robust fixed order $\mathrm{H}_{2}$ controller is designed [11] by considering the performance objective of minimization of $\mathrm{H}_{2}$ norm of the closed loop transfer function $\mathrm{T}_{\mathrm{zw}}$ of the generalized plant given in Fig. 2:

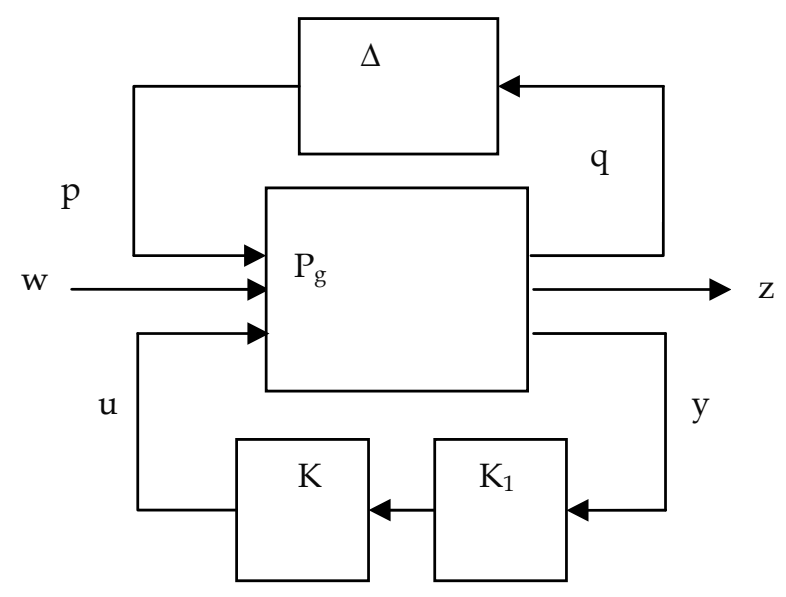

Fig. 2. Standard representation for $\mathrm{H}_{2}$ Design and Analysis

The configuration shown in Fig. 2 contains a generalized plant that is used for robust stability analysis and controller design. The signals ' $w$ ' and ' $z$ ' are exogenous inputs and performance variables respectively. ' $y$ ' is the measured variable, and ' $u$ ' is the control input. $\mathrm{P}_{\mathrm{g}}$ is the generalized plant representing the actual plant and all weighting functions. $\mathrm{K}_{1}$ represents the sensor dynamics including pre-amplifier gains and $\mathrm{K}$ is the controller to be designed. $\Delta$ is the set of all possible uncertainties, grouped in to a single block-diagonal finite dimensional linear time invariant system. The diagram in Fig. 2 is also referred to as a standard LFT formulation with lower linear fractional transformation (LLFT) on K, where $\mathrm{P}_{\mathrm{gK}} \mathrm{K}_{1}$ is the coefficient matrix of the LLFT and upper linear fractional transformation (ULFT) on $\Delta$ where $\mathrm{P}_{\mathrm{g}}$ is the coefficient matrix of the ULFT. LLFT is used in the controller design stage and ULFT is used during the robust performance analysis stage. 
The generalized plant, Fig. 2 can be represented in frequency domain as follows:

$$
\left[\begin{array}{l}
z(z) \\
y(z)
\end{array}\right]=P_{g}(z)\left[\begin{array}{l}
u(z) \\
u(z)
\end{array}\right]=\left[\begin{array}{ll}
P_{g_{11}}(z) & P_{g_{12}}(z) \\
P_{g_{21}}(z) & P_{g_{22}}(z)
\end{array}\right]\left[\begin{array}{l}
w(z) \\
u(z)
\end{array}\right]
$$

where the closed-loop transfer matrix from $\mathrm{w}$ to $\mathrm{z}$ can be given by,

$$
\begin{gathered}
\mathrm{z}=\mathrm{T}_{\mathrm{zw}} \cdot \mathrm{w} \\
\text { and } \mathrm{T}_{\mathrm{zw}}=\mathrm{P}_{\mathrm{g} 11}+\mathrm{P}_{\mathrm{g} 12} \mathrm{~K}_{1} \mathrm{~K}\left(\mathrm{I}-\mathrm{P}_{\mathrm{g} 22} \mathrm{~K}_{1} \mathrm{~K}\right)^{-1}
\end{gathered}
$$

The minimization of the $\mathrm{H}_{2}$ norm of the transfer function from $\mathrm{w}$ to $\mathrm{z}$ i.e., $\mathrm{T}_{\mathrm{zw}}$ over all realizable controllers $\mathrm{K}(\mathrm{z})$ constitutes the $\mathrm{H}_{2}$ control problem. The elements of the generalized plant $\mathrm{P}_{\mathrm{g}}$ are obtained by augmenting the frequency dependent weighting functions and corresponding output vector $\mathrm{z}$ into lower LFT form.

The transfer function, $\mathrm{T}_{\mathrm{zw}}$ between the performance outputs, i.e output sensitivity $\mathrm{S}_{0}$ $\left(S_{o}=\left(I+G K K_{1}\right)^{-1}\right)$ and control sensitivity $\mathrm{S}_{\mathrm{i}} \mathrm{K}$ (with $S_{i}=\left(I+K K_{1} G\right)^{-1}$ ) functions to the disturbance input, $\mathrm{w}$ is given by:

$$
\min \left\|T_{z w}\right\|=\min \left\|\left[\begin{array}{l}
W_{1}(z) S_{0}(z) \\
W_{2}(z) S_{i}(z) K(z)
\end{array}\right]\right\|_{2}
$$

where, $K(z)$ represents the controller transfer function. $W_{1}$ and $W_{2}$ are the weighting matrices used to minimize sensitivity and control sensitivity at low frequency and high frequency region, specified in the design specifications. Reduced fixed order controller, $\mathrm{K}(\mathrm{z})$, defined by:

$$
\begin{gathered}
x_{c}(k+1)=A_{c} x_{c}(k)+B_{c} y(k) \\
u(k)=C_{c} x_{c}(k)+D_{c} y(k)
\end{gathered}
$$

The controller parameters $\left(\mathrm{A}_{c}, \mathrm{~B}_{\mathrm{c}}, \mathrm{C}_{\mathrm{c}}, \mathrm{D}_{\mathrm{c}}\right)$ which minimizes the objective function (Eq.7) are obtained by iteratively solving the set of four coupled modified Riccati and Lyaponv equations known as Strengthened Discrete Optimal Projection Equations (SDOPEs) $[15,11]$

\section{4. $\mathrm{H}_{2}$ Performance Robustness Analysis}

Controllers are often designed for a simplified model of the physical plant that does not take into account all sources of uncertainty. Hence a posteriori robustness analysis is necessary to validate the design and obtain guarantees of stability and performance in the face of plant uncertainty. The plant uncertainty occurs due to the imperfect knowledge of the system parameters or because of the alteration of their behavior owing to changes in the operating conditions, aging etc. A feedback compensator is said to achieve robust performance if a 
certain level of closed-loop performance is achieved for all plants in a specified set or for all variations in the plant parameters. On the other hand, stability robustness is achieved if the closed loop remains stable in spite of modeling errors due to high frequency un-modeled dynamics and plant parameter variations. The following subsections explain the representation of the uncertainty and the conditions for robustness of the closed loop system in the face of the uncertainties.

\subsection{Representation of uncertainty}

Robust controller synthesis considers nominal model of the plant along with some assessment of its errors, called model uncertainties. A key assumption in the mathematical models of uncertainty, or errors, is that the uncertain part of the dynamics can be modeled separately from the known part as represented by a nominal model. The mechanism used to represent the uncertainties is called representation of uncertainty.

In robust control literature, the mathematical representation of uncertainties caused by unintentional exclusion of high frequency dynamics, generally take many forms of which the most commonly used is the multiplicative and additive uncertainty model. The additive and multiplicative uncertainties can be mathematically represented as,

$$
\begin{gathered}
\mathrm{G}_{\mathrm{p}}(\mathrm{s})=\mathrm{G}_{\mathrm{p} 0}(\mathrm{~s})+\Delta_{\mathrm{a}}(\mathrm{s}) \\
\mathrm{G}_{\mathrm{p}}(\mathrm{s})=\mathrm{G}_{\mathrm{p} 0}(\mathrm{~s})\left[\mathrm{I}+\Delta_{\mathrm{i}}(\mathrm{s})\right] \\
\mathrm{G}_{\mathrm{p}}(\mathrm{s})=\left[\mathrm{I}+\Delta_{\mathrm{o}}(\mathrm{s})\right] \mathrm{G}_{\mathrm{p} 0}(\mathrm{~s})
\end{gathered}
$$

where, $\Delta_{\mathrm{a}}$ represents an additive perturbation, $\Delta_{\mathrm{i}}$ an input multiplicative perturbation and $\Delta_{\mathrm{o}}$ an output multiplicative perturbation. $\mathrm{G}_{\mathrm{p} 0}(\mathrm{~s})$ is a nominal plant transfer function, which is a best estimate, in some sense, of the true plant behavior, and $G_{p}(s)$ denote the true transfer function of the plant.

In general, uncertainties are represented in two forms. i.e, uncertain state space model, which is relevant for systems described by dynamical equations with uncertain and/or time-varying coefficients and linear fractional representation where the uncertain system is described as an interconnection of known LTI systems with uncertain components called uncertain blocks. Each uncertain block $\Delta_{\mathrm{i}}($.$) represents a family of systems of which only a$ few characteristics are known.

\subsubsection{Uncertain state space model}

Physical models of a system often lead to a state space description of its dynamical behavior. The resulting state space equations typically involve physical parameters whose value is only approximately known, as well as approximations of complex and possibly nonlinear phenomena. In other words, the system is described by an uncertain state space model,

$$
\begin{aligned}
& E \dot{x}=A x+B u \\
& y=C x+D u
\end{aligned}
$$


where the state space matrices A, B,C, D, E ( $\mathrm{E}$ is nonsingular) depend on uncertain and/or time-varying parameters or vary in some bounded sets of space of matrices. Generally, these uncertain models are grouped in to two categories: i) Polytopic Models. ii) Affine Parameter dependent Models.

\section{i) Polytopic models}

A linear time varying system represented by,

$$
\begin{gathered}
E(t) \dot{x}=A(t) x+B(t) u \\
y=C(t) x+D(t) u
\end{gathered}
$$

whose system matrix,

$$
S(t)=\left[\begin{array}{cc}
A(t)+j E(t) & B(t) \\
C(t) & D(t)
\end{array}\right]
$$

varies within a fixed polytope of matrices, i.e.,

$S(t) \in \operatorname{Co}\left\{S_{1}, S_{2} \cdots \cdots S_{k}\right\}:=\left\{\sum_{i=1}^{k} \alpha_{i} S_{i}: \alpha_{i} \geq 0, \sum_{i=1}^{k} \alpha_{i}=1\right\}$ where, $S_{1}, S_{2} \cdots \cdots S_{k}$ are

given vertex systems: $S_{1}=\left[\begin{array}{cc}A_{1}+j E_{1} & B_{1} \\ C_{1} & D_{1}\end{array}\right] \cdots \cdots \cdots \cdots S_{k}=\left[\begin{array}{cc}A_{k}+j E_{k} & B_{k} \\ C_{k} & D_{k}\end{array}\right]$ is called a polytopic systems. $\mathrm{S}(\mathrm{t})$ is a convex combination of the system matrices $\mathrm{S}_{1}, \ldots \ldots \mathrm{S}_{\mathrm{k}}$. The nonnegative numbers $\alpha_{1} \cdots \cdots \cdots \alpha_{k}$ are called the polytopic coordinates of $\mathrm{S}$. These models also arises when the state space models depends affinely on time varying parameters.

\section{ii). Affine parameter dependent models}

When the equation of physics involves uncertain or time varying coefficients, the linear systems give rise to parameter dependent models (PDS) of the form,

$$
\begin{aligned}
& E(\theta) \dot{x}=A(\theta) x+B(\theta) u \\
& y=C(\theta) x+D(\theta) u
\end{aligned}
$$

where $\mathrm{A}(),. \mathrm{B}(),. \mathrm{C}(),. \mathrm{D}($.$) and \mathrm{E}($.$) are known functions of some parameter vector, \Theta=\left(\theta_{1}\right.$, $\left.\theta_{2}, \ldots \theta_{n}\right)$. The state matrix $A(\theta)$ depends affinely on the parameters $\theta_{\mathrm{i}}$ That is,

$$
\begin{aligned}
& A(\theta)=A_{0}+\theta_{1} A_{1}+\cdots \cdots \cdots \theta_{K} A_{K} \\
& B(\theta)=B_{0}+\theta_{1} B_{1}+\cdots \cdots \cdots \theta_{n} B_{n}
\end{aligned}
$$

and so on where $A_{0}, A_{1} \ldots A_{k} B_{0}, B_{1} \ldots B_{k}$ are known fixed matrices. Affine parameter dependent models are well suited for Lyapunov based analysis and synthesis and are easily converted to linear fractional uncertainty models for small gain based design. 


\subsubsection{Linear fractional models of uncertainty}

This is the more general form of uncertainty representation of the system's dynamical and parametric uncertainty. A standard Linear fractional form used for robustness analysis is depicted in Fig. 3 consisting of a nominal map Gp and a perturbation $\Delta$ that enters the system in feedback fashion. The overall uncertain system will be denoted by $(\mathrm{Gp}, \Delta)$. Gp is assumed to be finite dimensional, linear time invariant (LTI) stable system. Gp(s) includes all known LTI components like controller, nominal models of the system, sensor and actuators. The input $\mathrm{u}$ includes all external, actions on the system and output $\mathrm{y}$ consists of all output signals generated by the system. $\Delta$ is a structured description of the uncertainty. Generally $\Delta$ is represented in block diagonal form, $\Delta=\left(\Delta_{1} \ldots \Delta_{\mathrm{k}}\right)$ where each uncertainty block $\Delta_{\mathrm{i}}$ accounts for one particular source of uncertainty like, neglected dynamics, nonlinearity, uncertain parameter etc. In each case of $\Delta$, there is a restricted class $\Delta$ of allowed perturbations, which are usually assumed normalized to the ball of uncertainty: $\mathrm{B}_{\Delta}$ $=\{\Delta \in \Delta:|| \Delta|| \leq 1\}$ in some operator norm.

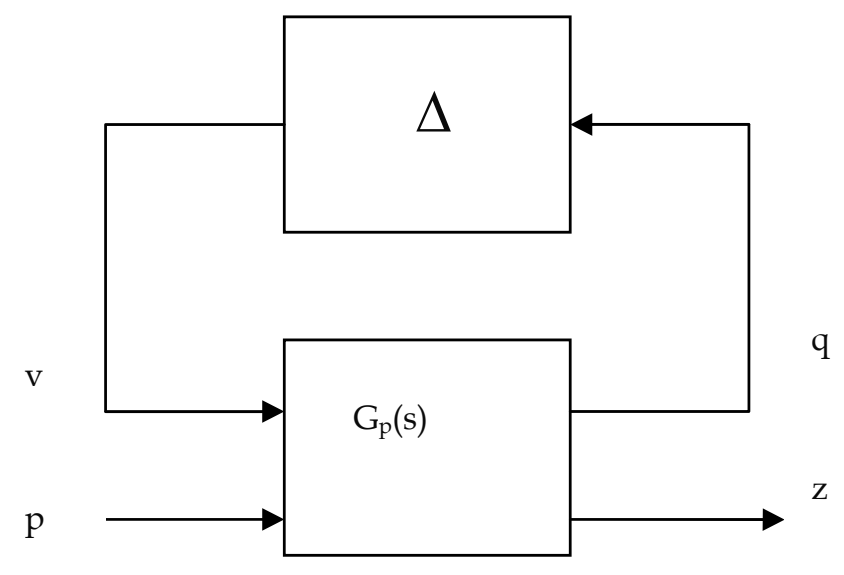

Fig. 3 LFT Formulation for Robust Analysis

\subsection{LFT Formulation for Robust Analysis Quantification of Parameter Uncertainty:}

Consider a linear time-invariant (closed loop) system $\sum(\theta)=(A(\theta), B(\theta), C(\theta)$ ), where $\theta \in \Theta$ is a vector of real uncertain parameters. Let $F(\theta)$ denote the square of the $\mathrm{H}_{2}$ norm of $\sum(\theta)$. The main problem is to compute the supremum of $F(\theta)$ as $\theta$ ranges in $\Theta$. This is a rather difficult performance robustness analysis problem. One among the different methods of robust performance analysis, consists of the uncertain linear systems that can be described by state space equations of the form given in Eqs (15-17), where $A_{0}, A_{1} \ldots A_{K}$ are known fixed matrices. It is also assumed that the lower and upper bounds of the parameter values and its rate variations is known. i.e,

1. Each parameter $\theta_{\mathrm{i}}$ ranges between known external values $\underline{\theta}_{i}$ and $\bar{\theta}_{\mathrm{i}}$ :

$$
\theta_{i} \in\left[\begin{array}{ll}
\underline{\theta}_{i} & \bar{\theta}_{i}
\end{array}\right]
$$

2. The rate of variation $\dot{\theta}_{i}$ is well defined at all times and satisfies: 


$$
\dot{\theta}_{i} \in\left[\underline{v}_{i} \bar{v}_{i}\right]
$$

where $\underline{v}_{i} \leq 0 \leq \bar{v}_{i}$ are known as lower and upper bounds on $\dot{\theta}_{i}$.

The first assumption means that the parameter vector $\theta$ is valued in any hyper- rectangle called parameter box. In the sequel,

$$
v:=\left\{\left(w_{1}, \cdots, w_{K}\right): w_{i} \in\left\{\underline{\theta}_{i}, \bar{\theta}_{i}\right\}\right\}
$$

denotes the set of the $2^{\mathrm{K}}$ vertices or corners of this parameter box. Similarly equation defines an hyper-rectangle of $\mathrm{R}^{\mathrm{K}}$ with corners in

$$
\mathfrak{R}:=\left\{\left(\tau_{1} \cdots \tau_{K}\right): \tau_{i} \in\left\{\underline{v}_{i}, \bar{\mho}_{i}\right\}\right\} .
$$

Note that 2) allows for more accurate modeling of the rate of variation than a mere bound on $\left|\dot{\theta}_{i}\right|$. Also equation - encompasses time invariant parameters as the special case $\underline{v}_{i}=\bar{v}={ }_{i} 0$. Though this model is somewhat restrictive, still it covers many relevant uncertain systems.

It is essential to distinguish between time in variant and time varying parameters. Time invariant uncertain parameters have a fixed value that is known only approximately. In this case the state equation is time invariant. In the case of time varying uncertain parameters, the parameter values vary in the range $\left[\underline{\theta}_{i} \quad \bar{\theta}_{i}\right]$ during the operation. The system is then time varying.

Generally, to accesses the robust performance, of the closed loop system, parametric uncertainty within the control bandwidth in the form of errors in frequency and model damping can be introduced.

\subsubsection{Robust Stability}

For an affine parameter dependent system given in Eq. 15, if a positive definite Lyapunov functions of the form,

$$
\begin{gathered}
V(x, \theta)=x^{t} Q(\theta)^{-1} x \\
\text { where, } Q(\theta)=Q_{0}+\theta_{1} Q_{1}+\cdots \cdots \theta_{n} Q_{n}
\end{gathered}
$$

is exists, then the system is robustly stable. $[7,8]$

\subsubsection{Quadratic stability}

A system, Eqn. 15, is said to be quadratically stable if there exists a positive-definite quadratic Lyapunov function $\mathrm{V}(\zeta)=\zeta \mathrm{TP} \zeta$ that decreases along every trajectory of the system. $[7,8]$ 


\section{Results and Analysis}

Suitable weighing matrices are selected by trial and error method and minimum order controller is designed to meet the design specifications. It is found that a third order controller is sufficient to meet the closed loop requirements. The two elements of transfer function matrix of the third order controller $\mathrm{K}_{1 \times 2}$ is given by,

$$
K(z)=\frac{1}{\Delta}\left[0.0019(z-0.1614)(z-0.9904) \quad 0.036\left(z^{2}-2.005 z+1.008\right)\right]
$$

where, $\Delta=(z-0.3828)(z-0.9397)(z-0.9875)$.

With this controller, at all flight conditions, short period and phugoid damping remains greater than 0.35 and 0.5 respectively, hence, the stringent level-one flying quality requirement is met.

\subsection{Nonlinear simulation results}

In practice, it is very difficult to fly the model continuously at constant altitude and to initiate control action from an equilibrium condition as assumed while designing the controller. The variation in altitude in real flight can give rise to variations in density, which in turn can affect the dynamics of the aircraft. Also, the effect of the coupling of longitudinal and lateral dynamics can play a major role on the aircraft performance. In order to assess the performance of the controller in the presence of such uncertainties, full scale closed loop nonlinear simulation with both longitudinal controller is presented in this section. The nonlinear program used for this purpose is the FAST package developed by NAL, Bangalore [14]. FAST is only an open loop simulation software package for the given aircraft. In order to simulate the closed loop response of Sarika-2, at first the input file is formulated in the standard format [14]. In order to simplify the controller implementation procedure in real time, controller is placed in the feedback path, in contrast to the cascade configuration used while designing the controller. This is because, in feedback configuration, initial conditions for controller can safely be set to zero.

In order to assess the performance of the controller, two different conditions are considered. First the aircraft is trimmed for different cruise speeds at constant altitude and the closed loop response to doublet input is simulated. Next, the aircraft is trimmed at different altitudes and closed loop response to doublet input is simulated.

\subsubsection{Closed loop Response due to variation in Cruise Speed}

The closed loop nonlinear responses are simulated at 3 different nominal flight speeds, (16 $\mathrm{m} / \mathrm{s}, 20 \mathrm{~m} / \mathrm{s}$ and $26 \mathrm{~m} / \mathrm{s}$ ) at constant altitude. After the aircraft is trimmed for straight and level flight, the simulation is started at $\mathrm{t}=0$ with a doublet input along the pitch axis. i.e., a positive $0.1 \mathrm{~ms}$ input is applied at $\mathrm{t}=0$ and held it for $2 \mathrm{~s}$. Next, a $-0.1 \mathrm{~ms}$. input is applied and is zeroed after $2 \mathrm{~s}$. The closed loop responses obtained from nonlinear simulation models, at different flight conditions, are given in Figs. $4-6$. 


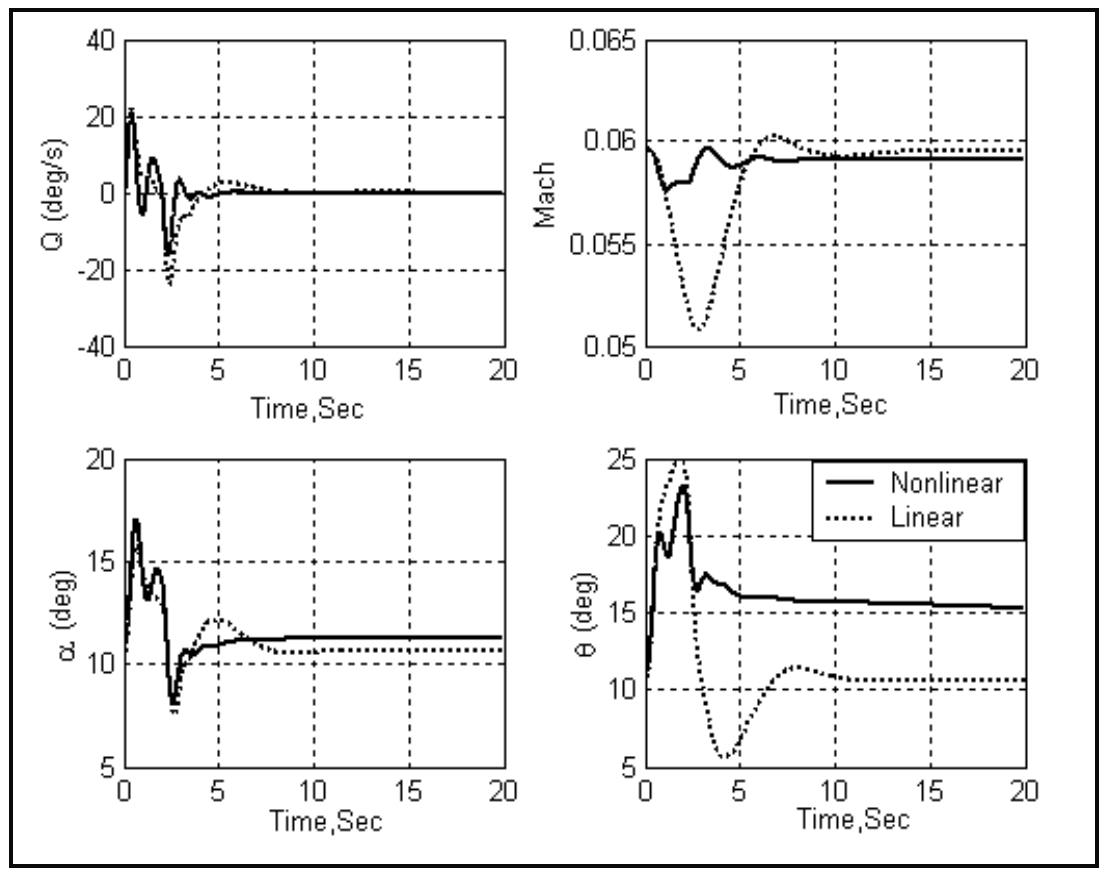

Fig. 4a Closed Loop Responses from Nonlinear and Linear Models at 20m/s

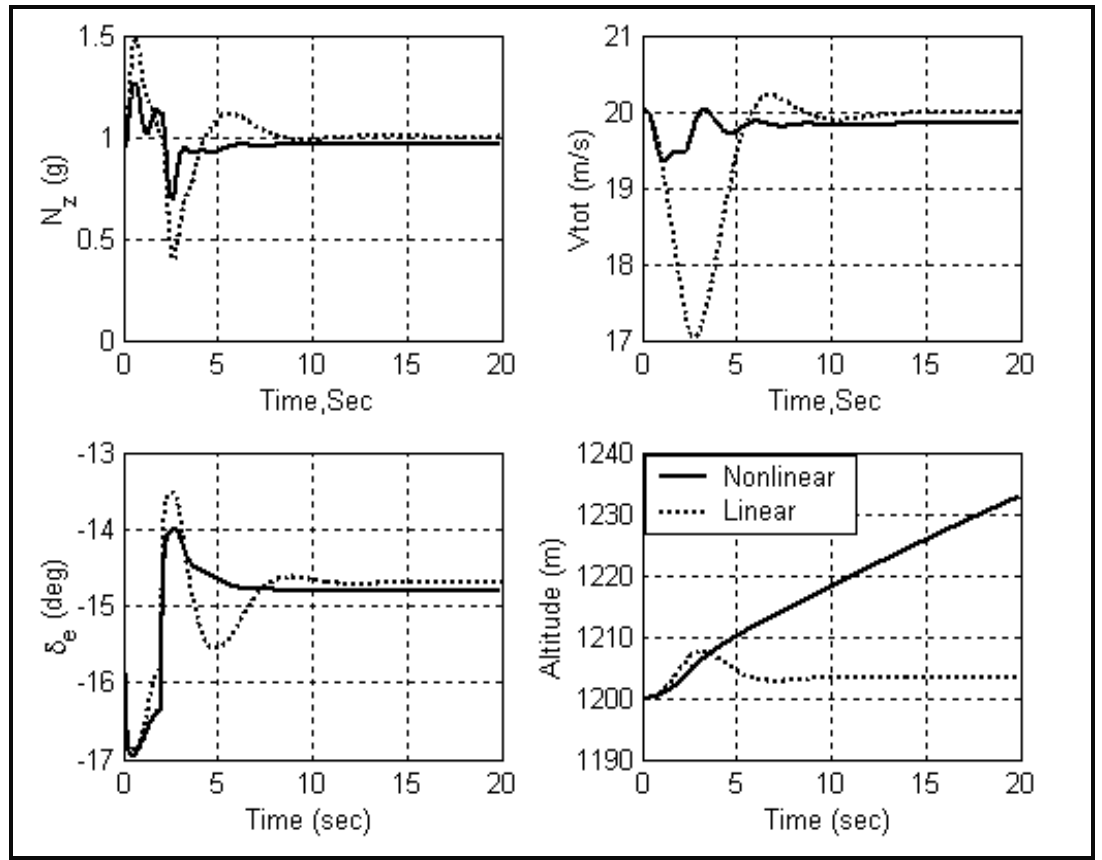

Fig. 4b Closed Loop Responses from Nonlinear and Linear Models at 20m/s 


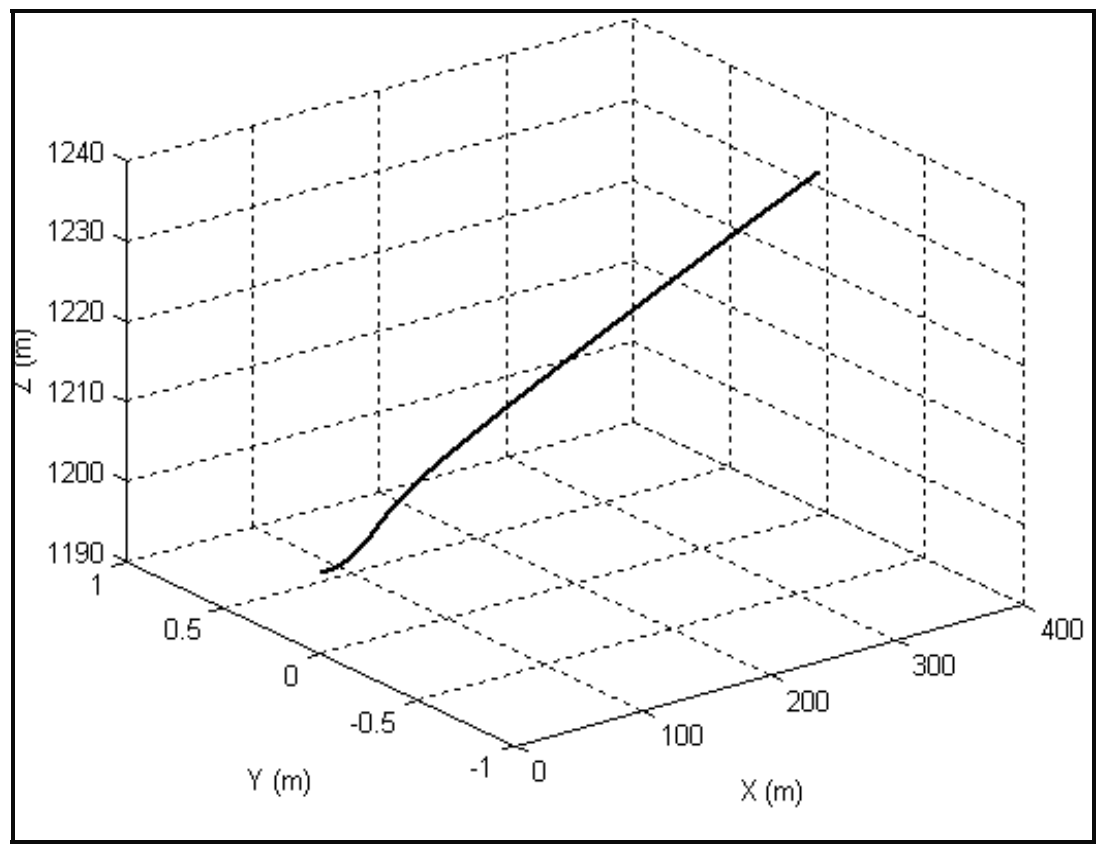

Fig. 4c Closed Loop Responses from Nonlinear and Linear Models at 20m/s
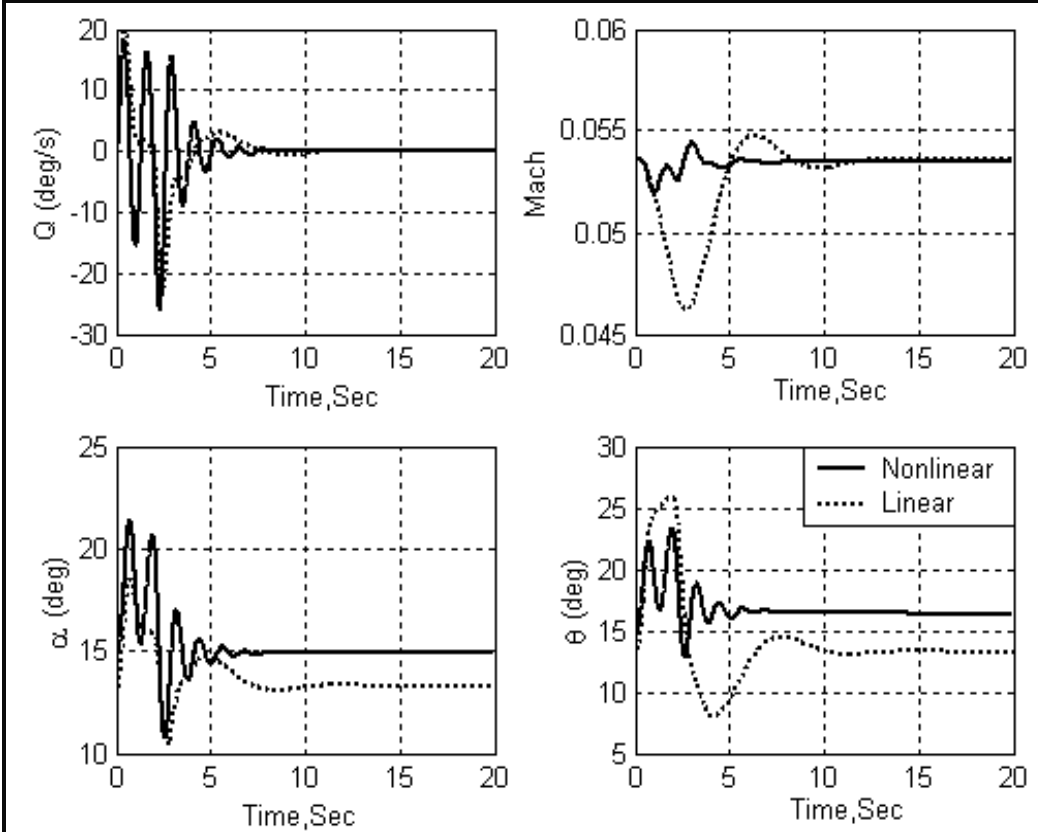

Fig. 5a Closed Loop Responses from Nonlinear and Linear Models at 16m/s 


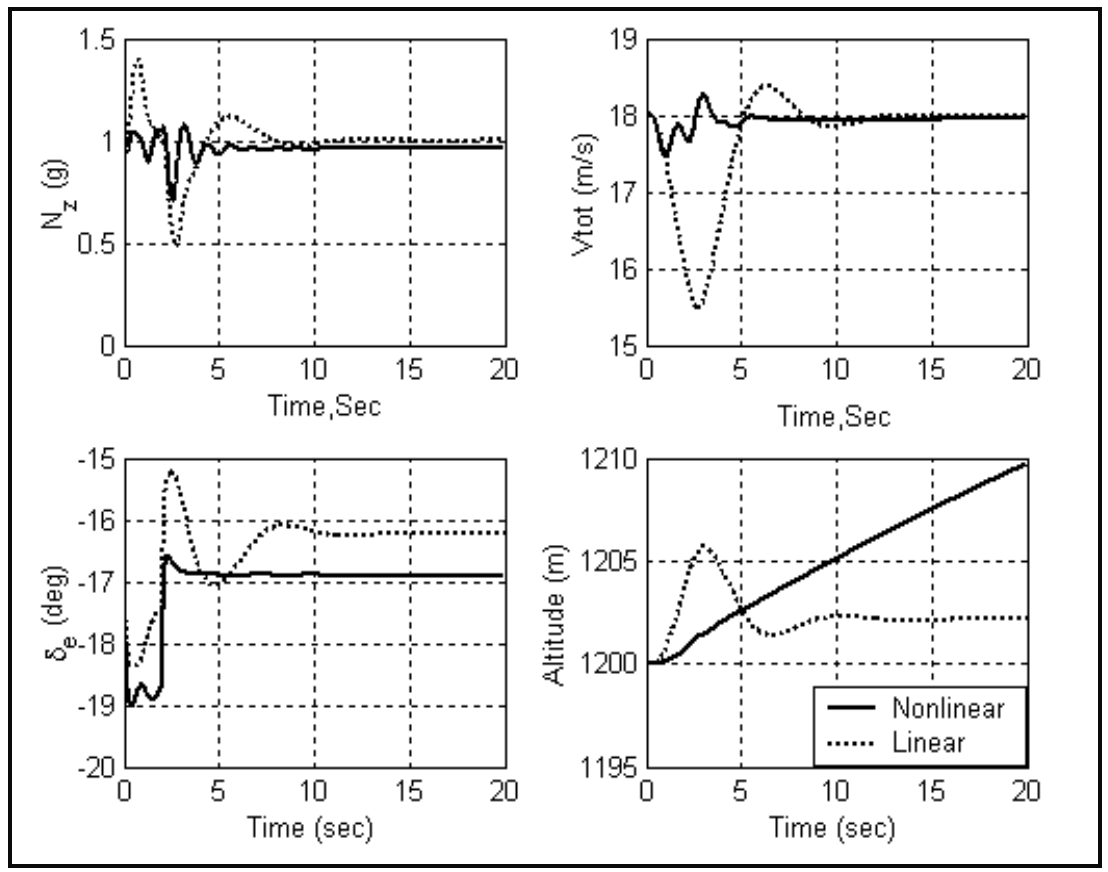

Fig. 5b Closed Loop Responses from Nonlinear and Linear Models at 16m/s

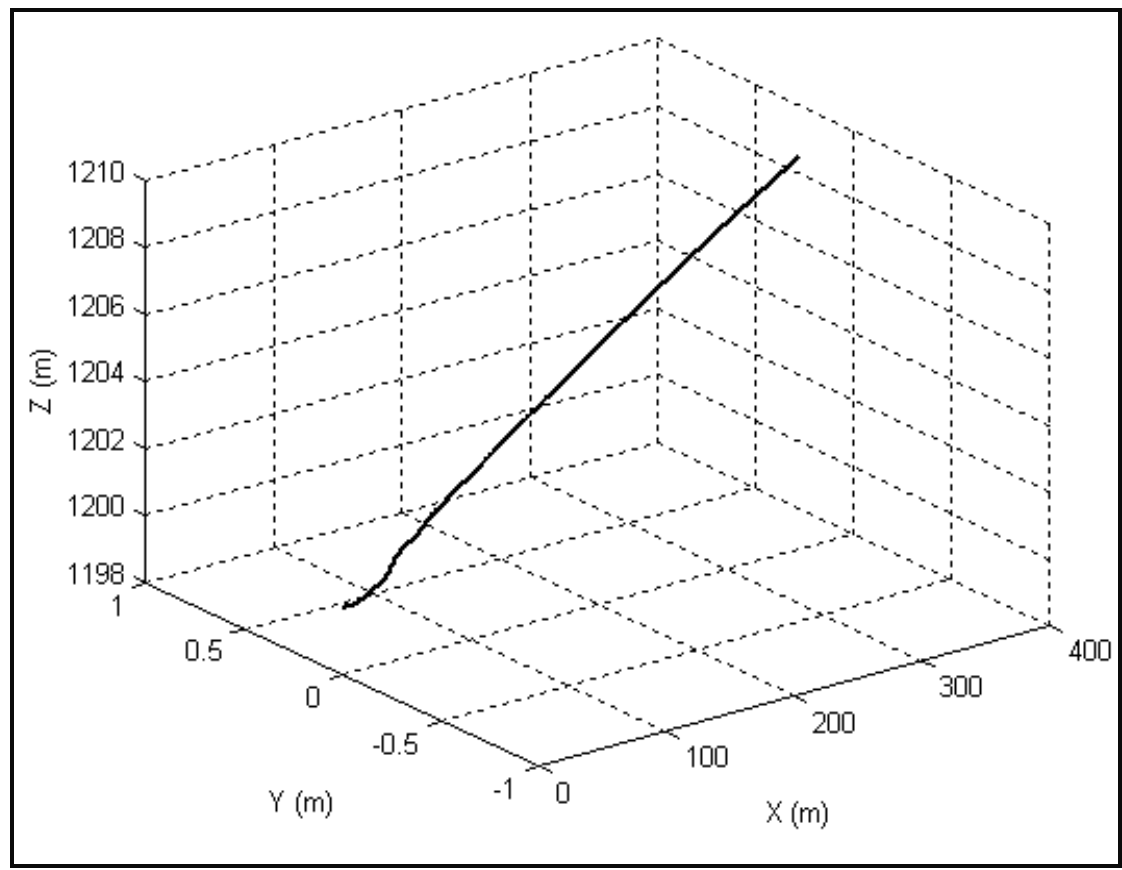

Fig. 5c Closed Loop Responses from Nonlinear and Linear Models at 16m/s 


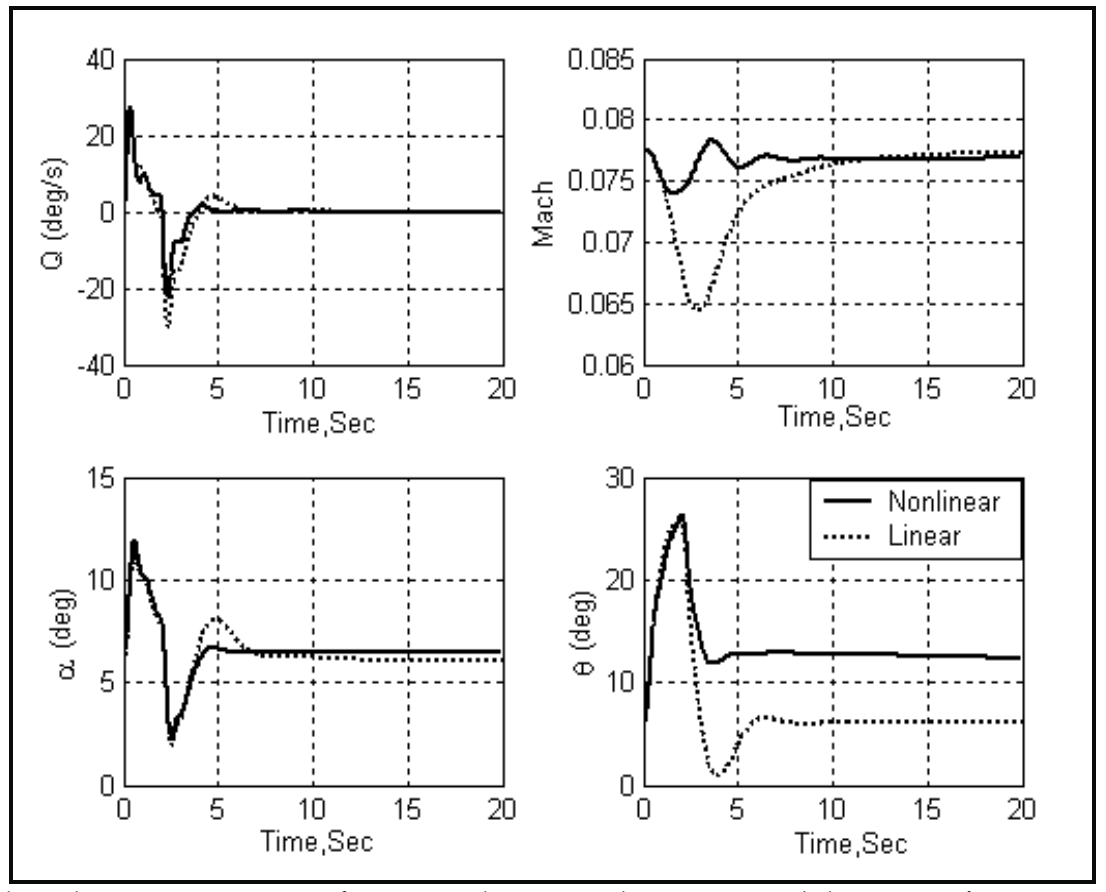

Fig. 6a Closed Loop Responses from Nonlinear and Linear Models at 26m/s

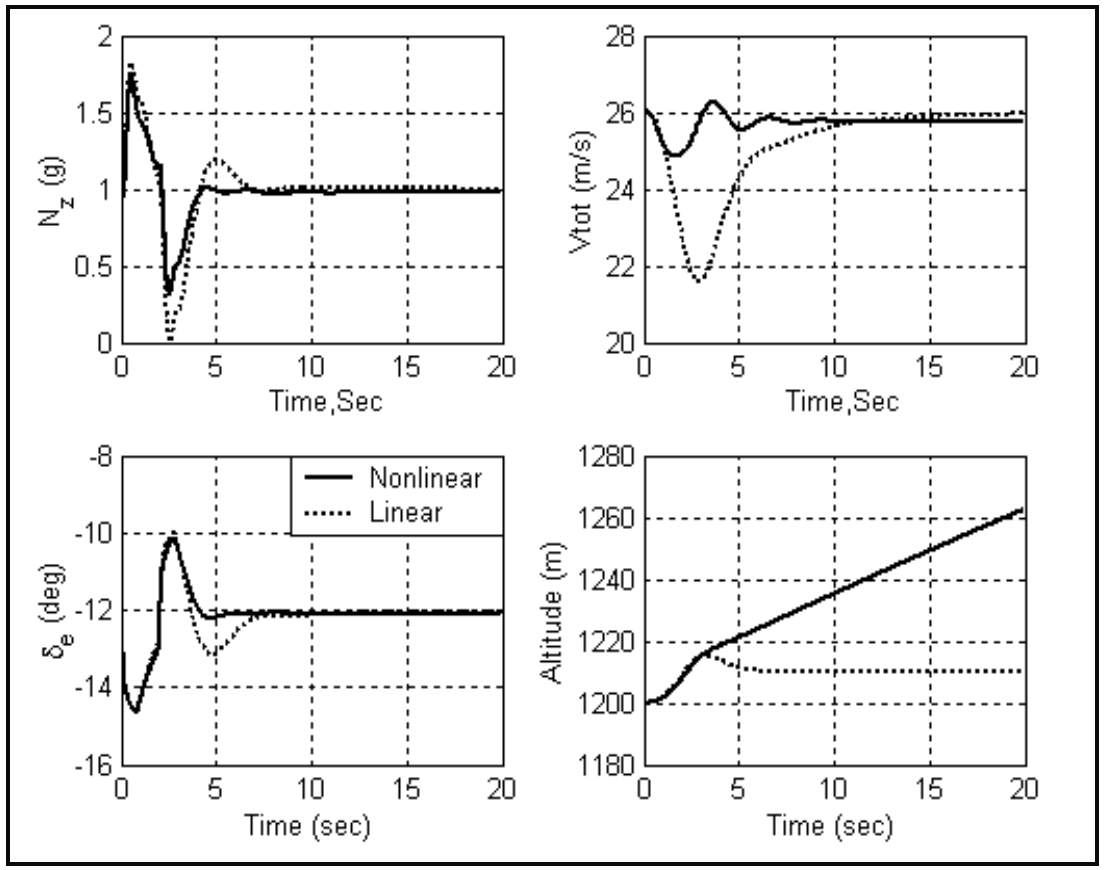

Fig. 6b Closed Loop Responses from Nonlinear and Linear Models at 26m/s 


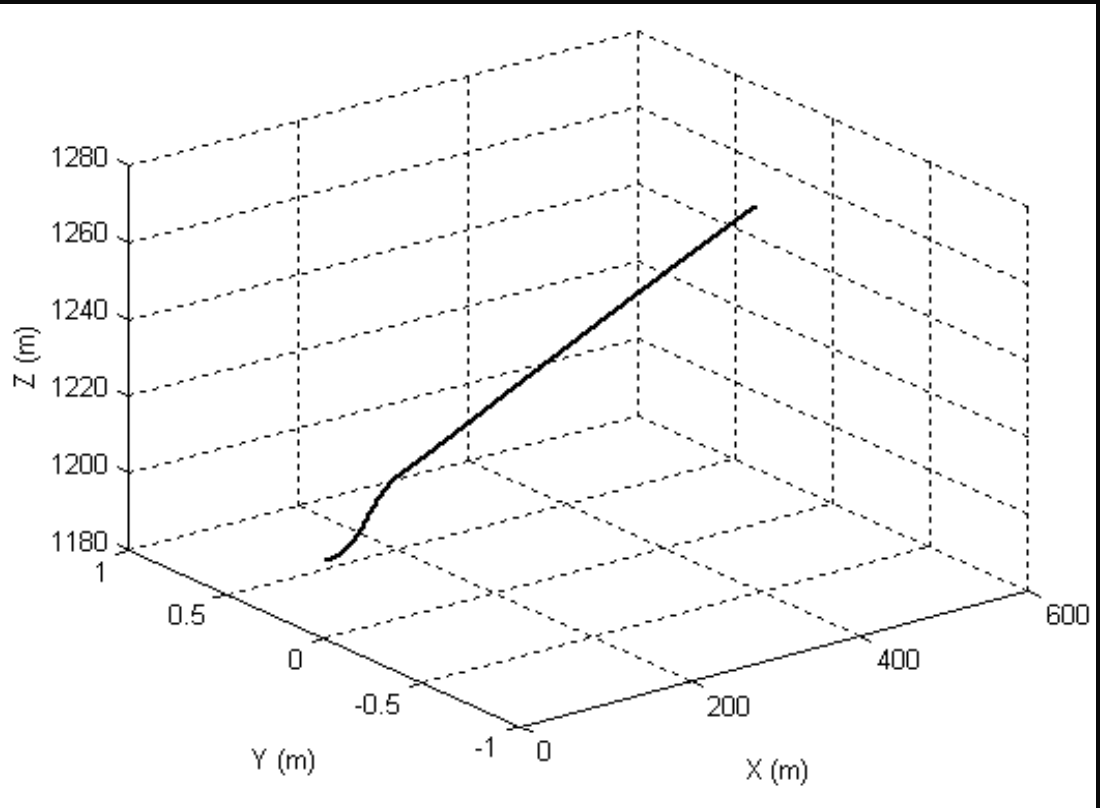

Fig. 6c Closed Loop Responses from Nonlinear and Linear Models at 26m/s

Closed loop responses simulated using linear models are also included in the same figures for the sake of comparison. At $18 \mathrm{~m} / \mathrm{s}$, responses from the nonlinear simulation are more oscillatory compared to linear simulation responses. However, at $20 \mathrm{~m} / \mathrm{s}$ and $26 \mathrm{~m} / \mathrm{s}$, the responses from nonlinear and linear simulations match well. Figures $4 c, 5 c$ and $6 c$ show the trajectory of the height variation at different flight conditions. Responses indicates that, that straight and level flight is maintained at all flight speeds, since, the gain/loss of height is very small (at $20 \mathrm{~m} / \mathrm{s}, 18 \mathrm{~m} / \mathrm{s}$ and $26 \mathrm{~m} / \mathrm{s}$, the height increases by $31 \mathrm{~m}, 9 \mathrm{~m}$ and $60 \mathrm{~m}$ respectively)

\subsubsection{Closed loop Response due to variation in Altitude}

The controller for Sarika-2 is designed based on the mathematical model derived at straight and level flight condition at an altitude of $1000 \mathrm{~m}$ above the sea level. However, the altitude at which the controller operates might be very much different from that at which it is designed. In order to analyze the degradation in performance with altitude, the aircraft is trimmed for level flight at altitudes of 1000, 1100 and $1200 \mathrm{~m}$ above sea level and its closed loop response are simulated. Figures $7 \mathrm{a}, \mathrm{b}$ and $\mathrm{c}$ shows the response of the closed loop system after trimming the aircraft at $20 \mathrm{~m} / \mathrm{s}$ for a doublet command input. 


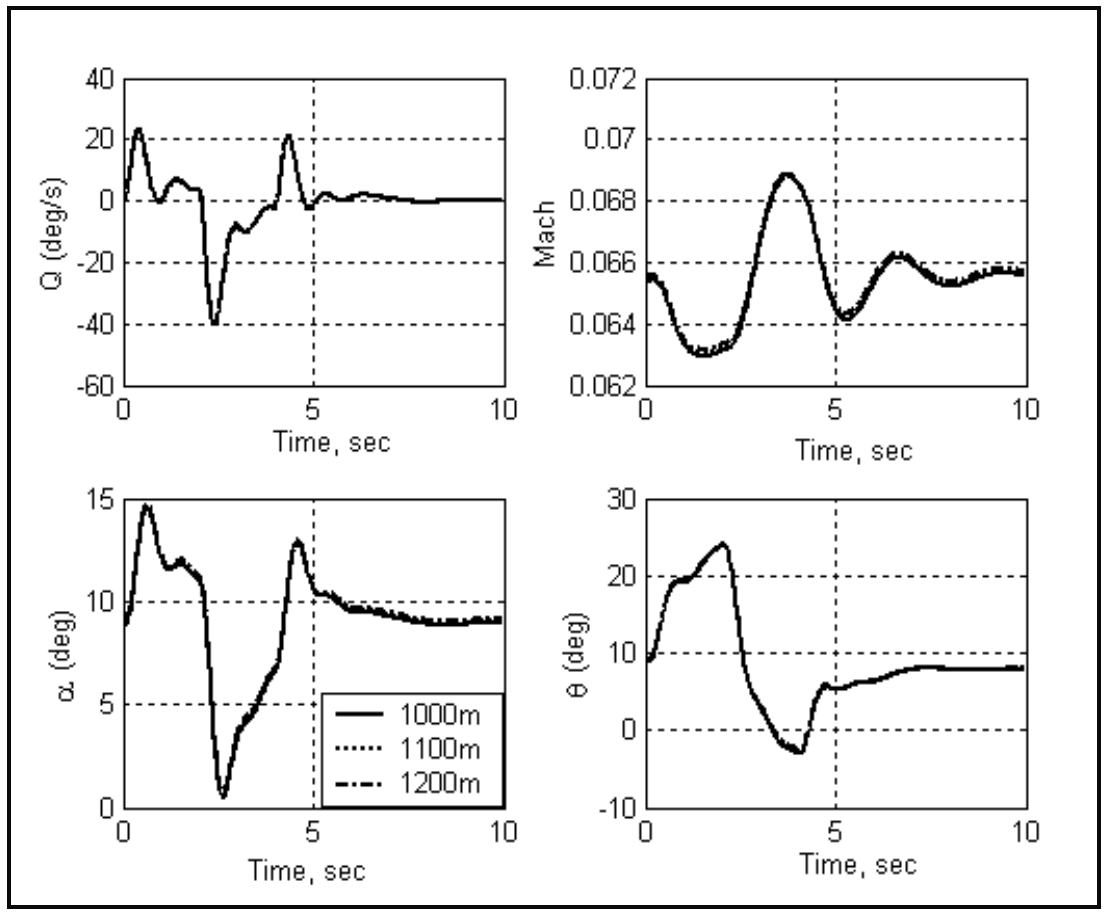

Fig. 7a Closed Loop Time Responses at different Altitude

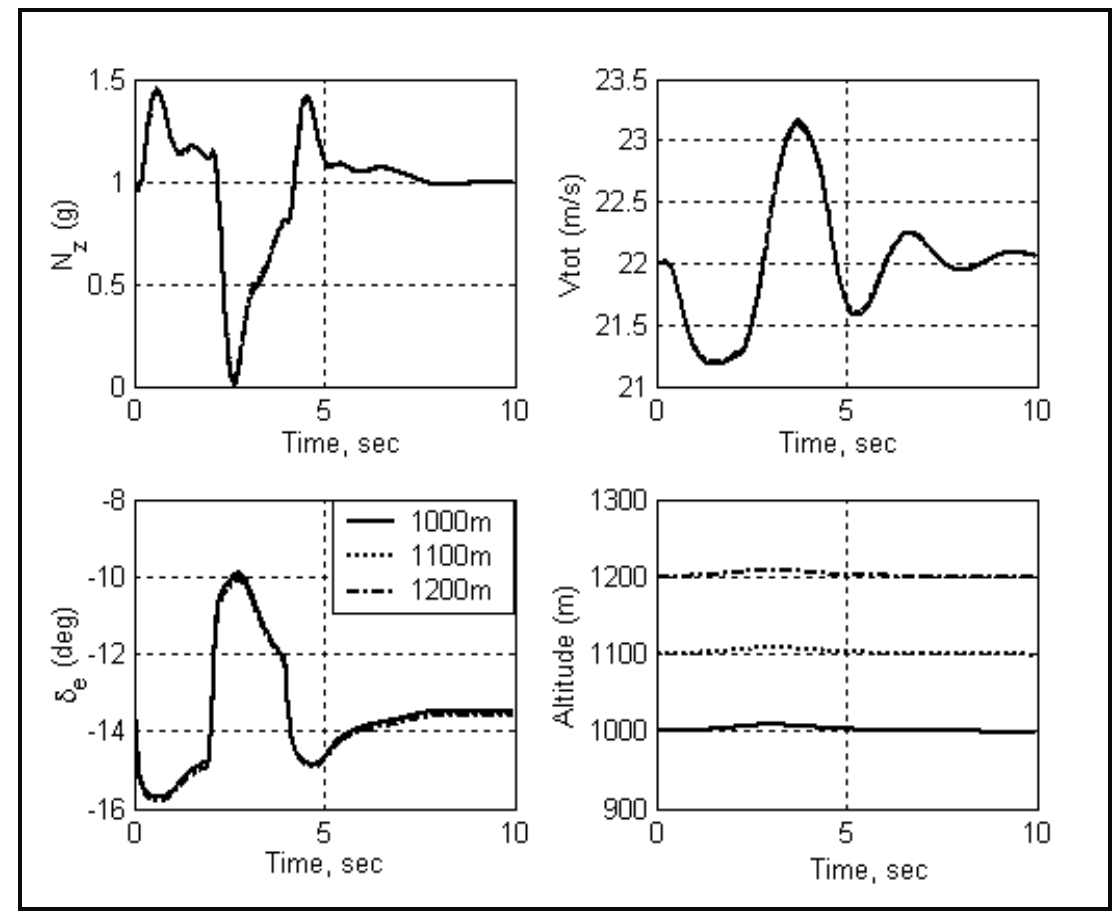

Fig. 7b Closed Loop Time Responses at different Altitude 


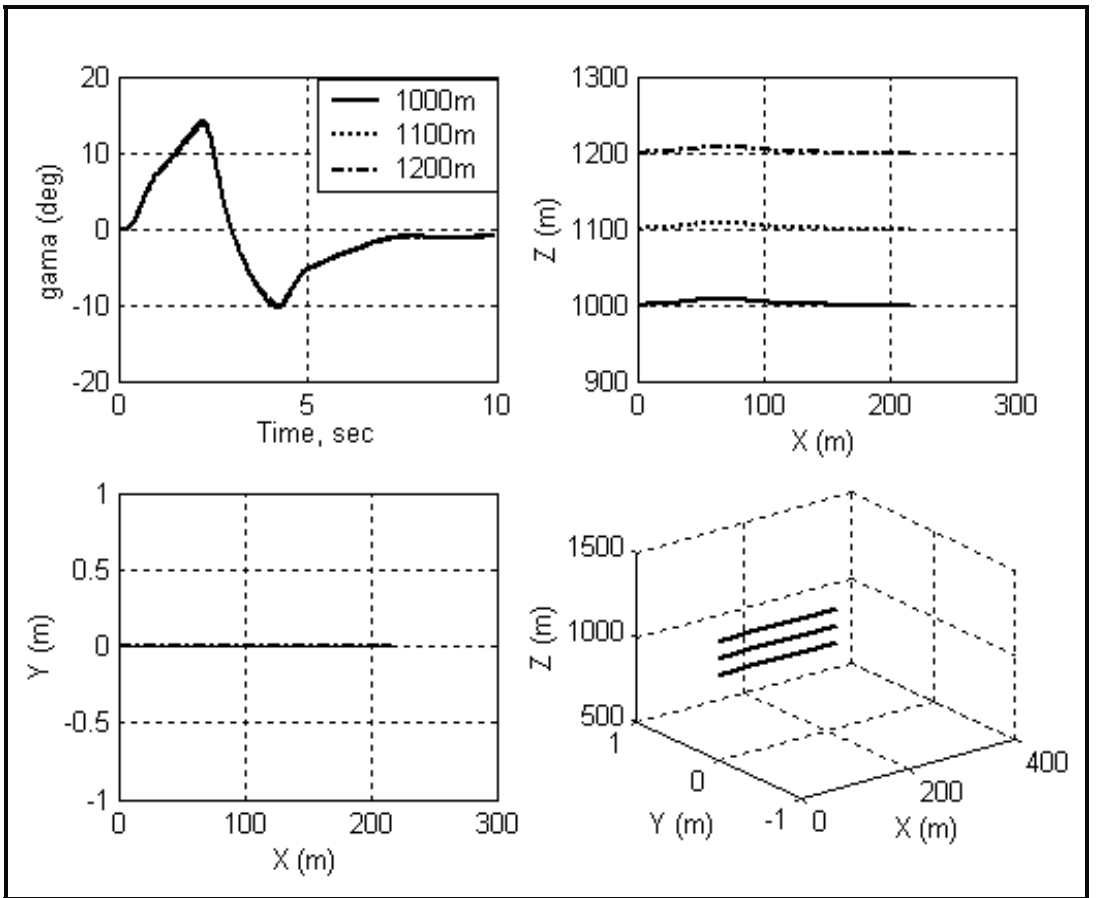

Fig. 7c Closed Loop Time Responses at different Altitude

A pulse of $-0.1 \mathrm{~ms}$ (corresponding to elevator deflection of $3.84^{\circ}$ ) and duration 2 seconds is applied at 0 seconds followed by a pulse of 0.1 milliseconds again of duration 2 seconds. However, this set of simulation does not include sensor noise and gust disturbances. Responses initiated from the trim speed of $20 \mathrm{~m} / \mathrm{s}$, shows that there is no much variation in responses due to the altitude variations. Thus, there will not be any performance degradation due to height variations in real flight. Hence, the controller is robust against the variations in altitude.

\subsection{Robust Performance Analysis with respect to real parametric uncertainty}

The affine parameter dependent uncertain model of the longitudinal dynamics is developed using the techniques mentioned before. The uncertainty levels considered in this analysis is given in the Table 3.

\begin{tabular}{|l|l|}
\hline Stability Derivatives & Control Derivatives \\
\hline$X_{\alpha}=20 \%$ & $Z_{\delta \mathrm{e}}=20 \%$ \\
$Z_{\alpha}=25 \%$ & $M_{\delta \mathrm{e}}=15 \%$ \\
$Z_{q}=10 \%$ & \\
$M_{\alpha}=50 \%$ & \\
$M_{q}=50 \%$ & \\
\hline
\end{tabular}

Table 3. Uncertainty Levels.

The robust stability and performance of the closed-loop is analyzed using LMI based tests [7,8]. With $\mathrm{H}_{2}$ controller, (eq. 24) Quadratic stability is established on $313.4852 \%$ of the 
prescribed parameter box given in Table 3. This implies that the closed-loop system is capable of withstanding at least $\pm 156.74 \%$ of plant uncertainty, without being destabilized. Similarly, testing for the existence of a parameter dependent Lyapunov function for establishing the robust stability over a given parameter range shows that $t_{\min }=-1.143 \times 10^{-4} \mathrm{~s}$ ( $t_{\min }$ should be negative for the existence of robust stability) $[7,8]$. For the same uncertainty levels, $\mu$ - upper bound is 0.2608 . Hence, largest amount of uncertainty factor $\Delta(j \omega)$ that can be tolerated without losing stability is 3.83 , which is greater than required lower bound of 1 .

\section{Conclusion}

This chapter describes design and validation of robust fixed order $\mathrm{H}_{2}$ controller for micro air vehicle named Sarika2. The controller performance is validated using linear as well as nonlinear simulation models. Simple methods to test for robust stability and performance of the closed loop system are performed using LMI based techniques. Results were proved that designed robust stability augmentation system is capable of providing the desired closed loop requirements.

\section{Reference}

Grasmeyer J. M., and Keennon M. T.,(2001) Development of the Black Widow Micro Air Vehicle, AIAA Paper 2001-0127, Published by the American Institute of Aeronautics and Astronautics, Inc.

McMicheal J.M., and Francis M.S,( 2003) Micro-Air Vehicles - Toward a New Dimension in Flight World Wide Web, http://www.darpa.mil/tto/mav/mav_auvsi.html .

Srinivasa Rao B.R., Surendranath V., and Prasanna H.R.S,(2001) Wind tunnel test results of SARIKA Airplane, Report No: AE/WT/IRR/16, Department of Aerospace Engineering, Indian Institute of .Science, Bangalore.

Bhat M. S., Meenakshi M., Govindaraju S. P., Surendranath V., and Jamadagni. H. S. (2002) Design and Development of Flight Control and Instrumentation for Micro Air Vehicle, Final Technical Report No. ARDB/MSB/TR-99-1050, Department of Aerospace Engineering, Indian Institute of Science, Bangalore.

Stoorvogel AA. (1993) The Robust $\mathrm{H}_{2}$ Control Problem: A Worst-case Design. IEEE Transactions on Automatic Control.; 38 (9): 1358- 1370

Goh K-C, Wu F. (1997) Duality and Basis Functions for Robust $\mathrm{H}_{2}$ - Performance Analysis. Automatica.; 33(11): 1949-1959.

Feron E, Apkarian P, Gahinet P (1996) Analysis and Synthesis of Robust Control Systems via Parameter-dependent Lyapunov Functions. IEEE Transactions on Automatic Control.; 41(7): 1041-1046.

Gahinet P, Nemirovski A, Laub AJ, Chilali M (1995), LMI Control Toolbox for use with MATLAB.:1.1-3.26

Green M., and Limebeer, D. J. N. (1995), Linear Robust Control, Prentice Hall, Englewood Cliffs, NJ.

Liu Y., and Anderson., B.D.O (1989), Controller Reduction: Concepts and Approaches, IEEE Transactions on Automatic Control, Vol. 34, No. 8, pp. 802-812. 
Meenakshi .M (2005), Design and Real Time Validation of Discrete Fixed Order Robust $\mathrm{H}_{2}$ Controller for Micro Air Vehicle, PhD Thesis, Dept. of Aerospace Engineering, I.I.Sc Bangalore.

Jan Roskam(1971), Flight Dynamics part 4. Roskam Aviation and Engineering Corporation Box 274 Ottawa Kansas 66067 USA:5.1-6.118.

Jan Roskam(1990), Airplane design part 6: Preliminary calculation of aerodynamic thrust and power characteristics. Roskam Aviation and Engineering Corporation Box 274 Ottawa Kansas 66067 USA: 213- 490.

Pashilkar A.A. (2003), FAST User's Manual Version 0.1, NAL PD FC 0314, Flight Mechanics \& Control Division, National Aerospace Laboratories.

Van Willigenburg. L.G and De Koning. W.L (2001), Numerical algorithms and issues concerning the discrete time optimal projection equations, European Journal of Control, Vol. 6, No. 1, pp. 93-110,. 


\title{
Six Sigma as a Quality Management Tool: Evaluation of Performance in Laboratory Medicine
}

\author{
Abdurrahman Coskun, Tamer Inal, Ibrahim Unsal and Mustafa Serteser \\ Acibadem University, School of Medicine, \\ Department of Medical Biochemistry, \\ Istanbul, Turkey
}

\section{Introduction}

In medical school, the first concept expressed to students is a Latin phrase, primum non nocere, meaning "first, do no harm." This phrase is well known among health workers and dates back to Hipocrates. However, in reality, the situation is slightly different. According to the report of the Institute of Medicine, each year in the USA, approximately 98,000 people die from medical errors (Kohn et al., 2000). Unfortunately, more people have died each year during mid-1990s from medical errors than from AIDS or breast cancer (Kohn et al., 2000). Despite this situation, we cannot say that adequate attention has been paid to the application of high standards in the healthcare sector to effectively prevent medical errors. Yet in industry, for more than a century, modern quality control has been applied to prevent errors and produce high quality goods. The result of these long-term efforts is that in many companies, the rate of errors approaches a negligible level. Regrettably, we cannot say the same thing for medical services, because the components that produce errors or defects in medical services are many more than those involved in any industrial or business sector. Despite these facts, it is clear that the quality of medical services is more important than the quality of most other goods. Consequently, healthcare professionals must pay more attention to quality than any industrial professionals do.

Among healthcare services, clinical laboratories are particularly important because physicians make their decisions mostly in accordance with laboratory results (Forsman, 1996). In this context, accurate test results are crucial for physicians and their patients. First, the laboratory must be able to produce an accurate test result before any other dimension of quality becomes important. From this point of view, the evaluation of laboratory performance is critical to maintaining accurate laboratory results (Coskun, 2007).

In clinical laboratories, we traditionally divide the total testing processes into three phases: pre-analytical, analytical, and post-analytical phases. However, the selection and interpretation of tests are also prone to errors and must be considered in the total testing process. For this reason, in laboratory medicine, we analyze the total testing process in five phases: pre-preanalytical, pre-analytical, analytical, post-analytical, and post-post-analytical phases 
(Goldschmidt, 2002). Errors that occur in each phase may affect patients negatively, and for a realistic approach, the total frequency of errors in all five phases must be calculated (Coskun, 2007). Except for the analytical phase, the quality of work in the other phases is not presently satisfactory (Coskun, 2007). In the past decade we have found that in clinical laboratories, the analytical errors made by instruments have been reduced to acceptable levels. The high quality of the analytical phase is a result of continuous efforts made by manufacturers because they must produce high-quality instruments to be competitive in the marketplace. As laboratory workers, we have to improve the quality of the other phases, especially the pre-analytical phase, to produce accurate test results for patients.

Mistakes are unfortunately a part of human nature; but fortunately, the ability to create solutions and find better alternatives is also a part of human nature. We can shift the balance toward solutions and better alternatives using modern quality-management tools such as Six Sigma.

Six Sigma methodology represents an evolution in quality assessment and management that has been implemented widely in business and industry since the mid-1980s (Westgard, 2006). Six Sigma methodology was developed by Motorola, Inc. to reduce the cost of products, eliminate defects, and decrease variability in processing. It consists of five steps: define, measure, analyze, improve, and control (DMAIC) (Westgard, 2006a; Westgard, 2006b; Brussee, 2004). These steps are universal and could be applied to all sectors of industry, business, and healthcare. The sigma value indicates how often errors are likely to occur; the higher the sigma value, the less likely it is that the laboratory reports defects or false test results. The best or "world class" processes for industry or business have a sixsigma level, which means that in such a process, fewer than 3.4 defects (or errors) occur per million products (Westgard, 2006a; Westgard, 2006b; Brussee, 2004). However, in the healthcare sector, the six-sigma level may not be adequate for many situations. For example, in blood banking or other critical medical services, an error may cause fatal or irreversible results. Thus, in medical services, the six-sigma level should not be accepted as the ultimate goal. We have to decrease the number of defects by as much as possible, and indeed, the sigma level should be higher than six. Our slogan should be 'zero defects.'

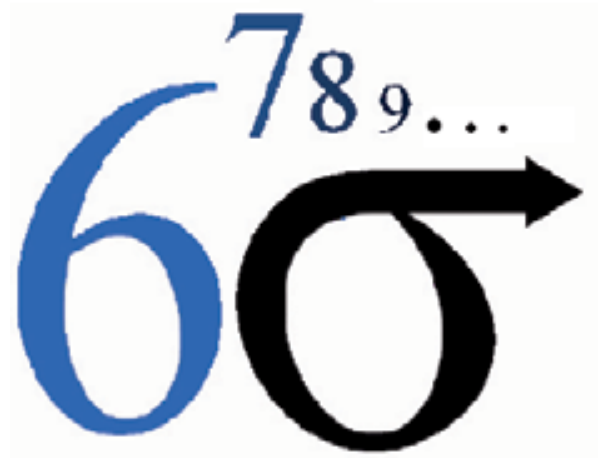

Fig. 1. Six Sigma may not be adequate for quality in healthcare sector

To calculate the sigma level of a laboratory, we have to determine the errors or defects and measure the performance of the unit or process in which we are interested. If you do not measure, you do not know, and if you do not know, you cannot manage. So Six Sigma shows us how to measure and, consequently, how to manage the laboratory. 
In this chapter we will examine the Six Sigma methodology and its application to healthcare services, particularly laboratory medicine. We will also evaluate laboratory performance using sigma metrics.

\section{Clinical Laboratories in the Healthcare Sector}

One of the most important units of the healthcare sector, particularly in hospitals, is undoubtedly clinical laboratories. Obviously, without accurate test results, physicians cannot make diagnoses or provide effective treatment. This is true even for experienced physicians. Currently, clinical laboratories affect $60 \sim 70 \%$ of all critical decisions, such as the admission, discharge, and drug therapy of patients (Forsman, 1996). Based on our experience, we believe that this rate is even higher. Despite these vital functions, in the healthcare sector, laboratory costs are a very low proportion $(5 \sim 10 \%)$ of the total cost of patient care (Forsman, 1996).

To be effective, clinical laboratories must be organized and accredited. Accreditation by independent non-profit organizations is indispensible for modern clinical laboratories. Accredited laboratories usually perform more than 500 different tests, and as many as 1500 tests may be performed in well-organized central laboratories. This means that the laboratory produces 1500 different products. This is very high in comparison with any industrial sector. Furthermore, the accuracy of each test (product) is vital because it is directly related to patient health. To obtain accurate test results, clinical laboratories are organized according to sub-disciplines such as clinical biochemistry, clinical microbiology, hematology, anatomical pathology, and genetics. Each sub-discipline may be organized further into sub-sub-disciplines. For example, clinical microbiology is further divided into immunology, virology, bacteriology, parasitology, and mycology. The organization scheme may differ from country to country and even from laboratory to laboratory. All these subdisciplines increase the diagnostic power of laboratories, which are crucial for hospitals.

Despite the vital functions of clinical laboratories, healthcare managers have not paid adequate attention to them. In addition, healthcare administrators frequently manipulate laboratories. These interventions decrease the diagnostic and competitive power of laboratories relative to other medical services.

\section{Total Testing Process}

Total testing process is a multistep process that begins and ends with the needs of the patient (Barr, 1994). The number of steps may vary according to test types and laboratory organisation. We can describe nine activity steps in laboratory medicine:

1. Test selection and ordering a laboratory test request

2. Collecting the sample (seum, plasma, urine and so on)

3. Identification

4. Transport the sample to laboratory

5. Preparation of the sample

6. Analysis

7. Reporting test results

8. Interpretation of test results

9. Action 
Historically in clinical laboratories, the total testing process was assumed to consist of only three phases:

1. Pre-analytical phase (step 2-5),

2. Analytical phase (step 6), and

3. Post-analytical phase (step 7).

Further, the pre-analytical phase contain two sub-phases:

a. Outside the laboratory (step 2-4) and

b. Within the laboratory (step 5).

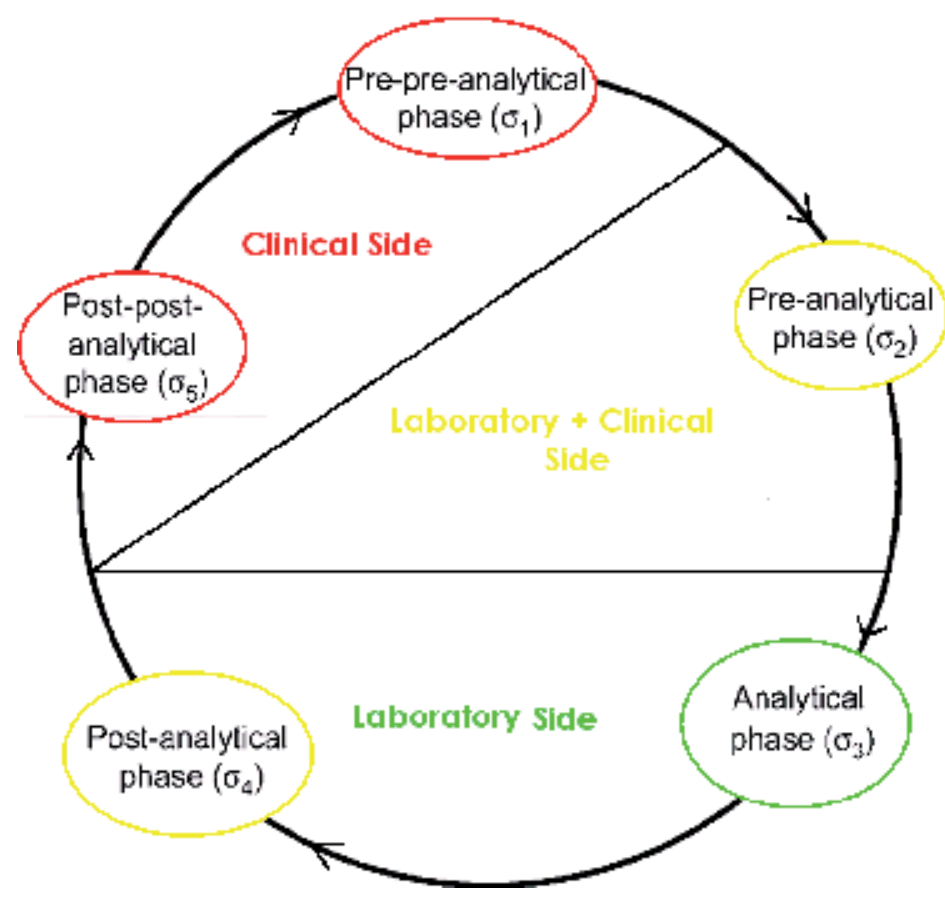

Fig. 2. Total testing process in modern clinical laboratories.

Currently this classical approach is not adequate for clinical laboratories. The total testing process begins when the patient is examined by a physician, and it ends when the patient leaves the hospital (Goldschmidt, 2002). To cover all steps in this cycle, currently we examined the total testing process in five phases. In addition to classical pre-analytical, analytical and post-analytical phases, pre-pre-analytical (step 1) and post-post-analytical phases (step 8 and 9) are also indispensable part of the total testing process. In the pre-pre-analytical phase, the physician decides which test(s) should be requested for the patient, and in the post-post-analytical phase, the physician interprets the test results. In daily practice items such as 'Pre-pre-' and 'post-post-' seem to be more abstract for many laboratory workers. Instead of these items we thought that the re-named of phases of total testing process which is listed below (Table 1) will be more useful. To evaluate laboratory performance, we must add the errors made in all phases of the total testing process. 


\begin{tabular}{|l|l|}
\hline \multicolumn{1}{|c|}{ Current names } & \multicolumn{1}{c|}{ Recommended names } \\
\hline Pre-pre-analytical phase & Clinical pre-analytical phase \\
\hline Pre-analytical phase & Laboratory pre-analytical phase \\
\hline Analytical hase & Analytical phase \\
\hline Post-analytical phase & Laboratory post-analytical phase \\
\hline Post-post-analytical phase & Clinical post-analytical phase \\
\hline
\end{tabular}

Table 1. Phases of total testin process. The names that we recommend is more meaningful and is not abstract

\section{Errors in Laboratory Medicine}

The report To Err is Human: Building a Safer Health System by Kohn et al. was a milestone in the history of quality and safety in the healthcare sector. The report stated, "Each year, more than 1 million preventable injuries and 44,000-98,000 preventable deaths occur in the United States alone" (Kohn, 2000). This report shocked many healthcare managers and officials, as they had not considered this reality. Furthermore, this report has broken the silence that has surrounded and masked medical errors. Since 1999, reducing medical errors and improving patient safety have become an international concern. The World Health Organization (WHO) has launched the World Alliance for Patient Safety (www.who.int/patientsafety) in response to increasing public and officials' awareness of this issue worldwide. In the United States, approximately 2 trillion dollars are spent on medical care each year, and the health standards are higher than in many other countries. Therefore, we postulate that preventable injury and death rates due to medical errors in many countries are higher than those in the United States.

To make a comparison, in 1999 (the year when the report was published), nobody died due to errors in the aviation sector in the United States. For healthcare managers, 1999 was a time when they had to accept reality. One of the main differences between the healthcare and aviation sectors is the application of quality assessment. Unfortunately, healthcare managers do not pay as much attention to quality assessment as do aviation managers. In the aviation sector, an error that has accident potential may mean the end of a company. The same is not true for a hospital. In addition, if a pilot makes a mistake that causes the plane to crash, he or she dies along with the passengers, but a doctor does not die when he or she kills a patient because of a mistake. To decrease medical errors to acceptable levels, physicians and other healthcare staff must periodically be strictly audited, both professionally and legally.

The reactions and approach of people to hospitals and aviation companies are quite different. The approach of people to hospitals is more psychological than logical. Community reactions to deaths in hospital and to deaths in accidents are not the same. The first may be accepted as an ordinary event, whereas this is not the case for an accident. Despite these realities, we cannot claim that adequate attention has been paid to quality in the healthcare sector. For example, Six Sigma quality management has been applied to almost all major industrial organizations since the mid-1980s. Unfortunately, as far as we know, no international hospital has applied Six Sigma quality management. This is partly due to the different types of work, services, and products produced in hospitals versus companies. However, despite all these differences, Six Sigma quality management can be 
easily applied to any hospital because Six Sigma quality management has no restrictions or limits that are not suitable for hospitals or any healthcare organization (Westgard, 2006a; Nevalainen, 2000). Six Sigma quality management is universal and can be applied to all sectors easily.

How much are clinical laboratories responsible for medical errors? Unfortunately we have limited data about medical errors originating from clinical laboratories (Bonini, 2002; Plebani, 1997). General practitioners from Canada, Australia, England, The Netherlands, New Zealand, and the United States reported medical errors in primary care in 2005. For all medical errors, the percentage of errors originating from the laboratory and diagnostic imaging were $17 \%$ in Canada and $16 \%$ in the other reporting countries. For 16 of the reported errors $(3.7 \%)$, patients had to be hospitalized, and in five cases $(1.2 \%)$, the patients died (Rosser, 2005). This result shows that erroneous laboratory results are not innocent and can lead to the death of patients. Therefore, we have to examine the nature and causes of laboratory errors in detail and find realistic solutions.

We can classify errors as errors of commission and of omission (Bonini, 2002; Plebani, 2007; Senders, 1994). Today, many scientists focus on errors of commission, such as wrong test results and delayed reporting of results. Many physicians and laboratory managers believe that all errors are errors of commission. However, the reality is quite different. Errors of omission are the dark side of known errors, and we have to include this category of errors in the overall error concept. Sometimes errors of omission may be more serious and cause patient death. For example, if a physician cannot make a diagnosis and discharges a patient with cancer, diabetes, or a serious infectious disease such as hepatitis $\mathrm{C}$ virus (HCV) or human immunodeficiency virus (HIV) because of inadequate test requests, he/she commits a serious error, and the result may be catastrophic for the patient. Consequently, we cannot neglect errors of omission. Unfortunately, this is not easy because, due to their nature, errors of omission are hidden, and it is quite difficult to quantify them.

In contrast to errors of omission, errors of commission can be measured. But with errors of commission, we have a limited ability to measure all components of the errors because these errors are not homogenous, and we have no method for measuring the errors exactly in the pre- and post-analytical phases. It is clear that "if you cannot measure you do not know, and if you do not know you cannot manage." This side of errors in laboratory medicine is also a weakness in contemporary quality assessment.

Only when we can measure the errors of commission and of omission in clinical laboratories exactly and take prevention actions will it be possible for hospitals to compete with the aviation sector.

\section{Quality Control in Laboratory Medicine}

Quality-control principles that are currently being applied in laboratory medicine originated in industry, and the philosophy behind them is also industry based (Westgard, 2006a; Westgard, 2006b; Westgard, 1991). These principles were developed with regard to industrial, rather than medical, requirements. Consequently, the goals and problem-solving methods are not appropriate to the healthcare sector. Despite this, the application of quality assessment in laboratory medicine has dramatically increased the reliability of test results and the diagnostic power of clinical laboratories. 
Within the five phases of the total testing process, quality-control rules, especially statistical ones, are applied properly only in the analytical phase, especially because it is much easier to apply statistical quality principles to machines and data than to people. No written quality principles have been issued by the IFCC or any other international laboratory organization for the pre-analytical or post-analytical phases. In these two phases, personal or organizational experience is more commonly a guide than are written principles. For the pre-pre-analytical and post-post-analytical phases, no quality rules are imposed to prevent errors. In fact, in these phases, we do not even know the error rates in detail. However, according to a limited number of studies, the error rates in these two phases are much higher than those in other phases of the total testing process (Goldschmidt, 2002).

Quality management means more than statistical procedures; it involves philosophy, principles, approaches, methodology, techniques, tools, and metrics (Westgard, 2006b). Without the physician's contribution, it is impossible to solve all the problems originating from laboratories (Coskun, 2007). In fact, laboratory scientists can solve only problems of the analytical and, to a degree, the pre-analytical and post-analytical phases. The pre-analytical and post-analytical phases are the gray side, and the pre-pre- and post-post-analytical phases are the dark side of clinical laboratories.

It is easier to apply quality principles to clinical laboratories than to other clinical services, such as surgery and obstetrics and gynecology, because laboratory scientists use technology more intensively than do other medical services. However, even within clinical laboratories, we cannot apply quality principles to all sub-disciplines equally. For example, we can apply quality principles to clinical biochemistry or hematology quite readily, but the same thing cannot be done for anatomical pathology. Consequently, the error rate in anatomical pathology is higher than that in clinical biochemistry.

Errors in analytical phases have two main components: random and systematic errors. Using these two components, we can calculate the total error of a test as

$$
\mathrm{TE}=\mathrm{Bias}+1.65 \mathrm{CV}
$$

where TE is total error, bias and CV (coefficient of variation) are the indicator of systematic and random errors respectively (Westgard, 2006b, Fraser, 2001).

For the pre- and post-analytical phases, we can prepare written guidelines and apply these principles to clinical laboratories. Then, we can count the number of errors within a given period or number of tests. For the pre-pre- and post-post-analytical phases, we do not have the experience to prepare guidelines or written principles. However, this does not mean that we can do nothing for these two phases. Laboratory consultation may be the right solution (Coskun, 2007).

\section{Six Sigma in Laboratory Medicine}

The sources of medical errors are different from those of industrial errors. To overcome the serious errors originating in clinical laboratories, a new perspective and approach seem to be essential. All laboratory procedures are prone to errors because in many tests, the rate of human intervention is higher than expected. It appears that the best solution for analyzing problems in clinical laboratories is the application of Six Sigma methodology. 
In the mid-1980s, Motorola, Inc. developed a new quality methodology called "Six Sigma." This methodology was a new version of total quality management (TQM) (Deming, 1982), and its origins can be traced back to the 1920s. At that time, Walter Shewhart showed that a three-sigma deviation from the mean could be accepted without the need to take preventive action (Shewhart, 1931). For technology in the 1920s, a three-sigma deviation may have been appropriate, but by the 1980s, it was inadequate. Bill Smith, the father of Six Sigma, decided to measure defects per million opportunities rather than per thousand. Motorola developed new standards and created the methodology and necessary cultural change for Six Sigma (Westgard, 2006a; Harry, 2000). Due to its flexible nature, since the mid-1980s, the Six Sigma concept has evolved rapidly over time. It has become a way of doing business, rather than a simple quality system. Six Sigma is a philosophy, a vision, a methodology, a metric, and a goal, and it is based on both reality and productivity.

Regrettably, we cannot say that Six Sigma methodology is being applied to the healthcare sector as widely as it is to business and industry more generally. However, we do not suggest that this is due to shortcomings in Six Sigma methodology. Based on our experience, we suggest that it is due to the approaches of healthcare officials. Within medical disciplines, laboratory medicine is the optimal field for the deployment of Six Sigma methodology.

Total quality management was popular by the 1990s, and it application in clinical laboratories is well documented (Westgard, 2006a; Westgard, 1991; Berwick, 1990). The generic TQM model is called "PDCA": plan, do, check, and act. First, one must plan what to do, and then do it. The next step is to check the data, and in the last step, act on the results. If this does not achieve a satisfactory result, one must plan again and follow the remaining steps. This procedure continues until the desired result is obtained.

The Six Sigma model is similar to TQM. The basic scientific model is "DMAIC": define, measure, analyze, improve, and control. In comparison with TQM's PDCA, we can say that define corresponds to the plan step, measure to the do step, analyze to the check step, and improve to the act step. The Six Sigma model has an extra step, control, which is important in modern quality management. With this step, we intend to prevent defects from returning to the process. That is, if we detect an error, we have to solve it and prevent it from affecting the process again. With this step, we continue to decrease the errors effectively until we obtain a desirable degree of quality (Westgard, 2006a; Gras, 2007).

Six Sigma provides principles and tools that can be applied to any process as a means to measure defects and/or error rates. That is, we can measure the quality of our process or of a laboratory. This is a powerful tool because we can plan more effectively, based on real data, and manage sources realistically.

\section{Sigma Metrics}

The number of errors or defects per million products or tests is a measure of the performance of a laboratory. Sigma metrics are being adopted as a universal measure of quality, and we can measure the performance of testing processes and service provision using sigma metrics (Westgard, 2006a).

Usually, manufacturers or suppliers claim that their methods have excellent quality. They praise their instruments and methods, but the criteria for this judgment frequently remain vague. Furthermore, in the laboratory, method validation studies are often hard to interpret. Many data are generated that can be used; many statistics and graphs are produced. Nevertheless, after all this laborious work, no definitive answer about the performance of 
the method is available. Although many things remain to be improved, statistical quality control procedures have significantly enhanced analytical performances since they were first introduced in clinical laboratories in the late 1950s. Method validation studies and application of quality control samples have considerably reduced the error rates of the analytical phase (Levey, 1950; Henry RJ, 1952). A simple technique that we can use in our laboratories is to translate the method validation results into sigma metrics (Westgard, 2006a; Westgard, 2006b). Performance is characterized on a sigma scale, just as evaluating defects per million; values range from 2 to 6 , where "state of the art" quality is 6 or more. In terms of Six Sigma performance, if a method has a value less than three, that method is considered to be unreliable and should not be used for routine test purposes. A method with low sigma levels would likely cost a laboratory a lot of time, effort, and money to maintain the quality of test results. Sigma metrics involve simple and minimal calculations. All that is necessary is to decide the quality goals and calculate the method's imprecision $(\mathrm{CV}$, coefficient of variation) and bias levels as one would ordinarily do in method validation studies. Then, using the formula below, the sigma level of the method in question can readily be calculated:

$$
\text { Sigma }=\left(\mathrm{TE}_{\mathrm{a}}-\text { bias }\right) / \mathrm{CV}
$$

where $\mathrm{TE}_{\mathrm{a}}$ is total error allowable (quality goal), bias and CV (coefficient of variation) are the indicator of systematic and random errors respectively.

For example, if a method has a bias of $2 \%$, a CV of $2 \%$, and $\mathrm{TE}_{\mathrm{a}}$ of $10 \%$, the sigma value will be $(10-2) / 2=4$. This calculation needs to be done for each analyte at least two different concentrations.

\section{Evaluation of Laboratory Performance Using Sigma Metrics}

Although the activities in laboratory medicine are precisely defined and therefore are more controllable than many other medical processes, the exact magnitude of the error rate in laboratory medicine has been difficult to estimate. The main reason for this is the lack of a definite and universally accepted definition of error. Additionally, the bad habits of underreporting errors and insufficient error-detection contribute to the uncertainty in error rates. The direct correlation between the number of defects and the level of patient safety is well known. However, number of defects alone means little. It is important to classify the defects first, and then to count the number of defects and evaluate them in terms of Six Sigma.

There are two methodologies and both are quite useful in clinical laboratories to measure the quality on the sigma-scale (Westgard, 2006a). The first one involves the inspecting the outcome and counting the errors or defects. This methodology is useful in evaluation of all errors in total testing process, except analytical phase. In this method, you monitor the output of each phase, count the errors or defects and calculate the errors or defect per million and then convert the data obtained to sigma metric using a standard Six Sigma benchmarking chart (Table 2). The second approach is useful especially for analytical phase. To calculate the sigma level of the process as described in equation (II) we have to measure and calculate some variables: bias (systematic errors), imprecision (CV, random errors) and total error allowable. 


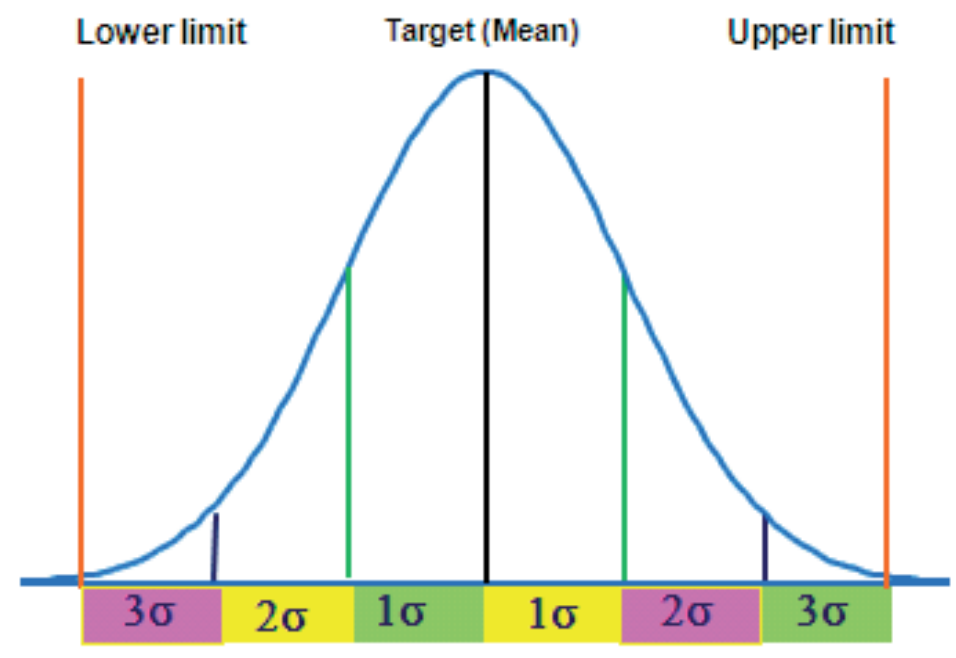

Fig. 3. A 3 sigma process.

The laboratory is responsible for the whole cycle of the testing process, starting from the physician's ordering a laboratory investigation to the use of the test results on behalf of the patient. To find realistic and patient based solution, total testing process, mentioned above, are examined in five main steps: pre-pre-analytical-, pre-analytical-, analytical, postanalytical and post-post-analytical phases (Figure 1). We can also analyze each step in detail. For example pre-analytical processes to be monitored include patient preparation, specimen collection, labeling, storage, transportation, rejection, and completeness of requisitions. The errors in each step can be monitored and consequently the performance of the step can be calculated.

The error rate in each step is quite different. For example the average error rates for the preanalytical, analytical, and post-analytical phases were reported by Stroobants and Goldschmidt as 2.0\% (Stroobants, 2003), 0.2\% (Stroobants, 2003), and 3.2\% (Goldschmidt, 2002) respectively. However the average error rates in pre-pre- and post-post-analytical phases are very high (Bonini, 2002; Stroobants, 2003; Dighe, 2007). Stroobants and co-workers reported that, in the pre-pre- and post-post-analytical phases the average error rate are approximately $12 \%$ and 5\% respectively (Stroobants, 2003). Among all the phases of a testing process, the analytical phase presents the lowest number of possible errors. Now if we calculate sigma level for only analytical phase we'll obtain 4.4 sigma for a $0.2 \%$ error rate which initially appear to be adequate. However this value does not reflect the reality and even mask it. Because analytical phase is not represent the total testing process and it is only a part of total testing process. However in many clinical laboratories, only analytical errors are taken into account and the laboratory performance are calculated usually based on only error rates in analytical phase. Consequently sigma is calculated for the analytical phase of a testing process. In this situation the laboratory manager may assume that the performance of laboratory is acceptable and he/she may not take any preventive actions but the reality is quite different.

The total error frequency of each phase must be calculated separately, and then expressed as error per million (epm) (Coskun, 2007). It should be noted that the characteristics of errors in all phases of total testing process are not homogenous. For example errors in the analytical 
phase show a normal distribution, whereas errors in other phases are binomially distributed. For this reason, errors in each phase of the total testing process should be treated as binomially distributed and summed. Then the total errors calculated for the total testing process can be converted to sigma levels using the standard Six Sigma benchmarking chart (Table 2) (Coskun, 2007).

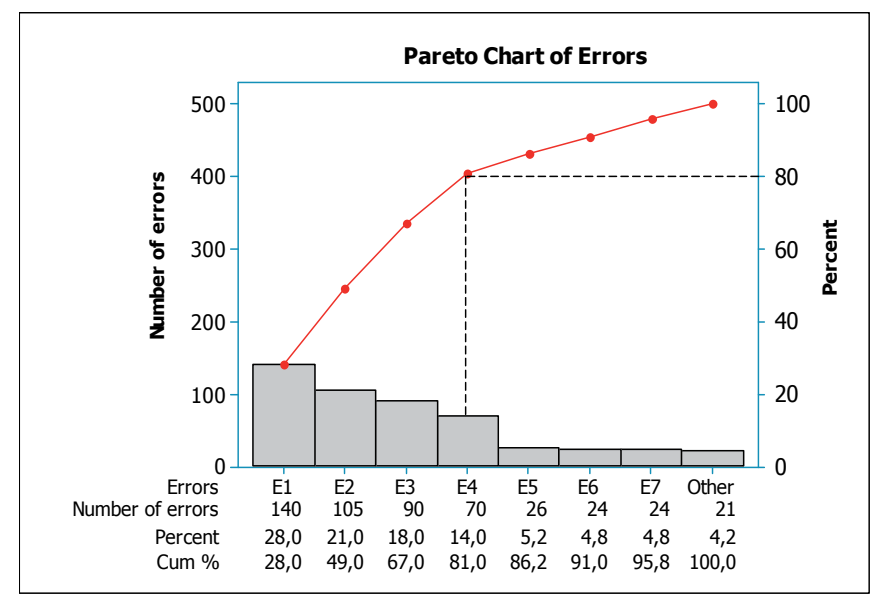

Fig. 4. Pareto chart. The chart was prepared for the source of 10 different errors. In the figure $80 \%$ of problems stem from only 4 sources.

The errors in clinical laboratories may originate from several sources. In this situation it is not cost effective and logical to deal with all error sources. Because, there may be numerous trivial sources of errors. Instead, we should deal with the sources which cause more errors. For this purpose we should use Pareto Chart to decide the most significant causes of errors (Nancy, 2004). According to Pareto principle $80 \%$ of problems usually stem from $20 \%$ of the causes and this principle is also known as $80 / 20$ rule. Thus if we take preventive action for $20 \%$ major sources of errors then $80 \%$ of errors will be eliminated (Figure 4 ).

\begin{tabular}{|cc|}
\hline Sigma Metric & Defects per million \\
1.0 & 698,000 \\
2.0 & 308,000 \\
2.5 & 159,000 \\
3.0 & 66,800 \\
3.5 & 22,750 \\
4.0 & 6,210 \\
4.5 & 1,350 \\
5.0 & 233 \\
5.5 & 32 \\
6.5 & 3.4 \\
\hline
\end{tabular}

Table 2. Sigma value of defects per million products or tests

To estimate the sigma level of errors, a trustworthy (reliable) technique to collect data is needed. Feedback from persons involved in any part of this cycle is crucial. The main point in collecting data is to encourage staff to acknowledge and record their mistakes. Then, we 
can count the mistakes; turn them into sigma values by calculating defects per million, and start to take preventive actions to prevent the same mistakes being repeated.

\section{Lean Concept}

In recent years, special emphasis has been placed on enhancing patient safety in the healthcare system. Clinical laboratories must play their role by identifying and eliminating all preventable adverse events due to laboratory errors to offer better and safer laboratory services. All ISO standards and Six Sigma improvements are aimed at achieving the ultimate goal of zero errors. The main idea is to maximize "patient value" while reducing costs and minimizing waste. The "lean concept" means creating greater value for customers (i.e., patients, in the case of laboratories) with fewer resources. A lean organization focuses on creating processes that need less space, less capital, less time, and less human effort by reducing and eliminating waste. By "waste," we mean anything that adds no value to the process. Re-done tasks, transportation of samples, inventory, waiting, and underused knowledge are examples of waste. One of the slogans of the lean concept is that one must "do it right the first time." Lean consultants start by observing how things work currently, and they then think about how things can work faster. They inspect the entire process from start to finish and plan where improvements are needed and what innovations can be made in the future. Finally, they subject this to a second analysis to find ways to improve the process. Lean projects can generate dramatic reductions in turnaround times as well as savings in staffing and costs. It is said that 'Time is money.' However, in laboratory medicine, time is not only money. Apart from correct test results, nothing in the laboratory is more valuable than rapid test results. The turnaround time of the tests is crucial to decision making, diagnoses, and the earlier discharge of patients. Although Six Sigma, and the lean concept look somewhat different, each approach offers different advantages, and they do complement each other. The combination of Lean with Six Sigma is critical to assure the desirable quality in laboratory medicine for patients benefit and safety.

Taken together, Lean Six Sigma combines the two most important improvement trends in quality science: making work better (using Six Sigma principles) and making work faster (using Lean Principles) (George, 2004).

\section{Laboratory Consultation}

The structure of laboratory errors is multi-dimensional. As mentioned previously, the total testing process has five phases, and errors in each phase contribute to errors in test results. Laboratory scientists predominantly focus on the analytical phases. Similarly, physicians focus on pre-pre-analytical and post-post-analytical phases. Errors of omission primarily occur in the pre-pre-analytical phase. A large proportion of errors of commission also occur in the pre-pre- and post-post-analytical phases. To decrease laboratory errors efficiently, consultation and appropriate communication are crucial (Coskun, 2007; Witte, 1997; Jenny, 2000).

Physicians, laboratory scientists or managers alone cannot overcome all laboratory errors. Errors outside laboratories which are the biggest part of total errors result from a lack of interdepartmental cooperation and organizational problems. As mentioned above the highest error rates in total testing process occur in pre-pre- and post-post-analytical phases. 
If we improve the communication between the laboratory and clinicians we may solve laboratory errors efficiently and consequently increase the performance of the laboratory. We should identify key measures to monitor clinical structures, processes, and outcomes. In addition to clinicians, laboratory scientists need help of technicians for laboratory information system and other technical subjects. The error rates in the post-analytical phase have also been significantly improved by the widespread use of laboratory information systems and computers with intelligent software.

\section{Conclusions}

To solve analytical or managerial problems in laboratory medicine and to decrease errors to a negligible level, Six Sigma methodology is the right choice. Some may find this assertion too optimistic. They claim that Six Sigma methodology is suitable for industry, but not for medical purposes. Unfortunately, such claims typically come from people who never practiced Six Sigma methodology in the healthcare sector. As mentioned previously, if we do not measure, we do not know, and if we do not know, we cannot manage. The quality of many commercial products and services is very high because it is quite easy to apply quality principles in the industrial sector. Regrettably, currently, the same is not true in medicine. Unfortunately, people make more errors than machines do, and consequently, if human intervention in a process is high, the number of errors would also be expected to be high. To decrease the error rate, we should decrease human intervention by using high-quality technology whenever possible. However, it may not currently be possible to apply sophisticated technology to all medical disciplines equally; however, for laboratory medicine, we certainly have the opportunity to apply technology. If we continue to apply technology to all branches of medicine, we may ultimately decrease the error rate to a negligible level.

Six Sigma is the microscope of quality scientists. It shows the reality and does not mask problems. The errors that we are interest are primarily analytical errors, which represent only the tip of the iceberg. However, the reality is quite different. When we see the whole iceberg and control it all, then it will be possible to reach Six Sigma level and even higher quality in clinical laboratories.

\section{References}

Barr JT, Silver S. (1994). The total testing process and its implications for laboratory administration and education. Clin Lab Manage Rev, 8:526-42.

Berwick DM, Godfry AB, Roessner J. (1990). Curing helath care: New strategies for quality improvement. San Fransisco, Jossey-Bass Publishers.

Bonini P, Plebani M, Ceriotti F, Rubboli F. (2002). Errors in laboratory medicine. Clin Chem; 48:691-8.

Brussee W. (2004). Statistics for Six Sigma made easy. New York: McGraw-Hill.

Coskun A. (2007). Six Sigma and laboratory consultation. Clin Chem Lab Med; 45:121-3.

Deming WE.(1982). Quality, productivity, and competitive position. Cambridge MA: Massachusetts Institute of Technology, Center for Advanced Study, Boston. 
Dighe A, Laposata M. (2007). "Pre-pre" and "post-post" analytical error: high-incidence patient safety hazards involving the clinical laboratory. Clin Chem Lab Med; 45:712719

Forsman RW. (1996). Why is the laboratory an afterthought for managed care organizations? Clin Chem; 42:813-6.

Fraser CG. (2001). Biological variation: from principles to practice. Washington: AACC Press, $151 \mathrm{pp}$.

George M, Rowlands R, Kastle B. (2004). What is lean six sigma? McGraw Hill, New York.

Goldschmidt HM. (2002). A review of autovalidation software in laboratorymedicine. Accredit Qual Assur; 7:431-40.

Gras JM, Philippe M. (2007). Application of the Six Sigma concept in clinical laboratories: a review. Clin Chem Lab Med; 45:789-96.

Harry M, Schroeder R. (2000). Six Sigma: The breakthrough management strategy revolutionizing the world's top corporations. New York, Currency.

Henry RJ, Segalove M. (1952). The running of standards in clinical chemistry and the use of the control chart. J Clin Pathol; 27:493-501.

Jenny RW, Jackson-Tarentino KY. (2000). Causes of unsatisfactory performance in proficiency testing. Clin Chem; 46:89-99.

Kilpatrick ES, Holding S. Use of computer terminals on wards to access emergency test results: a retrospective audit. Br Med J 2001;322:1101-3.

Kohn LT, Corrigan JM, Donaldson MS. (2000). To err is human, Building a safer health system. National Academy Press Washington, DC.

Levey S, Jennings ER. (1950). The use of control charts in the clinical laboratories. Am J Clin Pathol, 20:1059-66.

Nancy RT. (2004). The Quality Toolbox, Second Edition, ASQ Quality Press.

Nevalainen D, Berte L, Kraft C, Leigh E, Picaso L, Morgan T. (2000). Evaluating laboratory performance on quality indicators with the six sigma scale. Arch Pathol Lab Med; 124:516-9.

Plebani M. (2007). Errors in laboratory medicine and patient safety: the road ahead. Clin Chem Lab Med; 45:700-707.

Plebani M, Carraro P. (1997). Mistakes in stat laboratory: types and frequency. Clin Chem; 43:1348-51.

Rosser W, Dovey S, Bordman R, White D, Crighton E, Drummond N. (2005). Medical errors in primary care. Can Fam Physician; 51:386-7.

Senders JW. (1994). Medical devices, medical errors, and medical accidents. In: Bogner MS, editor. Human error in medicine. Hillsdale, NJ: Lawrence Erlbaum Associates, 159-69.

Shewhart WA. (1931). Economic control of quality of the manufactured product. New York, Van Nostrand.

Stroobants AK, Goldschmidt HM, Plebani M. (2003). Error budget calculations in laboratory medicine: linking the concepts of biological variation and allowable medical errors. Clin Chim Acta; 333:169-76

Westgard JO. (2006a). Six Sigma quality design and control. Westgard QC, Inc, Madison.

Westgard JO, Klee GG. (2006b). Quality management. In: Burtis CA, Ashwood ER, Bruns $\mathrm{DE}$, editors. Tietz textbook of clinical chemistry and molecular diagnostics. St Louis, MO: Elsevier Saunders Inc., 485-529. 
Westgard JO, Barry PL, Tomar RH. (1991). Implementing total quality management (TQM) in healtcare laboratories. CLMR; 5:353-70.

Witte DL, Van Ness SA, Angstadt DS, Pennell BJ. (1997). Errors, mistakes, blunders, outliers, or unacceptable results: how many? Clin Chem; 43:1352-6.

World Alliance for Patient Safety. Forward Programme 2005. www.who.int/patientsafety. Accessed Appril 2010. . 


\title{
Tesqual: A Microthesaurus for Use in Quality Management in European Higher Education
}

\author{
María Mitre \\ University of Oviedo \\ Spain
}

\section{Introduction}

Nowadays, the demand for quality has become an essential issue of concern within university education. The widespread introduction of systems of quality assessment for higher education makes necessary a controlled specific language for users who work in this field. This "normalized" vocabulary is designed so as to improve the processes which are to be evaluated. In this sense, there exists widespread agreement regarding the usefulness of these standardised languages which normalize certain words and vocabulary, and later will facilitate access to information.

The objective is to solve a growing problem in the areas of quality assessment and management in higher education, namely lexical dispersion and the limited control of specialized vocabulary within this subject field. Consequently, a document tool is created in order to help solve problems, such as the difficulties associated with the presentation of and access to information, or the processing and transfer of specialized information in this field. This tool is in the form of a microthesaurus, developed to cover the needs and expectations of those users who are involved in university education.

Microthesaurus Tesqual is a controlled vocabulary with a structure based on hierarchical, associative and equivalence relationships. It is aimed at scientists, researchers, education professionals, students and the general users who use a "key" vocabulary to conceptualize and define the content of specific documents. The final aim is to help experts store and recover these documents coming from a particular information system.

\section{Tesqual design}

For the design and production of the Microthesaurus, certain phases were followed. These were mainly established in the ISO 2788: 1986 norm, and they also observed Aitchinson's et al. (2000) guidelines, contained within his practical manual Thesaurus Construction and Use. The stages are the following: subject field, collection of terms, vocabulary control, organization into categories and subcategories, conceptual structure, relational structure and technological implementation. 


\subsection{Subject field}

The subjects covered by the Microthesaurus are grouped under nine subject categories, known as semantic fields. In fact, there is a list of semantic fields, ordered according to the number code assigned to each of them, which shows a set of hierarchical chains contained in each of the different fields.

The following descriptors have been established as series headings of the hierarchical systematisation of the Microthesaurus: University Administration, University Quality, Quality Management, Information and Communication, Integration in the Labour Market, University Policy, Results in Society and University System. The broadest semantic field is that of University Quality, which covers Accreditation, Certification, European Space for Higher Education and Institutional Assessment.

One of the characteristics of the thesauri in general and of the Microthesaurus Tesqual in particular, is that the division of the set of descriptors into subject fields is, to some extent, flexible. This is due to the fact that a few descriptors could actually belong to two or more subject fields. To solve this problem, it was determined to include these in just one of the fields, which is normally the one considered most natural by users.

\subsection{Collection of terms}

The second phase consisted of the collection of vocabulary through the simultaneous combination of the deductive or synthetic method and the inductive or analytical method. This task was based mainly on collecting the entire lexicon that was found within the consulted literature and also the terms derived from conversations maintained with experts on the subject matter.

On one hand, the deductive or analytical method involves indexing the most recent articles and monographs in order to obtain an updated lexicon. On the other hand, through the inductive or synthetic method, the number of descriptors is increased, taking them from other reference sources, such as technical dictionaries, glossaries, etc. For this purpose, users and specialists were also asked to give their opinions on the subject-matter.

Both procedures were combined in a single method of mixed-collection, which adds the advantages of the analytical method to the advantages of the synthetic one. This made it possible to create a solid term-base.

After this phase, checks were carried out to ensure that the pre-descriptors did not have several meanings so as to avoid ambiguity. In this stage, the list was reduced, since obvious repetitions were removed. This was considered a good moment to compare the lexicon we had to the vocabulary of other thesauri.

For the collection of terms, a database was based in which different files were created. These contained the words referring to each semantic field. Firstly, a file was created containing all the glossaries considered of interest for the design of the Tesqual. Secondly, another file was designed containing the pre-existing thesauri which were useful for the introduction and contrast of the terms of the Microthesaurus. Thirdly, specific files for each semantic field were also created. For example, for the semantic field 'University Quality' the following descriptor files were created: accreditation, certification, documentation of the ANECA National Agency of Quality and Accreditation Assessment, documentation of the Council for University Coordination, the European Space for Higher Education and Institutional Assessment. 


\subsection{Term control}

It is important to consider that, in order for a thesaurus to be able to fulfill the functions for which it has been designed, it must serve primarily as a tool for vocabulary control. In other words, the specific terms of a thesaurus and their particular form must necessarily go through a previous process of normalization so as to be used as controlled-vocabulary in the users' information search. To be more precise, a particular term has been chosen from a group of synonyms which express the same concept; polysemic words; the grammatical form: noun, adjective, adverb and verb; the choice between the singular and plural form, and compounds or abbreviations of the specific terms.

Each descriptor which is part of the Microthesaurus refers to one single concept, without the several different meanings assigned to a term in dictionaries. The hierarchical structure or hierarchical relationships of the Microthesarus will make clear the exact sense of the words. If this should not be enough to clarify the meaning, a specific explanatory note to the term would be added. When the lexicon is selected, the aim is to achieve a univocal concept among the different terms, that is to say, that linguistic expressions have one single form and represent one single concept. Given that in a thesaurus, terms cannot have different senses, the meaning which best fits the requirements of the system was selected, responding to the chosen indexing field. The other definitions were rejected, since they do not belong to the subject domain that concerns us here.

When we create a thesaurus, it is necessary to avoid synonymy and polysemy. Synonymy is produced when a single concept is represented by different signifiers. The most common thing is to choose an expression as a descriptor, maintaining its synonyms as nondescriptors (Gil, 1996).

Polysemy is defined as the existence of several meanings attributed to one single significant. This is considered detrimental to the thesaurus and has to be controlled.

In the case where a concept can be expressed by two or more synonyms, one of them will be selected as the preferred term (normally the most commonly used) and the rest will remain as non-preferred terms. These latter ones will direct the user to their corresponding preferred terms. The most representative synonyms have been chosen for the non-descriptor terms. These represent concepts related to the descriptors.

There are term categories that can be considered pure synonyms. The most obvious ones are abbreviations and acronyms. In general, the full term is preferred, whereas the abbreviation appears as a non-descriptor entry term. However, there are some cases in which an acronym or abbreviation is so common that we forget about the origin of the word it actually comes from. In these cases, it is recommended to use the acronym or abbreviation as preferred terms, considering the full term as an entry-term (Lancaster, 1995). There are also other cases in which the choice will be determined by the type of users to whom the thesaurus is addressed.

The infinitive verb must not be used as an indexing term. Actions must be expressed as noun forms.

Noun, adjectival and adverbial phrases must be expressed in the order of the natural language and not in the inverted form. The inverted form can result in being redirected towards the direct form.

According to the UNESCO recommendations, most of the indexing terms can be divided into a nucleus and a difference. This refers simply to the distinction between a generic term and a term which identifies one of its subclasses. 
This was one of the most laborious phases in the development of the Microthesaurus, as a huge number of terms within University Quality correspond to the same concept. All this vocabulary is included in the Microthesaurus, since the user will carry out the search and retrieve the information through the descriptors that he/she knows. In order to achieve this, the most representative sense is selected from amongst the different meanings: according to its frequency of occurrence and/or because it is the most commonly used. The term accepted as the most representative of a concept assumes the role of descriptor or main term, whilst those words which are not the most representative will be non-descriptors or secondary terms. The non-preferred terms will show different entry categories which will direct the user to the preferred term.

\subsection{Grouping into categories, subcategories}

This was the most important and difficult part in the process of the design of the Microthesaurus. It involved creating a single hierarchical structure, which presented all the information contained in the system in a systematic and synthetic way.

It consisted of dividing the whole future list of descriptors into subject areas which were proved to have similar meaning. At the same time, we provided each subject field with a name, doing the same with each subfield, and so on. This constituted the basic structure through which all descriptors were subsequently arranged.

In the following list, the relevant descriptors are assigned to each semantic field. Each of these subject categories is, in turn, subdivided into more specific areas:

\begin{tabular}{|cl|}
\hline C1 University Administration \\
C11 & University Autonomy \\
C12 & Legislation \\
C13 & Institutional Levels \\
C14 & International Institutions \\
C15 & University Administrative Bodies \\
C16 & European Union \\
C2 University Quality \\
C21 & Accreditation \\
C22 & Higher Education Accreditation \\
C23 & European Space for Higher Education \\
C24 & Institutional Assessment \\
C3 Quality Management \\
C31 & Total Quality Costs \\
C32 & Quality Specialists \\
C33 & Quality Evolution \\
C34 & Quality Models \\
C35 & Quality Rules \\
C36 & Quality Organizations \\
C37 & Quality Management Principles \\
C38 & Recognition for Management Excellence \\
C39 & Quality Techniques \\
C41 & Academic Management \\
\hline
\end{tabular}




\begin{tabular}{|c|c|}
\hline $\mathrm{C} 42$ & Human Resources \\
\hline $\mathrm{C} 43$ & Material Resources \\
\hline \multicolumn{2}{|c|}{ C5 Information and Communication } \\
\hline C51 & Communication \\
\hline C52 & Sources of Information \\
\hline C53 & Information Management \\
\hline C54 & Information \\
\hline C55 & Information Processing \\
\hline C56 & Information Services \\
\hline $\mathrm{C} 57$ & Information Technology \\
\hline \multicolumn{2}{|c|}{ C6 Integration in the Labour Market } \\
\hline C61 & Employment Conditions \\
\hline C62 & Employment Contracts \\
\hline C63 & Unemployment \\
\hline C64 & Employment \\
\hline C65 & Retirement \\
\hline C66 & Labour Market \\
\hline C67 & Labour Relations \\
\hline \multicolumn{2}{|c|}{ C7 University Policy } \\
\hline C71 & Education Rights \\
\hline $\mathrm{C} 72$ & Education Development \\
\hline C73 & University Planning \\
\hline $\mathrm{C} 74$ & University Reform \\
\hline $\mathrm{C} 75$ & International Relations \\
\hline C76 & University-Company Relations \\
\hline \multicolumn{2}{|c|}{ C8 Results in Society } \\
\hline $\mathrm{C} 81$ & Well-Being \\
\hline $\mathrm{C} 82$ & Social Change \\
\hline C83 & Social Structure \\
\hline C84 & Family \\
\hline C85 & Social Participation \\
\hline C86 & Population \\
\hline $\mathrm{C} 87$ & Social Problems \\
\hline C88 & Social Relations \\
\hline $\mathrm{C} 89$ & Social Responsibility \\
\hline $\mathrm{C} 8 \mathrm{a}$ & Economic Results \\
\hline $\mathrm{C} 8 \mathrm{~b}$ & Non-economic Results \\
\hline $\mathrm{C} 8 \mathrm{c}$ & Social Services \\
\hline \multicolumn{2}{|c|}{ C9 University System } \\
\hline C91 & Educational Institutions \\
\hline C92 & Education \\
\hline C93 & Private Education \\
\hline C94 & State Education \\
\hline C95 & University Education \\
\hline C96 & Academic Training \\
\hline
\end{tabular}

Table 1. Semantic fields and subfields 


\subsection{Conceptual structure}

The Microthesaurus is made up of a set of descriptor and non-descriptor terms, and a system of relationships which defines its semantic content.

A thesaurus is by definition a structured vocabulary that represents the relationships between concepts by means of the existing relations between the terms which are used to express these concepts.

The web of relationships that each descriptor establishes with the rest provides a particular definition for it. This is achieved by placing the descriptor in a specific semantic field. In fact, there are three types of semantic relationships in Microthesaurus Tesqual: equivalence, hierarchical and associative relationships.

It comprises nine general families which do not correspond to a normalized classification. In turn, these nine families are subdivided into more and more specific subjects or topics, finally reaching the degree of specificity required to understand the conceptual tree of the issue concerned.

The different constituent elements which make up the Microthesaurus, namely, the subject fields, the descriptors, the non-descriptors and the scope notes, are described below.

\subsubsection{Subject fields}

Descriptors are structured within semantic fields according to subject areas, which are intended to reflect the interdisciplinarity of the Tesqual. In this case, it is divided into nine semantic fields. The name of each field is preceded by the letter $C$ and a number, used to identify each descriptor, sending it from the alphabetic list of the Microthesaurus to the semantic field to which it belongs.

\begin{tabular}{|ll|}
\hline C1 & University Administration \\
C2 & University Quality \\
C3 & Quality Management \\
C4 & University Management \\
C5 & Information and Communication \\
C6 & Integration in the Labour Market \\
C7 & University Policy \\
C8 & Results in Society \\
C9 & University System \\
\hline
\end{tabular}

Table 2. Subject fields

\subsubsection{Descriptors}

Descriptors are words or expressions that denote the concepts which make up the area covered by the Microthesaurus without ambiguity. They can be composed of one word (simple descriptor or 'uniterm') or include several (compound descriptor or plural terms).

Example:

National Agency of Assessment

UF: ANECA

Table 3. Descriptor 


\subsubsection{Non-descriptors}

The non-descriptors are words or expressions which, in the natural language, refer to the same concept or to a concept considered equivalent to that of the descriptor. In this way, a relationship of equivalence, within the Microthesarus language, is established between them.

Example:

ANECA

USE: National Agency of Assessment

Table 4. Non-descriptor

\subsubsection{Scope notes}

The scope notes guide the users, by specifying or narrowing the use of certain descriptors which may be slightly ambiguous in terms of meaning, or simply require a particular explanation in the user's search or in the document indexing.

The scope notes are introduced through the symbol SN (Scope Note), situated between the descriptor and its application note.

Example:

National Agency of Assessment

SN: National Agency of Quality and Accreditation Assessment

Table 5. Scope note

\subsection{Relational structure}

The relationships established between the terms which comprise the Microthesaurus, equivalence, hierarchical and associative are described as follows:

\subsubsection{Equivalence relationships}

Equivalence relationships connect to each other all the terms expressing the same concept, but also all those words which could be considered equivalent. These are treated as synonyms in the language of the system, even if they are not strictly so in the natural language.

These relationships of synonymy are very important, since the more synonyms a thesaurus contains, the more it is able to take into account the different ways of denoting a concept in the natural language. In fact, this makes the thesaurus a tool which can be more effectively used by a wider variety of users.

The relationships of semantic equivalence between descriptors are indicated by the following symbols:

- USE (Use), situated between a non-descriptor and the corresponding descriptor. A non-descriptor must direct to a single descriptor.

- UF (Use for), situated between a descriptor and the non-descriptor (s) which it represents. There may be zero, one, two or more non-descriptors attributed to each descriptor. 
Example:

\begin{tabular}{|l|}
\hline QC \\
USE: Quality Cost \\
\hline $\begin{array}{l}\text { Quality Costs } \\
\text { UF: QC }\end{array}$ \\
\hline
\end{tabular}

Table 6. Equivalence relationships

\subsubsection{Hierachical relationships}

The hierarchical relationship links those descriptors which are either more generic or more specific, thus placing them in their exact context and avoiding ambiguity. The hierarchical relationship between descriptors is marked using the following symbols: BT (Broader Term), situated between a specific descriptor and a generic descriptor. NT (Narrower Term), situated between a generic descriptor and a specific descriptor.

The generic term is defined as that descriptor which denotes a broader notion including other narrower notions which are represented by their specific terms. Example:

Example:

Quality Costs

BT: Total Quality Costs

Table 7. Generic term

The specific term refers to that descriptor which denotes a notion included within a broader notion. This is represented by a generic term. Example:

Example:

Quality Costs
NT: Evaluation Costs
Prevention Costs

Table 8. Specific term

In Microthesarus Tesqual, there may be up to eight levels of hierarchy. Alphabetical order is used to arrange descriptors of the same hierarchical level depending on the same term. This is commonly used in most thesauri.

Example:

\begin{tabular}{|ll|}
\hline C & Thesarus about quality in Higher Education \\
C2 & University Quality \\
C21 & Higher Education Accreditation \\
C211 & ANECA Accreditation Programme \\
C2111 & Accreditation Pilot Projects \\
C21111 & Accreditation Agents \\
C211111 & ANECA Auditors \\
C211112 & Internal Assessment Committee \\
C211113 & National Accreditation Committee \\
C211114 & Sub-Committee coordinators \\
C2111141 & Sub-Committee on Health Sciences coordinators \\
\hline
\end{tabular}

Table 9. Levels of hierarchy 


\subsubsection{Associative relationships}

Associative relationships are established between terms which are not considered equivalent and cannot be connected by a hierarchical relationship. Their function is to provide information about further possibilities for indexing or information searching.

The associative relationship between descriptors is marked using the symbol RT (Related Term), which is situated between two associated descriptors.

The related term refers to one or more descriptors which, due to their meaning or use, maintain an associative or horizontal relationship with the main term.

Example:

Quality Costs

RT: Service Delivery Costs

Table 10. Related term

\subsection{Technological implementation}

Before deciding about the software which was to be used for the digital version of the Microthesaurus, several experts in thesaurus design were contacted in order to learn about their own experiences in this regard.

For the electronic version of the Microthesarus, the software Multites was used, as this allows conversion of files and generation of HTML files, as well as facilitating the introduction of the thesaurus in the web. Moreover, it is developed on the Windows operating system and it is not necessary to type terms when semantic relationships are established.

\section{Tesqual presentation}

At the beginning of the Microthesaurus, the main semantic categories and subcategories are presented to facilitate the task of looking up vocabulary. The written version of the Tesqual contains four parts: alphabetical presentation, hierarchical presentation, conceptual presentation, and KWOC permutation presentation. In addition, Microthesaurus Tesqual is available in digital and written formats. Each of these four parts is described below.

\subsection{Alphabetical presentation}

The alphabetical presentation describes the equivalence relationships considering the classification number of the descriptor. It contains the following information: descriptor, classification number and non-descriptor. They are alphabetically ordered. 
Example:

\begin{tabular}{|ll|}
\hline Cost of poor quality & \\
USE: Poor Quality Costs & \\
Evaluation Costs C3111 & \\
Failure Costs & C3121 \\
External Failure Costs & C31211 \\
Internal Failure Costs & C31212 \\
Higher Education Costs & C7314 \\
Poor Quality Costs & C312 \\
Quality Costs & C311 \\
\hline
\end{tabular}

Table 11. Alphabetical presentation

\subsection{Hierarchical presentation}

In the hierarchical presentation, the terms are ordered by categories or classes organized according to their meanings and logical interrelations. The hierarchical presentation contains nine semantic fields, established as the major series headings of the subject areas. These are, in turn, subdivided into semantic subfields.

In the hierarchical part, the descriptors appear according to main subject areas into which the Microthesarus has been divided, following the previously described method of classification. Therefore, each subject area contains only the descriptors which belong to its domain and their corresponding hierarchical relationships. Following this structure, each descriptor is placed in its own semantic context in a very precise way.

Under each descriptor entry, the user finds the descending hierarchy of the descriptors which constitute the tree-like structure of the upper term's descriptor. The specific descriptors are classified following a descending hierarchical order, and within each level of hierarchy, they are arranged in alphabetical order.

Example:

\begin{tabular}{|c|c|c|c|}
\hline Qual & Mana & nent & \\
\hline C31 & Total & ality Costs & \\
\hline & C 311 & Quality Costs & \\
\hline & & $\mathrm{C} 3111$ & Evaluation Costs \\
\hline & & C3112 & Prevention Costs \\
\hline & C 312 & Poor Quality Costs & \\
\hline & & C 3121 & Failure Costs \\
\hline & & & C31211 External Failure Costs \\
\hline & & & C31212 Internal Failure Costs \\
\hline
\end{tabular}

Table 12. Hierarchical presentation

\subsection{Conceptual presentation}

The conceptual presentation is the main part of the Microthesarus. It is developed in a systematic way, indicating which descriptors are the broadest. It allows the users to find the descriptors and non-descriptors in their alphabetical order and shows all hierarchical levels to which each descriptor belongs. In fact, each descriptor is shown as follows: 


\section{Descriptor entry}

- $\quad$ The text of the descriptor.

- The non-descriptor (or several), corresponding to the descriptor entry. They are classified in alphabetical order, preceded by 'UF' (Use For).

- The generic descriptor of the descriptor entry, preceded by 'BT' (Broader Term).

- Specific descriptors of the descriptor entry, preceded by 'NT' (Narrower Term). The specific descriptors are also arranged in alphabetical order.

- Terms associated with the entry term, preceded by 'RT' (Related Term) and classified in alphabetical order.

- Scope Note, where relevant, preceded by 'SN' (Scope Note).

- Classification number of the descriptor.

Example:

$$
\begin{aligned}
& \text { Quality Costs } \\
& \text { UF: QC } \\
& \text { BT: Total Quality Costs } \\
& \text { NT: Evaluation Costs } \\
& \text { Prevention Costs } \\
& \text { RT: Service Delivery Costs } \\
& \text { SC: C311 }
\end{aligned}
$$

Table 13. Conceptual presentation (descriptor)

Non-descriptor entry

- The text of the non-descriptor.

- The text of the corresponding descriptor, preceded by 'USE'.

Example:

\begin{tabular}{|ll|}
\hline PQC & USE: Poor Quality Costs \\
QC & USE: Quality Costs \\
PQC & USE: Poor Quality Costs \\
\multicolumn{2}{l}{ Quality Costs } \\
Poor Quality Costs & C311 \\
\hline
\end{tabular}

Table 14. Conceptual presentation (non-descriptor)

\subsection{KWOC permutation presentation}

The KWOC permutation presentation comprises two types of entry terms: descriptor and non-descriptor, which are ordered alphabetically using all the significant vocabulary they contain. 
Example:

\begin{tabular}{|ll|}
\hline Cost & Poor Quality Costs \\
& \\
& Evaluation Costs \\
& External Failure Costs \\
& Failure Costs \\
& Internal Failure Costs \\
& Higher Education Costs \\
& Poor Quality Costs \\
& Prevention Costs \\
& Service Delivery Costs \\
& Total Costs of Quality \\
\hline
\end{tabular}

Table 15. KWOC permutation presentation

\section{General statistics of the Tesqual}

The structure of the Tesqual is divided into nine general semantic fields, which are presented with no standardised or normalized classification. These fields include 2.425 terms, out of which 2.013 are descriptors and 412 are non-descriptors. The nine semantic fields are also subdivided into more specific sub-fields, within which we find particular words and terms with their respective equivalence, hierarchical and associative relationships. 2.012 hierarchical relationships and 441 associative relationships were established. Finally, 261 scope notes were also introduced.

\begin{tabular}{|l|l|}
\hline Terms & 2.425 \\
\hline Descriptors & 2.013 \\
\hline Non- descriptors & 412 \\
\hline Semantic fields & 9 \\
\hline Hierarchical relationships & 2.012 \\
\hline Associative relationships & 441 \\
\hline Scope notes & 261 \\
\hline
\end{tabular}

Table 16. Statistics of the Tesqual

\section{Microthesaurus test}

In order to test the Microthesaurus, a sample of documents was indexed in order to find out about the degree of coherence of the Tesqual's structure and its capacity of real application. In this stage, the frequency of the terms used in the indexing and the information retrieval processes were compared to the lexical entries which constituted the provisional version of the Microthesaurus. In this respect, it was detected that there were certain words which were present in the Microthesaurus, but not in the indexing or the information retrieval processes and vice versa; there were also terms from the document indexing and the information recovery process that were not collected within the Tesqual vocabulary. 
For this reason, some words were incorporated to the corpus; while others, which were not effective in the indexing process, were eliminated. This led to some changes in the hierarchical order, which had to be re-structured.

\section{Tesqual update}

Due to the long time that it takes to produce, the Microthesaurus must be frequently updated. This occurs because an indexing language can be out of date even before it gets published. As an example, the semantic field C2, University Quality, had to be re-structured two months after being completed because of the creation of the ANECA organization (National Agency of Quality and Accreditation Assessment). Before its creation, it was the CCU (Council of University Coordination) that was in charge of university quality management. One of the most relevant characteristics of a Microthesarus is its flexibility, which allows us to increase its vocabulary regularly.

A thesaurus must be revised on a continuous basis. Normally, a newly created thesaurus is updated approximately every six months, while in the case of those which have been in use for a longer period, this revision is done every two or three years (Gil, 1996).

The thesaurus has to be updated with a view to introducing the new terminology derived from the process of development of the subject concerned, but also to correct faults and errors detected from the real application of the thesaurus within a particular field of knowledge.

It is necessary to check the actual use of the terms which are part of the indexing language so as to evaluate each of the entry words. In the indexing process, there may be concepts that appear in the documents, but which are not covered in the vocabulary of the thesaurus. Therefore, when the indexer misses a concept, it notes the need for a new descriptor. This word is recorded, stored on a waiting list or filed as a candidate to become a descriptor. These terms will be revised and analysed in the updating process.

The introduction of the new descriptors cannot be done daily, since this would lead to confusion, breaking the characteristic structure of the thesaurus. We have to take into account that every time a term is modified, all the relationships established between them must be also altered within the whole indexing language.

The presence of synonyms and quasi-synonyms must also be considered in word-searching, including these terms necessarily, as this facilitates user access to information. This is due to the fact that a concept may be denoted by different names.

Chaumier (1986) notes the discordance existing between the use of terms when the documents are introduced into the system and their actual use in the search equations. For this reason, it is important to analyse the terminology used by most people, which is commonly reduced to a limited amount of vocabulary. To evaluate this aspect, statistical analysis is suggested in order to study the frequency of use of descriptors.

To conclude, the Tesqual updating is an ongoing process, which allows us to be aware of the real use of terms both in the indexing process and in information retrieval. This occurs because as happens with entry operations, consultations carried out by users in the natural language provide the actual terminology of the documental system or documentation centre. The search equations give us the percentage of accuracy and response achieved with descriptors. 


\section{References}

Aitchison, J.; Gilchrist, A. \& Bawden, D. (2000). Thesaurus construction and use: A practical manual. ( $4^{\mathrm{a}}$ ed.). Fitzroy Dearborn Publishers, Chicago

Chaumier, J. (1986). Análisis y lenguajes documentales: El tratamiento lingüístico de la información documental, Mitre, Barcelona

Drabenstott, K. M. \& Vizine-Goetz, D. (1994). Using subject headings for online retrieval: theory, practice and potential, Academic Press, San Diego, CA

Ganzmann, J. (1990a). Check-list for thesaurus software. International classification, vol. 17, no3/4, pp. 155-157

Ganzmann, J. (1990b). Criteria for the Evaluation of Thesaurus Software. International classification, vol. 17, n³/4, pp. 148-154

Gil Urdiciain, B. (1996). Manual de lenguajes Documentales, Noesis, Madrid

International Organization for Standardization (1985a). ISO 5963:1985. Documentation. Methods for examining documents, determining their subjects, and selecting indexing terms, ISO, Geneva

International Organization for Standardization (1985b). ISO 5964:1985. Documentation. Guidelines for the Establishment and Development of Multilingual Thesauri, ISO, Geneva

International Organization for Standardization (1986c). ISO 2788-1986. Documentation: Guidelines for the Establishment and Development of Monolingual Thesauri. 2nd. ed., ISO Geneva

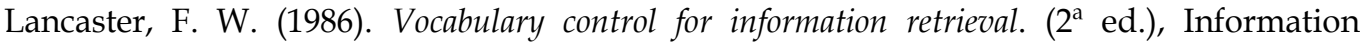
Resources Press, Arlington, VA

Lancaster, F. W. (1991). Indexing and abstracting in theory and practice, The Library Association, Londres

Lancaster, W. (1995). El control del vocabulario en la recuperación de información, Universidad de Valencia, Valencia

Milstead, J. L. (1997). Thesaurus in a full-text word, Proceeding of the 1997 Clinic on Library Applications of Data Processing, pp. 28-38, Urbana-Champaign, Illinois; Illinois University at Urbana-Champaign, Graduate School of Library and Information Science, March 1997, Cochrane, Pauline Atherton and Eric H. Jones (eds)

Multites. http:/ / www.multites.com [08 de abril de 2010]

UNESCO (1981). Curso sobre lenguajes de indización: Construcción de tesauros, UNESCO, París 

